\title{
Fire Protection Analysis of a Fresno Elementary School
}

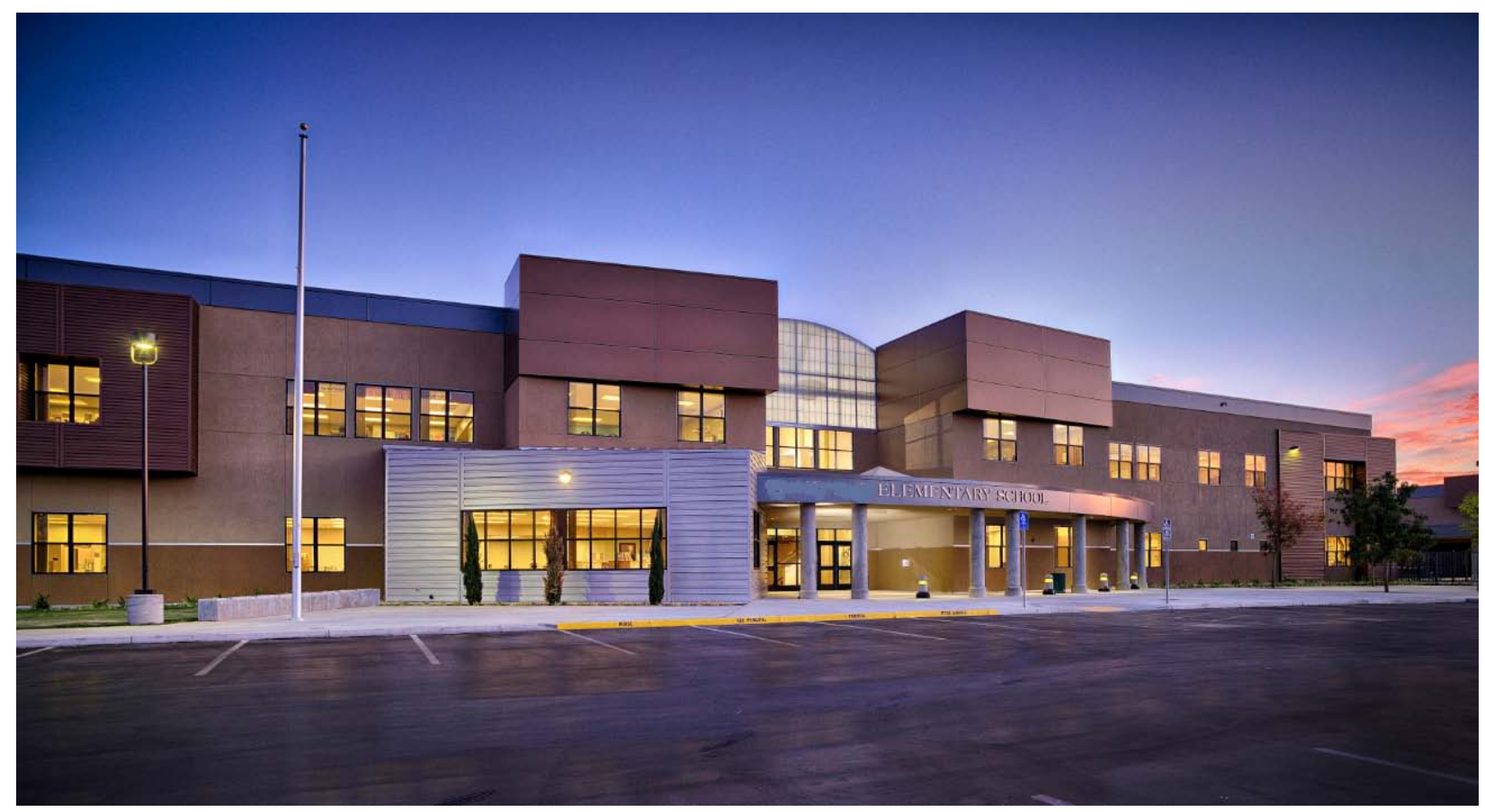

Prepared by:

Garen Lencioni June 10, 2013
Submitted to:

Dr. Frederick W. Mowrer, P.E.

Dr. Christopher Pascual, P.E.

California Polytechnic State University Fire Protection Engineering Program Culminating Project - Fire and Life Safety Report 


\section{Statement of Disclaimer}

This project report is a result of a class assignment; it has been graded and accepted as fulfillment of the course requirements. Acceptance of this report in fulfillment of the course requirements does not imply technical accuracy or reliability. Any use of information in this report is done at the risk of the user. These risks may include, but may not be limited to, catastrophic failure of the device or infringement of patent or copyright laws. California Polytechnic State University at San Luis Obispo and its staff cannot be held liable for any use or misuse of the project. 
BUILDING BACKGROUND INFORMATION 2

BUILDING REVIEWING AGENCIES

APPLICABLE CODES, LAWS, REGULATIONS AND STANDARDS 5

$\begin{array}{ll}\text { SITE FIRE PROTECTION REQUIREMENTS } & 6\end{array}$

$\begin{array}{ll}\text { SITE ACCESS } & 6\end{array}$

SITE FIRE HYDRANTS $\quad 6$

$\begin{array}{ll}\text { SITE FIRE PLAN } & 6\end{array}$

$\begin{array}{ll}\text { BUILDING EGRESS REQUIREMENTS } & 7\end{array}$

$\begin{array}{ll}\text { GENERAL BUILDING LAYOUT } & 7\end{array}$

$\begin{array}{ll}\text { OCCUPANCY CLASSIFICATION AND LOADS } & 7\end{array}$

GENERAL MEANS OF EGRESS HEIGHT REQUIREMENTS 9

$\begin{array}{ll}\text { MEANS OF EGRESS ILLUMINATION } & 10\end{array}$

$\begin{array}{ll}\text { CLASSROOM EXIT AND EXIT ACCESS DOORWAYS } & 10\end{array}$

$\begin{array}{ll}\text { EXIT ACCESS TRAVEL DISTANCE } & 10\end{array}$

$\begin{array}{ll}\text { CORRIDOR REQUIREMENTS } & 10\end{array}$

$\begin{array}{ll}\text { NUMBER OF EXIT REQUIREMENTS } & 10\end{array}$

$\begin{array}{ll}\text { EXIT DISCHARGE REQUIREMENTS } & 10\end{array}$

$\begin{array}{ll}\text { EXIT PATHS } & 11\end{array}$ 
BUILDING STRUCTURAL FIRE PROTECTION

GENERAL INFORMATION

GENERAL BUILDING CLASSIFICATION OPTIONS

ALLOWABLE BUILDING HEIGHTS AND AREAS WITH

NO SPRINKLER OR AREA INCREASES

FIRE-RESISTANCE RATING REQUIREMENTS FOR BUILDING

ELEMENTS WITH NO SPRINKLER OR AREA INCREASES

ALLOWABLE BUILDING HEIGHTS AND AREAS IF USING

SPRINKLER AND AREA INCREASE ALLOWANCE

FIRE-RESISTANCE RATING REQUIREMENTS FOR BUILDING

ELEMENTS WITH SPRINKLER AND AREA INCREASES

ACTUAL BUILDING EVALUATION

ACTUAL BUILDING AREA ALLOWANCES

FRONTAGE INCREASE

SPRINKLER INCREASE

SUMMARY OF ALLOWED BUILDING AREA

ACTUAL BUILDING CONSTRUCTION

VERTICAL EXIT REQUIREMENTS

ACTUAL BUILDING CONSTRUCTION MATERIALS

RATED CONSTRUCTIONS

FIRE DETECTION, ALARM AND COMMUNICATIONS SYSTEMS

FIRE ALARM TYPE AND COMPONENT INFORMATION

FIRE ALARM DESIGN METHODOLOGY

FIRE ALARM NOTIFICATION ANALYSES

FIRE ALARM SEQUENCE OF OPERATION

FIRE ALARM INSPECTION TESTING AND MAINTENANCE REQUIREMENTS 
VOLTAGE DROP AND BATTERY CALCULATIONS 30

VOLTAGE DROP AND BATTERY CALCULATIONS 30

$\begin{array}{ll}\text { SYSTEM COMMISSIONING } & 30\end{array}$

INSPECTION TESTING AND MAINTENANCE REQUIREMENTS 31

APPROVAL REQUIREMENTS 31

FIRE ALARM AND DETECTION SUMMARY 31

WATER-BASED FIRE SUPPRESSION 32

GENERAL SITE INFORMATION 32

GENERAL BUILDING FIRE SPRINKLER INFORMATION 32

FIRE SPRINKLER MATERIAL INFORMATION 33

BUILDING FIRE WATER SUPPLY INFORMATION 34

BUILDING SPRINKLER HYDRAULIC DEMAND REQUIREMENTS 35

GENERAL SPRINKLER DEMAND REQUIREMENTS 36

$\begin{array}{ll}\text { COMPUTER SOFTWARE } & 36\end{array}$

FIRE SPRINKLER PLAN REFERENCE PLANS 36

$\begin{array}{ll}\text { PERFORMANCE BASED ANALYSIS } & 37\end{array}$

PERFORMANCE BASED GOALS OVERVIEW 37

$\begin{array}{ll}\text { TENABILITY REQUIREMENTS } & 37\end{array}$

$\begin{array}{ll}\text { EVACUATION TIME CALCULATIONS } & 38\end{array}$

GENERAL INFORMATION 38

EGRESS FLOW CALCULATIONS 39

HAND CALCULATION OF MOVEMENT TIME STANDARD EGRESS WITH

ALL STAIRS AND DOORS AVAILABLE (THIS IS THE MOVEMENT TIME

$\begin{array}{ll}\text { USED FOR DESIGN FIRE 1) } & 40\end{array}$

HAND CALCULATION OF MOVEMENT TIME EGRESS WITH MAIN ENTRY

DOUBLE STAIRS AND DOORS UNAVAILABLE (THIS IS THE MOVEMENT 
TIME USED FOR DESIGN FIRE 2)

HAND CALCULATION OF MOVEMENT TIME EGRESS WITH ONE

SIDE STAIR UNAVAILABLE (THIS IS THE MOVEMENT TIME USED

FOR DESIGN FIRE 3 )

PATHFINDER MOVEMENT TIME STANDARD EGRESS WITH ALL

STAIRS AND DOORS AVAILABLE

PATHFINDER MOVEMENT TIME EGRESS WITH MAIN ENTRY

DOUBLE STAIRS AND DOORS UNAVAILABLE

PATHFINDER MOVEMENT TIME EGRESS WITH ONE SIDE STAIR UNAVAILABLE

EVACUATION MOVEMENT TIMES

ACTUAL OCCUPANT LOADS

DESIGN FIRE 1

SCENARIO OVERVIEW

FIRE SCENARIO DESCRIPTION 46

MODEL DESIGN FIRE 47

SMOKE DETECTOR AND FIRE SPRINKLER ACTIVATION 48

DESIGN FIRE 1 RSET

DESIGN FIRE 1 ASET TIMES

DESIGN FIRE 1 SUMMARY 57

DESIGN FIRE 2

SCENARIO OVERVIEW

FIRE SCENARIO DESCRIPTION

MODEL DESIGN FIRE

SMOKE DETECTOR AND FIRE SPRINKLER ACTIVATION

DESIGN FIRE 2 RSET

DESIGN FIRE 2 ASET TIMES

DESIGN FIRE 2 SUMMARY

DESIGN FIRE 3 
$\begin{array}{ll}\text { SCENARIO OVERVIEW } & 69\end{array}$

FIRE SCENARIO DESCRIPTION

$\begin{array}{ll}\text { MODEL DESIGN FIRE } & 72\end{array}$

SMOKE DETECTOR AND FIRE SPRINKLER ACTIVATION 72

DESIGN FIRE 3 RSET

DESIGN FIRE 3 ASET TIMES

DESIGN FIRE 3 SUMMARY

FIRE AND LIFE SAFETY ANALYSIS RECOMENDATIONS 82

$\begin{array}{ll}\text { REFERENCES } & 83\end{array}$

CODE AND STANDARD REFERENCES USED $\quad 83$ 
APPENDIX

APPENDIX A: EXIT PLANS

APPENDIX B: FIRE RATED WALL PLANS

APPENDIX C: FIRE ALARM PLANS

APPENDIX D: FIRE SPRINKLER PLANS

APPENDIX E: FIRE ALARM CUT SHEETS

APPENDIX F: FIRE ALARM SPECIFICATIONS

APPENDIX G: WATER FLOW MEMO

APPENDIX H: HYDRAULIC CALCULATIONS

APPENDIX I: FIRE SPRINKLER CUT SHEETS

APPENDIX J: FIRE EVACUATION AND SAFETY PLAN

APPENDIX K: FIRE SPRINKLER INSPECTION, TESTING AND MAINTENANCE REQUIREMENTS 


\section{LIST OF FIGURES:}

Figure 1 - Campus Site Diagram 3

Figure 2 - 1st and 2nd Overall Floor Plans 4

$\begin{array}{lr}\text { Figure 3 - Site Fire Plan } & 6\end{array}$

Figure 4-Occupant Classification Areas $\quad 8$

$\begin{array}{ll}\text { Figure 5 - Exit Path - First Floor } & 11\end{array}$

Figure 6-Exit Path - Second Floor 11

Figure 7 - First Floor Plan - Fire Rating 20

Figure 8-Second Floor Plan - Fire Rating 20

Figure 9 - UL 419 Corridor Interior Wall Rating Detail 22

Figure 10 - UL 419 Corridor Tunnel Rating Detail 23

Figure 11 - UL 469 Rated Shaft Detail 24

Figure 12 - Fire Alarm Sequence of Operation 29

Figure 13 - Site Fire Layout $\quad 32$

Figure 14 - Fire Suppression System Curve $\quad 34$

Figure 15 - Fire Sprinkler Hydraulic Demand Location 35

Figure 16 - Pathfinder Run with all egress available 42

Figure 17 - Pathfinder Model 42

Figure 18 - Pathfinder Run with entry egress unavailable 43

Figure 19 - Pathfinder Model with Center Stairs Removed 43

Figure 20 - Pathfinder Run with one side stair unavailable 44

Figure 21 - Pathfinder Model with Side Stairs Removed 44

Figure 22 - Design Fire 1 Location 45/46

Figure 23 - Amtrack trash bag HRR Curves $\quad 47$ 
Figure 24 - Design Fire 1 HRR Curve

Figure 25 - FDS Output of Device Activation

Figure 26 - FDS Design Fire 1 - CO at 259 s RSET

Figure 27 - FDS Design Fire 1 - CO at $600 \mathrm{~s}$

Figure 28 - FDS Design Fire 1 - Temperature at 259 s RSET

Figure 29 - FDS Design Fire 1 - Temperature at $600 \mathrm{~s}$

Figure 30 - FDS Design Fire 1 - Visibility at 259 s RSET

Figure 31 - FDS Design Fire 1 - Visibility at $600 \mathrm{~s}$

Figure 32 - FDS Design Fire 1 - Smoke Layer Height vs Time

Figure 33 - FDS Design Fire 1 - Image Looking North at RSET

Figure 34 - FDS Design Fire 1 - RSET vs ASET Summary

Figure 35 - Design Fire 2 Location

Figure 36 - Magazine Rack HRR from SFPE Figure 3-1.56

Figure 37 - Design Fire 2 HRR Curve

Figure 38 - FDS Output of Device Activation

Figure 39 - FDS Design Fire 2 - CO at 560 s RSET

Figure 40 - FDS Design Fire 2 - CO at $600 \mathrm{~s}$

Figure 41 - FDS Design Fire 2 - Temperature at 560 s RSET

Figure 42 - FDS Design Fire 2 - Temperature at $600 \mathrm{~s}$

Figure 43 - FDS Design Fire 2 - Visibility at 235 s as it drops below criteria 66

Figure 44 - FDS Design Fire 2 - Visibility at $600 \mathrm{~s}$

Figure 45 - FDS Design Fire 2 - Smoke Layer Height vs Time

Figure 46 - FDS Design Fire 2-Image Looking North at Sprinkler Activation 68

Figure 47 - FDS Design Fire 2 - RSET vs ASET Summary 
Figure 48 - Design Fire 3 Location

Figure 49 - Storage Unit HRR from SFPE Figure 3-1.15

Figure 50 - Design Fire 3 HRR Curve

Figure 51 - FDS Output of Device Activation

Figure 52 - FDS Design Fire 3 - CO at 453 s RSET

Figure 53 - FDS Design Fire 3 - CO at $600 \mathrm{~s}$ 75

Figure 54 - FDS Design Fire 3 - Temperature at 453 s RSET 76

Figure 55 - FDS Design Fire 3 - Temperature at $600 \mathrm{~s}$

Figure 56 - FDS Design Fire 3 - Visibility at 415 s as it drops below criteria 78

Figure 57 - FDS Design Fire 3 - Visibility at $600 \mathrm{~s}$

Figure 58 - FDS Design Fire 3 - Smoke Layer Height vs Time 80

Figure 59 - FDS Design Fire 3 Looking North at Sprinkler Activation 80

Figure 60 - FDS Design Fire 3 - RSET vs ASET Summary 81

Figure 61 - Typical Section at Corridor

82 
LIST OF TABLES:

Table 1 - Occupancy Classification per 2007 CBC Table 1004.1.1 7

Table 2 - Building Occupant Loads $\quad 9$

Table 3 - Allowable Stories 12

$\begin{array}{ll}\text { Table } 4 \text { - Fire Resistance Ratings } & 12\end{array}$

$\begin{array}{ll}\text { Table } 5 \text { - Height Increases } & 13\end{array}$

$\begin{array}{lr}\text { Table } 6 \text { - Rating Hours } & 14\end{array}$

$\begin{array}{lr}\text { Table } 7-\text { CBC Table } 601 & 15\end{array}$

$\begin{array}{ll}\text { Table } 8-\text { CBC Table } 602 & 16\end{array}$

Table 9-CBC Table 704.8 16

$\begin{array}{lr}\text { Table } 10 \text { - CBC Table 1017.1 } & 10\end{array}$ 


\section{Executive Summary}

This report details the fire and life safety analysis of a Fresno Elementary School. Both prescriptive and performance based analysis were used to determine compliance with the building codes and fire codes which the building was constructed under.

The prescriptive analyses included evaluation of the egress system, structural fire protection requirements, fire detection and alarm system and fire suppression systems. The prescriptive analyses were done to show the code requirements and how the building complies with them.

The performance analyses were done to analyze the performance of the building in the event of a fire scenario. Three fire scenarios were modeled using guidelines from NFPA 101 . The available safe egress time (ASET) and the required safe egress time (RSET) were both reviewed to determine the safety and ability to exit the building of occupants in a fire scenario. Fire Dynamics Simulator (FDS) was used for this analysis.

Recommendations based on the performance and prescriptive analyses are presented. 


\section{FIRE PROTECTION ANALYSIS OF A FRESNO ELEMENTARY SCHOOL}

\section{Project Scope}

The scope of this project was to perform a prescriptive analysis and a performance based analysis to evaluate the fire life safety requirements and goals of the building. The governing codes that were in place at the time of the building design and construction along with additional National Fire Protection Agency (NFPA) standards were used for this analysis. Fire selection scenarios for the performance based design were selected based on NFPA 101 Life Safety Code.

\section{Project Overview Information}

\section{Building Background Information}

This new elementary school is located in Fresno, CA. The elementary school consists of a 2story classroom and administration building. The building is a Type II-B construction, sprinklered building with an E occupancy totaling 50,358 SF. The building has a maximum height of 39' -3 " from the top of slab to the top of the parapets. The building consists of mainly classrooms, an administrative office area, library and support corridors and rest rooms. The first floor spaces have 9'-6" ceilings consisting of T-bar or hard gyp board surfaces. The second floor spaces have 10'-0" ceilings consisting of T-bar or hard gyp board surfaces. The entry corridor (Corridor 101) is open to the second floor ceiling and has a ceiling height of 29'-0".

Key Building Information

- 2 story elementary school

- Type II-B construction

- Sprinklered

- E occupancy

- $50,358 \mathrm{SF}$

- 39'-3" maximum height

- $1^{\text {st }}$ floor rooms have 9'-6" ceilings

- $\quad 2^{\text {nd }}$ floor rooms have $10^{\prime}-0^{\prime \prime}$ ceilings

- Entry corridor has a 29'-0" ceiling 
The building is situated on a new campus in an existing neighborhood. The campus consists of the main primary building which is the subject of this analysis, a multi-purpose building and in the future will have portable classroom and restroom buildings. The main public entry of the building is from the north with access from a gated parking lot with drive thru. At the rear of the building are sports courts which have access gates to allow fire truck drive thru access in a fire event. The 2-story primary classroom building consists of administration offices on the ground floor, a library area on the ground floor and classrooms on the ground floor and second floor. Pre-kindergarten and kindergarten classrooms are located on the ground floor only. Storage and restrooms spaces are located on both floors. Classrooms exit into a common interior corridor. The corridor is open to the entry area and connected to open stairs at both the east and west ends of the building along with a double set of stairs that is located in the center of the building's main entry area.

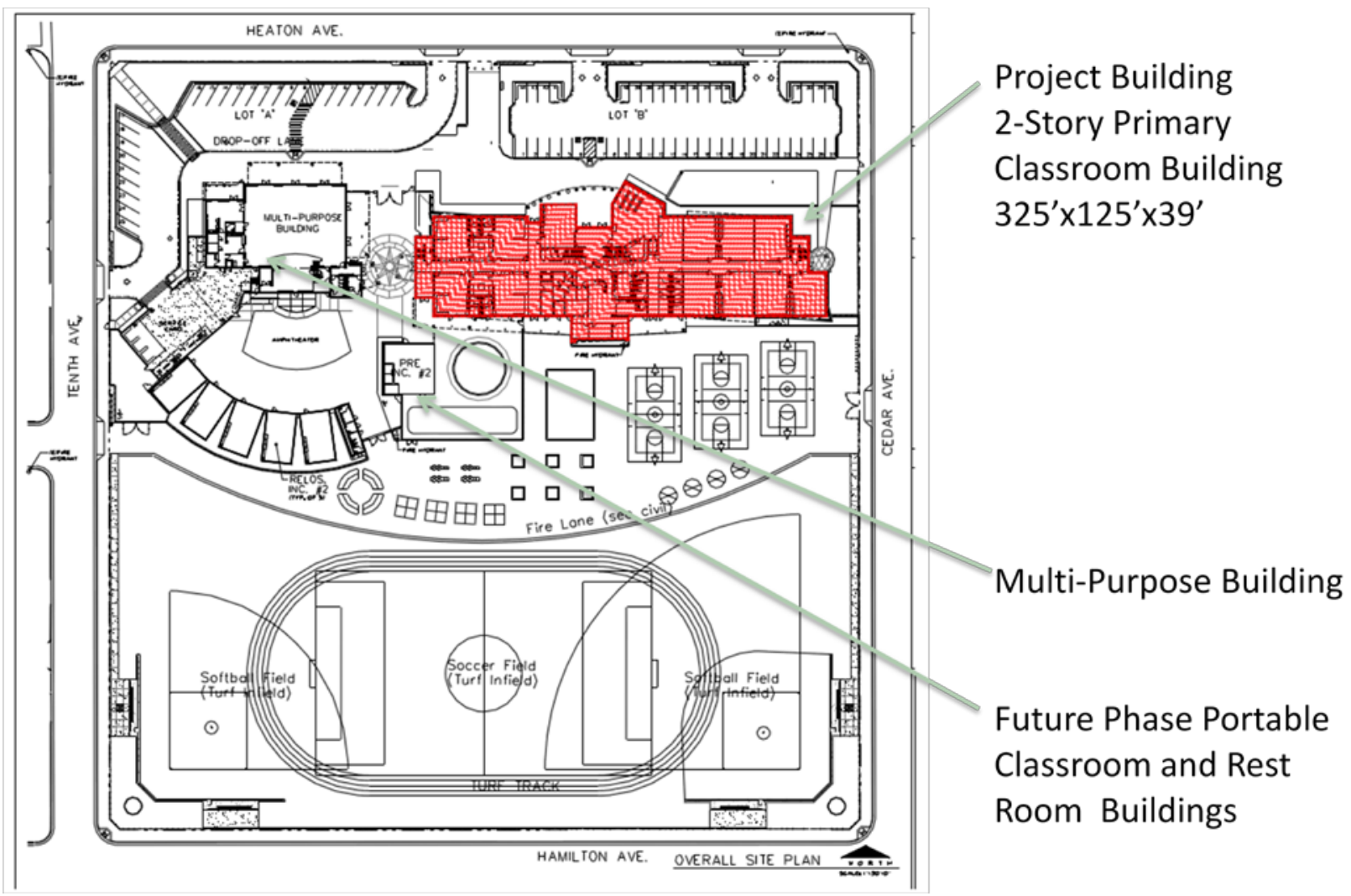

Figure 1 - Campus Site Diagram 

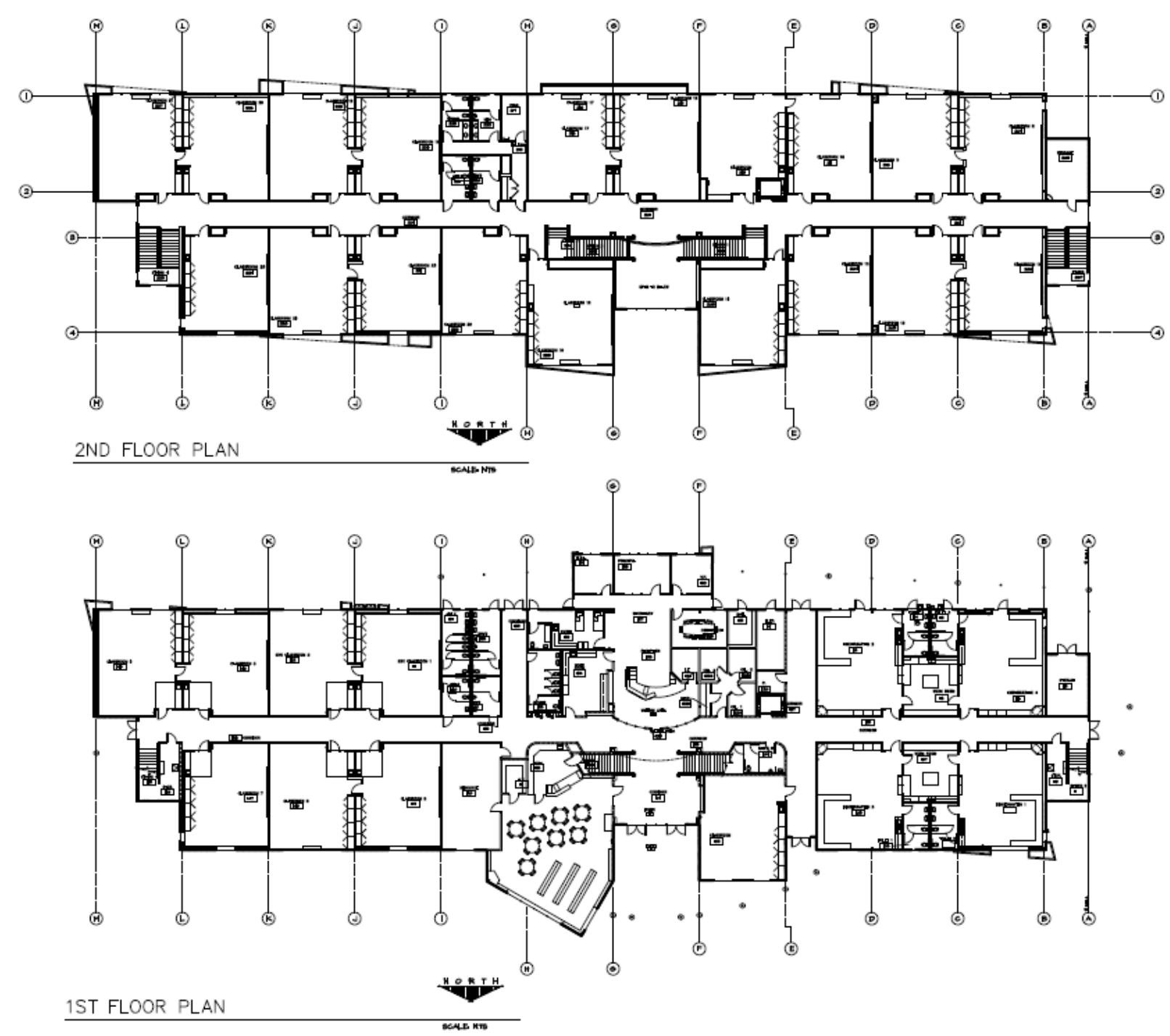

Figure 2-1st and 2nd Overall Floor Plans

\section{Building Reviewing Agencies}

Project plan review was done by the Division of State Architect (DSA) which has three main areas of review.

- $\quad$ Fire Life Safety

- Access and Compliance

- Structural 
The project was also reviewed and approved by the local Fire Agency who has local authority for fire life safety.

During construction a full time independent inspector employed by the owner was on sight to verify monitor the installation of systems with the design documents and code on a day to day basis.

The design team consisting of the architectural design firm and the various engineers including civil, structural, electrical and mechanical all provided construction management services during the construction and provided site observation inspections and reports.

\section{Applicable Codes, Laws, Regulations and Standards}

This new elementary school was designed under the following codes, laws, regulations and standards:

- 2007 CBC (Part2 Title 24), UBC with CA Amendments

- 2007 CEC (Part2 Title 24), NEC with CA Amendments

- 2007 CMC (Part2 Title 24), UMC with CA Amendments

- 2007 CFC (Part2 Title 24), UFC with CA Amendments

- 2007 CA Referenced Standards, Part 12, Title 24,

- NFPA 13, 2002

- NFPA 14, 2003

- NFPA 72 Fire Alarm Code with CA Amendments, 2002 Edition. 


\section{Site Fire Protection Requirements}

\section{$\underline{\text { Site Access }}$}

Per the CFC section 503.a.a an approved fire apparatus access road is required. Access is provided from a gate on the east side of the campus which allows a clear drive south of the building on the sports courts that conforms to the requirements of CFC chapter 5.

\section{Site Fire Hydrants}

Per the CFC appendix B table B105.1 a Type IIB construction building of 50,358 SF requires a fire flow of $4,750 \mathrm{gpm}$ for 4 hours. This requirement can be reduced up to $75 \%$ or a minimum of 1500 gpm per CFC appendix B section B105.2 if the building is sprinklered. This reduction reduces the building hydrant requirement to the minimum $1500 \mathrm{gpm}$. A hydrant is located at the center of the south side of the building and per civil plans meets the $1500 \mathrm{gpm}$ requirement.

\section{Site Fire Plan}

The site is served by a 10 inch diameter water fire loop. This loop serves the project building with a single 6 inch line to the fire hydrant and a single 4 inch line to the fire sprinkler riser at the south east corner of the building. Site fire information is detailed in the figure below.

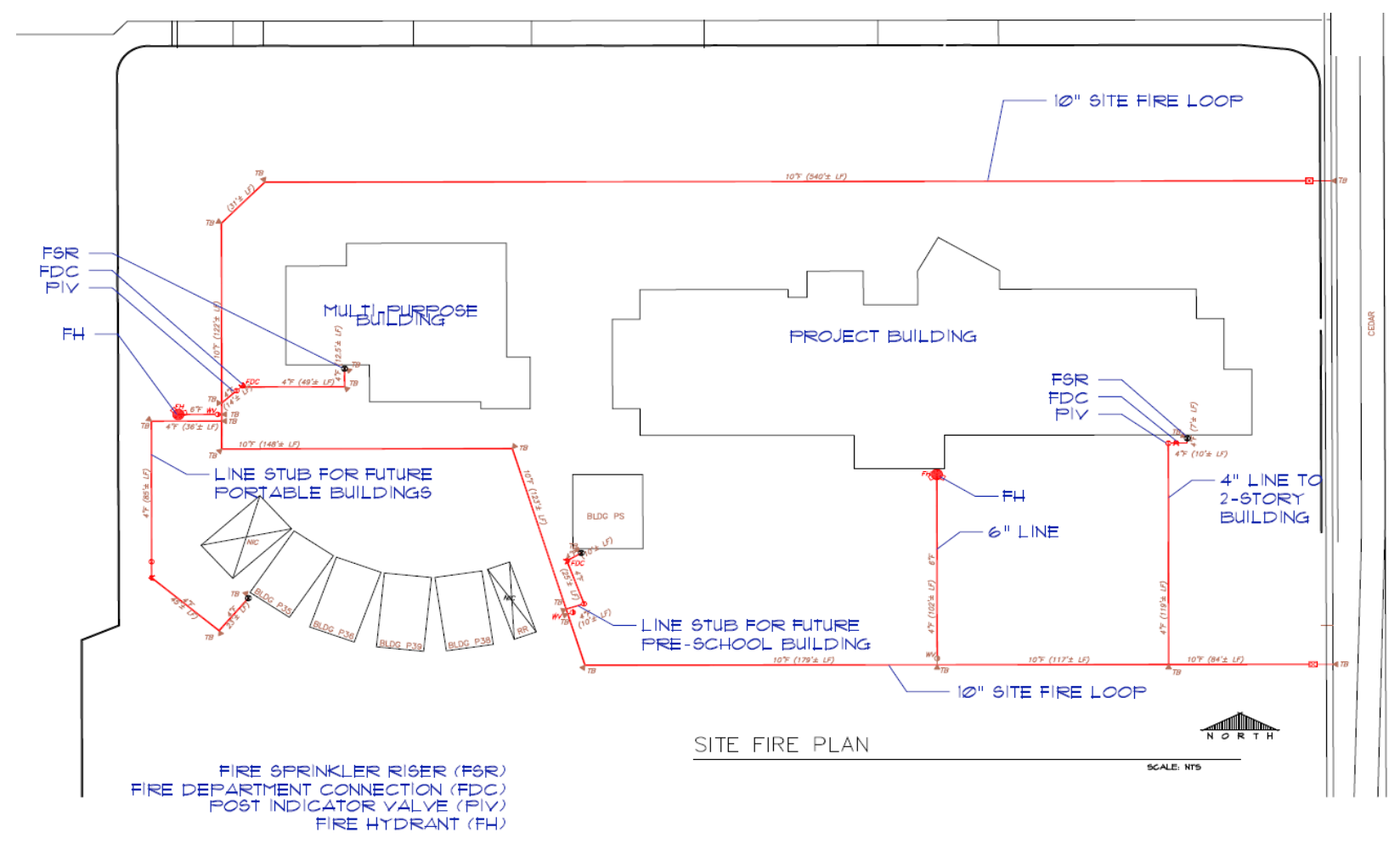

Figure 3 - Site Fire Plan 


\section{Building Egress Requirements}

\section{General Building Layout}

The building is designed to provide a fire rated interior corridor system to serve as the means of egress for the occupants. Classrooms on both the first and second floor exit to the corridor. From the corridor occupants on the second floor are directed to one of three groups of stairs two of which are located at each end of the building and the third is two stairs located in the center of the building. The stairs are open to the corridors on both the second floor and the ground floor. Occupants from the second floor merge with occupants from the second floor at the exterior exit doors. The exterior exit doors are located at the ends of the building and in the center of the building at the main entry.

\section{Occupancy Classification and Loads}

The building has four occupancy classifications per the CBC Table 1004.1.1. These occupancy classifications determine the number of occupants to be used for design occupant loads in determining means of egress.

\begin{tabular}{|l|l|}
\hline FUNCTION OF SPACE & FLOOR AREA IN SQ. FT. PER OCC. \\
\hline $\begin{array}{l}\text { Accessory storage area, mechanical equipment } \\
\text { room. }\end{array}$ & 300 gross \\
\hline Business areas & 100 gross \\
\hline Educational Classroom area & 20 net \\
\hline Library Reading rooms & 50 net \\
\hline
\end{tabular}

Table 1 - Occupancy Classification per 2007 CBC Table 1004.1.1 
The majority of the building areas are educational. The administration area which is a business occupancy is located in the south center of the first floor and is separated from the education area and has egress paths separate from those serving the education portion of the building. Occupant classifications are located in the building per the following figure.

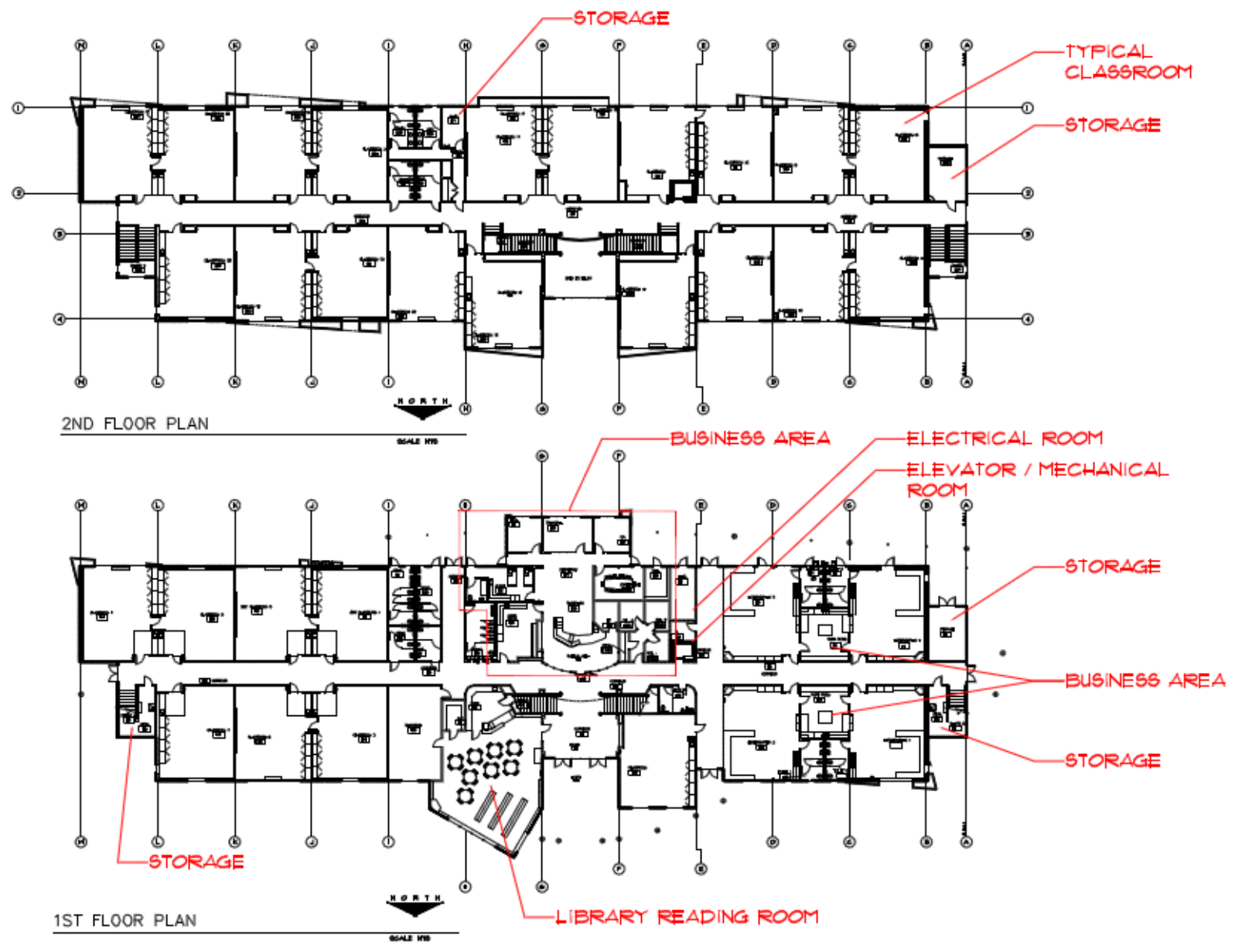

Figure 4-Occupant Classification Areas 
Occupant loads for the building are per the following table.

\section{FUNCTION OF SPACE}

First Floor

Accessory storage area, mechanical equipment room.

Business areas

Educational Classroom area

Library Reading rooms

First Floor Total

Second Floor

Accessory storage area, mechanical equipment room.

Educational Classroom area

Second Floor Total

Building Total
8

2

\section{OCCUPANT LOAD}

57

539

26

630 Occupants

842

844 Occupants

1474 Occupants

Table 2 - Building Occupant Loads

\section{General Means of Egress Height Requirements}

CBC 1003.2 requires that the ceiling height in the means of egress shall be not less than 7 feet 6 inches. All ceilings in the building are over 8 feet in height. 


\section{Means of Egress Illumination}

The exit discharge shall be illuminated at all times the building is occupied per CBC 1006.1 The illumination level shall not be less than 1 foot candle measured at the walking path surface level. Per CBC 1006.3 emergency power is required for a duration of 90 minutes by use of batteries or an onsite generator. The building complies with the above.

\section{Classroom Exit and Exit Access Doorways}

Typical classrooms are under 1000 SF which yields an occupant load of 49 or less per classroom. Per CBC section 1015 exits in type $E$ or B occupancy with less than 49 occupants require only 1 exit door. The arrangement of the door shall be that the availability is obvious and it shall remain unobstructed at all times.

\section{Exit Access Travel Distance}

Travel distance to exits complies with CBC section 1016. Per 1016.1 exists shall be located on each story such that the maximum length of exit travel measured from the most remote point within each story shall not exceed the distances of Table 1016.1. Per Table 1016.1 in an E occupancy with sprinklers the maximum exit travel distance is 250 feet. Per Table 1016.1 in a B occupancy with sprinklers the maximum exit travel distance is 300 feet. The building meets these requirements.

\section{Corridor Requirements}

Corridor requirements follow CBC 1017. Per Table 1017.1 a corridor served by 10 or more occupants in a type E occupancy of a fire sprinklered building shall have a fire resistance rating of 1 hour. The corridor system of the building has a one hour rating.

\section{Number of Exit Requirements}

Per CBC Table 1019.1 the second floor with an occupant load of 844 occupants will require a minimum of 3 exits. The first floor with an occupant load of 630 requires 3 exits. The total occupant load of 1474 requires 4 exits. The second floor has 3 exits and complies with the requirements and the ground floor has 5 main exits and complies with the requirements.

\section{Exit Discharge Requirements}

Exit discharge is per CBC 1024 and requires that exits discharge directly to the exterior of the building and that the capacity is not less than the required discharge capacity of the exits being served. The exits comply with the requirements of the code. 


\section{Exit Paths}

The following diagrams show general proposed exit paths for the building. Circled exterior doors represent primary exit doors serving the discharge of the second and first floor occupants. These plans are also in Appendix $\mathbf{A}$ in a larger scale.

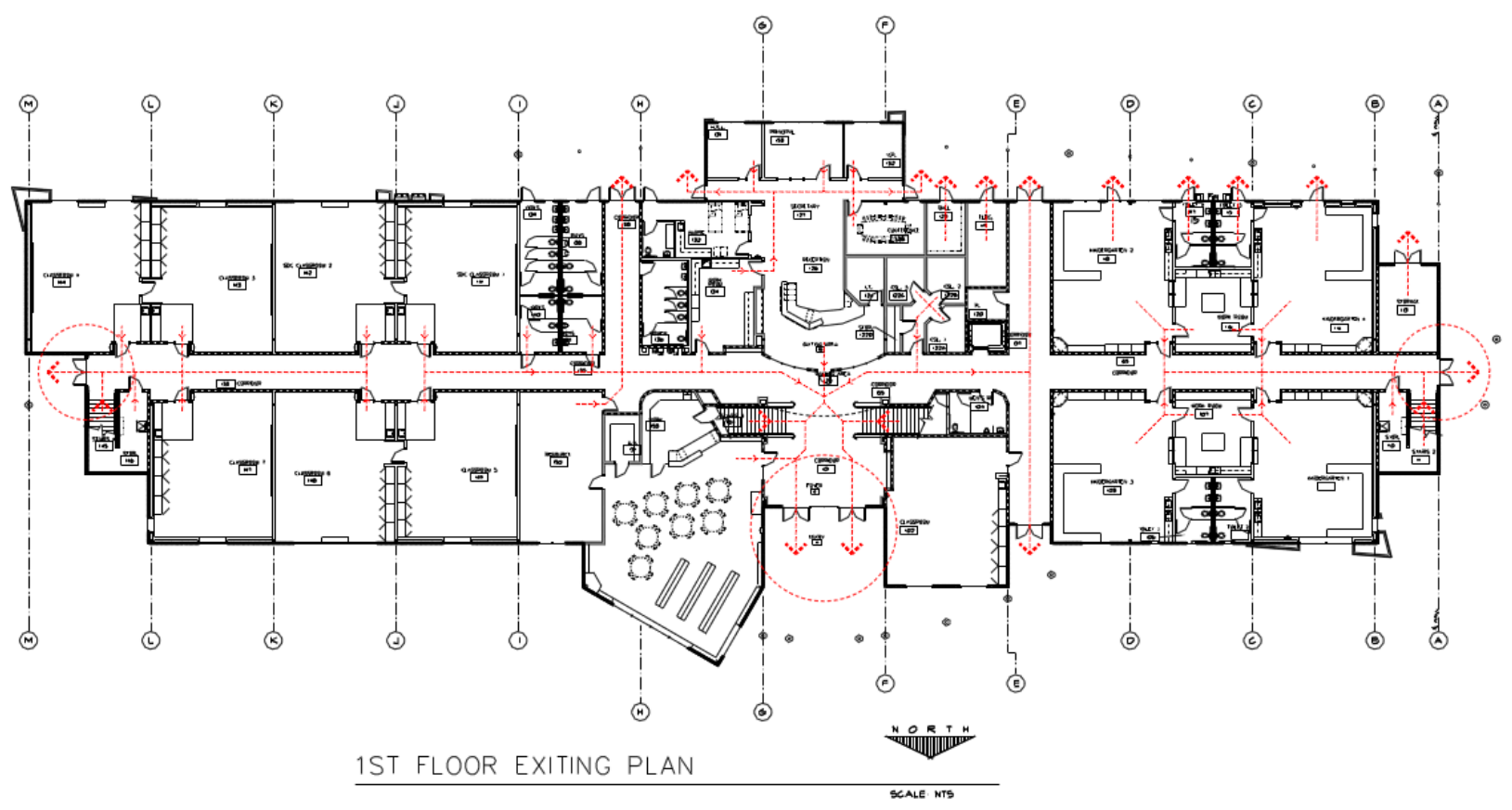

Figure 5 - Exit Path - First Floor

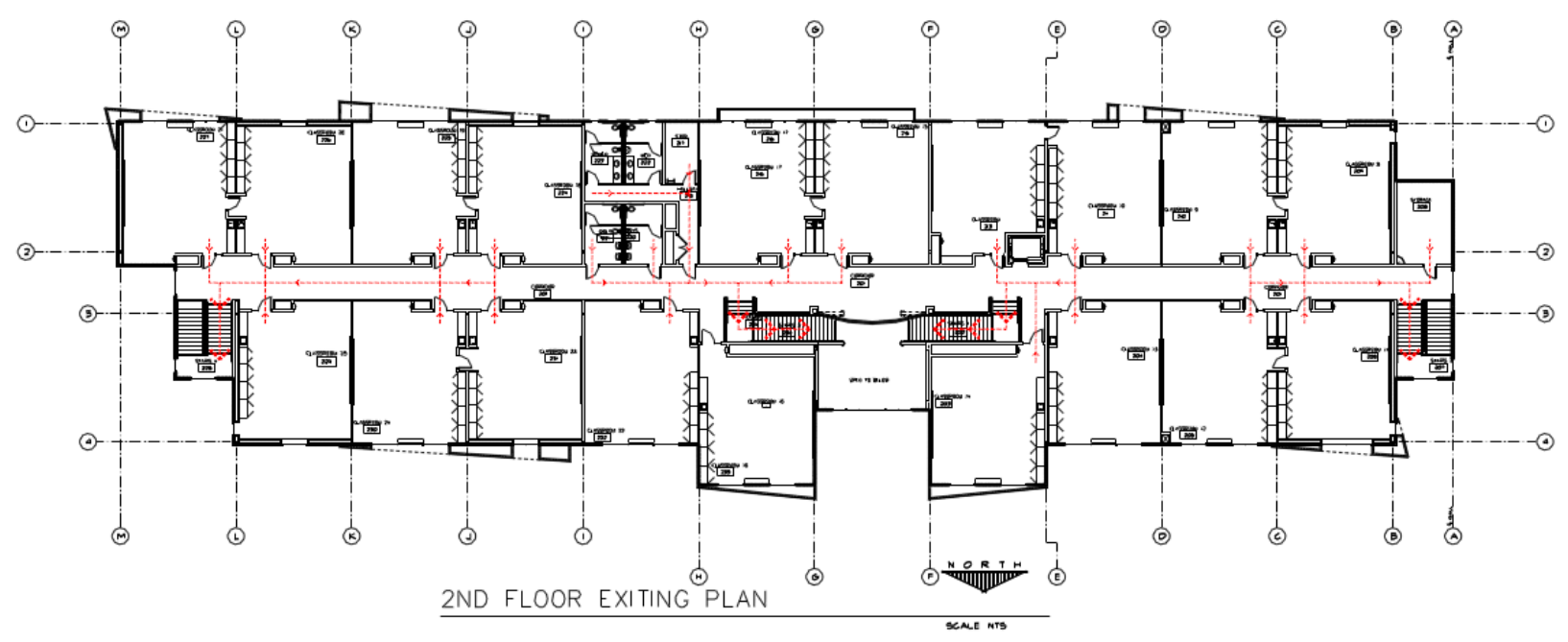

Figure 6 - Exit Path - Second Floor 


\section{Building Structural Fire Protection}

\section{General Information}

The structural fire protection evaluation details information on the minimum required and the actual construction classification, materials and fire resistance requirements for the project elementary building.

\section{General Building Classification Options}

Reviewing the requirements for the building in general as an E occupancy building with two stories each with $27,196.5$ SF for a total of 54,393 SF of area. From this area we can determine the following:

\section{Allowable Building Heights and Areas with no sprinkler or area increases}

(only construction types that meet building area are shown)

Allowable Building Heights and Areas Per CBC Table 503

$\begin{array}{ccc}\text { Construction Type } & \begin{array}{c}\text { Base \# } \\ \text { of Stories }\end{array} & \text { Tabular Floor } \\ \text { Area }\left(\mathrm{ft}^{\wedge} 2\right)\end{array}$

Table 3 - Allowable Stories

Fire-Resistance Rating Requirements for Building Elements with no sprinkler or area increases

(only construction types that meet building area are shown).

Fire-Resistance Rating Requirements for Building Elements Per CBC Table 601

Building Element

Primary Structural Frame

Bearing Wall Exterior

Bearing Wall Interior

Nonbearing Wall and Partitions

Inter.

Floor Const. and Secondary

Memb.

Roof Const. and Secondary

Memb.
Type IA

3

3

3

0

2

$1-1 / 2$
Ratings in Hours

Type IB

2

2

2

0

2

1

Table 4 - Fire Resistance Ratings 


\section{Allowable Building Heights and Areas if using sprinkler and Area increase allowance}

(only construction types that meet building area are shown)

Base Area

Frontage Increase

Sprinkler Increase

Area After

Increase

Construction

Type
Percent

100

11

200

311

Base \#

of Stories

Max. \# of Stories

Tabular Floor Area (ft^2)

UL

UL

UL

26500

14500

23500

14500

25500

18500

9500 a

Allowable Floor

Area (ft^2)

UL

UL

82415

45095

73085

45095

79305

57535

29545 b

Maximum

Building

Area ( $\left.\mathrm{ft}^{\wedge} 2\right)$

UL

UL

329660

135285

292340

135285

317220

115070

59090

UL = Unlimited

$\mathrm{a}=311$ percent times tabular

area

$b=$ stories $\mathrm{x}$ allowable floor area (max. 3 stories)

Table 5 - Height Increases 
Fire-Resistance Rating Requirements for Building Elements with Sprinkler and Area increases

(only construction types that meet building area are shown).

Fire-Resistance Rating Requirements for Building Elements Per Table 601

Building

Element

Primary

Ratings in Hours

Struct. Frame

Bearing

3

2

1

0

2

2

2

Type Type

Wall Exterior

Bearing

3

2

1

0

1

0

1/HT

1

0

Wall Interior

Nonbear. Wall

0

0

0

0

0

see

and Part. Inter.

FIr Const. and

2

2

1

0

1

0

HT

1

0

Secd. Memb.

Roof Const. and

$1-1 / 2$

1

1

0

1

0

HT

1

Secd. Memb.

Table 6 - Rating Hours

\section{Actual Building Evaluation}

The actual building has the following construction classification, materials and fire resistance requirements.

Number of Stories $=2$

Occupancy $=\mathrm{E}$

Construction Type $=\| \mathrm{I}-\mathrm{B}$

Fire Sprinklers $=$ Yes

Building Perimeter, $\mathrm{P}=921 \mathrm{ft}$

Perimeter fronting public way, $F=333 \mathrm{ft}$ 
Access way width, $\mathrm{W}=30 \mathrm{ft}$

Per Table 601 a Type II-B , 0-hour fire resistance rating is required for building elements including - Primary Structural Frame, Bearing Walls (interior and exterior), Non-Bearing Walls and Partitions, Floor Constructions, and Roof Constructions.

\begin{tabular}{|c|c|c|c|c|c|c|c|c|c|}
\hline \multirow[b]{2}{*}{ BUILDING ELEMENT } & \multicolumn{2}{|c|}{ TYPE I } & \multicolumn{2}{|c|}{ TYPE II } & \multicolumn{2}{|c|}{ TYPE III } & \multirow{2}{*}{$\begin{array}{c}\text { TYPE IV } \\
\text { HT }\end{array}$} & \multicolumn{2}{|c|}{ TYPE V } \\
\hline & A & в & $\mathbf{A}^{*}$ & 8 & $\mathrm{~A}^{*}$ & B & & $A^{*}$ & 8 \\
\hline Structural frame & $3^{b}$ & $2^{b}$ & 1 & 0 & 1 & 0 & HT & 1 & 0 \\
\hline \multicolumn{10}{|l|}{ Bearing walls } \\
\hline Exterior ${ }^{*}$ & 3 & 2 & 1 & 0 & 2 & 2 & 2 & 1 & 0 \\
\hline Interior & $3^{b}$ & $2^{\mathrm{b}}$ & 1 & 0 & 1 & 0 & $1 / \mathrm{HT}$ & 1 & 0 \\
\hline $\begin{array}{l}\text { Nonbearing walls and partitions } \\
\text { Exterior }\end{array}$ & \multicolumn{9}{|c|}{ See Table 602} \\
\hline $\begin{array}{l}\text { Nonbearing walls and partitions } \\
\text { Interior }\end{array}$ & 0 & 0 & 0 & 0 & 0 & 0 & $\begin{array}{c}\text { See Section } \\
602.4 .6\end{array}$ & 0 & 0 \\
\hline $\begin{array}{l}\text { Floor construction } \\
\text { Including supporting bearns } \\
\text { and joists }\end{array}$ & 2 & 2 & 1 & 0 & 1 & 0 & HT & 1 & 0 \\
\hline $\begin{array}{l}\text { Roof construction } \\
\text { Including supporting bearns } \\
\text { and joists }\end{array}$ & $1 \frac{1 / 2^{t}}{}$ & $1^{\mathrm{cod}}$ & $1^{\mathrm{c}, \mathrm{d}}$ & $0^{4}$ & $1^{\varepsilon, d}$ & $\theta$ & HT & $1^{0,4}$ & 0 \\
\hline
\end{tabular}

Por SI: 1 foot $=3048 \mathrm{~mm}$.

a. The structural frame shall be considered no be the columns and the girders, beams, tusses and spasdets having direct coenectioes to the columns and bracing nembers designed to carry gravity louts. The members of floor or rood panels which have no coanection to the columns shall be considered secondary members and not a part of the structural frame.

b. Roof supgerts. Fire-fesistance ratings of structaral frame and bearing walls are permitted to be reduced by 1 hour where supporting, a roof only

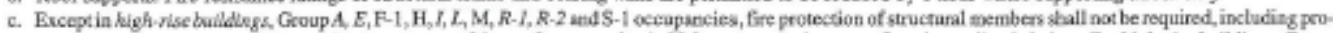

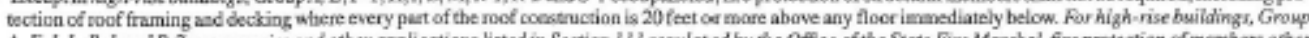

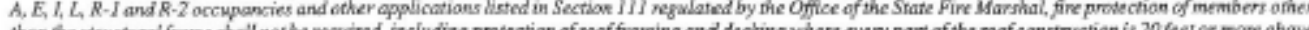

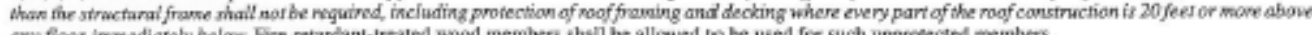
any floor immediarely below. Fice-retardant-trested wood members shali be allowed to be used for such unprotectod members.

d. In all occupancies, heawy timber stall be allowed ahere a 1-hour of less fire-resistance rating is required.

e. An approved antomatic sprinklet system in accordance with Section 9033.1 .1 shall be allowed to be substituted for 1-hour fire-resistance rated constraction. provifed such syssem is not orhereise required by other provisions of the code cr used for an allowable area increase in accordance with Section 506.3 ce an allowable height increase in accondance with Section 5042 The 1-bour substitufion for the fre resistance of exterior walls shall not be permitted.

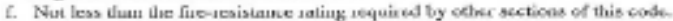

g. Not less than the fire-resistance rating bosed on fire separatice distance (ser Table 602).

Table 7 - CBC Table 601 
Per Table 602 Exterior Walls for the building have a fire-resistance rating or 0-hours because the fire separation distance is greater than 30 feet.

TABLE 602

Type E

FIRE-AESISTANCE RATWG REQUIREMENTS FOR EXTERIOA WALLS BASED ONIFIAE SEPARATION DISTANCE*

\begin{tabular}{|c|c|c|c|c|}
\hline $\begin{array}{l}\text { FIRE SEPARATION DISTANCE = } x \\
\text { (leEt) }\end{array}$ & TYPE OF CONSTRUCTION & $\begin{array}{l}\text { OCCUPANCY } \\
\text { GROUP K, L }\end{array}$ & $\begin{array}{l}\text { OCCUPANCY } \\
\text { GROUP F-1, M, s-1 }\end{array}$ & $\begin{array}{c}\text { OCCUPANCY } \\
\text { GAOUस } A, B, E, F-2, L, F, s-2, U^{\text {b.t }}\end{array}$ \\
\hline$x<5^{\circ}$ & All & 3 & 2 & 1 \\
\hline $5 \leq x<10$ & $\begin{array}{c}\text { IA } \\
\text { Others }\end{array}$ & $\begin{array}{l}3 \\
2\end{array}$ & $\begin{array}{l}2 \\
1\end{array}$ & $\begin{array}{l}1 \\
1\end{array}$ \\
\hline $10 \leq x<30$ & $\begin{array}{c}\text { IA, IB } \\
\text { IIB, VB } \\
\text { Others }\end{array}$ & $\begin{array}{l}2 \\
1 \\
1\end{array}$ & $\begin{array}{l}1 \\
0 \\
1 \\
\end{array}$ & $\begin{array}{l}1^{d} \\
0 \\
1^{d}\end{array}$ \\
\hline$x \geq 30$ & All & 0 & 0 & 0 \\
\hline
\end{tabular}

For Sl: 1 foos $=304.8 \mathrm{~mm}$.

a. Land-bearing exterior walls shall also coengly with the fire-resistance rating requirements af Thble 601 .

b. For special requiremesss for Group U occupancies see Section 406.1 .2

c. See Section 705.11 fur party walk.

d. Open perking gerazes complying with Seation 406 shull not he regained to hoe a fire-resiscance nating

c. The fire-resistance rating of anernetior wall is determined hased upan the fire sepestion distance of theexterior wall and the stary in which the wall is locsted.

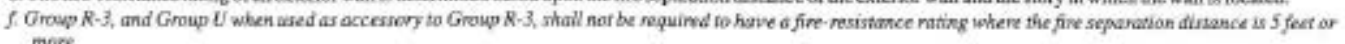
more.

Table 8 - CBC Table 602

Per Table 704.8 the allowable area opening is not limited because the Fire Separation Distance is greater than 30 feet and the building is classified as unprotected and sprinklered.

TABLE 704.8

MAXMUM AREA OF EXTERIOA. WALL OPENINGS"

\begin{tabular}{|c|c|c|c|c|c|c|c|c|}
\hline \multirow[b]{2}{*}{$\begin{array}{l}\text { CLASSIFICATION } \\
\text { OF OPENIING }\end{array}$} & \multicolumn{8}{|c|}{ FIRE SEPAAATION DISTANCE (lEei) } \\
\hline & 0 to $3^{4}$ & $\begin{array}{c}\text { Greater } \\
\operatorname{man} 3 \text { to } 5^{\circ} \theta\end{array}$ & $\begin{array}{c}\text { Grester } \\
\text { than } 5 \text { to } 10^{\text {ceas. }} \text {. }\end{array}$ & $\begin{array}{c}\text { Greater } \\
\text { than } 10 \text { to } 15^{\text {dace }}\end{array}$ & $\begin{array}{c}\text { Greater } \\
\text { than } 15 \text { to } 20^{\leq 0}\end{array}$ & $\begin{array}{c}\text { Greater } \\
\text { than } 20 \text { to } 25^{<4}\end{array}$ & $\begin{array}{c}\text { Creater } \\
\text { than } 25 \text { to } 30^{53}\end{array}$ & $\begin{array}{l}\text { Oreater } \\
\text { than } 30\end{array}$ \\
\hline Hinprotected & $\begin{array}{c}\text { Not } \\
\text { Permitted }\end{array}$ & $\begin{array}{c}\text { Not } \\
\text { Permitted }\end{array}$ & toget & $15 \%$ & $25 \%$ & $45 \%$ & $70 \%$ & No Limit' \\
\hline Protected & $\begin{array}{c}\text { Not } \\
\text { Permitted }\end{array}$ & $15 \%$ & $25 \%$ & $45 \%$ & $75 \%$ & No Limit? & No Limit" & No Limit \\
\hline
\end{tabular}

For SI 1 fout $=304.8 \mathrm{~mm}$.

a. Valuts given are percentage of the aves of the everioc wall

b. Nor used

c. For eccupancies in Oroup R-3, the maximum percentage of wtprotectod and protected evverier wall openings ahail be 25 percent

4. The ana of openines in an epes porking structure wich a fire separation distance of greater than 10 feet shall not be limited.

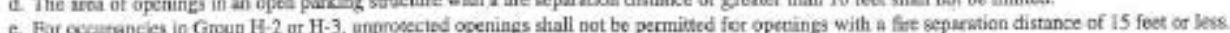

1. Ror requinemens for fire walls for builiengs with differing roof heiglte, see Section 705.6.1.

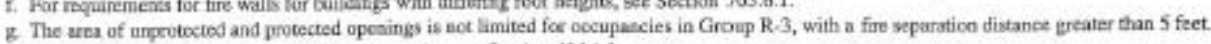

h. For ipecis requirements for Grorap U cocupansies, see Section 406.1 .2

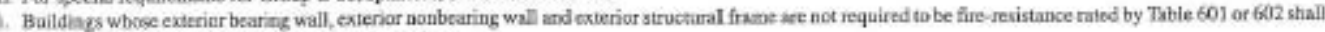

be pernitiod to have unimited ingeotested apenings.

j. Includes accessary buildines to Group $\mathrm{R}-3$.

Table 9 - CBC Table 704.8 
Per Table 1018.1 for an E occupancy with a corridor serving greater than 10 people and sprinklers the corridor is required to have a 1-hour rating. All penetrations of the rating are required to be protected.

\begin{tabular}{|c|c|c|c|}
\hline \multirow[b]{3}{*}{ OCCUPANCY } & \multicolumn{2}{|c|}{$\begin{array}{l}\text { TABLE } 1017.1 \\
\text { CORAIDOR FIRE-RESISTANCE RATING }\end{array}$} & \multirow{2}{*}{ E } \\
\hline & \multirow[b]{2}{*}{ OCOUPANT LOAD SERVED BY COARIDOA } & REQUIREO FRE-MESISTANCE RATING (houre) & \\
\hline & & without aprinkder aystam & With aprinater eystem" \\
\hline $\mathrm{H}-1, \mathrm{H}-2, \mathrm{H}-3, \mathrm{~L}$ & All & Not Permitted & 1 \\
\hline $\mathrm{H}-4, \mathrm{H}-5$ & Greater than 30 & Not Permitted & 1 \\
\hline$A^{d}, B, F, M, S, U$ & Greater than 30 & 1 & 0 \\
\hline $\mathrm{R}$ & Greater than 10 & Not Perminted & $I$ \\
\hline $1-2^{2}, 1-21,1-4$ & Greater then 6 & Noc Permitted & $t$ \\
\hline$[-1,1 \cdot 3$ & Greuter then 6 & Not Permitted & $1^{t}$ \\
\hline E & Greater than 10 & 1 & $I$ \\
\hline
\end{tabular}

Table 10 - CBC Table 1017.1

\section{Actual Building Area Allowances}

Per Table 503 a Group E occupancy Type II-B building is allowed 2 stories and 14,500^2 per floor.

The following allowances allow the floor area to increase as follows:

\section{Frontage Increase:}

If $=100 *\left[\frac{F}{P}-0.25\right] *[W / 30]$

Where

If $=$ Area increase due to frontage (percent)

$\mathrm{F}=$ Building perimeter which fronts public way or open space having $20 \mathrm{ft}$ minimum width.

$\mathrm{P}=$ Perimeter of the building

W = Minimum width of public way or open space.

If $=100 *\left[\frac{333}{921}-0.25\right] *[30 / 30]$

If $=11$ percent 


\section{Sprinkler Increase:}

Section 506.3 of the IBC allows buildings protected with an approved automatic sprinkler system to have an area increase of:

200 percent (Is $=200$ percent) for multi-storied buildings.

Is $=200$ percent

Area Modification per (IBC Section 506)

$\mathrm{Aa}=A t+[A t * I f / 100]+[A t * I s / 100]$

$\mathrm{Aa}=14,500^{\wedge} 2+\left[14,500^{\wedge} 2 * 11 / 100\right]+\left[14,500^{\wedge} 2 * 200 / 100\right]$

$A a=45,095^{\wedge} 2$ per floor

Where

$\mathrm{Aa}=$ Allowable area per floor $\left(\mathrm{ft}^{\wedge} 2\right)$

At $=$ Tabular area per floor in accordance with Table $503\left(\mathrm{ft}^{\wedge} 2\right)$

If $=$ Area increase due to frontage (percent) as calculated in accordance with Section 506.2 and shown below.

Is = Area increase due to sprinkler protection (percent) as calculated in accordance with Section 506.3.

\section{Summary of allowed building area:}

Building with 11 percent increase from frontage and 200 percent increase from the 14,500^2 allowed by table 503 . With these increases the building is allowed $45,095^{\wedge} 2$ per floor. The actual building is $27,196.5^{\wedge} 2$ per floor, thus the building meets the allowed code floor areas.

\section{Actual Building Construction:}

The only required area of the building requiring a rating is the interior corridor which requires a 1-hour rating. The corridor extends from the floor to the bottom of the floor above or the bottom of the roof deck. All opening including doors, glass and any penetrations for pipe or ductwork must maintain the rating. 


\section{Vertical Exit Requirements}

Per the requirements of $\mathrm{CBC}$ section 1020 the exit stairs serving the second floor corridors are not required to be enclosed from the exit corridors. The current configuration has the stairs open to both the second floor corridors and the first floor corridors. The code and exceptions for this are as follows:

\section{SECTION 1020 VERTICAL EXIT ENCLOSURES [B]}

\subsection{Enclosures required.}

Interior exit stairways and interior exit ramps shall be enclosed with fire barriers constructed in accordance with Section 706 of the California Building Code or horizontal assemblies constructed in accordance with Section 711 of the California Building Code, or both. Exit enclosures shall have a fire-resistance rating of not less than 2 hours where connecting four stories or more and not less than 1 hour where connecting less than four stories. The number of stories connected by the exit enclosure shall include any basements but not any mezzanines. An exit enclosure shall not be used for any purpose other than means of egress.

\section{Exceptions:}

9. In other than Group $\mathrm{H}$ and I occupancies, interior egress stairways serving only the first and second stories of a building equipped throughout with an automatic sprinkler system in accordance with Section 903.3.1.1 are not required to be enclosed, provided at least two means of egress are provided from both floors served by the unenclosed stairways. Such interconnected stories shall not be open to other stories. Unenclosed exit stairways shall be remotely located as required in Section 1015.2. 
Diagrams below show the fire rated corridors. These diagrams are also in Appendix B in a larger scale.

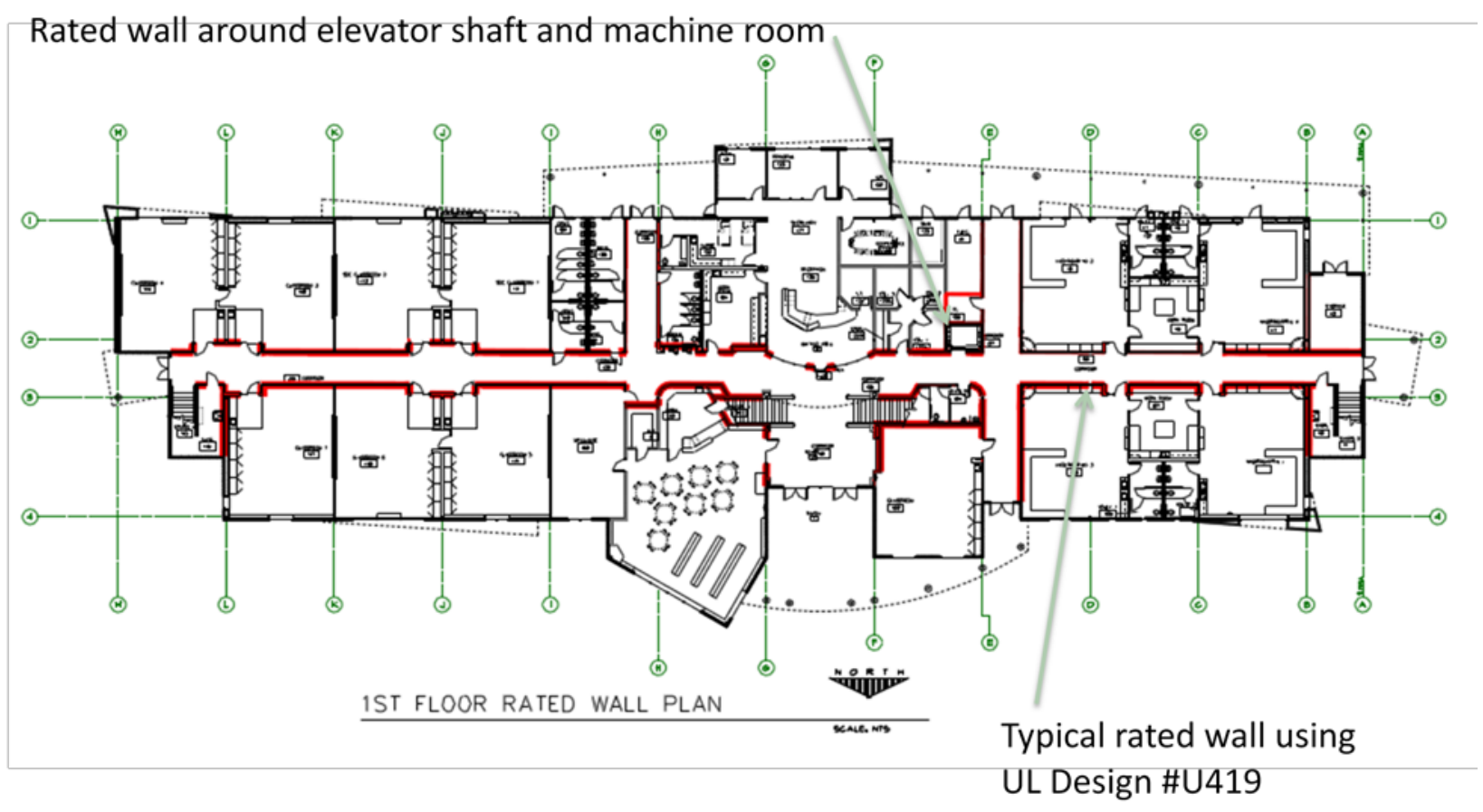

Figure 7 - First Floor Plan - Fire Rating

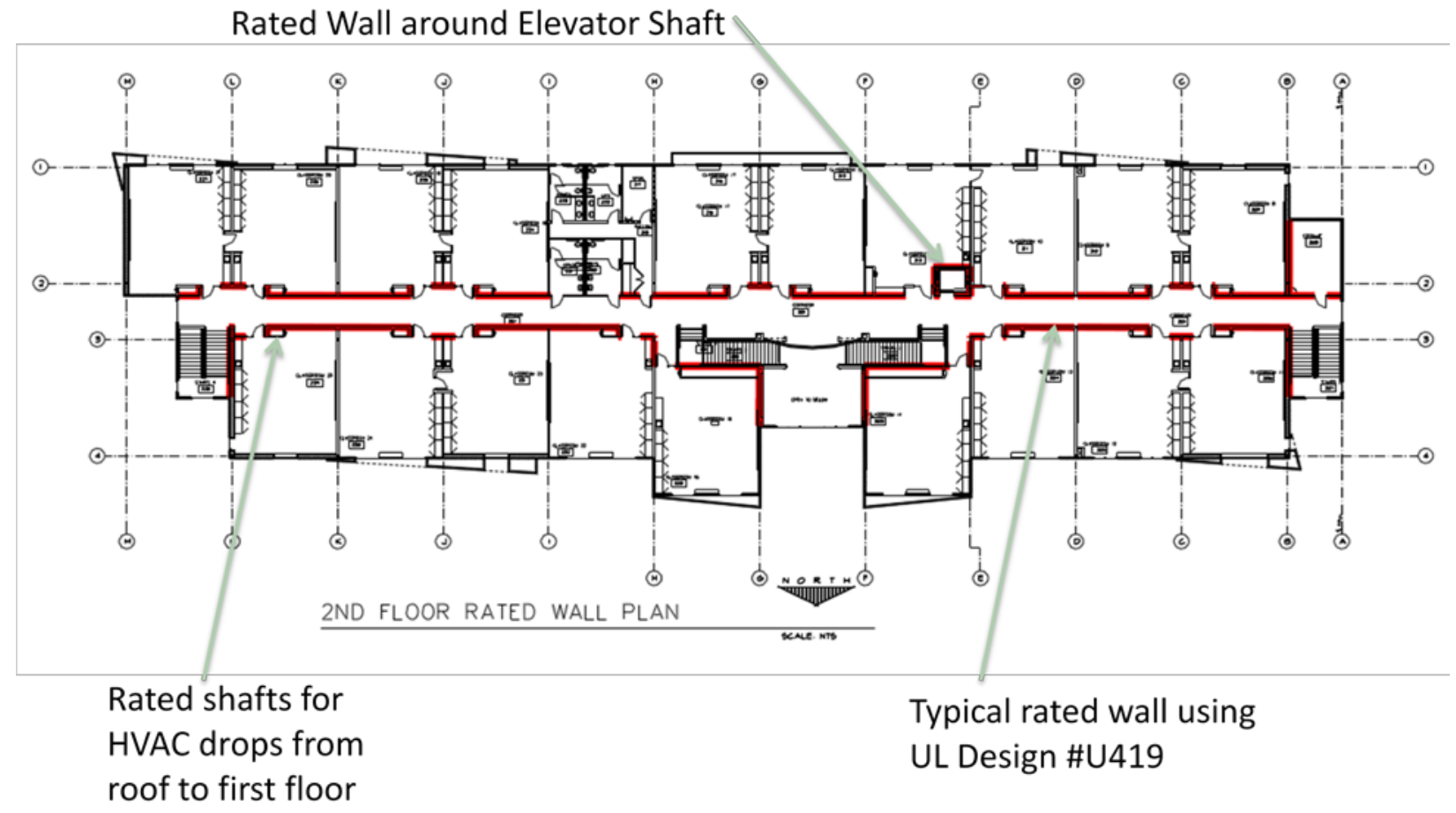

Figure 8 -Second Floor Plan - Fire Rating 


\section{Actual Building Construction Materials:}

\section{Roof Construction:}

Metal deck with insulation and built-up roofing above. Metal beams and framing.

\section{Structure:}

Metal construction consisting of various columns, beams, girders and joists of metal construction.

Walls (Interior and Exterior):

\section{Exterior Walls:}

6" metal studs at 16" O.C. with R-19 insulation. Exterior cement with plaster lath. Interior varies per room finish schedule.

Interior Walls (non-rated):

6" metal studs at 16" O.C. with sound batt insulation. Finish varies per room finish schedule. 


\section{Rated Constructions:}

Interior Walls (1-hour rated):

6" metal studs at 16 " O.C. with sound batt insulation. 5/8" type " $x$ " gyp. Bd. On each side. (UL \#419).

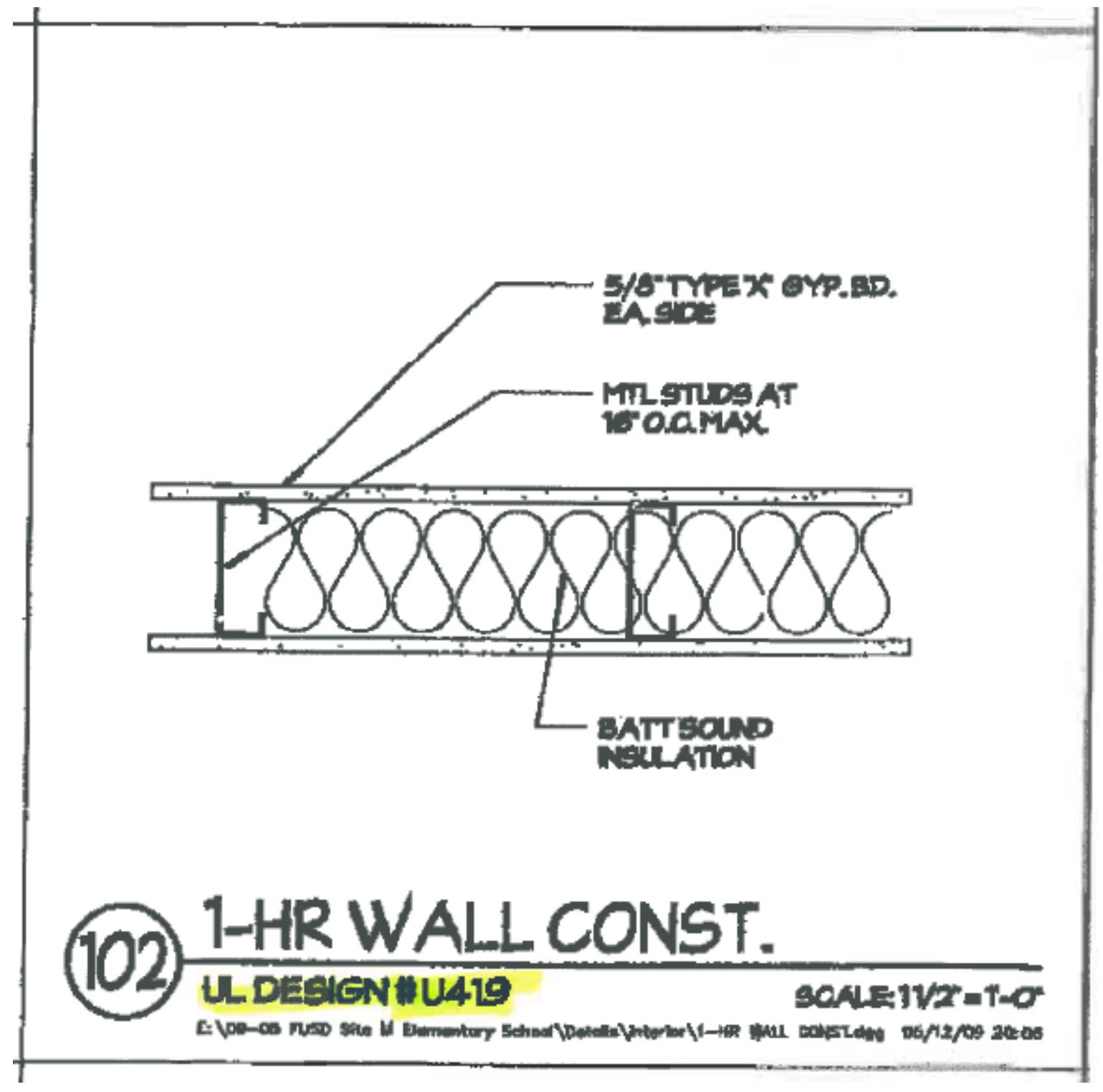

Figure 9 - UL 419 Corridor Interior Wall Rating Detail 
Interior Rated Corridor - wall and ceiling tunnel (1-hour rated):

6 " metal studs at 16 " O.C. with sound batt insulation. 5/8" type " $x$ " gyp. Bd. On each side. (UL \#419).

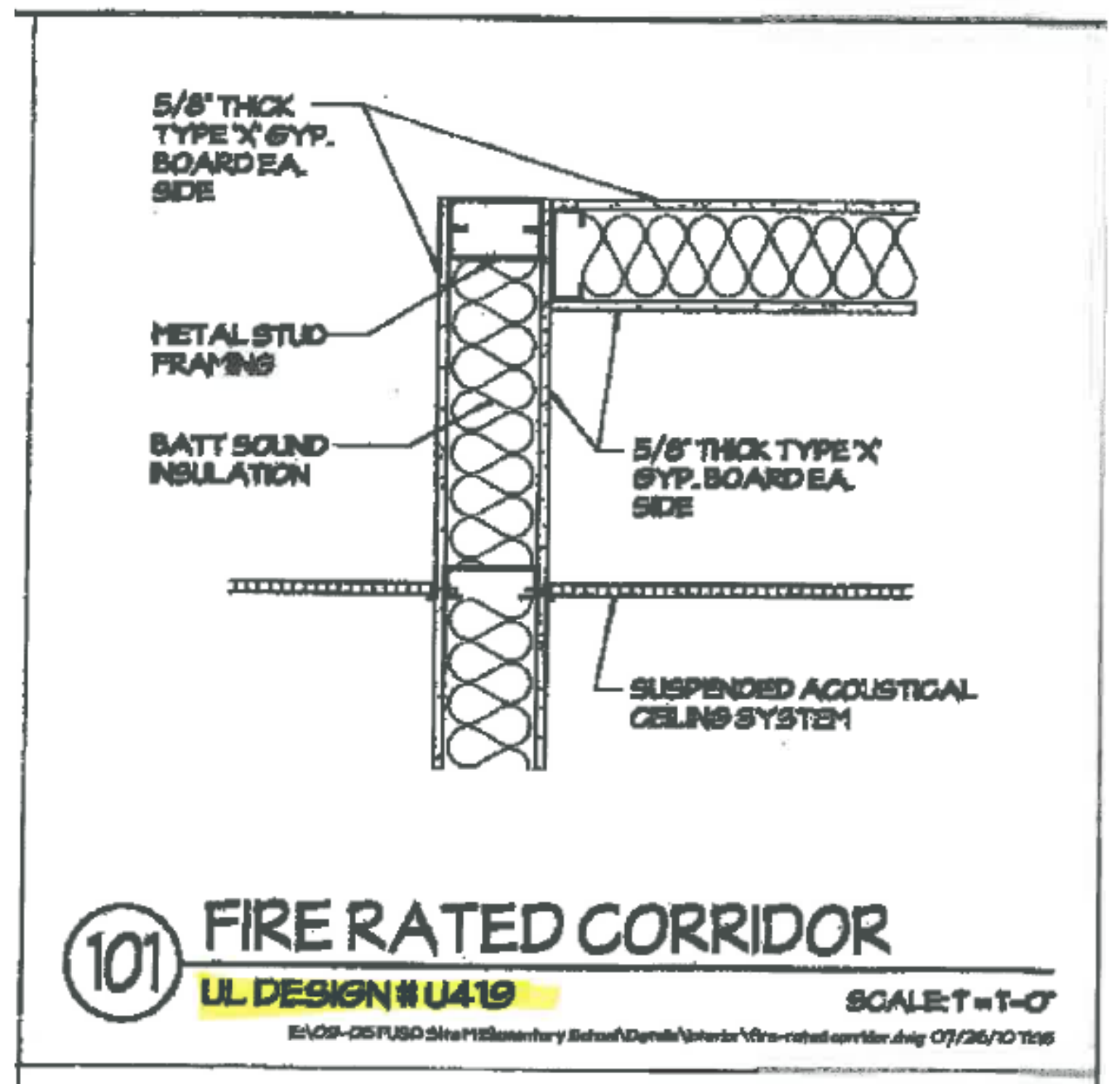

Figure 10 - UL 419 Corridor Tunnel Rating Detail 
Rated Shaft at Elevator (1-hour rated):

USG Steel Studs at 24" O.C. 5/8" type " $x "$ gyp. Bd. On each side. (UL \#469).

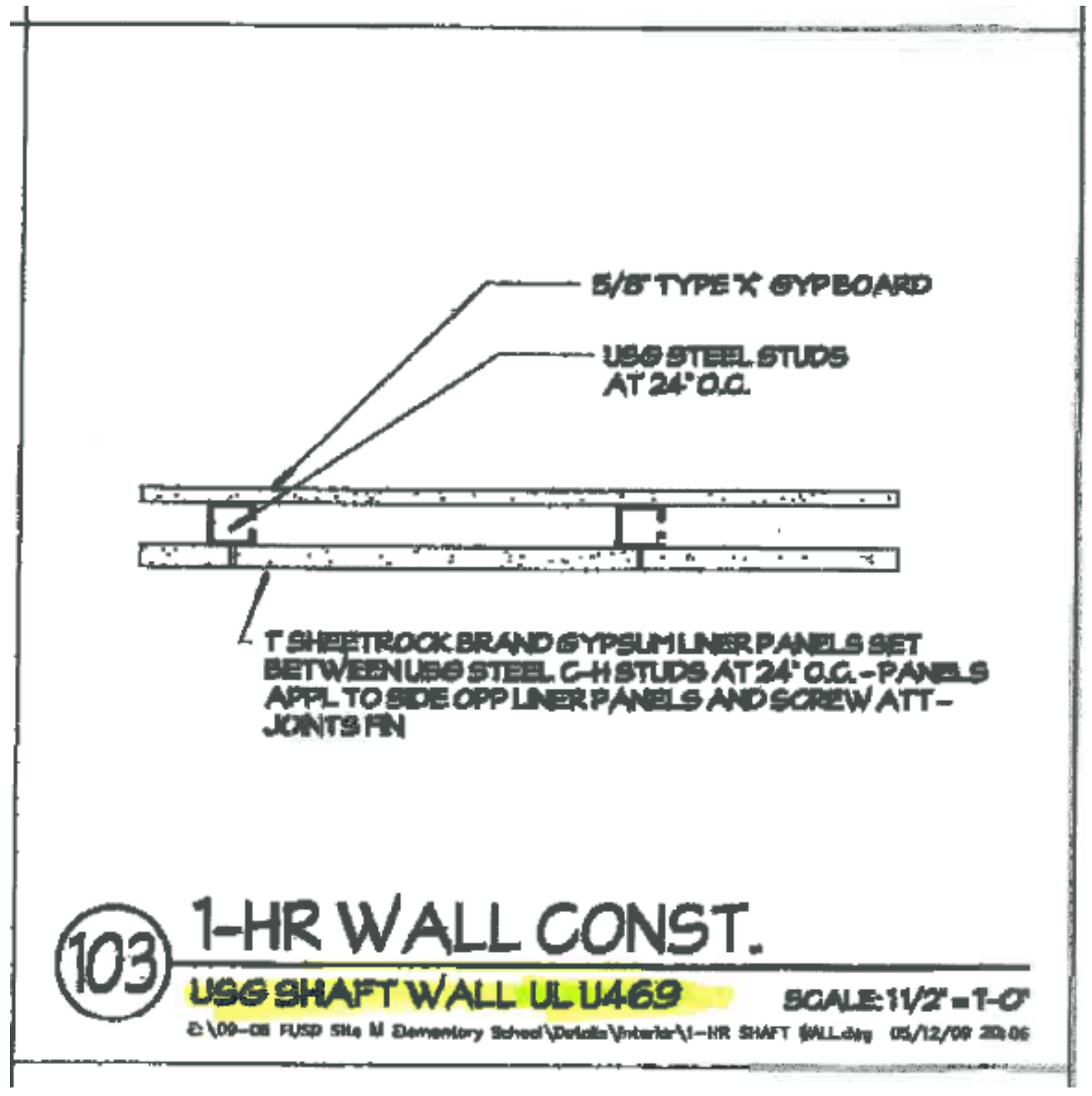

Figure 11 - UL 469 Rated Shaft Detail 


\section{Fire Detection, Alarm and Communications Systems}

\section{Fire Alarm Type and Component Information}

This new elementary schools alarm system is a Central Station type which is monitored by an independent central station. This central station conforms to the requirements of NFPA 72 as amended by Article 91. The fire alarm system consists of the key fire alarm components as listed below and all other components as required to provide a complete functioning system to monitor the building. Refer to Appendix C for fire alarm drawings (FAx.X) referenced in this section.

Key Fire Alarm Components (refer to Fire Alarm Symbols List on attached sheet FA0.1 and attached product cut sheets in Appendix E for additional information)

- Fire Alarm Control Panel - Gamewell-FCl - Model E3

- Fire Alarm Expander Panel - Gamewell-FCl - Model FF8

- Manual Pull Station - Gamewell-FCl - Model MS-7AF

- Heat Detector - Gamewell-FCl - Model ATD-L2F

- Attic Heat Detector - Gamewell-FCl - Model ATD-HL2F

- Smoke Detector - Gamewell-FCl - Model ASD-PL2F

- Duct Smoke Detector - Gamewell-FCl - Model ADPRF

- Fire Sprinkler Tamper Switch

- Fire Sprinkler Flow Switch

- Outside Horn with Black Box - Wheelock - Model AH-24WP-R WBBR

- Horn / Strobe Multi-Candela - Wheelock - Model ZNS-24MCW-FR

- Strobe Multi-Candela - Wheelock - Model ZRS-24MCW-FR

Key Fire Alarm Components Locations

- Fire Alarm Control Panel is located on the ground floor on the South Side of the middle of the building in Room Ball 123. Refer to attached drawing FA1.1.

- Fire Alarm Expansion Panels. The first floor panel is located on the ground floor on the South Side of the middle of the building in Room Ball 123. Refer to attached drawing FS1.1. The second floor panel is located on the second floor on the South Side of the middle of the building in Room Storage 217. Refer to attached drawing FA2.2.

- Fire sprinkler riser / tamper switch / flow switch are located on the ground floor in the South / West corner in room Storage 113. Refer to attached drawing FA1.1. 
- Manual Pull Stations are located throughout the building mounted at 48" A.F.F. at each exterior door. Refer to attached drawings for locations.

- Heat Detectors are located in the elevator equipment/machine rooms. Refer to attached drawings.

- Attic Heat Detectors are located throughout the building mounted above the ceiling in each attic space compartment. Refer to attached drawings.

- Duct Smoke Detectors are located throughout the building mounted in the ducts next to the fire smoke dampers at each penetration of fire rated walls. Refer to attached drawings.

- Duct Smoke Detectors are also located in the supply air plenums of the HVAC rooftop package units. These are not shown on the plans, but one is located in each unit.

- Outside Horns are located on the exterior of the building. Refer to attached drawings FA1.1 and FA1.2.

- Horn / Strobe Multi-Candela devices are located throughout the building mounted on the walls of most rooms and spaces. Refer to attached drawings.

- Strobe Multi-Candela devices are located throughout the building mounted on the walls of some storage and restrooms. Refer to attached drawings.

\section{Fire Alarm Design Methodology}

The fire alarm system is designed to meet the requirements of NFPA 72. The components as installed cover each individual room or areas as required.

The smoke detectors which are spot-type smoke detectors have been designed to meet the requirements of NFPA 72 17.7.3.2 at $30 \mathrm{ft}$ spacing.

Attic heat detectors layout is designed to meet the requirements of NFPA 71 Ch 17 and Annex B. The heat detectors are UL approved for $50 \mathrm{ft}$ center to center and FM approved for $25 \times 25$ $\mathrm{ft}$.

Typical layouts have been designed around these numbers.

\section{Fire Alarm Notification Analyses}

\section{Audio / Visual Notification Appliances}

The audio / visual strobe appliances have been evaluated in the following locations (Typical First Floor Classroom, Typical Second Floor Classroom, Main Two Story Entry and the Library) locations are as indicated on attached FA sheets. All of these appliances have a rating of 90 dBA which is above the requirements of NFPA 72 18.4.3 which states that the audible requirements must be $15 \mathrm{dBA}$ above the average ambient sound level and at least $5 \mathrm{dBA}$ above 
maximum sound level having duration of at least 1 minute. See the FA floor plan drawings in Appendix C for locations of all appliances

Location A (Typical First Floor Classroom, Kindergarten 1, Rm \#109)

Ceiling Height is 9'-6", Room dimensions are $28^{\prime} \times 33^{\prime}-4^{\prime \prime}$

(1) 75 cd device was used.

Per NFPA 72 Table 18.5.4.3.1(a) a single $75 \mathrm{~cd}$ wall mounted visible appliance will cover a maximum room size of $45^{\prime} \times 45^{\prime}$.

Spacing for this room is correct.

Location B (Typical Second Floor Classroom, Classroom 12, Rm \#205)

Ceiling Height is $10-0^{\prime \prime}$, Room dimensions are $28^{\prime} \times 34^{\prime}-6^{\prime \prime}$

(1) 75 cd device was used.

Per NFPA 72 Table 18.5.4.3.1(a) a single $75 \mathrm{~cd}$ wall mounted visible appliance will cover a maximum room size of $45^{\prime} \times 45^{\prime}$.

Spacing for this room is correct.

\section{Location C (Library)}

Ceiling Height is 9' $-6^{\prime \prime}$, Room dimensions area max. Of $40^{\prime}-6^{\prime \prime} \times 61^{\prime}-6^{\prime \prime}$ in a non uniform shape.

(3) devices were used (1) 15 cd device, (1) 75 cd device and (1) 110 cd device

Per NFPA 72 Table 18.5.4.3.1(a)

a single $15 \mathrm{~cd}$ wall mounted visible appliance will cover a maximum room size of $20^{\prime} \times 20^{\prime}$.

a single $75 \mathrm{~cd}$ wall mounted visible appliance will cover a maximum room size of $45^{\prime} \times 45^{\prime}$.

a single $110 \mathrm{~cd}$ wall mounted visible appliance will cover a maximum room size of 54'x54'.

With layout used and the (3) devices spacing for this room is correct. 
Location D (Main Entry, 2 Story, Corridor 101) and Location H (Corridors)

Ceiling Height is $29^{\prime}-0^{\prime \prime}$ at Main Entry and 9'-6" or 10'-0" at Corridors

$15 \mathrm{~cd}$ devices ware used.

Spacing for the corridors was done incompliance with Per NFPA 72 18.5.4.4.

Location E (Secretary 127 and Reception 126)

Ceiling Height is $9^{\prime}-6^{\prime \prime}$, Room dimensions are $29^{\prime}-4^{\prime \prime} \times 39^{\prime}$ in an L shape

(1) $75 \mathrm{~cd}$ device was used.

Per NFPA 72 Table 18.5.4.3.1(a) a single $75 \mathrm{~cd}$ wall mounted visible appliance will cover a maximum room size of $45^{\prime} \times 45^{\prime}$.

Spacing for this room is correct.

Location $\mathbf{F}$ (Conference 128)

Ceiling Height is $9^{\prime}-6^{\prime \prime}$, Room dimensions are $18^{\prime} \times 12^{\prime}$

(1) $15 \mathrm{~cd}$ device was used.

Per NFPA 72 Table 18.5.4.3.1(a) a single $15 \mathrm{~cd}$ wall mounted visible appliance will cover a maximum room size of $20^{\prime} \times 20^{\prime}$.

Spacing for this room is correct.

Location G (Work Room 107)

Ceiling Height is 9'-6", Room dimensions are $17^{\prime}-6 \times 19^{\prime}$

(1) $15 \mathrm{~cd}$ device was used.

Per NFPA 72 Table 18.5.4.3.1(a) a single $15 \mathrm{~cd}$ wall mounted visible appliance will cover a maximum room size of $20^{\prime} \times 20^{\prime}$.

Spacing for this room is correct. 


\section{Fire Alarm Sequence of Operation}

The following Diagram identifies the fire alarm sequence of operations.

\begin{tabular}{|c|c|c|c|c|c|c|c|}
\hline \multicolumn{8}{|c|}{ FRE ALARM SEQUENCE OF OPERATIONS } \\
\hline${ }_{A C T I O N}$ & $\begin{array}{l}\text { MANUAL RLL } \\
\text { STATION }\end{array}$ & $\begin{array}{l}\text { SHOKE / HEAT } \\
\text { DEIECTOR }\end{array}$ & $\begin{array}{l}\text { LOSS CF } \\
\text { POUER }\end{array}$ & $\begin{array}{l}\text { GROAND } \\
\$ A \Delta L T\end{array}$ & $\begin{array}{l}\text { WATERHLD } \\
\text { SultCH }\end{array}$ & $\begin{array}{l}\text { TAMFER } \\
\text { SUITCH }\end{array}$ & $\begin{array}{l}\text { DUCT SMOKE } \\
\text { DEIECTORS }\end{array}$ \\
\hline $\begin{array}{l}\text { ANWNCIATE ALARM } \\
\text { AT FRE ALARY } \\
\text { CONTRCL PANEL }\end{array}$ & YE5 & YE5 & - & $=$ & YES & - & YES \\
\hline 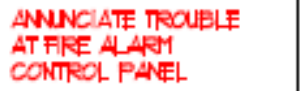 & - & - & TES & TES & - & - & - \\
\hline $\begin{array}{l}\text { ANWNCIATE } \\
\text { SUIFERVISORY AT FIFE } \\
\text { ALARYI CONIROL PANE }\end{array}$ & - & - & - & - & - & YES & - \\
\hline $\begin{array}{l}\text { ACTIVATIE AL } \\
\Delta \cup D I B L E / \\
\text { VSUAL ALANA1S }\end{array}$ & YES & YES & - & $=$ & YES & - & YES \\
\hline $\begin{array}{l}\text { TRANGERTO TO } \\
\text { BAMGRT } \\
\text { BACKAP }\end{array}$ & - & - & TES & - & - & - & - \\
\hline $\begin{array}{l}\text { ANWNCIATE ALARAM } \\
\text { AT CENTRAL STATION } \\
-\end{array}$ & YES & YES & - & - & YES & YES & YES \\
\hline $\begin{array}{l}\triangle N W W C A T E \text { TROLBLE } \\
\text { AT CENTRAL STATION } \\
-\end{array}$ & - & - & YES & rEs & - & - & - \\
\hline $\begin{array}{l}\text { ANINCIATE SUPERVISCRT } \\
\text { AT CENTRAL STATION } \\
=\end{array}$ & - & - & - & - & - & TES & - \\
\hline $\begin{array}{l}\text { CLOSE FIRE / } \\
\text { SMOKE DAMIIRS } \\
-\end{array}$ & - & - & - & - & - & - & YES \\
\hline $\begin{array}{l}\text { SHITDOUN } \\
\text { A/C UNITS } \\
-\end{array}$ & - & $\cdot$ & - & - & - & - & YES \\
\hline
\end{tabular}

Figure 12 - Fire Alarm Sequence of Operation 


\section{Fire Alarm Inspection Testing and Maintenance Requirements}

The inspection testing and maintenance of the alarm system will be the job of the company hired by the school district. NFPA guidelines, manufacturer and product guidelines and all local fire marshal requirements shall be followed.

\section{Fire Alarm Riser}

Refer to attached drawings sheet FA0.3 for the Fire Riser Diagram.

\section{Voltage Drop and Battery Calculations}

Refer to attached drawings sheet FA0.4 for the Fire Alarm Voltage Drop and Battery Calculations.

\section{System Commissioning}

The system shall be required to be commissioned per the contract documents. Per the following specification sections listed below the system is required to be operational, functioning and warranted for a period of 1 year from the date of first beneficial use. Specifications Sections:

$16710,1.03$, B.

$16710,1.04, \mathrm{G}$.

$16710,1.06$

$16710,1.07$

$16710,2.06$

Refer to attached project specifications in Appendix $\mathbf{F}$ 


\section{Inspection Testing and Maintenance Requirements}

The inspection testing and maintenance of the alarm system will be the job of the company hired by the school district. NFPA guidelines, manufacturer and product guidelines and all local fire marshal requirements shall be followed.

\section{Approval Requirements}

Per the specifications section 16710, 1.03 the school district shall review and approve the equipment and system prior to any installation. Per specification section $16710,1.04, \mathrm{G}$. the district shall review and approve the acceptance test procedures. Per specification section $16710,2.06$ the district and the local fire marshal shall be present to witness and approve testing. Refer to attached specifications.

\section{Fire Alarm and Detection Summary}

The intent of the system is to comply with NFPA 72 and provide a complete Fire Alarm System that operates as required to meet the intent of the code. As reviewed and evaluated the installed system meets these requirements. 


\section{Water-Based Fire Suppression}

\section{General Site Information}

The site is served by a 10 inch site fire water loop which serves the site fire hydrants and the fire sprinkler risers at the buildings. A fire hydrant is located on the south side of the building near the buildings center with drive in access for the fire department from gates at the street to the sports courts. The buildings fire riser is on the south east corner of the building on the exterior wall.

Site Fire Water Plan

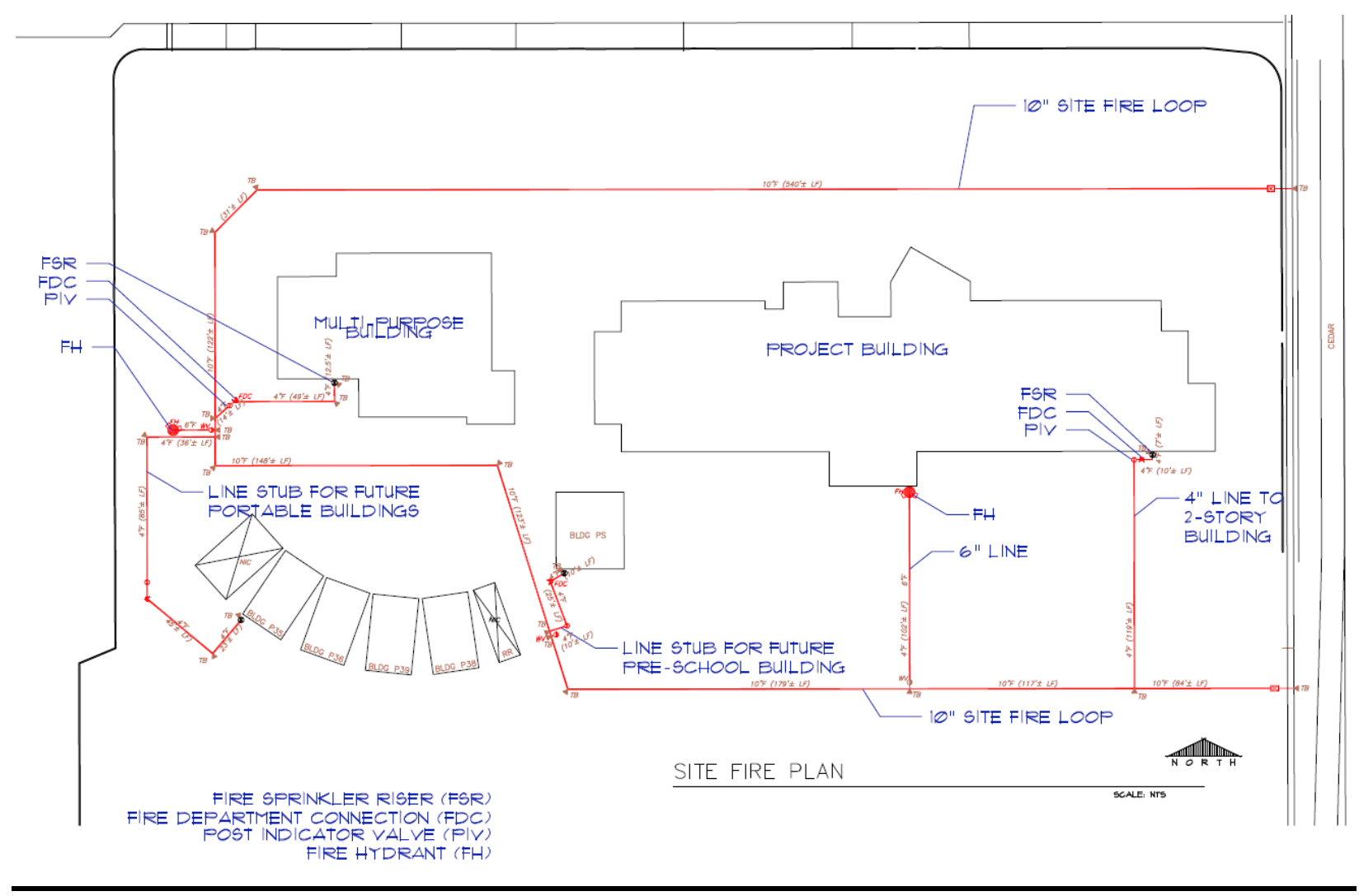

Figure 13 - Site Fire Layout

\section{General Building Fire Sprinkler Information}

The building is completely fire sprinklered per the requirements of NFPA 13, 2002. Quick response pendent heads are located in the T-bar and hard ceilings in all rooms. Attic space is not required to be sprinklered per exceptions in NFPA 13, 8.15.1.2.1 and per DSA IR 9-1 for 
buildings of non-combustible construction with fire sprinklers. The fire sprinkler riser is located in outside of the building at the South / East corner of the building. Sprinkler mains run above the ceilings of both floors.

\section{Fire Sprinkler Material Information}

The following are key components of the fire sprinkler system:

- Viking, Easy Riser swing check valve Models E-1 and F-1

- Viking, Microfast Standard Quick Response Extended Coverage Pendent Sprinklers

- Viking, Microfast Standard Quick Response Upright and Conventional Sprinklers

- Viking, Microfast and Microfast HP Quick Response Pendent Sprinklers

- Viking, Microfast Standard Quick Response Extended Coverage HSW Sprinkler VK606

- Viking, Microfast HP Quick Response Horizontal Sidewall Sprinklers VK305 and VK319

- Sprinkler Wrenches and Cabinets

- Potter, Bells PBA-AC and MBA-DC

- Potter, WFSR-F Waterflow Alarm Switch

- Potter, PCVS-1 and 2 Control Valve and Supervisory Switch

Refer to Appendix I for key component Product Data Sheets 


\section{Building Fire Water Supply Information}

The fire sprinkler water supply is by a single fire riser to the building. The water supply serving the building is characterized as follows per the attached water supply information as provided by Fresno Fire on May 1, 2009 refer to letter in Appendix G. This information represents design data to be used for design as provided by Fresno Fire and is not the actual flow data from a flow test.

Static: $\quad 45 \mathrm{psi}$

Residual: $\quad 35 \mathrm{psi}$

Flow: $\quad 1800 \mathrm{gpm}$

A 10\% "cushion" for design was not required as the actual flow test results were higher than the data given for the design model flow curve.

Design data for the sprinkler system matched that as provided by the City; reference the attached report data from the sprinkler hydraulic calculations Appendix $\mathbf{H}$ for the most hydraulically demanding classroom space.

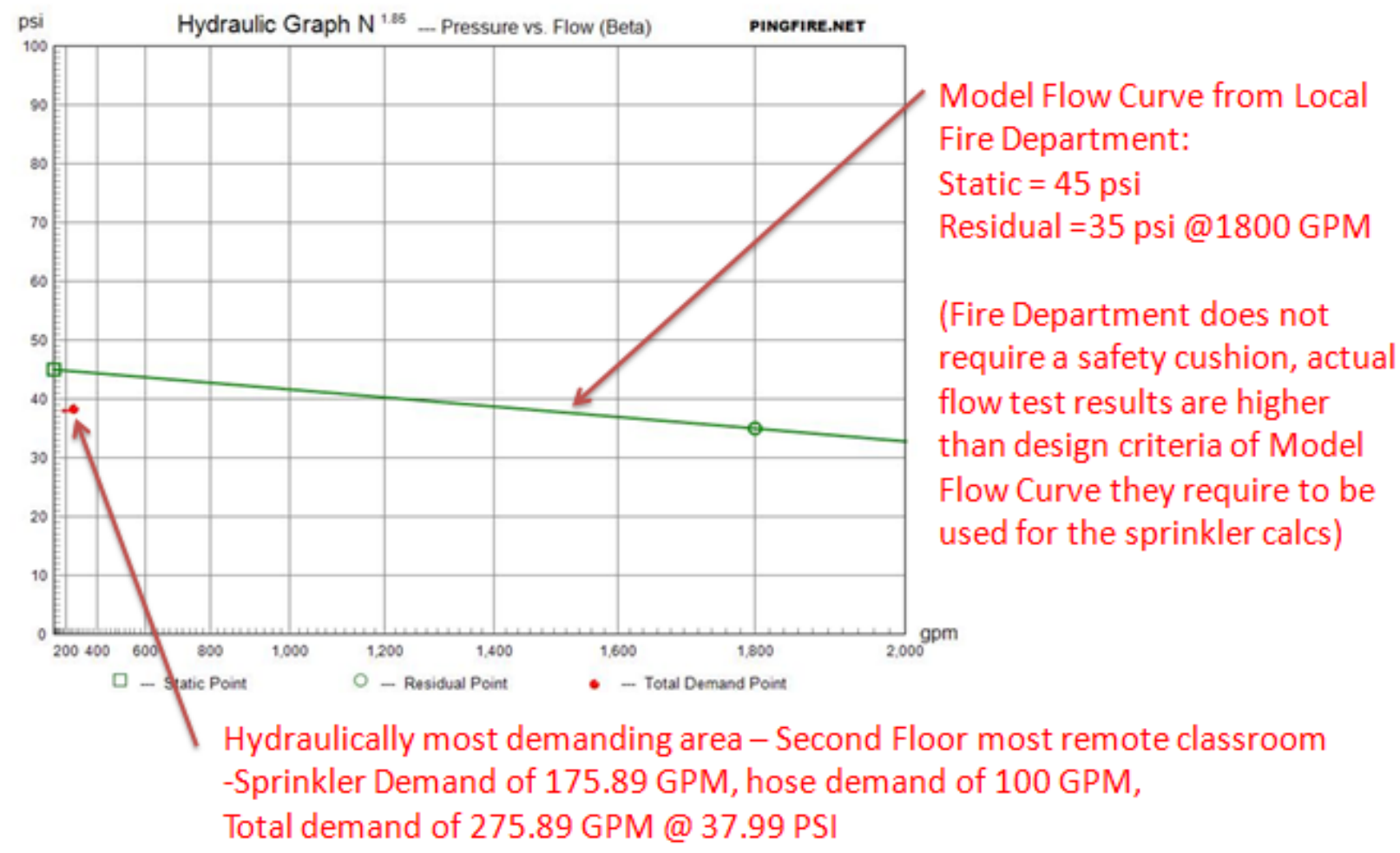

Figure 14 - Fire Suppression System Curve 


\section{Building Sprinkler Hydraulic Demand Requirements}

The most hydraulically demanding area of the system was determined to be the second floor classroom on the north side of the building at the west end of the building. This classroom was the furthest distance from the fire sprinkler riser which is located on the south side of the building at the east end of the building. The hydraulic calculations were done using the room design method from NFPA 13 section 14.4.4.1.2 and 11.2.3.3. This requires the use of 5 sprinkler heads in the calculation. Calculations included the four sprinkler heads in the room along with one sprinkler head from the corridor just outside of the classroom. The demand for this area was $175.89 \mathrm{gpm}$ for the sprinklers and $100 \mathrm{gpm}$ for the hose demand for a total of $275.89 \mathrm{gpm}$ at $37.99 \mathrm{psi}$. Refer to Appendix $\mathbf{H}$ for a copy of the hydraulic calculations .

Refer the figure below for reference locations.

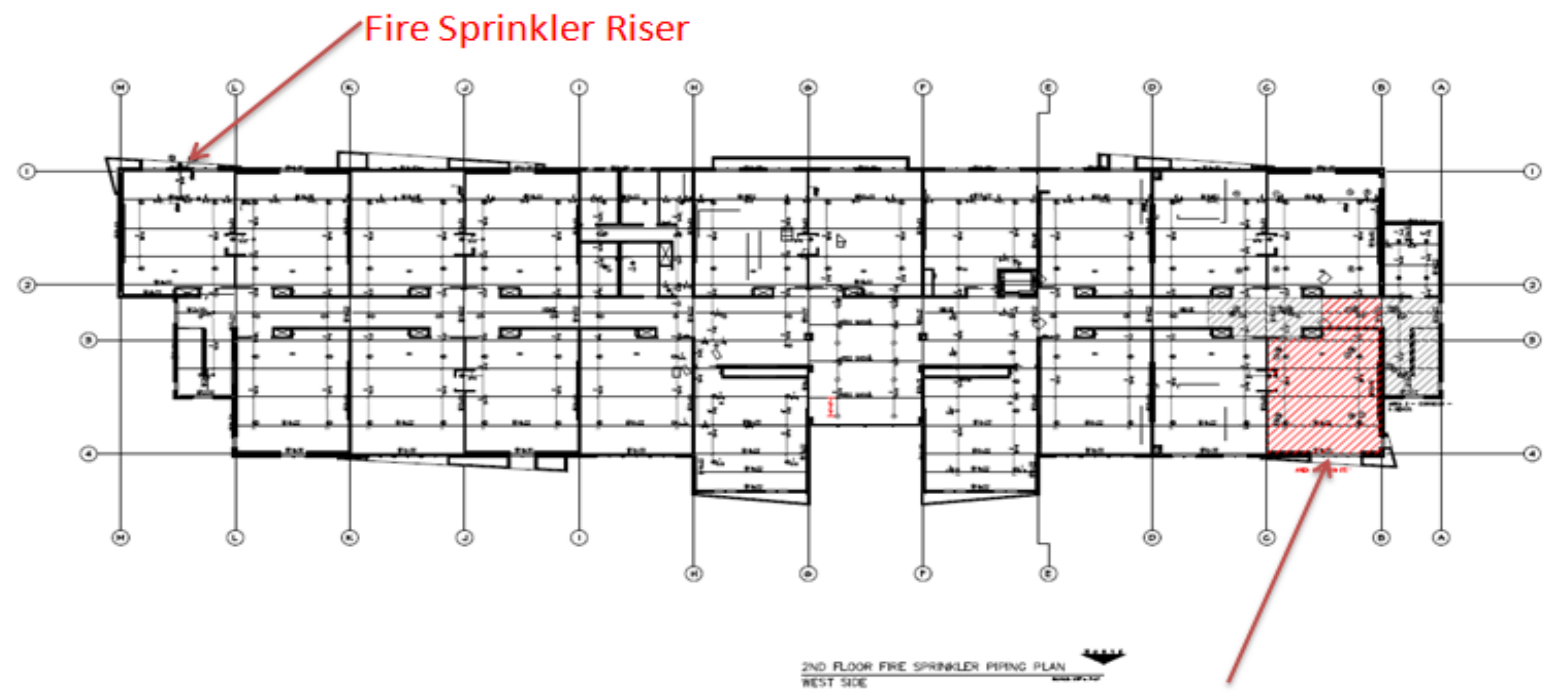

Hydraulic Calculations were done using the Room Design Method (NFPA 13 section 14.4.4.1.2)

-the hydraulically most demanding area is the most remote classroom on the second floor.

-Calculations include the 4 sprinkler heads in the classroom and one in the corridor (calculations use a maximum of 5 heads per section 11.2.3.3.6)

-Occupancy classification is Light Hazard with a Density of 0.1 - GPM / SF

-Sprinkler Demand of 175.89 GPM, hose demand of 100 GPM,

-Total demand of 275.89 GPM@37.99 PSI

Figure 15 - Fire Sprinkler Hydraulic Demand Location 


\section{General Sprinkler Demand Requirements}

Typical classrooms and spaces are designed around the following:

Occupancy Hazard Classification = Light Hazard

Density $=0.10 \mathrm{gpm} / \mathrm{ft}^{\wedge} 2$

Hose Stream Allowance $=100 \mathrm{gpm}$ Inside and Outside

Water Supply Duration $=30$ min duration

\section{Computer Software}

The software used for the hydraulic calculations was Hydratec Inc. Fire Protection by Computer Design software.

\section{Fire Sprinkler Plan Reference Plans}

Refer to Appendix D. 


\section{Performance Based Analysis}

\section{Performance Based Goals Overview}

The main performance based goal of the new elementary school is to maintain life safety and minimize fire related injuries and the loss of life from fire. Secondary goals are to maintain property protection by minimizing damage to property and minimizing downtime of facility use from fire damage.

The tenability goals of the project are set at 2 meters above the walking surfaces. The smoke layer should be maintained above $2 \mathrm{~m}$, when it drops below this level occupants become less likely to move through the smoke. The visibility criterion is to maintain $5 \mathrm{~m}$ in classrooms and $10 \mathrm{~m}$ for the corridors and entry areas. The maximum exposure of carbon monoxide is not to exceed 1,400 ppm. The heat exposure is to be less than 60 degrees $C$.

The available safe egress time (ASET) is the available safe egress time of the occupants in the event of a fire from the time of fire ignition to the time untenable conditions occur in the evacuation route. The required safe egress time (RSET) is the time required for occupants to reach an area of safety in the event of a fire from the time of fire ignition to the time evacuation is complete. These times need to be evaluated for each design fire scenario to determine if the ASET is greater than the RSET.

Design fires have been developed following the Design Fire Scenarios of NFPA $101 \mathrm{Ch} 5$ and evaluated using Fire Dynamics Simulator (FDS) version 5.5.3.

\section{$\underline{\text { Tenability Requirements }}$}

Tenability requirements for the building have been established based on a maximum evacuation time of 15 minutes or less which was derived from the code based and simulation based calculations from the building egress requirements. The building occupants range in age from pre-school age to senior citizen age with the majority in the age range of 4 to 13 years of age.

Visibility requirements for the elementary school are set at $5 \mathrm{~m}$ for small enclosures such as classroom and restrooms and $10 \mathrm{~m}$ for corridors, entry areas and paths of travel [1], [3]. These numbers are the minimum values and should be met or exceeded. If visibility is less than these values occupants may stop attempting to exit the building.

Exposure to toxic gases shall be limited to allow safe evacuation of students and teachers. The exposure layer is $2 \mathrm{~m}$ above the floor. The maximum exposure to carbon monoxide (CO) is 
$1,400 \mathrm{ppm}$ for duration of 30 minutes. Oxygen (O2) should be $12 \%$ or greater and Carbon Dioxide (CO2) should be less than 6\% [1].

Heat and temperature requirements for occupants are taken at $2 \mathrm{~m}$ above the floor. Radiant heat exposure should be limited to $2.5 \mathrm{KW} / \mathrm{m} 2$ from the upper layer for a period of not more than 5 min. Convective heat of 100 degree $\mathrm{C}$ with $10 \% \mathrm{H} 2 \mathrm{O}$ is the maximum temperature for exposure for the duration of the $8 \mathrm{~min}$ is the maximum acceptable criteria for this building with design criteria of 60 degree $C$ saturated for exposure duration of 30 min which covers the 15 min estimated maximum evacuation time [3]. Often the temperature of 120 degrees C [2], [4] is acceptable for exposure time of up to $7 \mathrm{~min}$ [2], [4] but due to the majority of the occupants being young children the lower values are being used to reduce risk and danger to them. The lower temperature which is more difficult to maintain will provide a greater level of safety.

\section{Evacuation Time Calculations}

\section{General Information}

The evacuation times for the building have been calculated using both hand calculation methods following the formulas in the NFPA Fire Protection Handbook $20^{\text {th }}$ edition Chapter 2 Section 4. Additionally the building was modeled using Pathfinder Version 2012 software and evaluated in the SFPE mode using basic collisions as a double check of occupancy egress times.

For the hand calculations several assumptions were made. First it was assumed that people would evenly use the available exits. Second travel time in the rooms to the exits was not accounted for as the assumption that the persons nearest the door would begin exiting first and the remainder of the occupants would begin queuing behind.

The occupant load for the building used in the calculations was 630 occupants on the ground floor and 844 occupants on the second floor for a total of 1474 occupants. For the purpose of the hand calculations the administrative staff is counted in the total occupant load of the first floor and was calculated to use the main exits with the students. The second floor has four stairs to the first floor. The first floor has 7 sets of double doors. For the hand calculations it was found that comparing the movement time differences between the doors and the stair flow times that in all cases the stair flow times were the limiting factor. Due to this the stairs were used to calculate the egress time.

Pre-movement time for classrooms is estimated to be 30 seconds to allow for the teachers and students to realize that there is an alarm and began exiting the classrooms. This information is based on reading case studies in the SPPE Hand Book of Fire Protection Engineering Section 3-12.

An alarm time of 5 seconds has been used which is an industry standard that allows for the detection and alarm devices to receive and send signals. 


\section{Egress Flow Calculations}

A. Estimate the flow capacity through the doors. From Table 4.2.8 the effective width of each double door is "free door width - (2) 6"".

Double doors have a free width of $68.5^{\prime \prime}$

Use 68.5" - (2)6" = 56.5"

Per Table 4.2.8 use 24.0 persons / $\mathrm{min} / \mathrm{ft}$ of flow

Using Equation 4 flow through double door $=\left(56.5^{\prime \prime} 0 " / 12 "\right.$ x $24.0=113$ person $/ \mathrm{min}$.

Single door has a free width of 33.63"

Use 33.63" - (2)6" = 21.63"

Per Table 4.2.8 use 24.0 persons / $\mathrm{min} / \mathrm{ft}$ of flow

Using Equation 4 flow through double door $=\left(21.63^{\prime \prime} / 12^{\prime \prime} \times 24.0=43\right.$ person $/ \mathrm{min}$.

B. Estimate the flow capability of the exit corridor. From Table 4.2.4 the effective width of the corridor is "free corridor width - (2) 6"'". Corridor has a width of 60". Use 60"-(2) 6" $=48^{\prime \prime}$

Per Table 4.2.8 use 24.0 persons / $\mathrm{min} / \mathrm{ft}$ of flow in corridor.

Using equation 4 flow through stairs $=\left(48^{\prime \prime} / 12^{\prime \prime}\right) \times 24=96$ person $/ \mathrm{min}$.

This is greater than the door flow for the corridor so use the door flow of 43 person / $\min$.

C. Estimate the flow capability of the stairway. From Table 4.2.4 the effective width of each stair is "free stair width - (2) 6"'". Stairs have a width of 66". Use 66"-(2) 6" = 54" Per Table 4.2.8 stairs with 7.0" rise and 11" tread gives us 18.5 persons / $\mathrm{min} / \mathrm{ft}$ of flow Using equation 4 flow through stairs $=\left(54^{\prime \prime} / 12^{\prime \prime}\right) \times 18.5=83$ person $/ \mathrm{min}$.

D. Estimate the movement time for the estimated stairway flow.

From Equation 1 the speed of movement down the stairs is $212-(2.86 \times 21 \times 0.175)=105$ $\mathrm{ft} / \mathrm{min}$

The travel distance between floors per Table 4.2.6 with stairs with a 7.0" rise and 11" tread $=1.85$, so $25.5 \times 1.85=47.25$ on the stair slope plus the travel landing of our stairs. Travel of the landing is 7.75 .

Stairway travel time is $47.75^{\prime}+7.75^{\prime}=55^{\prime}$

$55^{\prime} / 105=0.52 \mathrm{~min}$. for travel in stairway from second to first floor exit doors.

E. Estimate the movement time to stairs and from stairs to exit doors (worst case using center stairs). 
From Table 4.2.3 travel speed of $100 \mathrm{ft} / \mathrm{min}$ is used.

Travel distance to stairs $=15^{\prime}$ and travel distance from stairs to exit door $=17^{\prime}$

Travel distance is $15^{\prime}+17^{\prime}=32^{\prime}$

Travel time $=32^{\prime} / 100=0.34 \mathrm{~min}$.

F. Estimate the movement time to stairs and from stairs to exit doors (worst case using side stairs, for design fire where center stairs are not available).

From Table 4.2.3 travel speed of $100 \mathrm{ft} / \mathrm{min}$ is used.

Travel distance to stairs $=11^{\prime}$ and travel distance from stairs to exit door $=7^{\prime}$

Travel distance is $11^{\prime}+7^{\prime}=18^{\prime}$

Travel time $=18^{\prime} / 100=0.18 \mathrm{~min}$.

\section{Hand Calculation of Movement Time Standard Egress with All Stairs and Doors Available \\ (this is the Movement Time used for Design Fire 1)}

Hand Calculations use the above numbers for determination of egress time.

Travel distance in initial room not included in calculations.

Estimate of Standard Evacuation Movement Time per above:

844 occupants on second floor $/ 4$ stairs $=211$ occupants per stair

Flow time through stairs $=211$ people $/ 83$ person $/ \mathrm{min}$. thru stairs $=2.54 \mathrm{~min}$.

Estimated time for movement to and from stairs $=0.52 \mathrm{~min}$.

Estimated time for movement to and from stairs $=0.34 \mathrm{~min}$.

Total minimum evacuation time is $2.54+0.52+0.34=3.40 \mathrm{~min}$. or $204 \mathrm{sec}$

\section{Hand Calculation of Movement Time Egress with Main Entry Double Stairs and Doors Unavailable (this is the Movement Time used for Design Fire 2)}

Hand Calculations use the above numbers for determination of egress time.

Travel distance in initial room not included in calculations. 
Estimate of Standard Evacuation Movement Time per above:

844 occupants on second floor / 2 stairs $=422$ occupants per stair

Flow time through stairs $=422$ people $/ 83$ person $/ \mathrm{min}$. thru stairs $=5.08 \mathrm{~min}$.

Estimated time for movement through stairway $=0.52 \mathrm{~min}$.

Estimated time for movement to and from stairs $=0.18 \mathrm{~min}$.

Total minimum evacuation time is $5.08+0.52+0.18=5.78 \mathrm{~min}$. or $347 \mathrm{sec}$

\section{Hand Calculation of Movement Time Egress with One Side Stair Unavailable \\ (this is the Movement Time used for Design Fire 3 )}

Hand Calculations use the above numbers for determination of egress time.

Travel distance in initial room not included in calculations.

Estimate of Standard Evacuation Movement Time per above:

844 occupants on second floor / 3 stairs $=282$ occupants per stair

Flow time through stairs $=282$ people $/ 83$ person $/ \mathrm{min}$. thru stairs $=3.4 \mathrm{~min}$.

Estimated time for movement through stairway $=0.52 \mathrm{~min}$.

Estimated time for movement to and from stairs $=0.34 \mathrm{~min}$.

Total minimum evacuation time is $3.4+0.52+0.34=4.26 \mathrm{~min}$. or $256 \mathrm{sec}$ 


\section{Pathfinder Movement Time Standard Egress with All Stairs and Doors Available}

Results of Pathfinder run using SFPE mode with basic collisions $=221 \mathrm{sec}$

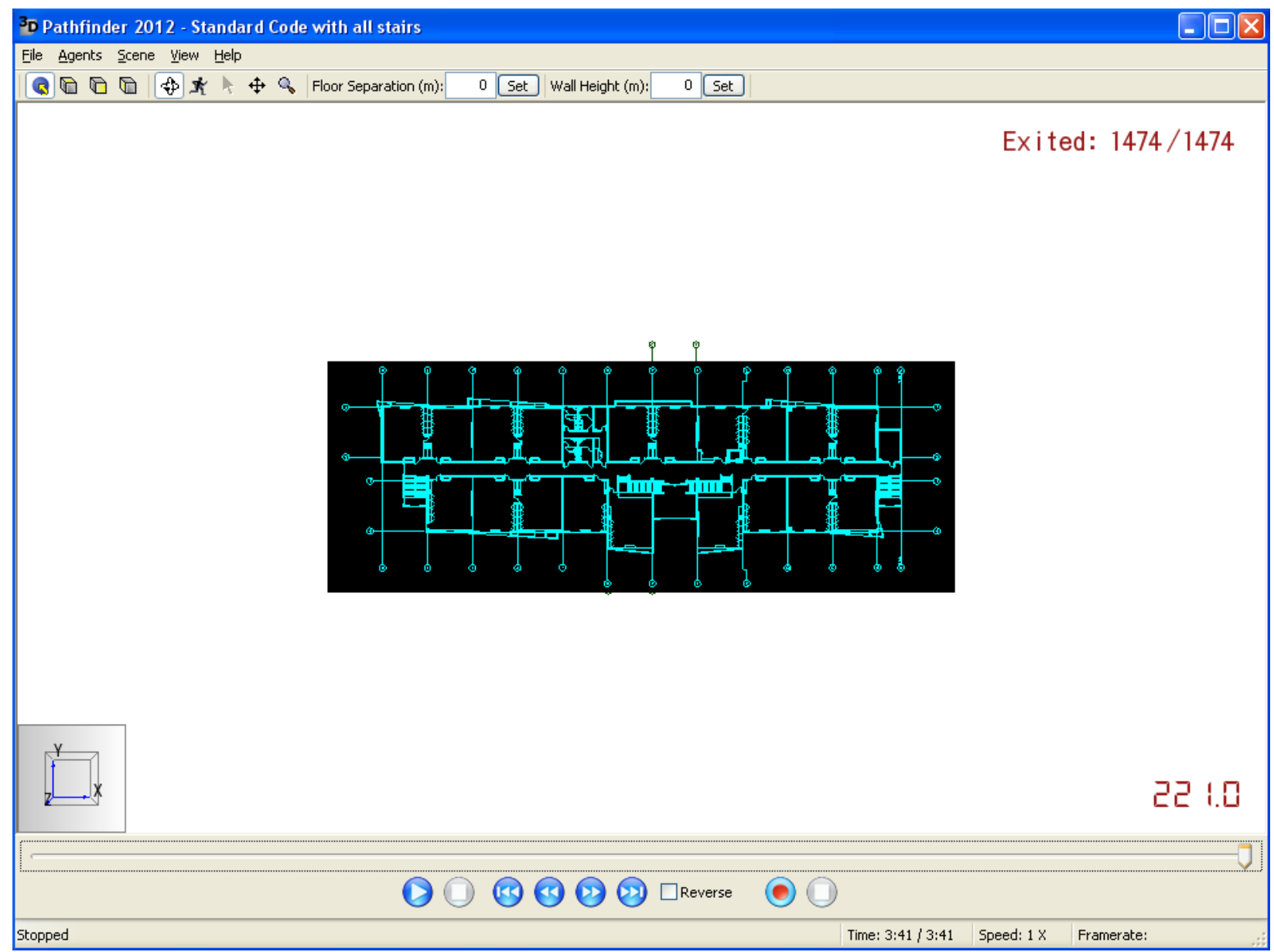

Figure 16 - Pathfinder Run with all egress available

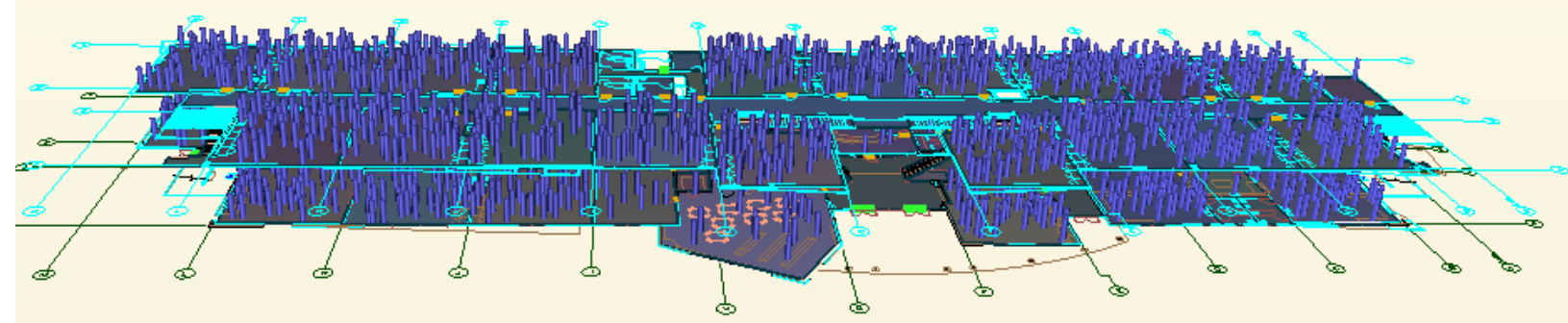

Figure 17 - Pathfinder Model 


\section{Pathfinder Movement Time Egress with Main Entry Double Stairs and Doors Unavailable}

Results of Pathfinder run using SFPE mode with basic collisions $=329 \mathrm{sec}$

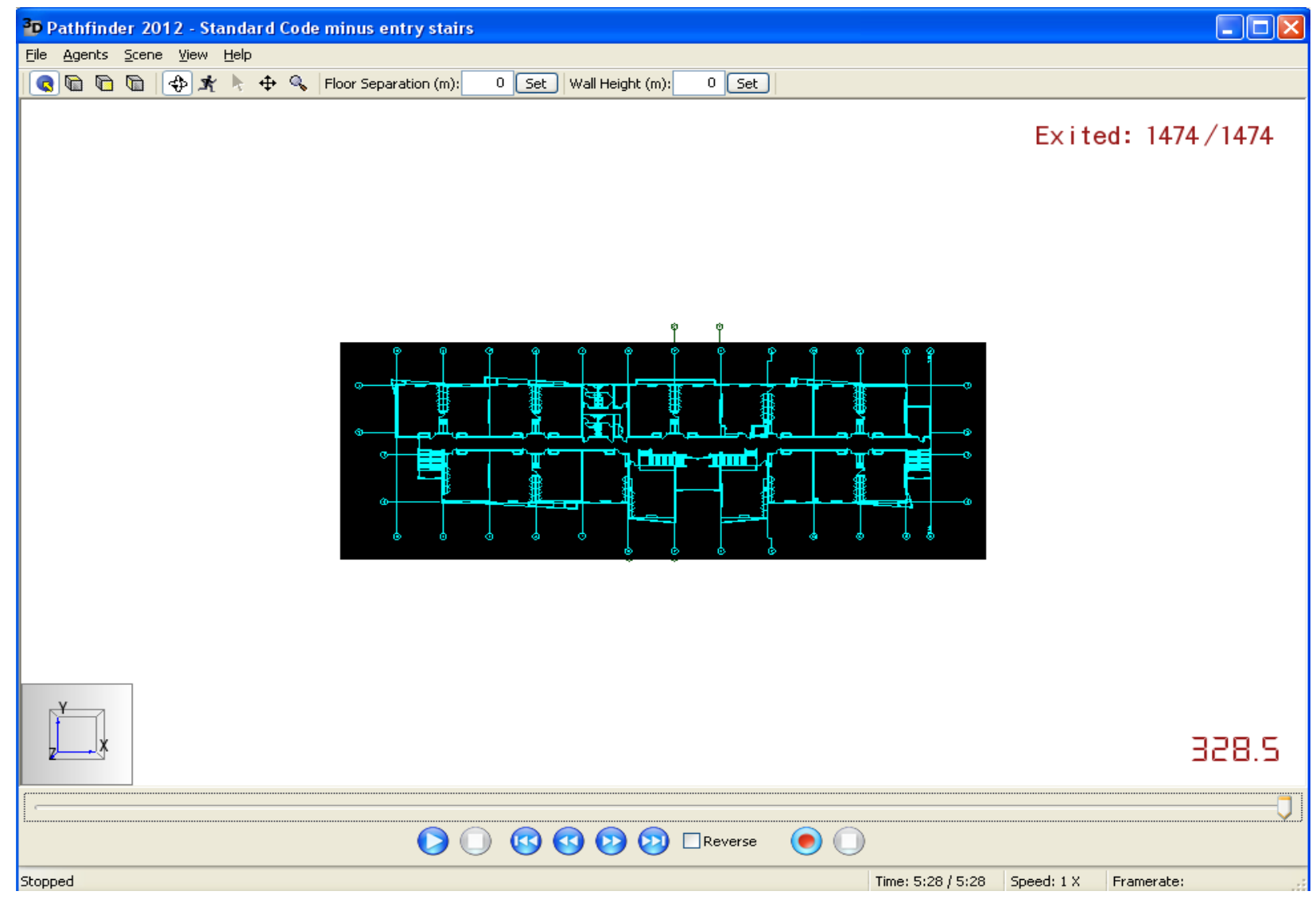

Figure 18 - Pathfinder Run with entry egress unavailable

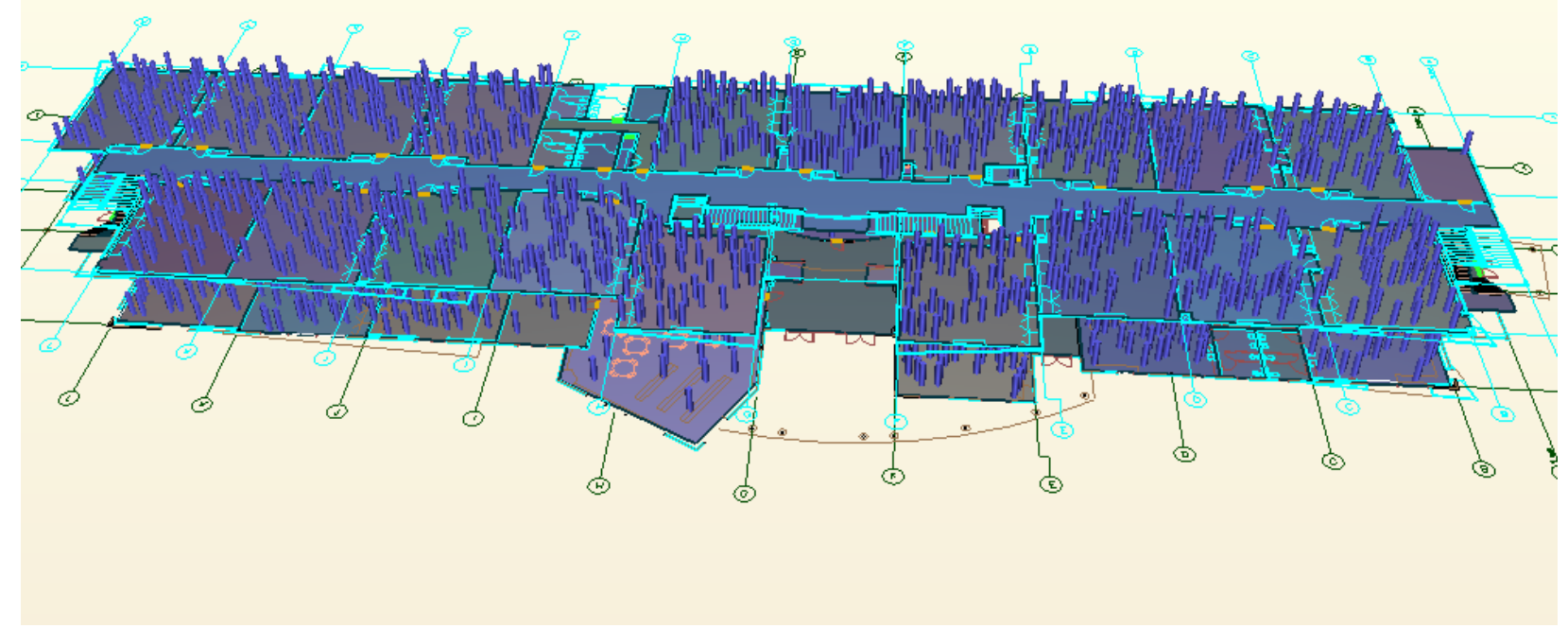

Figure 19 - Pathfinder Model with Center Stairs Removed 


\section{Pathfinder Movement Time Egress with One Side Stair Unavailable}

Results of Pathfinder run using SFPE mode $=223 \mathrm{sec}$

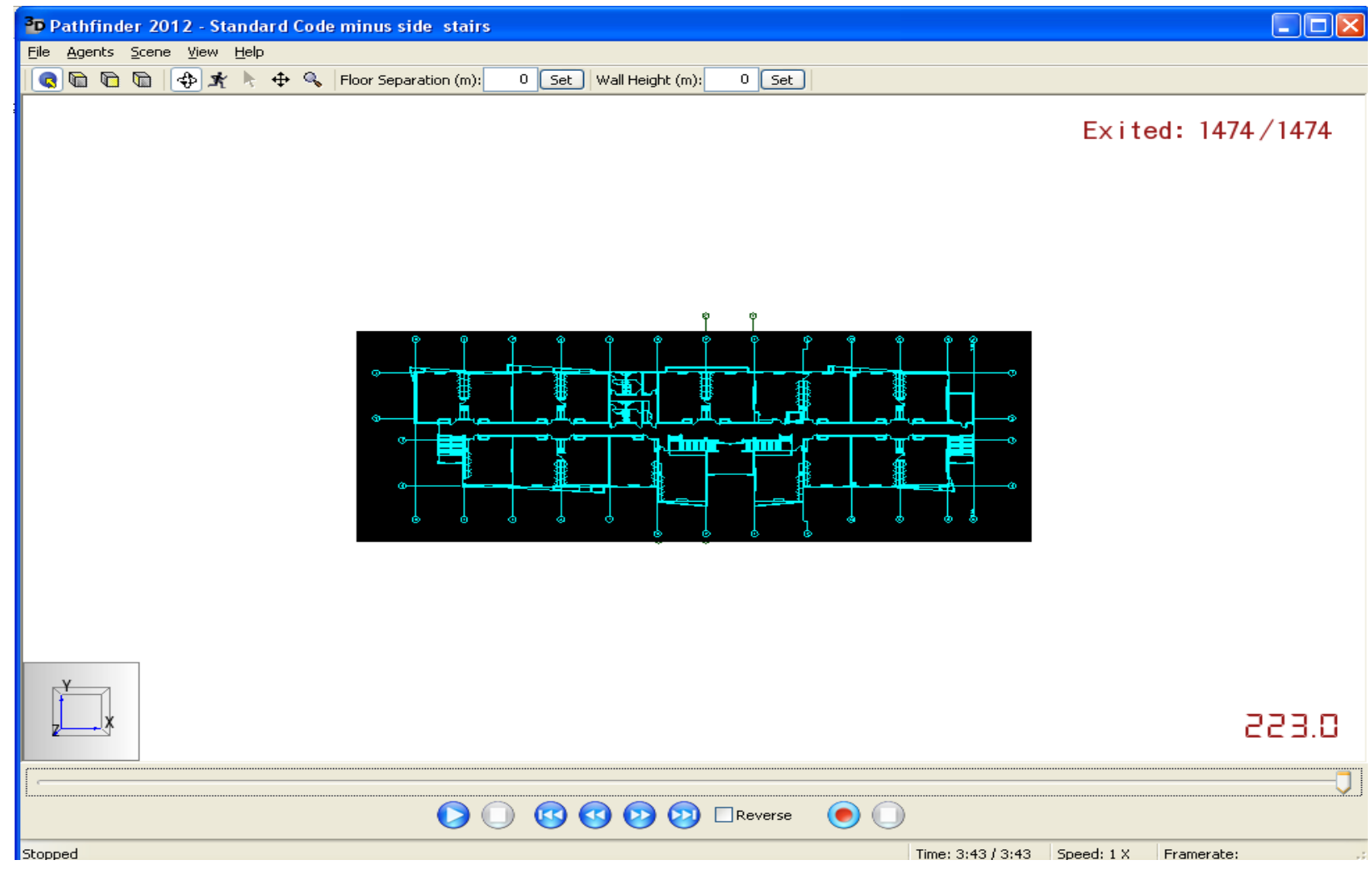

Figure 20 - Pathfinder Run with one side stair unavailable

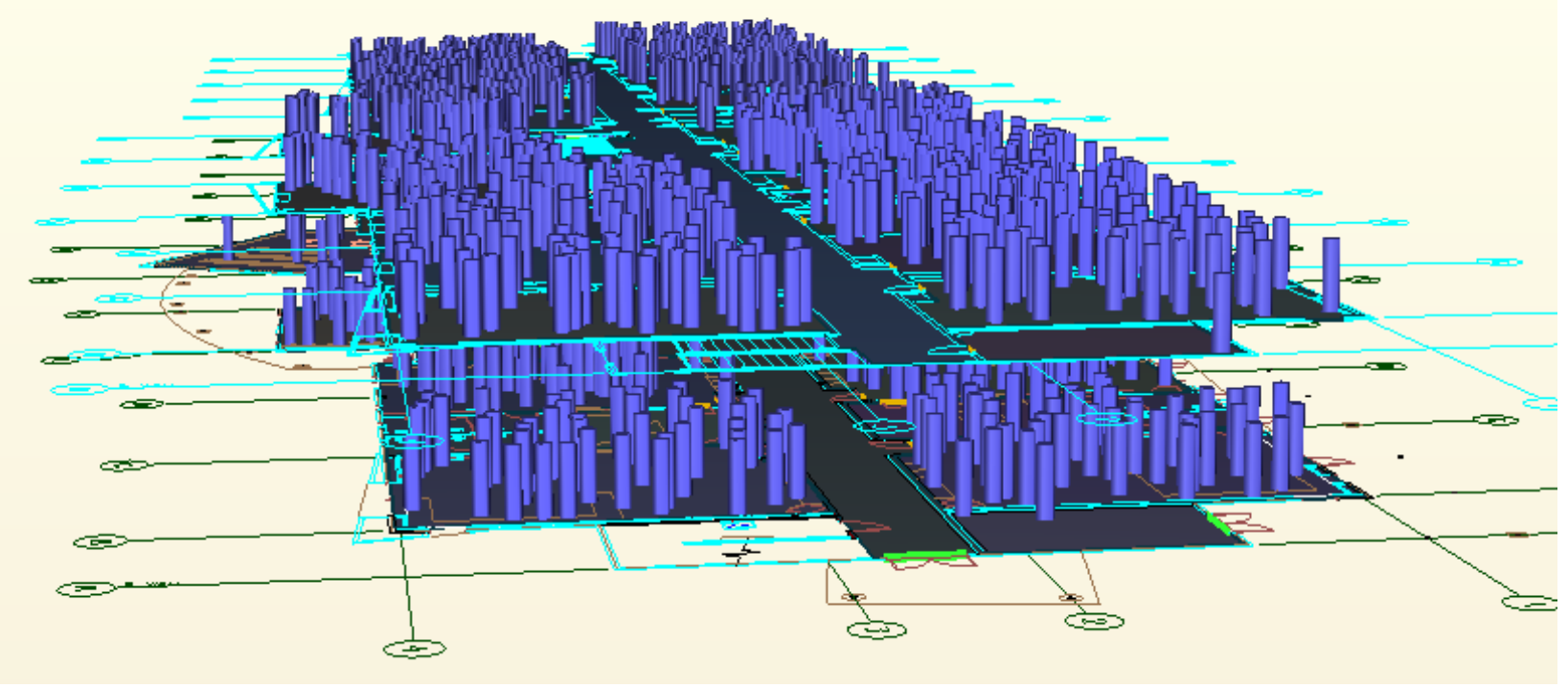

Figure 21 - Pathfinder Model with Side Stairs Removed 


\section{Evacuation Movement Times}

The evacuation movement time from the hand calculations compared to the times from the same run in Pathfinder using the SFPE mode with basic collisions showed a difference of between $5 \%$ and $15 \%$ for the various egress analysis. These are very close. For purposes of evaluating the RSET for the different design fire scenarios the hand calculation movement times are used as they were the more conservative times for two of the three egress analysis.

\section{Actual Occupant Loads}

The occupant numbers used as required by code for educational facilities are generally conservative. Typical classrooms have between 27 and 35 students not the 44 to 48 as calculated by the code. This would result in a lower occupant load of approximately 175 occupants on the second floor and 100 occupants on the first floor for a total of 275 less occupants than used for calculations.

\section{Design Fire 1}

\section{Scenario Overview}

This performance design scenario involves a fire in the main entry area of the building. Typically this area is free of flammable material but at certain time of the year there is material which could be fuel for a fire in this area. In this scenario during the two times a year that the school does a student book fair a magazine / book rack is on display in the entry area which is located directly outside of the library. For this scenario the magazine / book rack is set on fire and causes the two main entry doors and two main stairs to the entry to be unavailable for egress.

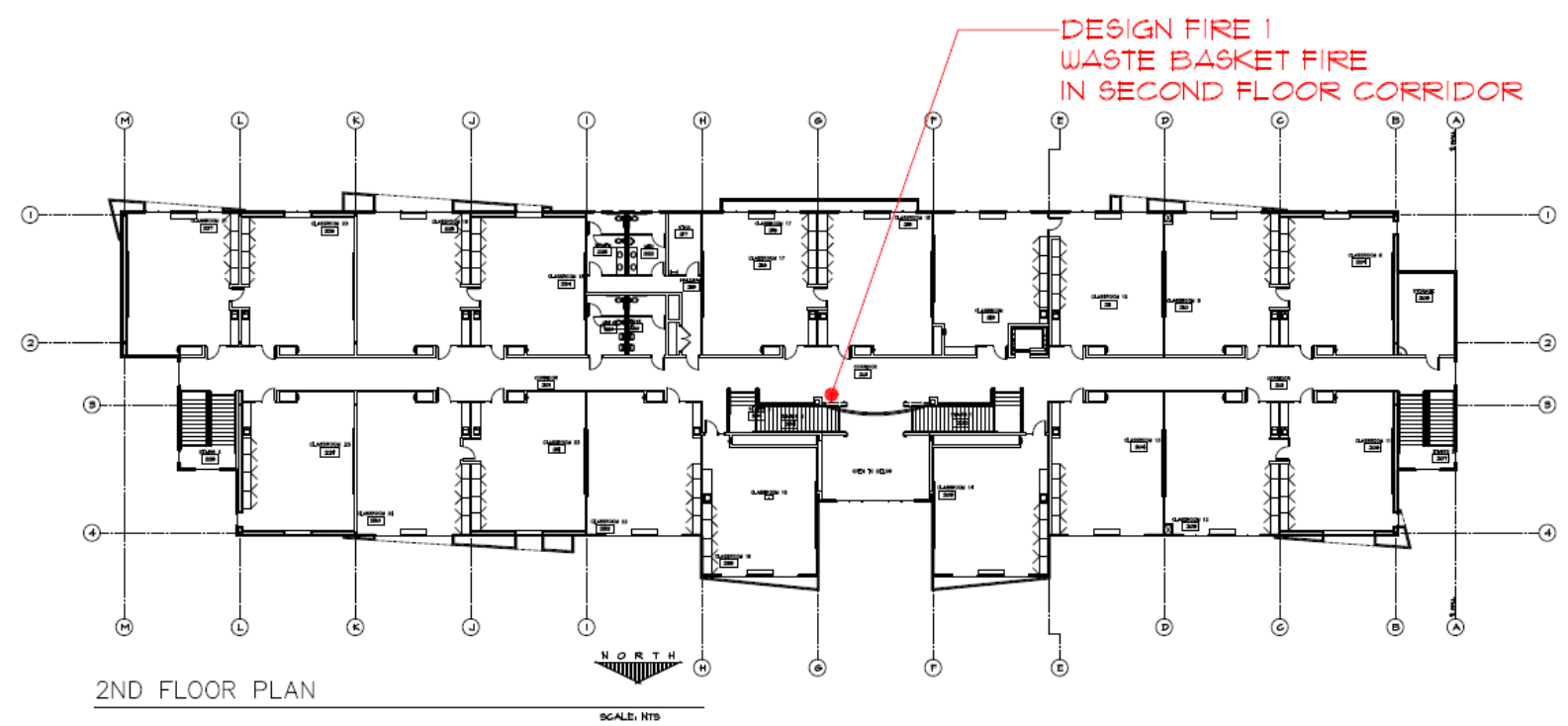




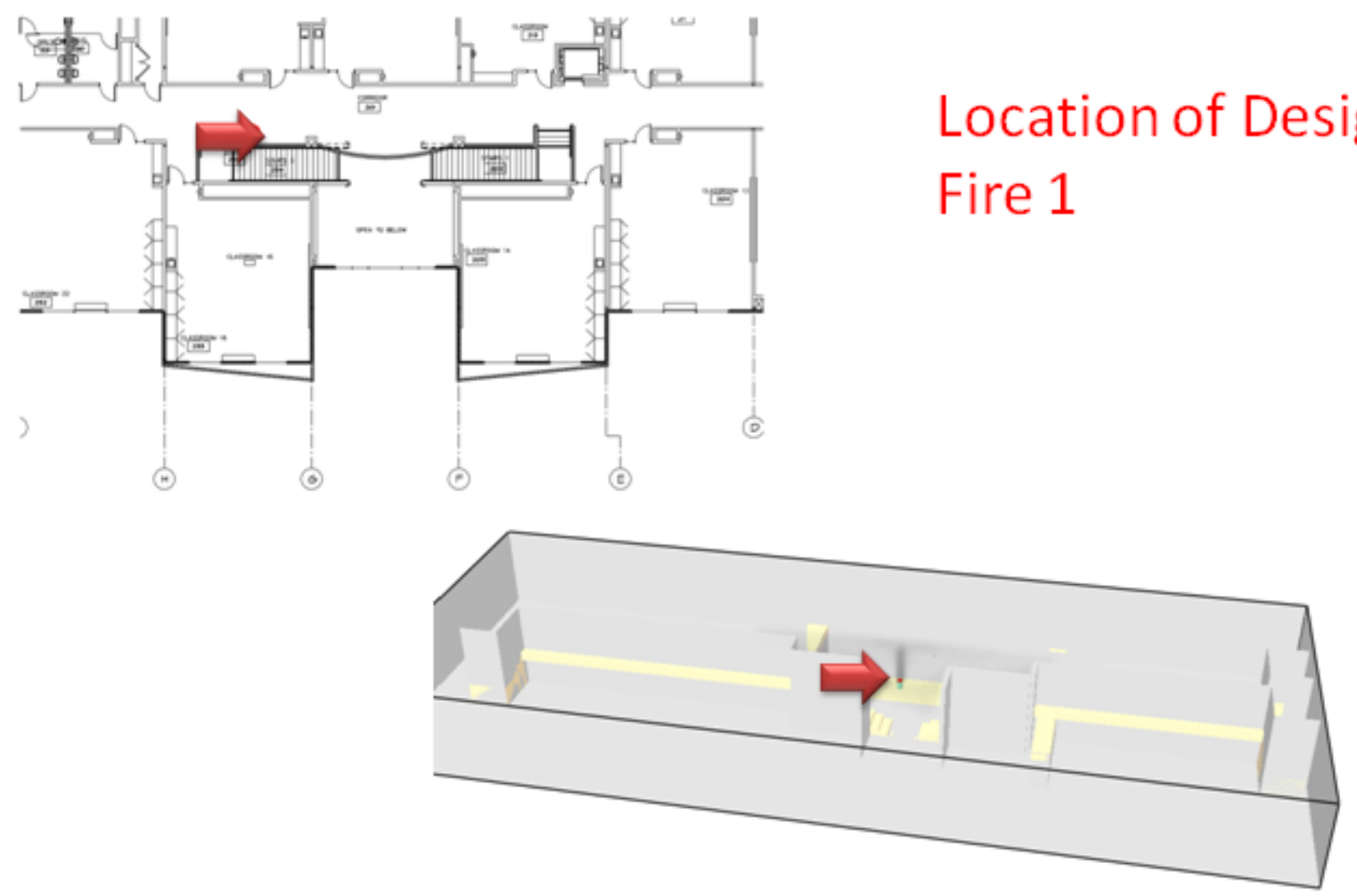

Figure 22 - Design Fire 1 Location

\section{Fire Scenario Description}

This fire is similar to NFPA 101 Design Fire Scenario 1. NFPA 101 defines this fire scenario as follows:

- (1) It is an occupancy-specific fire representative of a typical

fire for the occupancy.

- (2) It explicitly accounts for the following:

- (a) Occupant activities

- (b) Number and location of occupants

- (c) Room size

- (d) Contents and furnishings

- (e) Fuel properties and ignition sources 
- (f) Ventilation conditions

- (g) Identification of the first item ignited and its location

The conditions for this design fire scenario are as follows:

- Corridor 201, open to the primary entry access to the building and second floor egress corridors.

- Waste Basket in corridor is ignited.

The design fire used for this scenario is as follows:

- Design Fire Data the HRR of a standard Amtrack trash bag based on crumpled paper.

- Based on SFPE data from Figure 3-1.100

- Standard Trash bag with 110 sheets of crumpled newspaper in a 30 gallon HDPE container

- Peak HRR of $175 \mathrm{~kW}$

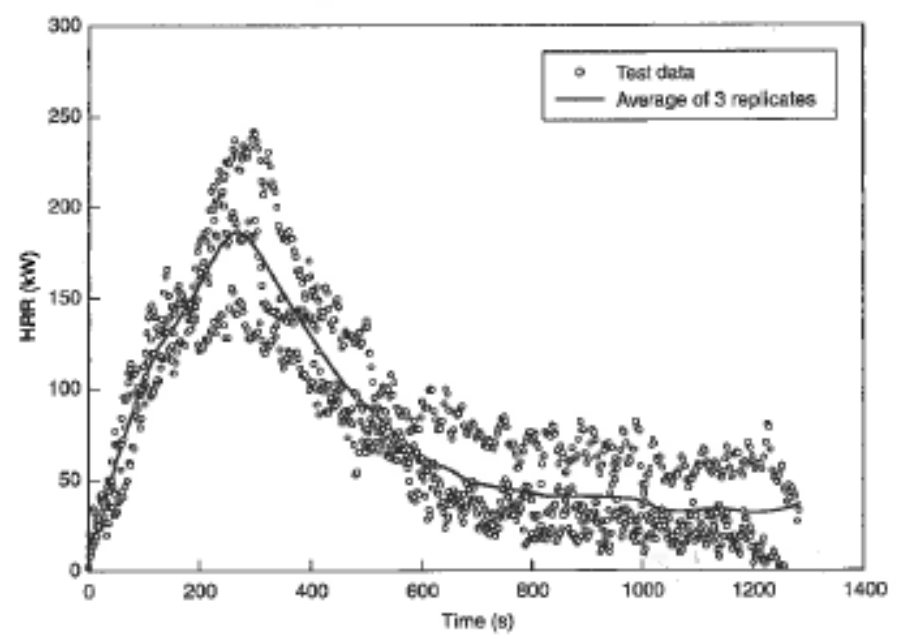

Figure 3-1.100. HRR of "standard" Amtrak trash bag, based on crumpled newspaper.

Figure 23 - Amtrack trash bag HRR Curves

\section{Model Design Fire}

For this design fire the fire the fire grows to a peak HRR of $175 \mathrm{~kW}$ at a time of 276 seconds and then begins to taper off as the fuel cannot sustain further growth. This fire model was run to 
600 seconds at which time the HRR had dropped to $60 \mathrm{~kW}$. For this fire scenario there were two smoke detectors located in the ceiling space of the room, the first activated at a time of 20 seconds after the start of the fire. Due to the low HRR and the large volume of the space none of the six sprinklers located in the room activated.

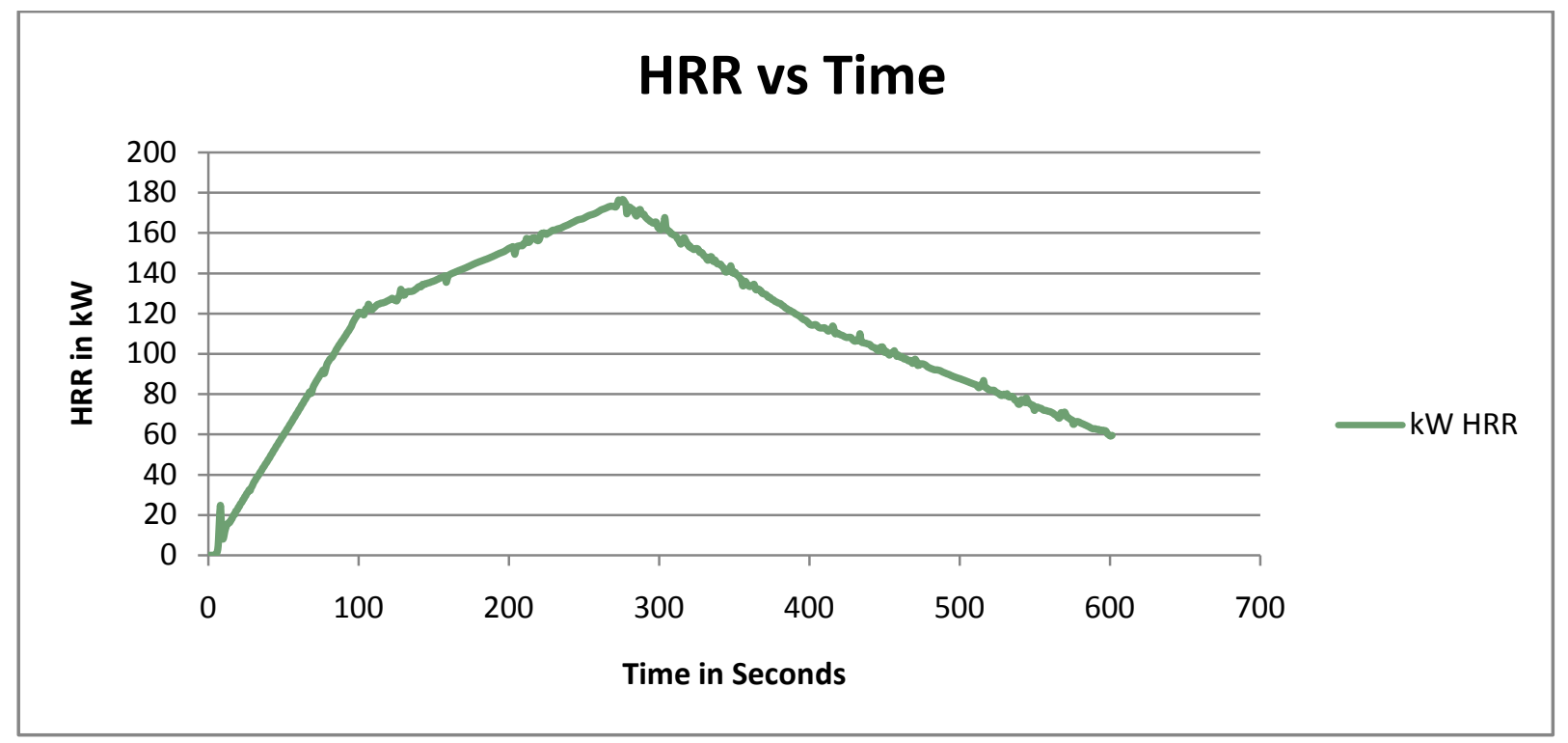

Figure 24 - Design Fire 1 HRR Curve

\section{Smoke Detector and Fire Sprinkler Activation}

For this fire the first smoke detector is activated at $20 \mathrm{~s}$.

No fire sprinklers activated.

DEVICE Activation Times

$\begin{aligned} 7 & \text { SPR1 } \\ 8 & \text { SPR2 } \\ 9 & \text { SPR3 } \\ 10 & \text { SPR4 } \\ 11 & \text { SPR5 } \\ 12 & \text { SPR6 } \\ 13 & \text { SPR7 } \\ 14 & \text { SPR8 } \\ 15 & \text { SD1 } \\ 16 & \text { SD2 }\end{aligned}$

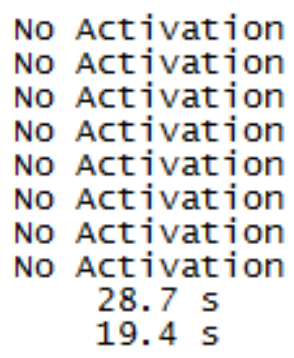

Figure 25 - FDS Output of Device Activation 


\section{Design Fire 1 RSET}

For design fire 1 the RSET is 259 s or 4.32 min based on the following:

Detection Time $\quad 20 \mathrm{~s}$ time of first smoke detector activation from FDS model run

Notification Time $\quad 5 \mathrm{~s}$ time delay for smoke detector activation to signal

Pre-Movement Time $30 \mathrm{~s}$ assumed time based on occupancy use

Movement Time $\quad 204 \mathrm{~s}$ time from hand calculations with all stairs and doors used

RSET $259 \mathrm{~s}$ total required time for safe evacuation 


\section{Design Fire 1 ASET Times}

For Design Fire 1 the ASET times for the various performance criteria are as follows:

The carbon monoxide level at $2 \mathrm{~m}$ above the second floor walking surface at the RSET time of $259 \mathrm{~s}$ is well below the 1,400 ppm tenability requirement. Criteria passes for RSET.

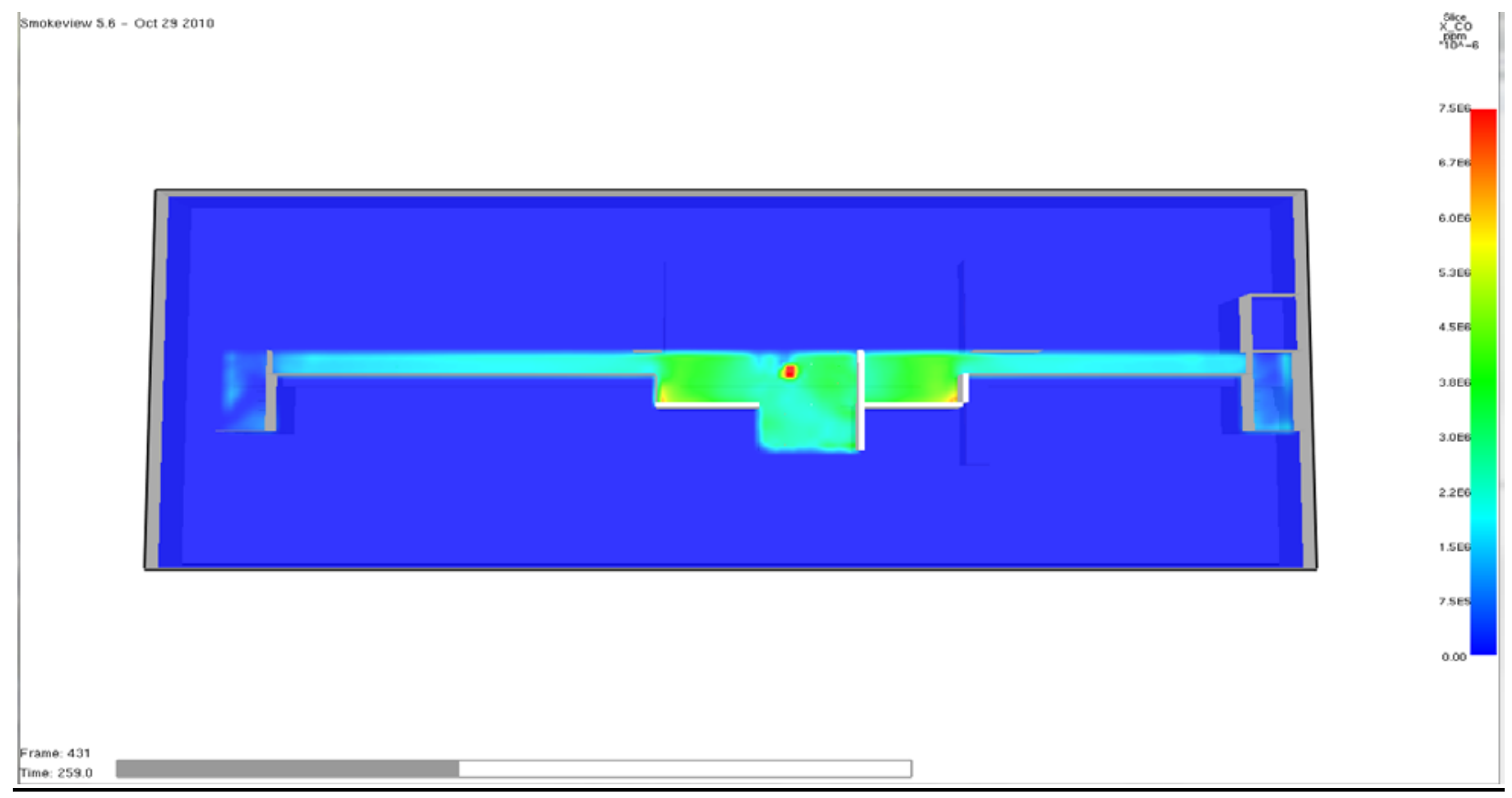

Figure 26 - FDS Design Fire 1 - CO at 259 s RSET 
The carbon monoxide level at $2 \mathrm{~m}$ above the second floor walking surface at the end of the simulation run (600 s) is well below the 1,400 ppm tenability requirement.

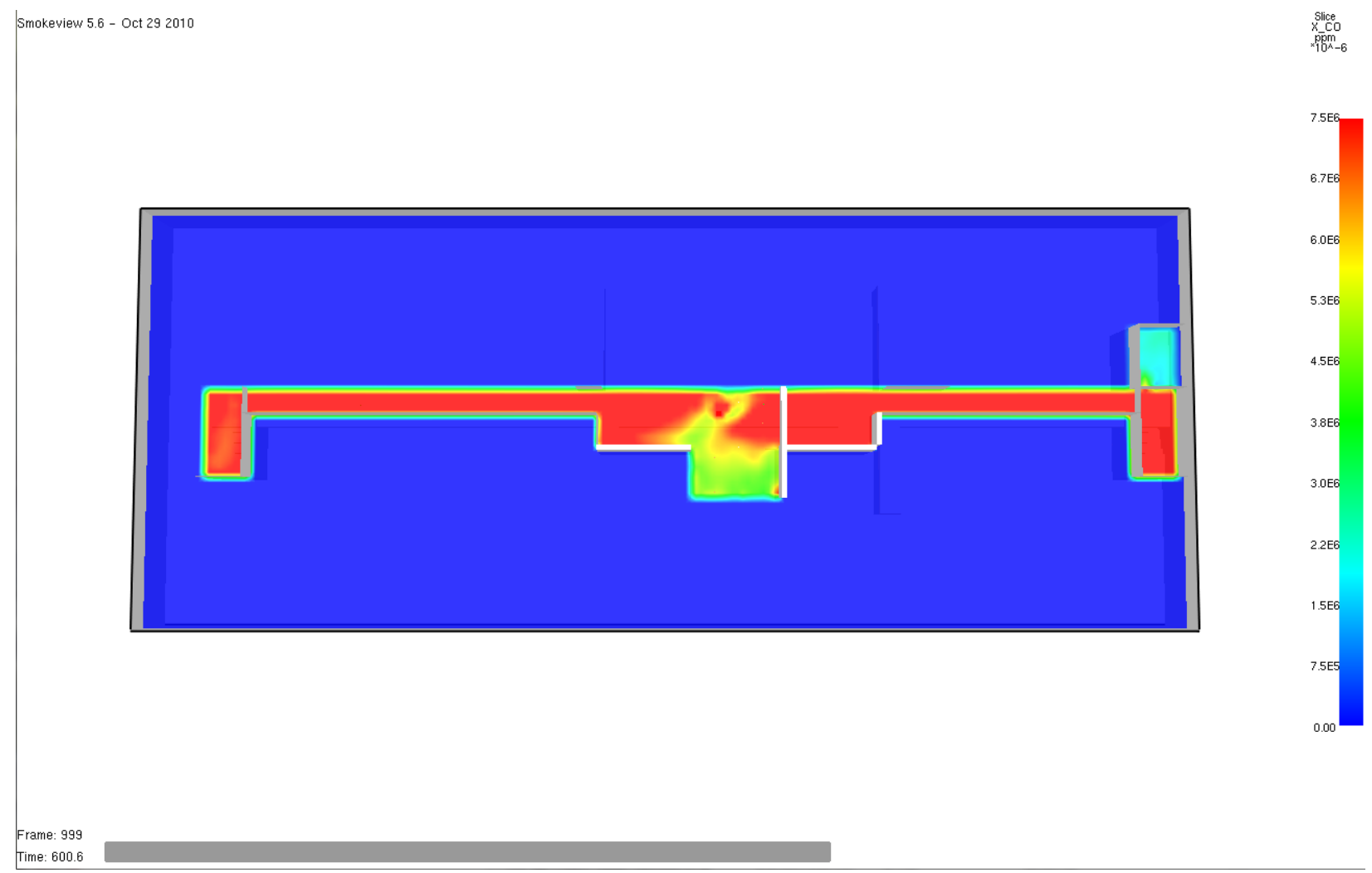

Figure 27 - FDS Design Fire 1 - CO at $600 \mathrm{~s}$ 
The maximum temperature at $2 \mathrm{~m}$ above the second floor walking surface is under 30 degree $\mathrm{C}$ at all egress path areas which is well below the required 60 degree $C$ criteria. Criteria passes.

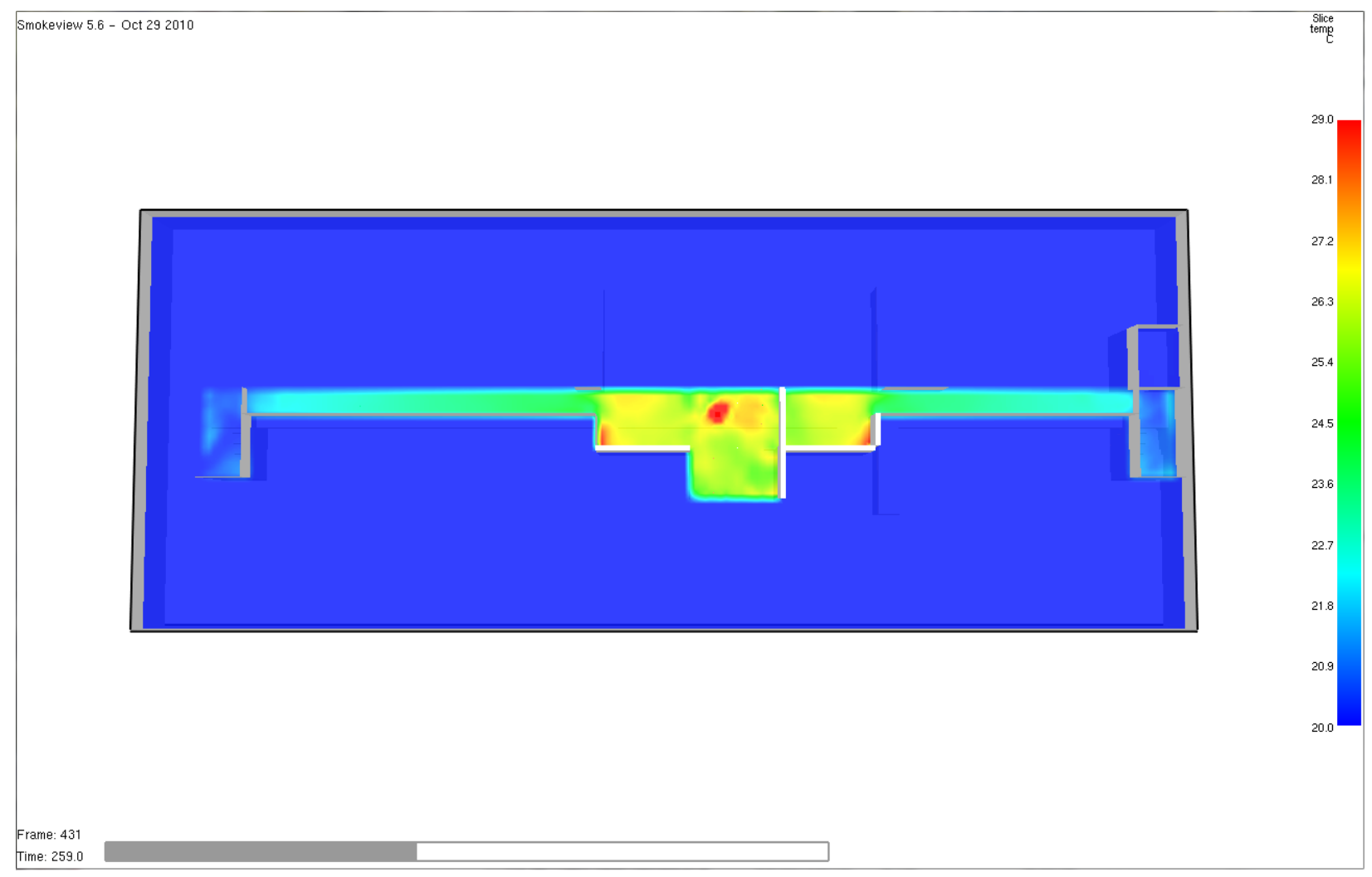

Figure 28 - FDS Design Fire 1 - Temperature at 259 s RSET 
The maximum temperature at $2 \mathrm{~m}$ above the second floor walking surface at the end of the simulation run (600 s) is well below the 60 degree $C$ criteria.

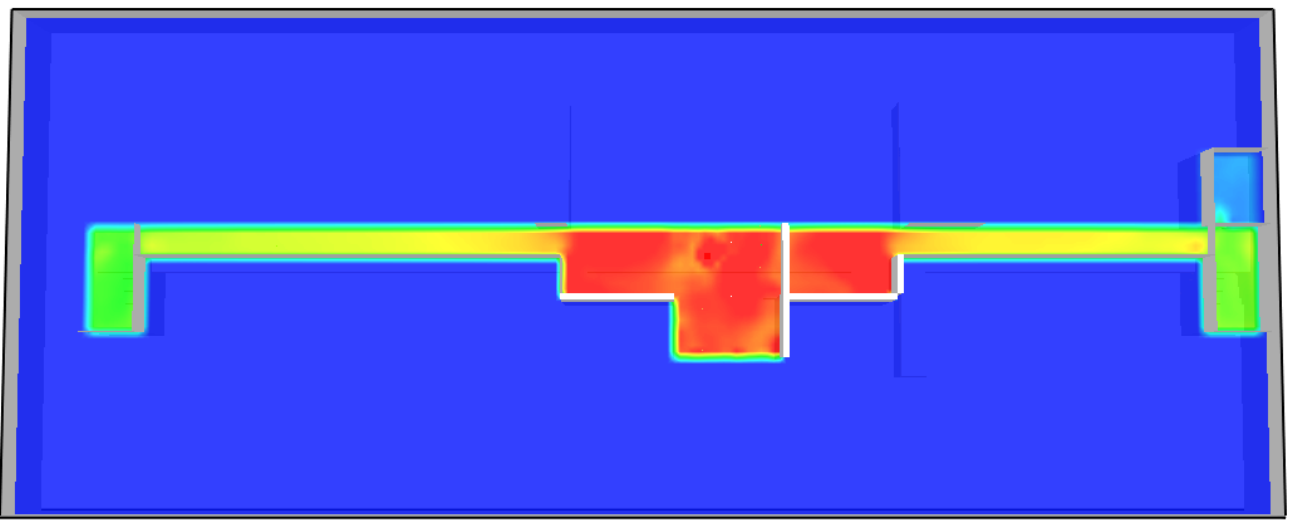

Figure 29 - FDS Design Fire 1 - Temperature at $600 \mathrm{~s}$ 
The minimum visibility at $2 \mathrm{~m}$ above the second floor walking surface at the RSET time of $259 \mathrm{~s}$ is at over $45 \mathrm{~m}$ which is above the $10 \mathrm{~m}$ requirement. Criteria passes for RSET.

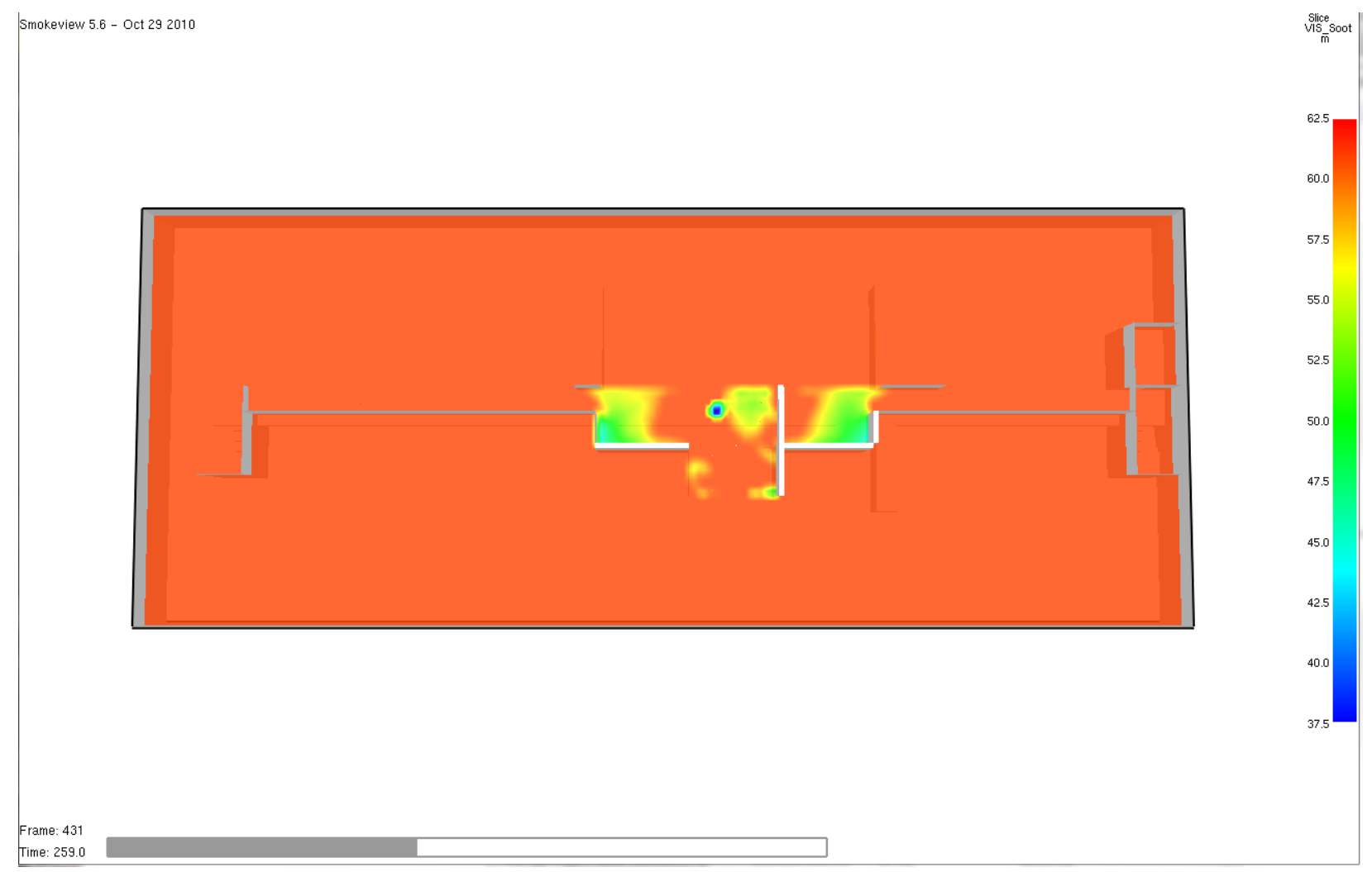

Figure 30 - FDS Design Fire 1 - Visibility at 259 s RSET 
The minimum visibility at $2 \mathrm{~m}$ above the second floor walking surface at the end of the simulation run (600 s) is greater than $35 \mathrm{~m}$ which is above the $10 \mathrm{~m}$ visibility criteria.

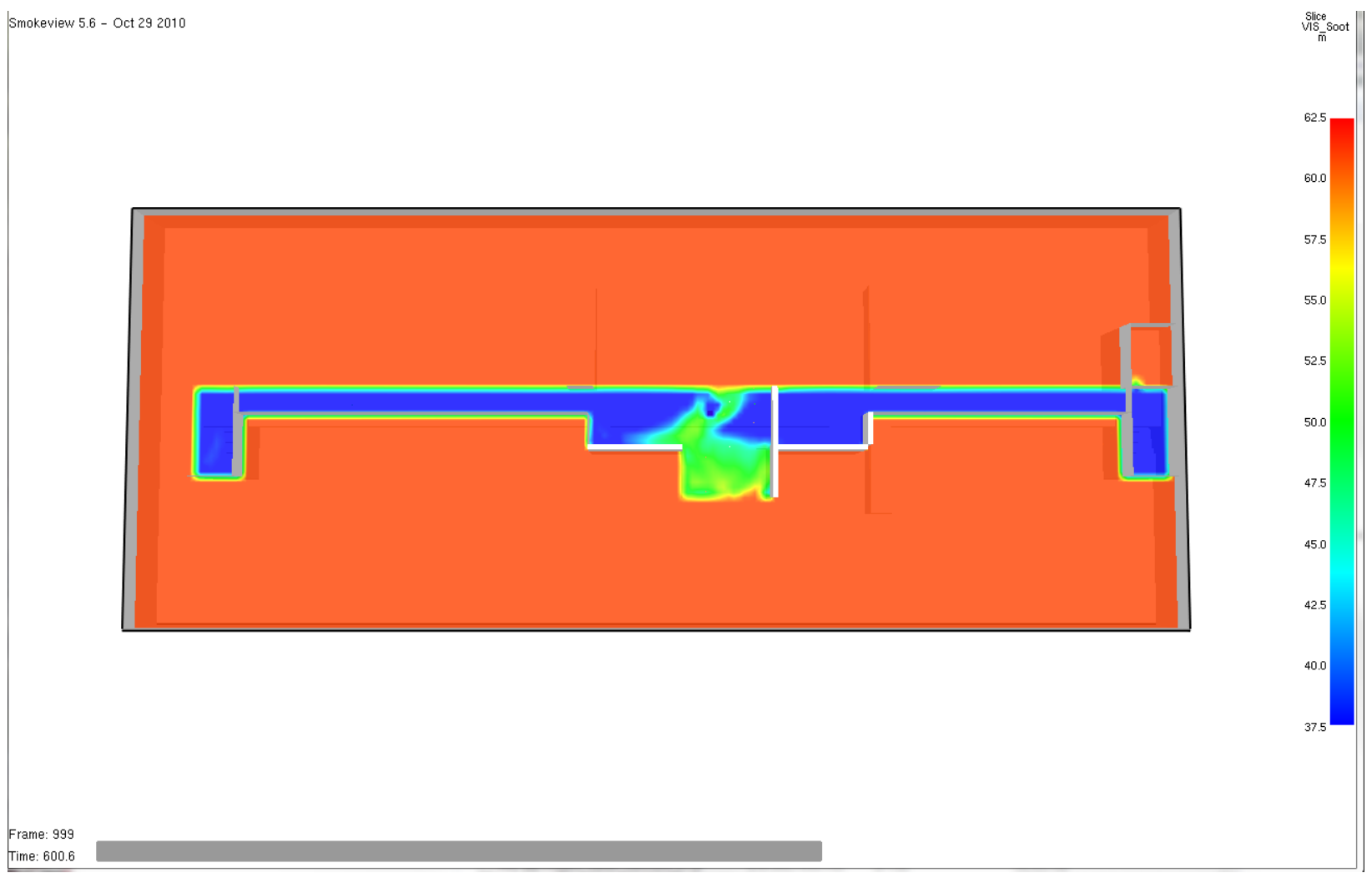

Figure 31 - FDS Design Fire 1 - Visibility at $600 \mathrm{~s}$ 
The smoke layer drops below the $2 \mathrm{~m}$ requirement at $236 \mathrm{~s}$ as shown in the graph below. This criteria fails for RSET. (Note: Smoke layer height is taken at a single point in the middle of each corridor which results in a sharp drop in the smoke layer height as the smoke layer moves down the corridor and hits the measuring point).

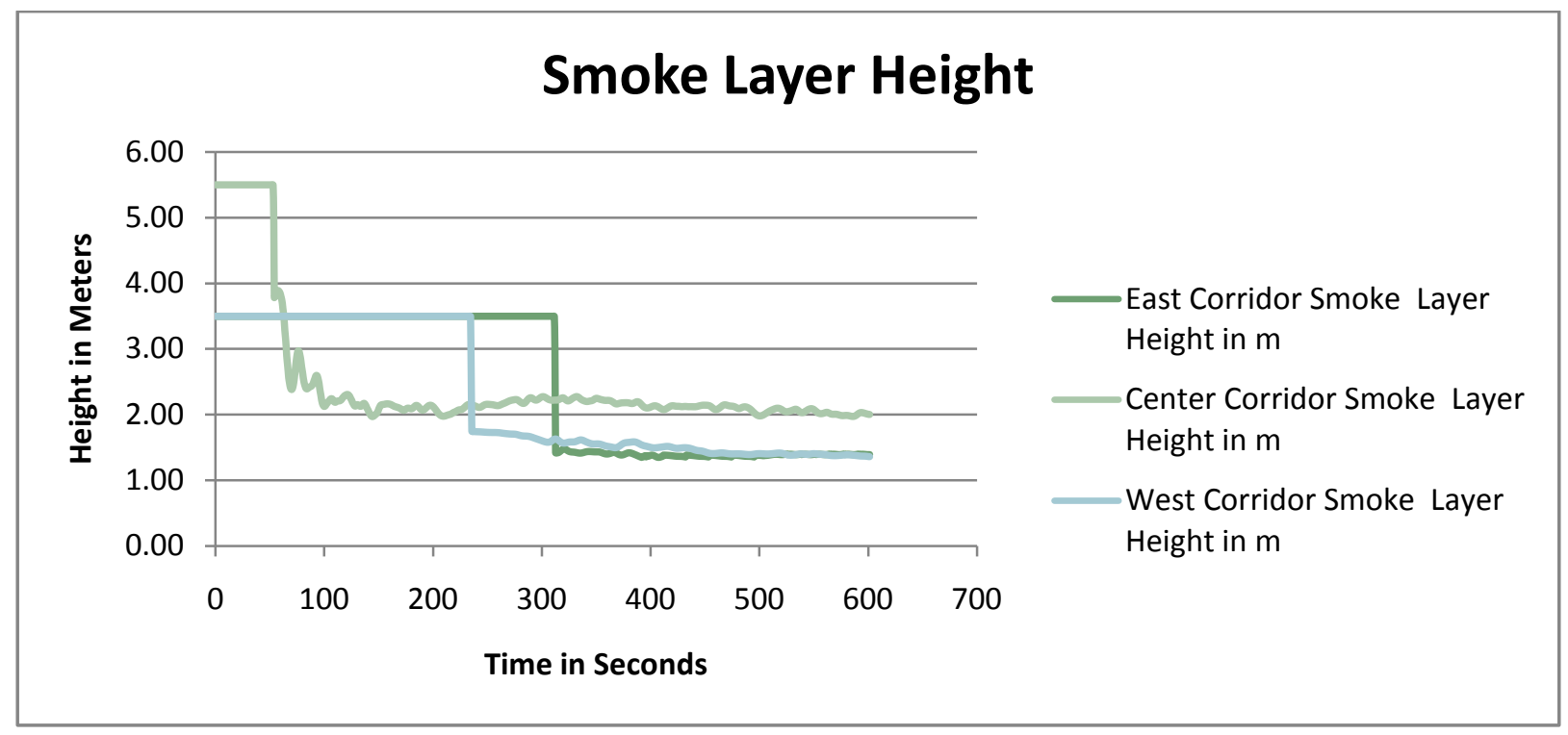

Figure 32 - FDS Design Fire 1 - Smoke Layer Height vs Time

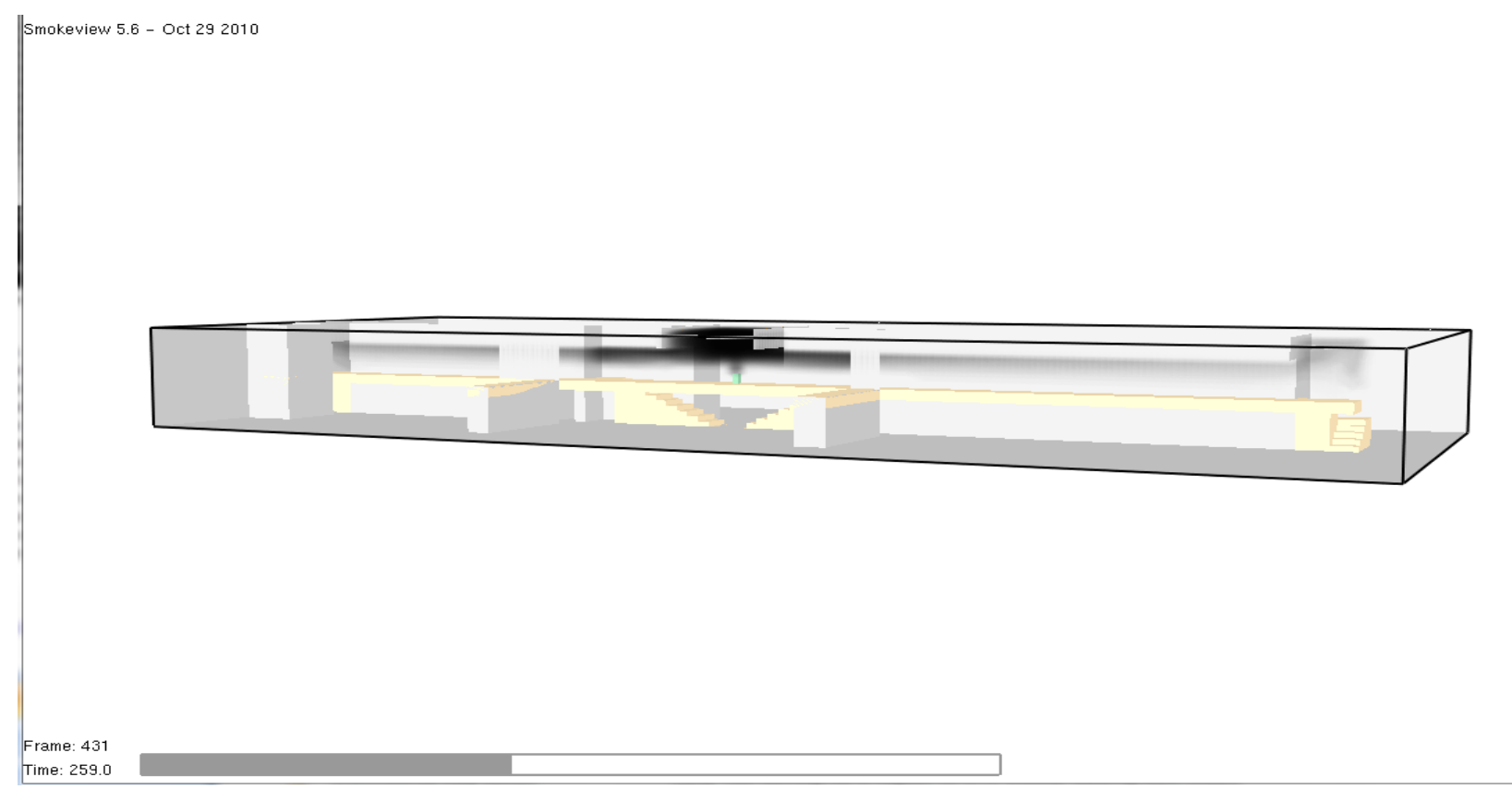

Figure 33 - FDS Design Fire 1 - Image Looking North at RSET 


\section{Design Fire 1 Summary}

This design fire scenario fails the performance criteria for the smoke layer height at a time of 236 seconds. The $\mathrm{CO}$, temperature and visibility all pass the performance criteria at the RSET time of $259 \mathrm{~s}$ and remains below required levels to the end of the simulation at a time of $600 \mathrm{~s}$.

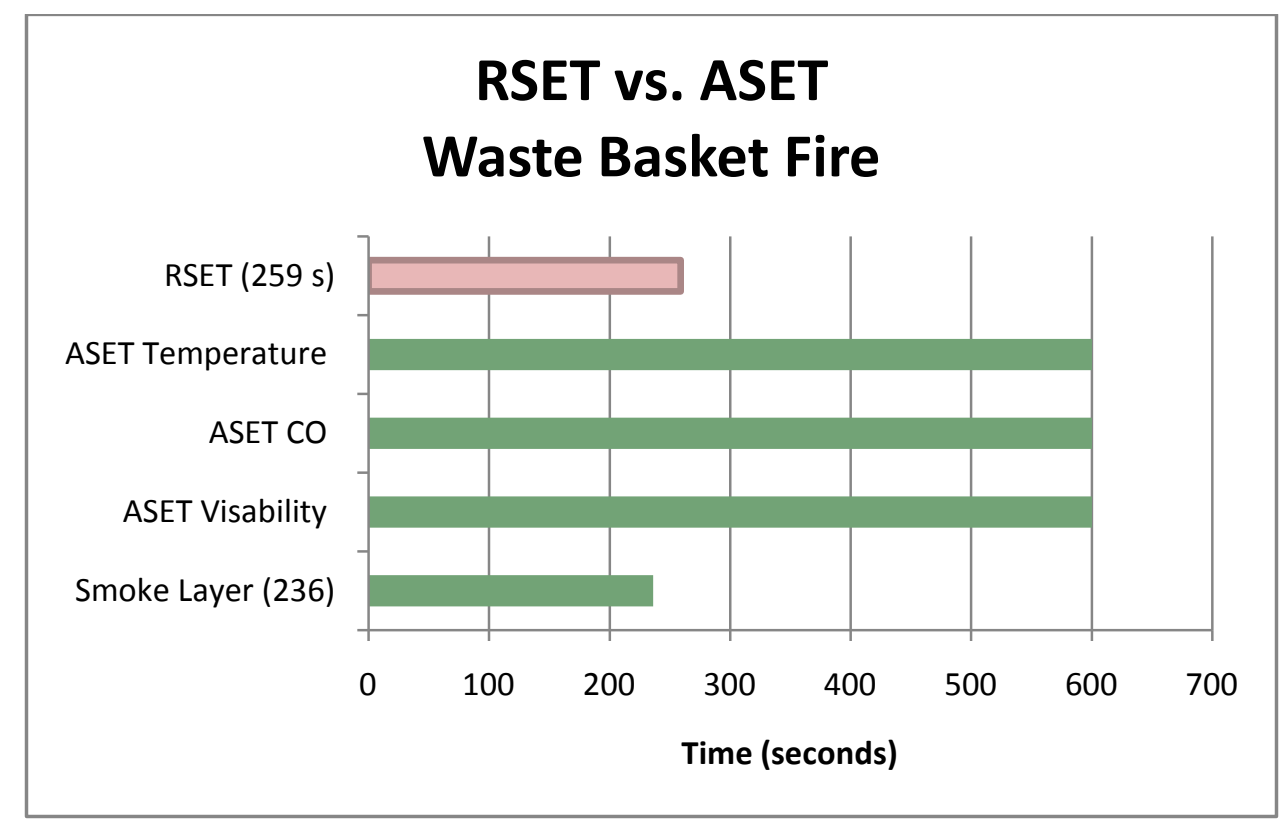

Figure 34 - FDS Design Fire 1 - RSET vs ASET Summary

\section{Design Fire 2}

\section{Scenario Overview}

This performance design scenario involves a fire in the main entry area of the building.

Typically this area is free of flammable material but at certain time of the year there is material which could be fuel for a fire in this area. In this scenario during the two times a year that the school does a student book fair a magazine / book rack is on display in the entry area which is located directly outside of the library. For this scenario the magazine / book rack is set on fire and causes the two main entry doors and two main stairs to the entry to be unavailable for egress. 

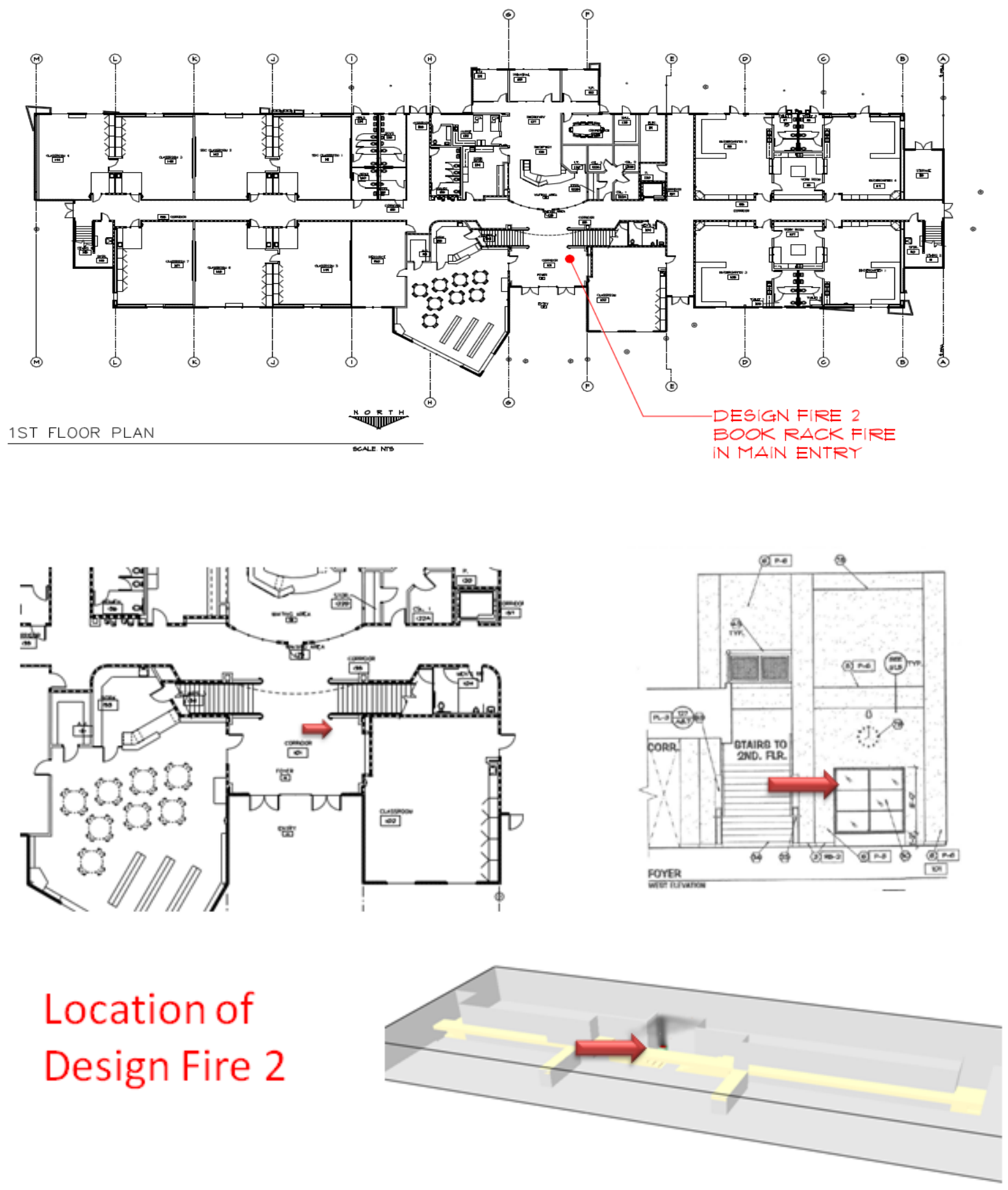

Figure 35 - Design Fire 2 Location 


\section{Fire Scenario Description}

This fire is similar to NFPA 101 Design Fire Scenario 2. NFPA 101 defines this fire scenario as follows:

- (1) It is an ultrafast-developing fire, in the primary means of egress, with interior doors open at the start of the fire.

- (2) It addresses the concern regarding a reduction in the number of available means of egress.

The conditions for this design fire scenario are as follows:

- Foyer 101 , open to second floor above and is the primary entry access to the building.

- Room serves as main access to the Media Lab / Library.

- A built in glass bookcase is on the West wall.

- Normally space is free of free standing display items.

- Fire Scenario Conditions

- During the schools book fair a rolling magazine / book rack for display is located in the entry in front of the west wall built in glass bookcase.

The design fire used for this scenario is as follows:

- Design Fire Data for Magazine / Book Rack holding magazines, newspapers and books.

- Based on SFPE data from Table 3-1.14 and Figure 3-1.56

- Rack Size of $1 \times 2.2 \mathrm{~m}$

- Mass of $15 \mathrm{~kg}$

- Ignition Source, $2 \mathrm{~L}$ of gasoline

- Peak HRR of $3500 \mathrm{kw}$ 


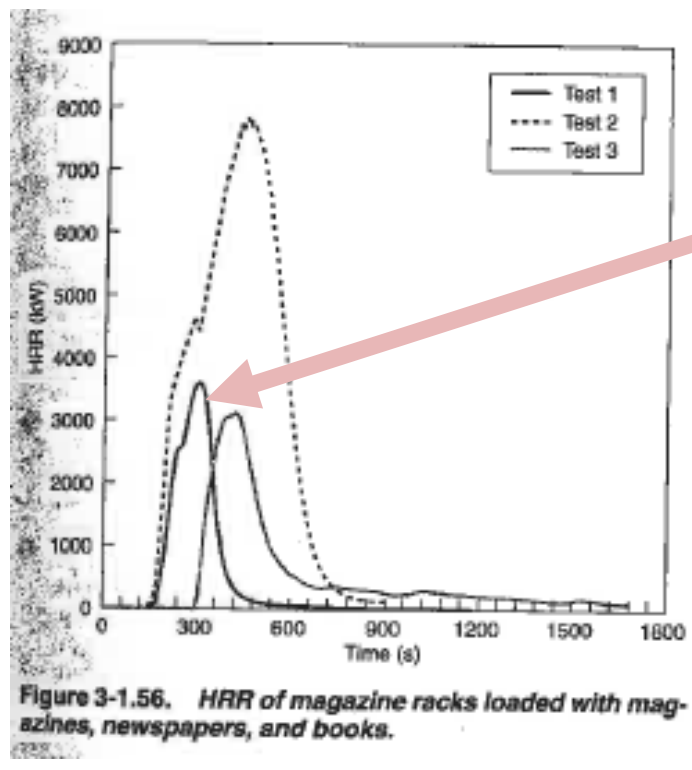

Selected Design Fire

Curve $-3600 \mathrm{~kW}$

Figure 36 - Magazine Rack HRR from SFPE Figure 3-1.56

\section{Model Design Fire}

For this design fire the develops very slowly at first and then at around 175 seconds ramps up very rapidly at a rate greater than an ultra fast fire ( growth to $1055 \mathrm{~kW}$ in 75 seconds). For this fire scenario there were two smoke detectors located in the ceiling space of the room, the first activated at a time of 178 seconds after the start of the fire. The room also has six fire sprinklers of which the first fire sprinkler is activated at $230 \mathrm{~s}$. At this time the fire becomes a fire sprinkler controlled fire and the fire growth rate levels off at around $2500 \mathrm{~kW}$ and remains steady at this HRR for the duration of the scenario as the fuel available is able to sustain this HRR for the duration of the scenario. This fire model was developed by doing an initial model run with the fire growing till the first sprinkler activated. The model fire growth was then capped at the time the sprinkler discharge began to cover the fire and the model was re-run with the capped HRR. The HRR is shown below. 


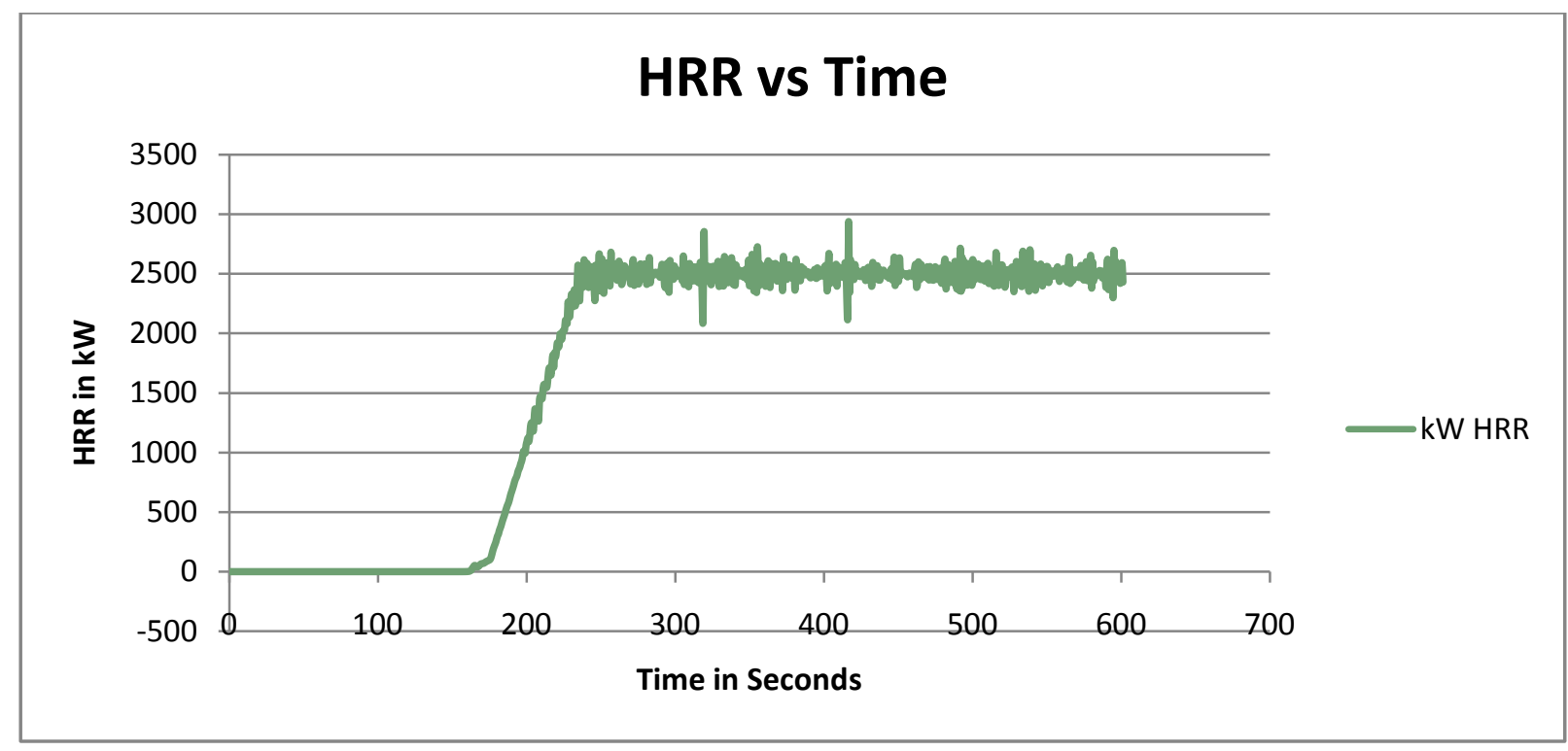

Figure 37 - Design Fire 2 HRR Curve

\section{Smoke Detector and Fire Sprinkler Activation}

For this fire the first smoke detector is activated at $230 \mathrm{~s}$.

The first fire sprinkler is activated at $230 \mathrm{~s}$.

\begin{tabular}{|c|c|c|}
\hline $\begin{array}{r}7 \\
8 \\
9 \\
10 \\
11 \\
12 \\
13 \\
14 \\
15 \\
16\end{array}$ & $\begin{array}{l}\text { SPR1 } \\
\text { SPR2 } \\
\text { SPR3 } \\
\text { SPR4 } \\
\text { SPR5 } \\
\text { SPR6 } \\
\text { SPR7 } \\
\text { SPR8 } \\
\text { SD1 } \\
\text { SD2 }\end{array}$ & $\begin{array}{l}479.5 \mathrm{~s} \\
229.6 \mathrm{~s} \\
284.6 \mathrm{~s} \\
243.1 \mathrm{~s} \\
\text { No Activation } \\
308.8 \mathrm{~s} \\
\text { No Activation } \\
323.3 \mathrm{~s} \\
177.9 \mathrm{~s} \\
186.2 \mathrm{~s}\end{array}$ \\
\hline
\end{tabular}

Figure 38 - FDS Output of Device Activation 


\section{Design Fire 2 RSET}

For design fire 2 the RSET is $560 \mathrm{~s}$ or 9.33 min based on the following:

Detection Time $\quad 20 \mathrm{~s}$ time of first smoke detector activation from FDS model run

Notification Time $\quad 5 \mathrm{~s} \quad$ time delay for smoke detector activation to signal

Pre-Movement Time $30 \mathrm{~s}$ assumed time based on occupancy use

Movement Time $\quad 347 \mathrm{~s}$ time from hand calculations with all stairs and doors used

RSET $560 \mathrm{~s}$ total required time for safe evacuation

\section{Design Fire 2 ASET Times}

For Design Fire 1 the ASET times for the various performance criteria are as follows:

The carbon monoxide level at $2 \mathrm{~m}$ above the second floor walking surface at the RSET time of $560 \mathrm{~s}$ is well below the 1,400 ppm tenability requirement. Criteria passes for RSET.

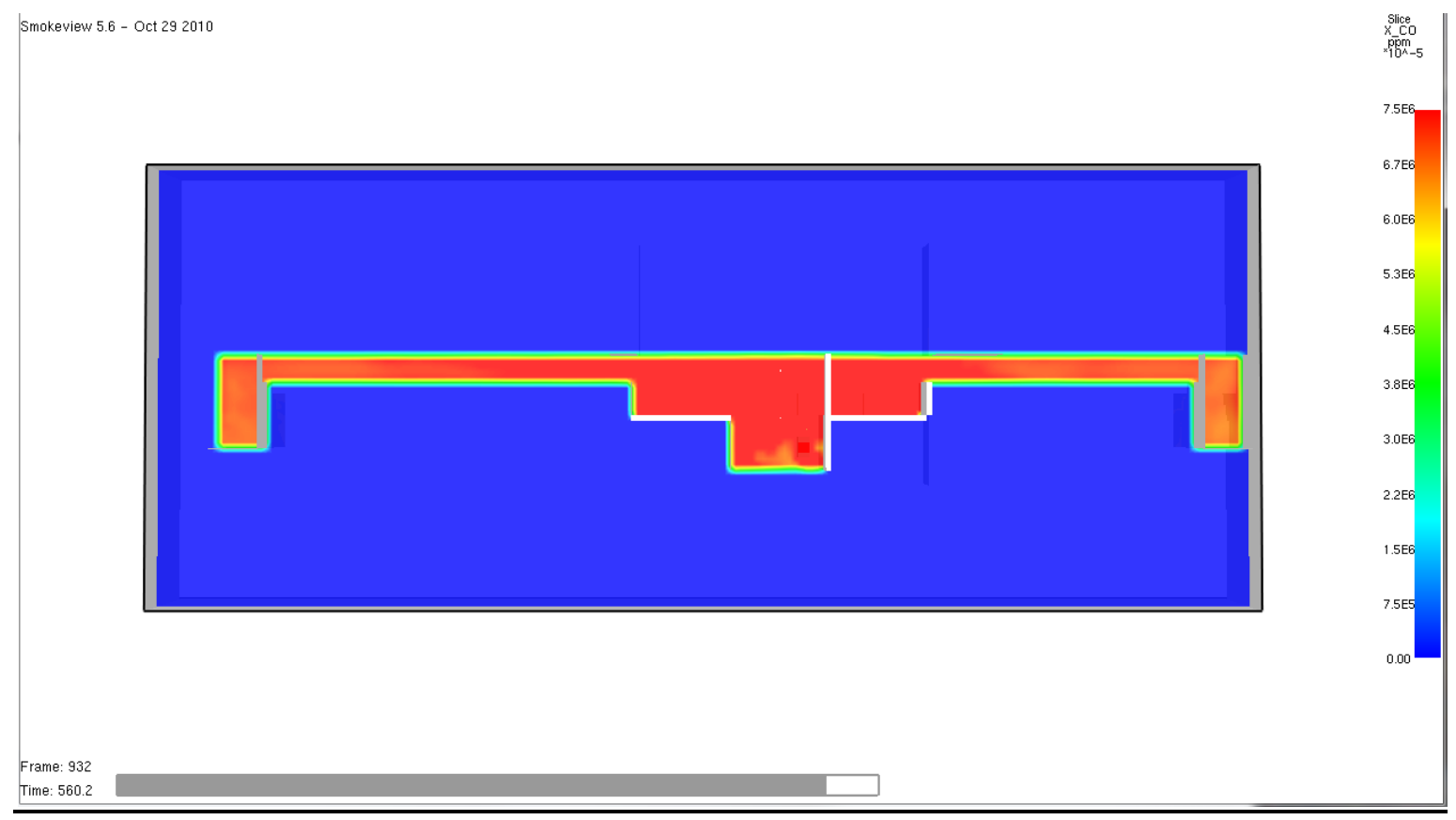

Figure 39 - FDS Design Fire 2 - CO at 560 s RSET 
The carbon monoxide level at $2 \mathrm{~m}$ above the second floor walking surface at the end of the simulation run (600 s) is well below the $1,400 \mathrm{ppm}$ tenability requirement.

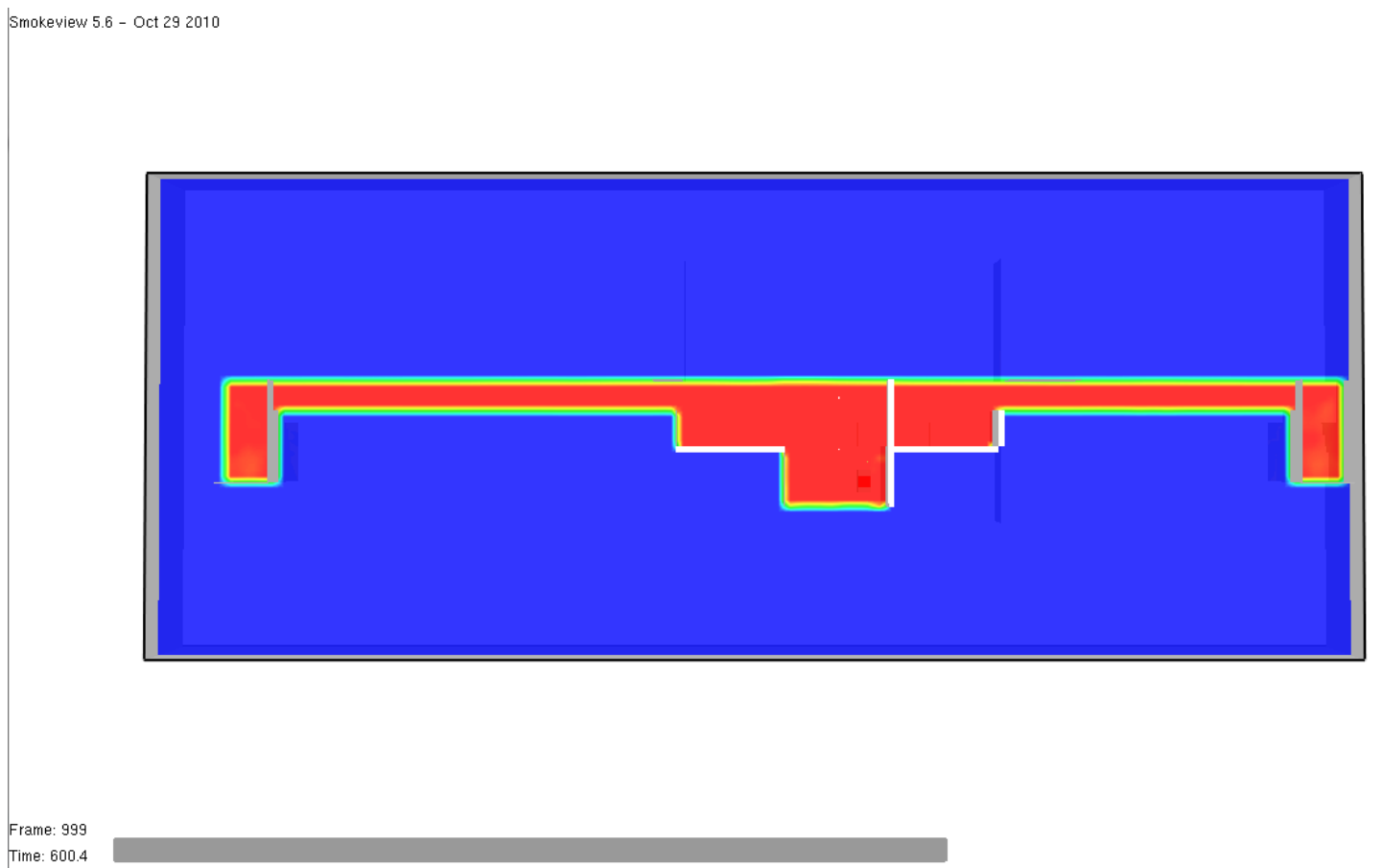

Figure 40 - FDS Design Fire 2 - CO at $600 \mathrm{~s}$ 
The maximum temperature at $2 \mathrm{~m}$ above the second floor walking surface at all area is under the 60 degree $C$ criteria. Criteria passes.

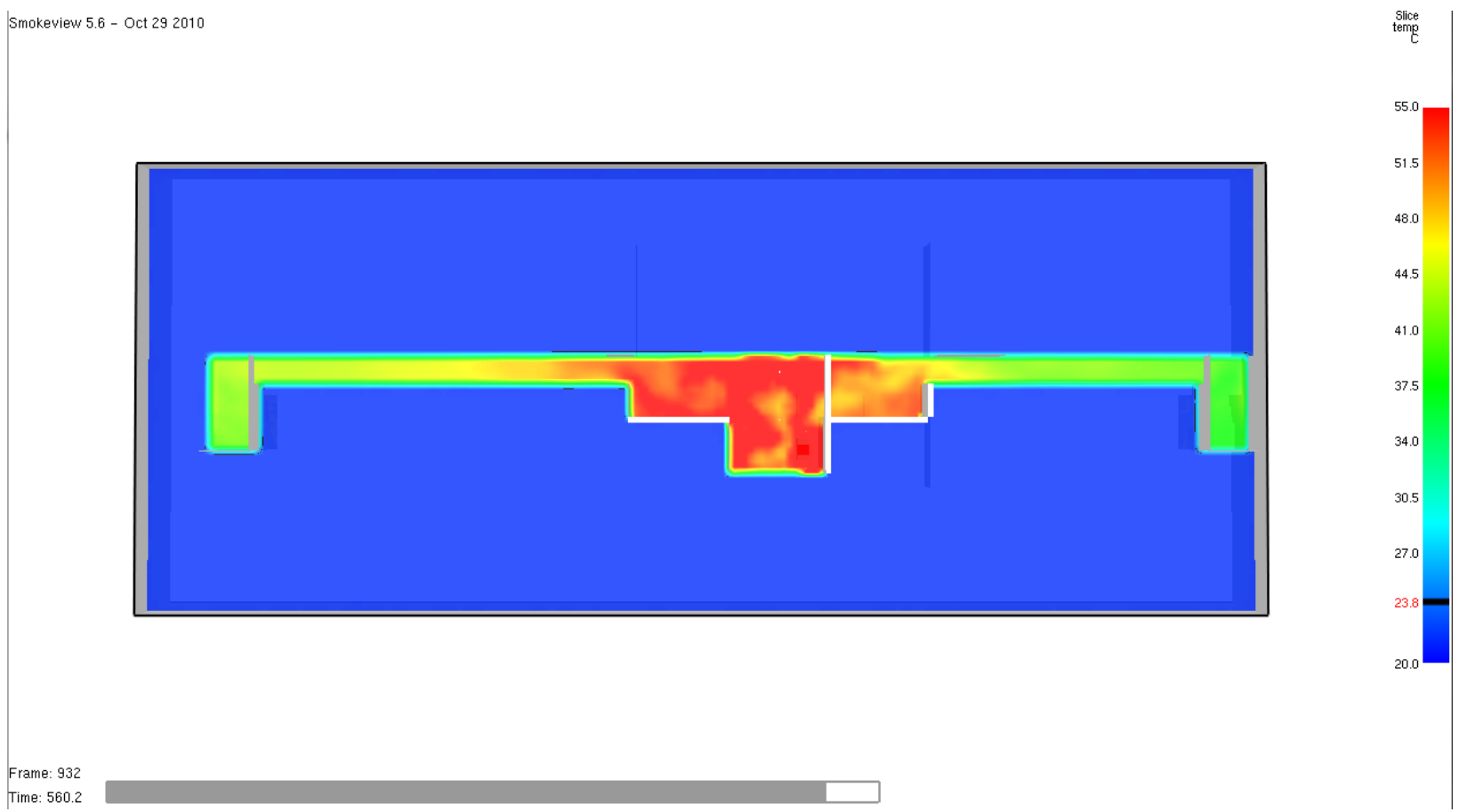

Figure 41 - FDS Design Fire 2 - Temperature at 560 s RSET 
The maximum temperature at $2 \mathrm{~m}$ above the second floor walking surface at the end of the simulation run (600 s) is still below the 60 degree $C$ criteria.

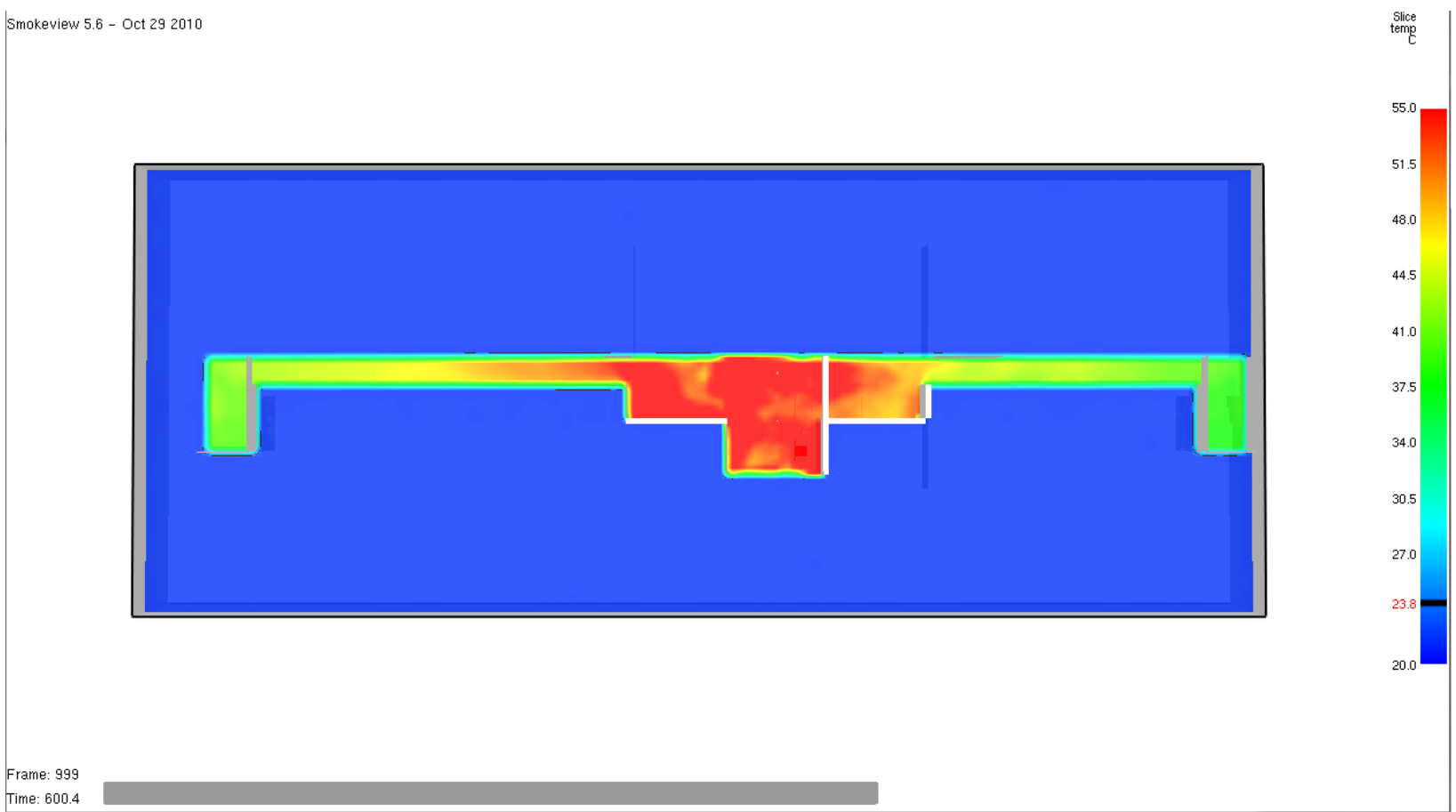

Figure 42 - FDS Design Fire 2 - Temperature at $600 \mathrm{~s}$ 
The minimum visibility at $2 \mathrm{~m}$ above the second floor walking surface drops below the $10 \mathrm{~m}$ criteria at around $235 \mathrm{~s}$. Criteria fails for RSET.

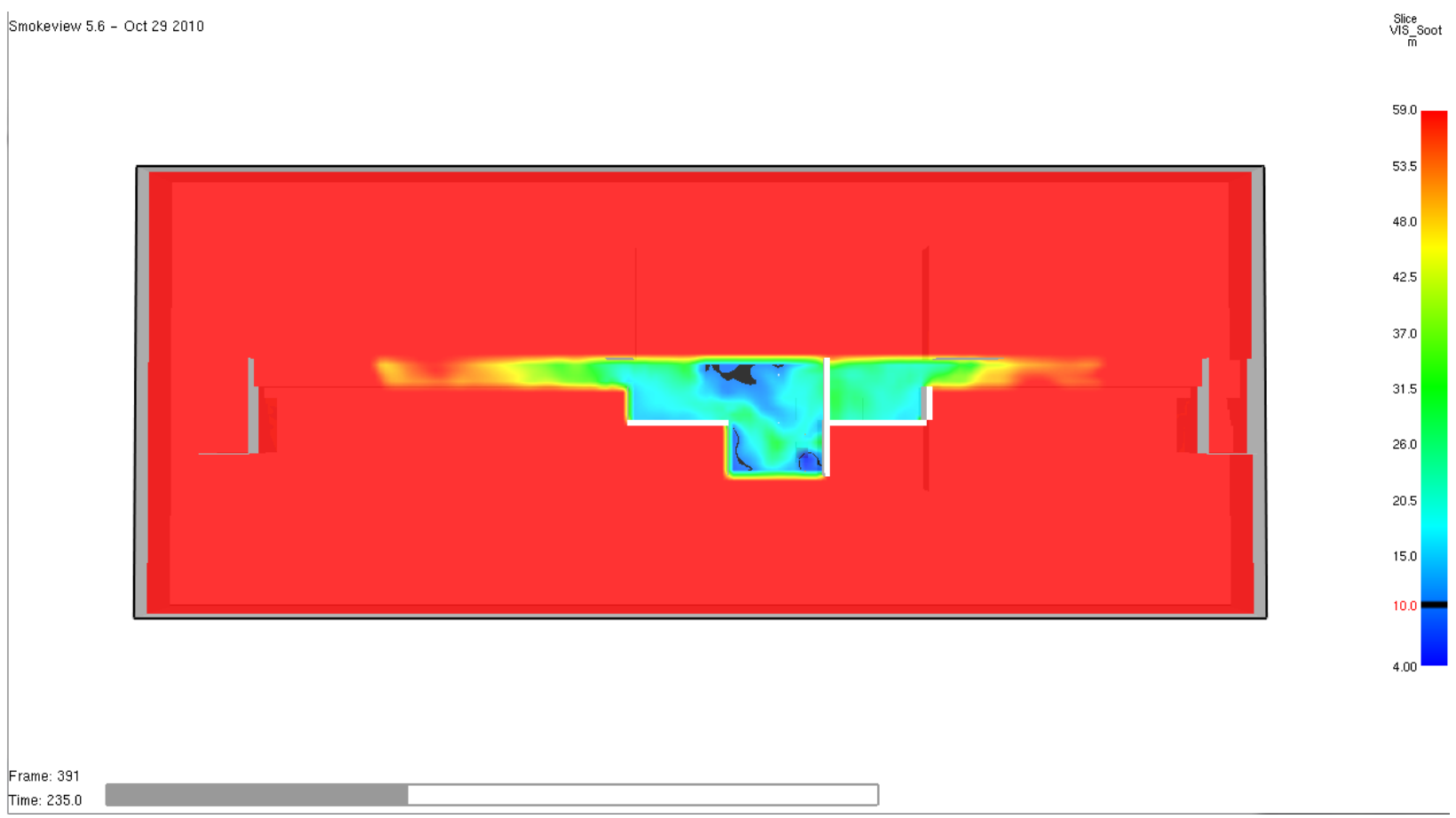

Figure 43 - FDS Design Fire 2 - Visibility at $235 \mathrm{~s}$ as it drops below criteria. 
The minimum visibility at $2 \mathrm{~m}$ above the second floor walking surface at the end of the simulation run (600 s) is well below the $10 \mathrm{~m}$ criteria in a large portion of the second floor corridor.

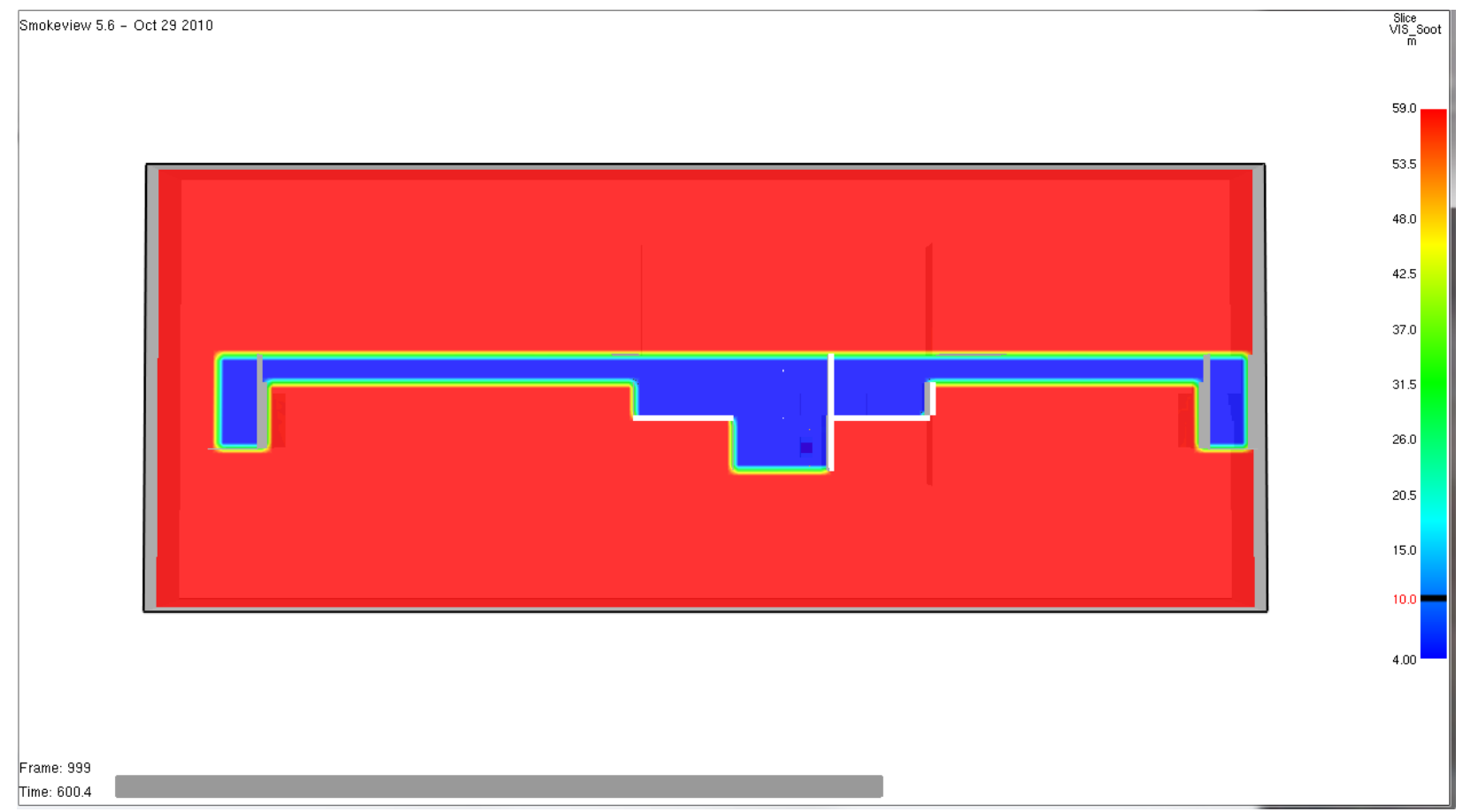

Figure 44 - FDS Design Fire 2 - Visibility at $600 \mathrm{~s}$ 
The smoke layer drops below the $2 \mathrm{~m}$ requirement at $210 \mathrm{~s}$ as shown in the graph below. This criteria fails for RSET. (Note: Smoke layer height is taken at a single point in the middle of each corridor which results in a sharp drop in the smoke layer height as the smoke layer moves down the corridor and hits the measuring point).

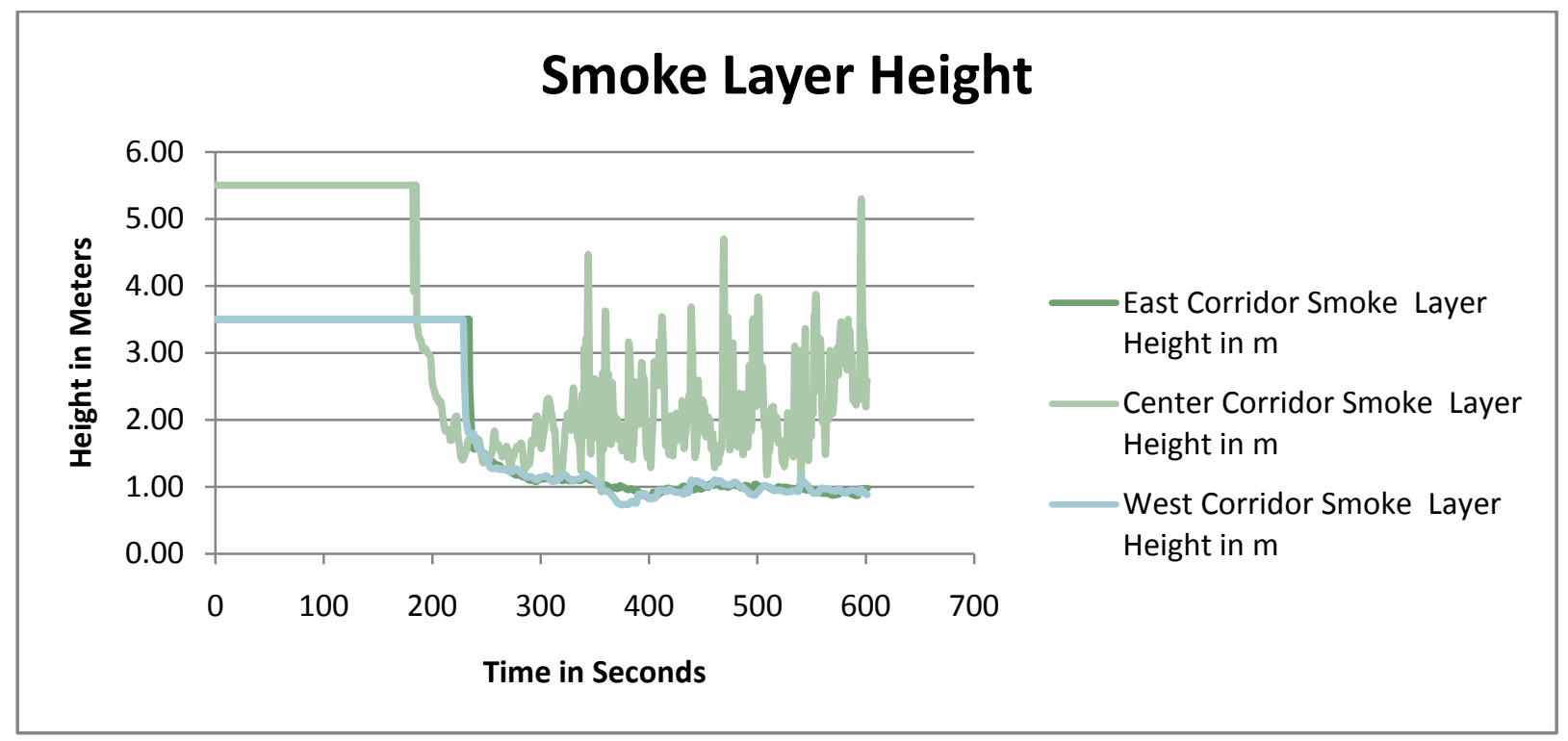

Figure 45 - FDS Design Fire 2 - Smoke Layer Height vs Time

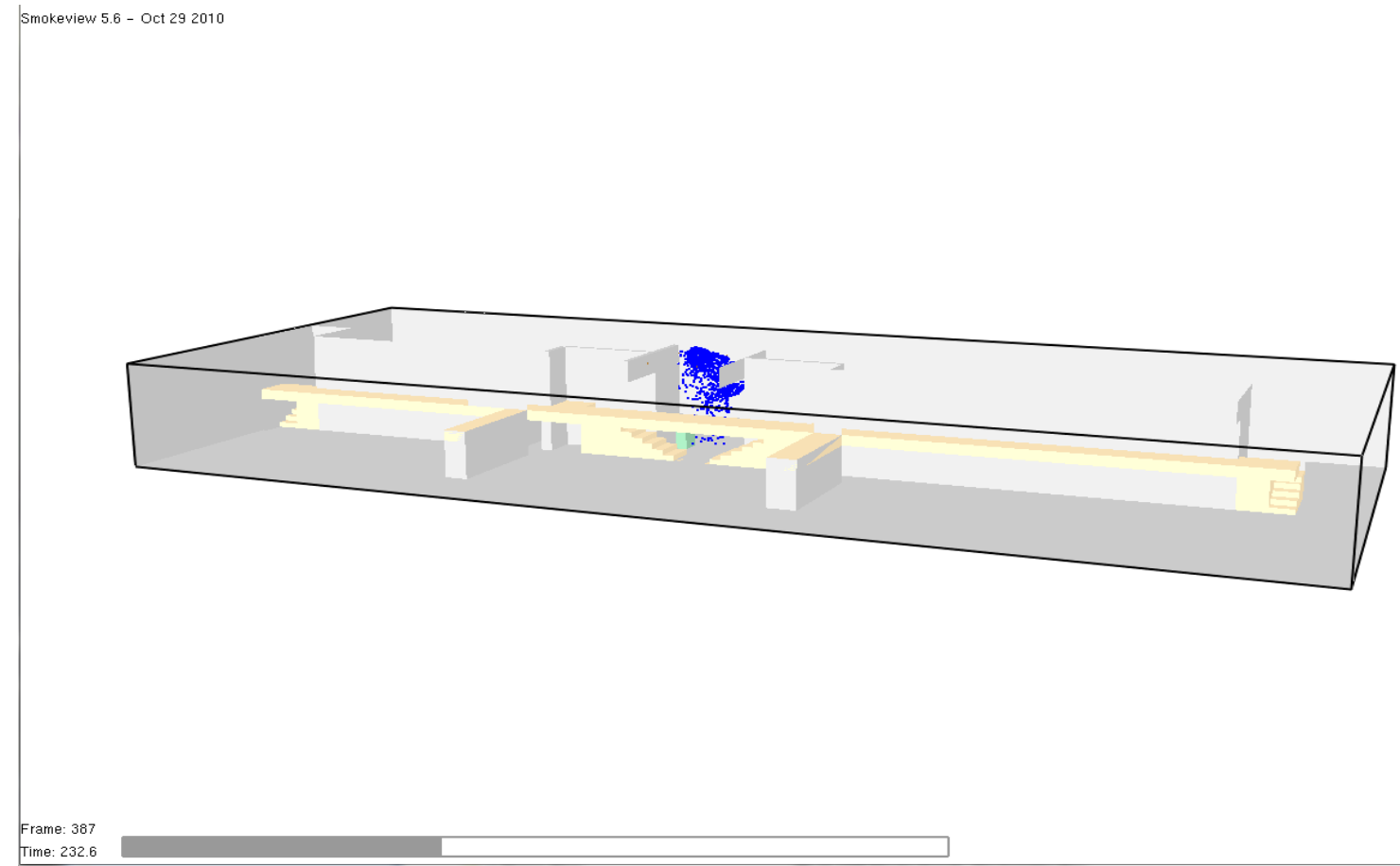

Figure 46 - FDS Design Fire 2 - Image Looking North at Sprinkler Activation 


\section{Design Fire 2 Summary}

This design fire scenario fails the performance criteria for the smoke layer height at a time of 210 seconds and fails the visibility criteria at 235 seconds both well below the RSET time of 560 seconds. The CO and temperature performance criteria pass at the RSET time of $560 \mathrm{~s}$ and remains below required levels to the end of the simulation at a time of $600 \mathrm{~s}$.

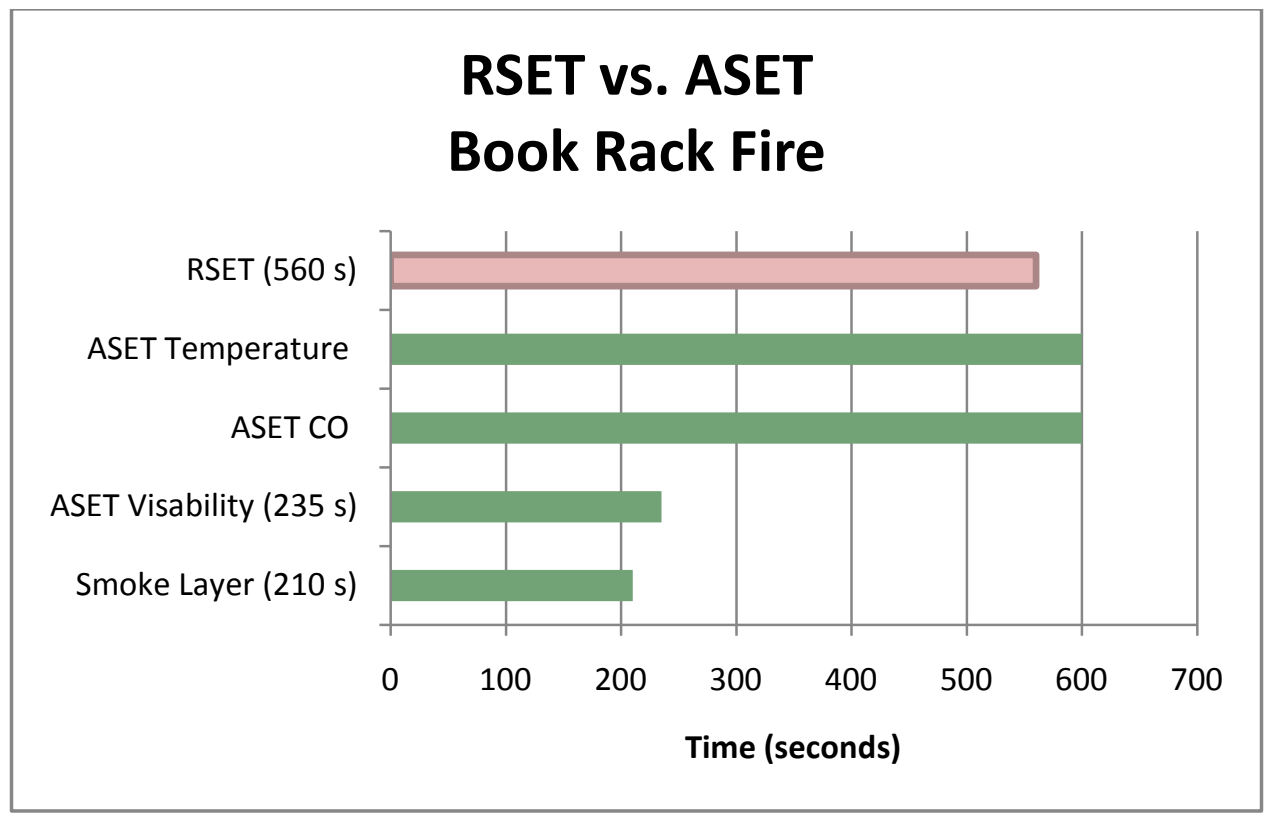

Figure 47 - FDS Design Fire 2 - RSET vs ASET Summary

\section{Design Fire 3}

\section{Scenario Overview}

This performance design scenario involves a fire in the second floor storage room located at the West side stairs. This room is used as a both a janitorial room and a storage room. In this scenario stack of polystyrene foam boards used by teachers is stored in the back of the room and is ignited by an electric heater being used by the janitor at his desk which is located in the room. The door to this room is propped open in this scenario as the janitor is coming and going from the room as he works. 

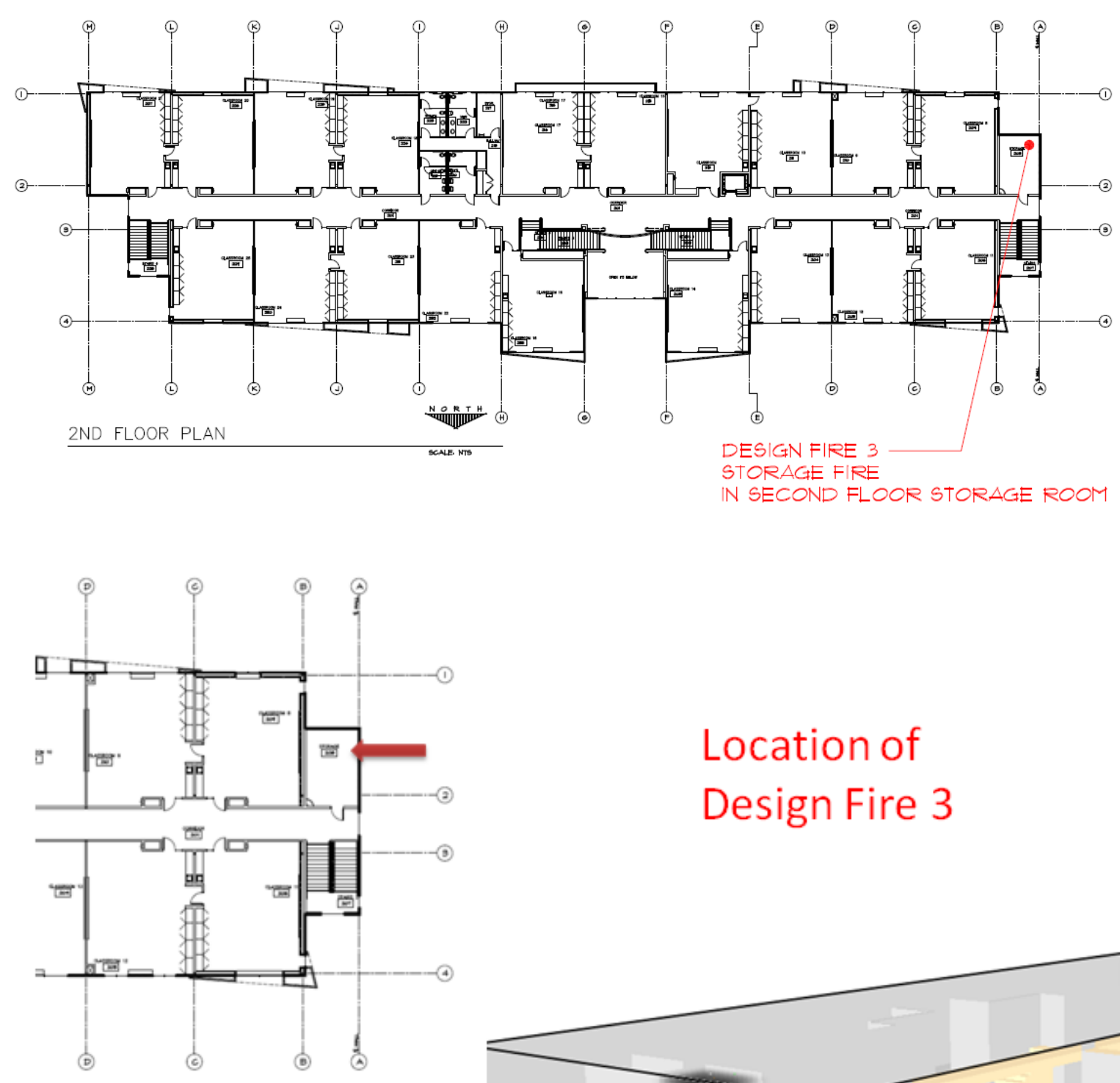

\section{Location of Design Fire 3}

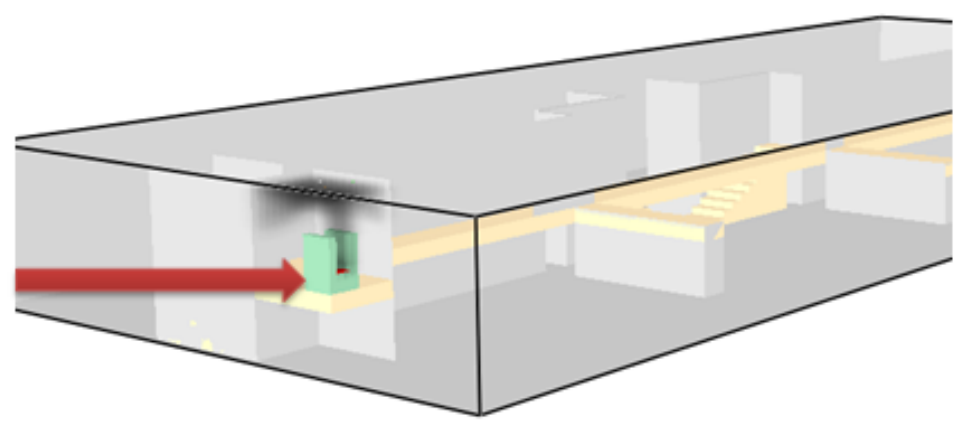

Figure 48 - Design Fire 3 Location 


\section{Fire Scenario Description}

This fire is similar to NFPA 101 Design Fire Scenario 2. NFPA 101 defines this fire scenario as follows:

- (1) It is an ultrafast-developing fire, in the primary means of egress, with interior doors open at the start of the fire.

- (2) It addresses the concern regarding a reduction in the number of available means of egress.

The conditions for this design fire scenario are as follows:

- One of the three primary egress paths for the second floor is located just outside of the room.

- $\quad$ The space is used for storage of various materials.

- The space is the main janitorial room and has a desk for the janitor to house paper work.

The design fire used for this scenario is as follows:

- Design Fire Data is based on storage room fire data from SFPE.

- Based on SFPE data from Figure 3-1.15

- Metal storage units, aisle with fuel

- Peak HRR of $1580 \mathrm{kw}$

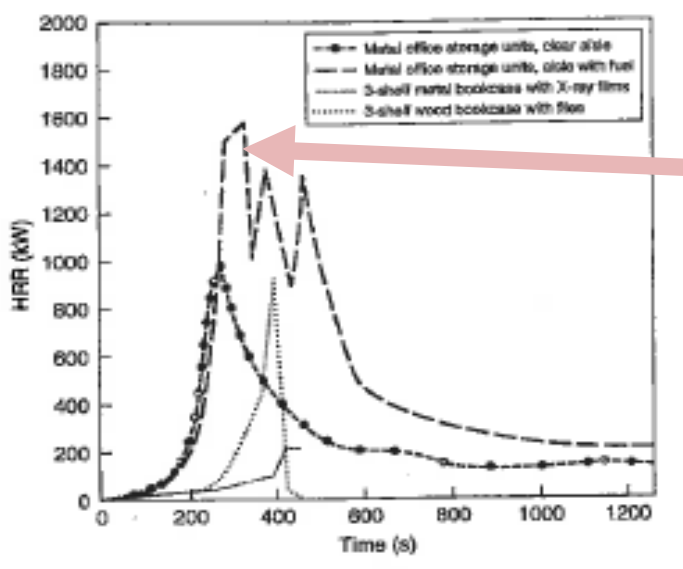

Selected Design Fire Curve - $1580 \mathrm{~kW}$

Figure 49 - Storage Unit HRR from SFPE Figure 3-1.15 


\section{Model Design Fire}

For this design fire the develops very slowly at first and then at around 150 seconds ramps up very rapidly at a rate similar to an ultra fast fire ( growth to $1055 \mathrm{~kW}$ in 75 seconds). For this fire scenario there is one smoke detector located in the ceiling space of the room which activates at a time of 162 seconds after the start of the fire. The room also has four fire sprinklers of which the first fire sprinkler is activated at $202 \mathrm{~s}$. At this time the fire becomes a fire sprinkler controlled fire and the fire growth rate levels off at around $1050 \mathrm{~kW}$ and remains steady at this HRR for the duration of the scenario as the fuel available is able to sustain this HRR for the duration of the scenario. This fire model was developed by doing an initial model run with the fire growing till the first sprinkler activated. The model fire growth was then capped at the time the sprinkler discharge began to cover the fire and the model was re-run with the capped HRR. The HRR is shown below.

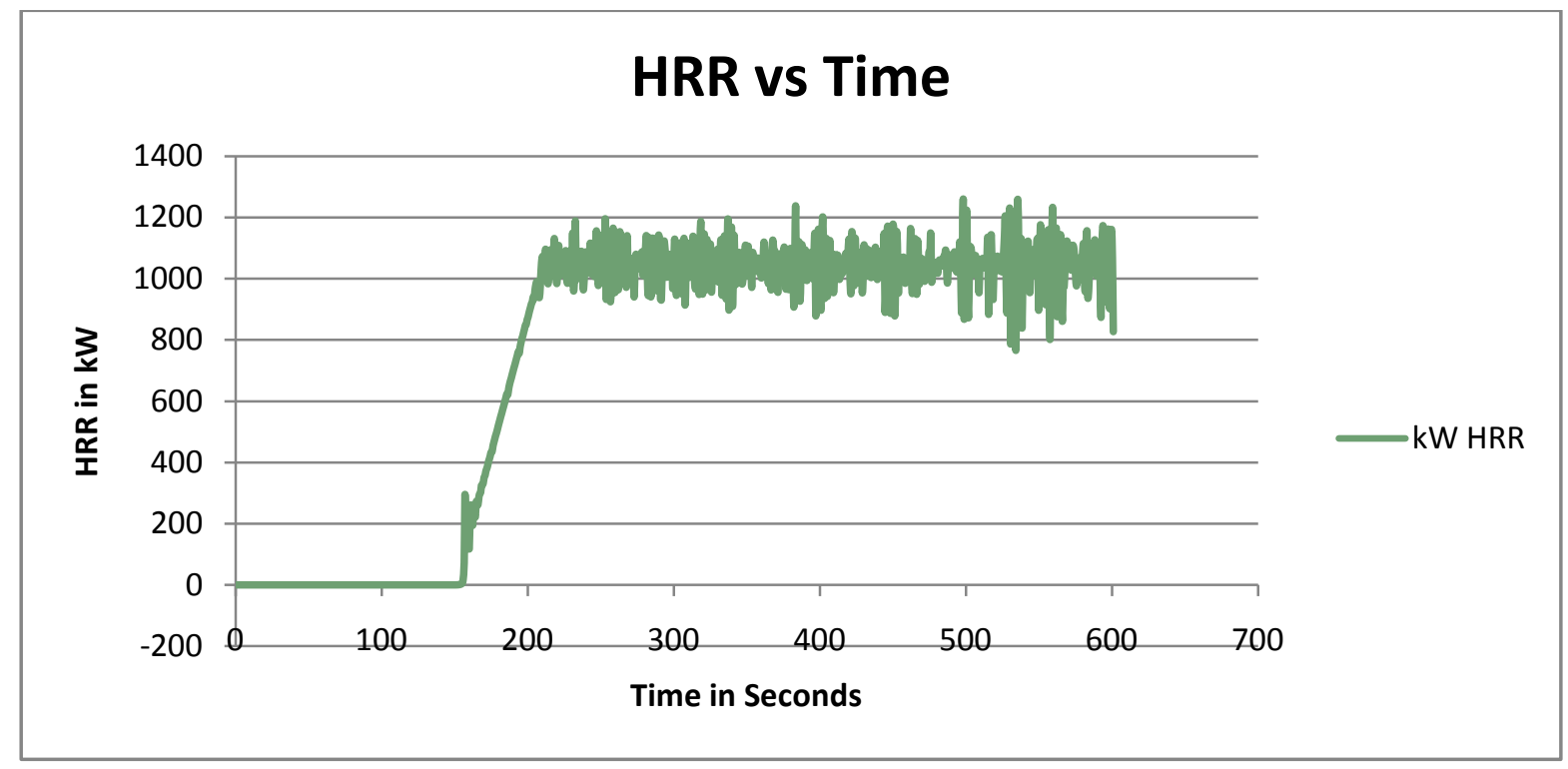

Figure 50 - Design Fire 3 HRR Curve

\section{Smoke Detector and Fire Sprinkler Activation}

For this fire the first smoke detector is activated at $162 \mathrm{~s}$.

The first fire sprinkler is activated at $202 \mathrm{~s}$. 
DEVICE ACtivation Times
10 SPR1
11 SPR2
12 SPR3
13 SPR4
14 SPR5
15 SD1
$266.0 \mathrm{~s}$
$211.7 \mathrm{~s}$
205.2 s
201. 2 s
No Activation
$161.8 \mathrm{~s}$

Figure 51 - FDS Output of Device Activation

\section{Design Fire 3 RSET}

For design fire 3 the RSET is 453 s or 7.55 min based on the following:

Detection Time $\quad 20 \mathrm{~s}$ time of first smoke detector activation from FDS model run

Notification Time $\quad 5 \mathrm{~s} \quad$ time delay for smoke detector activation to signal

Pre-Movement Time $\quad 30 \mathrm{~s}$ assumed time based on occupancy use

Movement Time $\quad 256 \mathrm{~s}$ time from hand calculations with all stairs and doors used

RSET $\quad 453 \mathrm{~s}$ total required time for safe evacuation 


\section{Design Fire 3 ASET Times}

For Design Fire 3 the ASET times for the various performance criteria are as follows:

The carbon monoxide level at $2 \mathrm{~m}$ above the second floor walking surface at the RSET time of $453 \mathrm{~s}$ is well below the 1,400 ppm tenability requirement. Criteria passes for RSET.

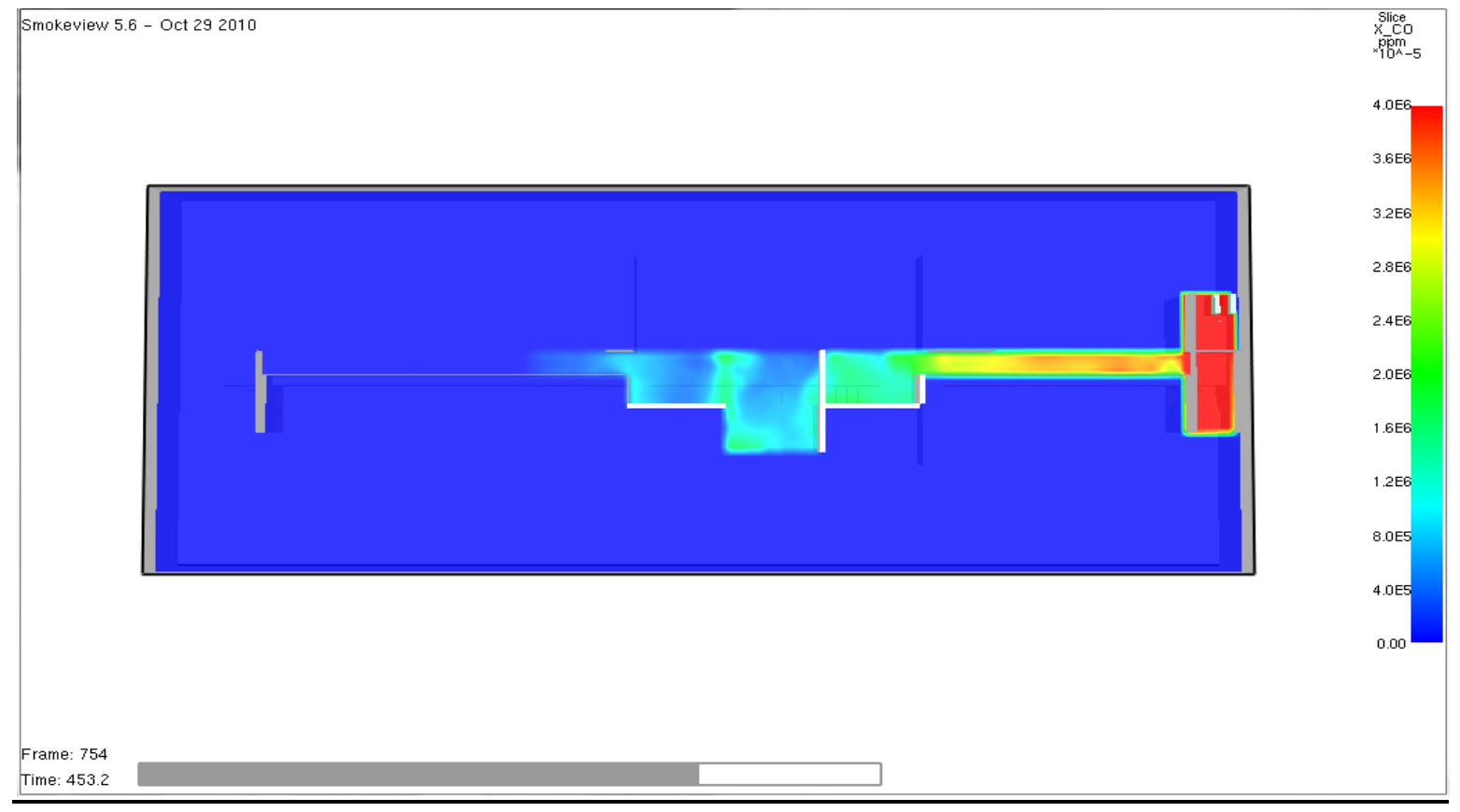

Figure 52 - FDS Design Fire 3 - CO at 453 s RSET 
The carbon monoxide level at $2 \mathrm{~m}$ above the second floor walking surface at the end of the simulation run (600 s) is well below the 1,400 ppm tenability requirement.

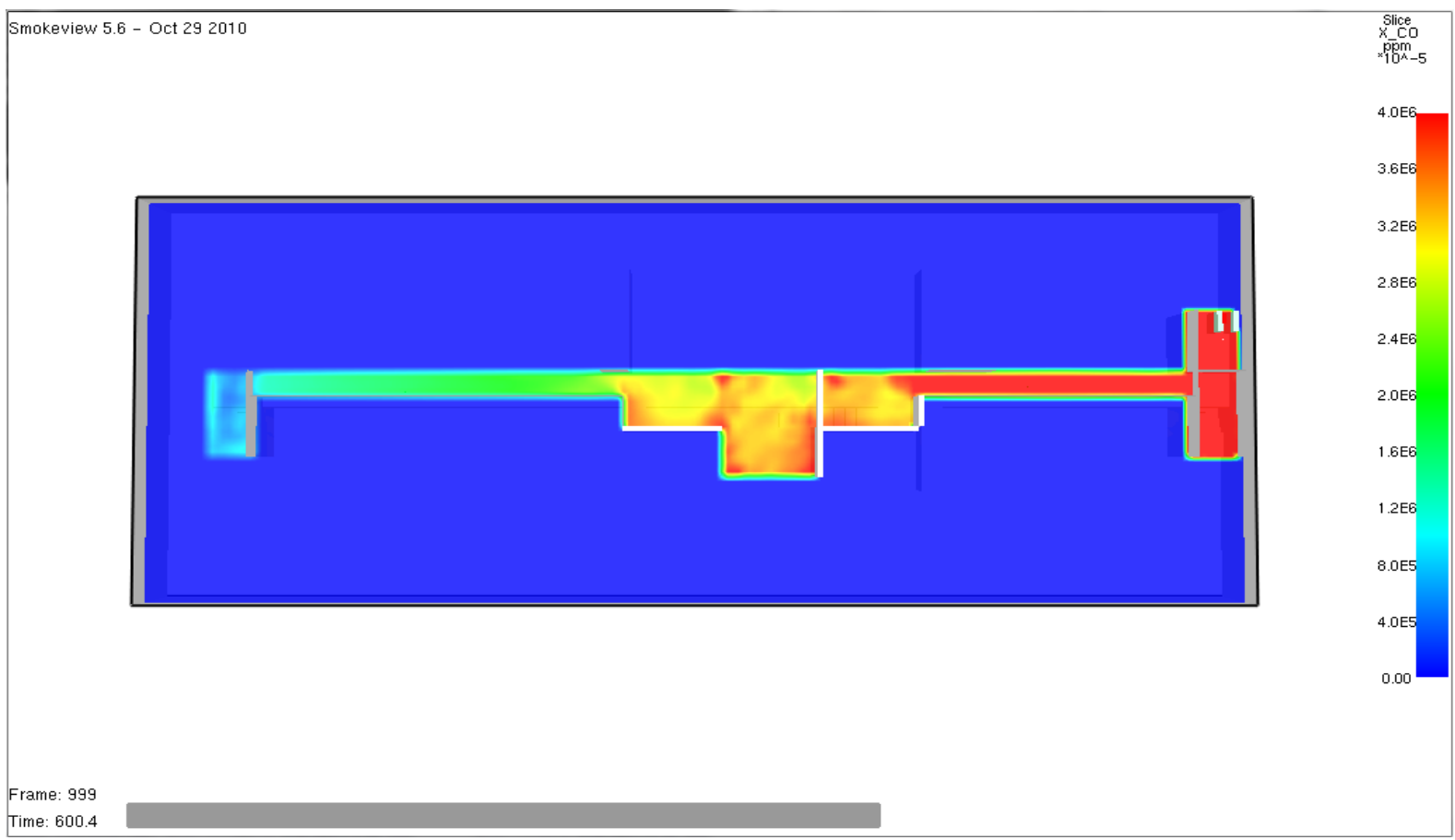

Figure 53 - FDS Design Fire 3 - CO at $600 \mathrm{~s}$ 
The maximum temperature at $2 \mathrm{~m}$ above the second floor walking surface at all area is under the 60 degree $C$ criteria. Criteria passes.

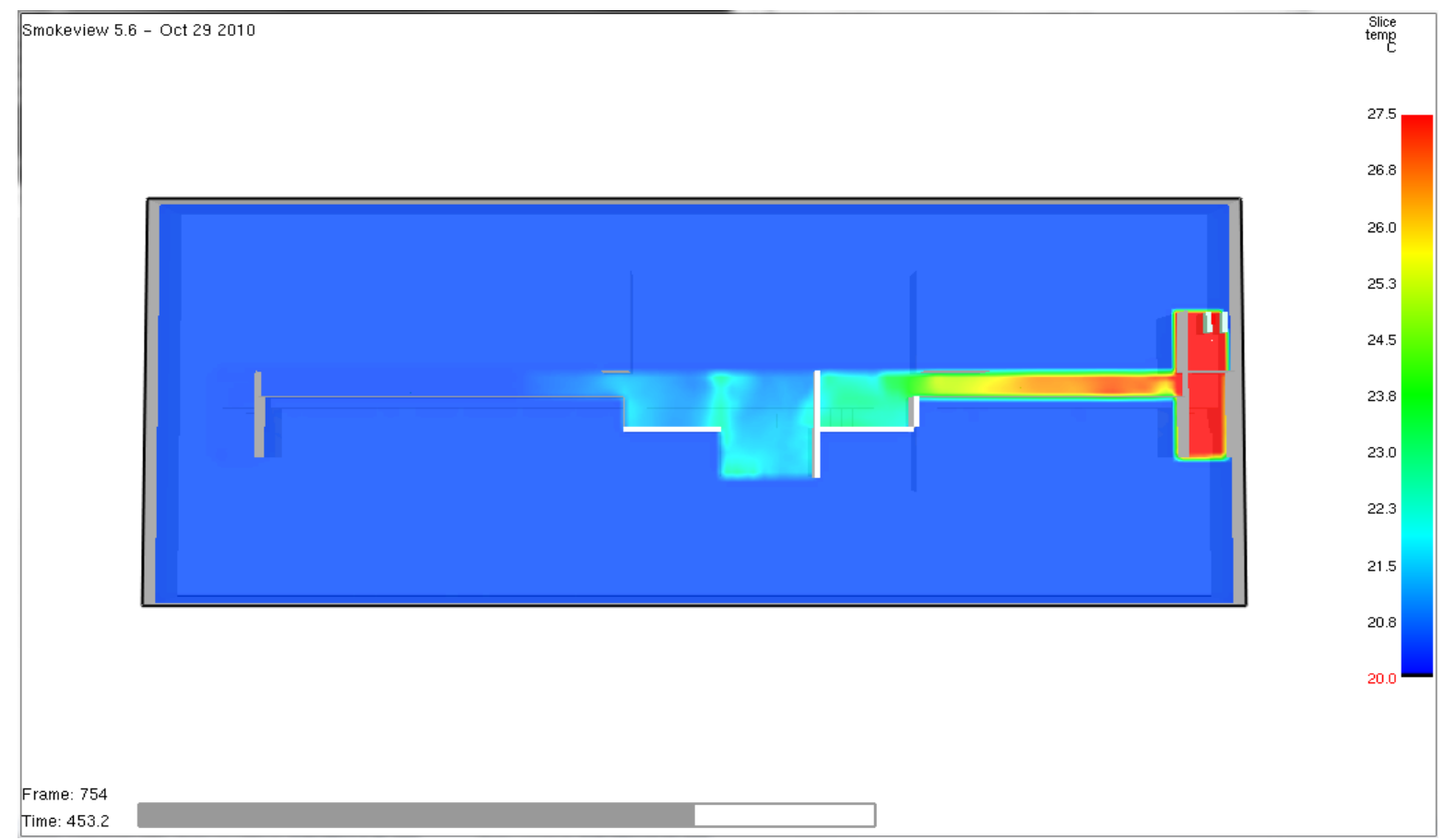

Figure 54 - FDS Design Fire 3 - Temperature at 453 s RSET 
The maximum temperature at $2 \mathrm{~m}$ above the second floor walking surface at the end of the simulation run (600 s) is still below the 60 degree C criteria.

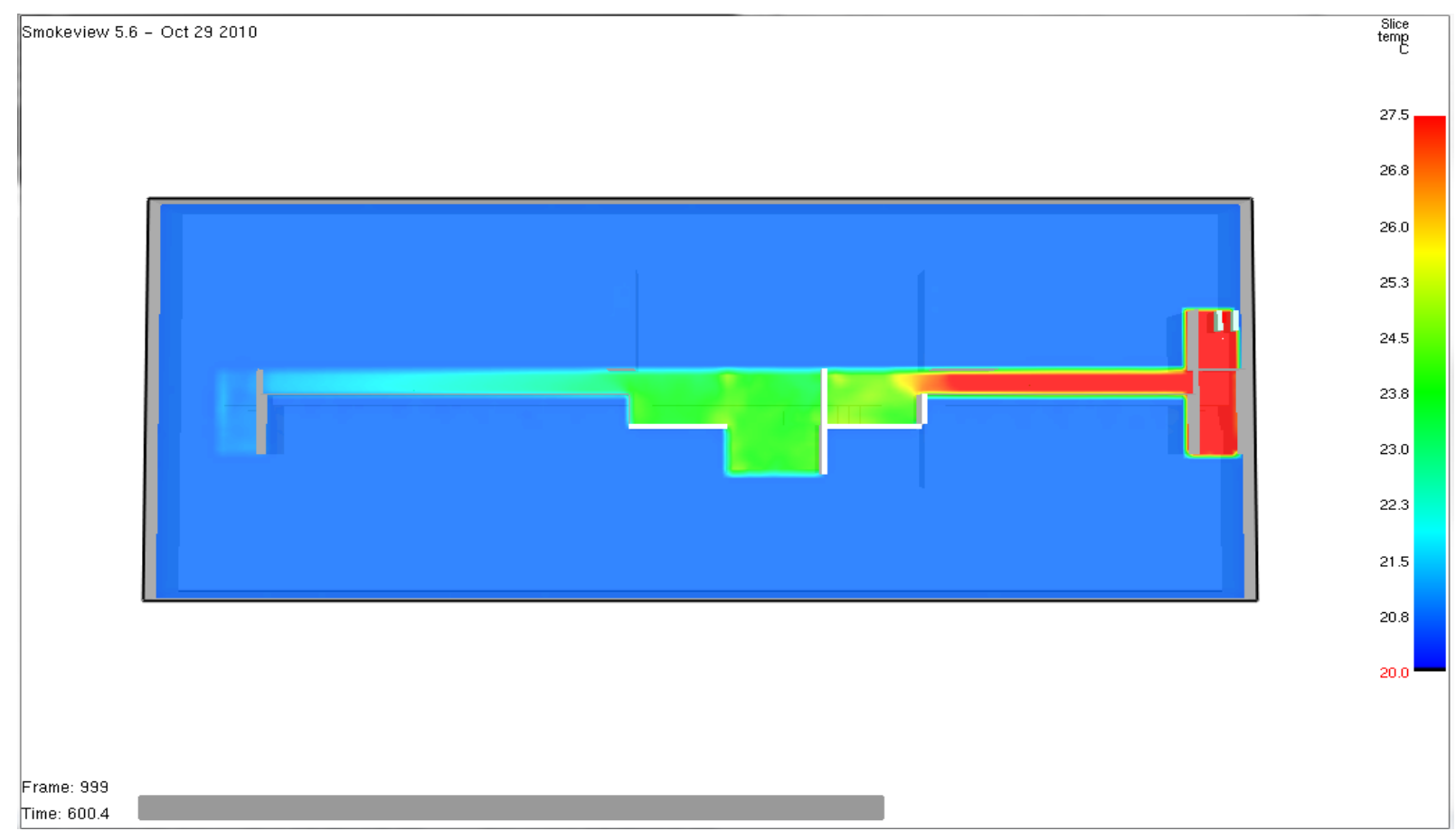

Figure 55 - FDS Design Fire 3 - Temperature at $600 \mathrm{~s}$ 
The minimum visibility at $2 \mathrm{~m}$ above the second floor walking surface drops below the $10 \mathrm{~m}$ criteria at around $415 \mathrm{~s}$. Criteria fails for RSET.

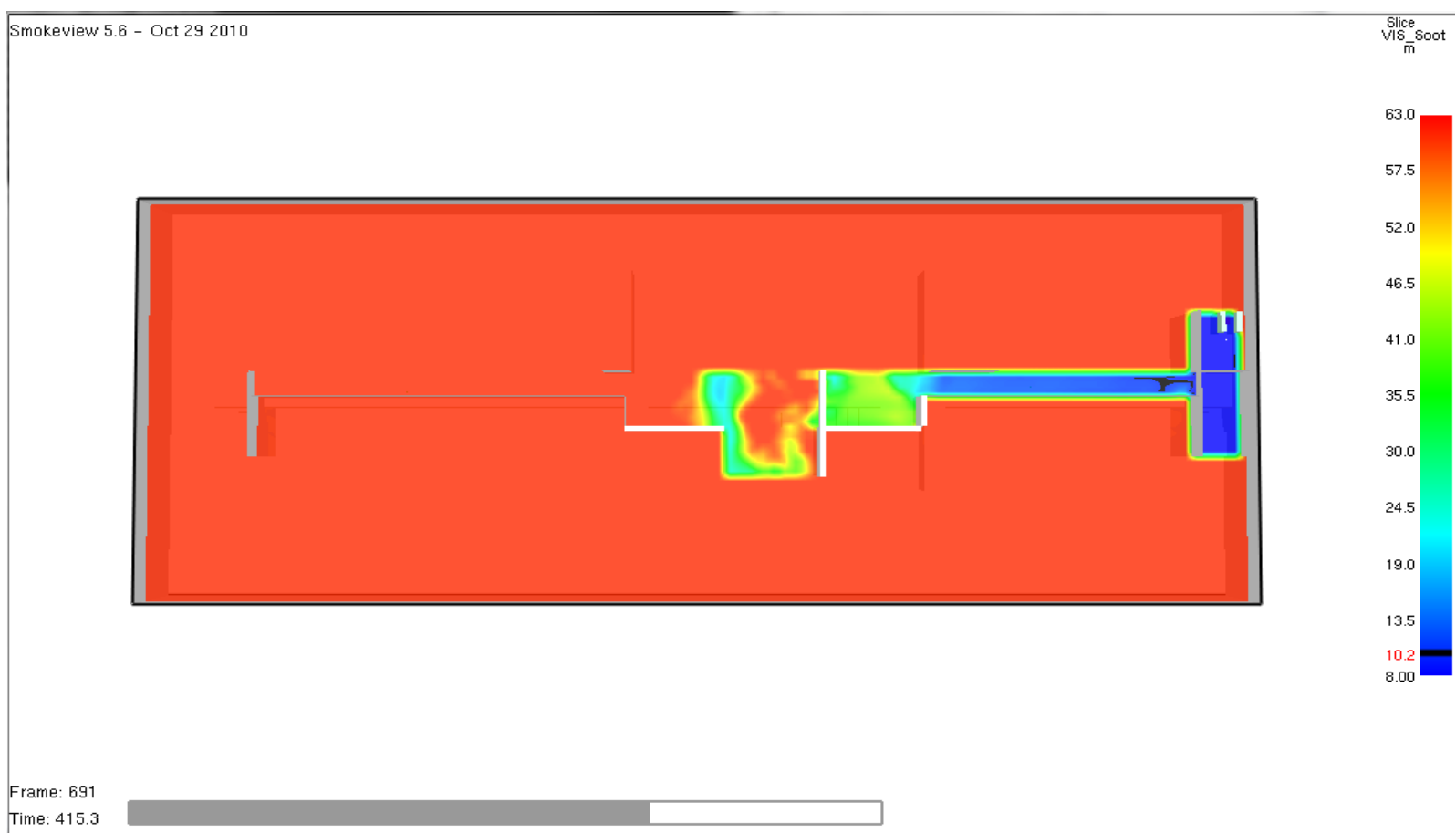

Figure 56 - FDS Design Fire 3 - Visibility at $415 \mathrm{~s}$ as it drops below criteria. 
The minimum visibility at $2 \mathrm{~m}$ above the second floor walking surface at the end of the simulation run (600 s) is well below the $10 \mathrm{~m}$ criteria in a large portion of the second floor corridor.

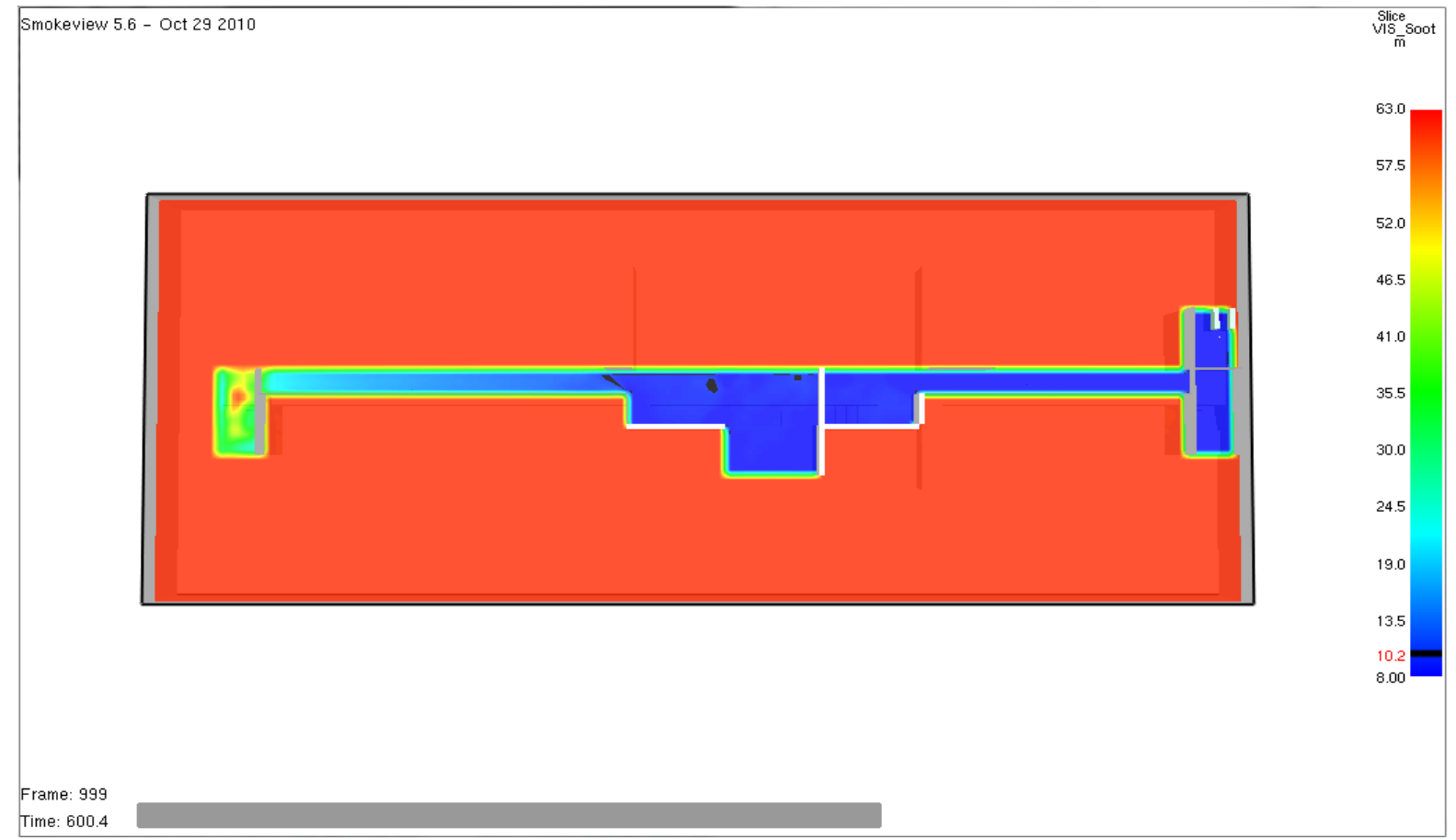

Figure 57 - FDS Design Fire 3 - Visibility at $600 \mathrm{~s}$ 
The smoke layer drops below the $2 \mathrm{~m}$ requirement at $358 \mathrm{~s}$ as shown in the graph below. This criteria fails for RSET. (Note: Smoke layer height is taken at a single point in the middle of each corridor which results in a sharp drop in the smoke layer height as the smoke layer moves down the corridor and hits the measuring point).

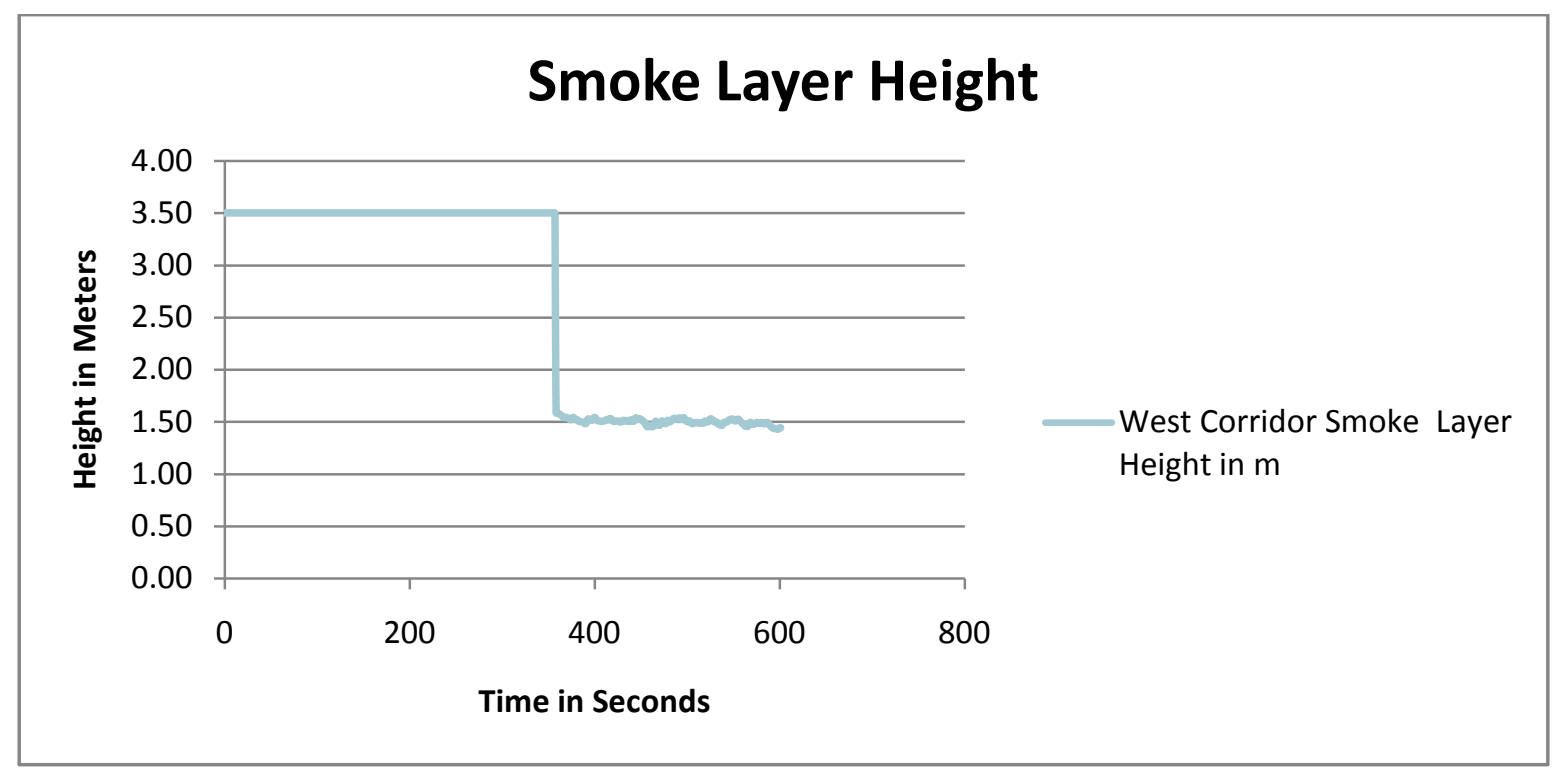

Figure 58 - FDS Design Fire 3 - Smoke Layer Height vs Time

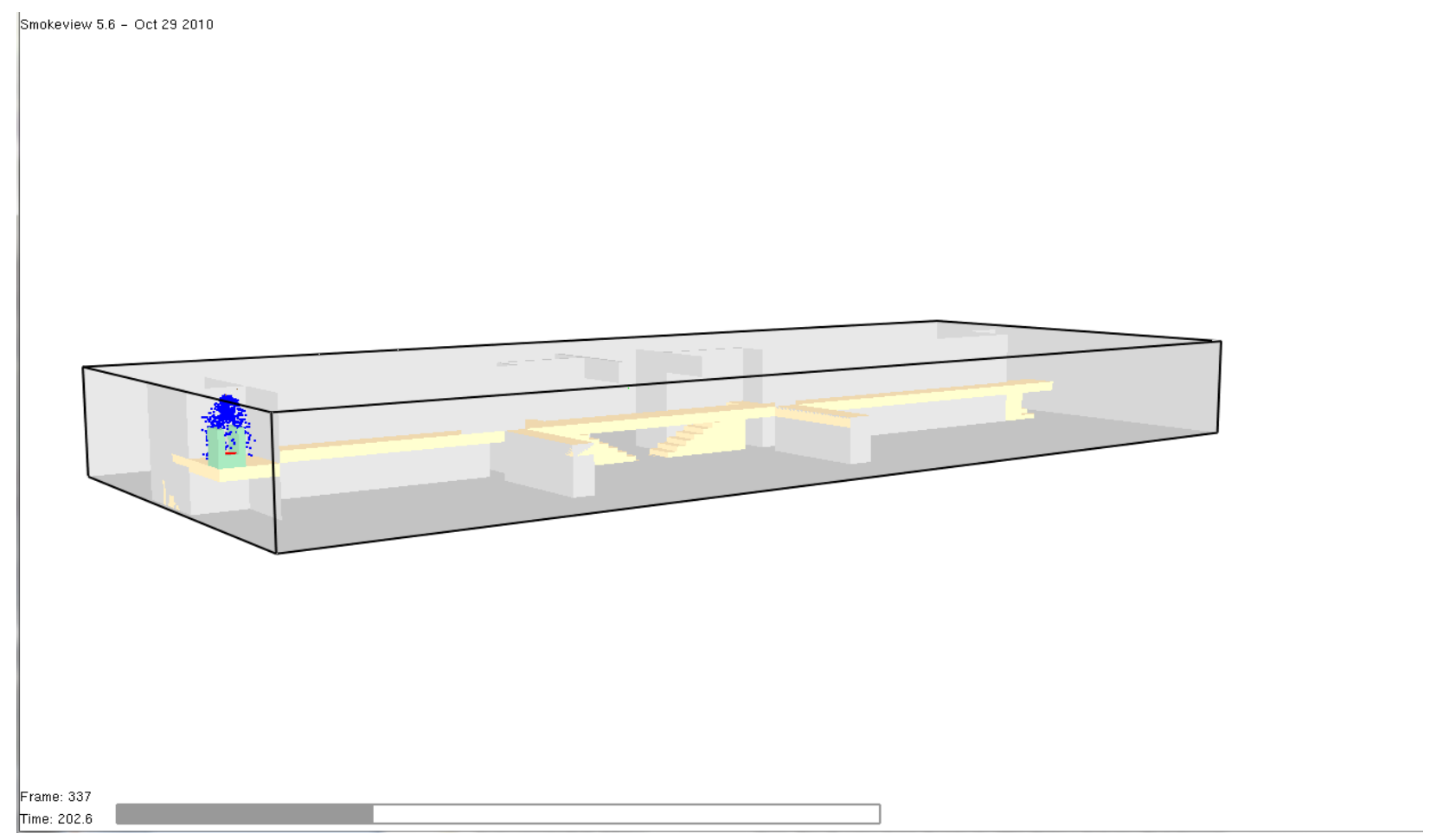

Figure 59 - FDS Design Fire 3 Looking North at Sprinkler Activation 


\section{Design Fire 3 Summary}

This design fire scenario fails the performance criteria for the smoke layer height at a time of 210 seconds and fails the visibility criteria at 235 seconds both well below the RSET time of 560 seconds. The CO and temperature performance criteria pass at the RSET time of $560 \mathrm{~s}$ and remain below required levels to the end of the simulation at a time of $600 \mathrm{~s}$. The temperature of the room never approached flashover temperature of $500 \mathrm{C}$.

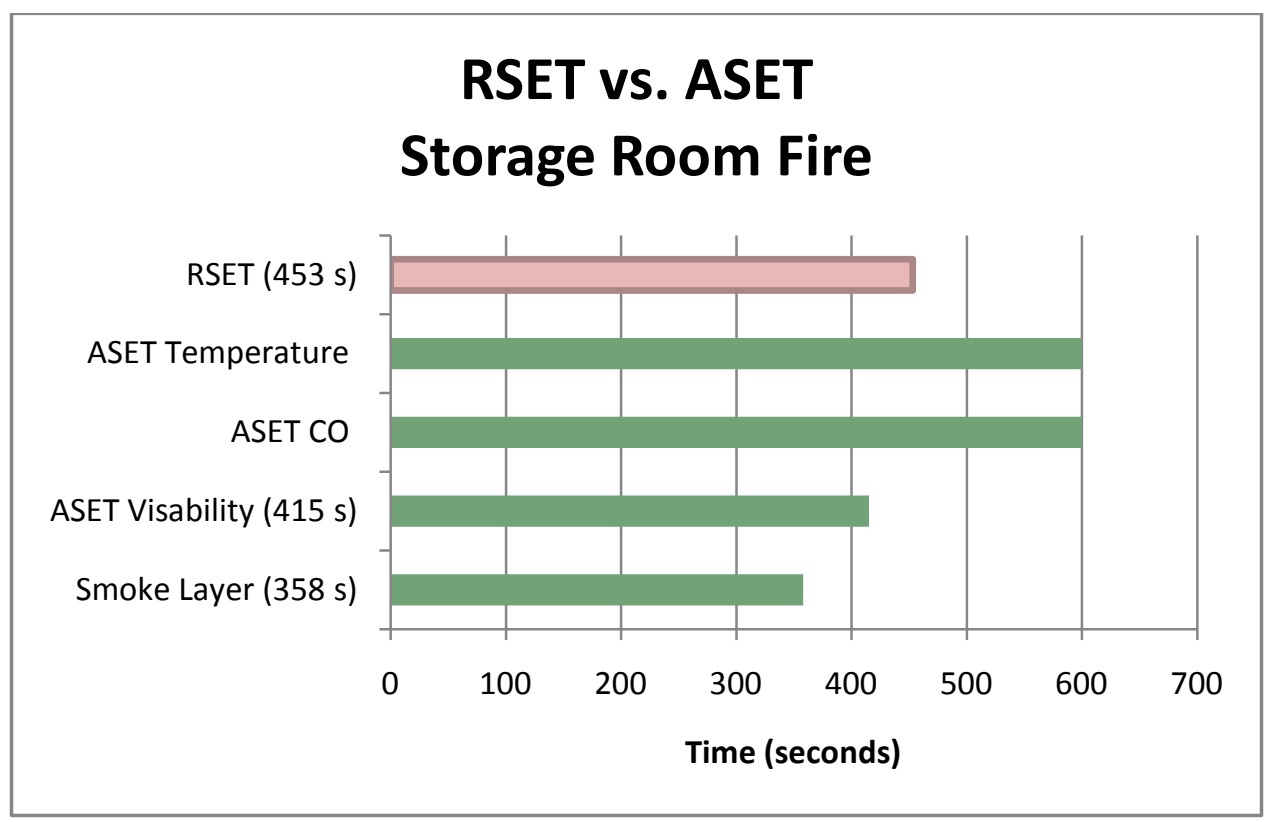

Figure 60 - FDS Design Fire 3 - RSET vs ASET Summary 


\section{Fire and Life Safety Analysis Recommendations}

The project building was constructed to and complies with the prescriptive requirements of the applicable codes at its time of design and plan approval. Review of the modeled design fires show that a fire directly in the main egress corridors or in rooms open to the corridors could potentially cause untenable conditions to occur in fire situations. The egress system is a combination of entry way area, corridors and open connected stair ways with the first and second floor egress being open to each other. Due to this design there is a high potential for the spread of smoke through the building in a fire scenario. The open egress areas should be left clear of any fuel sources during all times of the year to minimize any potential fires. Additionally it is also noted that the corridors on the second floor have dropped ceilings with the fire rated walls extending above them acting as a fire rated tunnel when they connect to the fire rated tunnel ceiling above the drop ceiling. These corridors are much lower than the man two story entry area of the building which is raised up to the bottom of the roof. If the drop ceiling was raised 2 to 3 feet this would provide an additional storage area for smoke in a fire event and extend the time before the smoke layer dropped to occupied spaces thus increasing the ASET. Refer to the Figure 61 below for section showing drop ceiling and rated tunnel above.

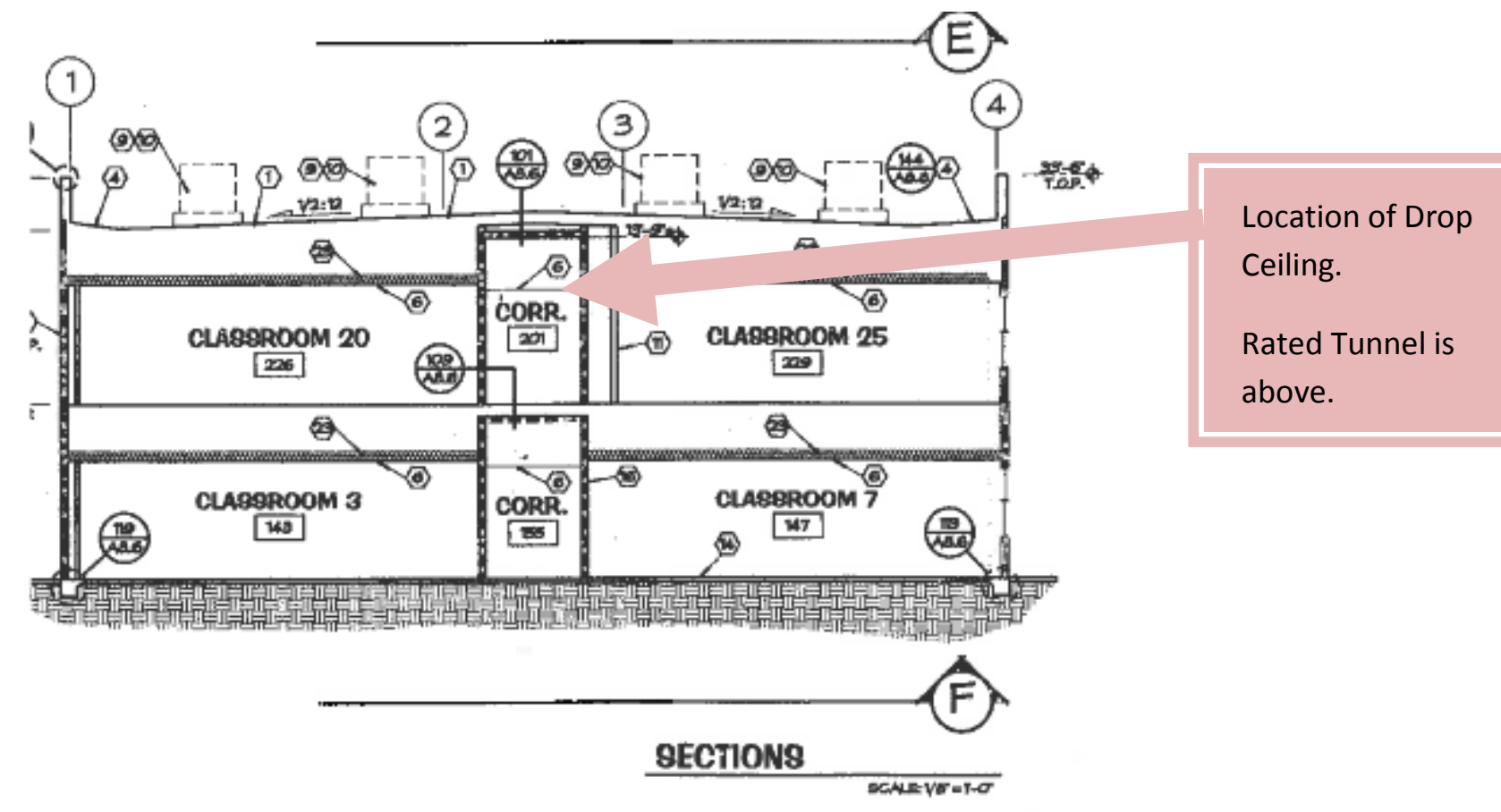

Figure 61 - Typical Section at Corridor 


\section{$\underline{\text { References }}$}

[1] "Tenability In Building Fires: Limits and Design Criteria" by Dr. Weng Poh

[2] "Handbook of Smoke Control Engineering" by ASHRAE

[3] "Fire Safety Engineering Concerning Evacuation from Buildings" CFPA Europe - European Guideline CFPA-E No 19:2009

[4] "Toxicity Assessment of Combustion Products" by D. Purser from the SFPE Third Edition.

\section{Code and Standard References Used}

The SFPE Handbook of Fire Protection Engineering, Fourth Edition

NFPA Fire Protection Handbook, $20^{\text {th }}$ Edition

NFPA Life Safety Code 101, 2010

NFPA 13 Installation of Sprinkler Systems, 2002

NFPA 14 Standard for the Installation of Standpipe and Hose Systems, 2002

NFPA 72 Fire Alarm and Signaling Code, 2002

2007 California Building Code (Part2 Title 24), UBC with CA Amendments

2007 California Electrical Code (Part2 Title 24), NEC with CA Amendments

2007 California Mechanical Code (Part2 Title 24), UMC with CA Amendments

2007 California Fire Code (Part2 Title 24), UFC with CA Amendments 


\section{APPENDIX A: EXIT PLANS}




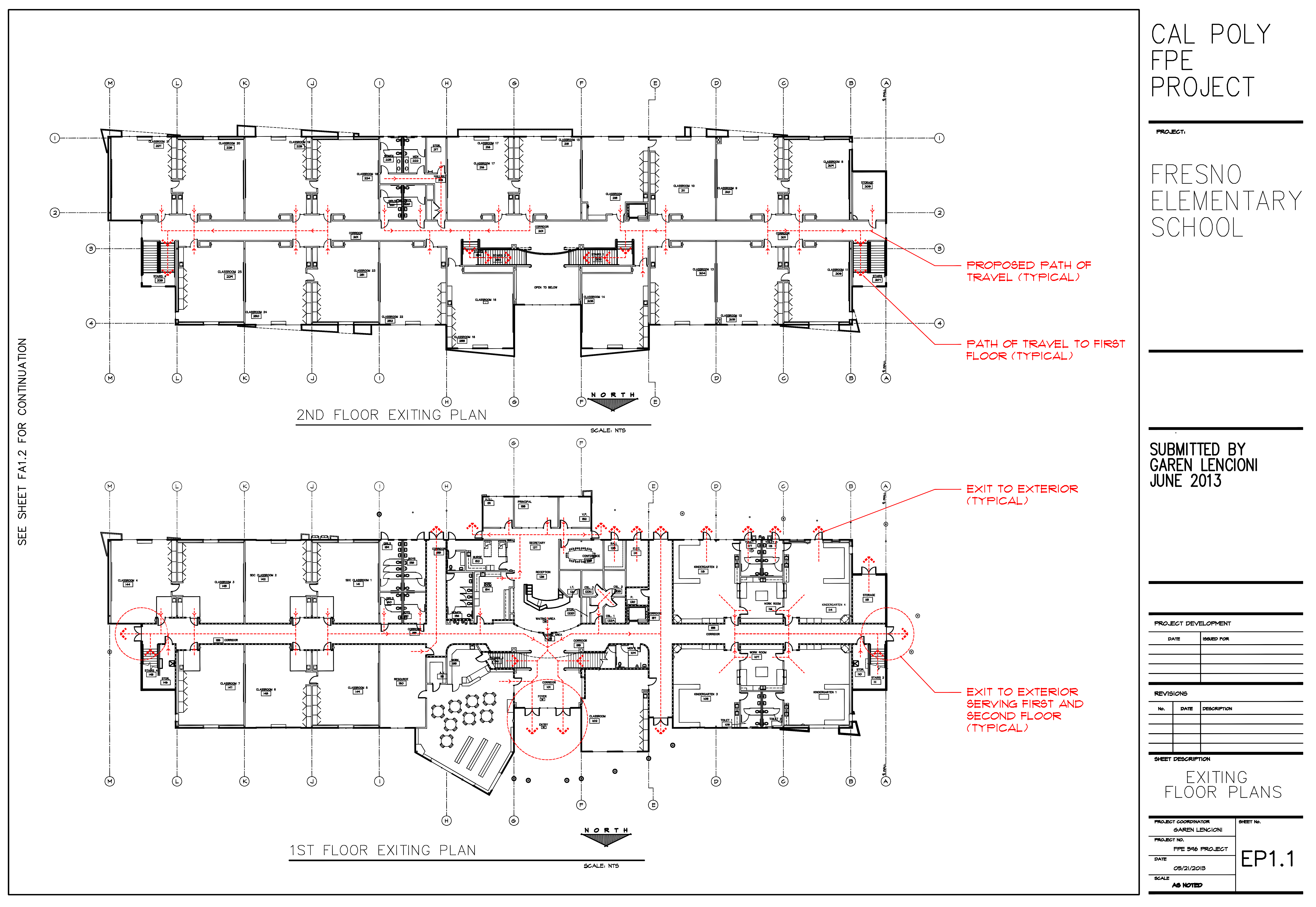




\section{APPENDIX B: FIRE RATED WALL PLANS}




\section{APPENDIX C: FIRE ALARM PLANS}




\begin{tabular}{|c|}
\hline CODES AND STANDARDS \\
\hline 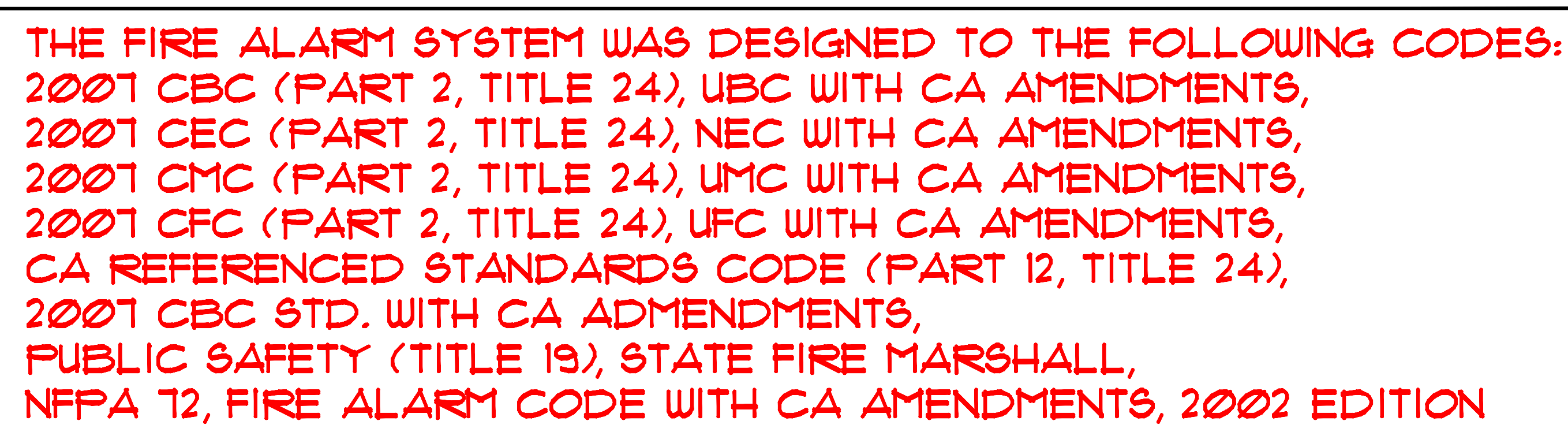 \\
\hline
\end{tabular}

\begin{tabular}{|c|c|c|c|}
\hline \multicolumn{4}{|c|}{ FIRE ALARM SYMBOL LIST } \\
\hline SMMBOL & MANUFACTURE & PART NUMBER & DESCRIPTION \\
\hline FACP & GAMEUWELL-FCI & E3 & FIRE ALARM CONTROL PANEL \\
\hline EXP & GAMEUELL-FCl & F8 & FIRE ALARM EXPANDER PANEL \\
\hline F & GAMEUELL-FCI & MS- $7 A F$ & MANUAL PLLL STATION \\
\hline (e) & GAMEUELL-FCI & ASD-PL2F & SMOKE DETECTOR UITH SMOKE DETECTOR BASE \\
\hline (A) & GAMEUELL-FCI & ATD-HL2F & ATTIC HEAT DETECTOR, FIXED $190^{\circ}$ HEAT DETECTOR BASE \\
\hline (D) & GAMEUELL-FCI & ADPRF & DUCT SMOKE DETECTOR WITH 5' SAMPLING TUBE \\
\hline 田 & GAMEUELL-FCI & ATD-L2F & HEAT DETECTOR, FIXED $135^{\circ}$ HEAT DETECTOR BASE \\
\hline TIS & - & - & FIRE SPRINKLER TAMPER SWITCH \\
\hline FS & - & - & FIRE SPRINKLER FLOW SWITCH \\
\hline$F / S$ & - & - & FIRE SMOKE DAMPER, BY MECHANICAL CONTRACTOR \\
\hline$\frac{\nabla}{\square}$ & WHEELOCK & AH-24UP-R WBBR & OUTSIDE HORN WITH BLACK BOX \\
\hline$\Delta]^{x x}$ & WHEELOCK & ZNS-24MCW-FR & HORN/STROBEMMLLTI-CANDELA - 15/30/75/110 CD \\
\hline$\nabla^{x x}$ & WHEELOCK & ZRS-24MCU-FR & STROBEMLLTI-CANDELA - 15/30/15/110 CD \\
\hline
\end{tabular}

CAL POLY

FPE

PROJECT

PROECT:

FRESNO

ELEMENTARY

SCHOOL

SUBMITTED BY

GAREN LENCION

JUNE 2013

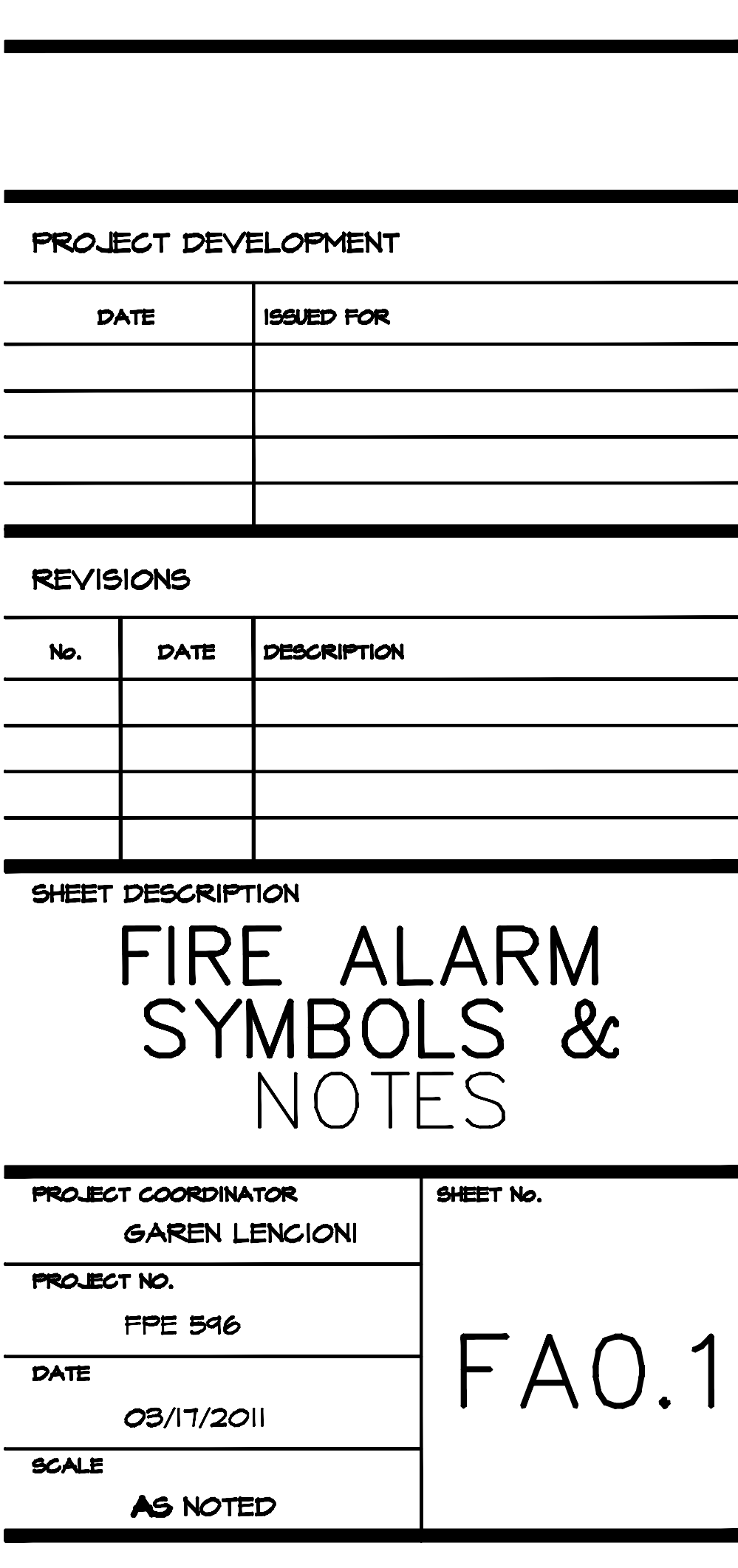




\begin{tabular}{|c|c|c|c|c|c|c|c|}
\hline \multicolumn{8}{|c|}{ FIRE ALARM SEQUENCE OF OPERATIONS } \\
\hline${ }_{\text {ACTION }}$ DEVICE & $\mid \begin{array}{l}\text { MANUAL PULL } \\
\text { STATION }\end{array}$ & $\begin{array}{l}\text { SMOKE / HEAT } \\
\text { DETECTOR }\end{array}$ & $\begin{array}{l}\text { LOSS OF } \\
\text { POUER }\end{array}$ & $\begin{array}{l}\text { GROUND } \\
\text { FALLT }\end{array}$ & $\begin{array}{l}\text { WATERFLOW } \\
\text { SWITCH }\end{array}$ & $\begin{array}{l}\text { TAMPER } \\
\text { SWITCH }\end{array}$ & \begin{tabular}{|l} 
DUCT SMOKE \\
DETECTORS
\end{tabular} \\
\hline $\begin{array}{l}\text { ANUNCIATE, ALARM } \\
\text { AT FRE ALAAY } \\
\text { CONTROL PANEL }\end{array}$ & YES & YES & - & - & YES & - & YES \\
\hline $\begin{array}{l}\text { ANMUNCIATE TROUBLE } \\
\text { AT FIRELLAPA } \\
\text { CONTROL PANEL }\end{array}$ & & - & YES & YES & - & & - \\
\hline $\begin{array}{l}\text { ANUNCIATE } \\
\text { SUPREVISORY AT FIRE } \\
\text { ALARY CONTROL PANEL }\end{array}$ & - & - & - & - & - & YES & - \\
\hline $\begin{array}{l}\text { ACTIVATE ALL } \\
\text { ALDIBLEI/ } \\
\text { VISUALALARMS }\end{array}$ & YES & YES & - & - & YES & - & YES \\
\hline $\begin{array}{l}\text { TRANSERE TO } \\
\text { BATERY } \\
\text { BACKUP }\end{array}$ & - & - & YES & - & - & - & - \\
\hline $\begin{array}{l}\text { ANNUNCIATE ALAAY } \\
\text { AT CENTRAL STATION }\end{array}$ & YES & YES & - & - & YES & YES & YES \\
\hline $\begin{array}{l}\text { ANMUNCIATE TROUBLE } \\
\text { AT CENTRAL STATION }\end{array}$ & - & - & YES & YES & - & - & - \\
\hline $\begin{array}{l}\text { ANNUNCIATE SUPERVISORY } \\
\text { AT CENTRAL STATION }\end{array}$ & - & - & - & - & - & YES & - \\
\hline $\begin{array}{l}\text { CLOSE FIRE / } \\
\text { SMOKE DAMPERS }\end{array}$ & - & - & - & - & - & - & YES \\
\hline $\begin{array}{l}\text { SHUTDOUN } \\
\text { A/C UNITS }\end{array}$ & & - & - & - & . & - & YES \\
\hline
\end{tabular}

CAL POLY

FPE

PROJECT

PROEECT

FRESNO

ELEMENTARY

SCHOOL

SUBMITTED BY

GAREN LENCION

JUNE 2013

.

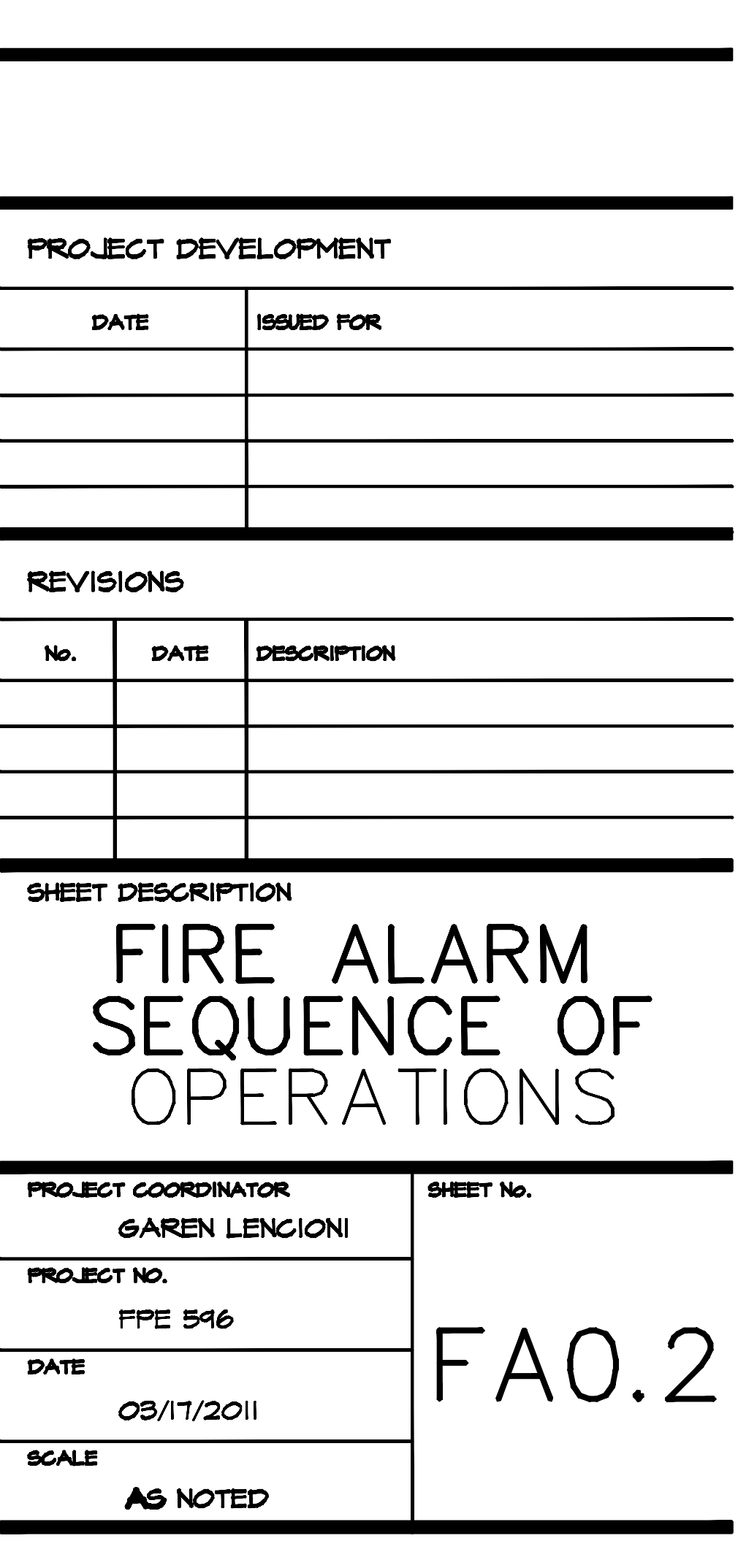


FIRE ALARM RISER

F-F (8) ZONES 101-108- FRST FLOOR PULL STATIONS

(2) ZONES 111-145- FRST FLOOR CENTER SMOKE DEEECTORS (A)——A (22) ZONES 151-182- FIRST FLOOR CENIER HEAT DEEECTORS

. (2) (2) (19) ZONES 191-209- FRST FLOOR WEST SMOKE DETECTORS

- (A) (A) (15) ZONES 211-225- FIRST FLOOR WEST HEAT DEEECTORS

- (2) (2) (2) (25) ZONES 231-255- FRST FLOOR EAST SMOKE DEETETORS (A)— - (A) (17) ZONES 261-277- FRST FLOOR EAST HEAT DETECTORS (1)———(1) (16) ZONES 261-297- FRRST FLOOR DUCTS DEEECTORS IMIFS ZONES 8- FRE SPRINKLER FLOW SWTCH 298

_ IM TS TROUBLE FRE SPRINKLER TAMPER SWTCH 299

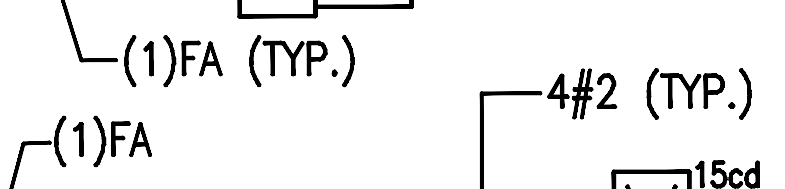

C.

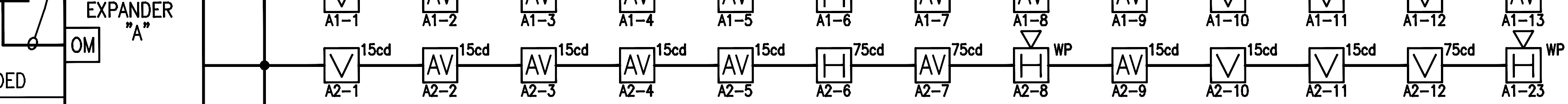

-(1) FA $\Gamma^{(1) F A}(\mathrm{TP}$.

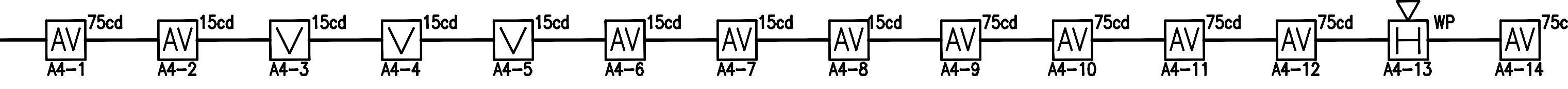

(2) (2) 2 (2) (17) ZONES 301-317- SECONO FLOOR WEST SMOKE DEEECORS

(A)—A (10) ZONES 321-331- SECOND FLOOR WEST HEAT DETECTORS

(2) (2) (18) ZONES 341-358- SECOND FLOOR EAST MHOKE DEILCOOOS

(2) - (2) (26) ZONES 381-406- SECOND FLOOR CENER SMOKE DEEECTORS

(A) ——A (18) ZONES 411-428- SECOND FLOOR CENTRAL HEAT DETECTOOS

(D) - (D) — (D) (5) ZONES 431-435- SECOND FLLOR CENTER DUCTS DETECTORS

(1)FA-

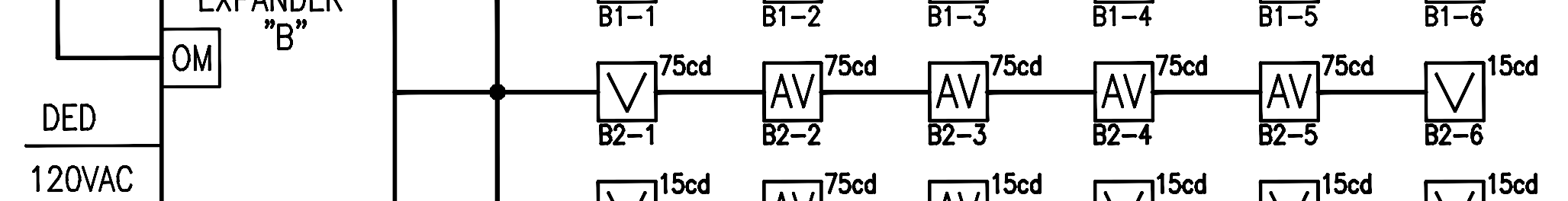

ALARM ZONES B1, B2, B3, \& B4

$-\phi$

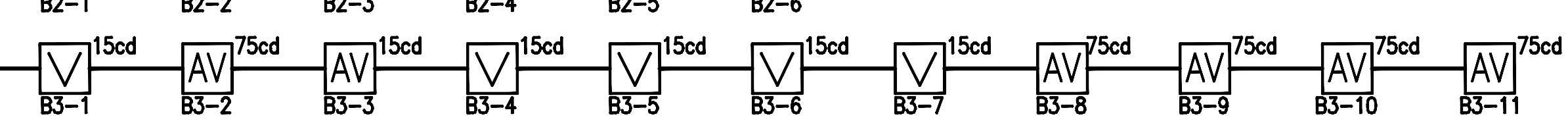

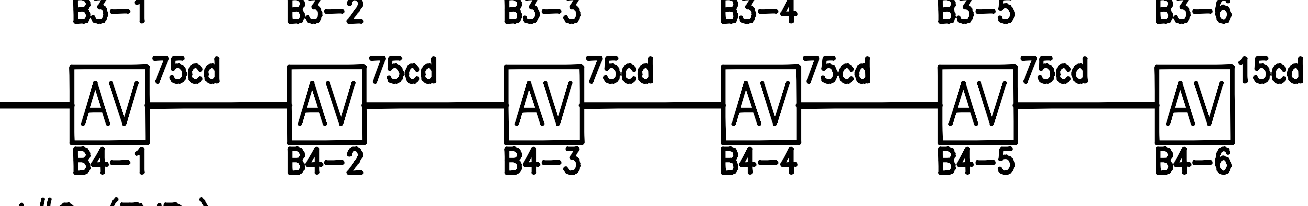



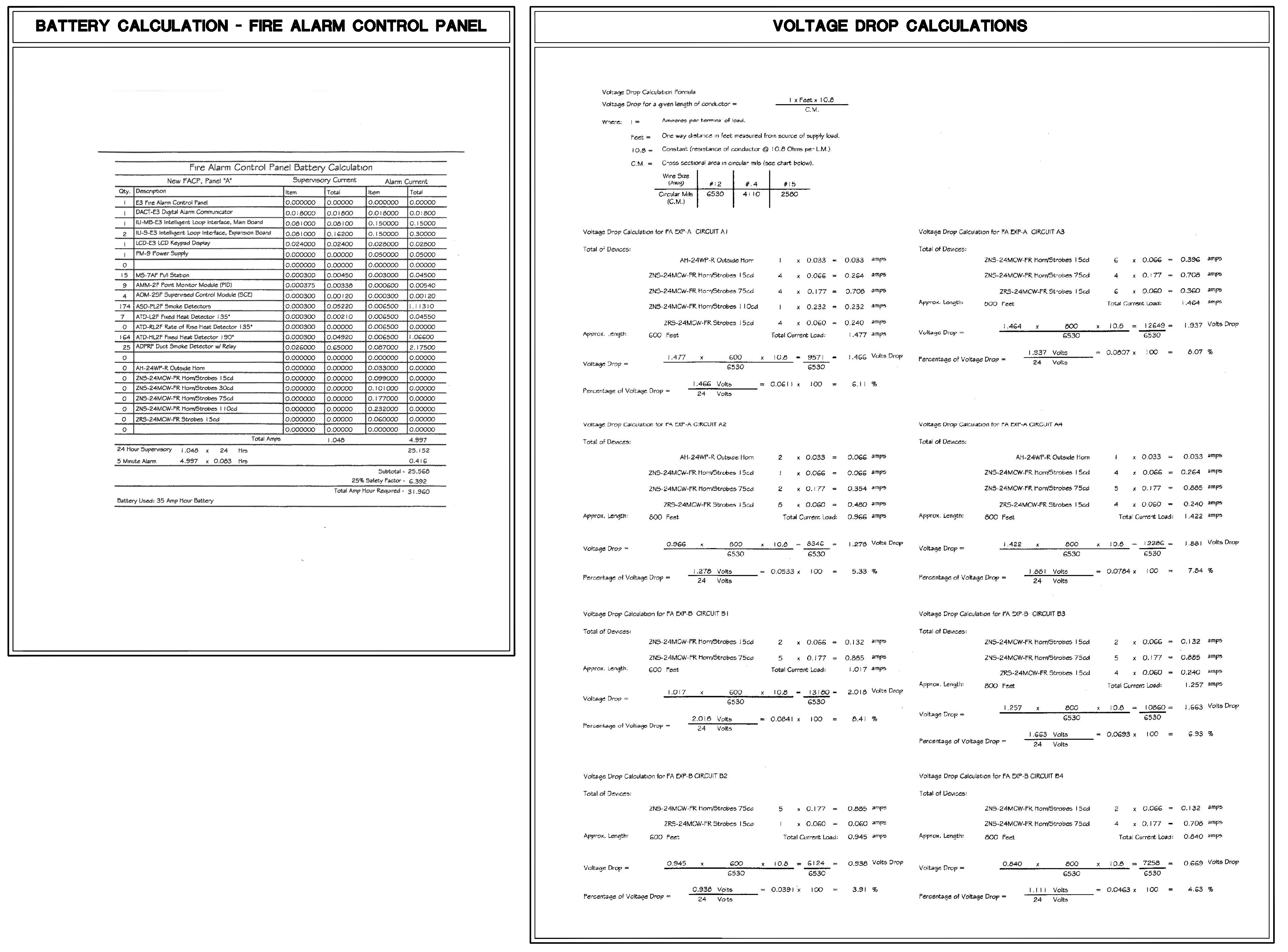

CAL POLY

FPE

PROJECT

PROEECT

FRESNO

ELEMENTARY

SCHOOL

SUBMITTED BY

GAREN LENCIONI

JUNE 2013

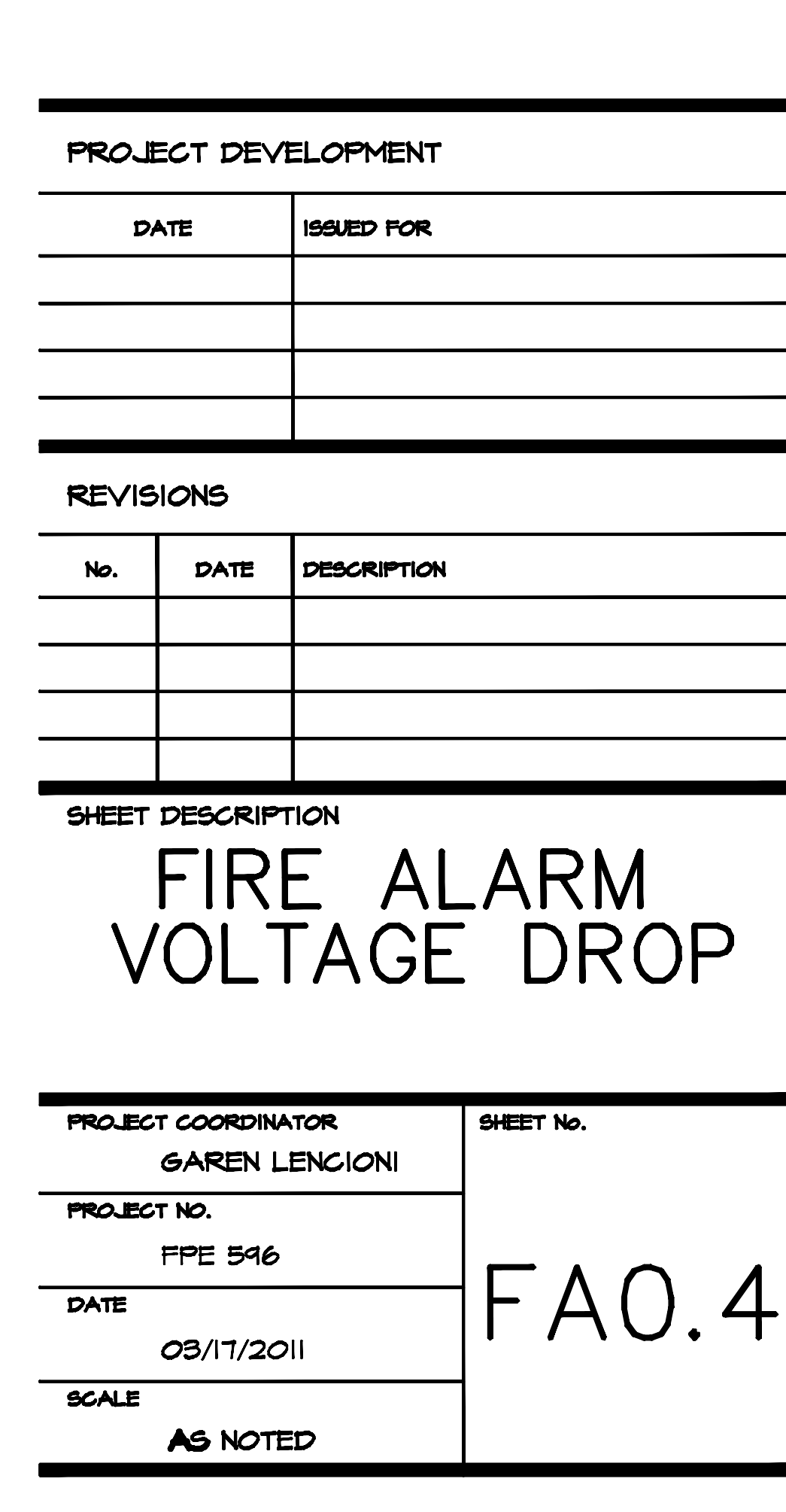




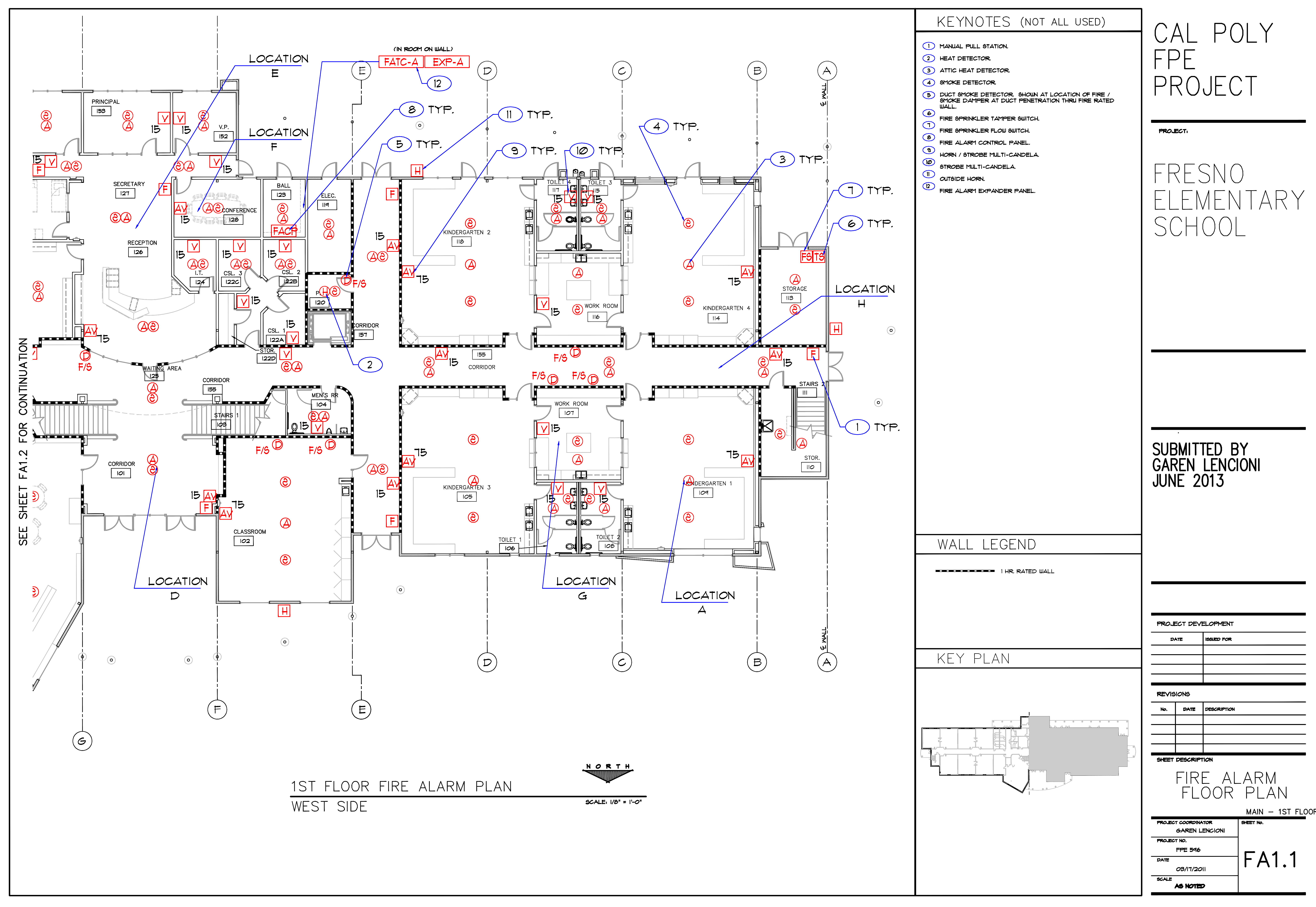




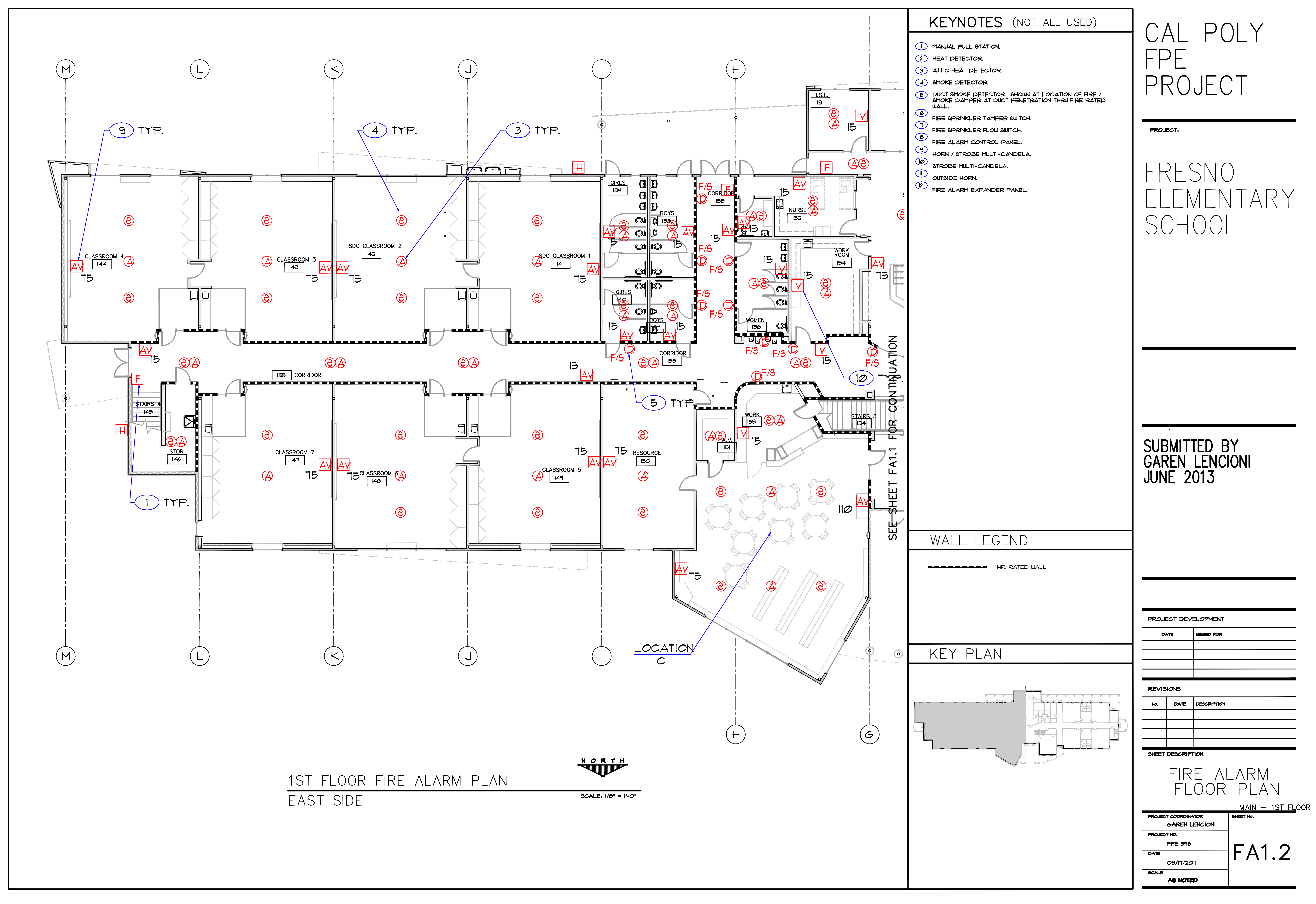




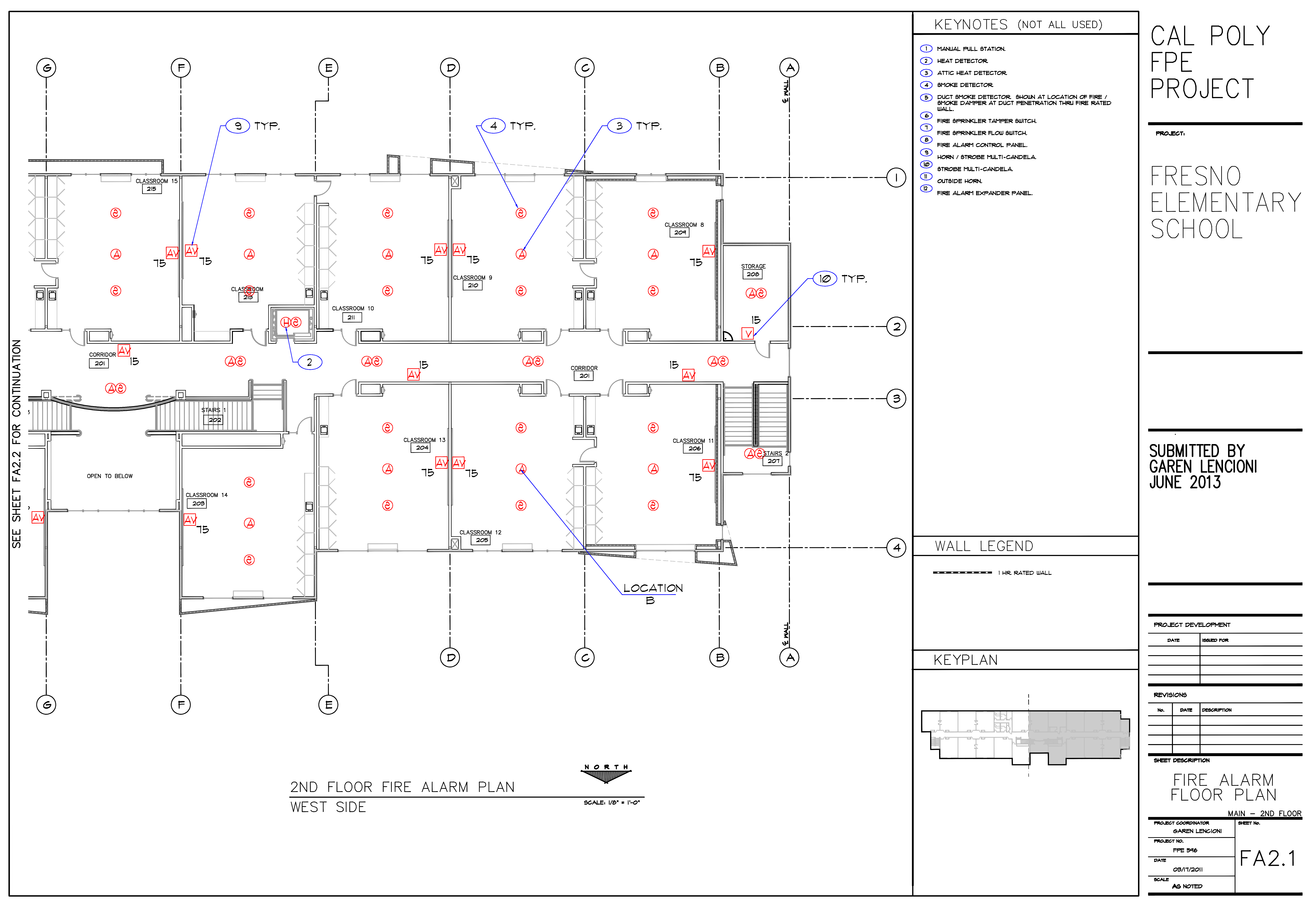




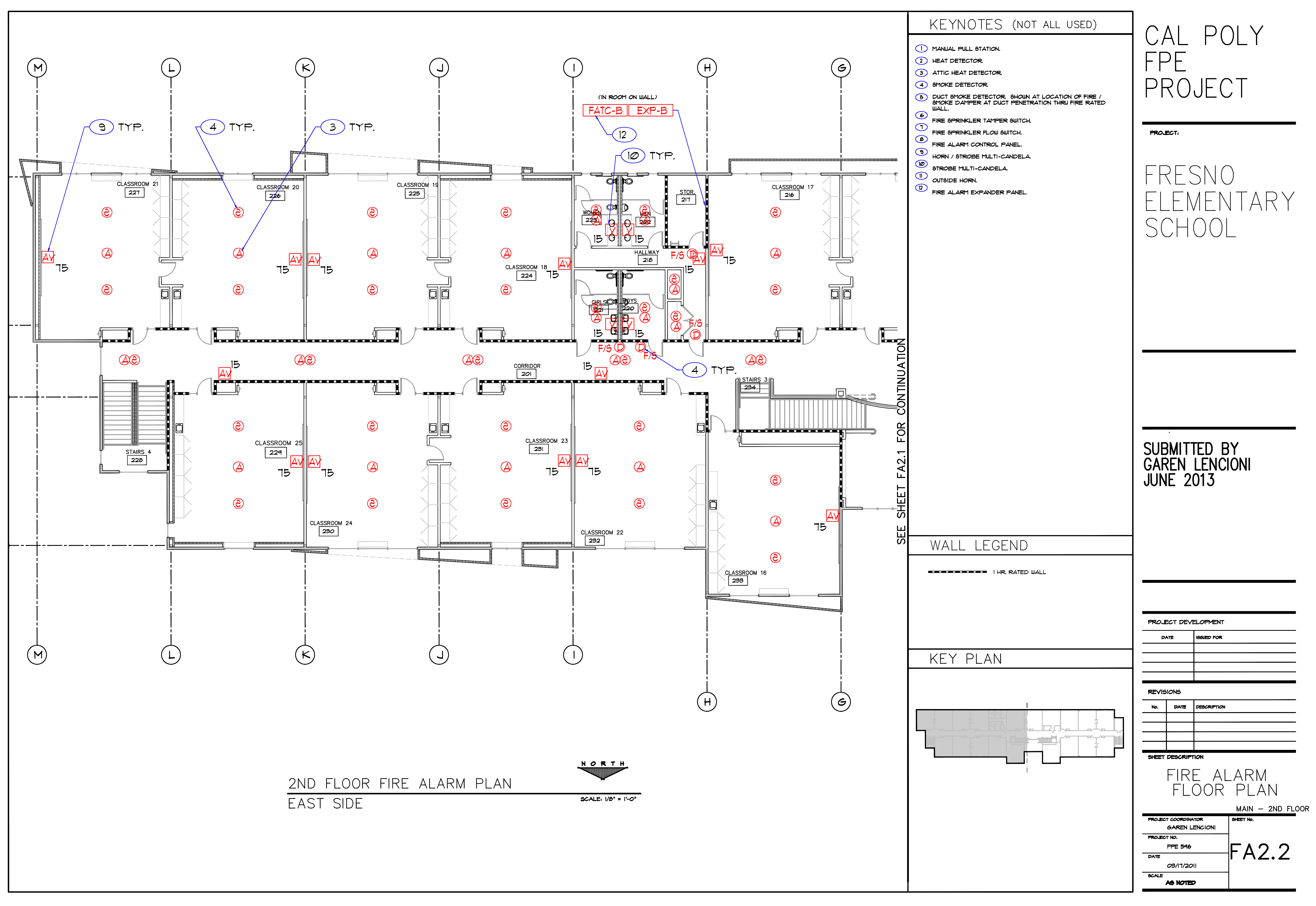




\section{APPENDIX D: FIRE SPRINKLER PLANS}




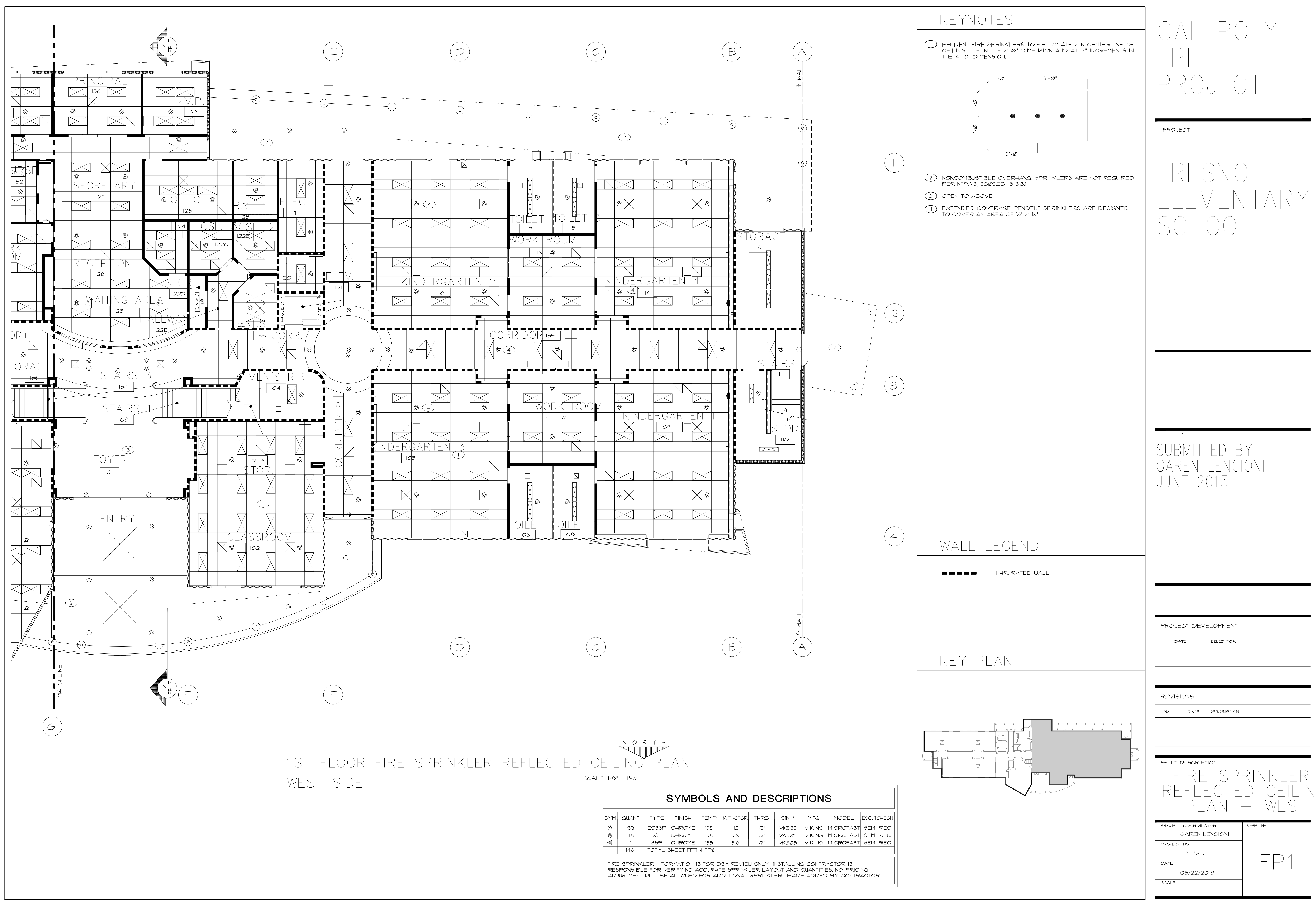




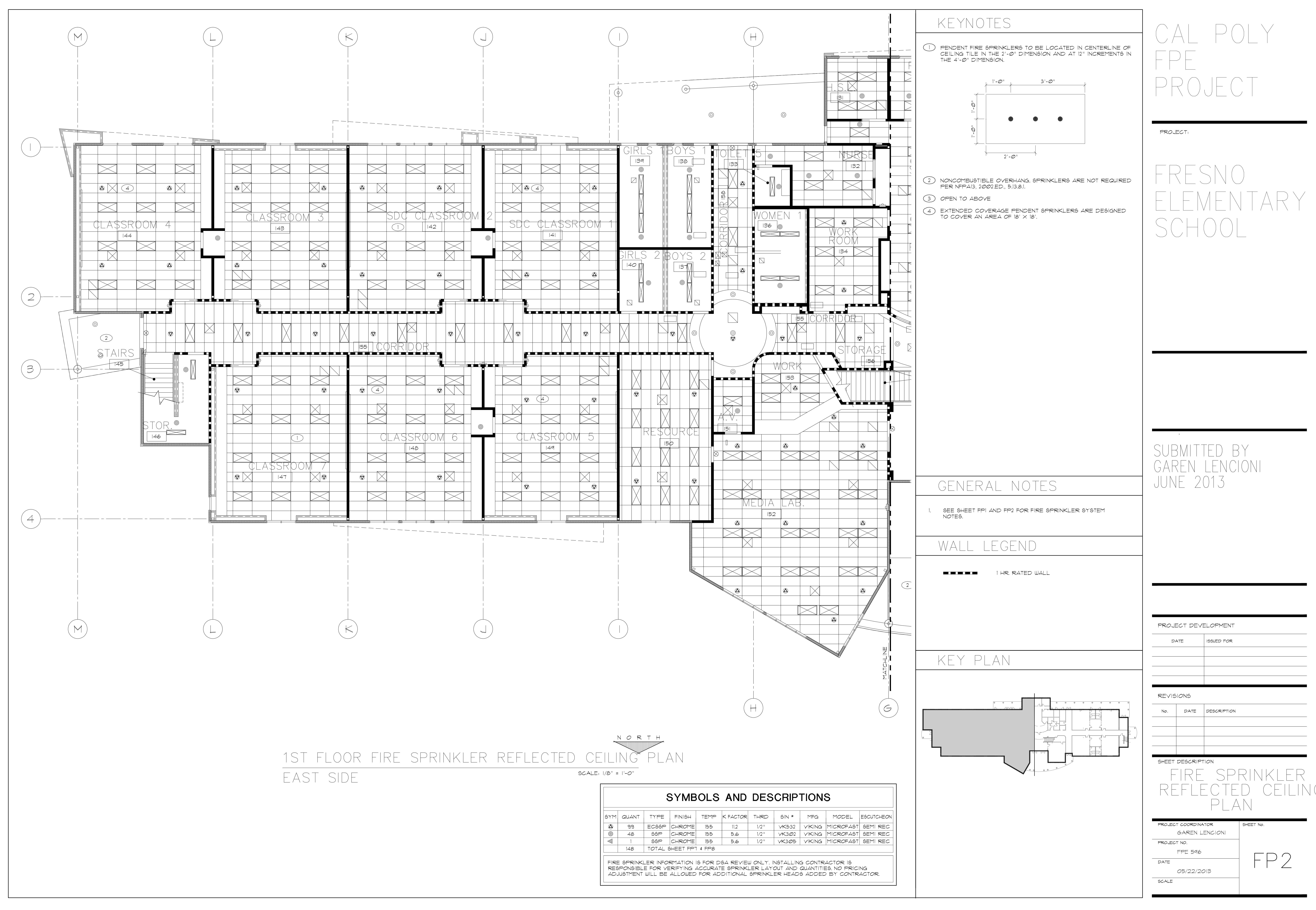




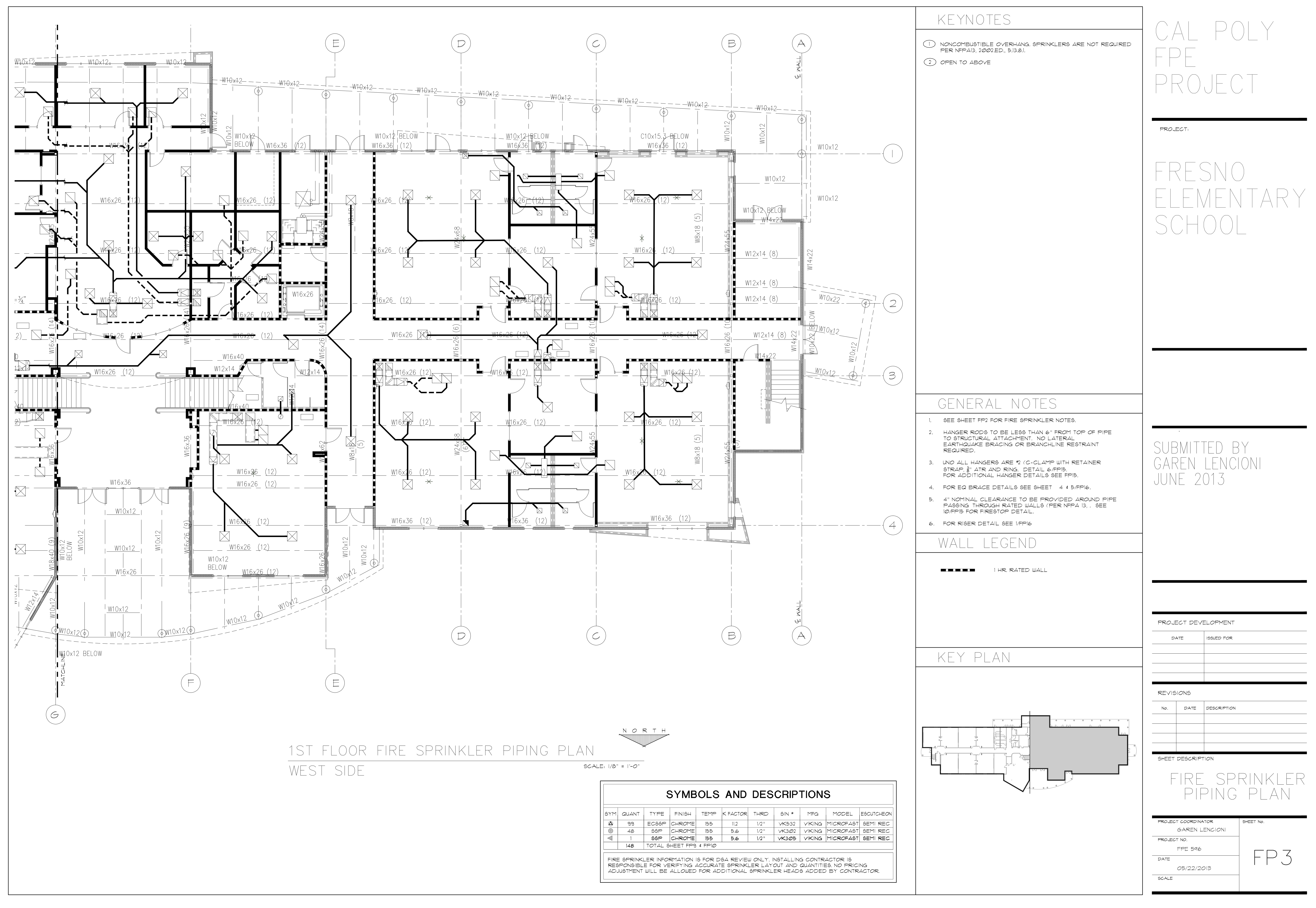




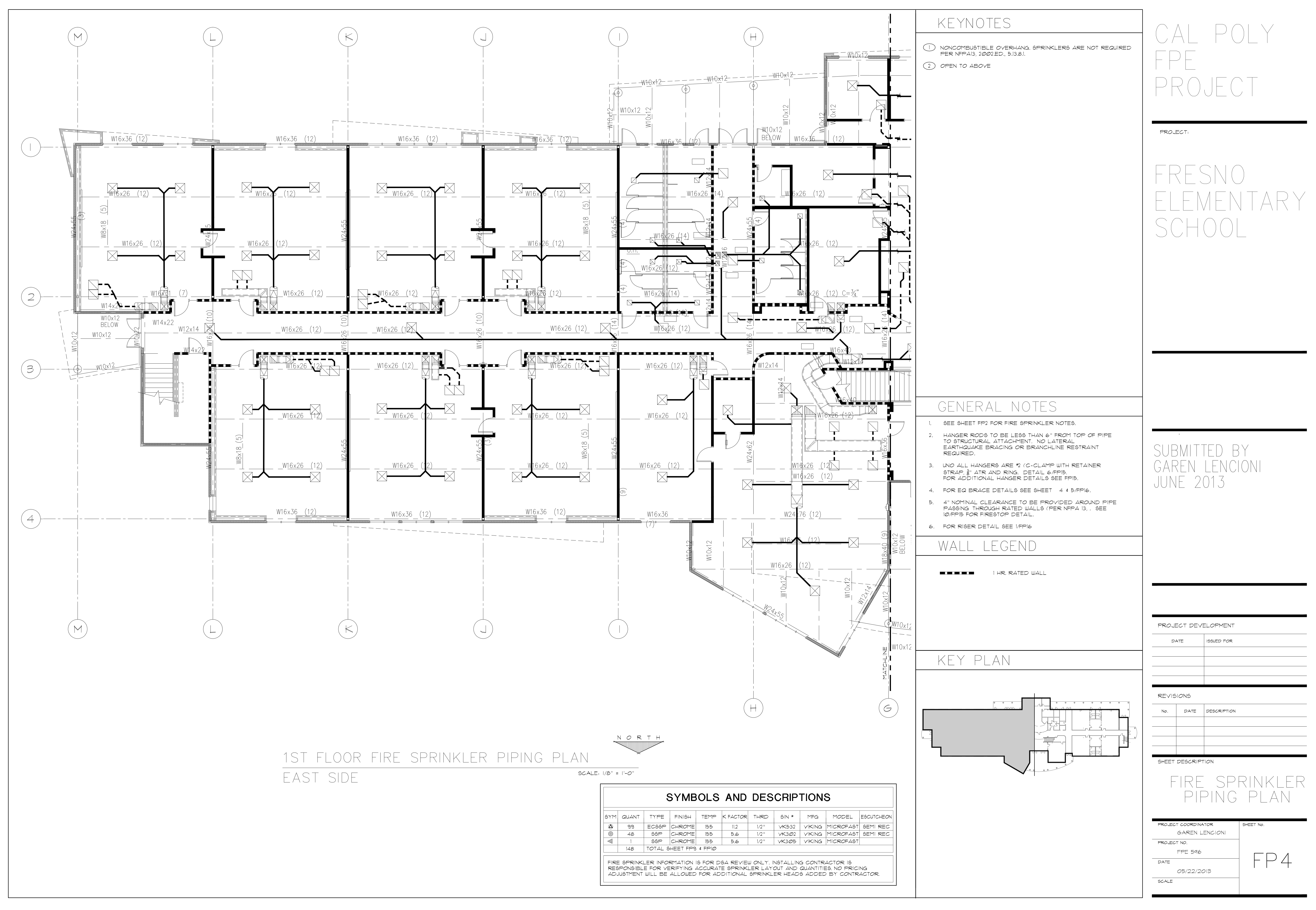




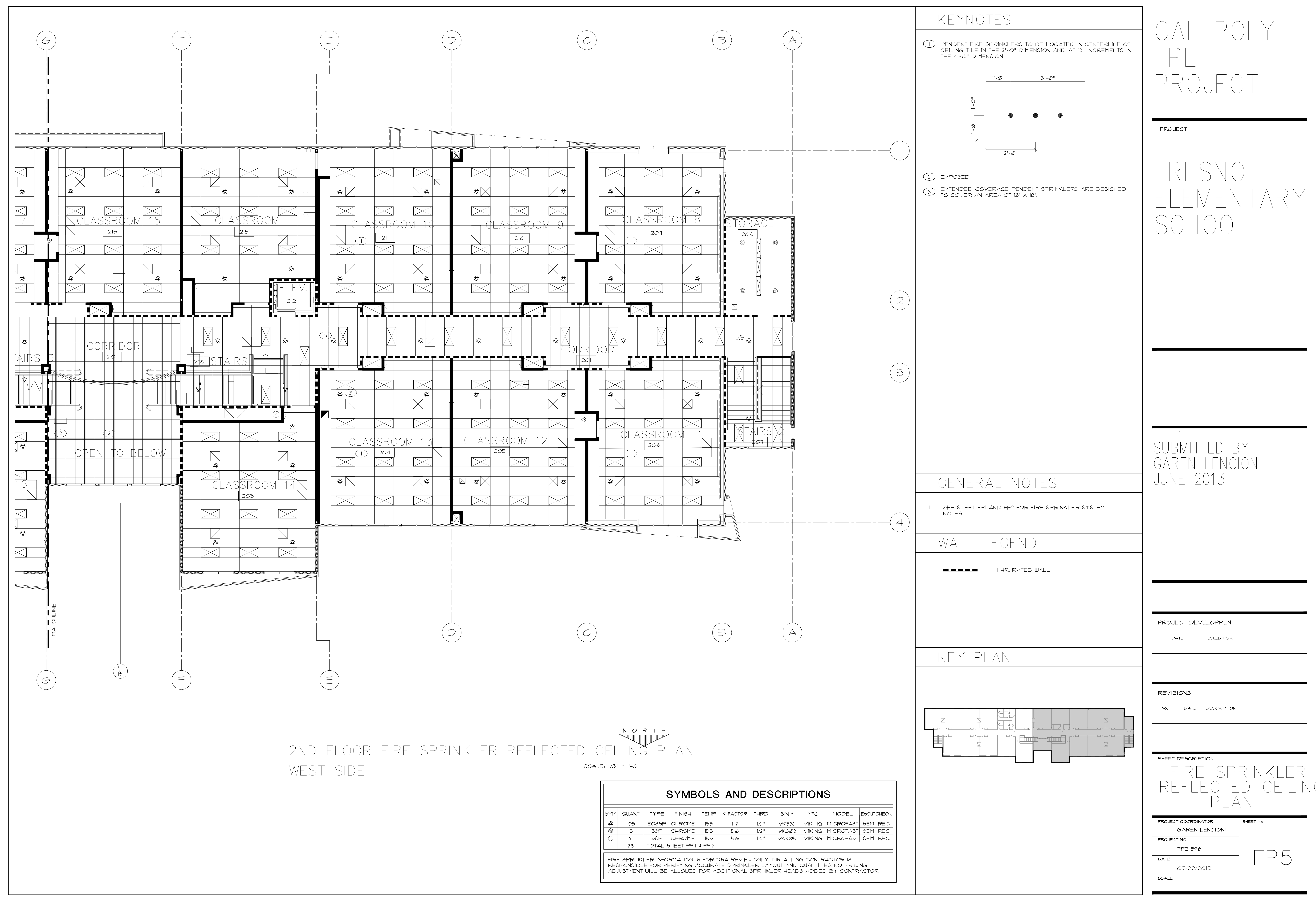




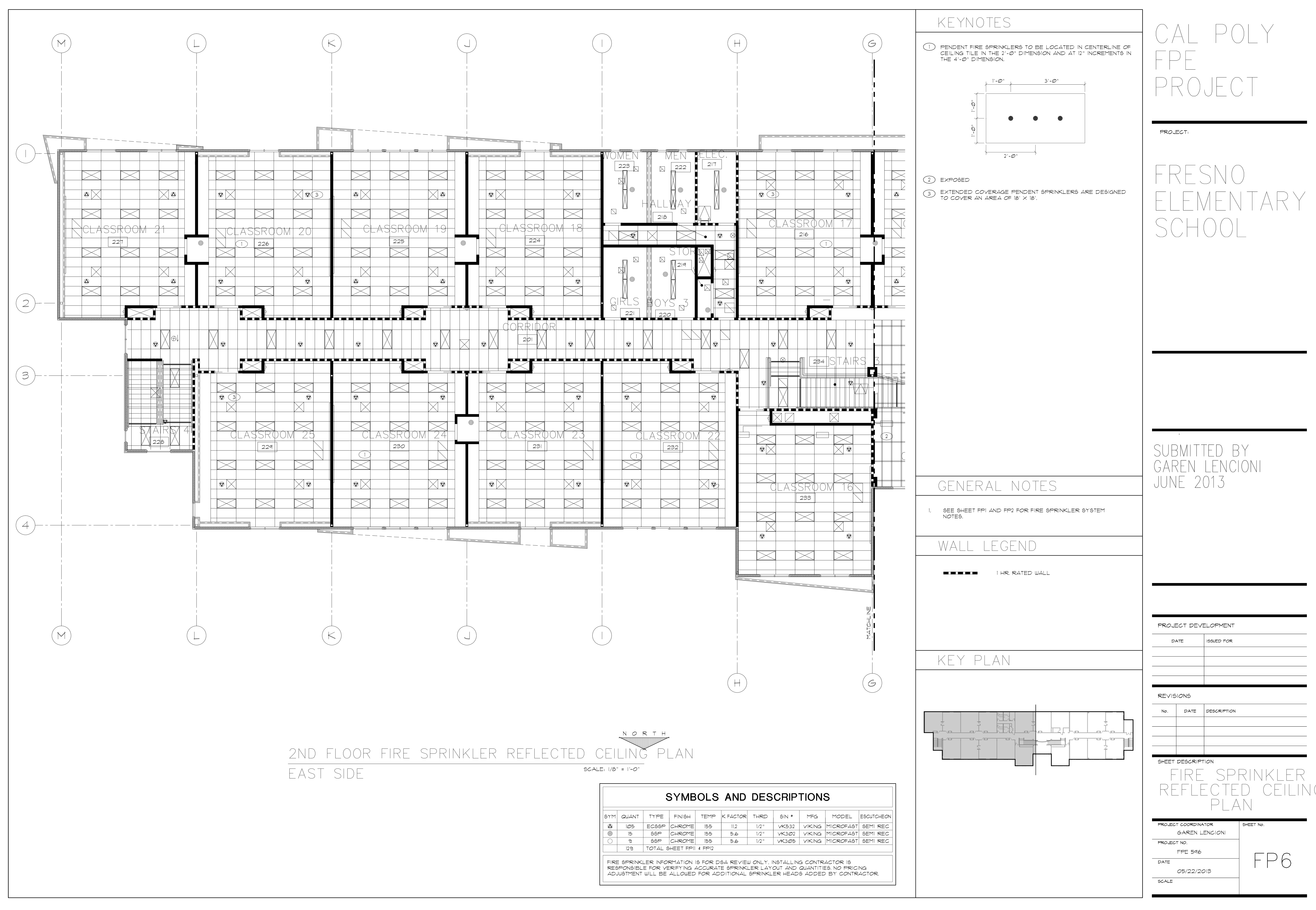




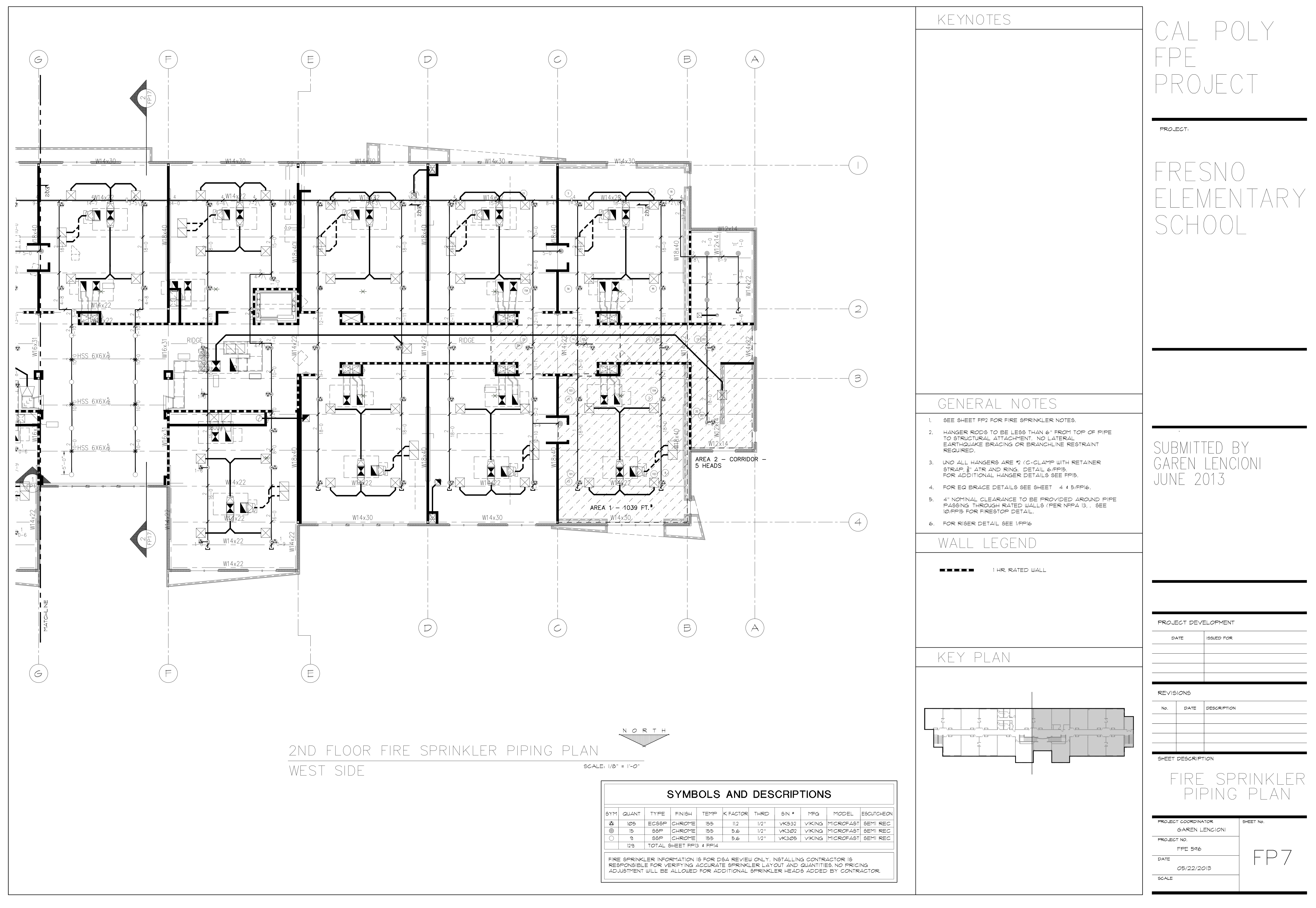




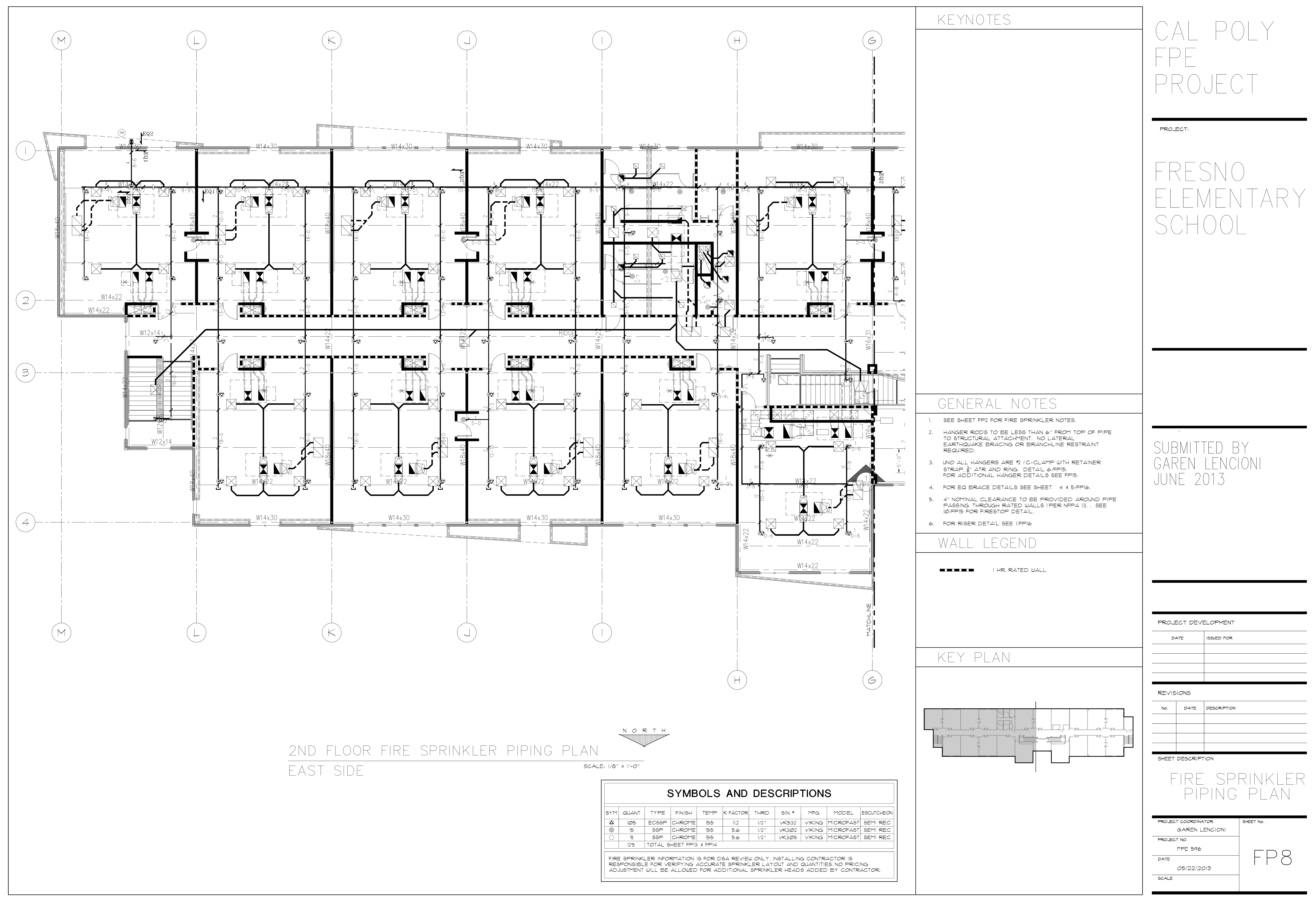



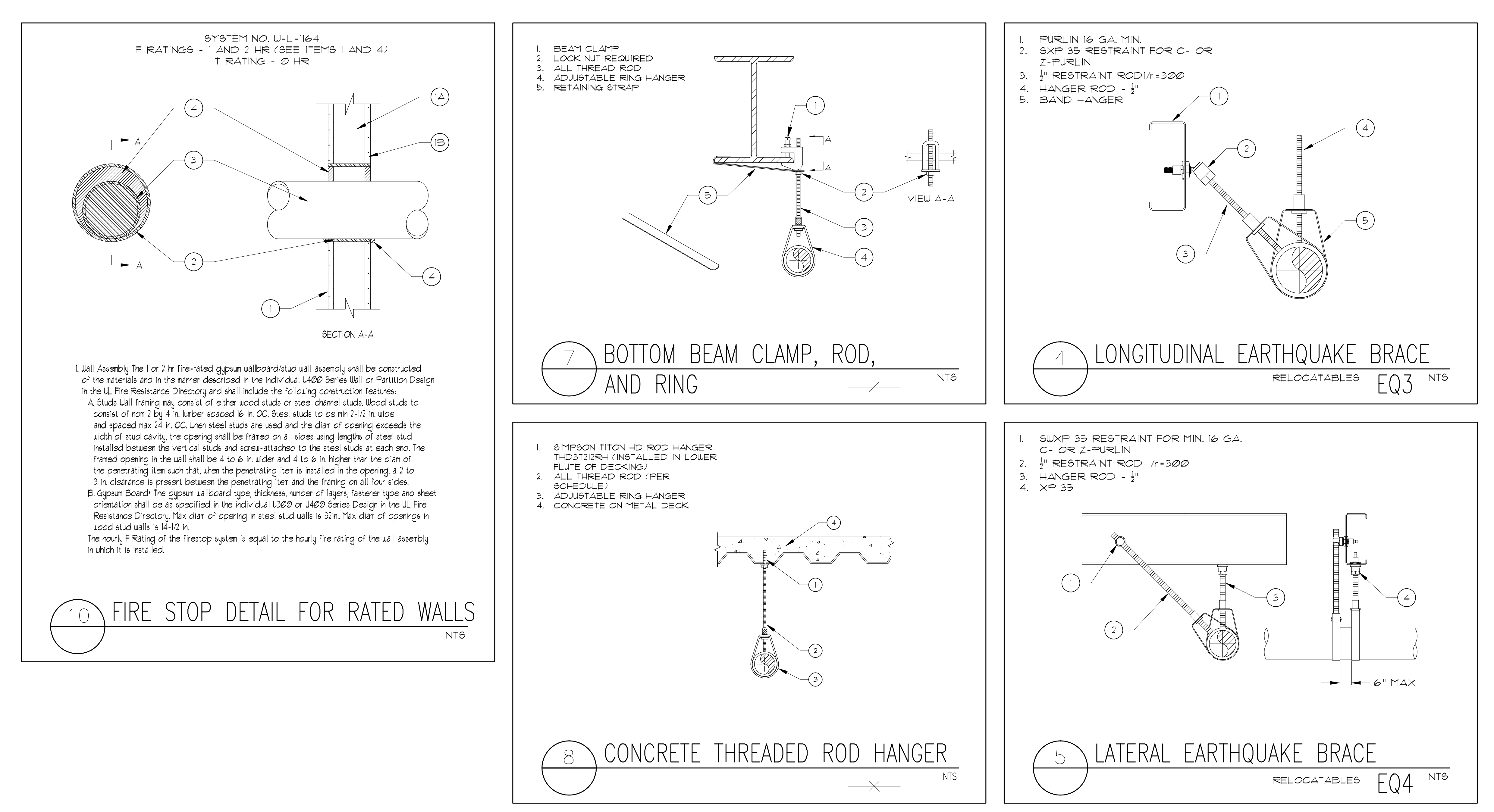

(1)
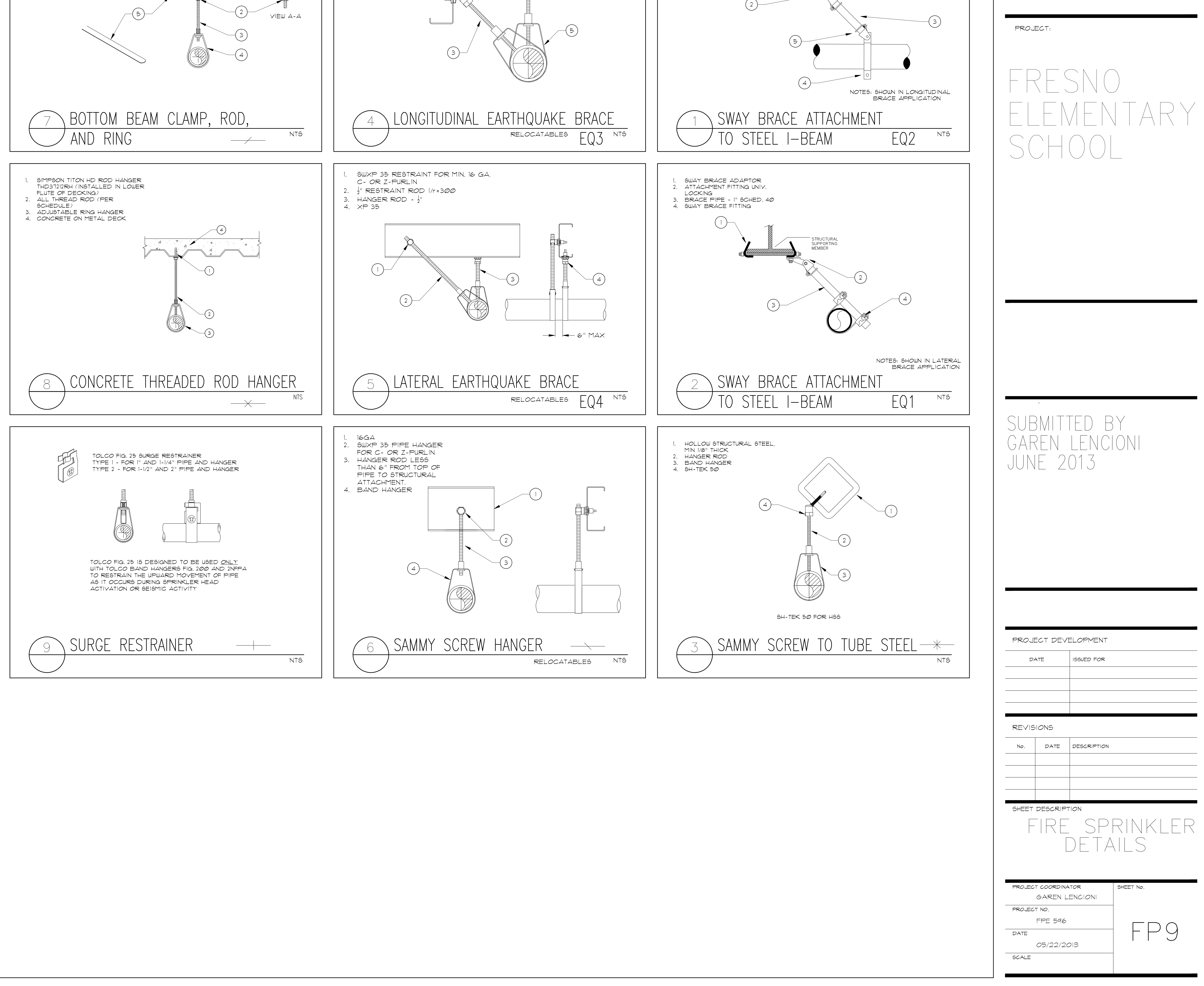


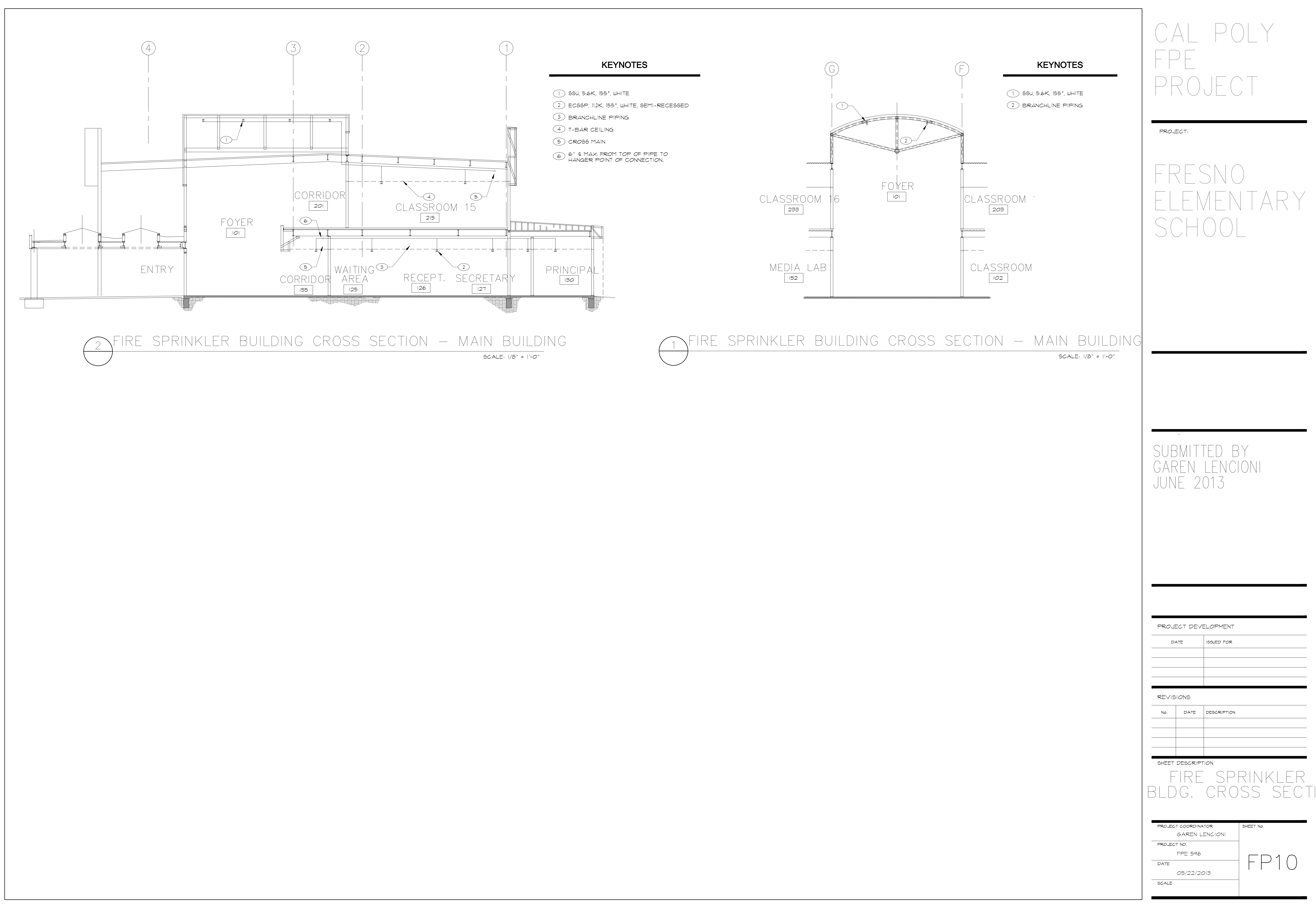




\section{APPENDIX E: FIRE ALARM CUT SHEETS}




\section{Description}

The E3 Series ${ }^{\circledR}$ Expandable Emergency Evacuation System by Gamewell-FCl is in the forefront of the latest generation of fire alarm control panels. Employing the new highspeed Velociti ${ }^{\circledR}$ sensors, the E3 Series provides previously unattainable polling speed and response together with the flexibility demanded by today's emergency evacuation systems. In addition to their high-speed polling rate, the Velocit Series of sensors feature bi-polar LEDs that flash green for normal polling, and light red steadily to indicate an alarm.

The E3 Series is equipped with an 80-character LCD-E3 alphanumeric LCD display that allows 40 characters to be user-defined for customizing installations. Up to six (6), keyboard LCD displays may also be remotely located in addition to five of the familiar LCD-7100 remote displays, allowing for instant system status information to be available in any desired area of an installation.

A high-speed 32-bit processor easily tackles a wide array of applications from small office buildings to sophisticated high-rise installations.

The (64) node networking is made possible by $625 \mathrm{~K}$ baud/ ARCNET communications using twisted-pair copper cable, fiber-optic cable, or a combination of both. In addition, the Addressable Node Expander (ANX) board expands the network to one hundred and twenty-two (122) nodes.

The basic E3 Series is equipped with an ILI-MB-E3/ILI95MB-E3 Intelligent Loop Interface-Main Board, ILI-S-E3/ ILI95-S-E3 Intelligent Loop Interface Expansion Board, ANX, and ASM-16 Addressable Switch Module that features sixteen (16), software programmable switches, each accompanied by red, green and yellow LEDs that can be programmed to indicate operation of the switches. Additional ASM-16 modules may be added to expand the operation to a plateau previously unimagined.

The Intelligent Loop Interface - Expansion Board (ILI-S-E3/ ILI95-S-E3 provides the E3 Series control panel with two (2), additional signaling line circuits. The layout is similar to the ILI-MB-E3/LI95-MB-E3 with the exception that a number of components are omitted. It occupies one node on the Broadband network.

E3 Series ${ }^{6}$ and Velociti ${ }^{0}$ are registered trademarks of Honeywell International Inc. $\mathrm{UL}^{(1)}$ is a registered trademark of Underwiters Laboratories inc.

\section{Expandable Emergency Evacuation System}

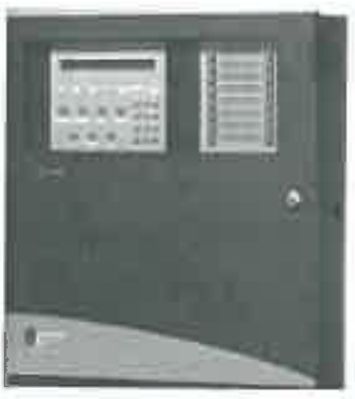

E3 Series

\section{Features}

- IBC Seismic Certified

- Listed under UL ${ }^{\oplus}$ Standard 864, 9th Edition

- UL Listed for smoke control (dedicated and non-dedicated) when properly configured

- FM/UL Listed for Pre-action/Deluge use

- Styles 4,6 , or $7^{*}$ signaling line circuits

- Two to (244) SLCs each supporting 159 sensors and 159 modules

- 625K baud ARCNET communications using wire, fiber, or mixed configurations for installation flexibility

- High-speed 32 bit processor and 4100 event history log

- Advanced Boolean logic-based programming such as AND, OR, NOT, time delay and calendar functions configurable via computer programming

- Supports up to (16), ASM-16 addressable switch or ANU-48 LED driver modules per ILI-MB-E3/LI95-MB-E3

- Two (2), Class A, Style Z or Class B, Style Y, notification appliance circuits rated at 2.0 amps. per circuit

- Integral city connection

- Flexible 115,200 baud high speed RS-232 interface

- 40 character user-defined text per device

- Supports up to five (5), LCD-7100 displays and six (6), LCD-E3 keyboard displays per ILI-MB-E3/LL195-MB-E3

"Style 7 wiring requires the use of System Sensor M500X isolator Modules.

continued on next page

\section{An ISO 9001-2000 Company}

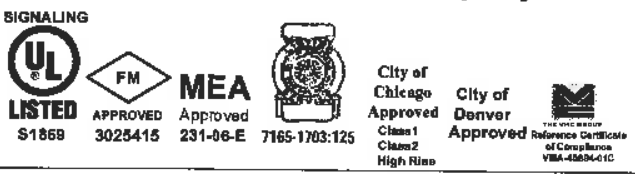




\section{Description (Continued)}

Each ILI-MB-E3/LI95-MB-E3 can support as many as sixteen (16), ANU-48 LED Driver modules supporting hundreds of LEDs on a 3rd party graphic annunciator for remote annunciation. The ANU-48 modules may be installed in any Listed remote annunciator. It can be remotely located vía an RS-485 serial interface.

An array of cabinets allows for neat, compact, attractive installations.

\section{Installation}

The E3 Series expandable emergency evacuation system offers four (4), cabinet size options. A typical cabinet includes a backbox, an inner door, and an outer door. The E3 Series cabinet assembly is a compact $193 / 8$ " $(49 \mathrm{~cm})$ wide wall-mounted enclosure.

Cabinet $\mathrm{A}$ includes the following four options:

- Cabinet A1 inner door mounted to the backbox. The backbox houses one NGA module.

- Cabinet A2 inner door mounted to the backbox. The backbox houses one LCD-E3 module.

- Two or three-bay inner door mounted to the backbox The backbox typically houses one (1) LCD-E3, or one (1) NGA, and one (1) or two (2), ASM-16 modules.

Cabinet B contains a space for the ILI-MB-E3/LLI95-MB-E3, PM-9/PM-9G modules and batteries set inside the backbox. Additional module options mounted on the backbox include the DACT-E3, and RPT-E3 or ILI-S-E3/ILI95-S-E3/ ANX. The 2-bay inner door houses one (1), LCD-E3 module and one (1), ASM-16 module.

Both Cabinets $\mathrm{C}$ and $\mathrm{D}$ include the following:

- Pre-assembled outer door that gives visibility to the fire fighter's phone handset and a microphone voice messaging system.

- Two inner door panel selections that may contain optional modules to meet the facility operation requirements.

In the Cabinet $B, C$ and $D$ backboxes, the ANX appears in the same place as the ILI-MB-E3/ILI95-MB-E3 and PM-9/ PM-9G. For information on the installation instructions for any of the E3 Series cabinets, refer to the E3 Series ${ }^{B}$ Expandable Emergency Evacuation Installation/Operating Manual Part Number: 9000-0574.

\section{Specifications}

\section{Operating Voltage: 24 VDC}

Operating Temperature: Not to exceed the range of $32^{\circ}$ to $120^{\circ} \mathrm{F}\left(0\right.$ to $\left.49^{\circ} \mathrm{C}\right)$

Relative Humidity: Not to exceed $93 \%$ non-condensing at $90^{\circ} \mathrm{F}\left(32^{\circ} \mathrm{C}\right)$

\section{Features (Continued)}

Velocititi Intelligent Sensor Features:

- Poll 318 devices in less than two (2) seconds

- Activate up to 159 outputs in less than five (5) seconds

- LED's blink associated device address during Walk Test

- Fully digital, hi-precision protocol

- Up to 9 levels of sensitivity adjustment

- Pre-Alarm adjustable between 15 levels for both Alert and Action

- Day/night automatic sensing adjustment

- Sensitivity windows:

- Ion .05 to $2 \%$ obscuration

- Photo 1 to $3 \%$ obscuration

- Laser 02 to $2 \%$ obscuration

- MCS Acclimate2F .5 to $4 \%$, also self-adjustable options 1 to $2 \%, 2$ to $3 \%$, and 3 to $4 \%$

- HARSH 1 to $3 \%$ obscuration

- Drift compensation

- Each Loop Card has its own integral processor providing maximum survivability on loss of any other component. SLC provides full response on loss of any other system processor

- Optional programmable switches can be configured to enable, disable or group any combination of output devices

- Integrated point or Grouped Cross Zoning allows for numerous devices installed at any location to cooperate and determine alarm condition

- Automatic detector sensitivity testing

- DIRTY and VERY DIRTY detector maintenance alerts

\section{Ordering Information}

\section{Part Number Description}

ILI-MB-E3 Intelligent Loop interface-Main Board

ILI95-MB-E3 Intelligent Loop Interface-Main Board

ILI-S-E3 Intelligent Loop Interface-Expansion Board

ILI95-5-E3 Intelligent Loop Interface-Expansion Board

ANX-SR Addressable Node Expander-Single Ring

ANX-MR-FO Addressable Node Expander-Multi-Ring Fiber Optic

ANX-MR-UTP Addressable Node Expander-Multi-Rìng

LCD-E3 $\quad$ LCD-E3, LCD Keypad Display

RPT-E3-FO Network Repeater (fiber and twisted-pair)

RPT-E3-UTP Network Repeater (twisted-pair only)

DACT-E3 Digital Alarm Communicator Transmitter

ANU-48 ANU-48 LED Driver Module

ASM-16 Addressable Switch Module

NGA LCD Network Graphic Annunciator

PM-9 Power Supply Module

PM-9G Power Supply Module

LCD-7100 Remote LCD Display

For additional information on the cabinets, refer to the E3 Series Cabinets data sheet (Part Number: 9020-0649).

Seismic Battery Bracket Kits

For information on the types of Seismic Battery Bracket Kits that are available and the Seismic Battery Bracket Kit Part Numbers, refer to the following documents:

- Seismic Battery Bracket Installation Guide, P/N: 53839

- E3 Series Cabinets Data Sheet, P/N: 9020-0649 


\section{国 Gamewell \\ by Honeywell}

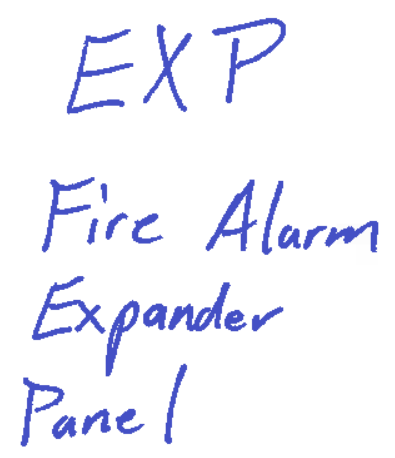

Firofored 8

\section{Description}

The FireForce 8 (FF8) from Gamewell-FCl is a Notification Appliance Circuit (NAC) extender panel designed to extend the power capabilities of existing NACs and provide power (1.5 A) for other ancillary devices. The FF8 will connect to any brand of a UL-Listed Fire Alarm Control Panel (FACP) to provide Notification Appliance Circuit expansion.

Designed with advanced switch-mode power-supply technology, the FireForce 8 provides filtered and electronicallyregulated power distributed to four (4) NACs. Each NAC is rated at 3.0 Amp. maximum, with a total output capacity of 8.0 Amp. The outputs may be configured as the following:

- Four (4), Class B (Style W, X, Y)

- Two (2), Class A (Style Z)

- Two (2), Class B and one Class A

- Four (4), Class A (Style Z) with the optional Class A adaptor installed

The FF 8 includes an internal battery charger.

Gamewell-FCl's FF8 provides independent output circuit supervision. In the event of a NAC fault, the FF8 can be configured to notify the FACP. The FF8 has field-selectable, built-in strobe and hom sync protocols. Protocols support Faraday, Gentex, System Sensor, Amseco, and Cooper-Wheelock devices; or pass through a pre-generated sync protocol from a single synchronization source. This eliminates the need for additional individual sync modules. Independent horn silencing via sync protocol allows synchronized horns and strobes to operate on a single circuit.

One of the most challenging aspects of a retrofit application is locating the existing EOL resistor. In retrofit applications that have EOL values other than the $3.9 \mathrm{~K}$ ohm EOL resistor normally used with the FF8, a single resistor matching the existing $E O L$ can be used as a reference $E O L$ for all outputs. This feature speeds installation and system checkout. The reference resistor must be within a range of $2 \mathrm{~K}$ ohm to $25 \mathrm{~K}$ ohm.

"FireForce 8 " labeling is placed on the cabinet front, making the FF8 ideal for all retrofit applications.

For enhanced notification appliance circuit survivability, the FF8 can utilize its dual-activation inputs for redundant trip operation.

\section{NAC Expander/Power Supply}

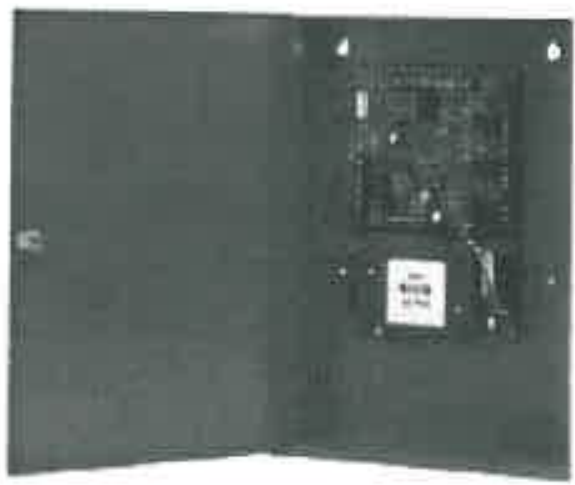

FireForce 8

\section{Features}

- Provides two fully-supervised input/control circuits

- Redundant activation option for survivability

- Multiple sync protocols, compatible with the following appliances: Cooper-Wheelock, Faraday, System Sensor, Amseco, and Gentex-as field-selectable options

- Four (4) configurable supervised NAC outputs

- 8.0 Amp., 24 VDC, fully regulated full-load output (power-limited)

- Output fault notification to FACP

- 1.5 A auxiliary power output

- Eight trouble and status LEDs

- Common trouble Form-C relay

- Isolated AC Fail Form-C relay, immediate or delayed six hours

- Ground fault detection

- $26 \mathrm{AH}$ battery charger capability

- Selectable temporal coding

- Facilitates multiple NAC synchronization for large areas

- Optional multipack for up to four FF8s in a single lockable enclosure

- Optional Class A adaptor
An ISO 9000-2000 Company

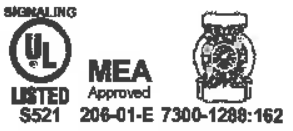




\section{Engineer's Specifications}

The Fire Alarm System shall be designed with remotely located Notification Appliance Circuit (NAC) Expander/ Power Supplies for the support of notification appliances. The remote Power Supplies shall be fully supervised and shall provide 8.0 Amps. of notification appliance power and 1.5 Amps, of auxiliary power output. The NAC Extender Panel shall be able to select strobe synchronization protocol via an internal dip switch. There shall be five selectable protocols available. The NAC Extender Panel shall synchronize all outputs simultaneously. The NAC Extender Panel shall be able to use existing notification appliance circuit's end-of-line resistors in the range of $2 \mathrm{~K}-25 \mathrm{~K}$ ohms for retrofit applications. The internal battery charging circuit shall charge up to 26 AH batteries. The NAC Expander/ Power Supply shall be a Gamewell-FCl FireForce 8.

\section{Options}

\section{1}

SCE-95 mounting plate provides a means to install two (2) SCE-95 modules. The addition of SCE-95s provides a means to run on FF8 outputs via a panel command on an SLC. The 31081 mounts over the main PCB and is hinged for access to FF8 terminal.

\section{FF8-MP}

Multipack FF8 option provides a means to place up to four (4) FF8s or 31085s (XP95 device mounting plates) in a single lockable enclosure. UL approved.

\section{6}

Class A adaptor converts the four (4) Class B outputs to four (4) Class A outputs.

\section{Specifications}

Primary Input Power: $120 \mathrm{VAC}, 60 \mathrm{~Hz}, 3.0 \mathrm{~A}$ or $220 \mathrm{~V}, 1.5 \mathrm{~A}$; jumper selectable

Secondary Power: $\quad$ 24-volt operation: two $7-24 \mathrm{AH}$ batteries

\section{Battery Charging} Capacity: Battery Space:

\section{Up to $26 \mathrm{AH}$ batteries} Up to two 12 AH batteries maximum inside the FF8 cabinet. Larger batteries require a separate battery cabinet

Total Output Power: $8.0 \mathrm{~A}$ maximum Standby Current: $\quad 0.030 \mathrm{~A}$

Auxiliary Power Output:

$0.15 \mathrm{~A}$ under all conditions $1.5 \mathrm{~A}$, if load is removed during operation (external relay or AC Fail relay use required).

NAC Output Ratings: 24 VDC fully regulated, $3.0 \mathrm{~A}$ maximum per circuit ( $8.0 \mathrm{~A}$ total)

End-of-Line Resistor

Range:

$2 \mathrm{~K}$ to $25 \mathrm{~K}, 1 / 2$ watt

Common Trouble

Relay, AC Fail Relay: 2.0 A/28 VDC or 120 VAC

\section{Specifications (Continued)}

Input Control Circuit: $16-30$ VDC @ 5 mA minimum Temperature Rating: $32^{\circ} \mathrm{F}$ to $120^{\circ} \mathrm{F}\left(0^{\circ} \mathrm{C}\right.$ to $\left.49^{\circ} \mathrm{C}\right)$

Relative Humidity: $10-93 \%$, non-condensing

Dimensions:

FF8 Cabinet:

18.0" $\mathrm{H} \times 12.5^{\mathrm{N}} \mathrm{W} \times 4.5^{\mathrm{m}} \mathrm{D}$

(45.72 Hx 31.75 W x 11.43 D cm)

FF8-MP Cabinet:

$37.2^{\prime \prime} \mathrm{H} \times 24.0^{\mathrm{n}} \mathrm{W} \times 6.0^{\mathrm{\prime \prime}} \mathrm{D}$

$(94.49 \mathrm{H} \times 60.96 \mathrm{~W} \times 15.24 \mathrm{D} \mathrm{cm})$

\begin{tabular}{|l|l|}
\hline \multicolumn{2}{|c|}{ Field Selectable NAC Signaling } \\
\hline \multicolumn{1}{|c|}{ INPUT } & \multicolumn{1}{c|}{ OUTPUT (Follows Input) } \\
\hline Steady & Tempora! \\
\hline Steady & Steady - SYNC \\
\hline Steady & Steady with Noise Eliminated \\
\hline Sync & Sync \\
\hline
\end{tabular}

\section{Ordering Information}

\begin{tabular}{|c|c|}
\hline Model & Description \\
\hline FF8 & $\begin{array}{l}24 \text { VDC, } 8.0 \text { Amp., fire alarm NAC } \\
\text { expander/ power supply with integral } \\
\text { battery charger }\end{array}$ \\
\hline FF8-MP & $\begin{array}{l}\text { Multipack cabinet with one FF8 and } \\
\text { space for up to three additional FF8-CMs } \\
\text { or } 31085 \text { s (See Options Section). }\end{array}$ \\
\hline FF8-CM & $\begin{array}{l}\text { Chassis assembly version of FF8, for } \\
\text { mounting in FF8-MP spaces }\end{array}$ \\
\hline 31076 & $\begin{array}{l}\text { Class A adaptor, converts signal circuits } \\
\text { to Class A wiring (See Options Section). }\end{array}$ \\
\hline 31081 & $\begin{array}{l}\text { Mounting plate for placing up to two } \\
\text { SCE-95 modules into the FF8 } \\
\text { (FF8 and FF8-MP compatible, See } \\
\text { Options Section). }\end{array}$ \\
\hline 31085 & $\begin{array}{l}\text { Mounting plate for placing XP95 devices } \\
\text { into the FF8-MP; includes standoffs for } \\
\text { eight devices }\end{array}$ \\
\hline BAT-1270 & $\begin{array}{l}\text { Battery, } 12 \text { VDC, } 7 \mathrm{AH} \\
\text { (two required for } 24 \mathrm{~V} \text { operation) }\end{array}$ \\
\hline 212 & $\begin{array}{l}\text { Battery, } 12 \text { VDC, } 12 \mathrm{AH} \\
\text { (two required for } 24 \mathrm{~V} \text { operation) }\end{array}$ \\
\hline
\end{tabular}




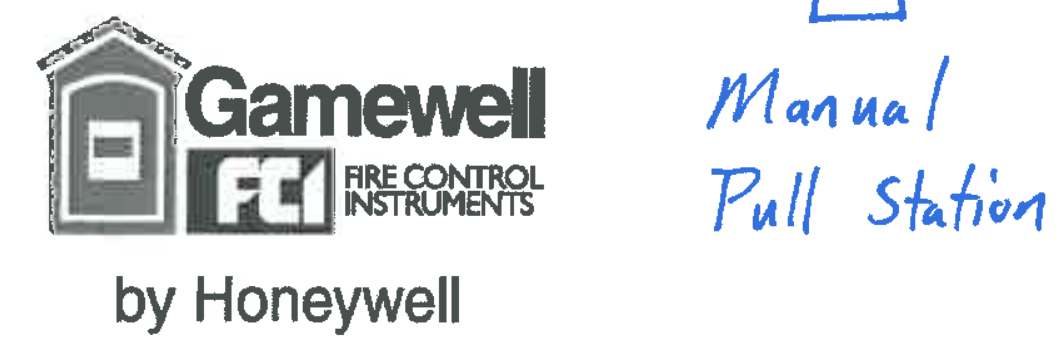

Ims-7 Serles

\section{Description}

The Gamewell-FCl, MS-7 Series manual fire alarm stations are available in a wide variety of configurations. The Stations comply with the Americans with Disabilities Act (ADA) 5-lb. maximum pull force requirement. Operating instructions and Braille text are engraved in the handle. All stations have a key lock/reset which is keyed alike with Gamewell- $\mathrm{FCl}$ fire alarm control panels and other manual fire alarm stations.

\section{MS-7AF Velociti Addressable Station}

The MS-7AF Velociti ${ }^{\circledR}$ Series addressable station is a double action station designed for installation in the signaling line circuit of Gamewell-FCI analog addressable control panels. Activation of the station causes its assigned address to register at the control panel. The door contains an LED which flashes green in normal condition and lights steady red when the station has been activated. ${ }^{*}$ The station features screw terminals.

\section{MS-7ASF Velociti Addressable Station}

The MS-7ASF Velociti ${ }^{(2)}$ Series addressable station is a single action station designed for installation in the signaling line circuit of Gamewell-FCl analog addressable control panels. Activation of the station causes its assigned address to register at the control panel. The door contains an LED which flashes green in nomal condition and lights steady red when the station has been activated. * The station features screw terminals.

The Velocit ${ }^{\circledR}$ Series stations use a communication protocol that substantially increases the speed of communication between the sensors and certain Gamewell-FCl analog addressable fire alarm controls. These devices operate in a grouped fashion. If one of the devices in the group has a status change, the panel's microprocessor stops the group poll and focuses on the single device. The net effect is response speed up to five times greater than earlier designs.

\section{MS-7 Double Action Station}

The MS-7 double action station is used with conventional fire alarm control panels. It features a set of single pole contacts and screw terminals for connection to an initiating circuit.

Velocit ${ }^{(1)}$ is a registered trademark of Honeywell Intemational Inc. $\mathrm{UL}^{\mathbb{1}}$ is a registered trademark of Underwiter's Laboratories Inc. LEXAN ${ }^{3}$ is a registered trademark of GE Plastics, a subsidiary of General Electric Company.

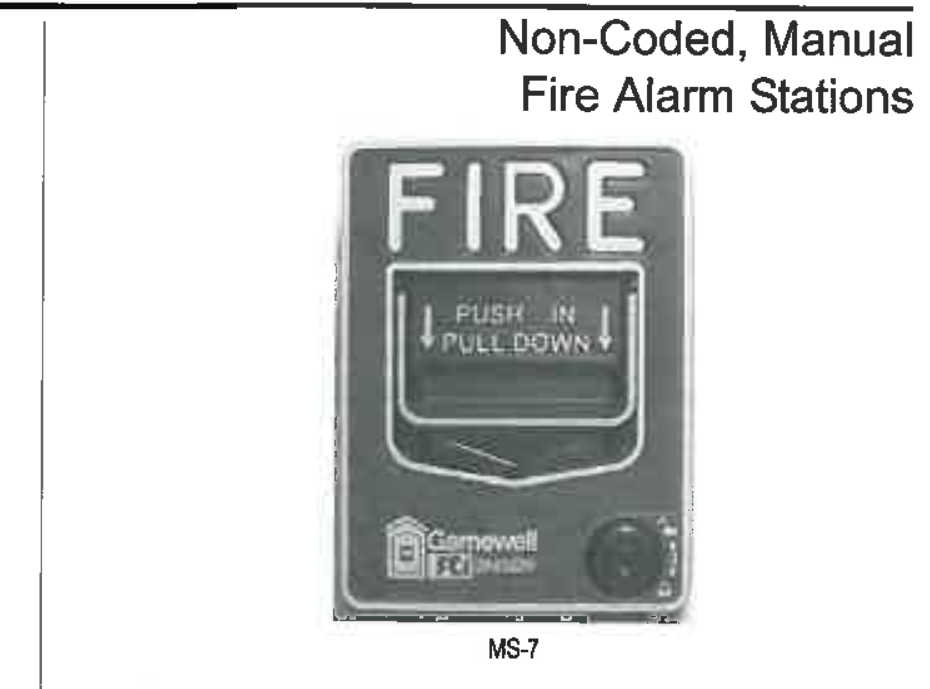

\section{Features}

- Addressable stations compatible with all Gamewell-FCl analog addressable fire alarm controls

- Conventional stations suitable for use with any UL ${ }^{\circledR}$ Listed control panel

- Both single and double action stations available

- Tumbler lock for test and reset keyed alike with Gamewell-FCl controls

- Surface or semi-flush mounting

- Shock and vibration resistant

- Stations (MS-7LOB) Listed for outdoor applications

- Complies with ADA pull force requirements

*Only the red LED is operative in panels that do not operate in Velociti mode.

\section{GAMEWELL-FCI} 12 Clintonville Road, Northford, CT 06472-1610 USA - Tel: (203) 484-7161 - Fax: (203) 484-7118 92010 by Honeywell Intemational Inc. All rights reserved. Www.gamewell-fci.com

An ISO 9001-2000 Company

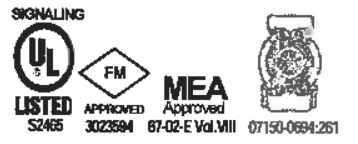




\section{MS-7S Single Action Station}

The MS-7S single action station is used with conventional fire alarm control panels. It features a set of single pole contacts and wire leads for connection to an initiating circuit.

\section{MS-7SP Double Action Station}

The MS-7SP is a double action station similar to the MS-7 station, with the additional feature of both English and Spanish instructions molded into the unit.

\section{MS-7LR Dual-action Agent Release Station}

The MS-7LR is designed for use with the Gamewell-FCI fire alarm control panels with releasing capabilities and Flex Series releasing systems. It features a set of single pole contacts and screw terminals for connection to an initiating circuit.

\section{MS-7LRA Agent Release Station with Abort}

The MS-7LRA is designed for use with the Gamewell-FCI fire alarm control panels with releasing capabilities and Flex Series releasing systems where system abort capabilities are required. It consists of an MS-7LR mounted on a plate with an abort switch and LED indicators for system normal, and system activated status.

\section{MS-7LOB Double Action Station \\ (Listed for Outdoor Applications)}

The MS-7LOB station must be mounted on a Model SB-I/O backbox. In retrofit applications, the station is UL Listed for use with the WP-10 backbox. It is intended for use with conventional control panels and has a set of single pole contacts and screw terminals.

\section{Mounting}

The MS-7 interior stations may be surface mounted or semi-flush mounted on a standard double-gang, or 4-inch $(10.2 \mathrm{~cm})$ square electrical box. An optional trim ring (BG12TR) may also be used for semi-flush mounting.

\section{NYC-Plate}

The NYC-Plate provides the backplate for the manual pull station. (See Figure 1).

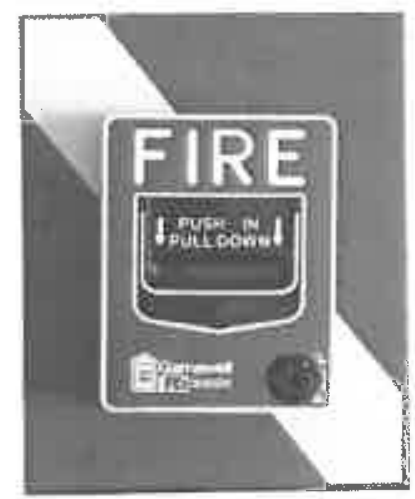

Figure 1 MYC-Plate

\section{Specifications}

\author{
Material: \\ $\operatorname{Lexan}^{1}$ \\ Contact Ratings: \\ 0.25 amps. @ 30 VAC/VDC \\ (resistive) \\ Dimensions: \\ $55 / 8^{n} \mathrm{H} \times 41 / 4^{n} \mathrm{~W} \times 11 / 4^{n} \mathrm{D}$ \\ $(14 \times 10.1 \times 3.2 \mathrm{~cm})$ \\ Operating Temperature \\ (MS-7AF, MS-7ASF): $\quad 32^{\circ}$ to $120^{\circ} \mathrm{F}\left(0^{\circ}\right.$ to $\left.49^{\circ} \mathrm{C}\right)$ \\ (MS-7LOB): \\ $-30^{\circ}$ to $150^{\circ} \mathrm{F}\left(-35^{\circ}\right.$ to $\left.66^{\circ} \mathrm{C}\right)$ \\ Relative Humidity \\ (MS-7AF, MS-7ASF): 10 to $93 \%$ (non-condensing) \\ (MS-7LOB): \\ $85 \% \pm 5 \% @ 86^{\circ} \pm 3.6^{\circ}$ \\ $\left(30^{\circ} \pm 2^{\circ} \mathrm{C}\right)$ \\ Alarm Current: \\ Supervisory Current \\ (MS-7AF, MS-7ASF): .00030 amps.
}

\section{Ordering Information}

\begin{tabular}{|c|c|}
\hline Part Number & Description \\
\hline MS-7 & Double action station \\
\hline 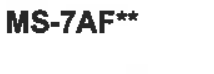 & $\begin{array}{l}\text { Velociti addressable double action } \\
\text { station }\end{array}$ \\
\hline MS-7ASF* & Velociti addressable single action station \\
\hline MS-7S & Single action station, wire leads \\
\hline MS-7SP & $\begin{array}{l}\text { Double action station, English and } \\
\text { Spanish instructions }\end{array}$ \\
\hline MS-7LR & Agent release station, dual-action \\
\hline MS-7LRA & $\begin{array}{l}\text { Agent release station with abort switch, } \\
\text { LED indicators, dual- action }\end{array}$ \\
\hline MS-7LOB & $\begin{array}{l}\text { Double action station, outdoor use } \\
\text { (Includes SB-I/O - Indoor/outdoor use } \\
\text { backbox) }\end{array}$ \\
\hline SB-1/O & Indoor/outdoor use backbackbox \\
\hline SB-10 & Surface backbox \\
\hline BG12TR & Trim ring for semi-flush mount, plastic \\
\hline NY-PLATE & NYC backplate for manual pull station \\
\hline
\end{tabular}




\section{Description}

The Gamewell-FCl Velociti ${ }^{\text {Series, }}$ addressable plug-in thermal sensors with integral communication provide features that surpass conventional sensors. Point ID capability allows each sensor's address to be set, providing exact locations for pinpointing alarm locations and for selective maintenance. ATD thermal sensors use an innovative thermistor sensing circuit to produce $135^{\circ} \mathrm{F} / 57^{\circ} \mathrm{C}$ fixed-temperature (ATD-L2F). The ATD-RL2F provides a combination $15^{\circ} /$ minute rate-of-rise with $135^{\circ}$ fixed thermal detection that is included in a low-profile package. The ATD-HL2F provides fixed high-temperature detection at $190^{\circ} \mathrm{F} / 88^{\circ} \mathrm{C}$. These thermal sensors provide cost-effective, addressable property protection in a variety of applications.

The Velociti ${ }^{\oplus}$ Series uses a communication protocol that substantially increases the speed of communication between the sensors and Gamewell-FCl analog addressable fire alarm controls. These devices operate in a grouped fashion. If one of the devices in the group has a status change, the panel's microprocessor stops the group poll and concentrates on the single device. The net effect is response speed up to five times greater than earlier designs.

\section{Installation}

ATD plug-in sensors use a separate base to simplify installation, service, and maintenance. A special tool allows maintenance personnel to plug-in and remove sensors without using a ladder.

Mount the base on a box which is at least $1.5 "(3.8 \mathrm{~cm})$ deep. Suitable mounting base boxes include:

- $4.0^{\prime \prime}(10.2 \mathrm{~cm})$ square box.

- $3.5^{\prime \prime}(8.9 \mathrm{~cm})$ or $4.0^{\prime \prime}(10.2 \mathrm{~cm})$ octagonal box.

- Single-gang box (except relay or isolator base).

- With B200SR base, mounted on a $4.0^{\prime \prime}(10.2 \mathrm{~cm})$ square box.

- With B224RB or B224BI base, mounted on a 3.5" (8.9 $\mathrm{cm})$ octagonal box, or a $4.0^{\prime \prime}(10.2 \mathrm{~cm})$ octagonal or square box.

NOTE: Because of the inherent supervision provided by the SLC, end-of-line resistors are not required. Wiring "Ttaps" or branches are permitted for Style 4 (Class “ $\mathrm{B}^{ }$) wiring.

Velocitit and E3 Series ${ }^{10}$ are registered trademarks of Honeywell Intemational Inc

$U L^{2}$ is a registered trademark of Underwiters Laboratories Inc.

ULC $^{\circledR}$ is a registered trademark of Underwriters Laboratories Canada Inc.

\section{Addressable Thermal Sensor}

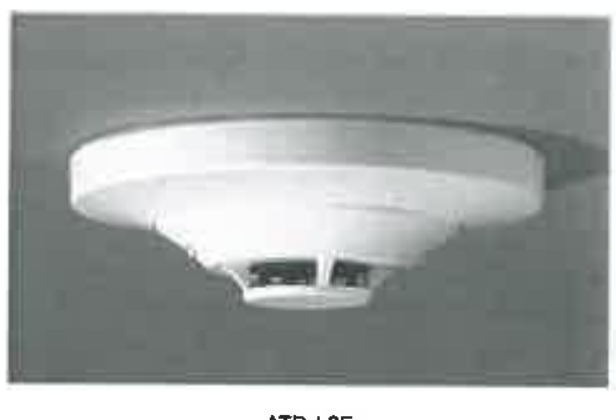

ATD-L2F

\section{Features}

- Sleek, low-profile design

- Visual rotary switch addressing

- Built-in functional test switch activated by an external magnet

- Bicolor LEDs flash green whenever the sensor is addressed, and light steadily red on alarm*

- Optional relay, isolator, or sounder bases

- Low standby current

- Addressable communication

- Stable communication technique with noise immunity

- Optional remote, single-gang LED accessory (RA-400Z)

- Suitable for installation in ducts

Note: *Only the red LED is operative in panels that do not operate in Velociti ${ }^{(3)}$ mode.

\section{An ISO 9000-2000 Company}

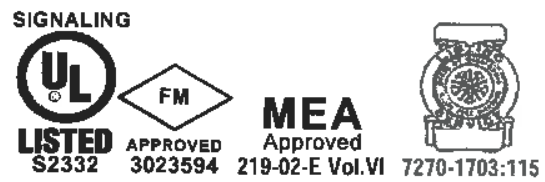




\section{Specifications}

Size:

Shipping Weight:

Operating

Temperature:

ATD-L2F or

ATD-RL2F

ATD-HL2

Sensor Spacing:

Relative Humidity:

ATD-L2F

ATD-RL2F

ATD-HL2F

Electrical Specifications

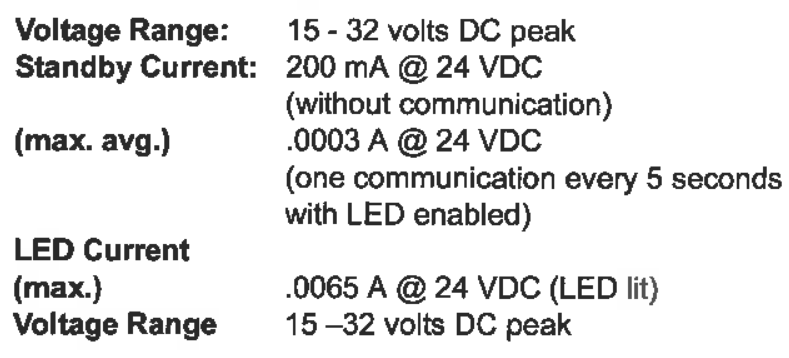

$2.1 "(5.3 \mathrm{~cm})$ high $\times 4.1 "(10.4 \mathrm{~cm})$ diameter installed in $\mathrm{B} 501$ base, 6.1 " $(15.5 \mathrm{~cm})$ diameter installed in the ADB-FLF base

$4.8 \mathrm{oz}$. (137 g)

$-4^{\circ} \mathrm{F}$ to $100^{\circ} \mathrm{F}\left(-20^{\circ} \mathrm{C}\right.$ to $\left.38^{\circ} \mathrm{C}\right)$ $-4^{\circ} \mathrm{F}$ to $150^{\circ} \mathrm{F}\left(-20 \mathrm{C}\right.$ to $\left.66^{\circ} \mathrm{C}\right)$

$\mathrm{UL}^{(B)}$ approved for $50 \mathrm{ft} .(15.2 \mathrm{~m})$ center to center FM approved for $25 \times 25 \mathrm{ft}$. $(7.6 \times 7.6 \mathrm{~m})$ spacing $10-93 \%$ (non-condensing) Fixed-temperature setpoint $135^{\circ} \mathrm{F}\left(57^{\circ} \mathrm{C}\right)$

Combination $135^{\circ} \mathrm{F}$ fixed temperature and $15^{\circ}\left(8.3^{\circ} \mathrm{C}\right)$ per minute rate-of-rise

Fixed-temperature setpoint $190^{\circ} \mathrm{F}\left(88^{\circ} \mathrm{C}\right)$

\section{Specifications}

\section{Bases and Options}

ADB-FLF $\quad 6.1^{\prime \prime}(15.5 \mathrm{~cm})$ diameter standard base

B501 4.1" (10.4 cm) diameter flangeless base

B200SR Standard Sounder base, UL ${ }^{\circledR} 8649$ th

Edition compliant, ULC ${ }^{(8)}$ Listed

Diameter:

B224RB

$$
6.875^{\prime \prime}(17.46 \mathrm{~cm})
$$

Relay Base

Up to 14 AWG $\left(2.0 \mathrm{~mm}^{2}\right)$

Relay type: Form-C

Rating:

2.0A @ 30 VDC resistive

$0.3 \mathrm{~A} @ 110 \mathrm{VDC}$ inductive

1.0 A@30 VDC inductive

B224RB Relay Base

Dimensions: $\quad 6.2^{\prime \prime}(15.7 \mathrm{~cm}) \times 1.2^{n}(3.0 \mathrm{~cm})$

B224BI Isolator Base

Dimensions: $\quad 6.2^{\prime \prime}(15.7 \mathrm{~cm}) \times 1.2^{\prime \prime}(3.0 \mathrm{~cm})$ Maximum 25 devices between isolator bases

RA-400Z Remote alarm indicator, LED

BCK-200 Black detector covers (box of 10)

\section{Ordering Information}

Model

ATD-L2F

ATD-RL2F

ATD-HL2F

\section{Description}

Addressable thermal sensor, fixed, $135^{\circ} \mathrm{F}$ Addressable thermal sensor, combination fixed, $135^{\circ} \mathrm{F}$ and $15^{\circ}$ minute rate-of-rise. Addressable thermal sensor, fixed, $190^{\circ} \mathrm{F}$ 


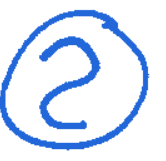

\section{Smoke Detector Velochiti ${ }^{\circledR}$ Sorios ASD-PL2F, ASD-PTI2F by Honeywell

\section{Description}

The Gamewell-FCI Velociti@ Series, analog addressable plug-in smoke sensors with integral communication provide features that surpass conventional sensors. Sensitivity can be programmed in the control panel software, and is continuously monitored and reported to the panel. Point ID capability allows each sensor's address to be set, providing exact locations for selective maintenance when the chamber contamination reaches an unacceptable level. The ASD-PL2F photoelectric sensor's unique optical sensing chamber is engineered to sense smoke produced by a wide range of combustion sources. Dual electronic thermistors add $135^{\circ} \mathrm{F}\left(57^{\circ} \mathrm{C}\right)$ fixed-temperature thermal sensing on the ASD-PTL2F model.

The Velociti ${ }^{@}$ Series use a communication protocol that substantially increases the speed of communication between the sensors and certain Gamewell-FCl analog addressable fire alarm controls. These devices operate in a grouped fashion. If one of the devices in the group has a status change, the panel's microprocessor stops the group poll and concentrates on the single device. The net effect is a response speed up to five times greater than earlier designs.

\section{Ordering Information}

\section{Model Description \\ ASD-PL2F Analog, addressable photoelectronic smoke sensor}

ASD-PTL2F Analog, addressable photoelectronic smoke sensor with thermal sensing

ASD-PL2FR Analog, addressable photoelectronic smoke sensor used with the DNR duct base when the remote test is required.

Velocit ${ }^{(8)}$ is a registered trademark of Honeywell International Inc. $\mathrm{UL}^{\circledR}{ }^{\circledR}$ is a registered trademark of Underwiters Laboratories Inc.

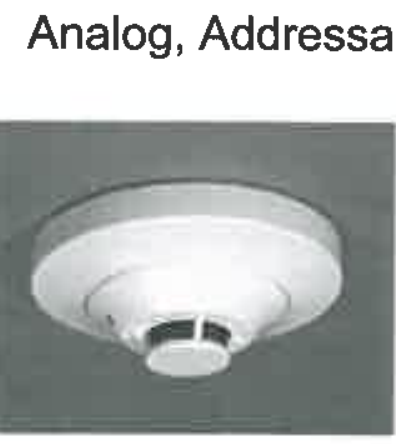

ASD-PL2F/ASD-PTL2F

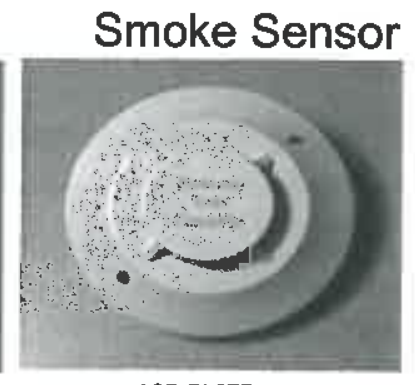

ASD-PL2FR

\section{Features}

- Sleek, low-profile design

- Visual rotary, decimal switch addressing (01-159)

- Built-in functional test switch activated by an external magnet

- Bicolor LEDs flash green whenever the sensor is addressed, and light steady red on alarm*

- Optional relay, isolator, or sounder bases

- Low standby current

- Analog addressable communication

- Stable communication technique with noise immunity

- Optional remote, single-gang LED Indicator (RA400Z)

- Compatible with Gamewell-FCl analog addressable panels

Note: "Only the red LED is operative in panels that do not operate in Velociti ${ }^{(3)}$ mode.

\section{An ISO 9001-2000 Company}

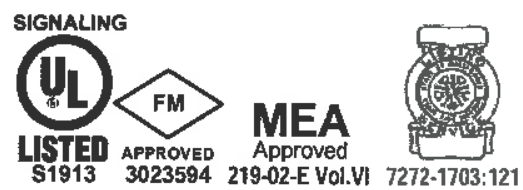




\section{Installation}

ASD-PL2F plug-in sensors use a separate base to simplify installation, service, and maintenance. A special tool allows maintenance personnel to plug-in and remove sensors without using a ladder.

Mount the base on a box which is at least $1.5^{\prime \prime}(3.8 \mathrm{~cm})$ deep. Suitable mounting base boxes include:

- $4.0^{\prime \prime}(10.2 \mathrm{~cm})$ square box

- 3.5 " $(8.9 \mathrm{~cm})$ or $4.0^{\prime \prime}(10.2 \mathrm{~cm})$ octagonal box

- Single-gang box (except relay or isolator bases)

- With B200SR base, mounted on a 4.0" (10.2 cm) square box

- With B224RB or B224BI base, mounted on a $3.5^{\prime \prime}$ $(8.9 \mathrm{~cm})$ octagonal box, or a $4.0^{\prime \prime}(10.2 \mathrm{~cm})$ octagonal or square box

NOTE: Because of the inherent supervision provided by the SLC, end-of-line resistors are not required. Wiring "T-taps" or branches are permitted for Style 4 (Class "B") wiring.

\section{Sensor Spacing}

Gamewell-FCI recommends that the spacing sensors be used in compliance with NFPA 72.

\section{Specifications}

Size:

$2.1^{n}(5.1 \mathrm{~cm})$ high $\times 4.1^{n}(10.4 \mathrm{~cm})$ diameter installed in the B501 base, $6.1^{\prime \prime}(15.5 \mathrm{~cm})$ diameter installed in the ADB-FL base.

Shipping Weight: 5.2 oz. (147 g)

Operating

Temperature: $\quad$ ASD-PL2F:

$32^{\circ} \mathrm{F}$ to $120^{\circ} \mathrm{F}\left(0^{\circ} \mathrm{C}\right.$ to $\left.49^{\circ} \mathrm{C}\right)$

ASD-PTL2F:

UL-Listed

$32^{\circ} \mathrm{F}$ to $100^{\circ} \mathrm{F}\left(0^{\circ} \mathrm{C}\right.$ to $\left.38^{\circ} \mathrm{C}\right)$

Velocity Range: $\quad 0-4000 \mathrm{ft} . / \mathrm{min} .(1,219.2 \mathrm{~m} / \mathrm{min}$.), suitable for installation in ducts.

Relative

Humidity: $\quad 10-93 \%$ (non-condensing)

Thermal Ratings: Fixed-temperature setpoint $135^{\circ} \mathrm{F}\left(57^{\circ} \mathrm{C}\right)$

\section{Electrical Specifications}

\author{
Voltage Range: $15-32$ volts DC peak \\ Standby Current: (max. avg.): .0003 A @ 24 VDC \\ (one communication every 5 \\ seconds with LED enabled) \\ Maximum Alarm \\ Current: $\quad$.0065 A @ 24 VDC (LED) lit).
}

\section{Bases and Options}

\begin{tabular}{|c|c|}
\hline \multirow{3}{*}{$\begin{array}{l}\text { ADB-FL } \\
\text { B200SR }\end{array}$} & $6.1^{\prime \prime}(15.5 \mathrm{~cm})$ diameter \\
\hline & $6.875^{\circ}(17.46 \mathrm{~cm})$ Base Diameter \\
\hline & $2.0^{\prime \prime}(5.08 \mathrm{~cm})$ Base Height \\
\hline \multicolumn{2}{|l|}{ B224RB } \\
\hline \multirow[t]{10}{*}{ Relay Base } & Screw terminals: \\
\hline & Up to 14 AWG $\left(2.0 \mathrm{~mm}^{2}\right)$ \\
\hline & Relay type: Form-C \\
\hline & Rating: \\
\hline & 2.0A@30 VDC resistive; \\
\hline & $0.3 A @ 110$ VDC inductive; \\
\hline & 1.0A@30 VDC inductive. \\
\hline & Dimensions: \\
\hline & $6.2^{\prime \prime} \times 1.2^{n}(15.7 \times 3.0 \mathrm{~cm})$ \\
\hline & $\begin{array}{l}\text { Maximum: } 25 \text { devices between } \\
\text { isolator bases. }\end{array}$ \\
\hline RA400Z & Remote alarm indicator, LED. \\
\hline BCK-200 & Black detector covers (box of 10 ) \\
\hline DNR & Duct smoke housing \\
\hline
\end{tabular}



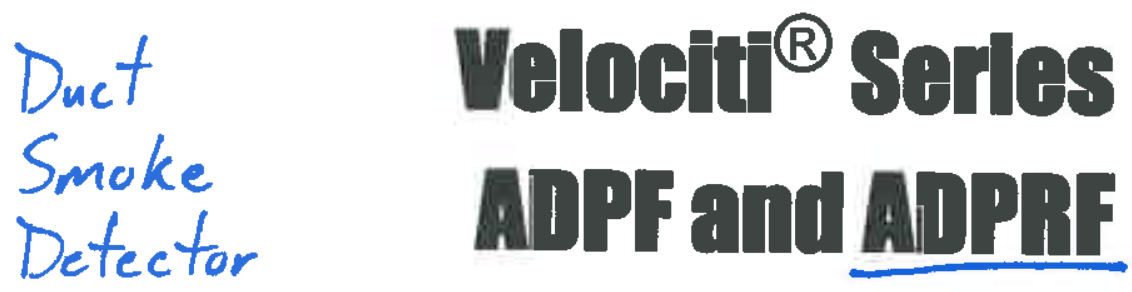

\section{Description}

The Gamewell-FCI Velociti ${ }^{(B)}$ Series, low-flow photoelectronic air duct smoke sensors are capable of sensing smoke in air velocities from 100 to 4,000 feet per minute (0.5 to $20.32 \mathrm{~m} / \mathrm{sec}$.).

ADPF sensors feature low-flow technology that enables duct smoke detection throughout a broad range of airflow environments. Many difficult to solve HVAC applications occur in low airflow duct applications where reliable smoke detection is critical. ADPF low-flow technology can detect smoke at air speed velocities of 100 feet per minute or greater, while continuing the same reliable performance to 4,000 feet per minute.

The ADPF sensor samples air currents passing through a duct and gives dependable performance for shutdown of fans, blowers, and air conditioning systems, preventing the spread of toxic smoke and fire gases through the protected area.

The Velociti ${ }^{(2)}$ Series use a communication protocol that substantially increases the speed of communication between the sensors and certain Gamewell-FCl analog addressable fire alarm controls. These devices operate in a grouped fashion. If one of the devices in the group has a status change, the panel's microprocessor stops the group poll and concentrates on the single device. The net effect is a response speed up to five times greater than earlier designs.

These intelligent sensors communicate and are continuously monitored through the signaling line circuit. Sensor sensitivity changes caused by dirt, temperature, or humidity are reported to the panel, allowing compensation algorithms to maintain the sensor's set sensitivity. An advance indication at the panel specifies the sensor address, allowing for selected maintenance to be performed as needed.

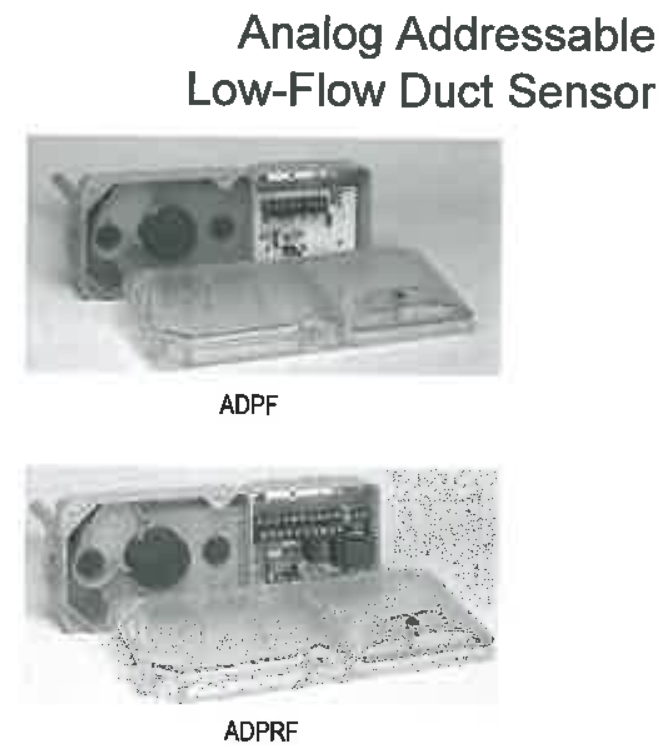

Features

- Air velocity rating from 100 to 4,000 feet per minute (0.5 to $20.32 \mathrm{~m} / \mathrm{sec}$.)

- Patented telescopic sampling tube

- Easily accessible code switches

- Outside mounting tabs

- Easy and quick mounting to round or rectangular ducts from 1'-12' (0.3-3.7 meters) wide

- Easy to clean

- UL recognized field-replaceable power and sensor boards

- Transparent cover for convenient visual inspection. Bi-color LEDs flash green whenever the sensor is addressed, and light steady red on alarm

*Note: Only the red LED is operative in panels that do not operate in Velociti mode.

\section{An ISO 9000-2000 Company}

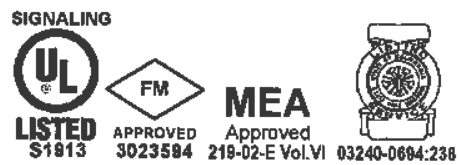




\section{Description (continued)}

Remote alarm annunciation can be accomplished by using the RA400Z remote annunciator or the RTS4510 RTS451KEY remote test station. Both these devices allow testing of the sensor from a remote location.

ADPF low-flow duct sensors are designed for simplified installation and easy maintenance. The modular construction allows for easy cleaning and uncomplicated field replacement of the UL recognized power and sensor boards.

The ADPF (non-relay) has outputs for a remote LED display and remote test switch. It incorporates zener diodes to conserve power for communications to other devices. The ADPF is a 2-wire device that requires signaling line circuit power only.

The ADPRF (with relay) has powered outputs for remote LED indication with a remote test switch and audible sounder. Two form " $\mathrm{C}$ " auxiliary contacts can be configured as a relay version or jumpered to mimic the non-relay version. It has a patented cover tamper trouble signal. The ADPRF is a 4-wire device that requires both signaling line circuit power and either 24VAC/DC or 120/240VAC for proper operation.

\section{Specifications}

Operating Temperature
Operating Humidity
Range:
Storage Temperature
Range:
Duct Air Velocity:

$32^{\circ}$ to $131^{\circ} \mathrm{F}\left(0^{\circ}\right.$ to $\left.55^{\circ} \mathrm{C}\right)$

10 to $93 \%$ relative humidity

(non-condensing)

$-22^{\circ}$ to $158^{\circ} \mathrm{F}$

$\left(-30^{\circ}\right.$ to $\left.+70^{\circ} \mathrm{C}\right)$

$100-4000 \mathrm{ft} . \mathrm{min}$

$(0.5-20.32 \mathrm{~m} / \mathrm{s})$

Shipping Weight:

ADPF: $\quad 3.35 \mathrm{lbs} .(1.5 \mathrm{~kg})$

ADPFRF:3.90 lbs. $(1.8 \mathrm{~kg})$

$\begin{array}{ll}\text { Dimensions } & \\ \text { Length: } & 143 / 4^{\prime \prime}(37 \mathrm{~cm}) \\ \text { Width: } & 51 / 2^{\prime \prime}(14 \mathrm{~cm}) \\ \text { Depth: } & 23 / 4^{\prime \prime}(7 \mathrm{~cm})\end{array}$

Model ADPF (Non-relay)

Voltage Range:

Standby Current:

15 to 32 VDC

$300 \mu \mathrm{A} @ 24$ VDC

(one communication every 5 seconds with LED flash enabled)

\section{Model ADPFRF (with Relay)}

\section{Current Requirements (using no accessories) \\ Power \\ Supply Voltage: $20-30 \mathrm{VDC} 30 \mathrm{VAC}, \quad 120 \mathrm{VAC}, \quad 22 / 240 \mathrm{VAC}$, $50-60 \mathrm{~Hz} \quad 50-60 \mathrm{~Hz} \quad 50-60 \mathrm{~Hz}$}

Max. Standby

\begin{tabular}{|c|c|c|}
\hline & $26 \mathrm{~mA}$ & $65 \mathrm{~mA}$ RMS $44 \mathrm{~mA}$ RMS $25 \mathrm{~mA}$ RM \\
\hline
\end{tabular}

Current: $\quad 87 \mathrm{~mA} \quad 182 \mathrm{~mA}$ RMS 52 mA RMS 30 mA RiMS

Alarm Response

Time: $\quad 3$ to $10 \mathrm{sec} .3$ to $10 \mathrm{sec} .3$ to $10 \mathrm{sec}$. 3 to $10 \mathrm{sec}$.

Auxiliary Relay Contact Ratings

Alarm auxiliary contacts* (DPDT):

10 A@ @ 30 VDC

$10 \mathrm{~A} @ 277$ VAC $(0.75$ power factor $)$

240 VA@249 VAC (0.4 power factor)

1/8 HP@120 VAC

1/4 HP@240VAC

Supervisory contact (SPST):

2.0 A@ 30 VDC (resistive)

Minimum switching current for auxiliary contact must be

100 mA DC minimum @ 5 VDC.

Accessory Current Loads at 24 VDC

$\begin{array}{ccc}\text { Device } & \text { Standby } & \text { Alarm } \\ \text { PA400 } & 0 \mathrm{~mA} & 15 \mathrm{~mA} \text { Max. } \\ \text { RA400Z } & 0 \mathrm{~mA} & 12 \mathrm{~mA} \text { Max. } \\ \text { RTS451/ } & 0 \mathrm{~mA} & 10 \mathrm{~mA} \text { Max. }\end{array}$

RTS451KEY

\section{Ordering Information}

$\begin{array}{ll}\begin{array}{ll}\text { Part Number Description } \\ \text { ADPF }\end{array} & \begin{array}{l}\text { Analog addressable low-flow photoelec- } \\ \text { tronic non-relay duct smoke sensor }\end{array} \\ \text { ADPRF } & \begin{array}{l}\text { Analog addressable low-flow photoelec- } \\ \text { tronic with relay duct smoke sensor }\end{array} \\ \text { ST-1.5 } & \text { Sampling tube duct widths 1'-2' } \\ \text { ST-3 } & \text { Sampling tube duct widths } 2^{\prime}-4^{\prime} \\ \text { ST-5 } & \text { Sampling tube duct widths } 4^{\prime}-8^{\prime} \\ \text { ST-10 } & \text { Sampling tube duct widths } 8^{\prime}-12^{\prime} \\ \text { A5060 } & \text { Replacement power board for ADPF-RF } \\ & \text { (w/relay) } \\ \text { A5067 } & \text { Replacement power board for ADPF } \\ & \text { (w/o relay) } \\ \text { Accessories } & \text { Description } \\ \text { RTS451 } & \text { Remote test station } \\ \text { RTS451KEY } & \text { Remote test station w/key } \\ \text { RA4002 } & \text { Remote LED } \\ \text { F36-09-11 } & \text { Replacement filters } \\ \text { M02-04-00 } & \text { Test magnet } \\ \text { P48-21-00 } & \text { End cap of metal sampling tube } \\ \text { P48-61-00 } & \text { End cap for plastic sampling tube } \\ \text { S08-39-01 } & \text { Replacernent photo insect screen } \\ & \end{array}$




\section{Weatherproof Appliances - Series AH Audibles, AS Audible Strobes, MT Multitone Strobes, RSS Strobes and ET70 Speaker Strobes and Weatherproof Mounting Accessories}
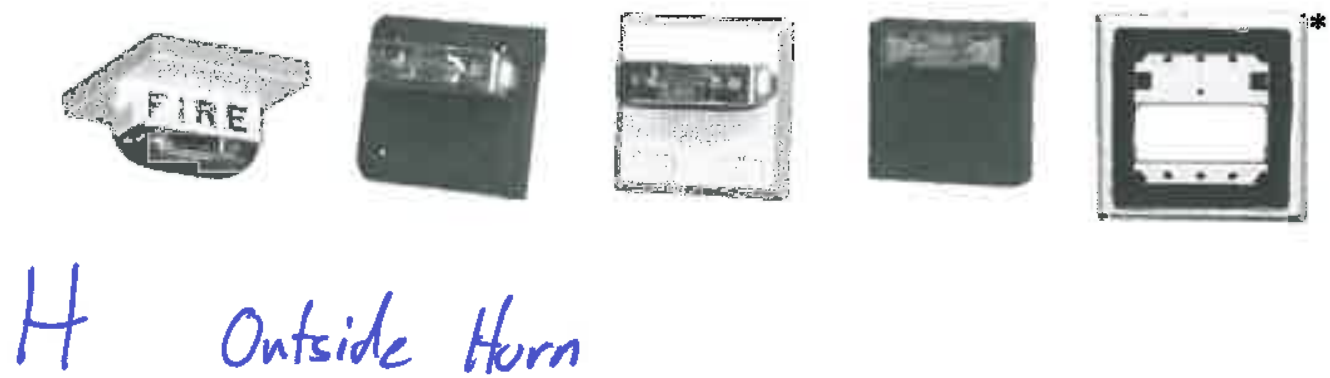

\section{Description:}

Designed for life safety, performance and reliability, Cooper Wheelock's cost effective weatherpoof notification appliances include:

Weatherproof Appliances

Strobes

Horn Strobes

Homs

Multitone Hom Strobes

Multitone Horns

Speaker Strobes

Speakers

Series
RSSWP
ASWP
AH-24WP, AH-12WP
MTWP
MT
ET70WP
ET-1010

All strobe models are UL dual listed - meeting both UL1638 and UL1971 requirements. As dual listed appliances, these weatherproof strobes, horn strobes and speaker strobes are listed for outdoor applications under UL 1638 as well as under UL 1971, the Standard for Safety Signaling Devices for Hearing Impaired. With an extended temperature range of $-31^{\circ} \mathrm{F}$ to $150^{\circ} \mathrm{F}\left(-40^{\circ} \mathrm{C}\right.$ to $66^{\circ} \mathrm{C}$ ). Wheelock weatherproof appliances meet or exceed UL outdoor test requirements for rain, humidity and corrosion resistance while providing multiple strobe intensity options, including the highest strobe ratings available for area coverage per NFPA 72 strobe spacing tables (up to 185 candela for wall mounting and 177 candela for ceiling mounting).

To enable weatherproof mounting, Cooper-Wheelock provides the industry's widest choice of mounting options for surface or unique semi-flush installation. Models are available for surface mounting to Wheelock weatherproof backboxes on walls or ceilings. The optional WP-KIT allows the weatherproof backboxes (IOB, WPBB or WPSBB) to be mounted to a recessed electrical box for concealed conduit installation. For semi-flush installation, the WPA* and WFPA ${ }^{\star}$ kits allow a customer to mount the weatherproof appliances to a recessed electrical box without the need for an external weatherproof backbox. See the Backboxes, Plates and Gaskets Table on page three of this document for a summarization of these mounting options and the required accessories.
All models may be synchronized using the Wheelock SM, DSM Sync Modules, Wheelock Power Supplies or other manufacturers panels incorporating the Wheelock Patented Sync Protocol. The hom output of hom strobes can be independently controlled on 2-wire circuits using the Wheelock patented sync protocol. MTWP horn strobe models are 4-wire appliances; the strobes can be synchronized while the audible can be connected to a coded fire alarm system or can be set to produce any of eight selectable tones.

\section{Features:}

- Approvals include: UL Standards 1971, 1638, 464 and 1480 California State Fire Marshal (CSFM) and New York City (MEA), Factory Mutual (FM) and Chicago (BFP). See agency approvals by model number on page two of this document

- Compliance with the following requirements: NFPA, UFC, ANSI 147.1, OSHA Part 29, 1910.165, ADA

- Weatherproof with extended temperature range of $-40^{\circ} \mathrm{F}$ to $150^{\circ} \mathrm{F}\left(-40^{\circ} \mathrm{C} \text { to } 66^{\circ} \mathrm{C}\right)^{*}$

- Dual Listed strobe models (UL 1638 and UL 1971)

- Industry's highest strobe candela options

- Synchronize using the Wheelock Sync Modules or panels with built-in Wheelock Patented Sync Protocol

- Models with field selectable tone, dBA and candela settings

- Wall or ceiling mounting options

- Surface of semi-flush mounting

- IN/OUT wiring termination accepting two \#12-18 AWG wires at each terminal

"The series RSSWP, ASWP, MTWP and ETTOWP have UL approval down to $-40^{\circ} \mathrm{F}$. The AH-24WP, MT-12/24 and the ET-1010 have been ULC tested and approved to $-40^{\circ} \mathrm{F}$, but not submitted to UL. The AH-12WP has UL/ULC approval to $-31^{\circ} \mathrm{F}$.

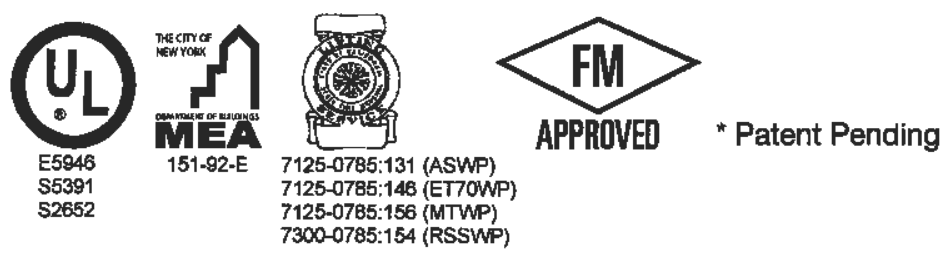


NOTE: All CAUTIONS and WARNINGS are identified by the symbol A. All warnings are printed in bold capital letters.

A WARNING: PLEASE READ THESE SPECIFICATIONS AND ASSOCIATED INSTALLATION INSTRUGTIONS CAREFULLY BEFORE USING, SPECIFYING OR APPLYING THIS PRODUCT. VISIT WWW.COOPERWHEELOCK.COM OR CONTACT COOPER WHEELOCK FOR THE CURRENT INSTALLATION INSTRUCTIONS. FAILURE TO COMPLY WTTH ANY OF THESE INSTRUCTIONS, CAUTIONS OR WARNINGS COULD RESULT IN IMPROPER APPLICATON, INSTALLATON ANDIOR OPERATION OF THESE PRODUCTS IN AN EMERGENCY SITUATION, WHICH COULD RESULT IN PROPERTY DAMAGE, AND SERIOUS INJURY OR DEATH TO YOU ANDIOR OTHERS.

\section{General Notes:}

- Strobes are designed to flash at 1 flash per second minimum over their UL Listed Regulated Voltage Range.

- All candela ratings represent minimum effective Strobe intensity based on UL Standards 1971 and 1638 as indicated in candela ratings table.

\section{Wall Mount}

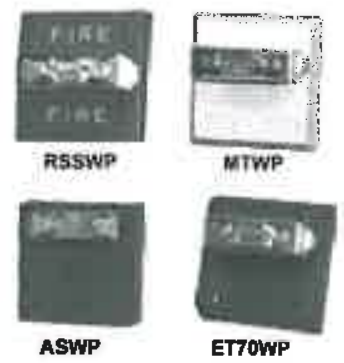

Strobe

RSSWP-2475W-FR Order Code

RSSWP-2475WFW Wh

RSSWP-24MCWH-FR Red 5161

RSSWP-24MCWH-FW White 5165

Audible Strobe

ASWP-2475W-FR Red 9012

ASWP-24MCWH-FR Red 5137

ASWP-24MCWH-FW White 5140

Multi-tone Strobe

MTWP-2475W-FR Red 8420

MTWP-2475W-FW White 3112

MTWP-24MCWH-FR Red 5132

MTWP-24MCWH-FW White 5134

Speaker Strobe

ET70WP-2475W-FR Red 9077

ET70WP-2475W-FW White 3179

ET70WP-24185W-FR Red 4885

ET70WP-24185W-FW White 4891

ET7OWP-24135W-FR Red 4872

ET70WP-24135W-FW White 4875
Ceiling Mount

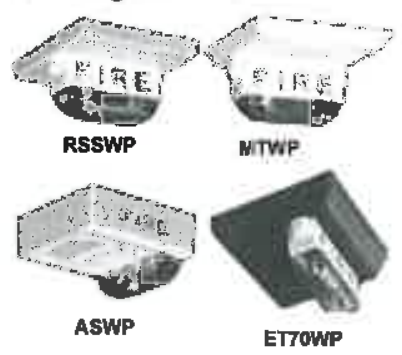

Strobe

RSSWP-2475C-FR Red

RSSWP-2475C-FW White

RSSWP-24MCCH-FR Red

RSSWP-24MCCH-FWWhite

Audible Strobe

ASWP-2475C-FR Red

ASWP-2475C-FW White

ASWP-24MCCH-FR Red

ASWP-24MCCH-FW White

Multi-tone Strobe

MTWP-2475C-FR Red

MTWP-2475C-FW White

MTWP-24MCCH-FR Red

MTWP-24MCCH-FW White

Speaker Strobe

ET70WP-2475C-FR Red

E170WP-2475C-FW White

ET70WP-24177C-FR Red

ET70WP-24177C-FW White

ET70WP-24115C-FR Red

ET70WP-24115C-FW White
Wall or Ceiling Mount

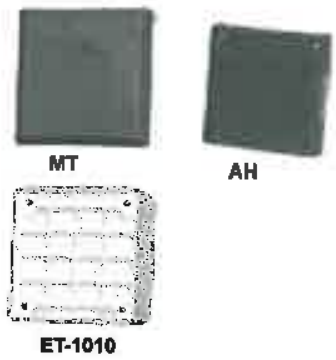

\section{Order Code}

4338

4446

5167

5187

4251

4502

5149

5157

4457

4478

5102

5122

4452

4454

4845

4859

4550

4732 $\longrightarrow$ Audible

Horn

MT-12/24-R

Speaker

ET-1010-R

ET-1010-W

\begin{tabular}{|l|c|c|}
\hline \multirow{2}{*}{ UL Max. Current } & \multicolumn{2}{|c|}{ AH } \\
\cline { 2 - 3 } & 24 VDC & 12 VDC \\
\hline High (99) dBA & 0.080 & 0.192 \\
\hline Med (95) dBA & 0.043 & 0.108 \\
\hline Low (90) dBA & 0.021 & 0.058 \\
\hline
\end{tabular}

UL Reverberant dBA @ 10 Feet

\begin{tabular}{|l|l|l|l|l|l|l|l|}
\hline Watts & $1 / 8$ & $1 / 4$ & $1 / 2$ & 1 & 2 & 4 & 8 \\
\hline
\end{tabular}

\begin{tabular}{|l|l|l|l|l|l|l|l|}
\hline ET-1010 & 77 & 80 & 83 & 86 & 87 & 92 & 94 \\
\hline
\end{tabular}

\begin{tabular}{|l|l|l|l|l|l|l|l|}
\hline ET70WP & 78 & 81 & 84 & 87 & 90 & 93 & 95 \\
\hline
\end{tabular}

\begin{tabular}{|c|c|c|c|c|c|c|c|}
\hline \multirow{3}{*}{ Series } & \multicolumn{7}{|c|}{ Candela Ratings } \\
\hline & \multirow{2}{*}{ UL 1971} & \multirow{2}{*}{$\begin{array}{l}\text { UL } 1638 \\
\text { @ } 77^{\circ} \mathrm{F} \\
\end{array}$} & \multirow{2}{*}{$\begin{array}{l}\text { UL } 1638 \\
@-40^{\circ} \mathrm{F}\end{array}$} & \multirow{2}{*}{$\begin{array}{c}\text { RSS, ET70WP and } \\
\text { MTWP UL Max Current } \\
\text { (Strobe Only) }\end{array}$} & \multicolumn{3}{|c|}{ ASWP } \\
\hline & & & & & High & Med & Low \\
\hline 2475 & $30^{* * *}$ & 180 & 115 & 0.138 & 0.168 & 0.155 & 0.150 \\
\hline \multirow{2}{*}{ MCWH } & 135 & 135 & 56 & 0.300 & 0.355 & 0.340 & 0.335 \\
\hline & 185 & 185 & 77 & 0.420 & 0.480 & 0.465 & 0.460 \\
\hline \multirow{2}{*}{$\mathrm{MCCH}$} & 115 & 115 & 47 & 0.300 & 0.355 & 0.340 & 0.335 \\
\hline & 177 & 177 & 73 & 0.420 & 0.480 & 0.465 & 0.460 \\
\hline 24185 & 185 & 185 & 77 & 0.420 & \multirow{2}{*}{\multicolumn{3}{|c|}{ *Wall mount rating only }} \\
\hline 24177 & 177 & 177 & 73 & 0.420 & & & \\
\hline
\end{tabular}

\begin{tabular}{|l|c|c|c|c|}
\hline $\begin{array}{l}\text { UL Max. Current } \\
\text { (Audibde) }\end{array}$ & \multicolumn{2}{|c|}{$\begin{array}{c}\text { MTWPMT } \\
\text { 24 VDC }\end{array}$} & \multicolumn{2}{c|}{$\begin{array}{c}\text { MT } \\
\text { 12 VDC }\end{array}$} \\
\hline dBA & HI & STD & HI & STD \\
\hline Hom & 0.108 & 0.044 & 0.177 & 0.034 \\
\hline Bell & 0.053 & 0.024 & 0.095 & 0.020 \\
\hline March Time & 0.104 & 0.038 & 0.142 & 0.034 \\
\hline Code 3 Hom & 0.091 & 0.035 & 0.142 & 0.034 \\
\hline Code 3 Tone & 0.075 & 0.035 & 0.105 & 0.021 \\
\hline Slow Whoop & 0.098 & 0.037 & 0.142 & 0.035 \\
\hline Siren & 0.104 & 0.036 & 0.152 & 0.030 \\
\hline Hi/Lo & 0.057 & 0.025 & 0.114 & 0.026 \\
\hline
\end{tabular}

\begin{tabular}{|c|c|c|c|c|c|}
\hline MTWP-2475 & $x$ & $x$ & $\bar{x}$ & $x$ & $*$ \\
\hline MTWP-MCWH & $x$ & $*$ & $x$ & 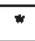 & * \\
\hline MTWP-MCCH & $\mathrm{x}$ & $*$ & $x$ & * & * \\
\hline \multicolumn{6}{|l|}{ Horns/Audibles } \\
\hline $\mathrm{AH}-24 \mathrm{WP}$ & $x$ & $x$ & $x$ & - & $x$ \\
\hline $\mathrm{AH}-12 \mathrm{WP}$ & $x$ & $x$ & $x$ & - & $\bar{x}$ \\
\hline MT-12/24 & $x$ & $x$ & $x$ & $x$ & $x$ \\
\hline \multicolumn{6}{|l|}{ Speaker Strobe } \\
\hline ET70WP-2475 & $x$ & $x$ & $x$ & * & * \\
\hline ET70WP-185 & $x$ & * & $x$ & \# & $*$ \\
\hline ET70WP-177 & $x$ & *. & $x$ & * & $"$ \\
\hline ET70WP-115 & $x$ & * & $x$ & * & * \\
\hline ET70WP-135 & $\bar{x}$ & * & $\bar{x}$ & * & $\star$ \\
\hline
\end{tabular}




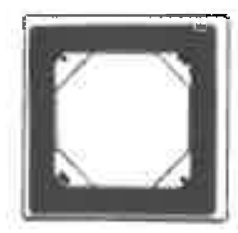

WFP

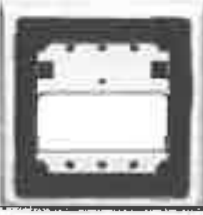

WFPA

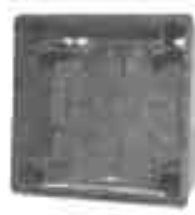

IOB

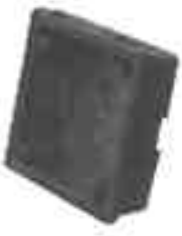

WPSBB

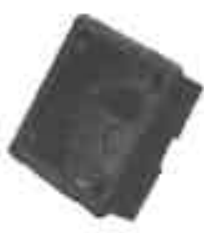

WPBB

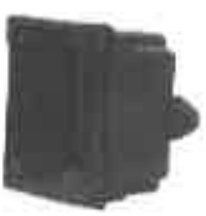

WBB
Gasket Kit WP-KIT

Flush Plates WFPA-R WFPA-W WFP-R WFP-W

Backboxes

IOB-R

IOB-W

WPSBB-R

WPSBB-W

WPBB-R

WPBB-W

WBB-R

WBB-W

$\begin{array}{lc} & \begin{array}{c}\text { Order Code } \\ \end{array} \\ & 4486 \\ \text { Red } & 4698 \\ \text { White } & 4701 \\ \text { Red } & 4696 \\ \text { White } & 4697 \\ & \\ \text { Red } & 5046 \\ \text { White } & 5047 \\ \text { Red } & 9751 \\ \text { White } & 3033 \\ \text { Red } & 9014 \\ \text { White } & 4692 \\ \text { Red } & 2959 \\ \text { White } & 2960\end{array}$

\begin{tabular}{l|c|c|c|}
\cline { 2 - 4 } & \multicolumn{3}{|c|}{ Backboxes, Plates, Gasket KIts } \\
\cline { 2 - 4 } & \multicolumn{2}{|c|}{ Surface Mount } & Flush \\
\cline { 2 - 4 } & Exposed Conduit & Concealed Conduit & Mount \\
\hline RSSWP Strobes & WPSBB & WPSBB + WP-KIT & WFP \\
\hline ET70WP Speaker Strobes & IOB & IOB + WP-KIT & WFP \\
\hline ASWP Horn Strobes & WPBB & WPBB + WP-KIT & WFPA \\
\hline AHWP Horns & WBB & - & WFP \\
\hline ET-1010 Speakers & WBB & - & WFP \\
\hline MTWP Multitone Hom Strobes & IOB & IOB + WP-KIT & WFP \\
\hline Multitone Horn & IOB & IOB + WP-KIT & WFP \\
\hline
\end{tabular}

\section{Wiring Diagrams}
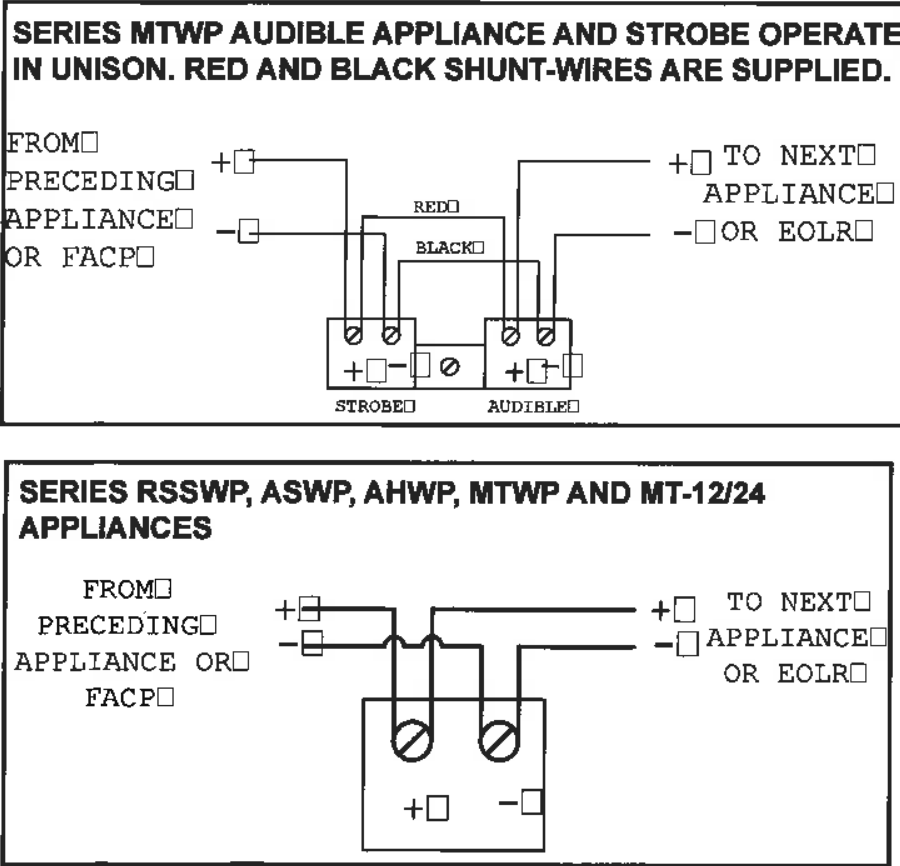

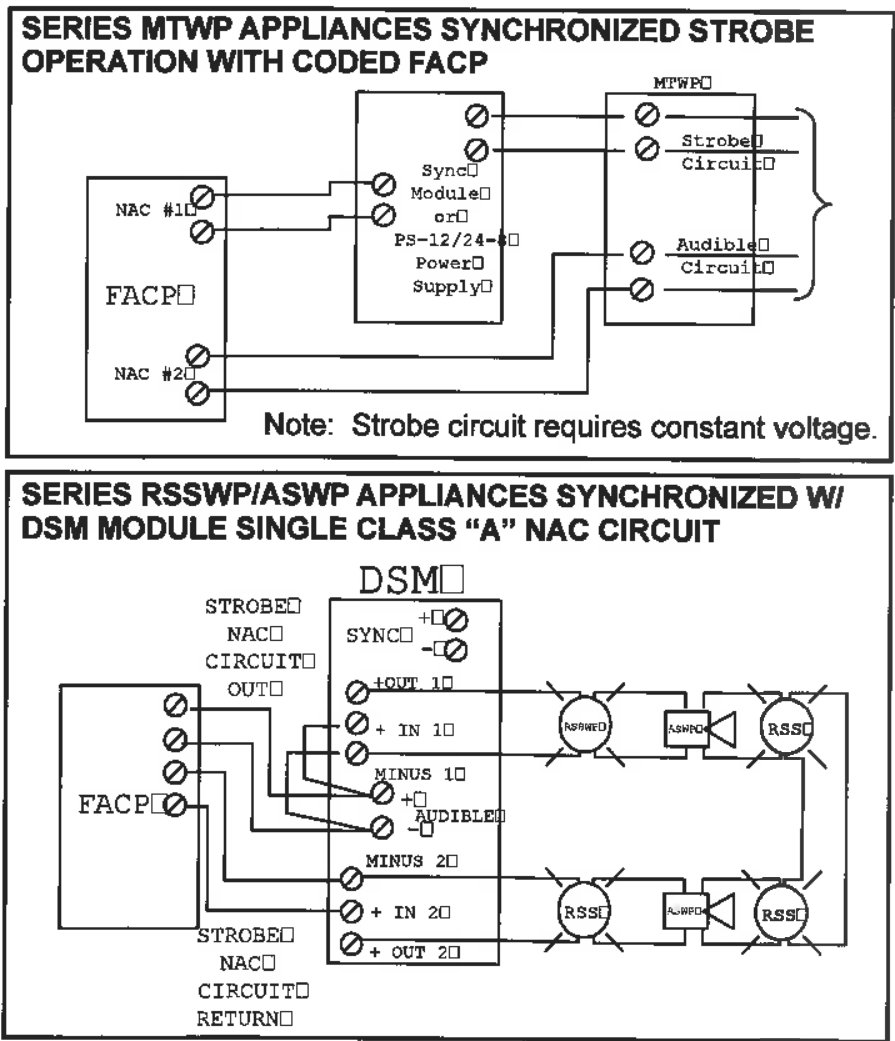

Note: Models are available in Red or White. Contact Customer Service for Order Code and Delivery. \#Refer to Data Sheet $\mathbf{S 7 0 0 0}$ for Mounting Options

NOTE: Due to continuous development of our products, specifications and offerings are subject to change without notice in accordance with Wheelock Inc. standard terms and conditlons. 


\section{General}

Weatherproof notification appliances shall be UL listed for outdoor use. Weatherproof Strobe appliances shall be listed under UL Standard 1638 (Standard for Visual Signaling Appliances) for Indoor/Outdoor use and UL Standard 1971 (Standard for Safety Signaling Devices for Hearing Impaired). The appliances shall be available for optional wall mounting or ceiling mounting to weatherproof backboxes using either exposed conduit or concealed conduit, or semi-flush mounting to a recessed electrical box in walls or ceilings using Wheelock mounting accessories.

\section{Weatherproof Strobes}

Weatherproof Strobe appliances shall produce a minimum flash rate of 60 flashes per minute over the UL Regulated Voltage Range of 16 to 33 VDC and shall incorporate a Xenon flashtube. The weatherproof strobes shall be available with UL 1971 candela ratings up to $185 \mathrm{~cd}$ for wall mounting and $177 \mathrm{~cd}$ for ceiling mounting. UL 1638 candela ratings up to $180 \mathrm{~cd}$ at $77^{\circ} \mathrm{F}$ shall be available. The strobes shall operate over an extended temperature range of $-40^{\circ} \mathrm{F}$ to $150^{\circ} \mathrm{F}\left(-40^{\circ} \mathrm{C}\right.$ to $\left.66^{\circ} \mathrm{C}\right)$ and be listed for maximum humidity of $95 \%$ RH. Strobe inputs shall be polarized for compatibility with standard reverse polarity supervision of circuit wiring by a Fire Alarm Control Panel (FACP).

Weatherproof Audibles and Audible/Strobe Combinations Weatherproof horns and multitone audibles shall be listed for Indoor/Outdoor use under UL Standard 464 . The horns shall be able to produce a continuous output or a temporal code- 3 output that can be synchronized. The horns shall have at least 3 sound level settings. Horn/Strobe combinations shall be able to be synchronized on a single NAC.

Multitone audibles shall be able to produce 8 distinct tones selectable by dip switch and shall have at least 2 sound level settings. Multitone Audible/Strobe combinations shall have independent inputs for the audible and strobe. The strobes shall be able to be synchronized. The audibles shall be able to be coded when operated on a separate NAC.

\section{Weatherproof Speakers and Speaker/Strobes}

Weatherproof speakers and speaker/strobes shall be listed for Indoor/Outdoor use under UL Standard 1480. All speakers shall provide field selectable taps for 1/8W to 8W operation for either 25 VRMS or 70 VRMS audio systems and shall incorporate a sealed back construction for extra protection and improved audibility. Speakers without strobes shall be Wheelock Series ET-1010. They shall be listed to produce up to $94 \mathrm{dBA}$ and shall incorporate a vandal resistant grille design. Speaker with strobes shall be Wheelock Series ET70WP. They shall be available for surface or semi-flush mounting to walls or ceilings and shall be listed to produce up to $93 \mathrm{dBA}$.

\section{Synchronization Modules}

When synchronization of strobes or temporal code-3 audibles is required, the appliances shall be compatible with the Wheelock Series SM, DSM Sync Modules, Wheelock Power Supplies or other manufacturers panels with built-in Wheelock Patented Sync Protocol. The strobes and audibles shall not drift out of synchronization at any time ciuring operation.

Series ASWP audibles and strobes shall be able to be synchronized on a 2-wire circuit with the ability to silence the audible if required. The strobes on Series MT multitone audible/strobe appliances shall be able to be synchronized and shall be able to be operated on a separate circuit from the audibles while the audible circuit is connected to a coded or continuous NAC.

\section{Weatherproof Mounting Accessories}

Weatherproof mounting options shall include surface mounting or semi-flush mounting to walls or ceilings. Surface mounted appliances shall mount to Wheelock IOB, WBB, WPBB or WPSBB weatherproof backboxes using either exposed conduit or concealed conduit. For concealed conduit the weatherproof backbox shall be mounted to a recessed electrical box with Wheelock's WP-KIT to provide a weatherproof seal for the electrical box. Semi-flush mounted appliances shall mount to a recessed electrical box using Wheelock WFP or WFPA flush plates to provide a weatherproof seal between the electrical box and the appliance.

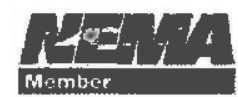

WE ENCOURAGE AND SUPPORT NICET CERTIFICATION

3 YEAR WARRANTY

Made in USA

S9004 WP 11/09
No Location
273 Bralletipon Ave.
Long Branchis Notzito
P:D00:631-2248
F) 7322222,8707
wowncoopernotification com

Cooper Notification is Wheelock CuC SAFEPATH waves
VALlocation

P: $877-459-7726$

F.7.703-29176560

shmela $\mathrm{Fl} 3 \mathrm{~s}^{2}$

P. 941.487.2300

F $941-487-2389$ 


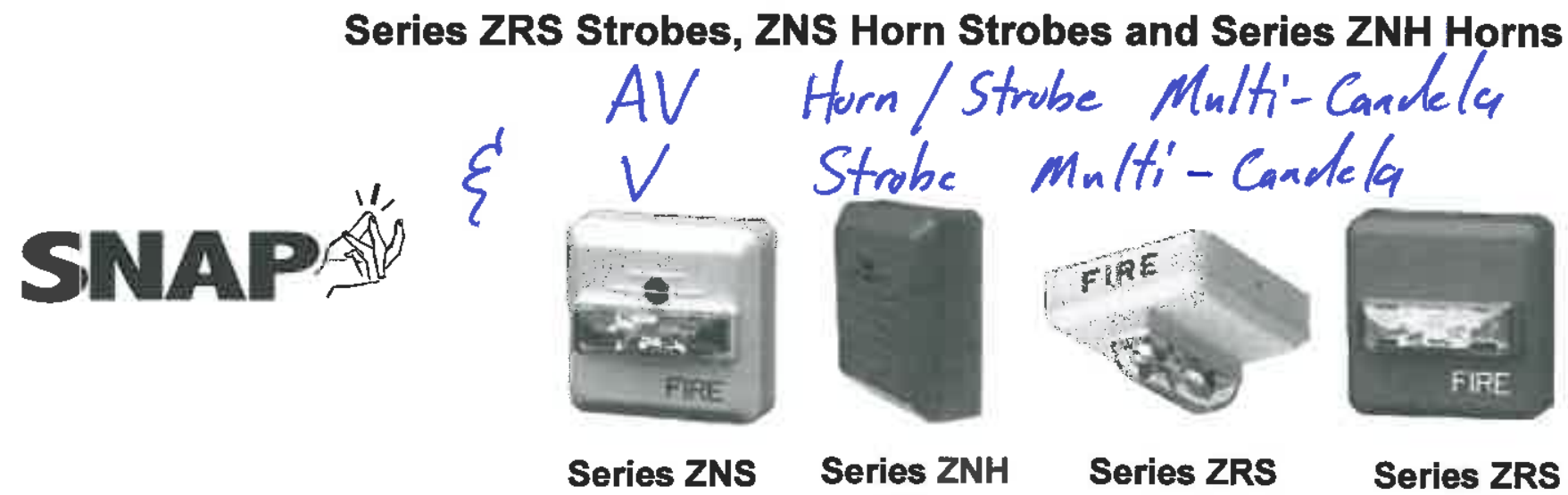

\section{Description:}

The Wheelock Series Z notification appliances feature an easy snap on base that is designed to simplify the installation and testing of horns, strobes, and horn/strobes. The separate Series Z snap on base can be pre-wired so circuit wiring can be fully tested before the appliance is installed and before the walls are covered. Once all surrounding work is complete, the appliance can be simply installed by snaping it on the base. Shorting contacts in the base, which provide continuity for circuit testing, are permanently opened when the appliance is installed so any subsequent removal of the appliance will indicate a trouble condition on that circuit at the control panel when circuit supervision is enabled. The same base is used for all Series Z horns, strobes and horn/strobes to provide consistent installation and easy replacement of appliances if required. A locking screw is also included for the appliance to provide extra secure installation.

The Wheelock Series Z appliances incorporate the same dependable circuitry and high efficiency optics that are used in Wheelock RSS strobes, NS horn/strobes and NH horns and have the same high performance ratings. The Series $Z$ appliances are compatible with all UL listed "Regulated" panels and all panels that are compatibility listed with Wheelock RSS, NS and NH appliances.

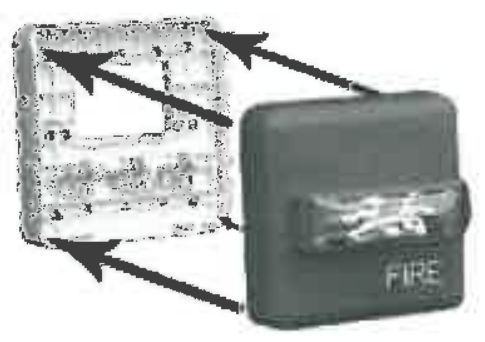

ZNS, ZNH and ZRS appliances go onto the base plate in a SNAP.

\section{Features:}

- Approvals include: UL Standard 1971, UL Standard 464, New York City (MEA), California State Fire Marshal (CSFM), Factory Mutual (FM) and Chicago (BFP). See approvals by model number in Specifications and Ordering Information

- ADANFPAJUFC/ANSI and OSHA 29, Part 1910, 165 compliant

- $\quad$ EZ Mount SNAP design, with separate base plate, provides ability to pre-wire the base and test the circuit wiring before the walls are covered

- The base plate is protected by a disposable cover and the appliances can quickly snap onto the base after the walls are painted.

- Patented EZ Mount Universal Mounting Plate (ZBASE) uses single plate for ceiling and wall mount installations

- Wall Mount models feature field selectable candela settings of 15/30/75/110cd and 135/185cd

- Ceiling Mount models feature field selectable candela settings of $15 / 30 / 75 / 95 \mathrm{~cd}$ and $115 / 177 \mathrm{~cd}$

- Synchronize using the Wheelock Sync Modules or panels with built-in Wheelock Patented Sync Protocol

- 12 and 24 VDC models with UL "Regulated Voltage" using filtered DC or unfiltered VRMS input voltage

- Strobes produce 1 flash per second over the "Regulated Voltage" range (ZNS, ZRS models)

- Selectable Continuous Horn or Temporal (Code-3) Tones with selectable 90 or $95 \mathrm{dBA}$ setting (ZNH, ZNS models)

- Selectable 12 or 24 VDC in 1 appliance (ZNH model)
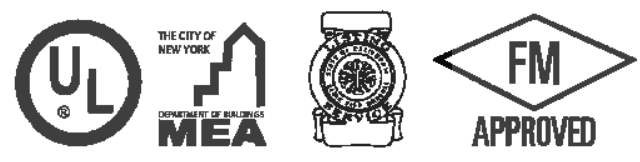
NOTE: AH CAUTIONS and WARNINGS are identified by the symbol A. All warnings are printed in bold capltal letters.

A WARNING: PLEASE READ THESE SPECIFICATIONS AND ASSOCIATED INSTALLATON INSTRUGTONS CAREFULLY BEFORE USING, SPECIFYING OR APPLYING THIS PRODUCT. VSIT WWW.COOPERWHEELOCK.COM OR CONTACT COOPER WHEELOCK FOR THE CURRENT INSTALLATION INSTRUCTIONS. FAILURE TO COMPLY WITH ANY OF THESE INSTRUCTIONS, CAUTIONS OR WARNINGS COULD RESULT IN IMPROPER APPLICATION, INSTALLATION ANDIOR OPERATION OF THESE PRODUCTS IN AN EMERGENCY SITUATION, WHICH COULD RESULT IN PROPERTY DAMAGE, AND SERIOUS INJURY OR DEATH TO YOU ANDIOR OTHERS.

\section{General Notes:}

- Strobes are designed to flash at 1 flash per second minimum over their "Regulated Voltage Range".

- All candela ratings represent minimum effective strobe intensity based on UL Standard 1971.

- Series ZNS Strobe products are listed under UL Standards 1971 and 464 for indoor use with a temperature range of $32^{\circ} \mathrm{F}$ to $120^{\circ} \mathrm{F}\left(0^{\circ} \mathrm{C}\right.$ to $49^{\circ} \mathrm{C}$ ) and maximum humidity of $93 \%$ ( $( \pm 2 \%)$.

- Series ZNH horns are listed under UL Standard 464 for audible signal appliances (Indoor use only).

- $\quad$ "Regulated Voltage Range" is the newest terminology used by UL to identify the voltage range. Prior to this change UL used the terminology "Listed Voltage Range".

\begin{tabular}{|l|c|c|c|}
\hline \multicolumn{1}{|c|}{ Table 1: Series ZNS Ratings Per UL Standard 1971 } \\
\hline Model & $\begin{array}{c}\text { Input } \\
\text { Voltage } \\
\text { VDC }\end{array}$ & $\begin{array}{c}\text { Regulated } \\
\text { Voltage } \\
\text { Range } \\
\text { VDClFWR }\end{array}$ & $\begin{array}{c}\text { Strobe Candela } \\
\text { (CD) }\end{array}$ \\
\hline ZNS-MCW & 24 & $16.0-33.0$ & $15 / 30 / 75 / 110$ \\
\hline ZNS-MCWH & 24 & $16.0-33.0$ & $135 / 185$ \\
\hline ZNS-MCC & 24 & $16.0-33.0$ & $15 / 30 / 75 / 95$ \\
\hline ZNS-MCCH & 24 & $16.0-33.0$ & $115 / 177$ \\
\hline
\end{tabular}

\begin{tabular}{|c|c|c|c|c|c|}
\hline \multirow{2}{*}{ Description } & \multirow{2}{*}{ Volume } & \multicolumn{2}{|c|}{$\begin{array}{l}\text { Reverberant dBA } \\
\text { (10ft per UL } 464\end{array}$} & \multicolumn{2}{|c|}{$\begin{array}{c}\text { Anechoic dBA } \\
@ 10 \mathrm{ft}\end{array}$} \\
\hline & & $\begin{array}{c}12 \\
\text { VDC }\end{array}$ & $\begin{array}{c}24 \\
\text { VDC }\end{array}$ & $\begin{array}{c}12 \\
\text { VDC } \\
\end{array}$ & $\begin{array}{c}24 \\
\text { VDC }\end{array}$ \\
\hline \multirow{2}{*}{$\begin{array}{l}\text { Continuous } \\
\text { Horn }\end{array}$} & High & 83 & 87 & 89 & 95 \\
\hline & Low & 76 & 81 & 84 & 90 \\
\hline \multirow{2}{*}{$\begin{array}{l}\text { Code } 3 \\
\text { Horn }\end{array}$} & High & 79 & 82 & 89 & 95 \\
\hline & Low & 72 & 76 & 84 & 90 \\
\hline
\end{tabular}

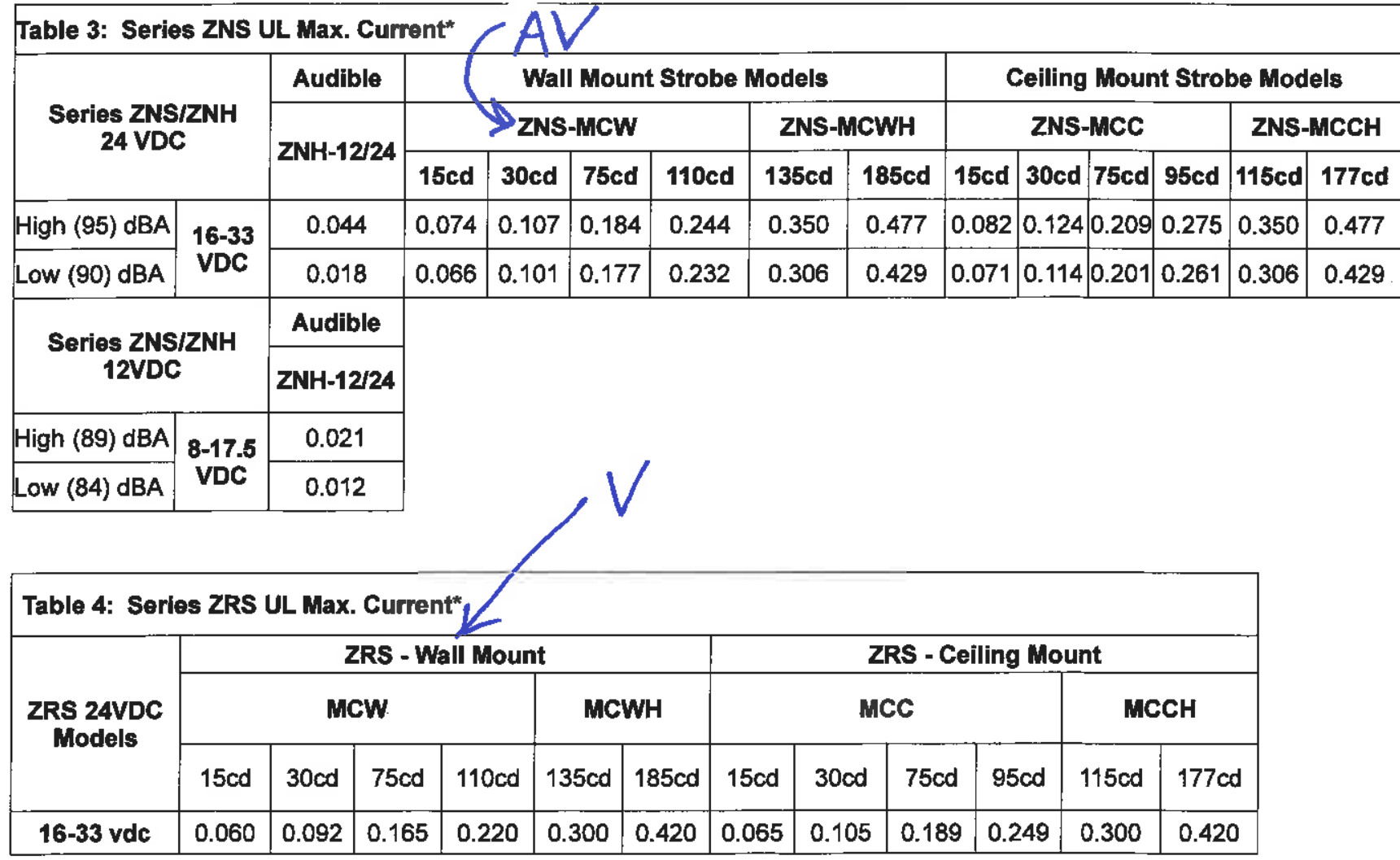

* UL max current rating is the maximum RMS current within the listed voltage range (16-33v for $24 \mathrm{v}$ units). For strobes the UL max current is usually at the minimum listed voltage ( $16 \mathrm{v}$ for $24 \mathrm{v}$ units). For audibles the max current is usually at the maximum listed voltage (33v for $24 \mathrm{v}$ units). For unfiltered FWR ratings, see installation instructions. 


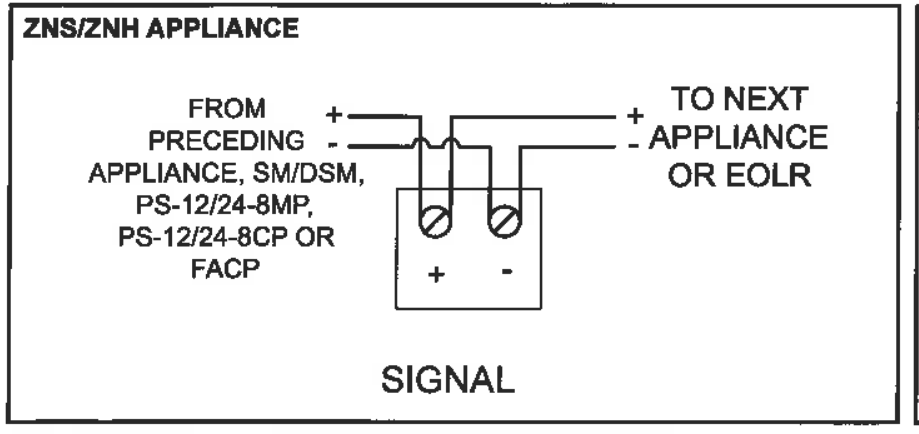

ZNS AND ZNH APPLIANCES SYNCHRONIZED WITH DSM MODULE DUAL CLASS "A" NAC CIRCUIT WITH NO AUDIBLE SILENCE FEATURE

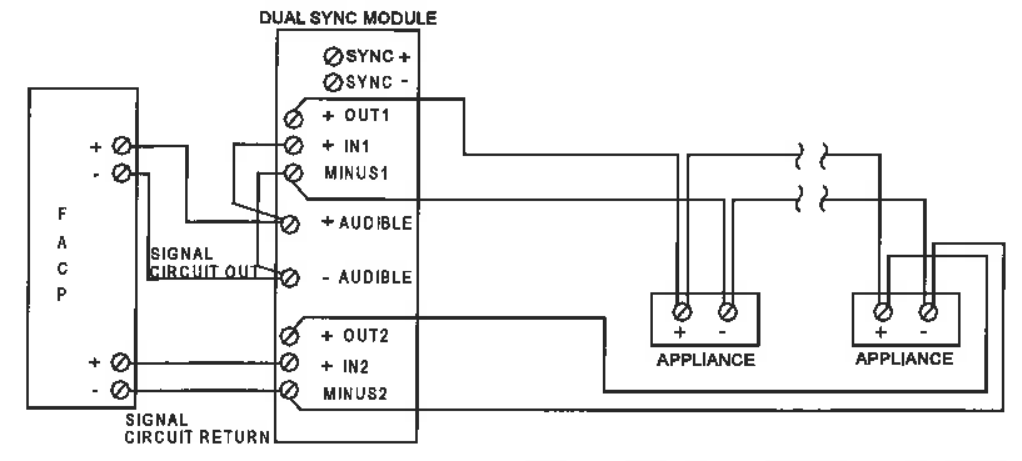

ZNS AND ZNH APPLIANCES SYNCHRONIZED WTH SH MODULE SINGLE CLASS "B" NAC CIRCUIT WITH AUDIBLE SILENCE FEATURE SM

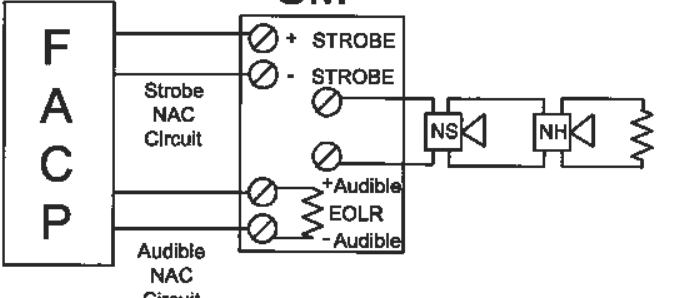

NOTE: ZNSIZNH must be set on Code-3 horn tone to achleve synchronlzed temporal (Code-3) tone. Refer to Installation Instruction (P83983, P83600 respectively).

* For detail using SM or DSM Sync Module refer to Data Sheet S3000 or Installation Instructions P83123 for SM and P83177 for DSM. For wiring information on the power supplies refer to Installation Instructions P84662 for PS-24-8MC.

SPECIFICATION \& ORDERING INFORMATION

\begin{tabular}{|c|c|c|c|c|c|c|c|c|c|c|c|}
\hline \multirow{2}{*}{ Model Number } & \multirow{2}{*}{$\begin{array}{l}\text { Order } \\
\text { Code }\end{array}$} & \multirow{2}{*}{$\begin{array}{l}\text { Strobe } \\
\text { Candela }\end{array}$} & \multirow{2}{*}{$\begin{array}{c}\text { Sync w/SM, } \\
\text { DSM or } \\
\text { PS-24-8Mc }\end{array}$} & \multirow{2}{*}{$\begin{array}{c}24 \\
\text { VDC }\end{array}$} & \multirow{2}{*}{$\begin{array}{c}12 \\
\text { VDC }\end{array}$} & \multirow{2}{*}{$\begin{array}{l}\text { Mounting } \\
\text { Options }\end{array}$} & \multicolumn{5}{|c|}{ Agency Approvals } \\
\hline & & & & & & & UL & MEA & CsFM & FM & BFP \\
\hline ZNS-MCW-FR & 0304 & $15 / 30 / 75 / 110$ & $x$ & $x$ & - & B, D, E, F & $x$ & * & $x$ & $x$ & $*$ \\
\hline ZNS-MCW-FW & 0305 & $15 / 30 / 75 / 110$ & $x$ & $x$ & - & B, D, E, F & $x$ & * & $x$ & $x$ & * \\
\hline ZNS-MCWH-FR & 0306 & $135 / 185$ & $\mathrm{x}$ & $x$ & - & $B, D, E, F$ & $x$ & $\star$ & $x$ & $\mathrm{X}$ & * \\
\hline ZNS-MCWH-FW & 0307 & $135 / 185$ & $x$ & $x$ & - & $B, D, E, F$ & $x$ & * & $x$ & $x$ & * \\
\hline $\mathrm{ZNH}-\mathbf{R}$ & 0300 & $=$ & $x$ & $x$ & $x$ & $B, D, E, F$ & $x$ & $*$ & $x$ & $x$ & * \\
\hline ZNH-W & 0301 & - & $x$ & $x$ & $x$ & $B, D, E, F$ & $x$ & $*$ & $x$ & $x$ & * \\
\hline ZNS-MCC-FR & 0310 & $15 / 30 / 75 / 95$ & $x$ & $x$ & - & B, D, E, F & $x$ & 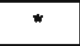 & $x$ & $x$ & $n$ \\
\hline ZNS-MCC-FW & 0311 & $15 / 30 / 75 / 95$ & $x$ & $x$ & - & $B, D, E, F$ & $x$ & $*$ & $\mathrm{x}$ & $x$ & * \\
\hline ZNS-MCCH-FR & 0312 & $115 / 177$ & $x$ & $x$ & - & $B, D, E, F$ & $x$ & 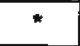 & $x$ & $x$ & * \\
\hline ZNS-MCCH-FW & 0313 & $115 / 177$ & $x$ & $x$ & - & $\mathrm{B}, \mathrm{D}, \mathrm{E}, \mathrm{F}$ & $\mathrm{x}$ & * & $x$ & $x$ & * \\
\hline ZRS-MCW-FR & 4085 & $15 / 30 / 75 / 110$ & $x$ & $x$ & - & $\mathrm{B}, \mathrm{D}, \mathrm{E}, \mathrm{F}$ & $\mathrm{x}$ & * & $x$ & $\mathrm{x}$ & * \\
\hline ZRS-MCW-FW & 0302 & $15 / 30 / 75 / 110$ & $x$ & $x$ & - & $B, D, E, F$ & $x$ & * & $x$ & $x$ & $*$ \\
\hline ZRS-MCWH-FR & 5242 & $135 / 185$ & $x$ & $\mathrm{x}$ & - & $B, D, E, F$ & $x$ & 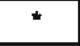 & $x$ & $x$ & " \\
\hline ZRS-MCWH-FW & 0303 & $135 / 185$ & $x$ & $x$ & - & B, D, E, F & $x$ & $*$ & $x$ & $x$ & $*$ \\
\hline ZRS-MCC-FW & 0309 & $15 / 30 / 75 / 95$ & $x$ & $x$ & - & $\mathrm{B}, \mathrm{D}, \mathrm{E}, \mathrm{F}$ & $\mathrm{x}$ & $*$ & $x$ & $x$ & * \\
\hline ZRS-MCC-FR & 0308 & $15 / 30 / 75 / 95$ & $x$ & $x$ & - & $\mathrm{B}, \mathrm{D}, \mathrm{E}, \mathrm{F}$ & $x$ & * & $x$ & $x$ & * \\
\hline ZRS-MCCH-FR & 5240 & $115 / 177$ & $x$ & $x$ & $=$ & $B, D, E, F$ & $x$ & * & $x$ & $x$ & * \\
\hline ZRS-MCCH-FW & 0314 & $115 / 177$ & $x$ & $x$ & - & $\mathrm{B}, \mathrm{D}, \mathrm{E}, \mathrm{F}$ & $x$ & * & $x$ & $x$ & * \\
\hline ZBASE & 5268 & \multicolumn{10}{|c|}{ Accessory - Includes base, dust cover, mounting screws and installation sheet } \\
\hline ZBB-R & 6036 & \multicolumn{10}{|c|}{ Backbox for indoor suface mounting of all SNAP models } \\
\hline ZBB-W & 6045 & \multicolumn{10}{|c|}{ Backbox for indoor suface mounting of all SNAP models } \\
\hline
\end{tabular}

\#The ZRS, ZNS and ZNH will mount to single-gang, double-gang, 4" octal, 4" square and 3-1/2" octal back boxes.

NOTE: Due to continuous development of our products, specifications and offerings are subject to change without notice in accordance with Wheelock Inc. standard terms and conditions. 


\section{General}

Audible/visual notification appliances shall be listed for indoor use and shall meet the requirements of FCC Part 15 Class B. These appliances shall be listed under UL Standard 1971, (Standard for Safety Signaling Devices for Hearing Impaired) and UL Standard 464 (Fire Protective Signaling). The appliances shall use a Patented Universal EZMount backplate that shall allow mounting to a singlegang, double-gang, 4-inch square, $4^{n}$ octal, or a 3-1/2" octal backbox. Two wire appliance wiring shall be capable of directly connecting to the mounting back plate. Continuity checking of the entire NAC circuit prior to attaching any audible/visual notification appliances shall be allowed. A dust cover shall fit and protect the mounting plate. The dust cover shall be easily removed when the appliance is installed over the backplate. Removal of an appliance shall result in an alarm condition by the Fire Alarm Control Panel (FACP).

\section{Strobes}

Strobe appliances shall produce a minimum flash rate of 60 flashes per minute ( 1 flash per second) over the Regulated Voltage Range of 16 to 33 VDC and shall incorporate a Xenon flashtube enclosed in a rugged Lexan lens. The strobes shall be available with two or four field selectable settings in one unit and shall be rated, per UL 1971, for up to 185 cd for wall mounting and 177 cd for ceiling mounting. The strobes shall operate over an extended temperature range of $32^{\circ} \mathrm{F}$ to $120^{\circ} \mathrm{F}\left(0^{\circ} \mathrm{C}\right.$ to $\left.49^{\circ} \mathrm{C}\right)$ and be listed for maximum humidity of $95 \% \mathrm{RH}$. Strobe inputs shall be polarized for compatibility with standard reverse polarity supervision of circuit wiring by a Fire Alarm Control Panel (FACP).

Audlbles and Audible/Strobe Combinations

Horns and horn/strobes shall be listed for Indoor use under UL Standard 464 . The horns shall be able to produce a continuous output or a temporal code-3 output that can be synchronized. The horns shall have at least 2 sound level settings of 90 and $95 \mathrm{dBA}$.

\section{Synchronization Modules}

When synchronization of strobes or temporal Code-3 audibles is required, the appliances shall be compatible with the Wheelock Series SM, DSM Sync Modules Wheelock Power Supplies or other manufacturers panels with built-in Wheelock Patented Sync Protocol. The strobes shall not drift out of synchronization at any time during operation. Audibles and strobes shall be able to be synchronized on a 2-wire circuit with the capability to silence the audible if required. If the sync module or power supply fails to operate (i.e., contacts remain closed), the strobes shall revert to a non-synchronized flashrate

WE ENCOURAGE AND SUPPORT NICET CERTIFICATION

3 YEAR WARRANTY

\section{Z1000 ZNS/ZNH ZRS $12 / 08$}

\begin{tabular}{|c|c|c|}
\hline Nu Location: & EL Location & VA Lociation, \\
\hline 273 Eranchport Aves & 7305 Gommerco ot & P. \\
\hline Long Brandi NS orin40 & Sarasota. Fi 34243 & $F=7039294.6500$ \\
\hline P. $8005631-2148$ & p. $941-487,2300$ & \\
\hline $\begin{array}{l}\text { F:732-22.2-8707 } \\
\text { www coopernotificalionscom }\end{array}$ & F:941-487 2389 & \\
\hline
\end{tabular}


Features an easy snap on base designed to simplify the installation and testing of strobes, horns and horn strobes.

Available features and options:

Color: Red or white

Mounting: Wall or ceiling

EZ mount SNAP design

Universal mounting plate - single plate for wall and ceiling mount installations

Disposable cover to protect base plate

Strobes produce 1 flash per second over the Regulated Voltage Range

\section{Strobes}

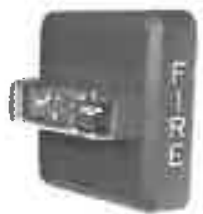

$F$

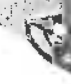

Wall Mount Strobes

ZRS-MCW-FR

ZRS-MCW-FW

ZRS-MCWH-FR

ZRS-MCWH-FW

Red

White

Red

White

0302

5242

0303

Ceiling Mount Strobes

ZRS-MCC-FW

White 0309

ZRS-MCC-FR $\quad$ Red 0308

ZRS-MCCH-FW White 0314

ZRS-MCCH-FR Red 5240
UL Max, Current $135 \mathrm{~cd} \quad 185 \mathrm{~cd}$

$\begin{array}{lll}24 \text { VDC } & 0.300 & 0.420\end{array}$

UL Max. Current 15cd 30cd 75cd 95cd

\begin{tabular}{lllll}
24 VDC & 0.065 & 0.105 & 0.189 & 0.249 \\
\hline
\end{tabular}

UL Max. Current 115cd 177cd

$\begin{array}{lll}24 \text { VDC } & 0.300 & 0.420\end{array}$

\section{Horns and Horn Strobes}
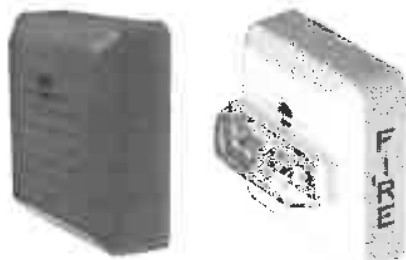

Wall or Ceiling Mount Horn

$\begin{array}{lll}\text { ZNH-R } & \text { Red } & 0300 \\ \text { ZNH-W } & \text { White } & 0301\end{array}$

Wall Mount Horn Strobe

$\begin{array}{lll}\text { ZNS-MCW-FR } & \text { Red } & 0304 \\ \text { ZNS-MCW-FW } & \text { White } & 0305 \\ \text { ZNS-MCWH-FR } & \text { Red } & 0306\end{array}$

ZNS-MCWH-FW White 0307

Ceiling Mount Horn Strobe

ZNS-MCC-FW White 0311

ZNS-MCC-FR Red 0310

ZNS-MCCH-FW White 0313

ZNS-MCCH-FR Red 0312

\begin{tabular}{|c|c|c|c|c|c|}
\hline M & & $15 \mathrm{~cd}$ & $30 \mathrm{~cd}$ & $75 \mathrm{~cd}$ & $110 \mathrm{~cd}$ \\
\hline High (96 & 27. & 0.074 & 0.107 & 0.184 & 0.244 \\
\hline Low (90) dBA & 24 VDC & 0.066 & 0.101 & 0.177 & 0.232 \\
\hline
\end{tabular}

\begin{tabular}{lllll}
\hline UL Max. Current & $15 \mathrm{~cd}$ & $30 \mathrm{~cd}$ & $75 \mathrm{~cd}$ & $95 \mathrm{~cd}$
\end{tabular}

\begin{tabular}{llllll}
\hline High (95) dBA 24 VDC & 0.082 & 0.124 & 0.209 & 0.275 \\
\hline
\end{tabular}

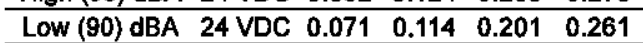

\begin{tabular}{lcc}
\hline UL Max. Current & & \\
\hline & $115 \mathrm{~cd}$ & $177 \mathrm{~cd}$ \\
\hline High (95) dBA & 0.350 & 0.477 \\
\hline Low (90) dBA & 0.306 & 0.429 \\
\hline
\end{tabular}

\begin{tabular}{lcc}
\hline UL Max. Current & \multicolumn{2}{c}{ Audible } \\
\hline & 24 VDC & 12 VDC \\
\hline High (95) dBA & 0.044 & 0.021 \\
\hline Low (90) dBA & 0.018 & 0.012 \\
\hline
\end{tabular}

(800) 631-2148 * wuw.cooperwheelock.com 


\section{APPENDIX F: FIRE ALARM SPECIFICATIONS}




\section{FIRE ALARM SYSTEM}

\section{SECTION 16710}

\section{PART 1: $\quad$ GENERAL}

\subsection{DESCRIPTION:}

A. Work Included:

1. The furnishing of all labor, equipment, materials and performance of all operations in connection with the installation of the Fire Alarm System as shown on the drawings and as herein specified.

2. The complete installation shall.conform to the applicable sections of NFPA-72 National Electrical Code.

3. All equipment, devices and cables shall be listed by Underwriters' Laboratories, Inc. and or approved by Factory Mutual for the purpose of fire alarm systems and shall be listed with the California State Fire Marshall.

4. It is the intent of the Contract Documents to provide an installation complete in every respect. In the event that additional details or special construction is required for work indicated or specified in this Section or work specified in other Sections, it shall be the responsibility of the Contractor to provide all material and equipment which is usually furnished with such systems in order to complete the installation, whether mentioned herein or not.

\subsection{DESIGN REQUIREMENTS:}

A. The Fire Detection System shall be responsible for continually supervising and monitoring by zone the following initiating, signaling and monitoring circuits designated as:

1. Manual fire pull stations.

2. Smoke and heat detectors, including those install under other Sections.

3. Alarm signaling circuits (alarm bells and visual alarm unit).

4. Remote Annunciator.

5. The system controls shall be Underwriters' Laboratory listed for power-limited applications per NEC 760-23.

B. The Fire Alarm System configurations for the projects shall be as follows:

1. Horns shall be used for fire alarm signaling. Class change signaling shall 
be independent of the fire alarm system.

2. Activation of duct smoke detectors in the Air Handling ducts shall be annunciated at the main Fire Alarm Control panel.

\subsection{DISTRICT APPROVAL:}

A. All fire alarm, signal and control equipment shall be approved by the District in addition to other required approvals.

B. Certification: Installation of the Fire Alarm System shall not be started until drawings, including State Fire Marshal listed numbers of all fire alarm components, are submitted to and approved by the State Fire Marshal (OSA). Written certification by the fire alarm equipment distributor or manufacturer shall be submitted to the Architect and the State Fire Marshal stating that the system and its component parts are as "approved and listed" by the State Fire Marshal and that the installation conforms in all respects to the requirements set forth in Article 72, Title 24, California Administrative Code.

C. The equipment and services described in these Specifications represent those supplied and supported by Fire Control Instruments Company, unless noted otherwise.

D. All equipment described has been established by Fresno Unified School District as the standard for service product in the School District. Fresno Unified School District has standardized on Fire Control Instruments as the sole manufacturer of its Fire Alarm master equipment to reduce parts required for repair and expansion. We have also chosen this manufacturer because of reduced personal training and high product reliability.

E. All equipment to be supplied under this section shall be $100 \%$ solid state in design.

\subsection{SUBMITTALS:}

A. All submittals shall be made in accordance with Section 01300.

B. Shop Drawings: Show equipment locations, wiring schematics, details, panel's configuration and size and a point-to-point schematics of circuits and zone schedules. Include front elevations, cabinet dimensions, type of mounting, doors, barriers, catalog number of locks, and finishes for all terminal cabinets. Show interfaces to equipment furnished by others, identifying numbers of wires and termination requirements. Responsibility for each end of the interfaces shall be noted.

C. Complete descriptive data indicating Underwriters' Laboratories and California State Fire Marshal listings for all system components.

D. Complete sequence of operations of the system.

E. Complete system wiring diagrams for components connected to the system and 
interfaces to existing equjpment.

F. A copy of any State or Local Fire Alarm System equipment approvals.

G. Provide one copy of acceptance test procedures for review.

H. Provide supplier's qualifications indicating years in business, service policies, warranty definitions and list of similar installations.

I. Equipment, other than specified, will be considered for approval provided it meets previous ltems $\mathrm{A}$ through $\mathrm{H}$ and the following is submitted in writing by the Electrical Contractor to the Engineer to Allow approval at least 14 days before the bid date:

1. Complete lists, descriptions and drawings of materials to be used, including all SFM listing numbers.

2. A complete riser diagram of fire alarm system.

3. A complete list of current drain requirements during normal supervisory conditions, trouble conditions and alarm system.

4. Battery standby calculations showing total standby needed to meet the system requirements as specified.

5. If any attempt is made to substitute that brand of equipment specified it shall be the Contractor's obligation to submit the above data and information to allow the specifying engineer time to consider the equality of the substituted items to that specified. It is the Contractor's responsibility to meet the entire intent of the Specifications. Deviations from the specified items shall be at the risk of the Contractor until the date of final acceptance by the Architect, Engineer and Owner's representative.

6. Approved submittals on substitute equipment shall only allow the Contractor to proceed with installing a substituted item and shall not be considered equal until such time as the Architect, Engineer and the Owner's representative have completely accepted the substituted item. All cost for removal, relocations or replacement of a substituted item shall be at the risk of the Electrical Contractor.

J. The Fire Alarm System shall be supplied form a single source and shall be labeled with the manufacturer's name and logo on all system equipment and devices.

\subsection{QUALITY ASSURANCE:}

A. Work shall be done by qualified Contractor holding C-10 and other licenses required by authorities having jurisdiction.

B. Each system shall be installed by an authorized manufacturer's representative with duly authorized local representation who can, upon request, give evidence 
satisfactory to the Engineer that he maintains a fully equipped service organization stocking the manufacturer's standard parts and capable of furnishing, in the sole judgment of the Engineer, adequate inspections and service to the system. All signal equipment shall be supplied and installed by a licensed and bonded signal contractor holding a valid California State Electrical Contractor's license with the proper endorsements for performing work of this specification.

\subsection{WARRANTY:}

A. The Contractor shall warrant the completed Fire Alarm System wiring and equipment to be free from inherent mechanical and electrical defects for a period of one year from the date of the completed and certiffed test or from the date of first beneficial use.

C. Trouble Calls: The Contractor shall guarantee response to a trouble call within 24 hours after the receipt of such a call.

B. The equipment manufacturer shall make available to the Owner a Maintenance Contract Proposal to provide a minimum of two inspections and tests per year in compliance with NFPA-72H guidelines.

\subsection{PERFORMANCE:}

A. Furnish and install a complete Fire Alarm System as described herein and as shown on the drawings to be wired, connected, and left in first class operating condition. The system shall use closed loop initiating device circuits with individual zone supervision, individual indicating appliance circuit supervision, incoming and standby power supervision. Include a control panel, manual pull stations, automatic fire detectors, horns, flashing lights, annunciator, all wiring, connections to devices, outlet boxes, junction boxes and all other necessary material for a complete operating system.

\subsection{FUNCTION: FIRE ALARM EVACUATION SYSTEM:}

A. The operation of a manual station or automatic activation of any smoke detector, heat detector or waterflow device shall cause:

1. All evacuation horns to sound and strobes to flash in a temporal code three pattern. All horns, horn circuits, strobes and strobe circuits shall be synchronized. Indicate on the control panel the zone in alarm. Indicate on the remote annunciator the zone in alarm. Automatically close all magnetically held doors. Perform any additional function as specified herein or as shown on the plans. Summon the fire department. The operated device is returned to normal and the control panel is manually reset, except that the alarms may be silenced as described elsewhere in these specifications.

a. An alarm may be silenced by a switch on the zone card in the control alarm. When silenced this shall not prevent the resounding of subsequent alarms if another zone should alarm (subsequent 
alarm feature).

b. When alarms are silenced: The zone indicating red LED's on the control panel and the remote annunciator shall remain on until the operated device is returned to normal and the control panel is manually reset.

B. A green pilot LED shall normally be on, indicating that the system is receiving normal $120 \mathrm{VAC}$ power. A failure of normal power shall cause the LED to extinguish.

C. An amber system trouble LED and sonalert operating together shall signal any trouble condition. Failure of normal power opens or short circuits on the indicating circuits disarrangement's in system wiring or ground faults shall cause the trouble LED to light and sonalert to sound. A silencing switch shall be provided to silence the sonalert, which shall be so arranged that the trouble LED will remain lit until the system is restored to normal. When the system is restored to normal, the sonalert shall resound to remind service personnel to return the silencing switch to the normal position (ringback feature).

D. All alarm signals shall be automatically "locked in" at the control panel until the operated device is returned to its normal condition, and the control panel is manually reset. A switch shall be provided on each zone card in the control panel for silencing the alarm devices by zone. Once silenced, it will not prevent the resounding of all alarm signals if an alarm condition should occur in another zone elsewhere in the building (subsequent alarm feature). When used for waterflow, the silence switch shall be bypassed through the use of a selectable jumper wire.

E. Each initiating circuit shall be represented on the zone cards in the control panel by an amber trouble LED and a red alarm LED. The LEDs for each zone shall be identified on the control panel by custom lettering showing the zone designation. Circuit trouble shall be indicated by the amber LED. Audible trouble and alarm devices shall be supervised. Control panels with incandescent lamps or control panels without supervised alarm lamps will not be accepted.

F. Each initiating and signal circuit shall be electrically supervised for opens and ground faults in the wiring and for short circuit faults on the signal circuit wiring, and shall be so arranged that a fault condition in any circuit or groups of circuits will not cause an alarm to be sounded. The occurrence of any fault will light a trouble LED and sound the sonalert, but will not interfere with the proper operation of any circuit which does not have a fault condition. The system shall be capable of being wired using Class A supervised circuits (a break or ground fault in one or both conductors will not prevent a device form operating on either side of the break) or Class B (a break or ground fault in any conductor will be reported as a trouble condition) at no extra cost.

G. All printed boards shall be of the plug-in type and shall be electrically supervised for position. All control panel components shall be contained in a16-gauge steel cabinet. All groups of circuits or common equipment shall be clearly marked and shall be expandable by inserting interchangeable plug-in units. Control panels that have plug-in modules that can be removed without causing a trouble condition will not be accepted. 
H. Circuitry shall be provided in the control panel to permit transmission of trouble and alarm signals over leased telephone cables to a remote central station. A reverse polarity transmitter and/or a masterbox circuit as required shall also be provided in the control panel. There shall be one supervised zone to allow testing of the fire alarm system without transmitting an alarm signal to the central station.

I. The control unit shall be beige in color and shall include the following features:

1. Auxiliary SPDT contacts in the control unit per zone and one set of SPDT contacts, which will operate on general alarm.

2. Auxiliary circuitry in the control panel to operate remote relays to control blowers in air handlers.

3. 24 hours of battery standby (as required) using rechargeable batteries with automatic hi-low rate charger to maintain standby batteries and operate the general trouble devices as specified herein but shall not cause an alarm to be sounded.

4. A power transfer circuit that will switch to standby power automatically and instantaneously if normal power fails. This circuit shall not be an integral part of the power supply but of the basic fire card to allow operation of the completed fire alarm system on the secondary source of power with the primary power supply removed.

5. Ground fault defector to detect positive or negative grounds on the initiating circuits, signal circuits, power circuits, and telephone line circuit. The ground fault detector shall have an individual LED for visual indication of either a positive or negative ground fault and operate the general trouble devices as specified herein but shall not cause an alarm to be sounded.

6. A short circuit LED shall be a standard feature of the fire alarm control panel. This circuit shail monitor the signal circuits for short circuits and shall have an individual LED for visual indication of circuits as well as operating trouble devices as specified herein, but shall not cause an alarm to be sounded.

7. All relays on printed circuit boards shall be plug-in type with dust proof protecting covers.

8. All transistors on common control and individual zone printed circuit boards shall be of the same exact type and shall be plug-in.

9. Lightning protection shall be a standard feature of the fire alarm control panel and shall be incorporated in the power supply circuit, common control circuits, signal circuits, smoke detector power circuits, and telephone line circuit. Systems that require an optional module to provide this protection will not be considered equal.

10. Individual circuit fuses shall be provided for the following: smoke detector 
power, main power supply, signal circuit \#1, signal circuit \#2, battery standby power and auxiliary output.

11. A battery test switch shall be a standard feature of the fire alarm control panel and shall test all supervised red alarm LED's and yellow trouble LED's power zone.

12. An overvoltage sensing circuit shall cause an amber LED to light and operate the system trouble devices should a fault occur within the power supply causing too high a voltage being supplied to the FC-72 system.

13. Provisions for supervised remote reset capabilities.

14. Provisions for a remote drill switch capability.

15. The control unit shall be flush mounted in a textured finish, \#16 gauge steel cabinet equipped with a hinged door, and secured by a lock keyed common to the manual stations. Reset switches, silence switches, fuses, etc., shall be clearly marked and shall be behind the locked door to prevent unauthorized entry. Opening of the main door shall expose all components for inspection or adjustment without further dismantling of the cabinet, control unit or wiring. The panel shall have provisions for a supervised remote trouble indication.

16. The audible trouble signal shall be an integral part of the control unit. Provisions shall be provided for an optional supervised remote trouble signal.

17. The 120VAC main power shall be converted to low voltage, rectified and regulated 24VDC for system operation. The entire system shall operate on 24VDC.

18. The rated current available from the power supply shall be 4 amps of filtered and regulated DC and shall comply with the latest issue of UL Standard \#864.

19. Battery charging unit shall be an automatically dual-rate type, having both a high rate and float charge capability.

20. Stations shall be capable of having a break-glass rod as a standard feature, but shall not depend on the glass rod to hold the station in normal position.

21. Stations shall be of extruded aluminum design with Fire Lettering on each side, for semi-flush or surface mounting and shall be of the double action design. Once activated, it must be clearly visible which station was activated from either the front or side view. Stations shall not be resettable without the use of a key and physically opening the station to reset. The key shall be the same as that used to open the control panel.

22. Audible and visual indicating devices shall be horn and flashing light 
assembly with the word "FIRE" on two sides. The horn and light assembly shall be capable of being flush or semi-flush mounted. Units shall be installed where shown on plans using supervised circuits. There are to be no more than $\mathbf{2 0}$ hom and light combination units per signal circuit.

23. All magnetic door holders shall operate through the contacts of the panel after an alarm condition has been initiated from any zone on the fire alarm control panel. All door holder circuits shall be separately fused.

24. The electromagnetic door holder devices shall hold fire and smoke barrier doors open until released by an alarm condition. The door holders have approximately $35 \mathrm{lb}$. $(15.9 \mathrm{~kg}$ ) holding power and offer fail safe operation.

\section{PART 2: $\quad$ PRODUCTS}

\subsection{FIRE ALARM CONTROL PANEL:}

A. Where shown on the drawings, provide and install an $\mathrm{FCl}-7100$ seriesFire Alarm Control Panel

\subsection{REMOTE ANNUNCIATOR:}

A. Where shown on the drawings, provide and install an FCl Weatherproof Annunciator. The annunciator shall be provided one alarm LCD-7100. The remote annunciator shall be electrically supervised from the control panel.

B. Provide output module at control panel for connection to District Central Station monitoring.

\subsection{PERIPHERAL DEVICES:}

\section{A. Manual Stations:}

FCI.Model MS-7AF

B. Duct Smoke Detectors:

Duct smoke detectors shall be FCI Model No. ASD-PL2F / ADB-FL Provide remote power/alarm indicator/key switch, Model RCM-601 for each detector. Duct sampling tube shall be sized to extend over full width of duct.

C. Visual Signal:

Visual signal shall be Wheelock RSS-24MCW-FR, Candela to depend on application.

D. Horns:

Alarm horns shall be Wheelock mt12-24WP-R. The horn assembly shall be capable of being flush or semiflush mounted. Horns shall be polarized and operated by 24 V.D.C. Unit shall be in die cast red housing.

E. Mini Horns:

Mini Horns shall be Wheelock MIZ-TC24-R. Combination horn strobe unit shall 
be Wheelock NS appliance.

F. Heat Detectors:

Heat Detectors shail be FCI No. ATD-L2F / ADB-FL and FCI No. ATD-HL2F /

ADB-FL fixed temperature detectors.

\subsection{WIRING:}

A. Raceways: All wiring shall be installed in raceways sized not to exceed $40 \%$ fill, or run exposed along the ceiling structure where indicated. Where run exposed, wiring shall be tied to structure at intervals so that wire ways present a neat and uniform appearance.

B. Cables:

1. Alarm signaling circuits (alarm horns and visual alarm unit) cable shall be \#12 Stranded wire, THHN Red and Black.

2. Detection (above ground) cable shall West Penn Cable, \#970 (2-\#18 awg, solid).

C. Splices: No splices shall be installed in conduit, Christy boxes or any inaccessible place. All splices shall be made on terminal blocks specifically designed for that purpose in terminal cabinets or locations as specifically approved by the Engineer.

D. Racks, Terminals, Cabinets and Special Assemblies:

1. Wiring shall be neatly bundled, fanned, tagged and laced. Leave minimum three-inch horizontal wiring between terminal block connection and fan.

2. Terminate incoming (homerun) cables on left of terminal block; with cables to devices terminated on right side.

3. Terminal Barrier Strips: Cinch 142 series barrier strips (minimum 6 points) for Fire Alarm system. Provide minimum two (2) space separation points between types of system cables. Strips shall include provisions for up to four (4) spare termination points. Ensure that system circuit loops are located on adjacent termination points on the barrier strip.

E. All underground conduit runs shall only use stranded type wires.

F. Wire terminators to devices and on terminal barrier strips shall be with "spade" type terminal connections (Thomas and Betts Sta-Kon or Engineer approved equivalent). Contractor shall use an approved Thomas and Betts Sta-Kon lugging tool.

G. All cables shall be labeled with Panduit Label, size MP-150C thru MP-350. The size will depend on the amount of information needed on each label. All labels shall contain information as to the source and the destination of the wire including 
the location and terminal can numbers.

\subsection{System Upgrades:}

When upgrading an existing system, the existing fire alarm shall be tested in the presence of a Fresno Unified employee prior to any work being started by a contractor. Upon completion of testing, it shall be the contractor's responsibility to note any discrepancy with the existing system. It will be contractor's responsibility to provide and complete working system, minus any discrepancies noted.

When upgrading an existing system, all end of line resistors shall be changed out to meet manufacturer's specifications for each individual fire panel. The contractor shall make a reasonable effort to locate the end of line resistors. If locations cannot be determined Fresno Unified shall provide assistance to the contractor.

When specifications call for a zone to be added, the contractor shall provide all equipment and terminations to make a completed working system, including all equipment necessary to annunciate the system to Fresno Unified's central station. It will be the contractor's responsibility to ensure that the equipment has sufficient space to accommodate extra zones.

When specifications call for the removal of existing equipment all equipment shall be returned to Fresno Unified School District's Electronics Shop.

2.06 Testing:

Upon completion of new system or an upgrade to an existing system, the contractor shall provide a minimum of two personnel for testing. Testing shall be done in the presence of an assigned Fresno Unified School District employee. The contractor shall provide reasonable notification prior to scheduling of any tests, so that Fresno Unified personnel can be in attendance. The Local Fire Marshall is required to be present during testing, and it shall be the contractor's responsibility to notify the fire department having jurisdiction.

\section{END OF SECTION}




\section{APPENDIX G: WATER FLOW MEMO}




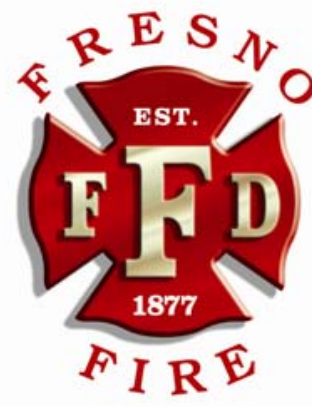

Bureau of Fire Prevention and Investigative Services

450 M Street

Fresno, California 93721-3083

(559) 621-4000 FAX (559) 498-4323

www.fresno.gov

\section{E-Mail Memorandum}

To: $\quad$ Frank Sen, PE,

Blair, Church and Flynn Consulting Engineers

From: $\quad$ Byron Beagles, Fire Prevention Engineer

Date: $\quad$ May 1, 2009

Subject: Water flow information for FUSD school site bounded by Hamilton, Cedar, Heaton and Tenth Avenues

The Fresno Fire Department uses water supply modeling for fire hydrant and fire sprinkler hydraulic calculations based on the water main infrastructure of the subject project area. The operating parameters of the City of Fresno Water Division are well documented and communication and cooperation between the Water and Fire departments is open and ongoing. The City of Fresno Water Division has an ISO Class I rating.

The following information assumes connection to the existing 10" transmission grid main in S. Cedar Ave:

Fresno Fire requires private fire hydrant fire flows of $1500 \mathrm{gpm}$ for buildings with fire sprinklers and $2500 \mathrm{gpm}$ for buildings without fire sprinklers. We provide the following parameters to design the onsite fire hydrant system:

$1500 \mathrm{gpm}$ : maximum friction loss from the most remote hydrant shall not exceed 23 psi from the source. This corresponds to a model curve of 50 static, 43 residual, $1500 \mathrm{gpm}$ flow.

2500 gpm: maximum friction loss allowed is 12 psi (if two or more hydrants, flow may be split between the two most remote hydratns). This corresponds to a model curve of 50 static, 34 residual, $2500 \mathrm{gpm}$ flow.

For purposes of fire sprinkler calculations, a flow curve of 45 static, 35 residual, and a flow of 1800 gpm would be required to be used for plans submitted to Fresno Fire.

Why the difference for fire sprinkler vs. hydrants? Fire sprinkler demand is typically much lower than fire flow and may not draw down system pressure enough to activate nearby water well pumps. The most critical design parameter for most fire sprinkler systems is available pressure.

An actual flow test was conducted in June of 2008 by ISO at the corner of Tenth and Woodward, just a few blocks from this site. Results were 54 static, 46 residual, and flow of $1700 \mathrm{gpm}$. As this an other flow tests are generally not taken at peak demand time of day or year, Fresno Fire would not allow this test to be used for hydraulic design. When using the model curve information above, we do not require a $10 \%$ "cushion".

If you have any further questions, please feel free to contact our office.

\section{Beran 7. Beagles}

Fire Prevention Engineer

Fire Prevention and Investigation Division

Fresno Fire Department

911 "H" Street, Fresno California 93721-3083

559-621-4112 (office) 559-498-4323 (fax)

Fire Sprinklers Save Lives 


\section{APPENDIX H: HYDRAULIC CALCULATIONS}




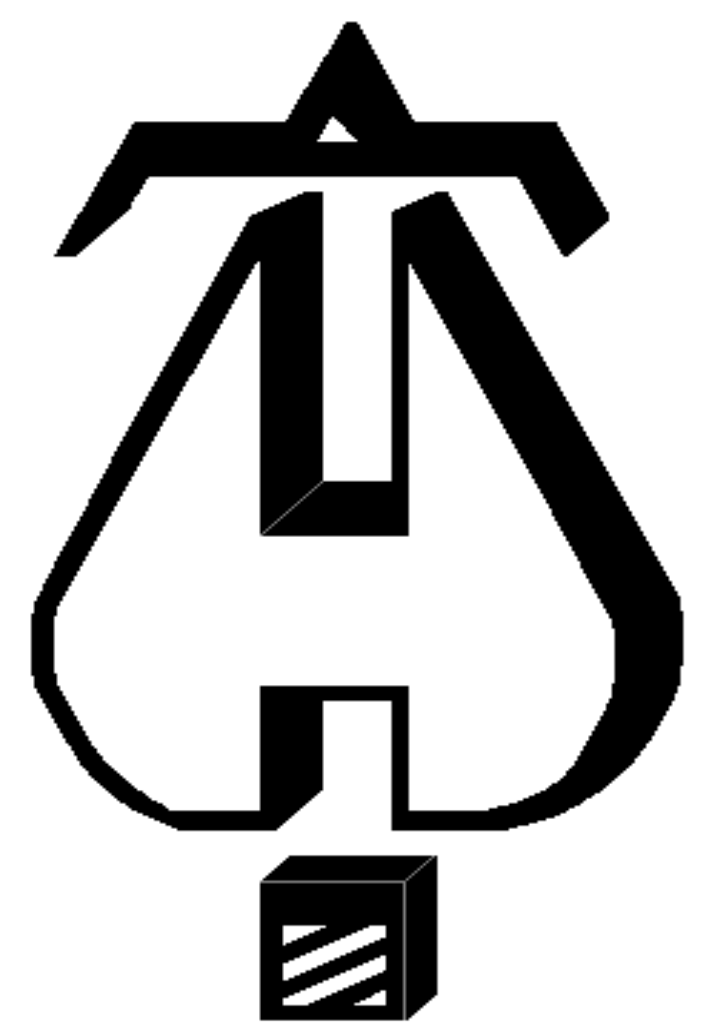

. . Fire Protection by Computer Design

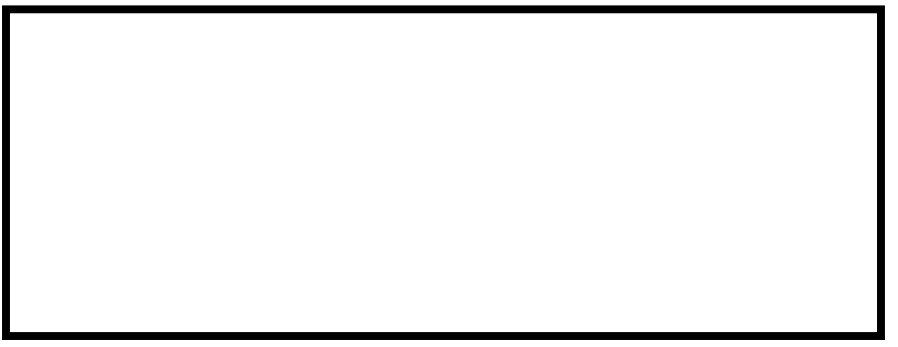

Job Name : Second Floor Piping Plan

Building : MAIN BLDG. - SECOND FLOOR

Location : HYDRAULIC CALCULATION AREA \#1

System : 1

Contract : 09-1032.2

Data File : Second Floor Piping Plan-Area 1 AREA 1.wxf 
Project name: CEDAR AND HEATON ELEMENTARY SCHOOL Location: HYDRAULIC CALCULATION AREA \#1

Drawing no: MAIN BLDG. - SECOND FLOOR

Date: $\quad 7-5-11$

Design

Remote area number: 1

Remote area location:

Occupancy classification: LIGHT HAZARD

Density: $\quad .1-\mathrm{Gpm} / \mathrm{SqFt}$

Area of application: $1039-\mathrm{SqFt}$

Coverage per sprinkler: $324 \mathrm{MAX}-\mathrm{SqFt}$

Type of sprinklers calculated: PENDENT

No. of sprinklers calculated: 5

In-rack demand: N/A - GPM

Hose streams: 100 - GPM

Total water required (including hose streams): 287.36 - GPM $\quad$ @ 44.46 - Psi

Type of system: WET

Volume of dry or preaction system: N/A - Gal

Water supply information

Date: $\quad$ 5-1-09

Location: CEDAR AND HEATON

Source: BYRON BEAGLES, CITY OF FRESNO FIRE DEPARTMENT

Name of contractor:

Address:

Phone number:

Name of designer:

Authority having jurisdiction: DSA

Notes: (Include peaking information or gridded systems here.) 


\section{Water Supply Curve C}

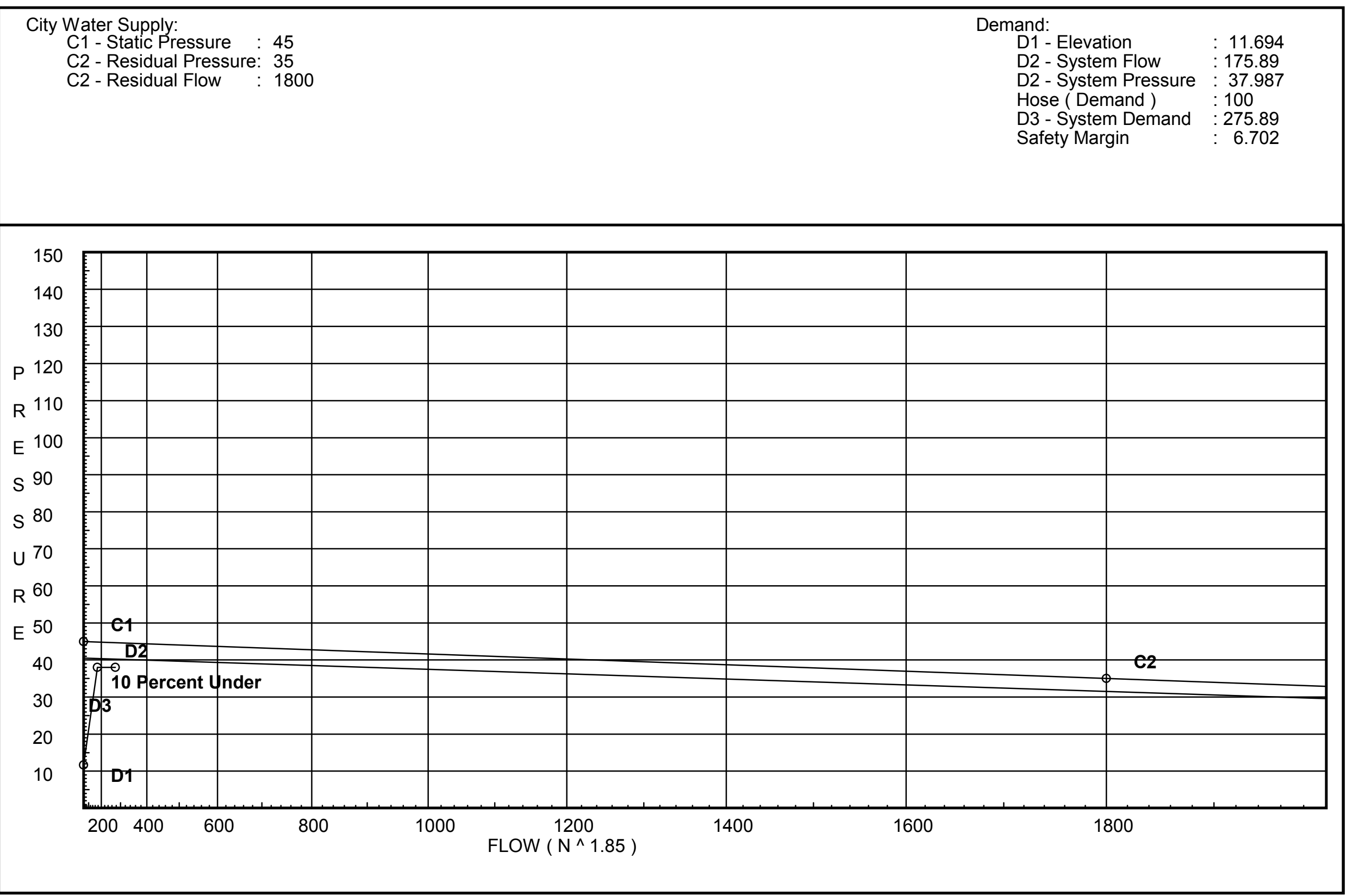




\section{Flow Diagram}

\section{Second Floor Piping Plan}

Page 3

\begin{tabular}{lrl}
\hline & & 34.2 \\
$\mathbf{4}$ & $\mathbf{3}$ & $\rightarrow \mathbf{2 0 3}$ \\
| & 100.9 & \\
$\mid$ & & 36.1 \\
$\mathbf{5}$ & $\mathbf{1 1}$ & $\rightarrow \mathbf{1 0 3}$
\end{tabular}

6 TEST 


\section{Fittings Used Summary}

Second Floor Piping Plan

Fitting Legend

Abbrev. Name

$\begin{array}{lllllll}1 / 2 & 3 / 4 & 1 & 11 / 4 & 11 / 2 & 2 & 21 / 2\end{array}$

C Roll Groove Coupling

E NFPA 1390 ' Standard Elbow

F NFPA $1345^{\prime}$ Elbow

G NFPA 13 Gate Valve

T NFPA $1390^{\prime}$ Flow thru Tee

$21 / 2 \quad 3 \quad 31 / 2$

111

$\begin{array}{llll}1 & 2 & 2 & 3 \\ 1 & 1 & 1 & 1\end{array}$

4

0

0

0

$\begin{array}{lllll}2 & 2 & 3 & 3 & 3 \\ 0 & 1 & 1 & 1 & 1 \\ 8 & 10 & 12 & 15 & 17\end{array}$

$\begin{array}{llll}4 & 5 & 6 & 8 \\ 1 & 1 & 1 & 1 \\ 10 & 12 & 14 & 18 \\ 4 & 5 & 7 & 9 \\ 2 & 2 & 3 & 4 \\ 20 & 25 & 30 & 35\end{array}$

$\begin{array}{lllllll}10 & 12 & 14 & 16 & 18 & 20 & 24 \\ 1 & 1 & 1 & 1 & 1 & 1 & 1 \\ 22 & 27 & 35 & 40 & 45 & 50 & 61 \\ 11 & 13 & 17 & 19 & 21 & 24 & 28 \\ 5 & 6 & 7 & 8 & 10 & 11 & 13 \\ 50 & 60 & 71 & 81 & 91 & 101 & 121\end{array}$

Units Summary

$\begin{array}{ll}\text { Diameter Units } & \text { Inches } \\ \text { Length Units } & \text { Feet } \\ \text { Flow Units } & \text { US Gallons per Minute } \\ \text { Pressure Units } & \text { Pounds per Square Inch }\end{array}$

Note: Fitting Legend provides equivalent pipe lengths for fittings types of various diameters. Equivalent lengths shown are standard for actual diameters of Sched 40 pipe and CFactors of 120 except as noted with *. The fittings marked with a * show equivalent lengths values supplied by manufacturers based on specific pipe diameters and CFactors and they require no adjustment. All values for fittings not marked with $a$ * will be adjusted in the calculation for CFactors of other than 120 and diameters other than Sched 40 per NFPA. 
Pressure / Flow Summary - STANDARD

\begin{tabular}{|c|c|c|c|c|c|c|c|c|}
\hline \multicolumn{6}{|c|}{ Second Floor Piping Plan } & \multicolumn{3}{|c|}{$\begin{array}{l}\text { Page } 5 \\
\text { Date }\end{array}$} \\
\hline $\begin{array}{l}\text { Node } \\
\text { No. }\end{array}$ & Elevation & K-Fact & $\begin{array}{c}\mathrm{Pt} \\
\text { Actual }\end{array}$ & $\mathrm{Pn}$ & $\begin{array}{l}\text { Flow } \\
\text { Actual }\end{array}$ & Density & Area & $\begin{array}{c}\text { Press } \\
\text { Req. }\end{array}$ \\
\hline 104 & 27.0 & 11.2 & 9.03 & na & 33.66 & 0.1 & 324 & 8.7 \\
\hline 2 & 28.0 & & 12.77 & na & & & & \\
\hline 3 & 28.0 & & 13.7 & na & & & & \\
\hline $4 \mathrm{~A}$ & 28.0 & & 14.93 & na & & & & \\
\hline 4 & 28.0 & & 18.18 & na & & & & \\
\hline 5 & 28.0 & & 18.23 & na & & & & \\
\hline TOR & 0.0 & & 32.96 & na & & & & \\
\hline BOR & -3.0 & & 34.48 & na & & & & \\
\hline D & 0.0 & & 34.64 & na & 100.0 & & & \\
\hline SRCA & 0.0 & & 37.99 & na & & & & \\
\hline 102 & 27.0 & 11.2 & 8.7 & na & 33.04 & 0.1 & 324 & 8.7 \\
\hline 8 & 28.0 & & 12.55 & na & & & & \\
\hline 203 & 27.0 & 11.2 & 9.32 & na & 34.18 & 0.1 & 324 & 8.7 \\
\hline 101 & 27.0 & 11.2 & 12.05 & na & 38.88 & 0.1 & 324 & 8.7 \\
\hline 13 & 28.0 & & 14.73 & na & & & & \\
\hline 11 & 0.0 & & 27.15 & na & & & & \\
\hline 14 & 28.0 & & 15.64 & na & & & & \\
\hline $5 \mathrm{~A}$ & 28.0 & & 16.35 & na & & & & \\
\hline 103 & 27.0 & 11.2 & 10.41 & na & 36.13 & 0.1 & 324 & 8.7 \\
\hline
\end{tabular}

The maximum velocity is 14.43 and it occurs in the pipe between nodes 101 and 13 
Final Calculations - Hazen-Williams - 2007

Second Floor Piping Plan

Page 6

Date

$\begin{array}{llllllll}\text { Hyd. } & \text { Qa } & \text { Dia. } & \text { Fitting } & \text { Pipe } & \text { Pt } & \text { Pt } & \text { Pv } \\ \text { Ref. } & & \text { "C" } & \text { or } & \text { Ftng's } & \text { Pe } & \text { Pv***** Notes } \\ \text { Point } & \text { Qt } & \text { Pf/Ft } & \text { Eqv. Ln. } & \text { Total } & \text { Pf } & \text { Pn } & \end{array}$

${ }^{*}$ REMOTE HEAD TO SUPPLY

\begin{tabular}{|c|c|c|c|c|c|c|c|}
\hline $\begin{array}{l}104 \\
\text { to } \\
2 \\
\end{array}$ & $\begin{array}{l}33.66 \\
33.66 \\
\end{array}$ & $\begin{array}{l}1.097 \\
120.0 \\
0.2742 \\
\end{array}$ & $\begin{array}{l}2 E \\
1 T\end{array}$ & $\begin{array}{l}4.974 \\
6.217 \\
0.0 \\
\end{array}$ & $\begin{array}{r}4.000 \\
11.191 \\
15.191 \\
\end{array}$ & $\begin{array}{r}9.033 \\
-0.433 \\
4.166 \\
\end{array}$ & $\begin{array}{l}\text { K Factor }=11.20 \\
\text { Vel }=11.43\end{array}$ \\
\hline $\begin{array}{r}2 \\
\text { to } \\
3\end{array}$ & $\begin{array}{l}33.04 \\
66.7\end{array}$ & $\begin{array}{l}2.067 \\
120.0 \\
0.0444\end{array}$ & $1 \mathrm{~T}$ & $\begin{array}{r}10.0 \\
0.0 \\
0.0\end{array}$ & $\begin{array}{l}11.080 \\
10.000 \\
21.080\end{array}$ & $\begin{array}{l}12.766 \\
0.0 \\
0.936\end{array}$ & Vel $=6.38$ \\
\hline $\begin{array}{l}3 \\
\text { to } \\
4 \mathrm{~A}\end{array}$ & $\begin{array}{r}34.18 \\
100.88 \\
\end{array}$ & $\begin{array}{l}2.067 \\
120.0 \\
0.0955\end{array}$ & & $\begin{array}{l}0.0 \\
0.0 \\
0.0\end{array}$ & $\begin{array}{c}12.860 \\
0.0 \\
12.860\end{array}$ & $\begin{array}{l}13.702 \\
0.0 \\
1.228\end{array}$ & Vel $=9.65$ \\
\hline $\begin{array}{l}4 \mathrm{~A} \\
\text { to } \\
4\end{array}$ & $\begin{array}{r}0.0 \\
100.88 \\
\end{array}$ & $\begin{array}{l}2.067 \\
120.0 \\
0.0955 \\
\end{array}$ & $1 \mathrm{~T}$ & $\begin{array}{r}10.0 \\
0.0 \\
0.0 \\
\end{array}$ & $\begin{array}{l}24.000 \\
10.000 \\
34.000\end{array}$ & $\begin{array}{l}14.930 \\
0.0 \\
3.247\end{array}$ & Vel $=9.65$ \\
\hline $\begin{array}{r}4 \\
\text { to } \\
5\end{array}$ & $\begin{array}{c}0.0 \\
100.88\end{array}$ & $\begin{array}{c}4.26 \\
120.0 \\
0.0028 \\
\end{array}$ & & $\begin{array}{l}0.0 \\
0.0 \\
0.0\end{array}$ & $\begin{array}{c}18.000 \\
0.0 \\
18.000\end{array}$ & $\begin{array}{c}18.177 \\
0.0 \\
0.051\end{array}$ & $\mathrm{Vel}=2.27$ \\
\hline $\begin{array}{l}5 \\
\text { to } \\
\text { TOR }\end{array}$ & $\begin{array}{r}75.01 \\
175.89 \\
\end{array}$ & $\begin{array}{c}4.26 \\
120.0 \\
0.0079\end{array}$ & $\begin{array}{l}1 \mathrm{~T} \\
2 \mathrm{E}\end{array}$ & $\begin{array}{c}26.334 \\
26.334 \\
0.0\end{array}$ & $\begin{array}{r}277.330 \\
52.668 \\
329.998 \\
\end{array}$ & $\begin{array}{r}18.228 \\
12.127 \\
2.604 \\
\end{array}$ & $\mathrm{Vel}=3.96$ \\
\hline $\begin{array}{l}\text { TOR } \\
\text { to } \\
\text { BOR }\end{array}$ & $\begin{array}{c}0.0 \\
175.89\end{array}$ & $\begin{array}{c}4.26 \\
120.0 \\
0.0079\end{array}$ & $1 \mathrm{C}$ & $\begin{array}{l}1.317 \\
0.0 \\
0.0\end{array}$ & $\begin{array}{r}27.000 \\
1.317 \\
28.317\end{array}$ & $\begin{array}{r}32.959 \\
1.299 \\
0.223\end{array}$ & Vel $=3.96$ \\
\hline $\begin{array}{l}\text { BOR } \\
\text { to } \\
D\end{array}$ & $\begin{array}{r}0.0 \\
175.89\end{array}$ & $\begin{array}{c}4.07 \\
150.0 \\
0.0065\end{array}$ & $\begin{array}{l}3 E \\
1 G \\
1 T\end{array}$ & $\begin{array}{r}47.796 \\
3.186 \\
31.864\end{array}$ & $\begin{array}{r}140.000 \\
82.846 \\
222.846 \\
\end{array}$ & $\begin{array}{r}34.481 \\
-1.299 \\
1.453\end{array}$ & $\mathrm{Vel}=4.34$ \\
\hline $\begin{array}{l}\text { D } \\
\text { to } \\
\text { SRCA }\end{array}$ & $\begin{array}{l}100.00 \\
275.89\end{array}$ & $\begin{array}{c}9.42 \\
150.0 \\
0.0003\end{array}$ & $\begin{array}{l}1 \mathrm{E} \\
4 \mathrm{~F} \\
1 \mathrm{G} \\
1 \mathrm{~T}\end{array}$ & $\begin{array}{r}24.61 \\
49.22 \\
5.593 \\
55.931\end{array}$ & $\begin{array}{r}1260.000 \\
135.353 \\
1395.353\end{array}$ & $\begin{array}{r}34.635 \\
3.000 \\
0.352\end{array}$ & $\begin{array}{l}\text { Qa }=100 \\
* * \text { Fixed Loss }=3 \\
\text { Vel }=1.27\end{array}$ \\
\hline
\end{tabular}

0.0

275.89

37.987

$\mathrm{K}$ Factor $=44.76$

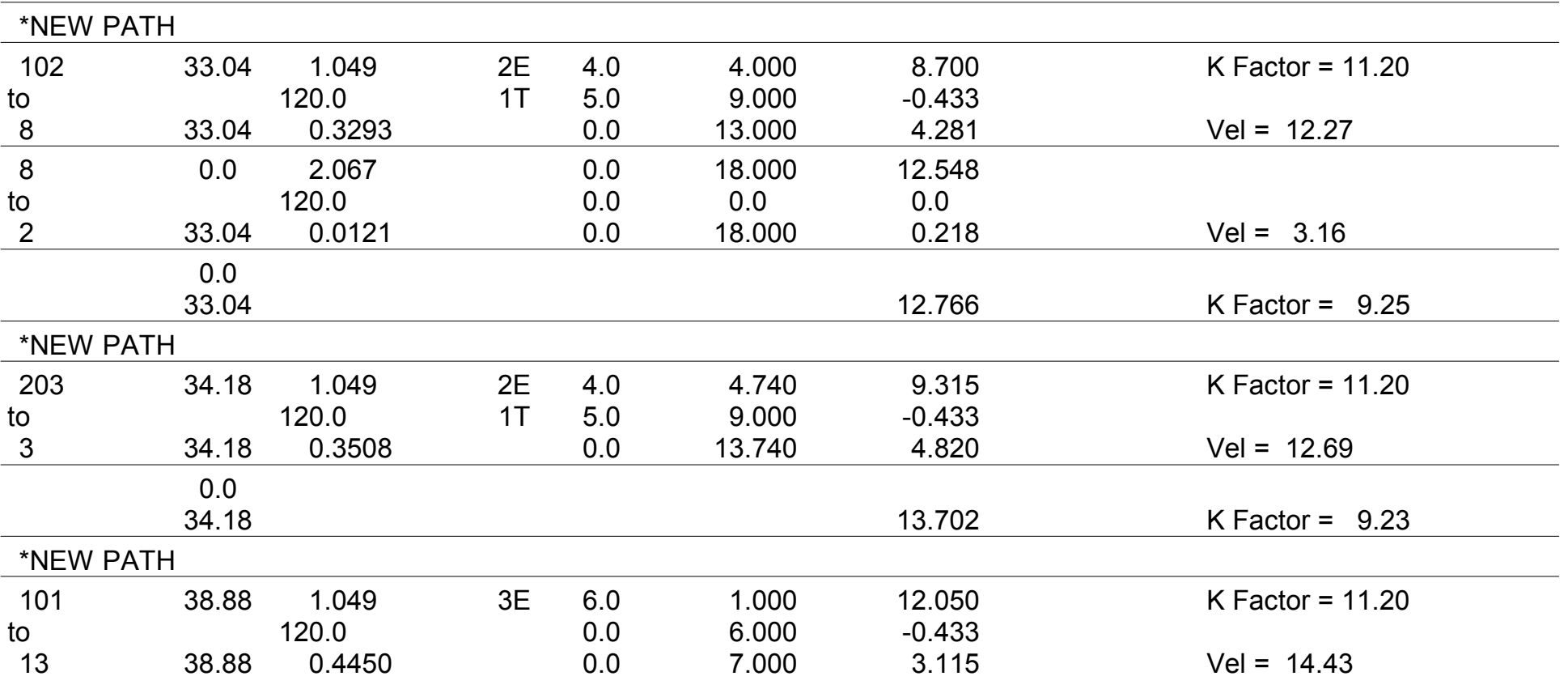

Computer Programs by Hydratec Inc. Route 111 Windham N.H. USA 03087 
Final Calculations - Hazen-Williams

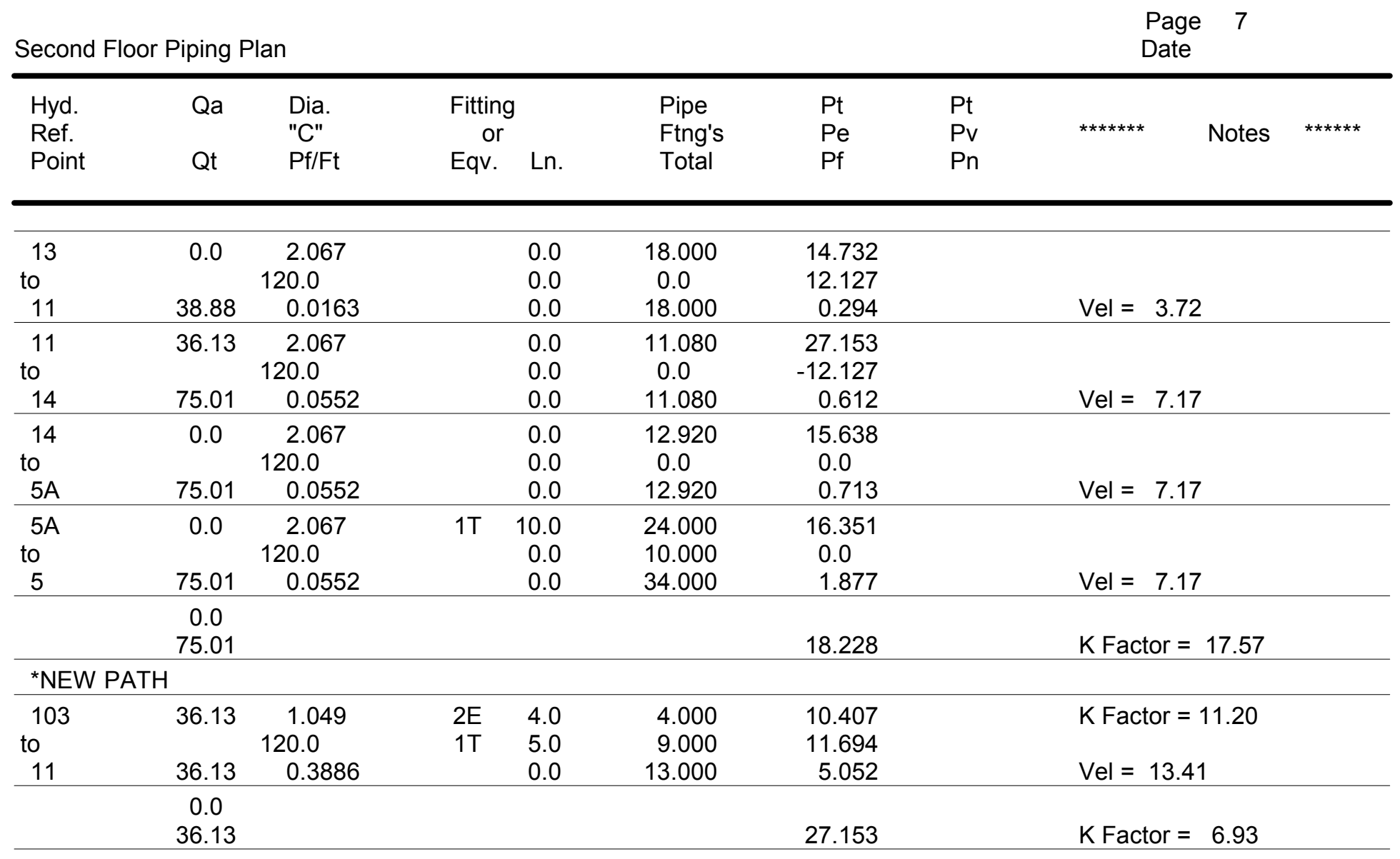




\section{APPENDIX I: FIRE SPRINKLER CUT SHEETS}




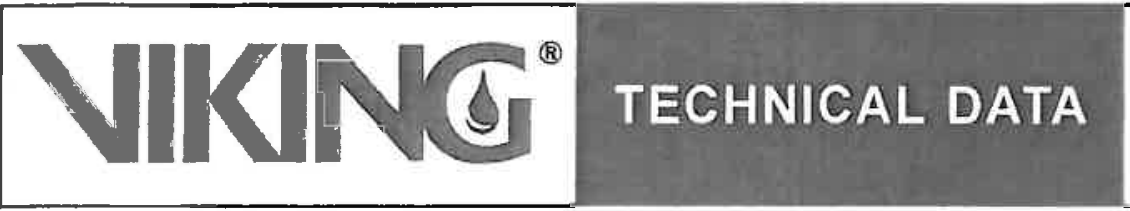

\section{EASY RISER ${ }^{\oplus}$ SWING \\ CHECK VALVE \\ MODELS E-1 \& F-1}

The Viking Corporation, 210 N Industrial Park Drive, Hastings Ml 49058

Telephone: 269-945-9501 Technical Services: 877-384-5464 Fax: 269-9454495 Email: techsvcs@vikingcorp.com

- System is designed so maximum operating pressures of the system do not exceed 175 PSI (12 bar).

- Refer to technical data pages 47a-c - Automatic Pressure Control System

Material Standards:

Refer to Figure 1

Ordering Information:

See Table 1 for part numbers and shipping weights

\section{INSTALLATION}

FOR THE VIKING ESFR COLD STORAGE SYSTEM, REFER TO DATA PAGE 45a-j FOR INSTRUCTIONS ON PLACING THE SYSTEM IN SERVICE.

The Easy Riser Swing Check Valve must be installed in an area not subject to freezing temperatures or physical damage. When corrosive atmospheres and/or contaminated water supplies are present, it is the owner's responsibility to verify compatibility with the Easy Riser Swing Check Valve, trim, and associated equipment.

Prior to installing the valve, thoroughly flush the water supply piping to verify that no foreign matter is present.

The Easy Riser Swing Check Valve may be installed in the vertical position with direction of flow up, or in the horizontal position with the access cover up.

1. Remove all plastic thread protectors from the openings of the Easy Riser Swing Check Valve.

2. Apply a small amount of pipe-joint compound or tape to the external threads of all pipe connections required. Take care not to allow any compound, tape, or other foreign matter inside any of the nipples or openings of the valve or trim components.

3. Easy Riser Swing Check Valve Trim Charts are provided with Trim Packages and in the Viking Engineering and Design Data book.

4. Verify that all system components are rated for the water working pressure of the system.

Hydrostatic Test:

The Easy Riser Swing Check Valve is manufactured and listed for use at a maximum water working pressure of 250 psi (17.2 bar). The valve is factory tested at $500 \mathrm{psi}$ ( 34.5 bar). Easy Riser Swing Check Valves may be hydrostatically tested at $300 \mathrm{psi}$ (20.7 bar) and/or $50 \mathrm{psi}$ ( $3.5 \mathrm{bar}$ ) above the normal water working pressure for limited periods of time (two hours) for the purpose of acceptance by the Authority Having Jurisdiction. If air testing is required, do not exceed 40 psi (2.8 bar) air pressure.

5. OPERATION (Refer to Figure 1)

Water flowing through the Viking Easy Riser ${ }^{\circ}$ Swing Check Valve lifts rubber-gasketed clapper (8 and 9$)$ off the seat (12) and flows into the sprinkler piping. When flow through the valve stops, the clapper (8) closes quickly. Rubber gasket (9) forms a tight seal against brass water seat (12), trapping pressurized water above the clapper and preventing reverse flow from the sprinkler piping.

\section{INSPECTIONS, TESTS AND MAINTENANCE}

FOR THE VIKING ESFR COLD STORAGE SYSTEM, REFER TO DATA PAGE 45 a-j FOR INSPECTIONS AND TESTS NOTICE: THE OWNER IS RESPONSIBLE FOR MAINTAINING THE FIRE-PROTECTION SYSTEM AND DEVICES IN PROPER OPERATING CONDITION.

The Viking Easy Riser Swing Check Valve and trim must be kept free of foreign matter, freezing conditions, corrosive atmospheres, contaminated water supplies, and any condition that could impair its operation or damage the device.

It is imperative that the system be inspected and tested on a regular basis. The frequency of the inspections may vary due to contaminated water supplies, corrosive water supplies, and corrosive atmospheres. For minimum maintenance and inspection requirements, refer to NFPA 25. In addition, the Authority Having Jurisdiction may have additional maintenance, testing, and inspection requirements that must be followed.

WARNING: ANY SYSTEM MAINTENANCE WHICH INVOLVES PLACING A CONTROL VALVE OR DETECTION SYSTEM OUT OF SERVICE MAY ELIMINATE THE FIRE-PROTECTION CAPABILITIES OF THAT SYSTEM. PRIOR TO PROCEEDING, NO. TIFY ALL THE AUTHORITY HAVING JURISDICTION. CONSIDERATION SHOULD BE GIVEN TO EMPLOYMENT OF A FIRE PATROL IN THE AFFECTED AREAS.

\section{6-A. Five-Year Internal Inspection}

Internal inspection of check valves is recommended every five years unless inspections and tests indicate more frequent inspections are required. (Refer to Figure 1)

1. Notify the Authority Having Jurisdiction, remote station alarm monitors, and those in the area affected that the system will be taken out of service. Consideration should be given to employment of a fire patrol in the affected areas. 


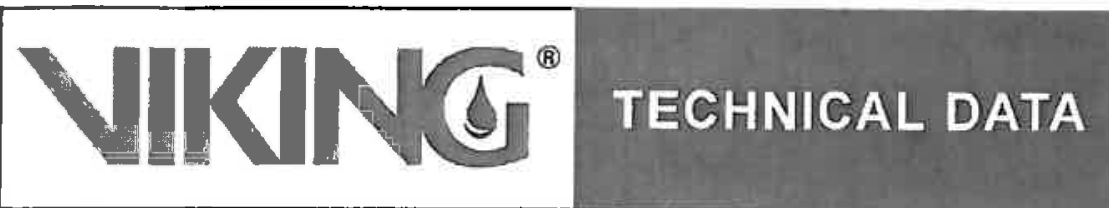

\section{EASY RISER SWING \\ CHECK VALVE \\ MODELS E-1 \& F-1}

The Viking Corporation, 210 N Ind ustrial Park Drive, Hastings Ml 49058

Telephone: 269-945-9501 Technical Services: 877-384-5464 Fax: 269-9454495 Email: techsvcs@vikingcorp.com

2. Close the water supply main control valve, placing the system out of service.

3. Open the main drain. If necessary, open the system test valve to vent and completely drain the system.

4. Use the appropriate wrench to loosen and remove cover screws (14), and remove cover/clapper assembly (2-11).

5. Inspect water seat (12). Wipe away all contaminants, dirt, and mineral deposits. Do not use solvents or abrasives.

6. Inspect cover/clapper assembly (2-11) and cover gasket (13). Test hinged clapper (8) for freedom of movement. Renew or replace damaged or worn parts as required. CAUTION: NEVER apply any lubricant to seats, gaskets, or any intemal operating parts of the valve. Petroleum-based grease or oil will damage rubber components and may prevent proper operation.

7. When intemal inspection of the Easy Riser Swing Check Valve is complete, perform step 6 of paragraph 11. MAINTENANCE to re-install cover/clapper assembly (2-11).

6-B. Maintenance (Refer to Figure 1)

FOR THE VIKING ESFR COLD STORAGE SYSTEM, REFER TO DATA PAGE 45a-j FOR MAINTENANCE INSTRUCTIONS.

1. Perform steps 1 through 5 of paragraph 6-A, FNE-YEAR INTERNAL INSPECTION.

2. To remove clapper rubber (9):

A. Use the appropriate wrenches to loosen and remove button-head socket screw (11), hex nut (6), sealing washer (7), and rubber retainer (10).

B. Remove the clapper rubber (9) for inspection. If the clapper rubber shows signs of wear, such as cracking, cuts, or excessively deep grooves where the rubber contacts the water seat, replace the rubber.

3. To re-install clapper rubber (9):

A. Place the clapper rubber ( 9 ) over the center hub of the rubber retainer (10).

B. Position the retainer (10) (with rubber in place) against the clapper (8) as shown in Figure 1.

C. Replace and tighten the button-head socket screw (11), sealing washer (7), and hex nut (6). The sealing washer (7) must be located on the top side of the clapper (8) as shown in Figure 1. DO NOT over-tighten.

4. To remove clapper (8), and/or hinge pin (4):

A. Remove the hinge pin retaining rings (5) to free the hinge pin (4) for removal. After the hinge pin (4) is removed, the clapper (8) can be removed.

5. To re-install clapper (8) and/or hinge pin (4):

A. Verify that the clapper rubber (9) is in good condition and that it is properly installed.

B. Position the clapper ( 8 ) with the elongated hinge holes aligned between the holes of the hinge bracket welded inside the cover (2). The system (top) side of the clapper (8) must face the direction indicated by the flow arrow stamped inside the cover (2).

C. Insert the hinge pin (4) through the holes at one end of the hinge assembly. Continue to push the hinge pin (4) through the holes at the remaining end of the hinge assembly.

D. Re-install the hinge pin retaining rings (5).

6. To re-install cover/clapper assembly (2-11):

A. Verify that the cover gasket (13) is in position and that it is in good condition.

B. Slide the cover/clapper assembly (2-11) into the Easy Riser Swing Check Valve so the clapper rubber (9) contacts the water seat (12).

C. Replace cover screws (14). Use the appropriate wrench to cross- tighten all cover screws to the torque values shown in Table 2 for the valve used. DO NOT over- tighten.

\section{AVAILABILITY}

The Viking Easy Riser Swing Check Valve is available through a network of domestic and international distributors. See the Viking Corp. Web site for closest distributor or contact The Viking Corporation.

\section{GUARANTEES}

For details of warranty, refer to Viking's current list price schedule or contact Viking directly. 


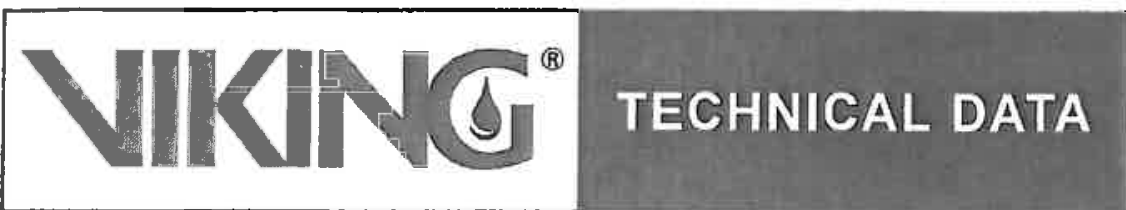

\section{EASY RISER ${ }^{\circledR}$ SWING \\ CHECK VALVE \\ MODELS E-1 \& F-1}

The Viking Corporation, 210 N Industrial Park Drive, Hastings MI 49058

Telephone: 269-945-9501 Technical Services: 877-384-5464 Fax: 269-9454495 Email: techsvcs@vikingcorp.com

\begin{tabular}{|c|c|c|c|c|}
\hline \multicolumn{5}{|c|}{ Table 1 - Valve Part Numbers and Specifications } \\
\hline Description & Nominalstee & $\begin{array}{c}\text { Part } \\
\text { Number }\end{array}$ & Friction Loss* & $\begin{array}{c}\text { Shipping } \\
\text { Wolght }\end{array}$ \\
\hline \multicolumn{5}{|l|}{ Flange/Flange } \\
\hline Flange Drilling & Model F-1 & & & \\
\hline ANSI & $3^{\prime \prime}$ & 08505 & $10 \mathrm{ft} \cdot(3.1 \mathrm{~m})$ & 35 lbs. (16 kg) \\
\hline ANSI, & $4^{\prime \prime}$ & 08508 & 13 ft. $(4.0 \mathrm{~m})$ & $27 \mathrm{lbs} .(12 \mathrm{~kg})$ \\
\hline ANSI & $6^{\prime \prime}$ & 08511 & $20 \mathrm{ft} .(6.0 \mathrm{~m})$ & $75 \mathrm{lbs} .(34 \mathrm{~kg})$ \\
\hline ANSIJJapan & DN100 & 09039 & 13 ft. $(4.0 \mathrm{~m})$ & 27 lbs. $(12 \mathrm{~kg})$ \\
\hline ANSUJJapan & DN150 & 09385 & $20 \mathrm{ft} .(6.0 \mathrm{~m})$ & $75 \mathrm{lbs} .(34 \mathrm{~kg})$ \\
\hline ANSUJapan & DN200 & 14023 & 23 tt. $(7.0 \mathrm{~m})$ & 119 lbs. $(54 \mathrm{~kg})$ \\
\hline PN10/16 & DN80 & 08796 & 10 ft. $(3.1 \mathrm{~m})$ & $35 \mathrm{lbs} .(16 \mathrm{~kg})$ \\
\hline PN10/16 & BN100 & 08797 & $13 \mathrm{ft} .(4.0 \mathrm{~m})$ & $27 \mathrm{lbs} .(12 \mathrm{~kg})$ \\
\hline PN10/16 & DN150. & 08835 & $20 \mathrm{fl} .(6.0 \mathrm{~m})$ & 75 lbs. (34 kg) \\
\hline PN10 & DN200 & 08836 & $23 \mathrm{ft} .(7.0 \mathrm{~m})$ & $119 \mathrm{lbs} .(64 \mathrm{~kg})$ \\
\hline PN16 & DN200 & 12355 & $23 \mathrm{ft} .(7.0 \mathrm{~m})$ & 119 lbs. $(54 \mathrm{~kg})$ \\
\hline \multicolumn{5}{|l|}{ FlangelGroove } \\
\hline $\begin{array}{r}\text { Flange Drilling / Pipe } \\
0 . \mathrm{D}\end{array}$ & Modelipi & & & \\
\hline ANSI $/ 89 \mathrm{~mm}$ & $3:$ & 08506 & 10 ft. $(3.1 \mathrm{~m})$ & $27 \mathrm{lbs} .(12 \mathrm{~kg})$ \\
\hline ANSI / 114mm & 4 & 08509 & $13 \mathrm{ft} .(4.0 \mathrm{~m})$ & $37 \mathrm{lbs} .(17 \mathrm{~kg})$ \\
\hline ANSI / 168mm & $6^{\circ}$ & 08512 & $20 \mathrm{ft} .(6.0 \mathrm{~m})$ & 64 lbs. $(29 \mathrm{~kg})$ \\
\hline ANSI $/ 219 \mathrm{~mm}$ & 8 & 08515 & $23 \mathrm{ft}(7.0 \mathrm{~m})$ & 119 lbs. $(54 \mathrm{~kg})$ \\
\hline PN10/16 / 89mm & DN8D & 12648 & 10 t. $(3.1 \mathrm{~m})$ & 27 lbs. $(12 \mathrm{~kg})$ \\
\hline PN10/16 / 114mm & DN1OO & 12649 & $13 \mathrm{ft.}(4.0 \mathrm{~m})$ & 37 lbs. $(17 \mathrm{~kg})$ \\
\hline PN10/16 / 165mm & Dedt5o & 12652 & $20 \mathrm{ft} .(6.0 \mathrm{~m})$ & 64 lbs. (29 kg) \\
\hline PN10/16/168mm & DN150 & 08512 & 20 ft. $(6.0 \mathrm{~m})$ & 64 lbs. $(29 \mathrm{~kg})$ \\
\hline PN10 $/ 219 \mathrm{~mm}$ & DN200 & 12651 & $23 \mathrm{ft} .(7.0 \mathrm{~m})$ & 119 lbs. (64 kg) \\
\hline PN16 / 219mm & BN200 & 12650 & $23 \mathrm{ft} .(7.0 \mathrm{~m})$ & 119 lbs. $(54 \mathrm{~kg})$ \\
\hline \multicolumn{5}{|l|}{ Groove/Groove } \\
\hline Pipe O.D. & Modd EA & & & \\
\hline $73 \mathrm{~mm}$ & 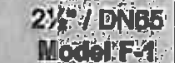 & 07929 & $6 \mathrm{ft} .(1.8 \mathrm{~m})$ & 16 lbs. (7kg) \\
\hline $89 \mathrm{~mm}$ & $3 /$ DNOO & 08507 & 10 ft. $(3.1 \mathrm{~m})$ & $20 \mathrm{lbs} .(9 \mathrm{~kg})$ \\
\hline $114 \mathrm{~mm}$ & 41 DNfOO & 08510 & $13 \mathrm{ft} .(4.0 \mathrm{~m})$ & 27 lbs. (12 kg) \\
\hline $165 \mathrm{~mm}$ & DN150 & 12356 & $20 \mathrm{ft} .(6.0 \mathrm{~m})$ & 51 lbs. $(23 \mathrm{~kg})$ \\
\hline $168 \mathrm{~mm}$ & $\left.6^{*}\right]$ DKT50 & 08513 & $20 \mathrm{ft}(0.0 \mathrm{~m})$ & $51 \mathrm{lbs} .(23 \mathrm{~kg})$ \\
\hline $219 \mathrm{~mm}$ & $\theta^{*} / D N_{200}$ & 08516 & $23 \mathrm{ft} .(7.0 \mathrm{~m})$ & 106 lbs. $(46 \mathrm{~kg})$ \\
\hline
\end{tabular}

\begin{tabular}{|c|c|c|}
\hline \multicolumn{3}{|c|}{$\begin{array}{c}\text { Table } 2 \text { - Torque Values for } \\
\text { Easy Riser Swing Check Valve } \\
\text { Cover Screws }\end{array}$} \\
\hline $\begin{array}{c}|c| \\
\text { Valve }\end{array}$ & $\begin{array}{c}\text { Screw } \\
\text { Size }\end{array}$ & $\begin{array}{c}\text { Torque } \\
\text { Value }\end{array}$ \\
\hline $2-1 / 2^{\prime \prime}$ & $3 / 8^{n}-16$ & $19 \mathrm{ft}-\mathrm{lb}$ \\
$(\mathrm{DN65})$ & H.H.C. & $(2.63 \mathrm{~kg}-\mathrm{m})$ \\
\hline $3^{n}$ & $3 / 8^{n}-16$ & $19 \mathrm{ft-lb}$ \\
$(\mathrm{DNBO})$ & H.H.C. & $(2.63 \mathrm{~kg}-\mathrm{m})$ \\
\hline $4^{\prime \prime}$ & $3 / 8^{n}-16$ & $19 \mathrm{ft}-\mathrm{lb}$ \\
$(\mathrm{DN100)})$ & H.H.C. & $(2.63 \mathrm{~kg}-\mathrm{m})$ \\
\hline $6^{\prime \prime}$ & $1 / 2^{\prime \prime}-13$ & $45 \mathrm{ft-lb}$ \\
(DN150) & H.H.C. & $(6.23 \mathrm{~kg}-\mathrm{m})$ \\
\hline $8^{\prime \prime}$ & $5 / 8^{\prime \prime}-11$ & $93 \mathrm{ft}-\mathrm{lb}$ \\
(DN200) & H.H.C. & $(12.9 \mathrm{~kg}-\mathrm{m})$ \\
\hline
\end{tabular}




\section{VIKINGi: TECHNICAL DATA}

\section{EASY RISER ${ }^{\circledR}$ SWING \\ CHECK VALVE \\ MODELS E-1 \& F-1}

The Viking Corporation, 210 N Industrial Park Drive, Hastings MI 49058

Telephone: 269-945-9501 Technical Services: 877-384-5464 Fax: 269-9454495 Email: techsvcs@vikingcorp.com

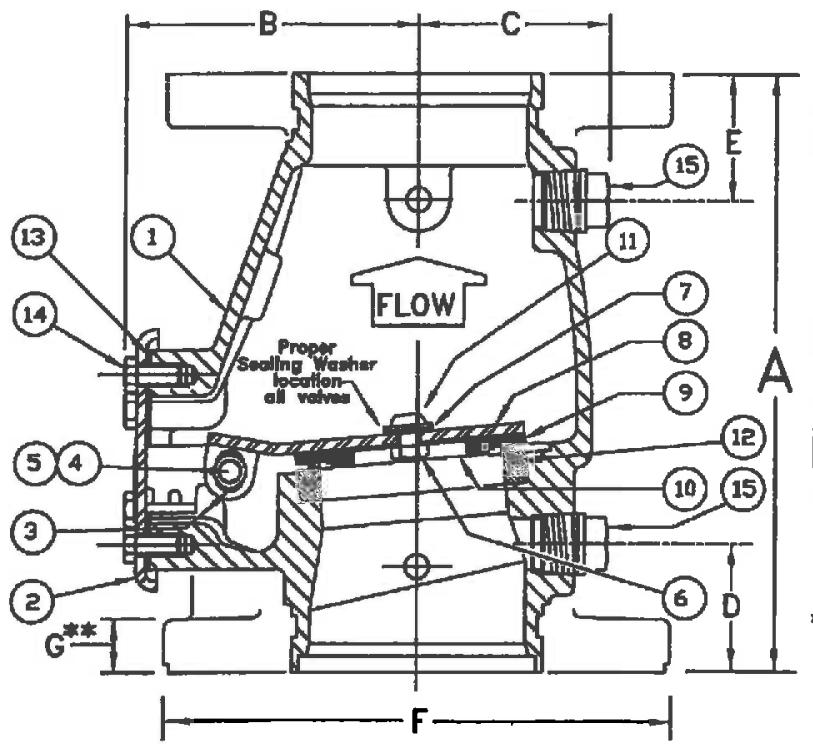

\begin{tabular}{|c|c|c|c|c|c|c|c|}
\hline S12E & $\stackrel{A}{=}$ & $B$ & C & D & $E$ & $F$ & * \\
\hline $\begin{array}{l}2-1 / 2^{m} \\
(65 m m)\end{array}$ & $(228,6)$ & $\left(2^{\prime \prime}\right.$ & $\begin{array}{l}2-5 / 8^{m} \\
(66,7)\end{array}$ & $\begin{array}{c}2^{\prime \prime} \\
(50,8)\end{array}$ & $(50,8)$ & \multicolumn{2}{|c|}{$\begin{array}{c}\mathrm{Flg} / \mathrm{Flg} \\
\text { Not Avalloble }\end{array}$} \\
\hline $\begin{array}{c}3^{m} \\
(80 \mathrm{~mm})\end{array}$ & $\begin{array}{c}0-3 / 16 \\
(259)\end{array}$ & $\begin{array}{l}4-3 / 4^{\prime \prime} \\
(120,7)\end{array}$ & $\begin{array}{c}2-3 / 4^{m} \\
(69,9)\end{array}$ & $(50,8)$ & $(50,8)$ & $\begin{array}{l}7-1 / 2^{n} \\
(196,5)\end{array}$ & \\
\hline $100 \mathrm{~mm})$ & $\begin{array}{l}10-5 / 8^{2} \\
(269,9)\end{array}$ & $\begin{array}{l}5-3 / 16^{2} \\
(131,8)\end{array}$ & $\begin{array}{l}3-3 / 8^{m} \\
(85,7)\end{array}$ & $\begin{array}{l}2-1 / 8^{\prime \prime} \\
(54,0)\end{array}$ & $\begin{array}{l}2-1 / 4^{\prime \prime} \\
(57,2)\end{array}$ & $\begin{array}{c}9^{\prime \prime} \\
(228,6)\end{array}$ & \\
\hline $\begin{array}{c}6^{\circ} \\
150 \mathrm{~mm})\end{array}$ & & $\begin{array}{l}6-3 / 4^{4} \\
(171,5)\end{array}$ & $\begin{array}{l}4-3 / 8^{m} \\
(111,1)\end{array}$ & $\frac{2-1 / 4^{n}}{(57,2)}$ & $\begin{array}{l}2-1 / 4^{n} \\
(57,2)\end{array}$ & & $(25,4)$ \\
\hline $\begin{array}{c}8^{\prime \prime} \\
00 \mathrm{~mm})\end{array}$ & $\begin{array}{c}17^{\prime \prime} \\
(431,8)\end{array}$ & $\begin{array}{l}8-3 / 4^{4} \\
(222,3)\end{array}$ & $\begin{array}{l}5-3 / 8^{11} \\
136,5)\end{array}$ & $\begin{array}{l}2-1 / 2^{21} \\
(63,5)\end{array}$ & $\begin{array}{l}2-7 / 8^{11} \\
(73,0)\end{array}$ & $\begin{array}{l}3-1 / 2^{m} \\
(342,9)\end{array}$ & $\begin{array}{l}1-1 / 8^{2} \\
(28,58)\end{array}$ \\
\hline
\end{tabular}

Dimansions shown in porentheses are millimeter.

* For avollability of $\mathrm{Flg} \times \mathrm{Flg}$, Flg $\times$ Grv, or Gry $\times$ Grv optiona rafer to Table 1.

" 4", 6", and $8^{\prime \prime}$ valves ore manufactured with sculpfurod flonges. Dimension indicates thickness of flonge at bolt holes.

Figure 1 - Replacement Parts

\begin{tabular}{|c|c|c|c|c|c|c|c|c|c|c|c|c|}
\hline \multirow{3}{*}{ ITEM } & & PAI & RT NUME & BER & & \multirow{3}{*}{ DESCRIPTION } & \multirow{3}{*}{ MATERIAL } & \multirow{2}{*}{\multicolumn{5}{|c|}{ NO. REQ'D }} \\
\hline & \multirow{2}{*}{$\begin{array}{c}E-1 \\
2-1 / 2 " \\
\text { (DNES) }\end{array}$} & \multirow{2}{*}{$\begin{array}{c}F-1 \\
3^{\prime \prime} \\
(D N 80)\end{array}$} & \multirow{2}{*}{\begin{tabular}{|c|}
$F-1$ \\
$4^{n}$ \\
(DN100)
\end{tabular}} & \multirow{2}{*}{\begin{tabular}{|c|}
$F-1$ \\
$6^{\prime \prime \prime}$ \\
(DN150) \\
\end{tabular}} & \multirow{2}{*}{\begin{tabular}{|c|}
$F-1$ \\
$g^{n}$ \\
[ON2DOS
\end{tabular}} & & & & & & & \\
\hline & & & & & & & & $2 \cdot 1 / 2^{m}$ & $3 "$ & \multicolumn{3}{|c|}{\begin{tabular}{|l|l|l|}
$4^{\prime \prime}$ & $6^{11}$ & $8^{11}$ \\
\end{tabular}} \\
\hline 1 & - & - & - & - & - & Body & $\begin{array}{l}\text { Ductile 1ron, ASTM A536 } \\
(65-45-12)\end{array}$ & 1 & 1 & 1 & 1 & 1 \\
\hline 2 & - & - & - & - & - & Cover Assembly & \begin{tabular}{|l|} 
E-Coated HSLASteel,A715 and \\
Stainless Steel, UNS-S30400
\end{tabular} & 1 & 1 & 1 & 1 & 1 \\
\hline 3 & 07576 & 07576 & 07576 & 07576 & None & Bushing & Lubricomp 189 Ryton & 2 & 2 & 2 & 2 & D \\
\hline 4 & $05355 \mathrm{~A}$ & $05355 \mathrm{~A}$ & $04900 \mathrm{~A}$ & $04991 \mathrm{~A}$ & $05334 \mathrm{~A}$ & Clapper Hinge Pin & Stainless Steel, UNS-S30400 & 1 & 1 & 1 & 1 & 1 \\
\hline 5 & $05445 \mathrm{~A}$ & 05445A & $0.5445 \mathrm{~A}$ & 05445A & $05369 \mathrm{~A}$ & Hinge Pin Retalning Ring & Stainless Steel, UNS-S15700 & 2 & 2 & 2 & 2 & 2 \\
\hline 6 & $01755 \mathrm{~A}$ & & & & & Clapper Hex Jam Nut \#10-24 UNC & Stalnless Steel, UNS-S30400 & 1 & 0 & 0 & 0 & 0 \\
\hline & & 08159 & 08159 & & & Clapper Hex Jam Nut 3/8"-24 UNF & Stainless Steel, UNS-S30400 & 0 & 1 & 1 & 0 & 0 \\
\hline & & & & 08144 & 08144 & Clapper Hex Jam Nut $y_{2}^{\prime \prime}-20$ UNF & Slainless Sted, UNS-S30400 & 0 & 0 & 0 & 1 & 1 \\
\hline 7 & - & 08158 & 08158 & 08143 & 08143 & Sealing Washer & EPDM and Stalnless Steel & 1 & 1 & 1 & 1 & 1 \\
\hline 8 & - & - & * & - & * & Clapper & \begin{tabular}{|l} 
Teflon Coated HR Steel UNS- \\
G10180
\end{tabular} & 1 & 1 & 1 & 1 & 1 \\
\hline 9 & * & - & 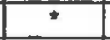 & $\div$ & 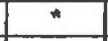 & Clapper Rubber & EPDM, ASTM D2000 & 1 & 1 & 1 & 1 & 1 \\
\hline 10 & $\div$ & * & 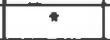 & " & 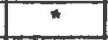 & Clapper Rubber Retainer & Stainless Steel, UNS-S30400 & 1 & 1 & 1 & 1 & 1 \\
\hline \multirow{4}{*}{11} & $06595 \mathrm{~A}$ & & & & & H.H.C. Screw, \#10-24 UNC x $1 / 2^{n}(12.7 \mathrm{~mm}) \mathrm{lg}$. & Stainless Steel, UNS-S30400 & 1 & 0 & 0 & 0 & 0 \\
\hline & & 10194 & 10194 & & & $\begin{array}{l}\text { Serew, Button Head, Socket, 3/8" - } 24 \text { UNF X } \\
1 / 2(12.7 \mathrm{~mm}) \mathrm{lg} .\end{array}$ & Stainless Steel, UNS-S30400 & 0 & 1 & 1 & 0 & 0 \\
\hline & & & & 10308 & & $\begin{array}{l}\text { Screw, Button Head, Socket, } 1 / 2^{n} \text { - } 20 \text { UNF x } \\
3 / 4(19.1 \mathrm{~mm}) \mathrm{lg} \text {. }\end{array}$ & Stainless Steel, UNS-S30400 & 0 & 0 & 0 & 1 & 0 \\
\hline & & & & & 10686 & $\begin{array}{l}\text { Screw, Button Head, Socket, } 1 / 2^{\mathrm{m}} \text { - } 20 \text { UNF X } \\
7 / 8(22.2 \mathrm{~mm}) \mathrm{lg} \text {. }\end{array}$ & Stainless Steal, UNS-S30400 & 0 & 0 & 0 & 0 & 1 \\
\hline 12 & - & - & - & - & - & Seat & Brass, UNS-C84400 & 1 & 1 & 1 & 1 & 1 \\
\hline 13 & $05354 \mathrm{~B}$ & $05354 \mathrm{~B}$ & $04649 \mathrm{~B}$ & 04992B & $05339 \mathrm{C}$ & Cover Gaskel & EPDM, ASTM D2000 & 1 & 1 & 1 & 1 & 1 \\
\hline \multirow{3}{*}{14} & 01517A & $01517 A$ & $01517 A$ & & & $\begin{array}{l}\text { Screw Hex Head Cap, } 3 / 8^{\prime \prime}-16 \text { UNC X } \\
3 / 4(19.1 \mathrm{~mm}) \mathrm{lg} \text {. }\end{array}$ & Steel, Zinc Plated & 4 & 4 & 6 & 0 & 0 \\
\hline & & & & $04993 \mathrm{~A}$ & & Screw, Hex Head Cap, 1/2" - $13 \times 7 / 8(22.2 \mathrm{~mm}) \mathrm{kg}$ & Steel, Zinc Plated & 0 & 0 & 0 & 6 & 0 \\
\hline & & & & & |01922A & $\begin{array}{l}\text { Screw, Hex Head Cap, 5/8" - } 11 \text { UNC x } \\
\text { 1-1/4" (31.8 mm) lg. }\end{array}$ & Steel, Zinc Plated & 0 & 0 & 0 & 0 & 6 \\
\hline 15 & $=$ & - & - & - & $=$ & $1 / 2^{\mathrm{n}}(15 \mathrm{~mm})$ NPT Pipe Plug & Steel & 2 & 2 & 2 & 2 & 2 \\
\hline \multicolumn{13}{|c|}{$\begin{array}{l}\text { - Indicates replacoment part is not avaliable } \\
\text { - Indlicatas replactament part only aveslable ir }\end{array}$} \\
\hline \multicolumn{13}{|c|}{ Sub-Assemblies } \\
\hline $3,6-11$ & 05499B & 08518 & 08519 & 08520 & 08521 & Clapper Assembly & & & & & & \\
\hline $6,7,13$ & $06349 \mathrm{~A}$ & 08522 & 08523 & 08524 & 08525 & Replacement Rubber Kit & & & & & & \\
\hline
\end{tabular}




\section{VIIKING: TECHNICAL DATA}

\section{EASY RISER ${ }^{\circledR}$ SWING \\ CHECK VALVE}

MODELS E-1 \& F-1

The Viking Corporation, 210 N Industrial Park Drive, Hastings MI 49058

Telephone: 269-945-9501 Technical Services: 877-384-5464 Fax: 269-9454495 Email: techsvcs@vikingcorp.com

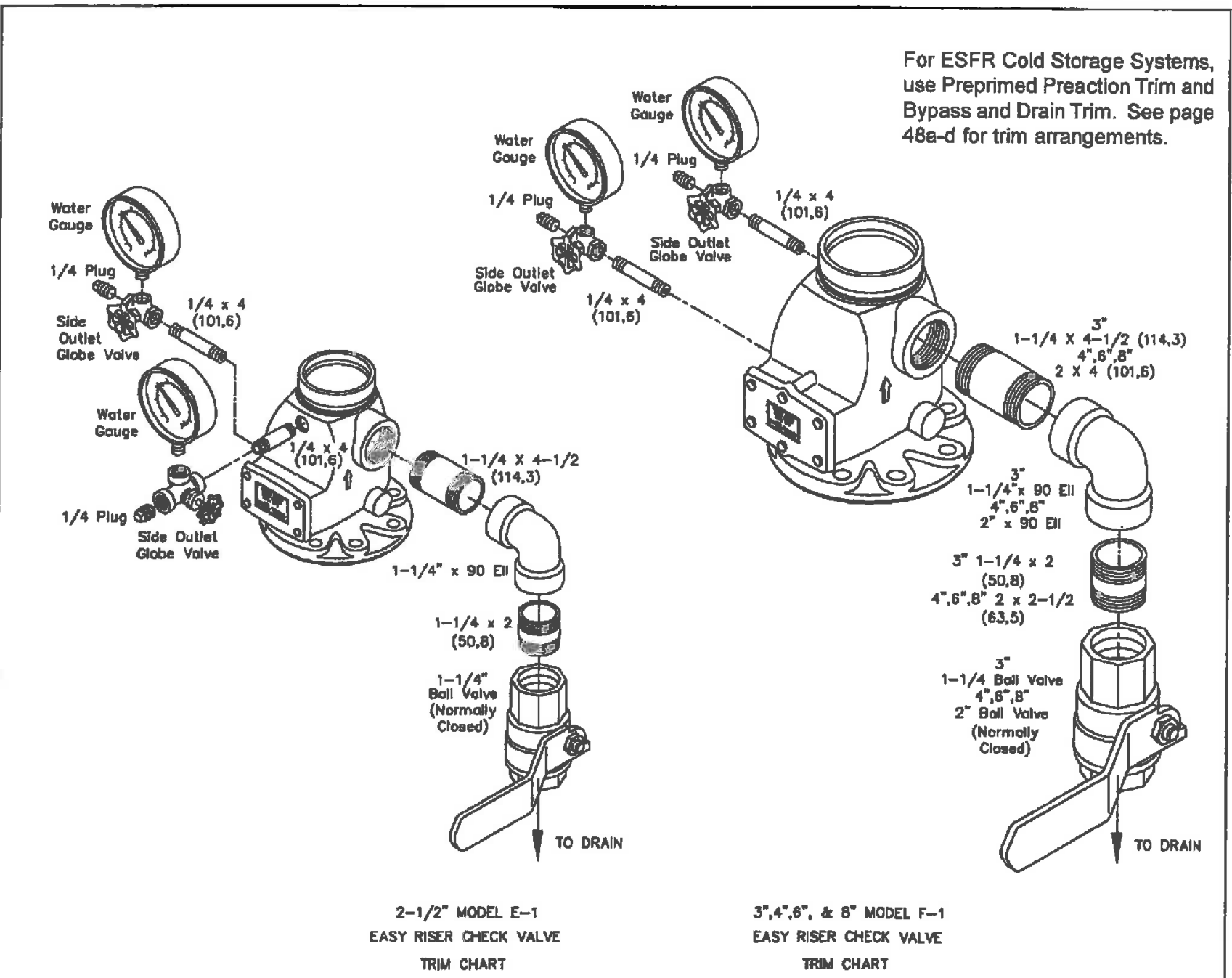

Figure 2

Note 1: 300 psi (20.7 bar) water pressure gauges are provided with trim. 600 psi ( 41.4 bar) water pressure gauges are available. Order separately when needed". Refer to Viking's current price schedule.

* NFPA 13 requires gauges to have a minimum limit not less than twice the normal water working pressure at the point where the gauges are installed. When normal water working pressure exceeds $150 \mathrm{psl}$ (10.3 bar), order 600 psi (41.4 bar) water pressure gauges separately.

Note 2: System Drain Ball Valve is UL Listed and FM Approved for 250 psi (17.2 bar) water working pressure. 


\section{TECHNICAL D/ATA}

EASY RISER ${ }^{\circledR}$ SWING

CHECK VALVE

MODELS E-1 \& F-1

The Viking Corporation, 210 N Industrial Park Drive, Hastings Ml 49058

Telephone: 269-945-9501 Technical Services: 877-384-5464 Fax: 269-9454495 Email: techsvcs@vikingcorp.com

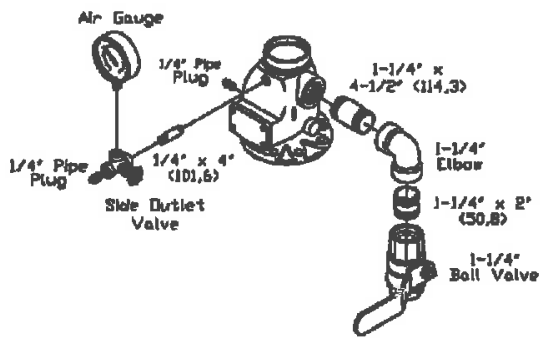

e-1/25 [DN65] MODEL E-1

EASY RISER PREACTION
TRIM CHART

Part No. 13776

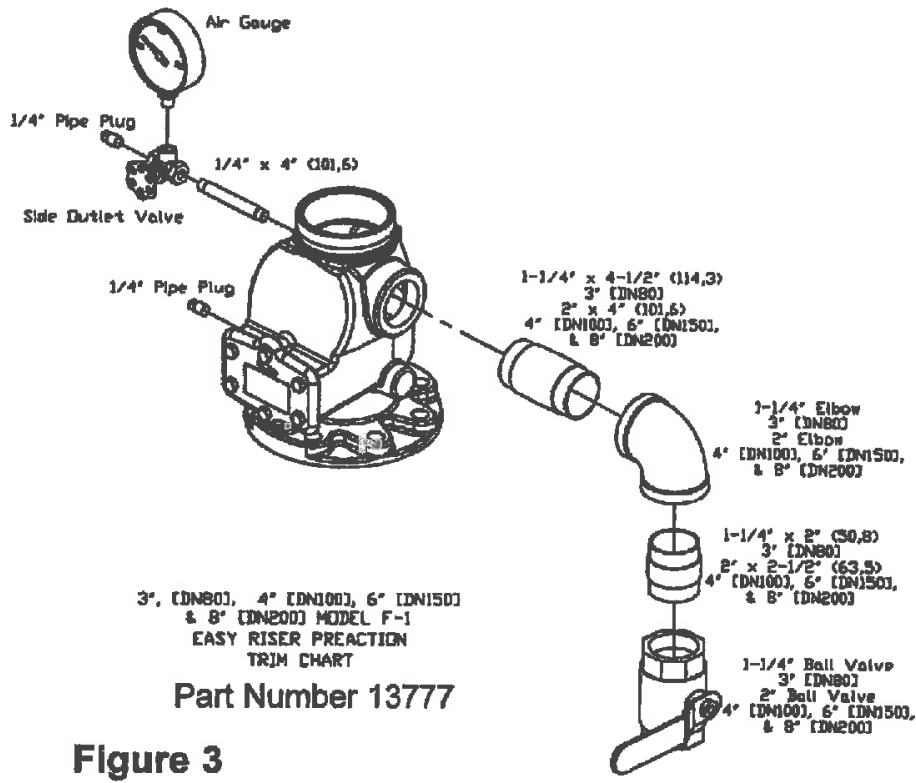

Figure 3

For use on Preaction Systems

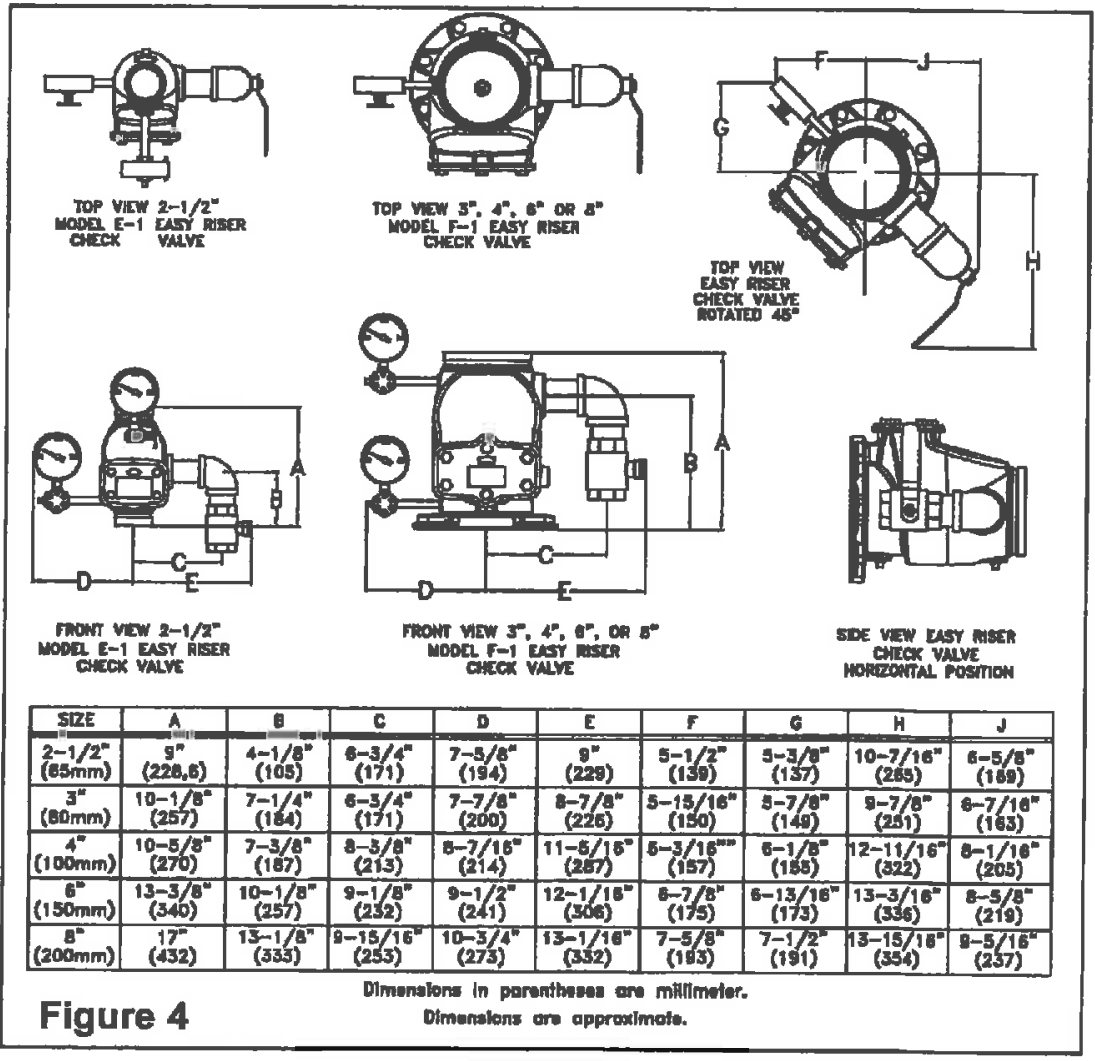




\section{THIS PAGE INTENTIONALLY LEFT BLANK}




\begin{tabular}{|l|l|}
\hline TECHNICAL DATA & $\begin{array}{c}\text { MICROFAST }{ }^{\circ} \text { STANDARD/ } \\
\text { QUICK RESPONSE } \\
\text { EXTENDED COVERAGE } \\
\text { PENDENT SPRINKLERS }\end{array}$ \\
\hline
\end{tabular}

The Viking Corporation, 210 N Industrial Park Drive, Hastings MI 49058

Telephone: 269-945-9501 Technical Services: 877-384-5464 Fax: 269-818-1680 Email: techsvcs@vikingcorp.com

\section{DESCRIPTION}

Viking Microfast EC/QREC Pendent Sprinklers are small thermosensitive spray sprinklers available in several different finishes and temperature ratings to meet varying design requirements. These sprinklers have both standard response and quick response listings. The fast response type glass bulb and special deflector combine speed of operation and area of coverage to meet quick response extended coverage standards.

The special Polyester coating can be used in decorative applications where colors are desired.

\section{LISTINGS AND APPROVALS}

cULus Listed: Category VNIV

FM Approved: Class 2020

NYC Approved: City of New York Board of Standards and Appeals, Calendar No. 219-76-SA

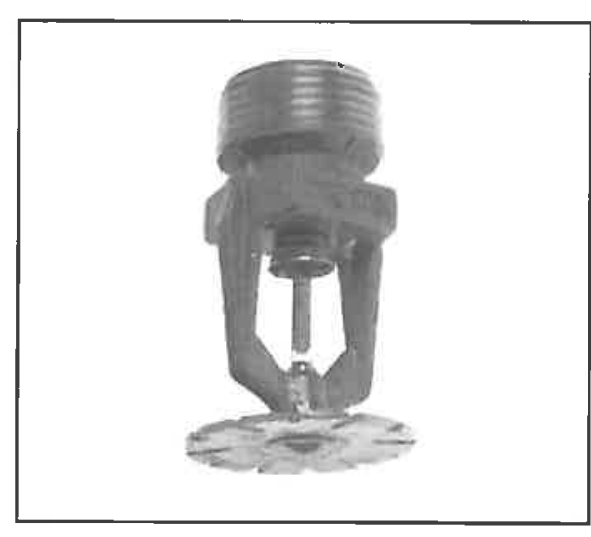

For Light Hazard Occupancies Only

Refer to Approval Chart 1 and Design Criteria on pages 81c-d for cULus Listing requirements, and refer to Approval Chart 2 and Design Criteria on page 81e for FM Approval requirements that must be followed.

\section{TECHNICAL DATA}

Specifications:

Available since 1988.

Minimum Operating Pressure: Refer to the Approval Charts.

Maximum Working Pressure: 175 psi (12 Bar). Factory tested hydrostatically to 500 psi (34.5 bar).

Factory tested hydrostatically to 500 psi (34.5 bar).

Testing: U.S.A. Patent No. 4,831,870

Thread sizes: Part No. 06778B: 1/2" (15 mm) NPT

Part No. 07077: 3/4" (20 mm) NPT

Nominal K-Factors: 06778B: 5.6 U.S. (80.6 metric $)$ )

07077: 8.0 U.S. (115.2 metric†)

Viking Technical Data may be found on

The Viking Corporation's Web site at http://www.vikinggroupinc.com.

The Web site may Include a more recent edition of this Technical Data Page.

†Metric K-factor measurement shown is when pressure is measured in Bar. When pressure is measured in $\mathrm{kPa}$, divide the metric $\mathrm{K}$-factor shown by 10.0 .

Glass-bulb fluid temperature rated to $-65^{\circ} \mathrm{F}\left(-55^{\circ} \mathrm{C}\right)$

Overall Length: Part No. 06778B: 2-5/16 (59 mm)

Part No. 07077: 2-3/8" (61 mm)

Material Standards:

Sprinkler Frame: Brass UNS-C84400 or QM Brass for Sprinkler 06778B. Brass UNS-C84400 for all other sprinklers.

Deflector: Brass UNS-C26000

Bulb: Glass, nominal $3 \mathrm{~mm}$ diameter

Belleville Spring Sealing Assembly: Nickel Alloy, coated on both sides with Teflon Tape

Screw: Brass UNS-C36000

Pip Cap and Insert Assembly: Copper UNS-C11000 and Stainless Steel UNS-S30400

For Polyester Coated Sprinklers: Belleville Spring-Exposed

Ordering Information: (Also refer to the current Viking price list.)

Order Microfast EC/QREC Pendent Sprinklers by first adding the appropriate suffix for the sprinkler finish and then the appropriate suffix for the temperature rating to the sprinkler base part number.

Finish Suffix: Brass = A, Chrome-Enloy ${ }^{\circ}=F$, White Polyester $=M-M$, and Black Polyester $M-/ B$

Temperature Suffix $\left({ }^{\circ} \mathrm{F} /{ }^{\circ} \mathrm{C}\right): 135^{\circ} / 57^{\circ}=\mathrm{A}, 155^{\circ} / 68^{\circ}=\mathrm{B}, 175^{\circ} / 79^{\circ}=\mathrm{D}$

For example, sprinkler VK600 with a Brass finish and a $155^{\circ} \mathrm{F} / 68^{\circ} \mathrm{C}$ temperature rating $=$ Part No. $06778 \mathrm{BAB}$

Available Finishes And Temperature Ratings: Refer to Table 1

Accessories: (Also refer to the "Sprinkler Accessories" section of the Viking data book.) 


\section{VIKING}

\section{TECHNICAL DATA}

\section{MICROFAST ${ }^{\circledR}$ STANDARD/ QUICK RESPONSE EXTENDED COVERAGE PENDENT SPRINKLERS}

The Viking Corporation, 210 N Industrial Park Drive, Hastings MI 49058 Telephone: 269-945-9501 Technical Services: 877-384-5464 Fax: 269-818-1680 Email: techsvcs@vikingcorp.com Sprinkier Wrenches:

A. Standard Wrench: Part No. 10896W/B (available since 2000)

B. Wrench for recessed pendent sprinklers: Part No. 13577 W/B $^{* *}$ (available since 2006)

${ }^{*} A \mathrm{~A} 12^{n}$ ratchet is required (not available from Viking). Sprinkler Cabinets:

A. Six-head capacity: Part No. 01724A (available since 1971)

B. Twelve-head capacity: Part No. 01725A (available since 1971)

\section{INSTALLATION}

Refer to appropriate NFPA Installation Standards.

\section{OPERATION}

During fire conditions, the heat-sensitive liquid in the glass bulb expands, causing the glass to shatter, releasing the pip cap and sealing spring assembly. Water flowing through the sprinkler orifice strikes the sprinkler deflector, forming a uniform spray pattern to extinguish or control the fire.

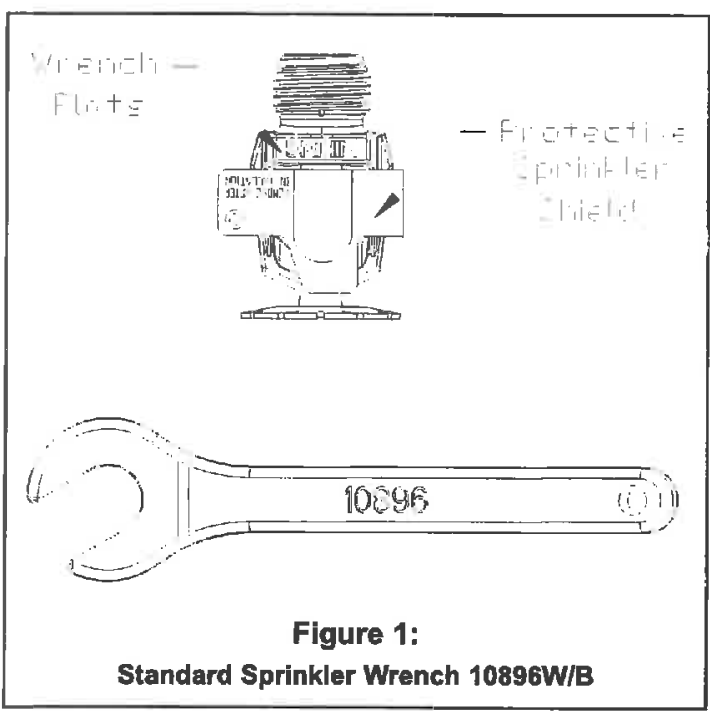

\section{INSPECTIONS, TESTS AND MAINTENANCE}

Refer to NFPA 25 for Inspection, Testing and Maintenance requirements.

\section{AVAILABILITY}

Viking Microfast ${ }^{\star} \mathrm{EC} / \mathrm{QREC}$ Pendent Sprinklers are available through a network of domestic and international distributors. See The Viking Corporation web site for the closest distributor or contact The Viking Corporation.

\section{GUARANTEE}

For details of warranty, refer to Viking's current list price schedule or contact Viking directly.

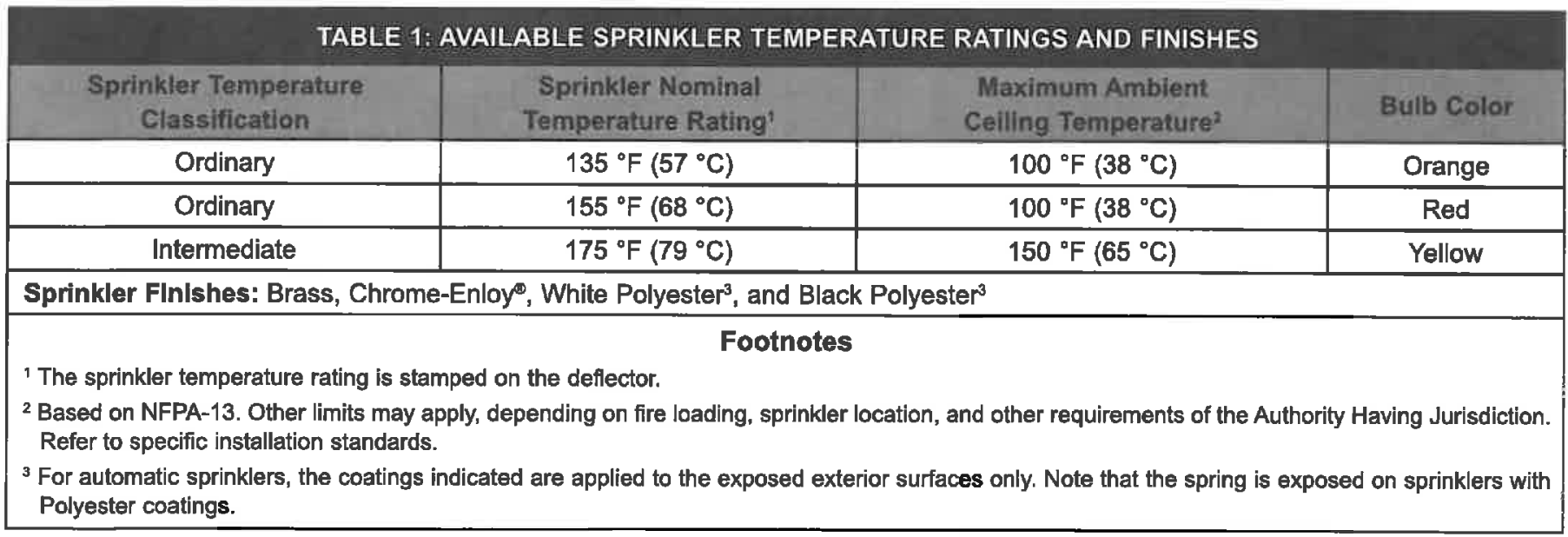


MICROFAST ${ }^{\circledR}$ STANDARD/ QUICK RESPONSE EXTENDED COVERAGE PENDENT SPRINKLERS

The Viking Corporation, $210 \mathrm{~N}$ Industrial Park Drive, Hastings MI 49058

Telephone: 269-945-9501 Technical Services: 877-384-5464 Fax: 269-818-16:B0 Emall: techsvcs@vikingcorp.com

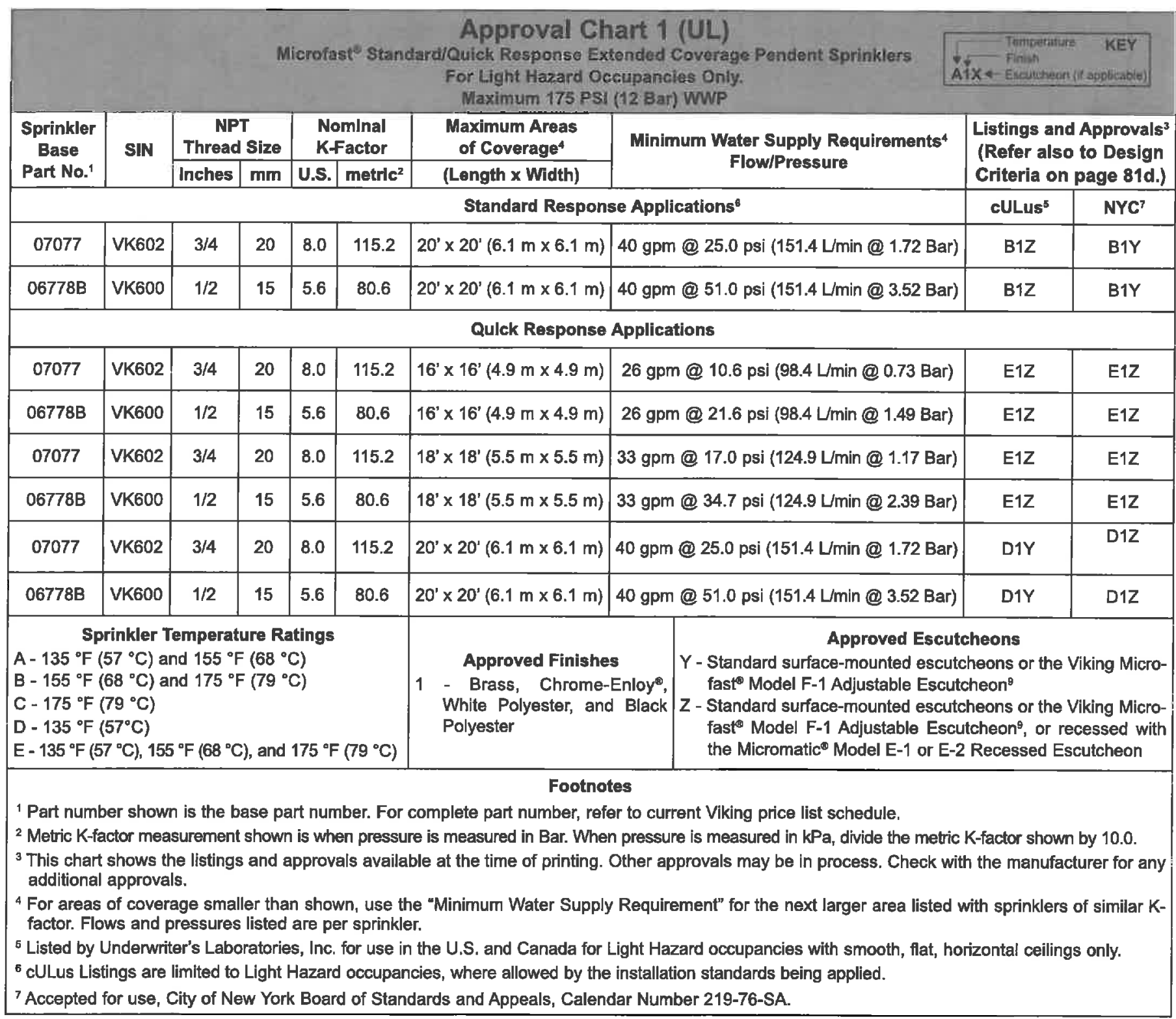




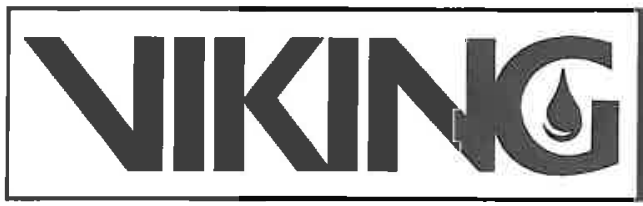

\section{TECHNICAL DATA}

The Viking Corporation, $210 \mathrm{~N}$ Industrial Park Drive, Hastings MI 49058

Telephone: 269-945-9501 Technical Services: 877-384-5464 Fax: 269-1318-1680 Email: techsvcs@vikingcorp.com

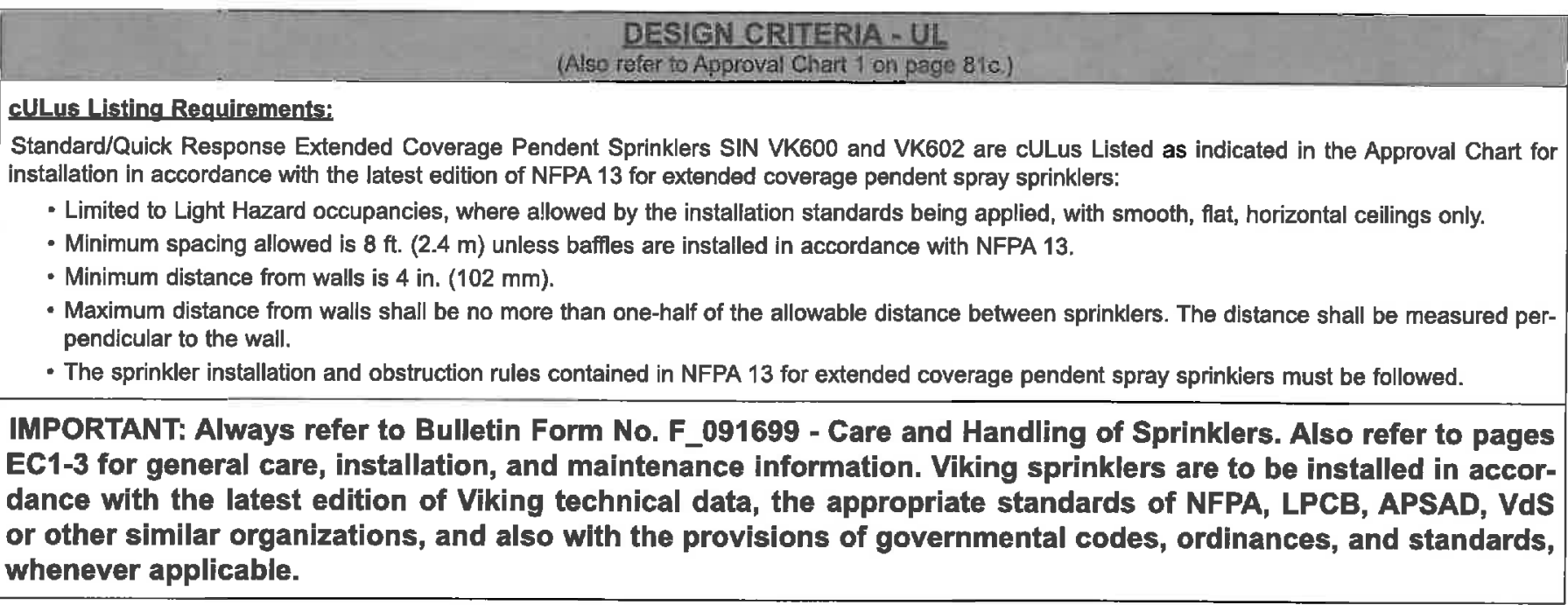

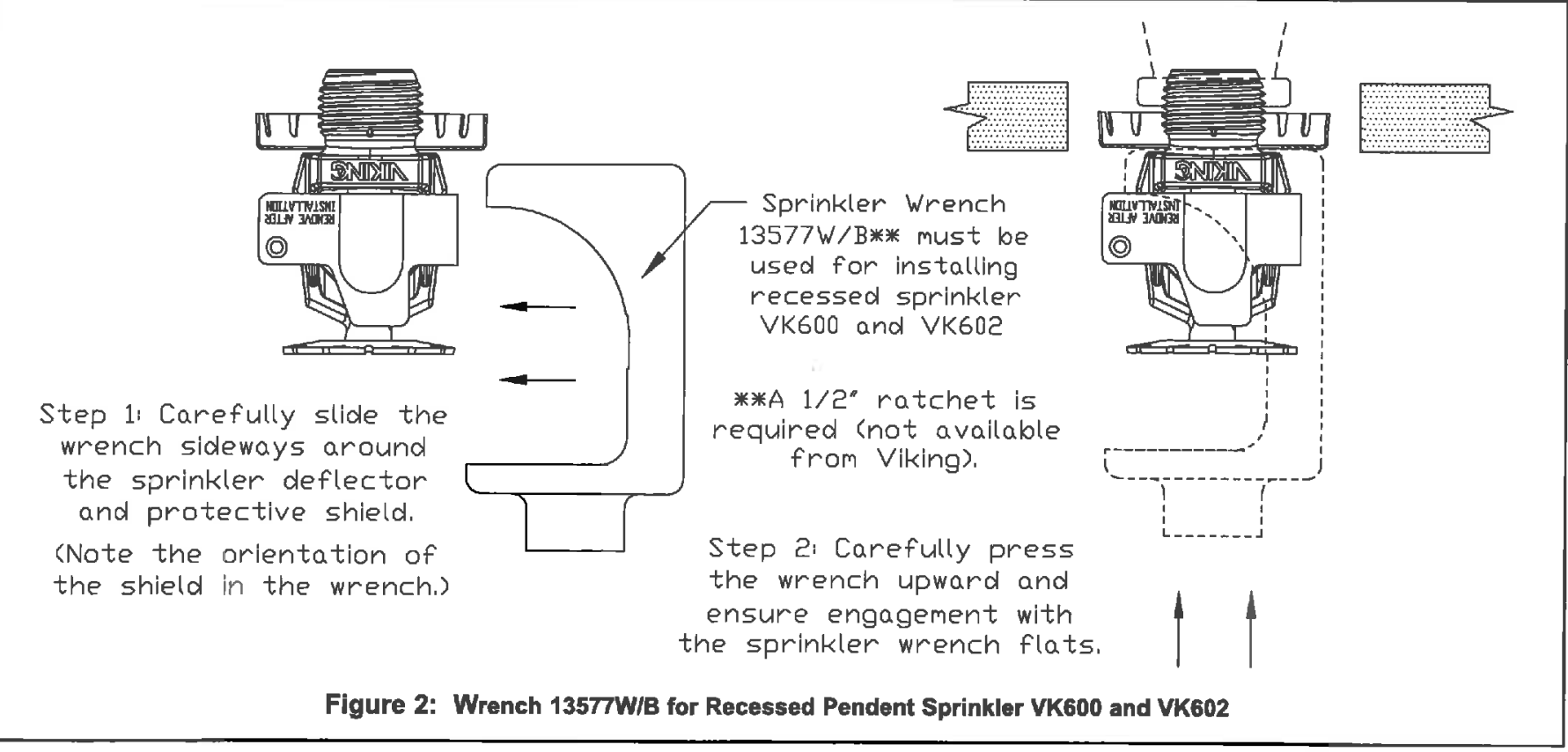




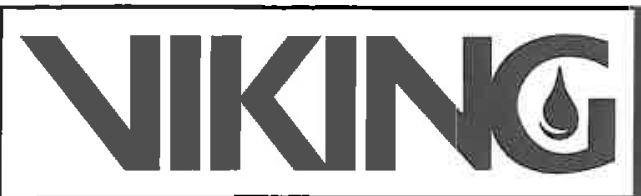

TECHNICAL DATA

MICROFAST ${ }^{\circledR}$ STANDARD/ QUICK RESPONSE EXTENDED COVERAGE PENDENT SPRINKLERS

The Viking Corporation, $210 \mathrm{~N}$ Industrial Park Drive, Hastings MI 49058 Telephone: 269-945-9501 Technical Services: 877-384-5464 Fax: 269-818-1630 Emall: techsvcs@vikingcorp.com

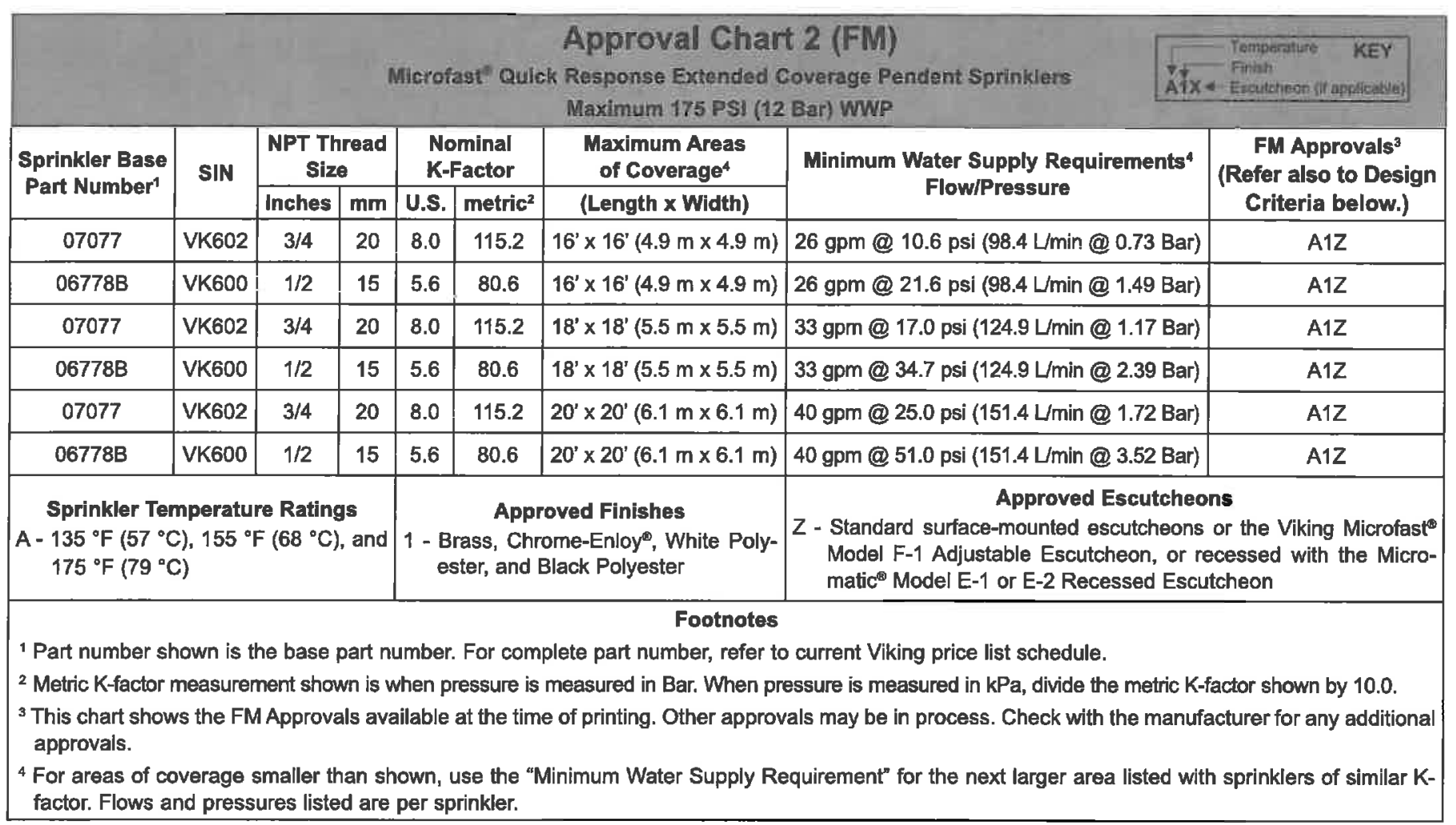

\section{DESIGN CRITERIA - FM}

(Also refer to Approval Chart 2 above)

\section{EM Approval Requirements:}

Quick Response Extended Coverage Pendent Sprinklers VK600 and VK602 are FM Approved as quick response Non-Storage extended coverage pendent sprinklers as indicated in the FM Approval Guide. For specific application and installation requirements, reference the latest applicable FM Loss Prevention Data Sheets (including Data Sheet 2-0). FM Global Loss Prevention Data Sheets contain guidelines relating to, but not limited to: minimum water supply requirements, hydraulic design, ceiling slope and obstructions, minimum and maximum allowable spacing, and deflector distance below the ceiling.

NOTE: The FM installation guidelines may dlffer from cULus and/or NFPA criteria.

IMPORTANT: Always refer to Bulletin Form No. F_091699 - Care and Handling of Sprinklers. Also refer to pages EC1-3 for general care, installation, and maintenance information. Viking sprinklers are to be installed in accordance with the latest edition of Viking technical data, the appropriate standards of NFPA, FM Global, LPCB, APSAD, VdS or other similar organizations, and also with the provisions of governmental codes, ordinances, and standards, whenever applicable. 


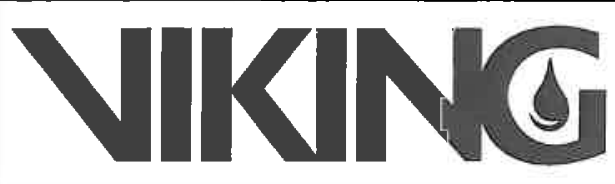

\section{TECHNICAL DATA}

MICROFAST ${ }^{\oplus}$ STANDARDI QUICK RESPONSE EXTENDED COVERAGE PENDENT SPRINKLERS

The Viking Corporation, 210 N Industrial Park Drive, Hastings MI 49058

Telephone: 269-945-9501 Technical Services: 877-384-5464 Fax: 269-818-1680 Email: techsvcs@vikingcorp.com
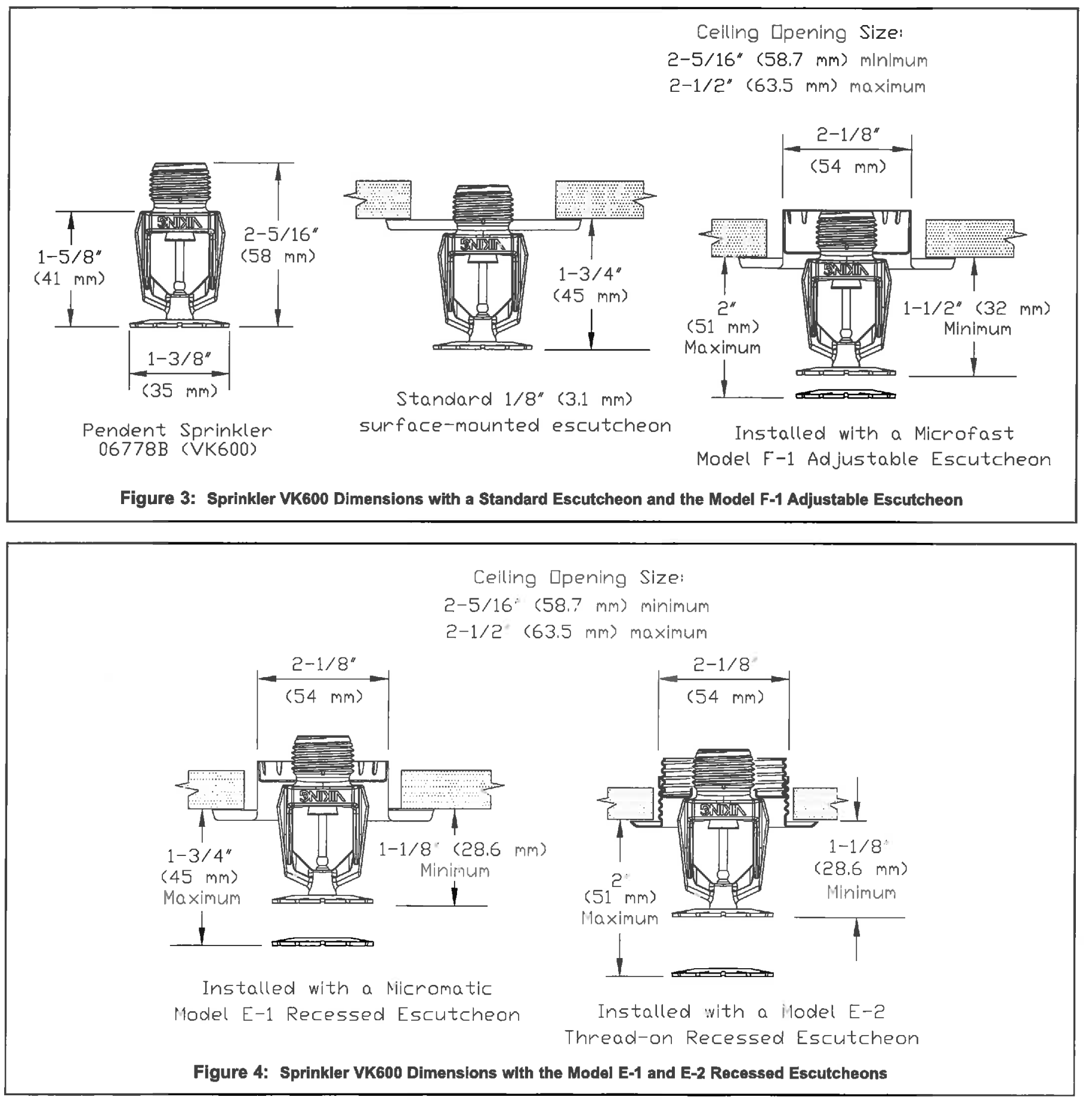


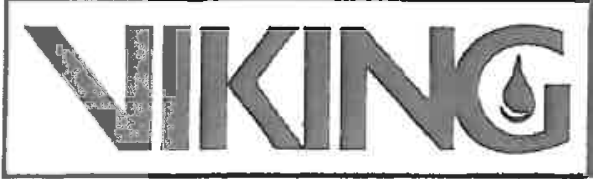

TECHNICAL DATA

MICROFAST AND
MicrofastHP* QUICK
RESPONSE UPRIGHT AND
CONVENTIONAL SPRINKLERS

The Viking Corporation, 210 N Industrlal Park Drive, Hastings MI 49058

Telephone: 269-945-9501 Technical Services: 877-384-5464 Fax: 269-818-1680 Emall: techsvcs@vikingcorp.com

1. DESCRIPTION

Viking Microfast and MicrofastHP Quick Response Upright and Conventional (Old Style) Sprinklers are small, thermosenslthe, glass-bulb spray sprinklers avaijable in several different finishes, temperature ratings, and K-Factors to meet design requirements. The special Polyester and Teflon coatings can be used in decorative applications where colors are desired. In addjtion, these coatings have been investigaled for Installation in corrosive atmospheres and are cULus Ilsted as corrosion resistant as indicated in Approval Chart 1. (Note: FM Global has no approval classification for Tefion and Polyester coatings as corrosion resistant.)

\section{LISTINGS AND APPROVALS}

cUlus Listed: Category VNIV

FM Approved: Classes 2002 and 2020

NYC Approved: Calendar Number 219-76-SA and MEA 89-92-E, Volume 16

ABS Certified: Certificate 04-HS4079B4B-PDA

VdS Approved: Certificates G4060054, G4060056, G4880046, G4930039, and G4980020

LPC Approved: Ref. No. 096e/03, TE30401, and TE30872

CE Certified: Standard EN 12259-1, EC-certificate of conformlty 0832-CPD-2001, 0832-CPD-2003, 0786-CPD-40131, and 0786-CPD-40171

MED Certified: Standard EN 12259-1, EC-certificate of conformity 0832-MED-1003 and 0B32-MED-1008

NOTE: Other Intemational approval certficates are avallable upon request.

Refer to Approval Chart 1 and Design Criteria on pages 51c-d for cULus Listing requirements, and refer to Approval Chart 2 and Design Criteria on page 51e for FM Approval requirements that must be followed.

\section{TECHNICAL DATA}

\section{Speciflcations:}

Avallable since 1987.

Minimum Operating Pressure: 7 psi ( 0.5 bar)*

Maximum Working Pressure: Sprinklers VK315 and VK340 are rated for use with water working pressures ranging from the minimum 7 psi (0.5 bar) up to 250 psi (17 bar) for high-pressure systems. High-pressure (HP) sprinklers can be identified by locating "250" stamped on the deflector. All other Part Nos. not mentioned above are rated to a maximum 175 psi (12 bar) mup.

Factory tested hydrostatically to $500 \mathrm{ps}$ ( 34.5 bar)

Testing: U.S.A. Patent No. 4,831,870

Thread size: Refer to the Approval Charts

Nominal K-Factor: Refer to the Approval Chents

Gless-bulb fluid (emperature rated to $-65^{\circ} \mathrm{F}\left(-55^{\circ} \mathrm{C}\right)$

Overall Length: Refer to the Approval Charts

"clulus Liating, FM Approval, and NFPA 13 installs require a minimum of 7 psi $(0.5$ bar). The minimum operaling pressure for LPCB and CE Approvals ONLY is 5 pst (0.35 bar).

Material Standards:

Frame Casting: Brass UNS-C84400 or QM Brass for Sprinklers 06661B, 06766B, 07060, and 12281. Brass UNS-CB4400 for all other sprinklers.

Deffector: Brass UNS-C23000 or Copper UNS-C19500 for Sprinklers 06661 B and 12281. Copper UNS-C19500 for Sprinklers 06665B, 06764B, 07060, and 14817. Brass UNS-C26000 for all other Sprinklers.

Bushing (for Sprinklers 06719B, 06717B, and 12286): Brass UNS-C36000

Bulb: Glass, nominal $3 \mathrm{~mm}$ diameter

Belleville Spring Sealing Assembly: Nickel Alloy, coaled on both sides with Teflon Tape

Screw: Brase UNS-C36000

Form No. F_080488 Replaces page 51a-e, dated April 25, 2008. (Updated for Sprinkler 14817. Added VdS to Sprinklers 06665B, 06764B, and 14817. Updated FM Approvals and split the Approval Charts to separate UL Listing requirements from FM Approval requirements. Changed the metric K-factor for K4.2 sprinklers to 57.) 


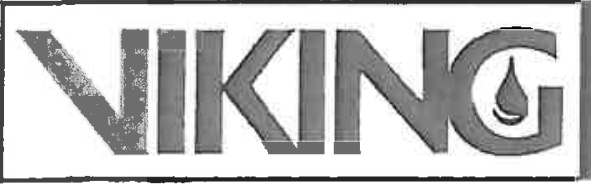

TECHNICAL DATA

MICROFAST॰ AND
MicrofastHP॰ QUICK
RESPONSE UPRIGHT AND
CONVENTIONAL SPRINKLERS

The Viking Corporation, 210 N Industrial Park Drive, Hastings MI 49058

Telephone: 269-945-9501 Technical Services: 877-384-5464 Fax: 269-818-1680 Email: techsvcs@vikingcorp.com

Pip Cap and Insert Assembly: Copper UNS-C11000 and Stainless Steel UNS-S30400

For Teflon Coated Sprinklers; Belleville Spring-Exposed, Screw-Nickel Plated, Pip Cap-Téflon Coated

For Polvester Coated Sprinklers: Belleville Spring-Exposed

Ordering Information: (Also refer to the current Viking price list.)

Order Microfast" and MicrofastHP* Quick Response Upright and Conventional Sprinklers by first adding the appropriate suffix for the sprinkler finish and then the appropriate suffix for the temperature rating to the sprinkler base part number.

Finish Suffix: Brass $=A$, Chrome-Enloy $=F$. White Polyester $=M-N$, Black Polyester $=M-/ B$, and Black Teflon $=N$

Temperature Suffix $\left({ }^{\circ} \mathrm{F} /{ }^{\circ} \mathrm{C}\right): 135^{\circ} / 57^{\circ}=A, 155^{\circ} / 68^{\circ}=B, 175^{\circ} / 79^{\circ}=D, 200^{\circ} / 93^{\circ}=E$, and $286^{\circ} / 141^{\circ}=G$

For example, sprinkler VK300 with a $1 / 2^{\prime \prime}$ thread, Brass finlsh and a $155^{\circ} \mathrm{F} / 68^{\circ} \mathrm{C}$ temperature rating = Part No. 06661BAB

Avallable Finishes And Temperature Ratings: Refer to Table 1.

Accessories: (Also refer to the "Sprinkler Accessories" section of the Viking data book.)

Bprinkler Wrench: Standard Wrench: Part No. 10896W/B (available since 2000)

Sprinkler Cabinets:

A. Slx-head capacity: Part No. 01724A (avallable since 1971)

B. Twelve-head capacity: Part No. 01725A (avallable since 1971)

\section{INSTALLATION}

Refer to appropriate NFPA Installation Standards.

\section{OPERATION}

During fire condltions, the heat-sensittve liquld in the glass bulb expands, causing the glass to shalter, releasing the pip cap and sealing spring assembly. Water flowing through the sprinkler orifice strikes the sprinkler deflector, forming a uniform spray pattern to extinguish or control the fire.

\section{INSPECTIONS, TESTS AND MAINTENANCE}

Refer to NFPA 25 for Inspection, Testing and Maintenence requirements.

\section{AVAILABILITY}

The Viking Microfast and MicrofasthPo Quick Response Upright and Conventional Sprinklers are available through a network of domestic and international distributors. See The Viking Corporation web stte for the closest distributor or contact The Viking Corporation.

\section{GUARANTEE}

For details of warranty, refer to Vking's current list price schedule or contact Viking directly.

\begin{tabular}{|c|c|c|c|}
\hline $\begin{array}{l}\text { Sprinklar Tomporaturs } \\
\text { flustileadon }\end{array}$ & 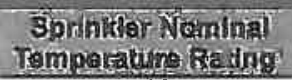 & $\begin{array}{l}\text { Haximum Amblent } \\
\text { falings Ternparaturs? }\end{array}$ & Bulb colon \\
\hline Ordinary & $135^{\circ} \mathrm{F}\left(57^{\circ} \mathrm{C}\right)$ & $100^{\circ} \mathrm{F}\left(38^{\circ} \mathrm{C}\right)$ & Orange \\
\hline Ordinary & $155^{\circ} \mathrm{F}\left(6 \mathrm{~B}^{\circ} \mathrm{C}\right)$ & $100^{\circ} \mathrm{F}\left(38^{\circ} \mathrm{C}\right)$ & Red \\
\hline Intermediate & $175^{\circ} \mathrm{F}\left(79^{\circ} \mathrm{C}\right)$ & $150^{\circ} \mathrm{F}\left(65^{\circ} \mathrm{C}\right)$ & Yellow \\
\hline Intermediate & $200^{\circ} \mathrm{F}\left(93^{\circ} \mathrm{C}\right)$ & $150^{\circ} \mathrm{F}\left(65^{\circ} \mathrm{C}\right)$ & Green \\
\hline High & $286^{\circ} \mathrm{F}\left(141^{\circ} \mathrm{C}\right)$ & $225^{\circ} \mathrm{F}\left(107^{\circ} \mathrm{C}\right)$ & Blue \\
\hline \multicolumn{4}{|c|}{$\begin{array}{l}\text { Sprinkler Finishes: Brass, Chrome-Enloy", White Polyester, Black Polyester, and Black Terion" } \\
\text { Corroslon-Resistant Coatings": White Polyester, Black Polyester, and Black Teflon }\end{array}$} \\
\hline \multicolumn{4}{|l|}{$\begin{array}{l}\text { lon-resistant coal } \\
\text { od do not represer } \\
\text { itable for the prop } \\
\text { pring is exposed }\end{array}$} \\
\hline
\end{tabular}




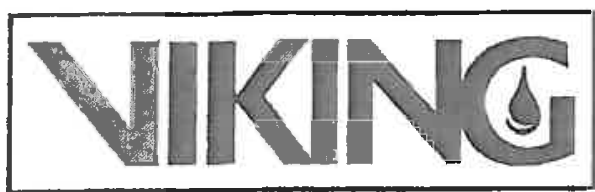

TECHNIGAL DATA

MICROFAST` AND
MicrofastHP॰ QUICK
RESPONSE UPRIGHT AND
CONVENTIONAL SPRINKLERS

The Viking Corporation, $210 \mathrm{~N}$ Industrial Park Drive, Hastings MI 49058

Telephone: 269-945-9501 Technical Services: 877-384-5464 Fax: 269-818-1680 Email: techevcs@vikingcorp.com

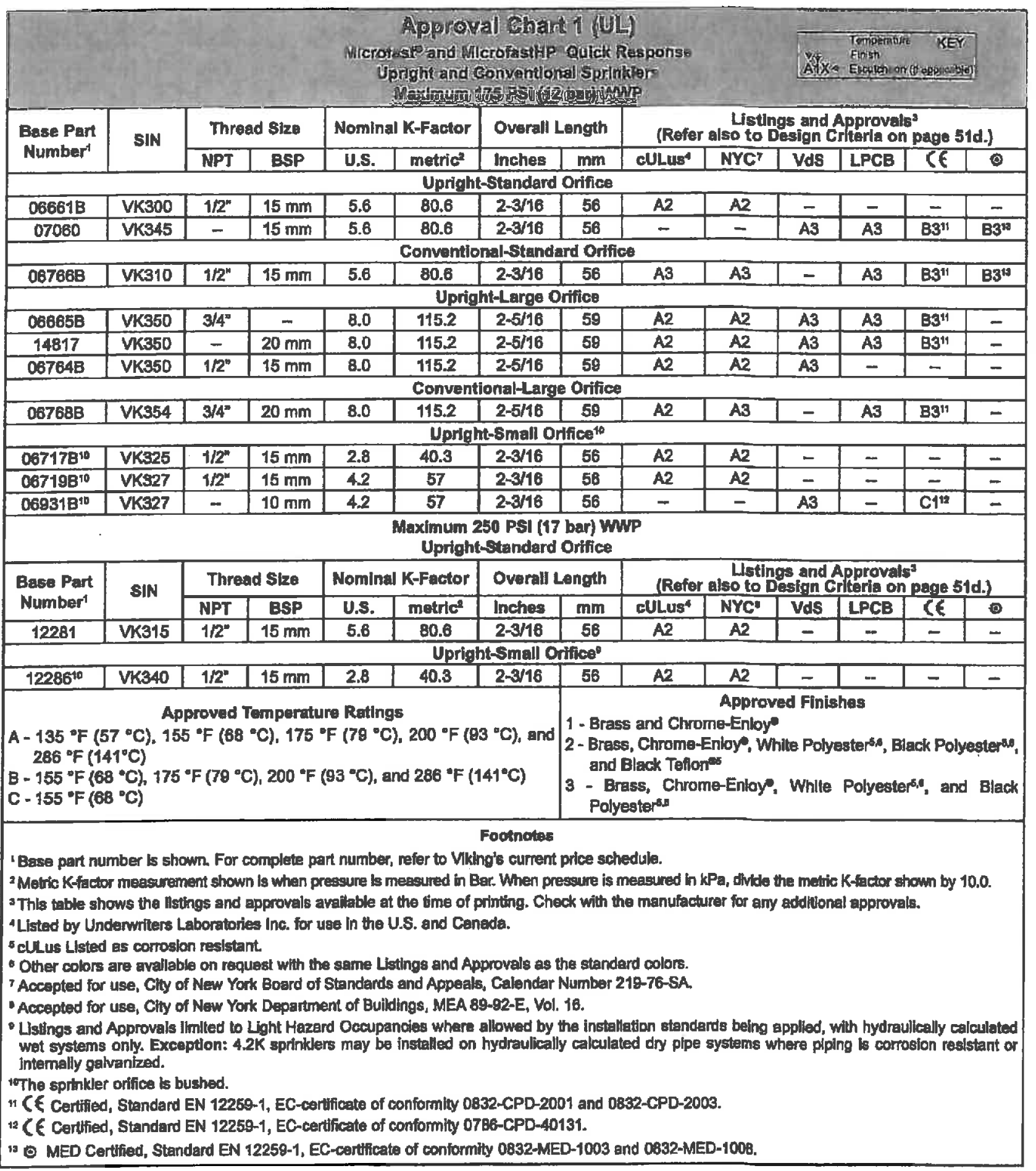




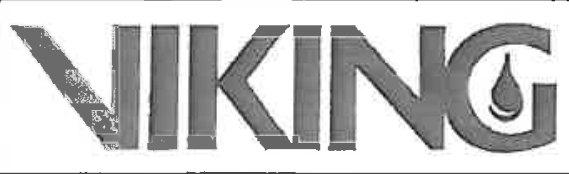

TECHNICAL, DATA

MICROFAST॰ AND
MicrofastHP॰ QUICK
RESPONSE UPRIGHT AND
CONVENTIONAL SPRINKLERS

The Viking Corporation, $210 \mathrm{~N}$ Industrial Park Drive, Heıstings M 49058

Telephone: 269-945-9501 Technical Services: 877-384-5464 Fax: 269-818-1680 Emall: techsvcs@vikingcorp.com DESITNLRRDERIALUL

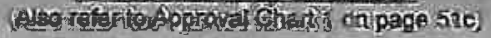

\section{cllLus Llsting Requirements:}

Microfas" and MicrofastHP• Quick Response Upright and Conventional Sprinklers are cULus Listed as indicated in Approval Chart 1 for Installation In accordance with the latest edliton of NFPA 13 for standard spray sprinkJers, or old style (conventonal) sprinklers.

- Designed for use in Light and Ordinary Hazard occupancles (exception: smill orifice sprinklers are limiled to Light Hazand where allowed by the installalion stendards beling appliad, with hydraulically calculated wet systems only).

- The sprinkler installation rules contained in NFPA 13 for standard spray upright sprinklers must be followed. For conventtonal sprinklers, refer to the installation guidelines for old style (conventional) sprinklers.

IMPORTANT: Always refer to Bulletin Form No. F_091699 - Care and Handling of Sprinklers. Also refer to page QR1-3 for general care, Installation, and maintenance information. Viking sprinklers are to be installed in accordance with the latest edition of Viking technical data, the appropriate standards of NFPA, LPCB, APSAD, VdS or other similar organizations, and also with the provisions of governmental codes, ordinances, and standards, whenever applicable.

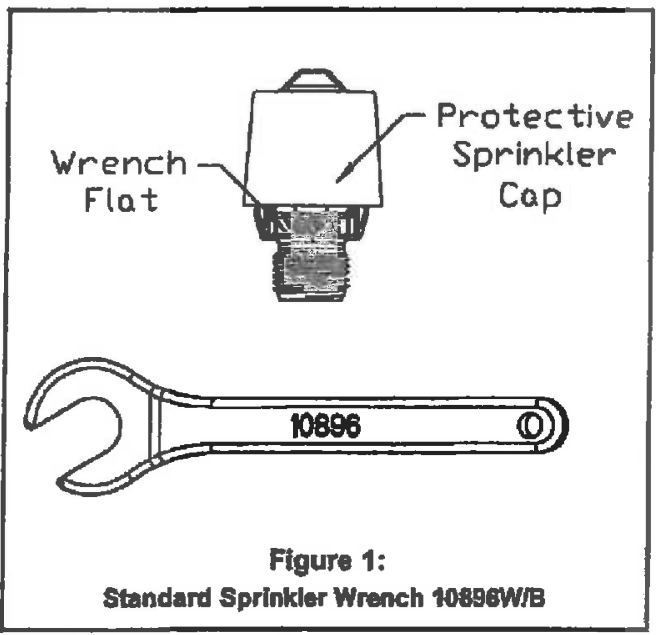




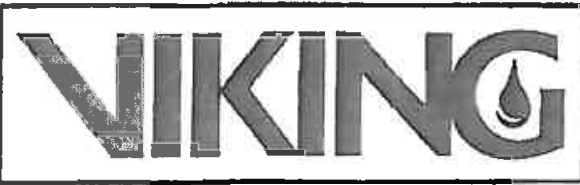

TECHNICAL DATA

\begin{tabular}{c}
\hline MICROFAST॰ AND \\
MicrofastHP॰ QUICK \\
RESPONSE UPRIGHT AND \\
CONVENTIONAL SPRINKLERS
\end{tabular}

The Viking Corporation, $210 \mathrm{~N}$ Industrial Park Drive, Hastings MI 49058

Telephone: 269-945-9501 Technical Services: 877-384-5464 Fax: 269-818-16:30 Email: techsves@vikingcorp.com

\begin{tabular}{|c|c|c|c|c|c|c|c|c|}
\hline \multirow{3}{*}{$\begin{array}{l}\text { Base Part } \\
\text { Number' }\end{array}$} & \multirow{3}{*}{$\mathbf{S I N}$} & \multicolumn{6}{|c|}{ 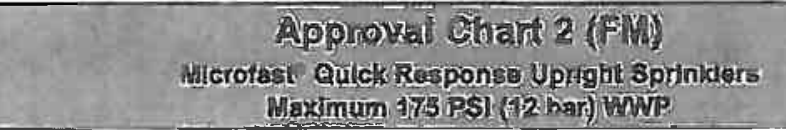 } & \multirow{3}{*}{ 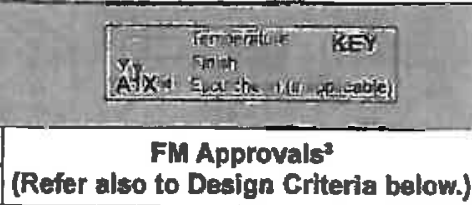 } \\
\hline & & \multicolumn{2}{|c|}{ Thread Slze } & \multicolumn{2}{|c|}{ Nominal K-Factor } & \multicolumn{2}{|c|}{ Overall Length } & \\
\hline & & NPT & BSP & U.S. & metric & Inches & $\mathbf{m m}$ & \\
\hline \multicolumn{9}{|c|}{ Standard Ortfice } \\
\hline $06661 \mathrm{~B}$ & VK300 & $9 / 2^{\prime \prime}$ & $15 \mathrm{~mm}$ & 5.6 & 80.6 & $2-3 / 16$ & 56 & $A 2$ \\
\hline 07060 & VK345 & - & $15 \mathrm{~mm}$ & 5.6 & 80.6 & $2-3 / 16$ & 66 & A2 \\
\hline \multicolumn{9}{|c|}{ Large Orifice } \\
\hline 06665B & VK350 & $3 / 4^{\prime \prime}$ & - & 8.0 & 115.2 & $2-6 / 16$ & 69 & $A 2$ \\
\hline 14817 & VK350 & - & $20 \mathrm{~mm}$ & 8.0 & 116.2 & $2-6 / 16$ & 59 & $A 2$ \\
\hline \multicolumn{9}{|c|}{ 8mall Orificot } \\
\hline $06717 B^{*}$ & VK325 & $1 / 2^{\prime \prime}$ & $15 \mathrm{~mm}$ & 2.8 & 40.3 & $2-3 / 16$ & 56 & A1 \\
\hline \multicolumn{7}{|c|}{ 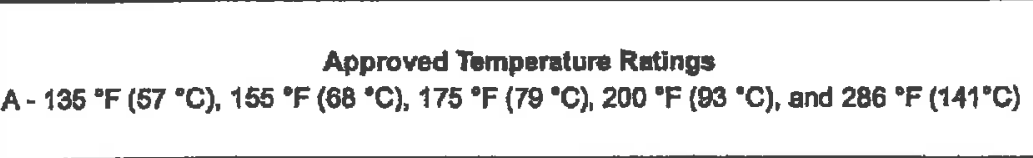 } & \multicolumn{2}{|c|}{$\begin{array}{l}\text { Approved Finishes } \\
1 \text { - Brass and Chrome-Enloy" } \\
2 \text { - Brass, Chrome-Enloy", While Polyester, and } \\
\text { Black Polyesters }\end{array}$} \\
\hline \multicolumn{9}{|c|}{ 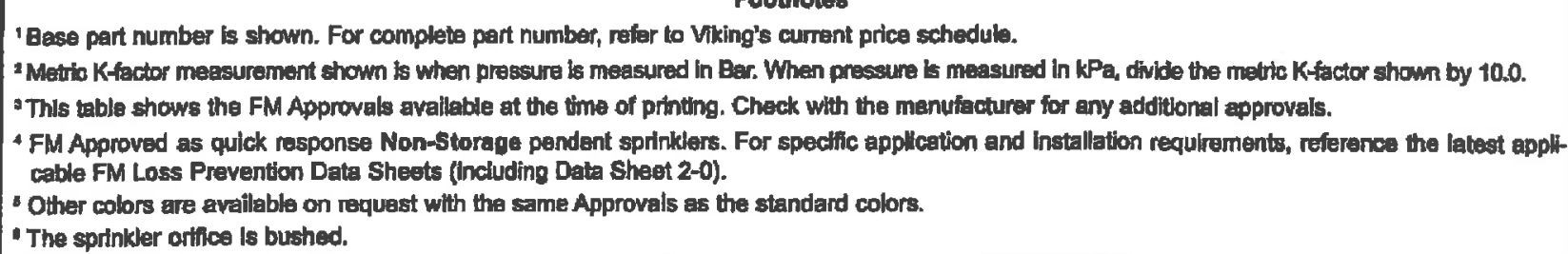 } \\
\hline
\end{tabular}

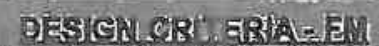

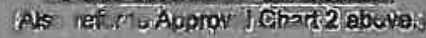

ENLAproyalRequirements:

The spinklers indicated in Approval Chart 2 are FM Approved as quick response Non-Storage upright sprinklers as indicated in the FM Approvel Gulde. For spectic application and installation requlrements, reference the latest applicable FM Loss Prevention Data Sheets (including Date Sheet 2-0). FM Global Loss Prevention Data Sheets contain guldelines relatting to, but not limited to: minimum water supply requirements, hydraulic deslgn, ceilling slope and obstructions, minimum and maximum alowable spacing, and defiector diatance below the celling.

NOTE: The FM installation guldolines may differ from cULus and/or NFPA criteria.

IMPORTANT: Always refer to Bulletin Form No. F_091698 - Care and Handling of Sprinklers. Also refer to page QR1-3 for general care, instaliation, and maintenance Information. Vking sprinklers are to be installed in accordance with the latest edHion of Viking technical data, the appropriate standards of NFPA, FM Clobal, LPCB, APSAD, VdS or other similar organizations, and also with the provisions of governmental codes, ordinances, and standards, whenever applicable. 


\section{THIS PAGE INTENTIONALLY LEFT BLANK}

Form No. F_080488 Replaces page 51a-e, dated April 25, 2008. (Updated for Sprinkler 14817. Added VdS to Sprinklers 06665B, 06764B, and 14817. Updated FM Approvals and split the Approval Charts to separate UL Listing requirements from FM Approval requirements. Changed the metric K-factor for K4.2 sprinklers to 57 .) 


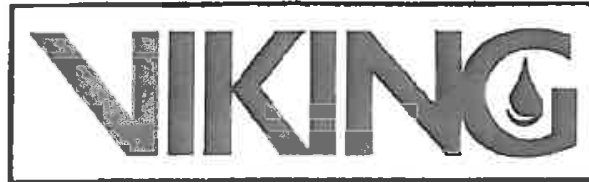

TECHNICAL DATA

MIICKOFAST AND

MicrofastHPE QUICK

RESPONSE PENDENT

SPRINKLERS

The Viking Corporation, 210 N Industrial Park Drive, Hastings MI 49058

Telephone: 269-945-9501 Technical Services: 877-384-5464 Fax: 269-818-1680 Email: techsvcs@vikingcorp.com

\section{DESCRIPTION}

Vking Microfest and MicrofastHP॰ Quick Response Pendent Sprinklers are small, thermosensttive, glass-bulb spray sprinklers avallable in several different finishes and temperature ratings and K-Factors to meet design requlrements. The special Polyester and Teflon coatings can be used in decoratlve appllcalions where colors are desired. In addition, these coatings have been investigated for installation in corrosive atmospheres and are cULus listed as corrosion reststam as Indicated in the Approval Chart. (Note; FM Global has no approval classification for Teflon ${ }^{\circ}$ and Polyester coatings as corrosion resistant.)

\section{LISTINGS AND APPROVALS}

cULus Listed: Category VNIV

FM Approved: Class 2020

NYC Approved: Calendar Number 219-76-SA and MEA 80-92-E, Volume 16

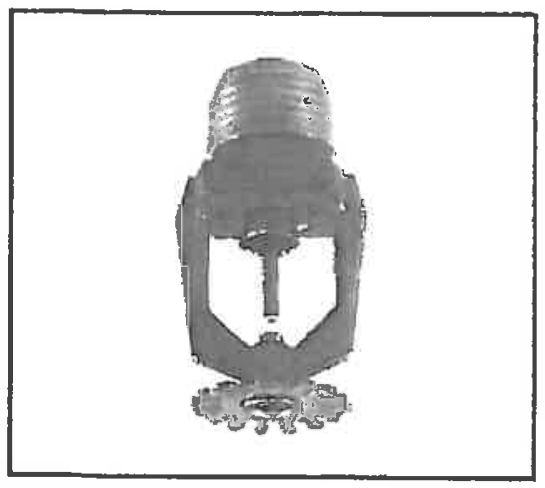

ABS Certified: Certificate 04-HS407984C-PDA

VdS Approved: Certificates G4040095, G4040097, G4060056, G4060057, G4880045, G4930038, and G4980021

LPC Approved: Ref. Nos. $096 \mathrm{e} / 03$ and 096e/04

CE Certifled: Standard EN 12259-1, EC-certificate of conformity 0832-CPD-2001, 0832-CPD-2003, 0786-CPD-40130, and 0786-CPD-40170

MED Certfied: Standard EN 12269-1, EC-certificate of conformity 0832-MED-1003 and 0832-MED-1008

NOTE: Other International approval cerificates are available upon request.

Refer to Approval Chart 1 and Design Criteria on page $41 \mathrm{~d}$ for cULus Listing requiremente and refer to Approval Chart 2 and Design Criterla on pege 41e for FM Approval requirements that must be followed.

\section{TECHNICAL DATA}

\section{Specifications:}

Available since 1987.

Minimum Operating Pressure: 7 psi ( 0.5 bar)*

Maximum Working Pressure: Sprinklers 12282 and 12290 are rated for use with water working pressures ranging from the minimum 7 psi ( 0.5 bar) up to 250 pei (17 bar) for high-pressure systems. High-pressure (HP) sprinklers can be Identifiled by locating "250" stamped on the defiector. All other Part Nos. not mentioned above are rated to a maximum $175 \mathrm{ps}$ (12 bar) wro.

Fectory tested hydrostatically to 500 psi (34.5 bar)

Testing: U.S.A. Patent No. 4,831,870

Thread size: Refer to the Approval Charts

Nominal K-Factor: Refer to the Approval Charts

Glass-bulb fluid temperature rated to $-66^{\circ} \mathrm{F}\left(-55^{\circ} \mathrm{C}\right)$

Overall Lenglth: Refer to the Approval Charts

"culus Listing, FM Approval, and NFPA 13 installs require a minimum of 7 psi (0.5 bar). The minimum operating pressure for LPCB and CE Approvals ONLY is 5 psi (0.35 bar)

Material Standards:

Frame Casting: Brass UNS-C84400 or QM Brass for Sprinklers 06662B and 12282. Brass UNS-C84400 for all other sprinklers. Deflector: Phosphor Bronze UNS-C51000 or Copper UNS-C19600 for Sprinklers 06662B, 06666B, and 08765B. Copper UNSC19500 for Sprinkler 12282. Brass UNS-C26000 for all other Sprinkers.

Bushing (for Sprinklers 06718B, 06720B, and 12290): Brass UNS-C36000

Bulb: Glass, nominal $3 \mathrm{~mm}$ diameter

Belleville Spring Sealing Assembly: Nickel Alloy, coated on both sides with Teflon Tape

Screw: Brass UNS-C36000

Pip Cap and Insert Assembly: Copper UNS-C11000 and Stainless Steel UNS-S30400

Form No. F_081296 


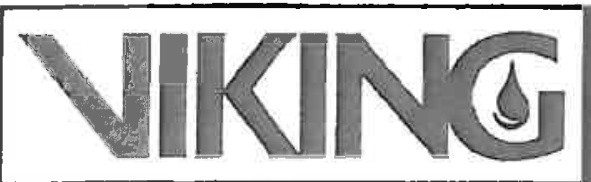

\section{TECHNIGAL DATA}

\section{MICROFAST: AND MicrofastHP• QUICK RESPONSE PENDENT SPRINKLERS}

The Viking Corporation, 210 N Industrial Park Drlve, Hastings MI 49058

Telephone: 269-945-9501 Technical Services: 877-384-5464 Fax: 269-818-1680 Emall: techsvcs@vikingcorp.com

For Teflon" Coeted Sorinklers; Belleville Spring-Exposed, Screw-Nicked Plated, Pip Cap-Teflon ${ }^{\circ}$ Coated For Polvester Coated Sprinklers: Belleville Spring-Exposed

Ordering Information: (Also refer to the current Viking price list)

Order Microfast and MicrofastHPo Quick Response Pendent Sprinklers by first adding the appropriate surfix for the sprinkler finish and then the appropriate suffix for the temperature rating to the sprinkler base part number.

Finish Sufflx: Brass $=A$, Chrome-Enloy $=F$, White Polyester $=M-W$, Black Polyester $=M-1 B$, and Black Teflon $\pi^{\circ}=N$

Temperature Sufix $\left({ }^{\circ} \mathrm{F} /{ }^{\circ} \mathrm{C}\right.$ ): $135^{\circ} / 57^{\circ}=\mathrm{A}, 155^{\circ} / 68^{\circ}=\mathrm{B}, 175^{\circ} / 79^{\circ}=\mathrm{D}, 200^{\circ} / 93^{\circ}=\mathrm{E}$, and $286^{\circ} / 141^{\circ}=\mathrm{G}$

For example, sprinkler VK302 with a $1 / 2^{\prime \prime}$ thread, Brass finlsh and a $155^{\circ} \mathrm{F} / 68^{\circ} \mathrm{C}$ temperature rating $=$ Part No. 06662BAB

Available Finishes And Temperature Ratings:

Refer to Table 1.

Accessories: (Also refer to the "Sprinkler Accessorles" section of the Viking data book.)

Sprinkler Wrenches:

A. Standard Wrench: Part No. 10896W/B (available since 2000).

B. Wrench for Coated and/or Recessed Sprinklers: Part No. 12144W/B* (available since 2003)

C. Optional Protective Sprinkler Cap Remover/Escutcheon Installer Tool ${ }^{\text {t* }}$ Part No. 15915 (avallable since 2010.)

NOTE: RECESSED PENDENT SPRINKLERS WTTH PROTECTIVE CAPS MUST USE WRENCH 12144 WIB.

"A Y." ratchet is requlred (not avallable from Viking).

-Allows use from the floor by atteching a length of 1" diameler CPVC tubling to the tool. Ideal for sprinkler cabinats. Refer to Bulleth F_051B08. Sprinkler Cabinets:

A. Six-head cepacity: Part No. 01724A (avallable since 1971)

B. Twelve-head capaclty: Part No. 01725A (available since 1971)

\section{INSTALLATION}

Refer to appropriate NFPA Installation Standards.

\section{OPERATION}

During fire condltions, the heat-sensitive liquid in the glass bulb expands, causing the glass to shatter, releasing the plp cap and sealing spring assembly. Water flowing through the sprinkler orfice strikes the sprinkler deflector, forming a uniform spray pattem to extinguish or control the fire.

6. INSPECTIONS, TESTS AND MAINTENANCE

Refir to NFPA 25 for Inspaction, Testing and Maintenance requlrements.

\section{AVAILABILITY}

The Viking Microfest" and MicrofastHP० Qulck Response Pendent Sprinklers are available through a network of domestic and intemational distributors. See The Viling Corporation web site for the closest distributor or contact The Viking Corporation.

\section{GUARANTEE}

For details of warranty, refer to Viking's current llst price schedule or contact Viking directly.

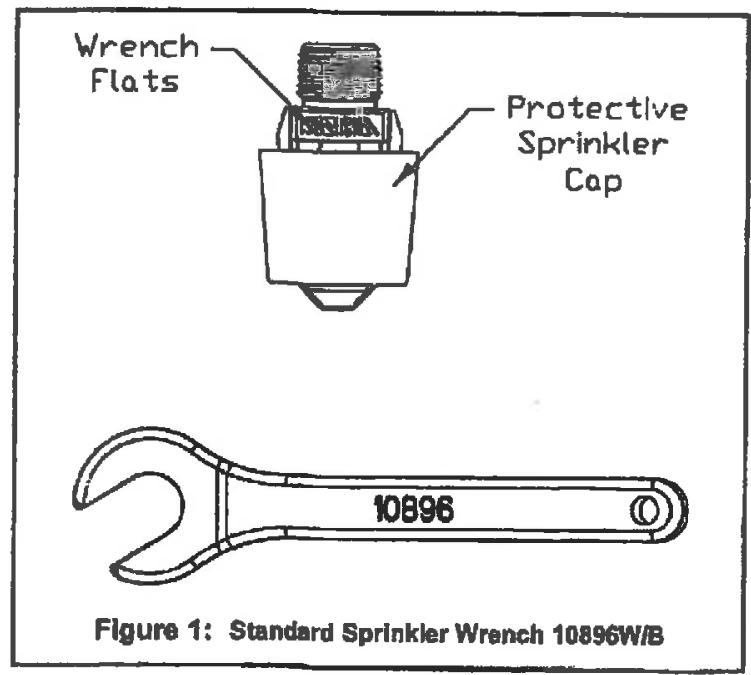




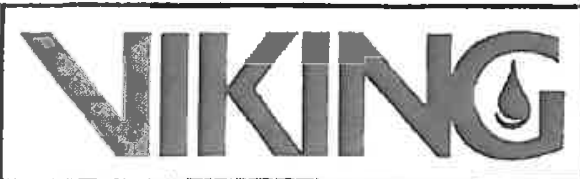

TECHNICAL DATA

MICROFAST AND
MicrofastHP० QUICK
RESPONSE PENDENT
SPRINKLERS

The Viking Corporation, $210 \mathrm{~N}$ Industrial Park Drive, Hastings Ml 49058

Telephone: 269-945-9501 Technical Services: 877-384-5464 Fax: 269-818-1680 Emall: techsvcs@vikingcorp.com

\begin{tabular}{|c|c|c|c|}
\hline 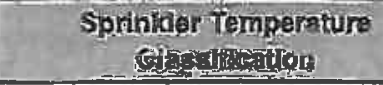 & $\begin{array}{l}\text { Spriditer Sominal } \\
\text { Tamparafure Ratind }\end{array}$ & $\begin{array}{l}\text { Miaximum Amblent } \\
\text { felling Tamporatuge }\end{array}$ & Bulb Golor \\
\hline Ordinary & $135^{\circ} \mathrm{F}\left(57^{\circ} \mathrm{C}\right)$ & $100^{\circ} \mathrm{F}\left(3 \mathrm{~B}^{\circ} \mathrm{C}\right)$ & Orange \\
\hline Ordinary & $155^{\circ} \mathrm{F}\left(68^{\circ} \mathrm{C}\right)$ & $100^{\circ} \mathrm{F}\left(38^{\circ} \mathrm{C}\right)$ & Red \\
\hline Intermedlate & $175^{\circ} \mathrm{F}\left(79^{\circ} \mathrm{C}\right)$ & $150^{\circ} \mathrm{F}\left(65^{\circ} \mathrm{C}\right)$ & Yellow \\
\hline Intermedlate & $200^{\circ} \mathrm{F}\left(93^{\circ} \mathrm{C}\right)$ & $150^{\circ} \mathrm{F}\left(65^{\circ} \mathrm{C}\right)$ & Green \\
\hline High & $286^{\circ} \mathrm{F}\left(141^{\circ} \mathrm{C}\right)$ & $225^{\circ} \mathrm{F}\left(107^{\circ} \mathrm{C}\right)$ & Blue \\
\hline \multicolumn{4}{|c|}{ 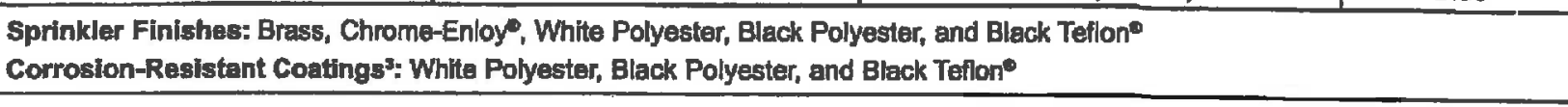 } \\
\hline \multicolumn{4}{|c|}{ 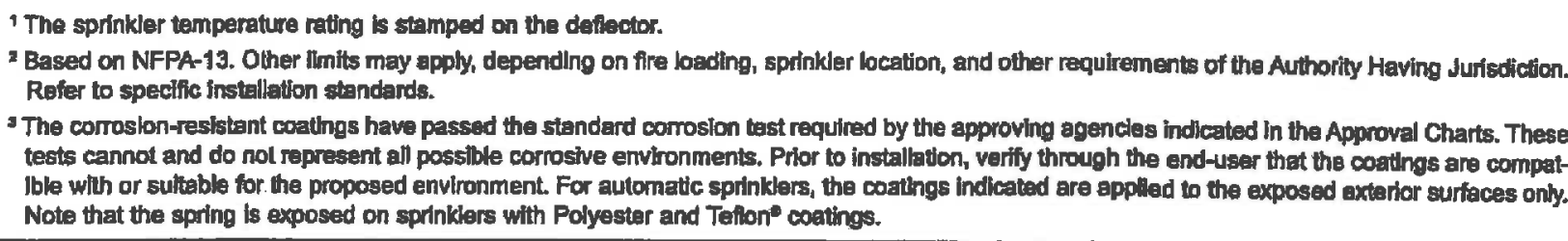 } \\
\hline
\end{tabular}

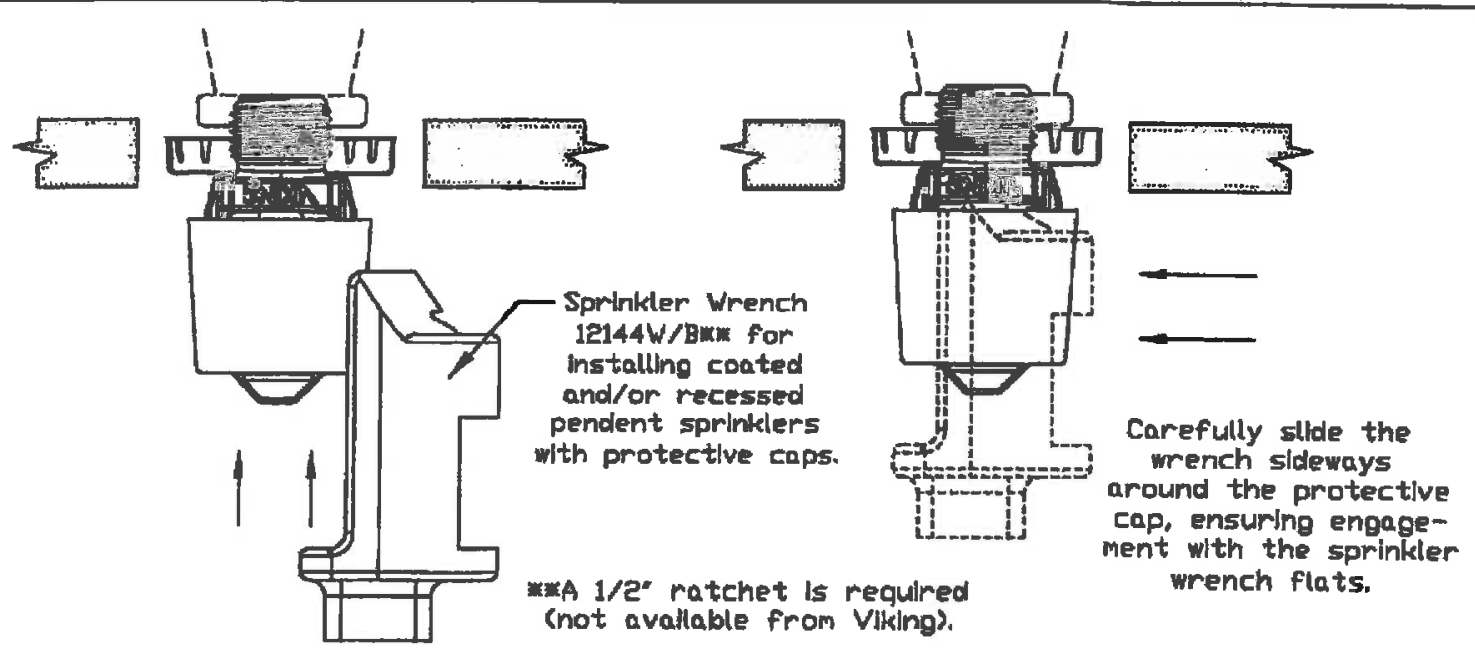

Figure 2: Wrench 12144W/B for Coated and/or Recesed Pendent Sprinklers 


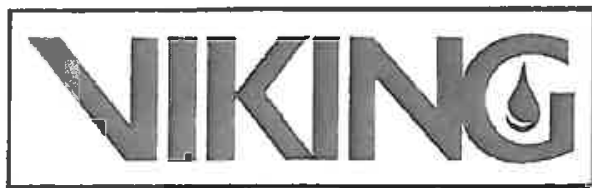

TECHNICAL DATA

\section{MICROFAST ARV MicrofastHP• QUICK RESPONSE PENDENT SPRINKLERS}

The Viking Corporation, $210 \mathrm{~N}$ Industrial Park Drive, Hastings MI 49058

Telephone: 269-945-9501 Technical Services: 877-384-5464 Fax: 269-818-1680 Email: techsvcs@vikingcorp.com

\begin{tabular}{|c|c|c|c|c|c|c|c|c|c|c|c|c|c|}
\hline \multirow{3}{*}{$\begin{array}{l}\text { Sprinkler } \\
\text { Base } \\
\text { Part No." }\end{array}$} & \multirow{3}{*}{ SIN } & \multicolumn{10}{|c|}{ 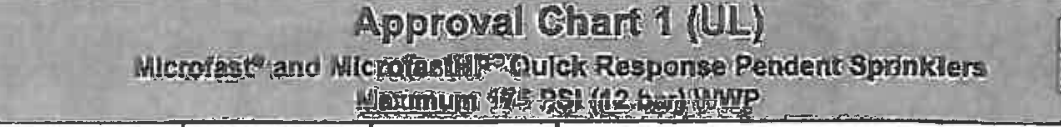 } & \multicolumn{2}{|c|}{ 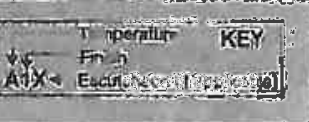 } \\
\hline & & \multicolumn{2}{|c|}{ Thread \$ize } & \multicolumn{2}{|c|}{$\begin{array}{l}\text { Nominal } \\
\text { K-Factor }\end{array}$} & \multicolumn{2}{|c|}{$\begin{array}{l}\text { Overall } \\
\text { Length }\end{array}$} & \multicolumn{6}{|c|}{$\begin{array}{l}\text { Listings and Approvals } \\
\text { (Refer also to Design Criteria on page 416.) }\end{array}$} \\
\hline & & NPT & BSP & U.S. & metric ${ }^{2}$ & Inch & es $\mathrm{mm}$ & culust & NYG & Vds & LPGB & $C E$ & 0 \\
\hline \multicolumn{14}{|c|}{ Standard Orifice } \\
\hline 06662B & Vk302 & $1 / 2^{*}$ & $15 \mathrm{~mm}$ & 5.6 & 80.6 & $2-1 / 4^{\prime \prime}$ & 58 & $\mathrm{~A} 1 \mathrm{X}, \mathrm{B} 1 \mathrm{Y}$ & $A 1 X, B 1 Y$ & $\mathrm{~A}^{3}$ & $A 3 X, B 3 Y$ & C3X, Earm & C3X, E3Y \\
\hline \multicolumn{14}{|c|}{ Large Ortice } \\
\hline 066668 & VK352 & $3 / 4^{n}$ & $20 \mathrm{~mm}$ & 8.0 & 115.2 & $2-3 / 8^{\prime \prime}$ & 60 & $A \mid X, B\} Y$ & $A 1 X, B T Y$ & $A 3$ & $A 3 X$ & $\mathrm{C}^{19}$ & - \\
\hline 067658 & VK352 & $1 / 2^{n}$ & $15 \mathrm{~mm}$ & 8.0 & 115.2 & $2-918^{\circ}$ & 60 & $A 1 X, B 1 Y$ & $A 1 X, B 1 Y$ & $A 3$ & - & - & - \\
\hline \multicolumn{14}{|c|}{ Small Orfifics' } \\
\hline $067188^{\circ}$ & VK329 & $1 / 2^{\mu}$ & $16 \mathrm{~mm}$ & 2.8 & 40.3 & $2-3 / 46^{\circ}$ & \begin{tabular}{|l|l|}
$6^{\circ}$ & 56 \\
\end{tabular} & A1X, B1Y & A1X, BIY & - & - & - & - \\
\hline $06720 \mathrm{~B}^{\circ}$ & $v k 331$ & $1 / 2^{n}$ & $16 \mathrm{~mm}$ & 4.2 & 57 & $2-1 / 4^{\prime \prime}$ & 58 & $A 1 X, B 1 Y$ & A1X, BIY & - & - & - & - \\
\hline 06932B & VK331 & - & $10 \mathrm{~mm}$ & 4.2 & 57 & $2-3 / 8^{\prime \prime}$ & 60 & - & - & $A 3$ & - & $62^{12}$ & - \\
\hline \multicolumn{14}{|c|}{$\begin{array}{c}\text { Maximum } 250 \text { PSI (17 bay) WMP } \\
\text { Standard Orifice }\end{array}$} \\
\hline \multirow{2}{*}{$\begin{array}{l}\text { Sprinkler } \\
\text { Base } \\
\text { Part No' }\end{array}$} & \multirow[t]{2}{*}{ SIN } & \multicolumn{2}{|c|}{ Thread Size } & \multicolumn{2}{|c|}{$\begin{array}{l}\text { Nominal } \\
\text { K-Factor }\end{array}$} & \multicolumn{2}{|c|}{$\begin{array}{l}\text { Overall } \\
\text { Length }\end{array}$} & \multicolumn{6}{|c|}{ (Refer } \\
\hline & & NPT & BSP & U.S. & matric ${ }^{2}$ & Inches & as $\mathrm{mm}$ & cULus4 & NYC ${ }^{\text {sD }}$ & Vds & LPCB & $C \epsilon$ & 0 \\
\hline 12282 & VK317 & $1 / 2$ & $15 \mathrm{~mm}$ & 5.6 & 80.6 & $2-1 / 4^{\prime \prime}$ & 58 & $\mathrm{~A} 1 \mathrm{X}, \mathrm{B} 1 \mathrm{Y}$ & AfX & - & - & - & - \\
\hline \multicolumn{14}{|c|}{$\begin{array}{c}\text { Maximum } 250 \text { PSI (17 bar) WWP } \\
\text { Small Orlfica" }\end{array}$} \\
\hline $12290^{10}$ & VK342 & $1 / 2^{n}$ & $15 \mathrm{~mm}$ & 2,8 & 40.3 & $2-3 / 1$ & \begin{tabular}{l|l|}
$6^{\circ}$ & 56 \\
\end{tabular} & AIX, BIY & $\mathrm{A} 1 \mathrm{X}$ & - & - & - & - \\
\hline \multicolumn{7}{|c|}{ Approved Temperature Ratings } & \multicolumn{3}{|c|}{$\begin{array}{l}\text { Approved Finishas } \\
\text { 1- Brass, Chrome-Enloy", Whlte } \\
\text { Polyester," Black Polyester", } \\
\text { and Black Tallon" } \\
\text { 2. Brass and Chrome-Enloye } \\
\text { 3- Bress, Chrome-Enloy", White } \\
\text { Polyester", and Black Polyester" }\end{array}$} & \multicolumn{4}{|c|}{ 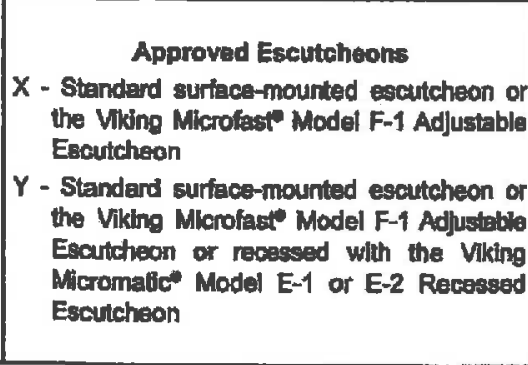 } \\
\hline \multicolumn{14}{|c|}{ 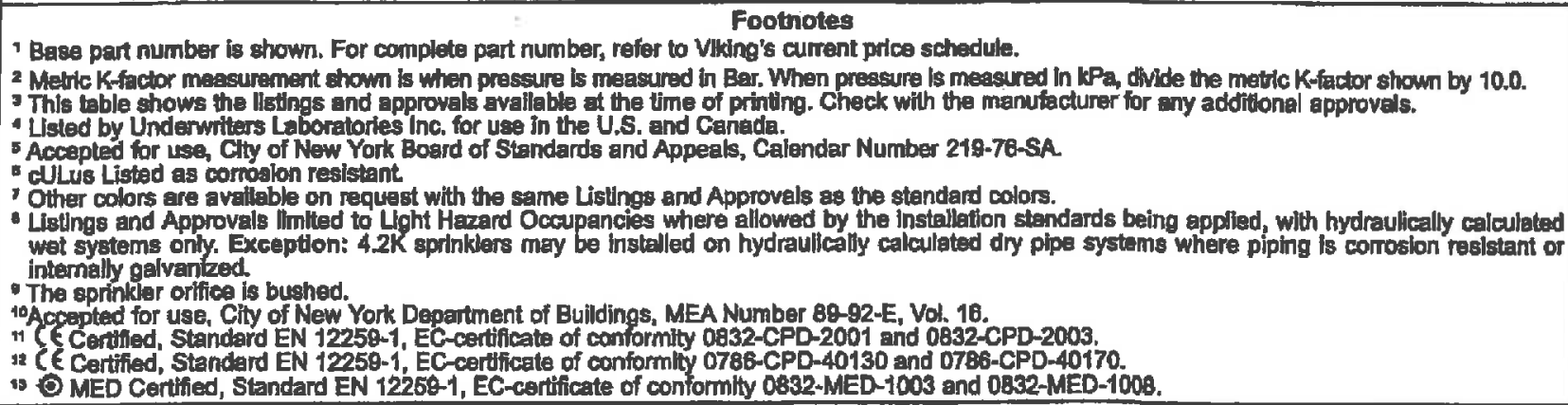 } \\
\hline
\end{tabular}




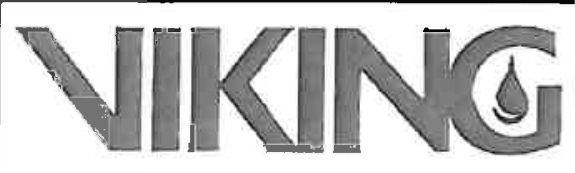

TECHNICAL DATA

MICROFAST AND

MicrofastHP॰ QUICK

RESPONSE PENDENT

SPRINKLERS

The Viking Corporation, 210 N Industrial Park Drive, Hastings MI 49058

Telephone: 269-945-9501 Technical Services: 877-384-5464 Fax: 269-818-1680 Email: techsvcs@vikingcorp.com

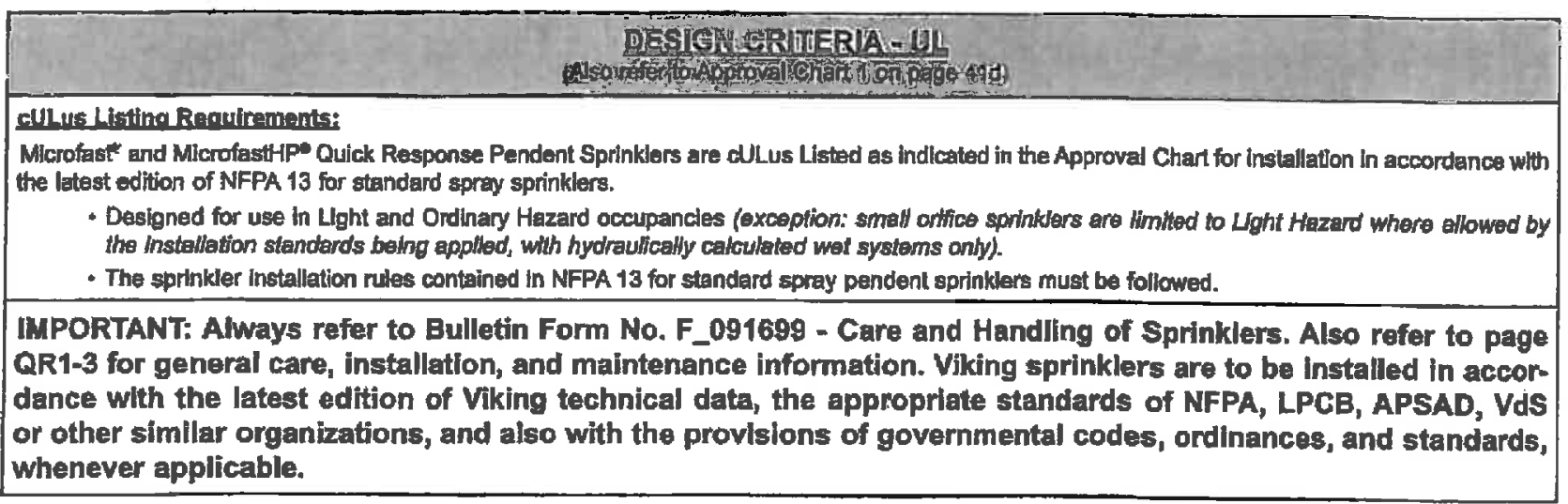
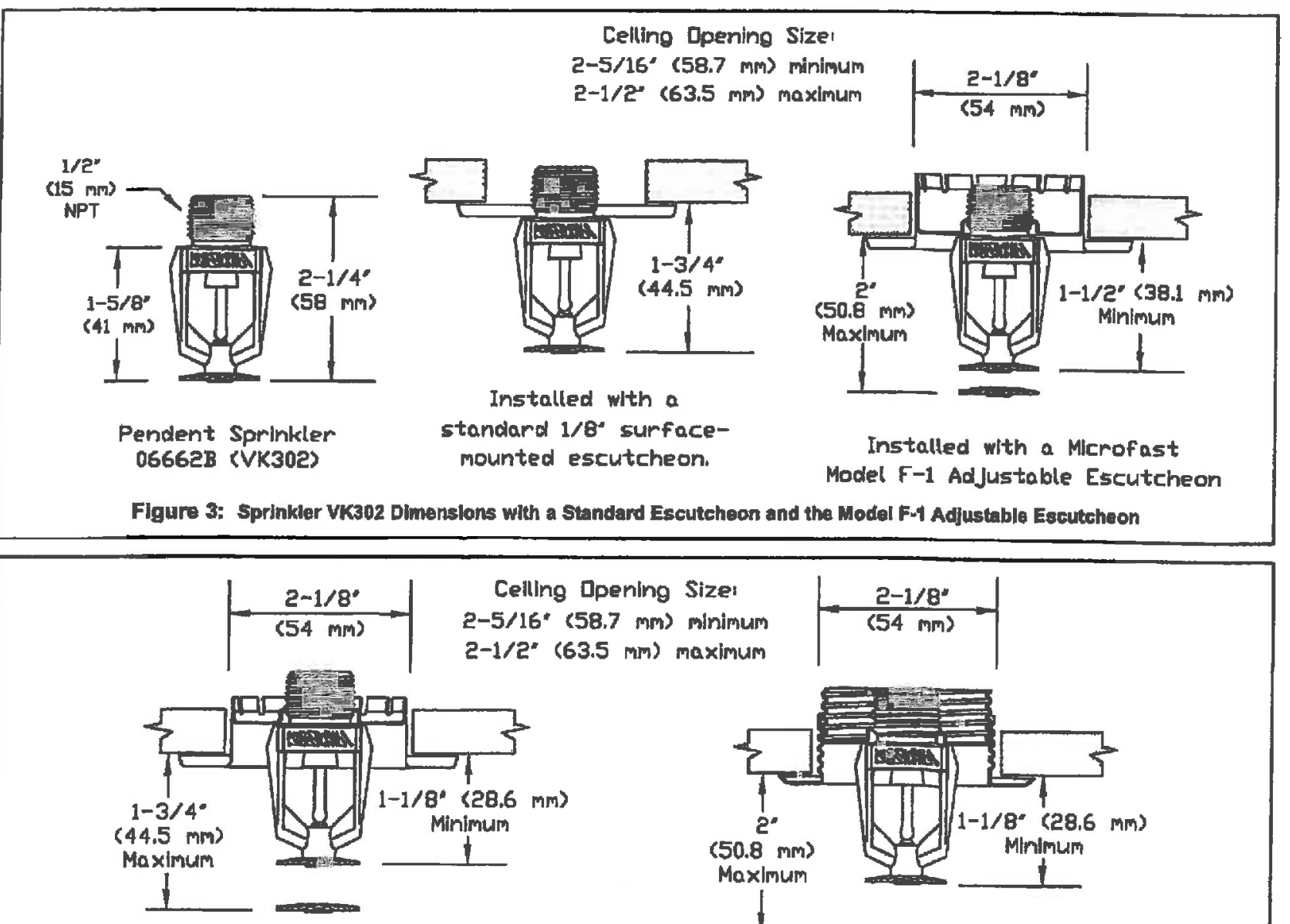

Installed with a Micromatic Model E-1 Recessed Escutcheon
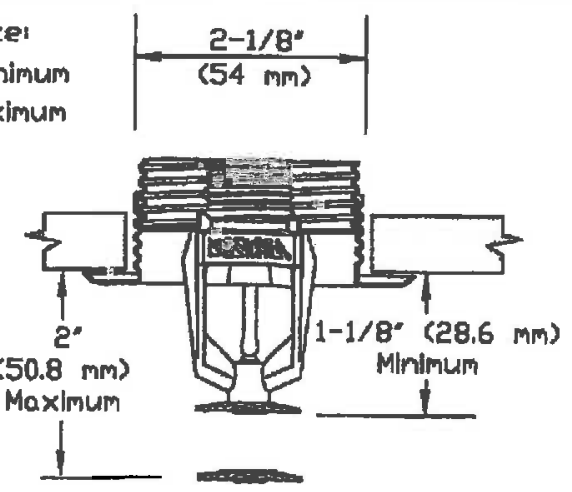

Installed with a thread on Model E-2 Recessed Escutcheon

Figure 4: Sprlinker VK302 Dimensions with the Model E-1 and E-2 Recessed Escutcheons 


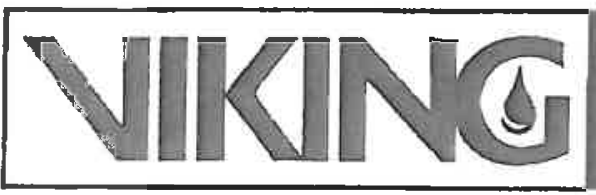

\section{TECHNICAL DATA}

\section{MICROFAST AND MicrofastHPO QUICK RESPONSE PENDENT SPRINKLERS}

The Viking Corporation, 210 N Industrial Park Drive, Hastings MI 49058

Telephone: 269-945-9501 Technical Senvices: 877-384-5464 Fax: 269-1318-1680 Email: techsves@vikingcorp.com

\begin{tabular}{|c|c|c|c|c|c|c|c|c|}
\hline \multirow{3}{*}{$\begin{array}{c}\text { Sprinkler } \\
\text { Base Part No.' }\end{array}$} & \multirow{3}{*}{ SIN } & \multicolumn{6}{|c|}{ 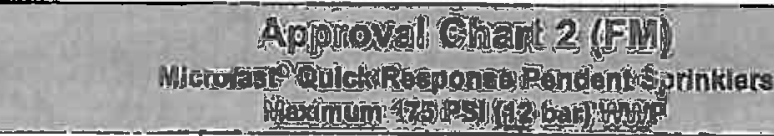 } & \multirow{3}{*}{ 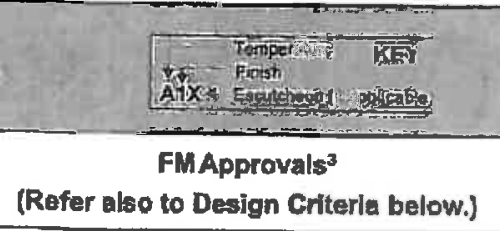 } \\
\hline & & \multicolumn{2}{|c|}{ Thread size } & \multicolumn{2}{|c|}{ Nomina] K-Factor } & \multicolumn{2}{|c|}{ Overall Length } & \\
\hline & & NPT & BSP & U.s. & metric 2 & Inches & $\mathrm{mm}$ & \\
\hline \multicolumn{9}{|c|}{ Standard Orifice } \\
\hline 066628 & VK302 & $1 / 2^{n}$ & $15 \mathrm{~mm}$ & 5.6 & 80.6 & $2-1 / 4^{\prime \prime}$ & 58 & $A 2 X, B 2 Y$ \\
\hline \multicolumn{9}{|c|}{ Latge Orfilice } \\
\hline $06666 \mathrm{~B}$ & VK352 & $3 / 4^{\prime \prime}$ & $20 \mathrm{~mm}$ & 8.0 & 115.2 & $2-3 / 8^{\prime \prime}$ & 60 & $\mathrm{~A} 1 \mathrm{X}, \mathrm{B} 1 \mathrm{Y}$ \\
\hline \multicolumn{9}{|c|}{ Small Oriflee" } \\
\hline $067188^{7}$ & VK329 & $1 / 2^{\prime \prime}$ & $15 \mathrm{~mm}$ & 2.8 & 40.3 & $2-3 / 16^{n}$ & 56 & $A 1 X$ \\
\hline \multicolumn{4}{|c|}{$\begin{array}{l}\text { Approved Temperature Ratings } \\
\text { A- } 135^{\circ} \mathrm{F}\left(57^{\circ} \mathrm{C}\right), 155^{\circ} \mathrm{F}\left(68^{\circ} \mathrm{C}\right), 175^{\circ} \mathrm{F}\left(79^{\circ} \mathrm{C}\right), \\
200^{\circ} \mathrm{F}\left(93^{\circ} \mathrm{C}\right) \text {, and } 288^{\circ} \mathrm{F}\left(141^{\circ} \mathrm{C}\right) \\
\text { B- } 135^{\circ} \mathrm{F}\left(57^{\circ} \mathrm{C}\right), 155{ }^{\circ} \mathrm{F}\left(68^{\circ} \mathrm{C}\right), 175^{\circ} \mathrm{F}\left(79^{\circ} \mathrm{C}\right) \\
\text { and } 200^{\circ} \mathrm{F}\left(9^{\circ} \mathrm{C}\right)\end{array}$} & \multicolumn{3}{|c|}{$\begin{array}{l}\text { Approved Finishes } \\
\text { Brass and Chrome-Enloy" } \\
\text { Brass, Chrome-Enloy", White Polyester, } \\
\text { and Black Polyester" }\end{array}$} & \multicolumn{2}{|c|}{\begin{tabular}{|l} 
Approved Escutcheons \\
X-Standard surfaco-mounted escutcheon or the Viking \\
Microfase Model F-1 Adjustable Escutchson \\
Y - Standard surfacemounted escutcheon or the \\
Viking Microtast Model F-1 Adjustable Escutcheon \\
or recessed with the Viking Micromatic Model E-1 \\
or E-2 Rocessed Escurtcheon
\end{tabular}} \\
\hline \multicolumn{9}{|c|}{ 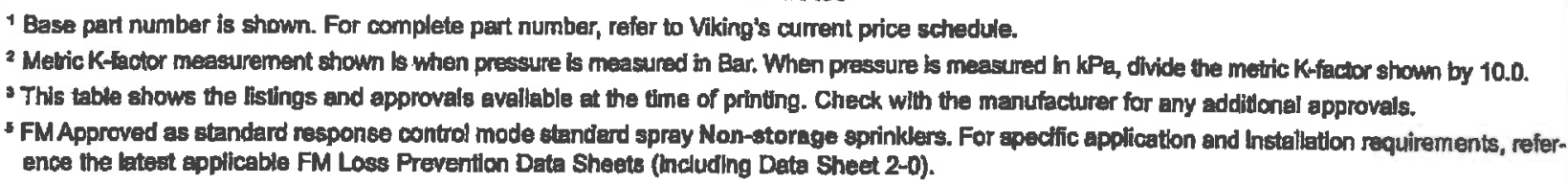 } \\
\hline
\end{tabular}

DESIGN CRDDERTLWEM

(Also refer to:Apporal cha (t's abovo) )

\section{EM Approval Reauiramentsi}

The spinklers indicated in Approval Chart 2 ars FM Approved as standard response Non-atorage standard spray pendent sphinklers as indicated in the FM Approval Gulde. For specilic application and installation requirements, refenence the latest appliceble FM Loss Prevention Data Shegts (including Data Sheet 2-0). FM Global Loss Prevention Data Sheets contain guidelines relating to, but not limited to: minimum water supphy requlrements, hydraulic design, celling slope and obstuctions, minimum and maximum allowable spacing, end deflector distance below the celling.

NOTE: The FM instaliation guidelinos may differ from cULus andfor NFPA critaria.

MPORTANT: Aways refer to Bulletin Form No. F_091699 - Care and Handling of Sprinklers. Also refer to page QR1-3 for general care, installation, and maintenance information. Viking sprinklers are to be installed in accordance with the latest edition of Viking technical data, the appropriate standards of NFPA, FM Global, LPCB, APSAD, VdS or other similar organizations, and also with the provisions of governmental codes, ordinances, and standards, whenever applicable. 
The Viking Corporation, 210 N Industrlal Park Drive, Hastings Ml 49058

Telephone: 269-945-9501 Technical Services: 877-384-5464 Fax: 269-818-1680 Email: techsvcs@vikingcorp.com

\section{DESCRIPTION}

Viking Microfast' Standard/Quick Response Extended Coverage Horizontal Sidewall Sprinkler VK606 is a thermosensitive spray sprinkler available in several different finIshes and temperature ratings to meet varying design requirements. The small glass bulb operating element and special deflector combine speed of operation and area of coverage to meet quick response extended coverage standards.

The special Polyester and Teflon coatings can be used in decorative applications where colors are desired.

\section{LISTINGS AND APPROVALS}

cULus Listed: Category VNIV

FM Approved: Class 2022

NYC Approval: Clty of New York Board of Standards and Appeals, Calendar No. 219-76-SA

Refer to Approval Chart 1 and Design Criterla on page 82c for cULus Listing requirements, and refer to Approval Chart 2 and Design Criteria on page B2d for FM Approval

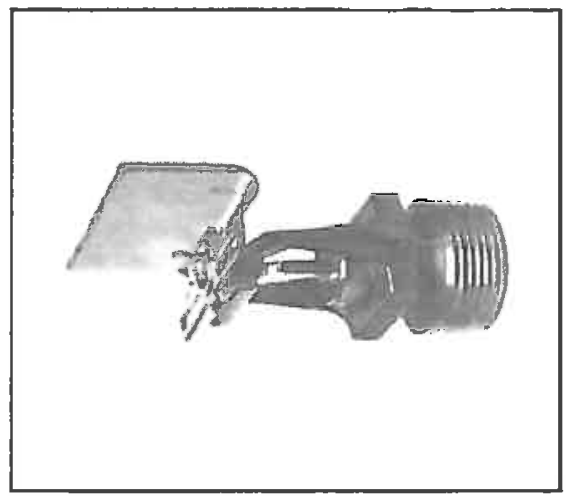

For Light Hazard Occupancies Only requirements that must be followed.

\section{TECHNICAL DATA}

\section{Specifications:}

Available since 1996.

Minimum Operating Pressure: Refer to the Approval Chart.

Maximum Working Pressure: 175 psi (12 bar). Factory tested hydrostatically to 500 psi (34.5 bar).

Testing: U.S.A. Patent No, 4,831,870

Thread size: $3 / 4^{\prime \prime}(20 \mathrm{~mm})$ NPT

Nominal K-Factor: 8.0 U.S. (115.2 metric*)

"Metric K-factor measurement shown is when pressure is measured in Bar. When pressure is measured in $\mathrm{kPa}$, divide the metric K-factor shown by 10.0 . Glass-bulb fluid temperature rated to $-65^{\circ} \mathrm{F}\left(-55^{\circ} \mathrm{C}\right)$

Overall Length: $3-1 / 8^{*}(80 \mathrm{~mm})$

Material Standards:

Sprinkler Frame: Brass UNS-C84400

Deflector: Phosphor Bronze UNS-C51000

Bulb: Glass, nominal $3 \mathrm{~mm}$ dlameter

Pip Cap: Brass UNS-C31400 or UNS-C31600

Compression Screw: Brass UNS-C36000

Belleville Spring Sealing Assembly: Nickel Alloy, coated on both sides with Tefion Tape

For Tefion ${ }^{\oplus}$ Coated Sprinklers: Belleville Spring-Exposed, Screw-Nickel Plated, Pip Cap-Teflon ${ }^{\circ}$ Coated

Eor Polvester Coated Sorinklers; Belleville Spring-Exposed

Ordering Informatlon: (Also refer to the current Viking price list.)

Order Sprinkler VK606 by first adding the appropriate suffix for the sprinkler finish and then the appropriate suffix for the temperature rating to the sprinkler base part number.

Finish Suffix: Brass = A, Chrome-Enloy $=F$, Whlte Polyester $=M-M$, Black Polyester $=M-/ B$, and Black Teflon $=N$

Temperature Suffix $\left({ }^{\circ} \mathrm{F} /{ }^{\circ} \mathrm{C}\right): 135^{\circ} / 57^{\circ}=\mathrm{A}, 155^{\circ} / 68^{\circ}=\mathrm{B}, 175^{\circ} / 79^{\circ}=\mathrm{D}$

For example, sprinkler VK606 with a Brass finish and a $155^{\circ} \mathrm{F} / 68^{\circ} \mathrm{C}$ temperature rating = Part No. $13005 \mathrm{AB}$.

Avallable Finishes And Temperature Ratings: Refer to Table 1.

Accessories: (Also refer to the "Sprinkler Accessories" section of the Viking data book.) 


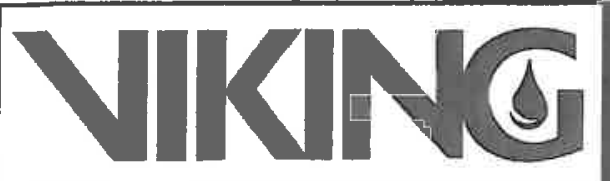

TECHNICAL DATA

MICROFAST' STANDARD/

QUICK RESPONSE

EXTENDED COVERAGE HSW SPRINKLER VK606

The Viking Corporation, 210 N Industrial Park Drive, Hastings Ml 49058

Telephone: 269-945-9501 Technical Services: 877-384-5464 Fax: 269-818-1680 Email: techsvcs@vikingcorp.com

\section{Sprinkler Wrenches:}

A. Standard Wrench: Part No. 10896W/B (available since 2000)

B. Wrench for coated and/or recessed sprinklers: Part No. 13655W/B*: (available since 2006)

"A $1 / 2$ " ratchet is required (not available from Viking). Sprinker Cabinets:

A. Six-head capacity: Part No. 01724A (available since 1971)

B. Twelve-head capacity: Part No. 01725A (available since 1971)

\section{INSTALLATION}

Refer to appropriate NFPA Installation Standards.

\section{OPERATION}

During fire conditions, the heat-sensitive liquid in the glass bulb expands, causing the bulb to shatter, releasing the pip cap and sealing spring assembly. Water flowing through the sprinkler orifice strikes the sprinkJer deflector, forming a uniform spray pattern to extinguish or control the fire.

\section{INSPECTIONS, TESTS AND MAINTENANCE}

Refer to NFPA 25 for Inspection, Testing and Maintenance requirements.

\section{AVAILABILITY}

The Viking Model VK606 Sprinkler is available through a network of domestic and international distributors. See The Viking Corporation web site for the closest distributor or contact The Viking Corporation.

\section{CUARANTEE}

For details of warranty, refer to Viking's current list price schedule or contact Viking directly.

\begin{tabular}{|c|c|c|c|}
\hline $\begin{array}{l}\text { Sprinkler Temperature } \\
\text { Classification }\end{array}$ & $\begin{array}{l}\text { Spripkier Norninal } \\
\text { Temperature Rating' }\end{array}$ & $\begin{array}{l}\text { Maximum Ambient: } \\
\text { Colling Temperaturet }\end{array}$ & Bulb Color \\
\hline Ordinary & $135^{\circ} \mathrm{F}\left(57^{\circ} \mathrm{C}\right)$ & $100^{\circ} \mathrm{F}\left(38^{\circ} \mathrm{C}\right)$ & Orange \\
\hline Ordinary & $155^{\circ} \mathrm{F}\left(68^{\circ} \mathrm{C}\right)$ & $100^{\circ} \mathrm{F}\left(38^{\circ} \mathrm{C}\right)$ & Red \\
\hline Intermediate & $175^{\circ} \mathrm{F}\left(79^{\circ} \mathrm{C}\right)$ & $150^{\circ} \mathrm{F}\left(65^{\circ} \mathrm{C}\right)$ & Yellow \\
\hline \multicolumn{4}{|c|}{ Avallable Sprinkler Finishes: Brass, Chrome-Enloy (patents pending), White Polyester, Black Polyester ${ }^{3}$, and Black Teflon ${ }^{\star 3}$} \\
\hline \multicolumn{4}{|c|}{ Footnotes } \\
\hline \multicolumn{4}{|c|}{$\begin{array}{l}\text { 'The sprinkler temperature rating is stamped on the defiector. } \\
2 \text { Based on NFPA-13. Other limits may apply, depending on fire loading, sprinkler location, and other requirements of the Authority Having Jurisdiction. } \\
\text { Refer to specific installation standards. }\end{array}$} \\
\hline \multicolumn{4}{|c|}{$\begin{array}{l}\text { The coatings indicated are applied to the exposed exterior surfaces only. For Teflon" coated open sprinklers only, the waterway is coated. Note that } \\
\text { the spring is exposed on sprinklers with Teflon" and Polyester coatings. }\end{array}$} \\
\hline
\end{tabular}

Note: Sprinkler is turned

sidewa; for clarit. (R.efer

to Figures 3 and 4 for correct deflector orientation.)
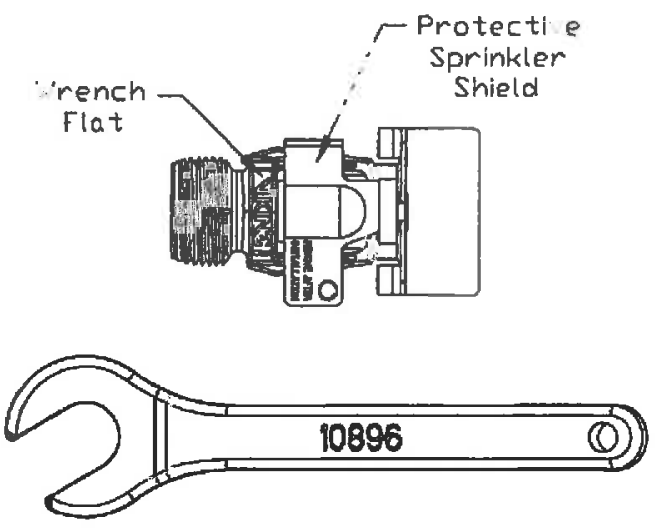

Figure 1:

Standard Sprinkler Wrench 10896W/B 


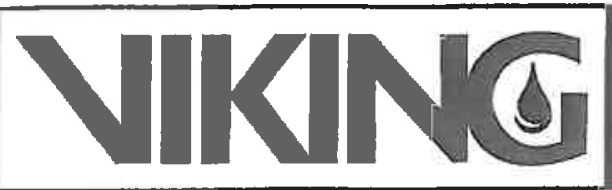

MICROFAST STANDARD/ QUICK RESPONSE EXTENDED COVERAGE HSW SPRINKLER VK606

The Viking Corporation, 210 N Industrial Park Drive, Hastings MI 49058

Telephone: 269-945-9501 Technical Services: 877-384-5464 Fax: 269-818-1680 Email: techsvcs@vikingcorp.com

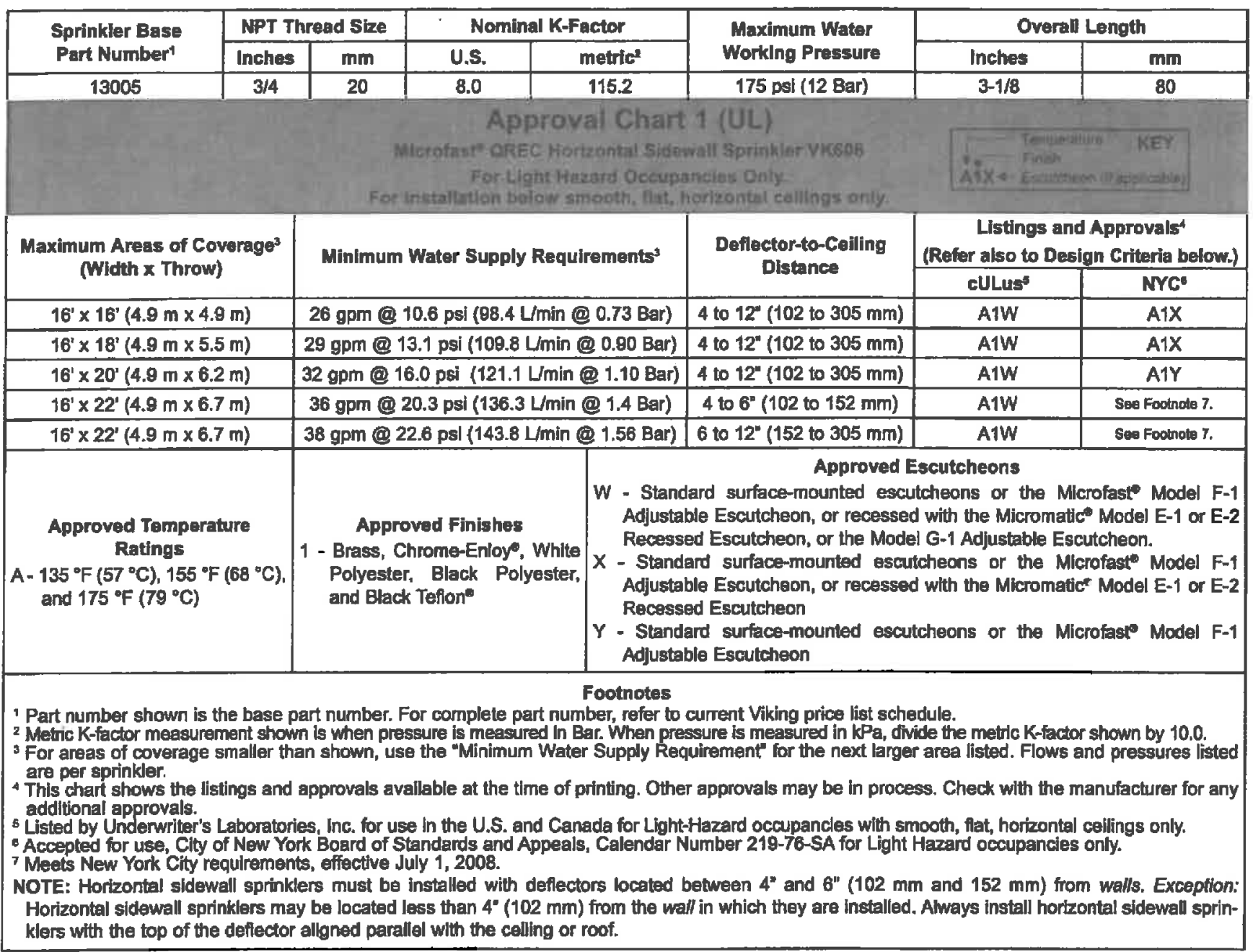

\section{cULus Listing Ronuirements:}

Microfast Extended Coverage Horkzontal Sidewall Sprinkler VK606 is cULus Lsted as a quick response sprinkler as indicated in Approval Chart 1 for installation in accordance with the latest edition of NFPA 13 for extended coverage sidewall spray sprinklers:

- Limited to Light Hazard occupancies with smooth, flat, hortzontal ceilings only.

- Refer to Approval Chart 1 for required deflector distance below the ceiling. Install with the leading edge of the deflector and sprinkler frame arms oriented parallel to the ceiling (see Figure 3). THE TOP 8URFACE OF THE DEFLECTOR IS MARKED "TOP". The sprinkler must be oriented as shown in Figure 3.

- Minimum distance from end walls is 4 in. (102 mm).

- Meximum distance from the end wall shall be no more than one-half of the allowable distance between sprinklers. The distance shall be measured perpendicular to the wall.

- The sprinkler installation and obstruction rules contained in NFPA 13 for extended coverage sidewall spray sprinklers must be followed.

IMPORTANT: Always refer to Builetin Form No. F_091699 - Care and Handling of Sprinklers. Also refer to pages EC1-3 for general care, installation, and maintenance information. Viking sprinklers are to be installed in accordance with the latest edition of Viking technical data, the appropriate standards of NFPA, LPCB, APSAD, VdS or other similar organizations, and also with the provisions of governmental codes, ordinances, and standards, whenever applicable. 


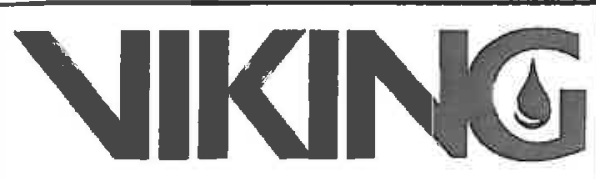

TECHNICAL DATA

MICROFAST' ${ }^{\circ}$ STANDARD/

QUICK RESPONSE

EXTENDED COVERAGE

HSW SPRINKLER VK606

The Viking Corporation, 210 N Industrial Park Drive, Hastings MI 49058

Telephone: 269-945-9501 Technical Services: 877-384-5464 Fax: 269-818-1680 Emali: techsvcs@vikingcorp.com
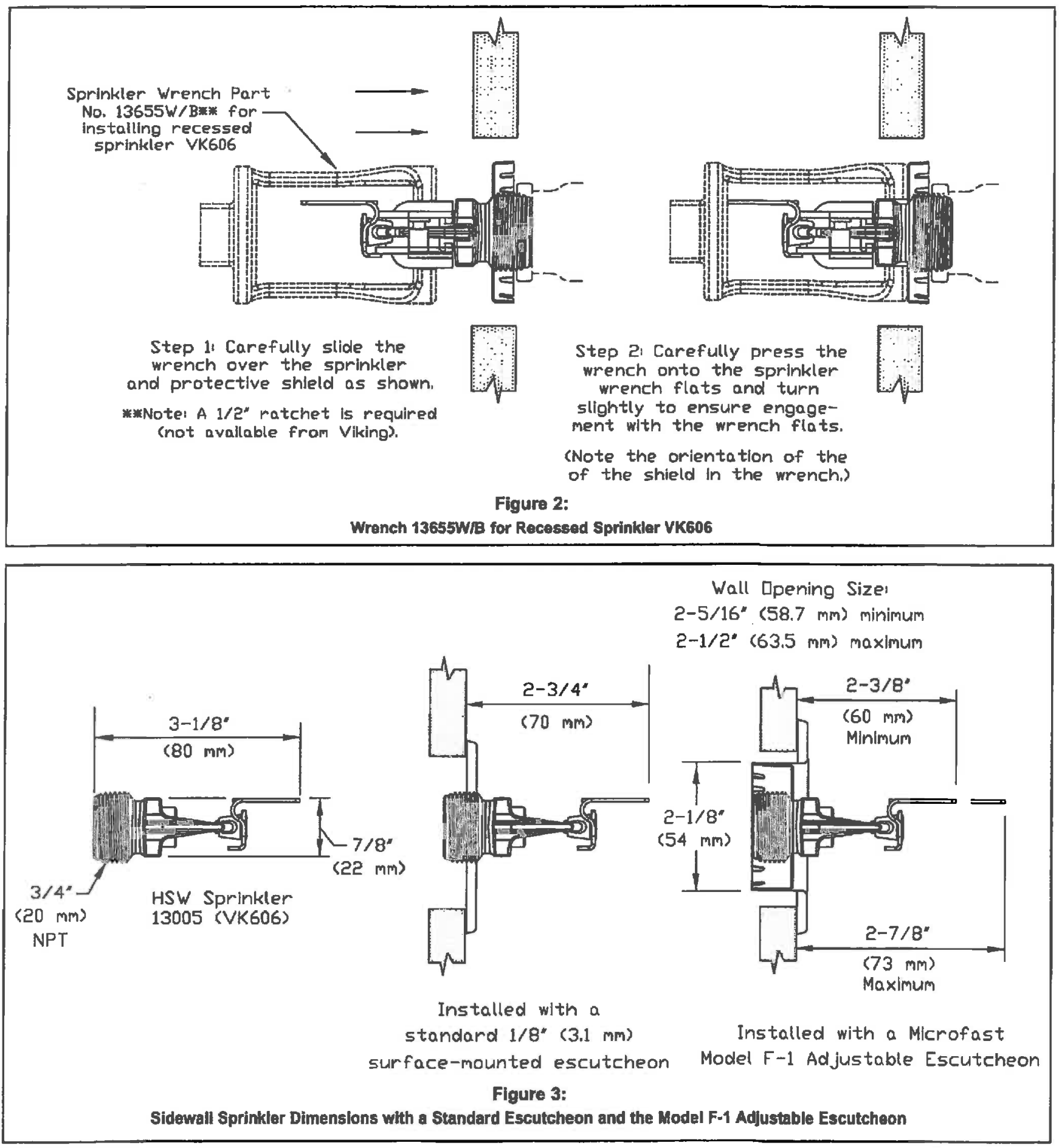
November 4, 2010

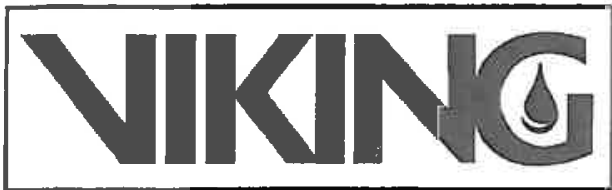

TECHNICAL DATA

MICROFAST STANDARD/

QUICK RESPONSE

EXTENDED COVERAGE

HSW SPRINKLER VK606

The Viking Corporation, 210 N Industrial Park Drive, Hastings MI 49058

Telephone: 269-945-9501 Technical Services: 877-384-5464 Fax: 269-818-1680 Email: techsvcs@vikingcorp.com

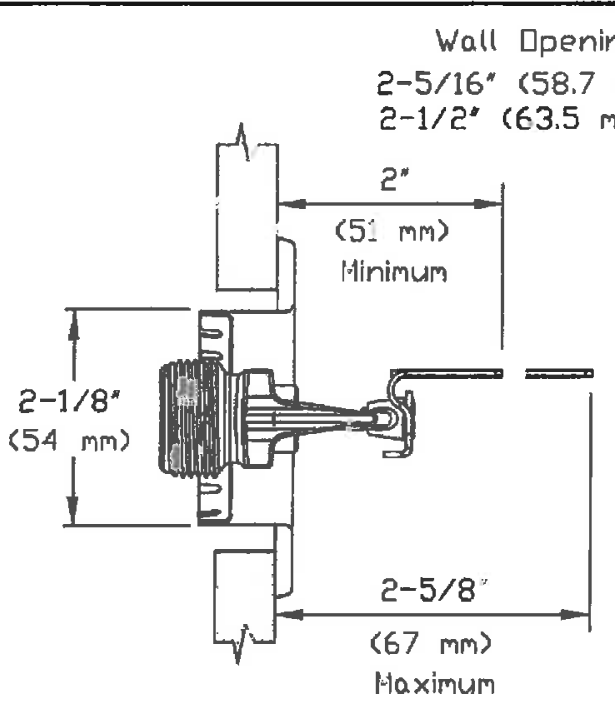

Installed with a Micromatic llodel E-1 Recessed Escutcheon

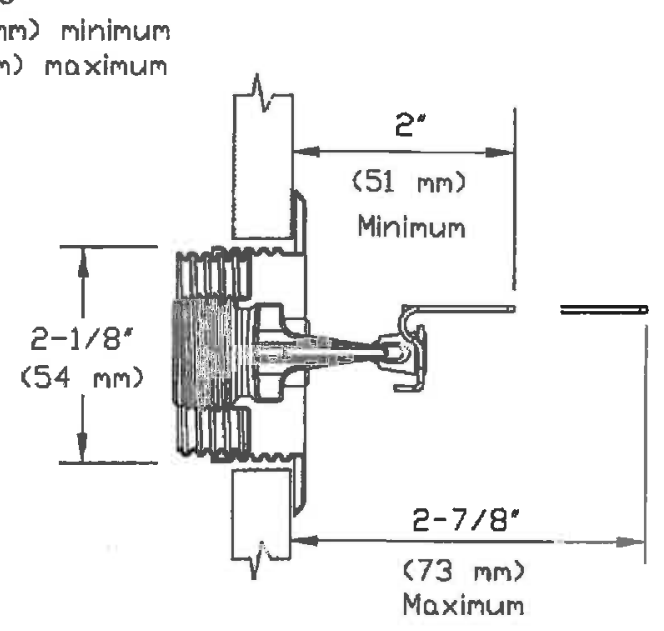

Installed with a Model E-2

Thread-on Recessed Escutcheon

Figure 4:

Sidewall Sprinkler Dimensions with the Model E-1 and E-2 Recessed Escutcheons

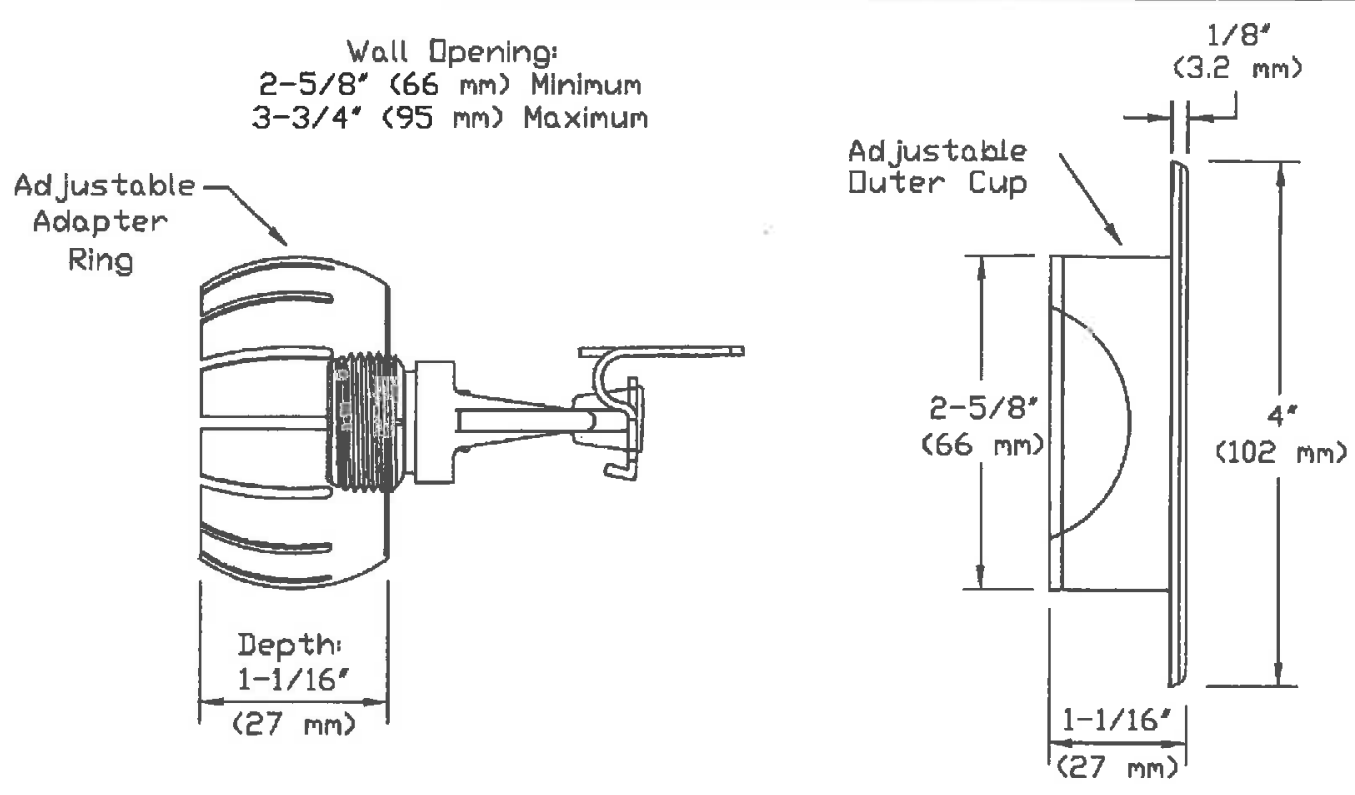

Figure 5:

Sidewall Sprinkler Dimensions with the Model G-1 Adjustable Escutcheon 


\begin{tabular}{|l|l|} 
TECHNICAL DATA & $\begin{array}{c}\text { MICROFAST AND MICRO- } \\
\text { FASTHP® QUICK RESPONSE } \\
\text { HORIZONTAL SIDEWALL } \\
\text { SPRINKLERS (VK305\& VK319) }\end{array}$ \\
\hline
\end{tabular}

The Viking Corporation, 210 N Industrial Park Drive, Hastings MI 49058

Telephone: 269-945-9501 Technlcal Servlces: 877-384-5464 Fax: 269-818-1680 Email: techsvcs@vikingcorp.com

\section{DESCRIPTION}

Viking Microfast and MicrofastHP॰ Quick Response Horizontal Sidewall Sprinklers are small thermosensitive glass bulb spray sprinklers available with various finishes and temperature ratings to meet design requirements. The special Polyester and Teflon coatings can be used in decorative applications where colors are desired. In addition, these coatings have been investigated for installation in corrosive atmospheres and are cULus listed as corrosion resistant as indicated in the Approval Chart. (Note: FM Global has no approval classification for Teflon ${ }^{\circ}$ and Polyester coatings as corrosion resistant.)

\section{LISTINGS AND APPROVALS}

cULus LIsted: Category VNIV

FM Approved: Class 2020

NYC Approved: MEA 89-92-E, Volume 16

Refer to Approval Chart 1 and Design Criteria on page 43d for cULus Listing requirements, and refer to Approval Chart 2 and Design Criteria on page $43 f$ for FM Approval requirements that must be followed.

\section{TECHNICAL DATA}

\section{Specifications:}

Available since 2003.

Minimum Operating Pressure: 7 psi (0.5 bar)

Maximum Working Pressure: Sprinkler VK319 is rated for use with water working pressures ranging from the minimum 7 psi ( 0.5 bar) up to 250 psi (17 bar) for high-pressure systems. High-pressure (HP) sprinklers can be Identified by locating " 250 " stamped on the deflector. Sprinkler VK305 is rated to a maximum 175 psi (12 bar) wwp.

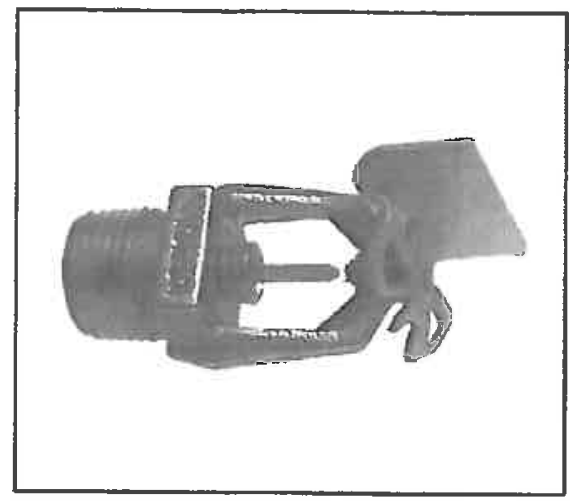
Factory tested hydrostatically to 500 psi (34.5 bar)

Testing: U.S.A. Palent No. 4,831,870

Nominal K-Factor: 5.6 U.S. (80.6 motric*)

"Metric K-factor measurement shown is when pressure is measured in Bar. When pressure is measured in $\mathrm{KPa}$, divide the metric K-factor shown by 10.0 .

Glass-bulb fluid temperature rated to $-65^{\circ} \mathrm{F}\left(-55^{\circ} \mathrm{C}\right)$

Overall Length: 2-11/16" $(68 \mathrm{~mm})$

\section{Material Standards:}

Frame Casting: Brass UNS-C84400

Deflector: Copper UNS-C19500

Bulb: Glass, nominal $3 \mathrm{~mm}$ diameter

Belleville Spring Sealing Assembly: Nickel Alloy, coated on both sides with Teflon Tape

Screw: Brass UNS-C36000

Pip Cap: Copper UNS-C11000 and Stainless Steel UNS-S30400

Pip Cap Attachment (for Sprinkler VK319): Brass UNS-C36000

Eor Teflon Coated Sprinklers: Belleville Spring-Exposed, Screw-Nickel Plated, Pip Cap-Teflon Coated

Eor Polvester Coated Sprinklers: Belleville Spring-Exposed

Ordering Information: (Also refer to the current Viking price list.)

Order Quick Response Horizontal Sidewall Sprinklers by first adding the appropriate suffix for the sprinkler finish and then the appropriate suffix for the temperature rating to the sprinkler base part number.

Finish Suffix: Brass $=A$, Chrome-Enloy ${ }^{2}=F$, White Polyester $=M-W$, Black Polyester $=M-1 B$, and Black Teflon $=N$

Temperature Suffix $\left({ }^{\circ} \mathrm{F} /{ }^{\circ} \mathrm{C}\right): 135^{\circ} / 68^{\circ}=\mathrm{A}, 155^{\circ} / 68^{\circ}=\mathrm{B}, 175^{\circ} / 79^{\circ}=\mathrm{D}, 200^{\circ} / 93^{\circ}=\mathrm{E}$, and $286^{\circ} / 141^{\circ}=\mathrm{G}$

For example, sprinkler VK305 with a Brass finish and a $155^{\circ} \mathrm{F} / 68^{\circ} \mathrm{C}$ temperature rating = Part No. 12121AB

Form No. F_030103 


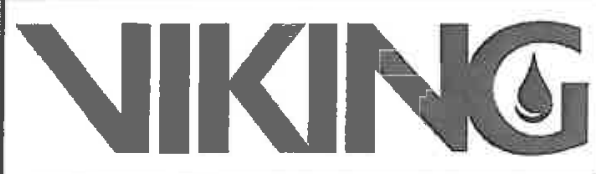

\section{TECHNICAL DATA}

MICROFAST ${ }^{\ominus}$ AND MICROFASTHP QUICK RESPONSE HORIZONTAL SIDEWALL SPRINKLERS (VK305\& VK319)

The Viking Corporation, 210 N Industrial Park Drive, Hastings Ml 49058

Telephone: 269-945-9501 Technical Services: 877-384-5464 Fax: 269-818-1680 Emall: techsvcs@vikingcorp.com

Avallable Finishes And Temperature Ratings:

Refer to Table 1

Accessories: (Also refer to the "Sprinkler Accessories" section of the Viking data book.)

Sprinkler Wrenches:

A. Standard Wrench: Part No. 10896W/B (avallable since 2000).

B. Wrench for recessed sprinklers with protective shields: Part No. 13655W/B ${ }^{\text {th }}$ (available since 2003)

"A $1 / 2 "$ ratchet is required (not available from Viking).

\section{Sprinkler Cabinets:}

A. Six-head capacity: Part No. 01724A (available since 1971)

B. Twelve-head capacity: Part No. 01725A (avallable since 1971)

\section{INSTALLATION}

Refer to appropriate NFPA Installation Standards.

\section{OPERATION}

During fire condlitions, the heat-sensitive liquid in the glass bulb expands, causing the glass to shatter, releasing the pip cap and sealing spring assembly. Water flowing through the sprinkler orifice strikes the sprinkler deflector, forming a unlform spray pattem to extingulsh or control the fire.

\section{INSPECTIONS, TESTS AND MAINTENANCE}

Refer to NFPA 25 for Inspection, Testing and Maintenance requirements.

\section{AVAILABILITY}

Viking Quick Response Horizontal Sidewall Sprinklers are available through a network of domestic and intemational distributors. See The Viking Corporation web site for the closest distributor or contact The Viking Corporation.

\section{GUARANTEE}

For details of warranty, refer to Viking's current list price schedule or contact Viking directly.

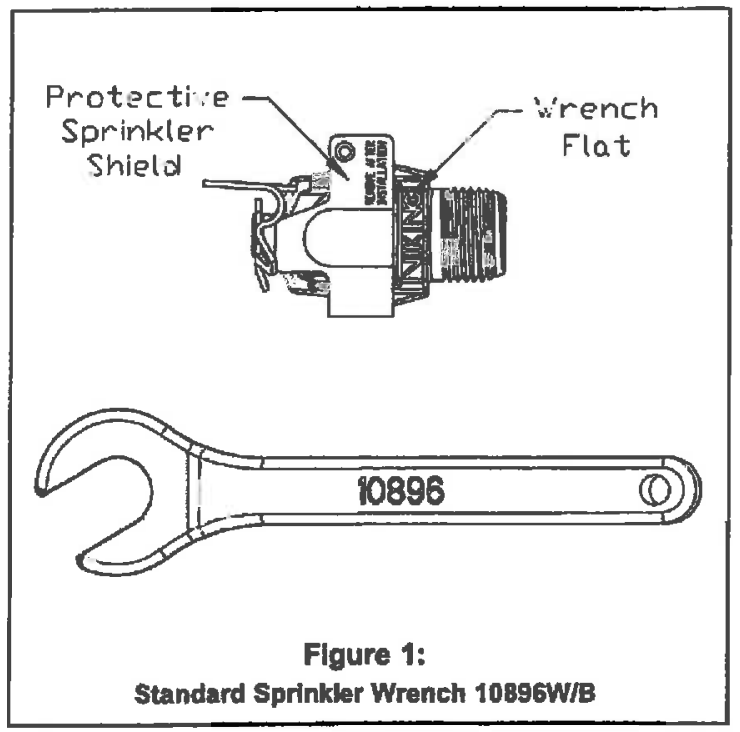




\section{VIKING}

\section{TECHNICAL DATA}

MICROFAST ${ }^{\oplus}$ AND MICRO-
FASTHP® QUICK RESPONSE
HORIZONTAL SIDEWALL
SPRINKLERS (VK305 \& VK319)

The Viking Corporation, $210 \mathrm{~N}$ Industrial Park Drive, Hastings M] 49058

Telephone: 269-945-9501 Technical Services: 877-384-5464 Fax:269-818-16:B0 Emali: techsvcs@vikingcorp.com

\begin{tabular}{|c|c|c|c|}
\hline $\begin{array}{l}\text { Sprinider Temperature } \\
\text { Classtrication }\end{array}$ & $\begin{array}{l}\text { Sprinkier Nominal } \\
\text { Tomperature Rating" }\end{array}$ & Maximum Ambient & Bulb Color \\
\hline Ordinary & $135^{\circ} \mathrm{F}\left(57^{\circ} \mathrm{C}\right)$ & $100^{\circ} \mathrm{F}\left(38^{\circ} \mathrm{C}\right)$ & Orange \\
\hline Ordinary & $155^{\circ} \mathrm{F}\left(68^{\circ} \mathrm{C}\right)$ & $100^{\circ} \mathrm{F}\left(38^{\circ} \mathrm{C}\right)$ & Red \\
\hline Intermediate & $175^{\circ} \mathrm{F}\left(79^{\circ} \mathrm{C}\right)$ & $150^{\circ} \mathrm{F}\left(65^{\circ} \mathrm{C}\right)$ & Yellow \\
\hline Intermediate & $200^{\circ} \mathrm{F}\left(93^{\circ} \mathrm{C}\right)$ & $150^{\circ} \mathrm{F}\left(65^{\circ} \mathrm{C}\right)$ & Green \\
\hline High & $286^{\circ} \mathrm{F}\left(141^{\circ} \mathrm{C}\right)$ & $225^{\circ} \mathrm{F}\left(107^{\circ} \mathrm{C}\right)$ & Blue \\
\hline \multicolumn{4}{|c|}{$\begin{array}{l}\text { Sprinkler Finishes: Brass, Chrome-Enloy, White Polyester, Black Polyester, and Black Teflon } \\
\text { Corroslon-Resistant Coatings. White Polyester, Black Polyester, and Black Teflon }\end{array}$} \\
\hline \multicolumn{4}{|c|}{$\begin{array}{l}\text { 'The sprinkler tempersture rating is stamped on the deflector. } \\
\text { 2 Based on NFPA-13. Other limits may apply, depending on fire loading, sprinkler location, and other requirements of the Authorlty Having Jurisdictior } \\
\text { Refer to specific installation standards. }\end{array}$} \\
\hline \multicolumn{4}{|c|}{$\begin{array}{l}\text { The corrosion-resistant coatings have passed the standard corrosion test required by the approving agencies indicated in the Approval Chart. These } \\
\text { tests cannot and do not represent all possible corrosive environments. Prior to installation, verify through the end-user that the coatings are compat } \\
\text { lble with or suitable for the proposed environment. For automatic sprinklers, the coalings indicated are applied to the exposed exterior surfaces only } \\
\text { Note that the spring is exposed on sprinklers with Polyester and Teflon coatings. }\end{array}$} \\
\hline
\end{tabular}

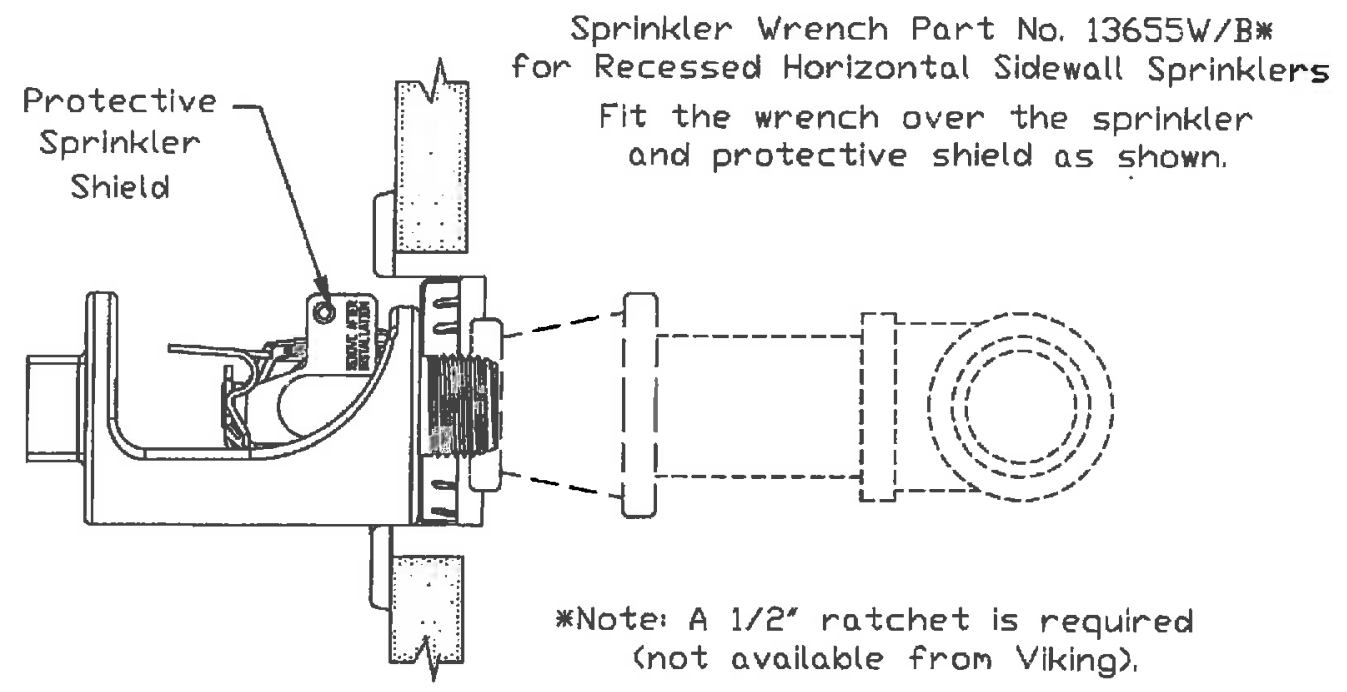

Figure 2: Wrench 13655W/B for Recessed Horizontal Sidewall Sprinklers 


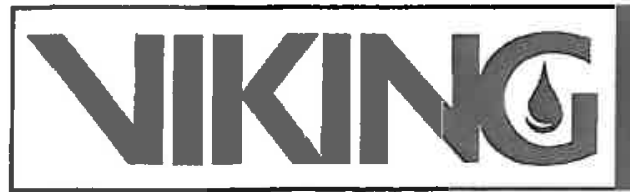

\section{TECHNICAL DATA}

MICROFAST' AND MICRO-
FASTHPO QUICK RESPONSE
HORIZONTAL SIDEWALL
SPRINKLERS (VK305 \& VK319)

The Vking Corporation, $210 \mathrm{~N}$ Industrial Park Drive, Hastings MI 49058

Telephone: 269-945-9501 Technical Services: 877-384-5464 Fax: 269-818-1680 Email: techsvcs@vikingcorp.com

\begin{tabular}{|c|c|c|c|c|c|c|c|c|c|c|c|c|c|}
\hline \multirow{3}{*}{$\begin{array}{l}\text { Base Part } \\
\text { Number' }\end{array}$} & \multirow{3}{*}{ SIN } & \multirow{3}{*}{$\begin{array}{l}\text { Maximum } \\
\text { Pressure }\end{array}$} & \multirow{2}{*}{\multicolumn{4}{|c|}{$\begin{array}{l}\text { Approval } \\
\text { crotasthpe oulck } \\
\text { Nominal K-Factor }\end{array}$}} & \multirow{2}{*}{\multicolumn{2}{|c|}{ Overall Length }} & \multirow{2}{*}{\multicolumn{5}{|c|}{$\begin{array}{l}\text { Listings and Approvals" } \\
\text { (Refer also to Design Criteria below.) }\end{array}$}} \\
\hline & & & & & & & & & & & & & \\
\hline & & & NPT & BSP & U.S. & metric $^{2}$ & Inches & $\mathrm{mm}$ & cULus' & Nrc & LPCB & & 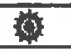 \\
\hline \multicolumn{14}{|c|}{$\begin{array}{c}\text { Maximum 175 PSI (12 Bar) WWP } \\
\text { For Light or Ordinary Hazard Occupancies. } \\
\text { Deflector must be located 4" to } 12^{\prime \prime} \text { (102 } \mathrm{mm} \text { to } 305 \mathrm{~mm} \text { ) below the celling. }\end{array}$} \\
\hline 12121 & VK305 & $175 \mathrm{psi}$ & $1 / 2^{\prime \prime}$ & $15 \mathrm{~mm}$ & 5.6 & 80.6 & $2-11 / 16$ & 68 & A1Y, B1X & A1Y & $\ldots$ & - & - \\
\hline \multicolumn{14}{|c|}{ Deflect } \\
\hline \multirow{2}{*}{12121} & \multirow{2}{*}{ VK305 } & \multirow{2}{*}{$175 \mathrm{psi}$} & \multirow{2}{*}{$1 / 2^{n}$} & \multirow{2}{*}{$15 \mathrm{~mm}$} & \multirow{2}{*}{5.6} & \multirow{2}{*}{80.6} & \multirow{2}{*}{$2-11 / 16$} & \multirow{2}{*}{68} & culus & NYC & LPCB & & 1 \\
\hline & & & & & & & & & $\mathrm{A} 1 \mathrm{Y}, \mathrm{B} 1 \mathrm{X}$ & Sor Foominale 6 . & - & - & - \\
\hline \multirow{2}{*}{\multicolumn{14}{|c|}{ Deflector must b }} \\
\hline \multirow{2}{*}{12285} & \multirow{2}{*}{ VK319 } & & & & & & & \multirow{2}{*}{68} & cULus' & NYC & LPCB & & 要 \\
\hline & & $250 \mathrm{psi}$ & $1 / 2^{\prime \prime}$ & $15 \mathrm{~mm}$ & 5.6 & 80.6 & $2-11 / 16$ & & $\mathrm{~A} 1 \mathrm{Y}, \mathrm{B} 1 \mathrm{X}$ & A1Y & - & - & - \\
\hline \multicolumn{5}{|c|}{ 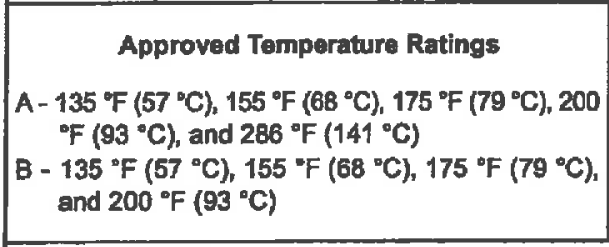 } & \multicolumn{3}{|c|}{$\begin{array}{l}\text { Approved Finishes } \\
\text { 1-Brass, Chrome-Enloy, White } \\
\text { Polyester", Black Polyester?, } \\
\text { and Black Teflon }\end{array}$} & \multicolumn{6}{|c|}{$\begin{array}{l}\text { Approved Escutcheons } \\
\text { X - Installed with standard surface-mounted escutcheons or } \\
\text { the Viking Microfast" Model F-1 Adjustable Escutcheon", or } \\
\text { recessed wlth the Viking Micromatic Model E-1, E-2 or G-1 } \\
\text { Recessed Escutcheon } \\
\text { Y- Installed with standard surface-mounted escutcheons or the } \\
\text { Viking Microfast" Model F-1 Adjustable Escutcheon" }\end{array}$} \\
\hline \multicolumn{14}{|c|}{ 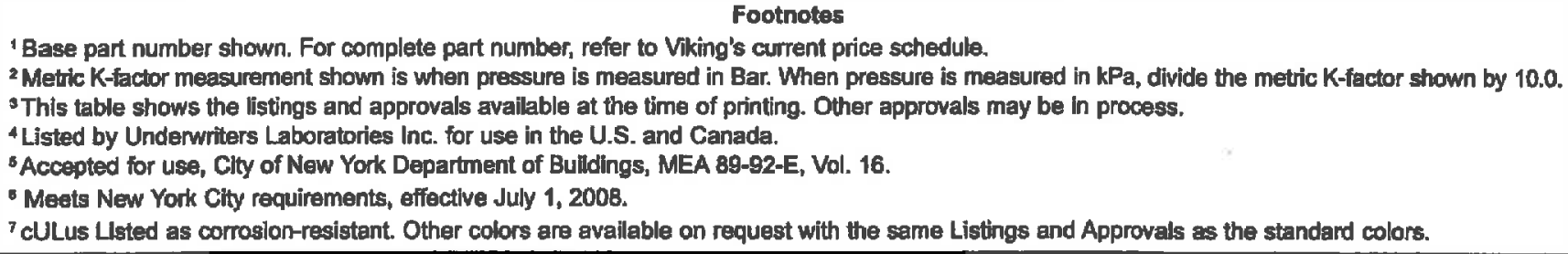 } \\
\hline
\end{tabular}

\section{cUl-us Listing Raquirements:}

Quick Response Horizontal Sprinklers VK305 and VK319 are cULus Listed as indicated in the Approval Chart for installation in accordance with the latest edition of NFPA 13 for sidewali standard spray sprinklers.

- Designed for use in Light and Ordinary Hazard occupancies.

- Locate the deflector $4^{\prime \prime}$ to $12^{n}$ (102 $\mathrm{mm}$ to $305 \mathrm{~mm}$ ) below the ceiling.

- Protection areas and maximum spacing shall be in accordance with the tables provided in NFPA 13.

- Minimum spacing allowed is $6 \mathrm{ft}$. $(1.8 \mathrm{~m})$.

- Align the top of the deflector parallel with the ceiling.

- Locate no less than $4^{*}$ (102 mm) from end walls.

- Maximum distance from end walls shall be no more than one-half of the allowable distance between sprinklers. The distance shall be measured perpendicular to the wall.

- The sprinkler installation and obstruction rules contained in NFPA 13 for sidewall standard spray sprinklers must be followed.

IMPORTANT: Always refer to Bulletln Form No. F_091699 - Care and Handling of Sprinklers. Also refer to page QR1-3 for general care, installation, and maintenance information. Viking sprinklers are to be installed in accordance with the latest edition of Viking technical data, the appropriate standards of NFPA, LPCB, APSAD, VdS or other similar organizations, and also with the provisions of governmental codes, ordinances, and standards, whenever applicable. 


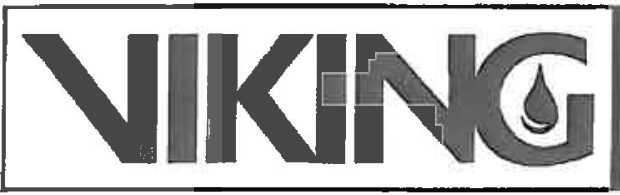

\section{TECHNICAL DATA}

MICROFAST AND MICRO-
FASTHP QUICK RESPONSE
HORIZONTAL SIDEWALL
SPRINKLERS (VK305 \& VK319)

The Viking Corporation, 210 N Industrial Park Drive, Hastings Ml 49058

Telephone: 269-945-9501 Technical Services: 877-384-5464 Fax: 269-818-1680 Email: techsvcs@vikingcorp.com

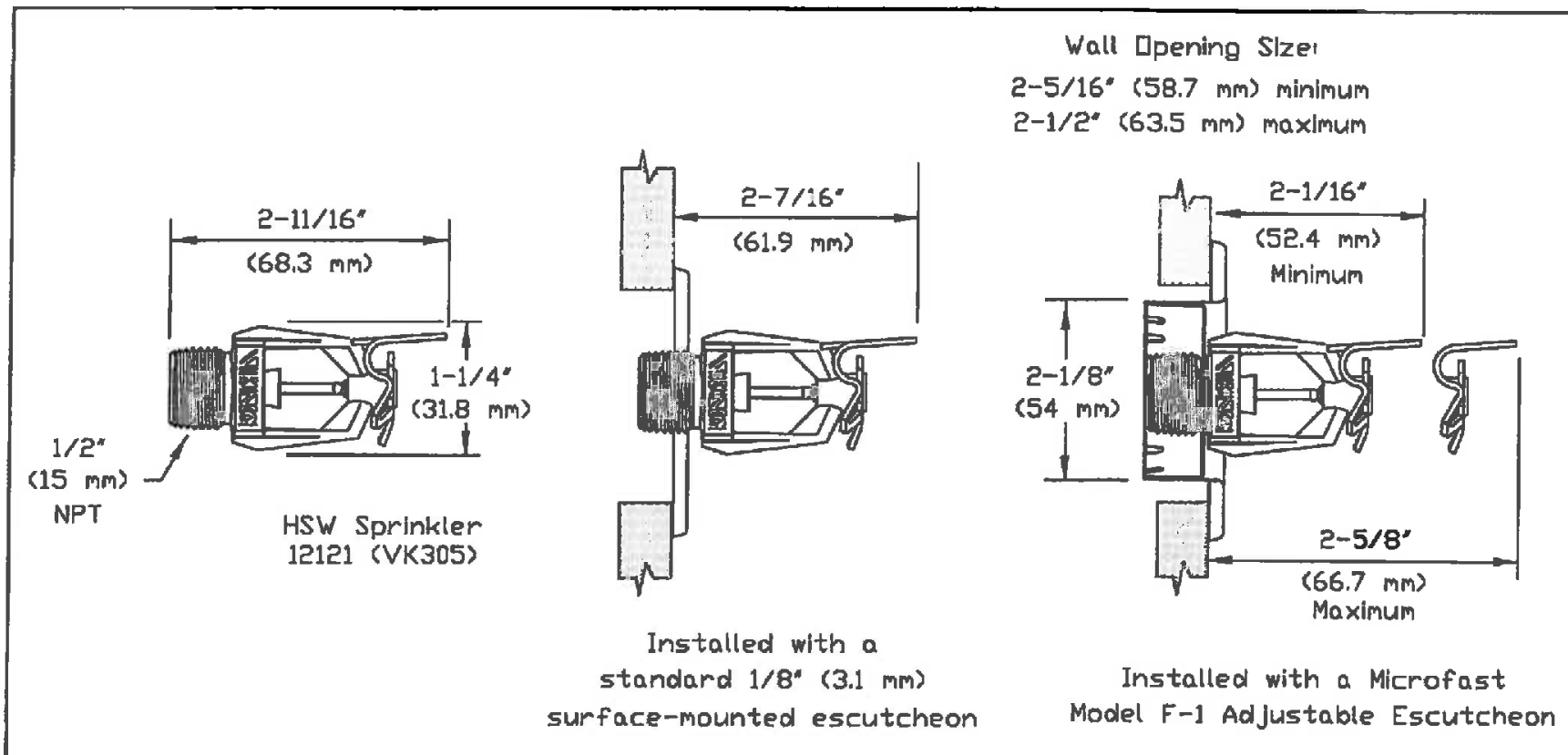

Figure 3: Sidewall Sprinkler VK305 Dimensions with a Standard Escutcheon and the Model F-1 Adjustable Escutcheon

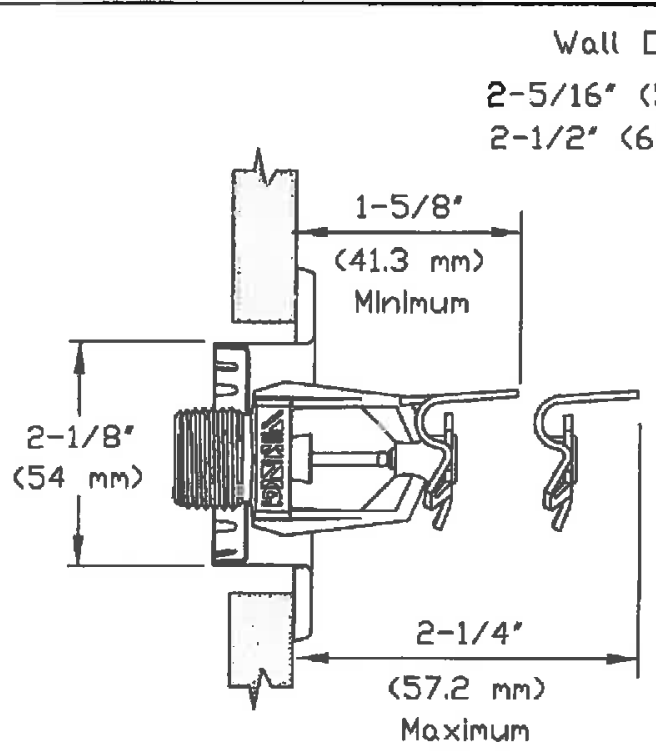

Installed with a Micromatic Model E-1 Recessed Escutcheon

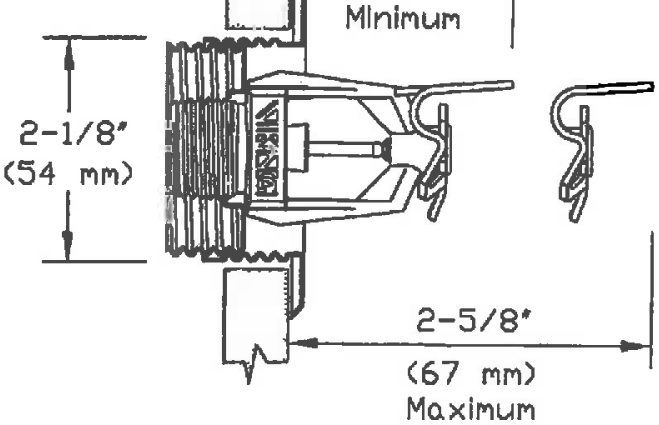

Installed with a Model E-2

Thread-on Recessed Escutcheon

Figure 4: Sidewall Sprinkler VK305 Dimensions with the Model E-1 and E-2 Recessed Escutcheons 


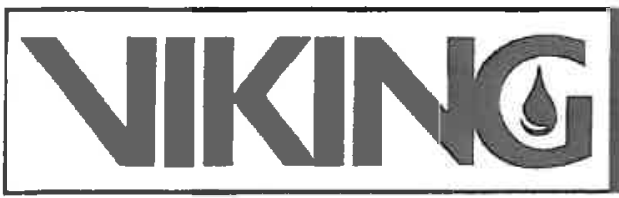

TECHNICAL DATA

MICROFAST AND MICRO-
FASTHP QUICK RESPONSE
HORIZONTAL SIDEWALL
SPRINKLERS (VK305\& VK319)

The Viking Corporation, $210 \mathrm{~N}$ Industrial Park Drive, Hastings Ml 49058

Telephone: 269-945-9501 Technical Services: 877-384-5464 Fax: 269-818-1680 Email: techsvcs@vikingcorp.com

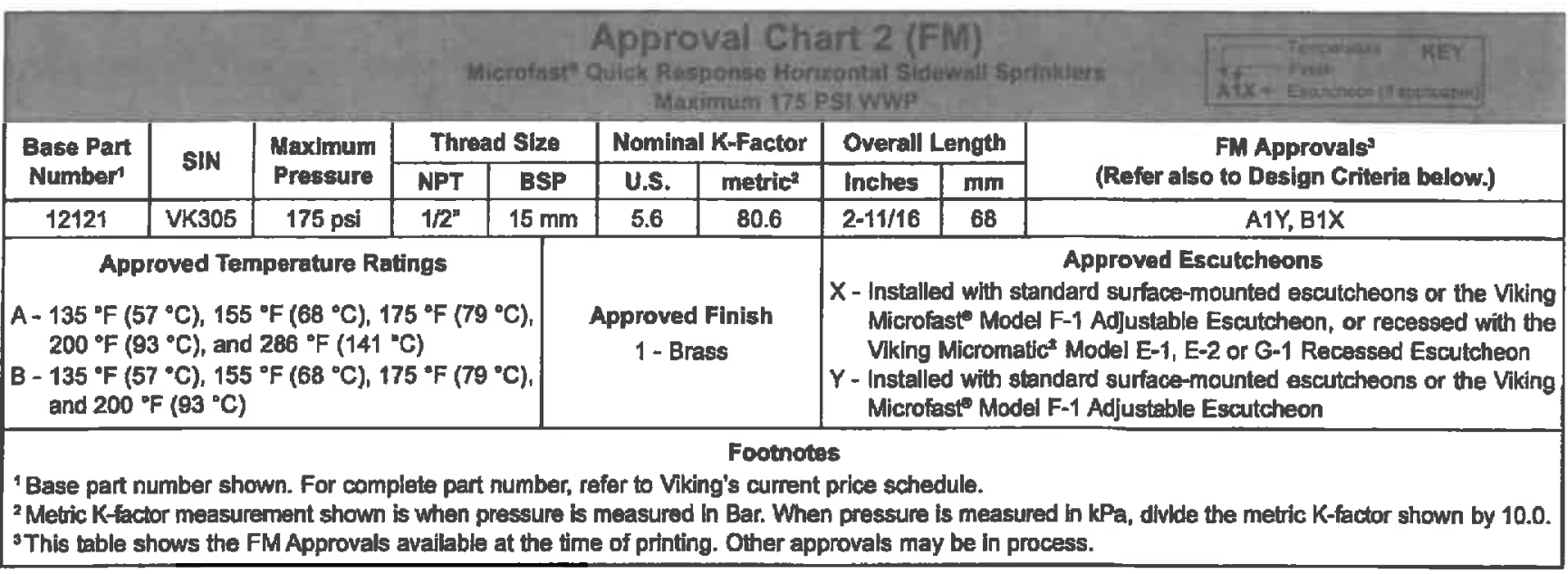

\section{EMAnproval Requirements:}

Horizontal Sidewall Sprinkler VK305 is FM Approved as a quick response Non-Storage sidewall sprinkler as indicated in the FM Approval Guide. For specific applicetion and installation requirements, reference the latest applicable FM Loss Prevention Data Sheets (Including Data Sheet 2-0). FM Global Loss Prevention Data Sheets contain guidelines relating to, but not limiled to: minimum water supply requirements, hydraulic design, ceiling slope and obstructions, minimum and maximum allowable spacing, and defiector distance below the ceiling.

NOTE: The FM installation guidelines may differ from cULus andlor NFPA criteria.

IMPORTANT: Always refer to Bulletin Form No. F_091699 - Care and Handling of Sprinklers. Also refer to page QR1-3 for general care, installation, and malntenance information. Viking sprinklers are to be installed in accordance with the latest edition of Viking technical data, the approprlate standards of NFPA, FM Global, LPCB, APSAD, VdS or other similar organizations, and also with the provisions of governmental codes, ordinances, and standards, whenever applicable.

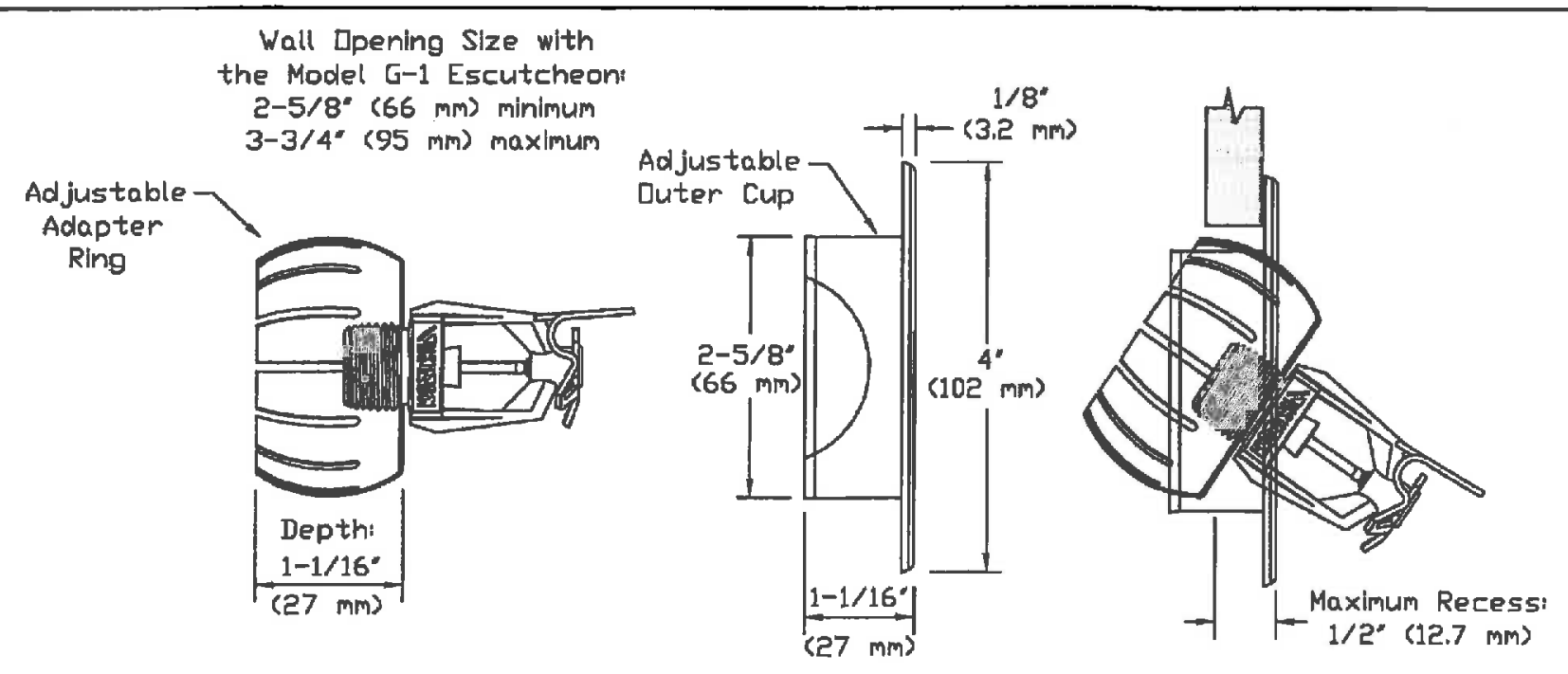

Figure 5: Sidewall Sprinkler VK305 Dimensions with the Model G-1 Recessed Escutcheons

Form No. F_030103

Replaces page 43a-f, dated February 13, 2009. (Updated FM Approvals, split the Approval Charts to separate cULus Listings from FM Approvals. Revised pip cap for Sprinkler VK305.) 
The Viking Corporatlon, 210 N Industrial Park Drive, Hestings MI 49058

Telephone: 269-945-9501 Technical Services: 877-384-5464 Fax: 269-818-1680 Email: techsvcs@vikingcorp.com

1. DESCRIPTION

A. Sprinkler Cabinats

Vking sprinkler cabinets are metal enclosures constructed to store an emergency supply of spare sprinklers and a sprinkler installation wrench.

NFPA 13 requires a representative number of each type and temperature rating of sprinkler head to be kept In a cabinet on the premise6. NFPA 13 also requires a special sprinkler wrench to be provided in the cabinet. This allows for immadiate removal and replacement of sprinklers that have operated or that have become damaged.

Stock of spare sprinklers should include sprinklers of all the types and temperature ratings as are Installed in the sprinkler system, In the following quantities:

\begin{tabular}{|c|c|}
\hline $\begin{array}{c}\text { Number of } \\
\text { Sprinklers in } \\
\text { System }\end{array}$ & $\begin{array}{c}\text { Minimum Number } \\
\text { of Spare Sprinklers } \\
\text { Required }\end{array}$ \\
\hline Under 300 & 6 \\
\hline $300-1,000$ & 12 \\
\hline Over 1,000 & 24 \\
\hline
\end{tabular}

\section{B. Sprinkler Wrenches}

Viking sprinkler wrenches are special installation tools specifically designed for use with the various Vking sprinklers and spray nozzles. The appropriate wrenches must be used with the indicated sprlnklers and nozzles to provide the proper leverage when tlghtening sprinklers or nozzles and to minimize slippage during Installation.

Using wrenches other than the ones designated for installation may damage the sprinkler. Refer to Table 2 and the appropriate sprinkler or spray nozde data page for the correct installation wrenches that must be used.

Wrenches 10896W/B, 07297W/B, 05118CW/B, and 13635W/B provlde the amount of leverage needed to tighten Bprinklers and spray nozzles into plpe fittings whlle preventing sprinkler damage. No additional tools are necessary with these wrenches.

The following wrenches require a separate $1 / 2$ " ratchet (not avallable from Viking) to provide the correct amount of leverage: 08336W/B, 10366W/B, 07565W/B, 11663W/B, 12144W/B, 13032W/B, 13577W/B, 13619, 15466, 13623W/B, 15467W/B, 15209W/R, $13655 \mathrm{~W} / \mathrm{B}, 14031,14047 \mathrm{~W} / \mathrm{B}, 1620 \mathrm{BW} / \mathrm{R}$, and 16267.

The internal dlameters of sprinkler wrenches 08336W/B, 10366W/B, 15209W/R, 12144W/B, 16208W/R, and 16267 are designed for use with the sprinkler contained in the protective shell. (A protective shell should be retained in the spare sprinkler cabinet.)

Wrench part number 10551 W/B is required for threading Institutional escutcheon plates onto institutlonal sprinklers. Wrench pert number 10729 is a 2-1/2" (63.5 mm) C-C face spanner wrench used for removing instltutional escutcheon plates from institutional sprinklers (refer to the DISASSEMBLY section of institutional sprinkler technicst data pages).

Wrench part number 15915 is optlonal for removing protectlve sprinkler caps and for installing E-1 and F-1 Escutcheons on frame style pendent sprinklers from the floor by attaching a length of 1" diameter CPVC tubing to the tool. Refer to Technical Bulletin Form No. 051808 .

\section{LISTINGS AND APPROVALS}

Refer to the specific sprinkler or spray nozzle technical data pages for sprinkler listings and approvals.

\section{TECHNICAL DATA}

\section{Specifications:}

Sprinkler Cabinets: Designed with four $3 / 16^{*}$ diameter holes In back. Spacing of mounting holes: $3-1 / 2^{\prime \prime}(88.9 \mathrm{~mm})$ length, 3-1/2" $(88.9 \mathrm{~mm})$ height. The sprinKler cabinet should be located adjacent to the main system riser.

Material Standards:

Sprinkler Cabinets: Cold Rolled Steol. Finish: Painted high-gloss red enamel interior and exterior, chrome plated door knob.

Wrenches: Ductle Iron, Steel, Acetal, or $\mathbf{5 0 \%}$ glass filled nyjon (for head cabinet wrenches)

Form No. F_122598

Viking Technical Date may be found on The Viking Corporation's Web site at http: /hwrww.vikinggroup Inc.com.

The Web ste may include a more recent adtition of this Techalcal Data Page. 


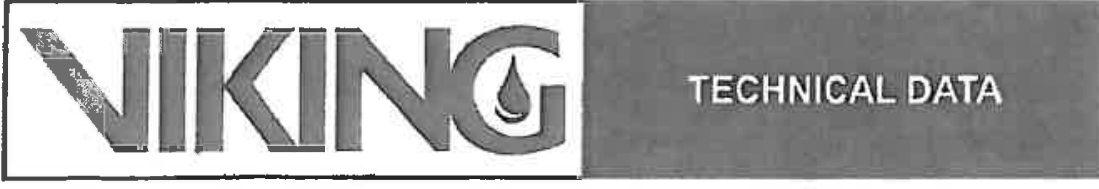

\section{SPRINKLER WRENCHES AND CABINETS}

The Viking Corporation, 210 N Industrial Park Drive, Hastings MI 49058

Telephone: 268-945-9501 Technical Services: 877-384-5464 Fax: 269-818-1680 Email: techsves@vikingcorp.com

Ordering Information: (Also refer to the current Viking price list.)

A. Sprinkler Cablnets

1. Determine appropriate cabinet from Table 1 on this page for use with the specific model/number of sprinklers to be contalned in the cabinet.

2. Specify cabinet part number and quantty needed.

B. Sprinkler Wrenches

1. Determine the appropriate wrench for use with the given sprinkler or spray nozzle model from Table 2.

2. Specily the wrench part number and quantity needed.

NOTE: Sprinklers and sprinkler wrenches are not supplied wth the cabinets; they must be ordered separately.

\section{INSTALLATION}

Rejer to the appropriate sprinkler or spray nozzle technlcal data page.

\section{OPERATION}

Refer to the sprinkler or spray nozzle techical data page for the particular model used.

\section{INSPECTIONS, TESTS AND MAINTENANCE}

Refer to NFPA 25 for Inspection, Testing and Maintenance requirements.

7. AVAILABILITY

The Viking sprinkler wrenches and cabinets are avallable through a network of domestic and international distributors. See The Viking Corporation web stte for the closest distributor or contact The Viking Corporation.

8. GUARANTEE

For details of warranty, refer to Viking's current list price schedule or contact Viking directly.

\begin{tabular}{|c|c|c|c|c|c|}
\hline \multirow{2}{*}{ For Sprinkler Models: } & \multirow{2}{*}{$\begin{array}{l}\text { Cabinet } \\
\text { Capaclty }\end{array}$} & \multirow{2}{*}{$\begin{array}{l}\text { Cabinet } \\
\text { Part No. }\end{array}$} & \multicolumn{3}{|c|}{ Sire } \\
\hline & & & Length & Helght & Depth \\
\hline Vking frame style sprinklers & 6 sprinklers & $\begin{array}{c}01724 \mathrm{~A} \\
\text { Avallable since } 1971 .\end{array}$ & $\begin{array}{c}10-3 / 16^{*} \\
(259 \mathrm{~mm})\end{array}$ & $\begin{array}{c}4-11 / 16^{n} \\
(103 \mathrm{~mm})\end{array}$ & $\begin{array}{l}2-9 / 16^{n} \\
(65 \mathrm{~mm})\end{array}$ \\
\hline $\begin{array}{l}\text { Vking frame style and } \\
\text { ESFR K14 and K16.8 pendent } \\
\text { sprinklers }\end{array}$ & 12 sprinkders & $\begin{array}{c}01725 A \\
\text { Available since } 1971 .\end{array}$ & $\begin{array}{c}10-3 / 16^{n} \\
(259 \mathrm{~mm})\end{array}$ & $\begin{array}{c}8-9 / 16^{n} \\
(217 \mathrm{~mm})\end{array}$ & $\begin{array}{c}2-9 / 16 \\
(65 \mathrm{~mm})\end{array}$ \\
\hline $\begin{array}{l}\text { Viking concealed and flush style } \\
\text { sprinklers, ESFR K25.2 } \\
\text { pendent sprinklers, and K19.6 } \\
\text { CMSA sprinklers }\end{array}$ & 6-6 sprinklers & $\begin{array}{c}01731 \mathrm{~A} \\
\text { Avallable since } 1971 .\end{array}$ & $\begin{array}{l}13-13 / 16= \\
(351 \mathrm{~mm})\end{array}$ & $\begin{array}{c}5-11 / 16^{n} \\
(144 \mathrm{~mm})\end{array}$ & $\begin{array}{c}3^{\prime \prime} \\
76 \mathrm{~mm})\end{array}$ \\
\hline $\begin{array}{l}\text { High Challenge" Sprinklers, } \\
\text { upright ESFR sprinklers, } \\
\text { and Intermediate Level Sprinklers }\end{array}$ & 6 sprinklers & $\begin{array}{c}\text { 03985A } \\
\text { Avallable since } 1977\end{array}$ & $\begin{array}{c}12-5 / 8^{*} \\
(321 \mathrm{~mm})\end{array}$ & $\begin{array}{c}9-1 / 8^{m} \\
(232 \mathrm{~mm})\end{array}$ & $\begin{array}{c}4-1 / 8^{m} \\
(105 \mathrm{~mm})\end{array}$ \\
\hline & & 1e 1: Sprinkler Ca & & & \\
\hline
\end{tabular}




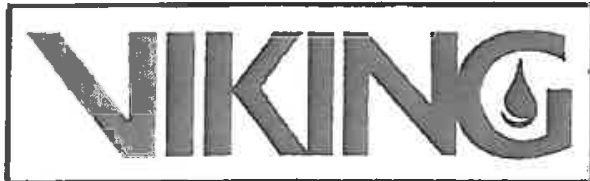

\section{TECHNICAL DATA}

SPRINKLER WRENCHES AND CABINETS

The Viking Corporation, 210 N Industrial Park Drive, Hastings MI 49058

Telephone: 269-945-9501 Technical Services: 877-384-5464 Fax: 269-818-1680 Emall: techsvos@vikingcorp.com

The sprinkler cabinet should be easily accessible.

The sprinkler cabinet must not be exposed to corrostve atmospheres or temperatures above $100{ }^{\circ} \mathrm{F}\left(38^{\circ} \mathrm{C}\right)$.

The stock of spare sprinklers should include an adequate number of sprinklers of each type and temperature rating.

The stock of sprinklers must be in good condition.

A sprinkler wrench of the approprlate type must be included in the cablnet.

Orient sprinklers and sprinkler wrench as indicated in Flgure 1 below.

CAUTION: When replacing automatic sprinklers in an existing system, be sure to replace with sprinklers of the correct type, thread size, orifice size, temperature raling, and finish.

IMPORTANT: Always refer to Bulletin Form No. F_ 091699 - Care and Handling of Sprinklers. Also refer to the appropriate sprinkler data page. Viking sprinklers and spray nozzles are designed to be installed in accordance with the latest edition of Viking technical data, the latest standards of NFPA, FM Global, LPCB, APSAD, VdS or other similar organizations, and also with the provisions of governmental codes, ordinances, and standards whenever applicable. The use of certain types of sprinklers may be limited due to occupancy and hazard. Refer to the Authority Having Jurlsdiction prior to installation.

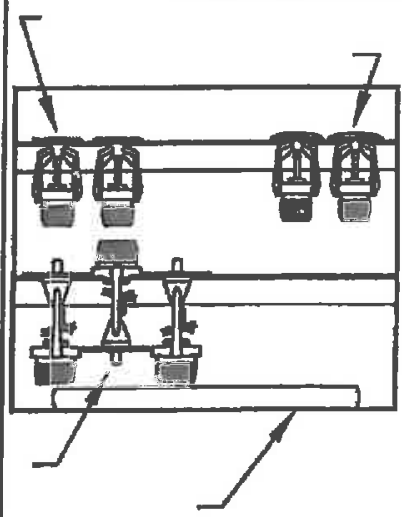

Figure 1: Correct orientation of sprinklers and wrench inside cabinet. (12-head cabinet shown)

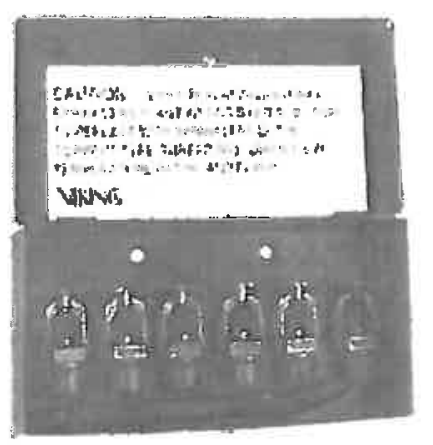

Figure 2: SprinkJer Cabinet $01724 \mathrm{~A}$ (Sprinklers and wrench not included)

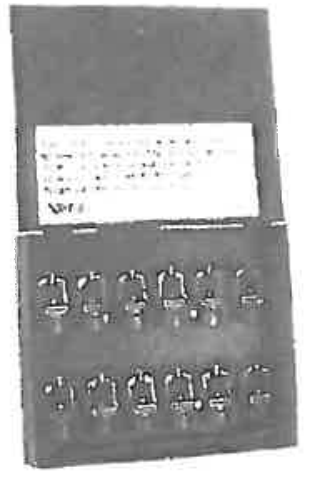

Figure 3: Sprinkler Cabjnet 01725A (Sprinklers and wrench not included) 


\section{VIING}

TECHNIGAL DATA

\section{SPRINKLER WRENCHES AND CABINETS}

The Viking Corporation, 210 N Industrial Park Drive, Hastings MI 49058

Telephone: 269-945-9501 Technical Services: 877-384-5464 Fax: 269-818-1680 Emall: techsvos@vikingcorp.com

\begin{tabular}{|c|c|}
\hline For Sprinkler Models: & Use Wrench: \\
\hline Frame-style sprinklers and spray nozzles & $\begin{array}{l}\text { 10896W/B Available since } 2000 \\
\text { or 05000CW/B }\end{array}$ \\
\hline $\begin{array}{c}\text { Recessed pendent sprinkers with protective shields, } \\
\text { wax coated sprinklers, and domed concealed } \\
\text { oendent spinkless }\end{array}$ & $\begin{array}{l}\text { 13577W/B Avallable since } 2006 \\
\text { replaces O739o W* }\end{array}$ \\
\hline Recessed pendent sprinklers with protectlve caps & 12144W/B Avallable since 2003 \\
\hline $\begin{array}{l}\text { Recessed horizontal sidewall sprinkless } \\
\text { with protectlve shlelds and domed concealed } \\
\text { horizontel sidewall sprinlders }\end{array}$ & $\begin{array}{c}\text { 13665W/B } \\
\text { Avallable since } 2006\end{array}$ \\
\hline Coated and recessed ECOH K14 sprinkler & 13032W/B Available since 2004 \\
\hline $\begin{array}{l}\text { Standard adjustable and plain barrel dry } \\
\text { sprinklers, K16.8 and ECOH K14 spinklers }\end{array}$ & 07297WB Avallable since 1991 \\
\hline Recessed and domed concealed doy sprinklers & 07565 WD Avallable since 1981 \\
\hline $\begin{array}{l}\text { High Challenge sprinklers, } \\
\text { upright ESFR gprinklars, and ELO sprinklers" }\end{array}$ & $\begin{array}{c}\text { 05118CWB } \\
\text { Avallable since } 1981\end{array}$ \\
\hline $\begin{array}{l}\text { Coated, recessed, and domed } \\
\text { concealed ELO sprinklers }\end{array}$ & $\begin{array}{c}11663 W / B \\
\text { Avallable since 2001 }\end{array}$ \\
\hline Pendent K14 and K16.8 ESFR sprinklers & $\begin{array}{l}13695 W / B \text { dotble ended (use Side A) } \\
\text { Avallable since } 2006 \text { or } 10285 \mathrm{WB}^{*}\end{array}$ \\
\hline $\begin{array}{l}\text { Pendent K25.2 ESFR sprinklers } \\
\text { end K19.6 CMSA Sprinkler YK592 }\end{array}$ & $\begin{array}{l}\text { 13635W/B double ended (use Side B) } \\
\text { Avellable since 2006, or 12143W/B* }\end{array}$ \\
\hline $\begin{array}{l}\text { QR and EC conceled Sprinkers VK467, VK462, } \\
\text { VK463, VK464, VK465, VK632, and VK634 } \\
\text { (also onional for can removall }\end{array}$ & $\begin{array}{c}14031 t \\
\text { Avallable slnce } 2006\end{array}$ \\
\hline $\begin{array}{c}\text { QR and EC Concealed Sprinklers VK461, VK462, } \\
\text { VK463, VK464, VK465, VK632, and VK634 }\end{array}$ & $\begin{array}{l}\text { 14047W/B (heavy duty) } \\
\text { Avallable since } 2003\end{array}$ \\
\hline $\begin{array}{l}\text { Residential Concealed Sprinklers VK456, VK457, and } \\
\text { VK474 (also optional for removel of protecthve caps) }\end{array}$ & $\begin{array}{c}13619+(\mathrm{red}) \\
\text { Avaliable since } 2006\end{array}$ \\
\hline $\begin{array}{c}\text { Residental Concealed Sprinklers } \\
\text { VK450, VK457, and VK474 }\end{array}$ & $\begin{array}{l}1362 \text { twiB (heavy duty) } \\
\text { Avallable since } 2000\end{array}$ \\
\hline Residential Concealed HSW Sprinkler VK480 & $\begin{array}{l}16267 t \text { or } 1620 \text { bWIR (heavy duty) } \\
\text { Avallable since } 2010\end{array}$ \\
\hline $\begin{array}{l}\text { Mrage } \text { QR ELO Concealed Sprinkler VK469 } \\
\text { (also optional for removal of protective caps) }\end{array}$ & $\begin{array}{c}16460 \dagger \\
\text { Avallable since } 2000\end{array}$ \\
\hline Mirege ${ }^{\circ}$ OR ELO Concealed Sprinicler VK469 & $\begin{array}{l}15467 \text { Wha (heavy duly) } \\
\text { Avallable since } 2000\end{array}$ \\
\hline Mlirage Concealed and fush shle sprinklers & D8336W/B (heay duty) Avaliable since 1993 \\
\hline Mirage Concesied and fiush style sprinklars & 10966W/B+ Avallable since 1998 \\
\hline Residential Flush Pendent Sprinkier VK476 & 15209W/R (heaw duty) Avaliable since 2009 \\
\hline $\begin{array}{l}\text { Mirage and Freedom Concealed Sptinklers VK461, } \\
\text { VK462, VK463, VK464, VK465, VK469, VK474, VK632, } \\
\text { and VKO34 (optionel concealed cover installer tool) }\end{array}$ & $\begin{array}{l}\text { 14412t, or } 14867 \text { for the large diameter } \\
\text { cover, Avallable since } 2007\end{array}$ \\
\hline Shipging Cap Removen Escutcheon hostaller (Cplional') & $15915+$ Avallable since 2010. \\
\hline $\begin{array}{l}\text { Institulional style flush sprinklers } \\
\text { (for installation of the escutcheon plate) }\end{array}$ & $\begin{array}{c}\text { 10551W/B } \\
\text { Avalable elnce } 1998\end{array}$ \\
\hline 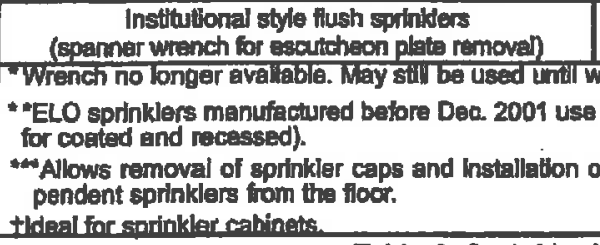 & $\begin{array}{l}10729 \\
\text { ble since } 1999 \\
\text { ber o7297w/B (0756 } \\
\text { scutcheons on frame }\end{array}$ \\
\hline \multicolumn{2}{|c|}{ Table 2: Sprinkler Wrenches } \\
\hline Part No. 15208 & Wh Part No. 15915 Pait No. 16208WIR \\
\hline
\end{tabular}

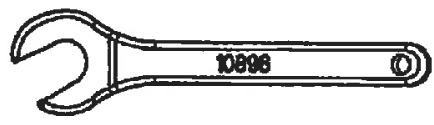

Part No. 10896W/B

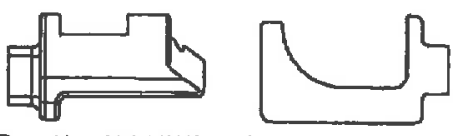

Part No. 12144w/B

Part No. $1357 \mathrm{NW}$ \& $13032 W / B$

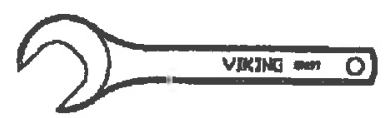

Part No. 07297W/E

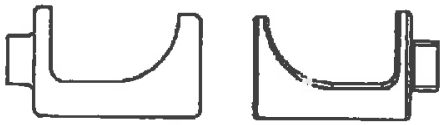

Part Nos. 07565W/B Part No. 13655W/B 8. 11653W/B

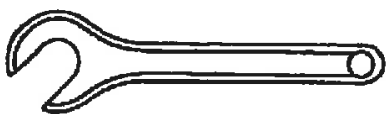

Part No. 05418CWE

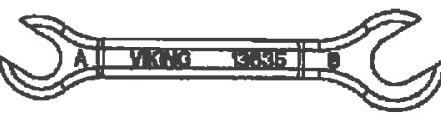

Part No. 13635W/:

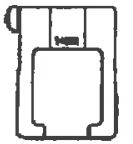

Part No. 14031

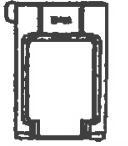

Port Nos. 13619

A 15466
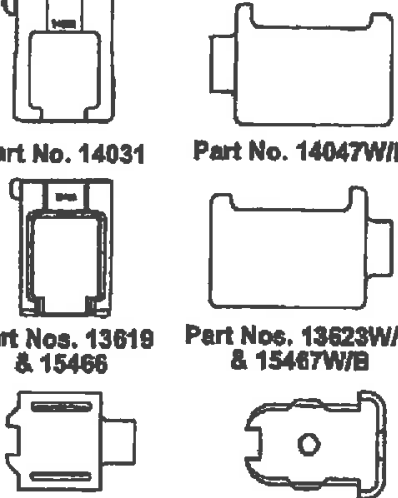

Pant No. 14047w/s

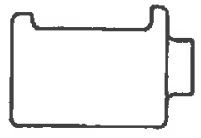

Part Nos, 13623w/s 8 1546 Tw:

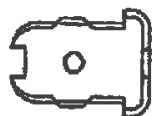

Part No. 08336w/s Part No. 1036sw/g

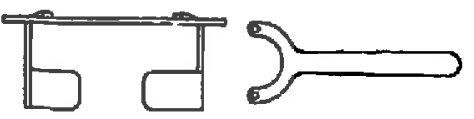

Part No. 10551W/B Part No. 10720

Figure 4: Sprinkler Wrenches 
$=0$

$10=0$

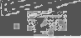

F P P !

\section{Fire Sprinkler Accessories}

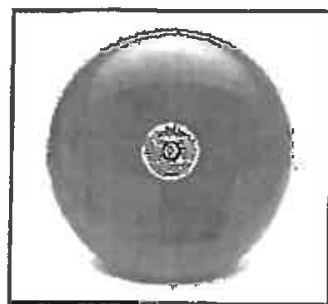

a
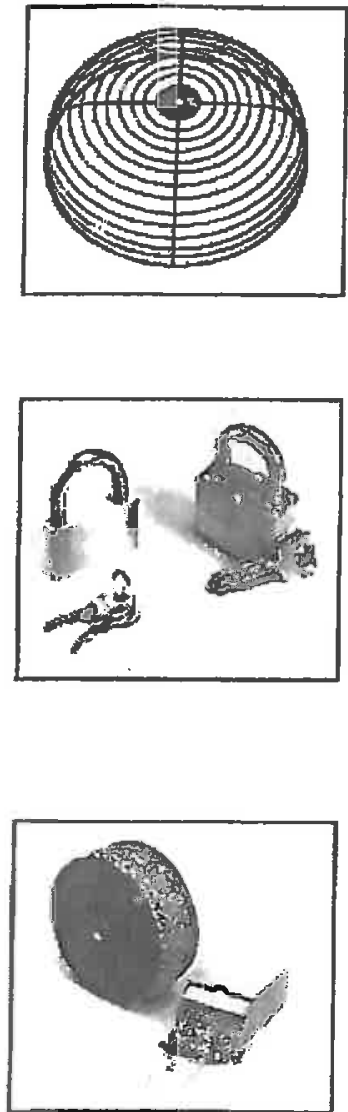

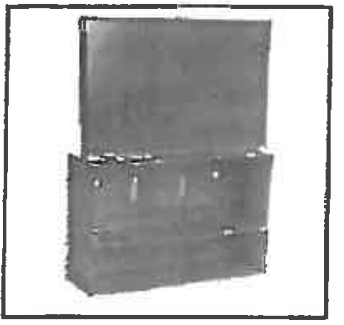

10

\section{Alarm Bells and Bell Accessories}

Part No. Description

02-450 Alarm Bell, 10" 120VAC

Box Oty.

$02-452$

$02-455$

02-457

Alam Bell, 6" 120VAC

Alam Bell Back Box

Bell Guard

20

48

20

\section{Break Shackle Locks}

FPPI offers break shackle locks to prevent tampering with controlled valves. Locks are keyed alike to allow easy access to secured valves by authorized personnel.

$\begin{array}{llc}\text { Part No. } & \text { Description } & \text { Box Ory. } \\ 02-410 & \text { Break Shackle Lock \#764-40 } & 250 \\ 02-411 & \text { Master Break Lock \#500KABRK197 } & 72\end{array}$

\section{Sign Chain}

Znc plated for corrosion resistance. Suitable for use in exposed areas.

$\begin{array}{llc}\text { Part No. } & \text { Description } & \text { Box Oty. } \\ 02-200 & \# 16 \text { Sign Chain, 100' Box } & 20 \\ 02-201 & \# 16 \text { Sign Chain, 250' Reel } & 1\end{array}$

\section{Spare Sprinkler Head Cabinets}

All Spare Sprinkler Head Cabinets are equipped with "knockouts" to accommodate $1 / 2$ " or 3/4" sprinkler heads. ESFR head box will accommodale 3/4" or 1" IPS sprinklers. Finish: Red Enamel

$\begin{array}{llc}\text { Part No. } & \text { Description } & \text { Box Qty } \\ 02-400 & \text { Spare Head Box, 12 Head } & 20 \\ 02-401 & \text { Spare Head Box, 6 Head } & 25 \\ 02-402 & \text { Spare Head Box, 3 Head } & 20 \\ 02-403 & \text { ESFR Spare Head Box, 6 Head } & 20\end{array}$



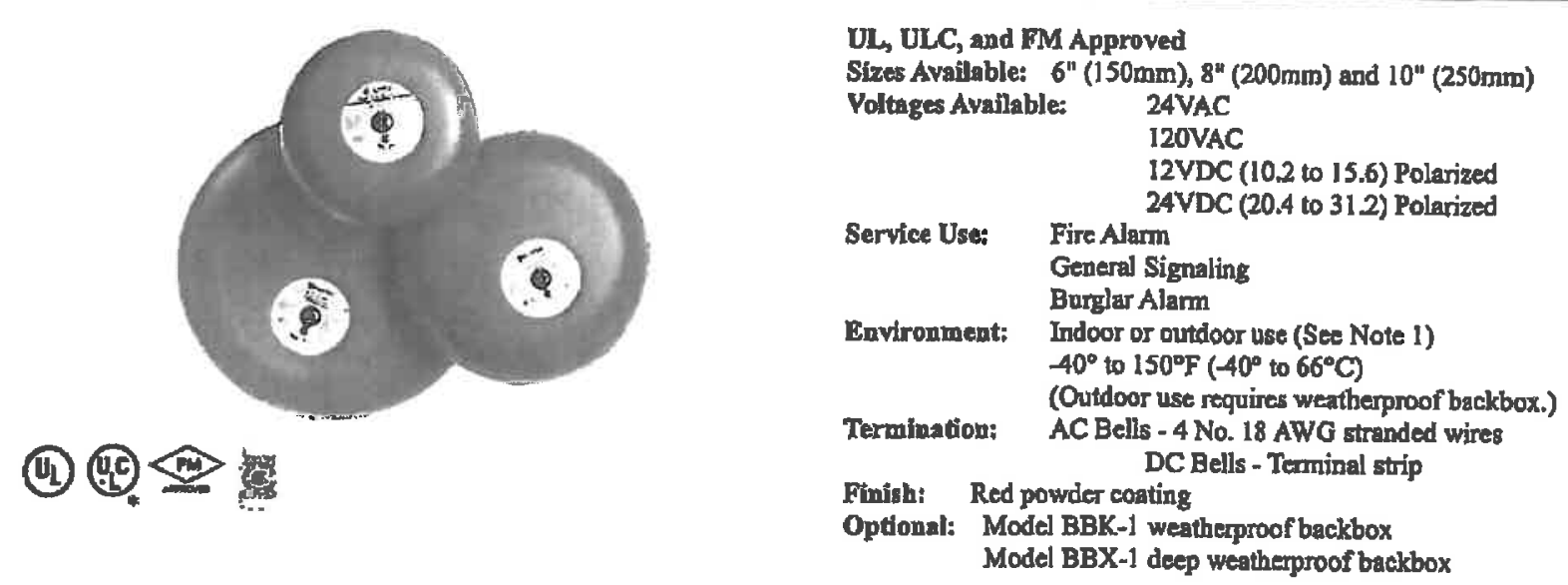

These vibrating type bells are designed for use as fire, burglar or general signaling devices. They have low power consumption and high decibel ratings. The unit mounts on a standard $4^{\prime \prime}$ (101ma) square electrical box for indoor use or on a model BBK-1 weatherproof backbox or BBX-1 deep weatherproof backbox for outdoor applications. Weatherproof beckbox model BBK-1. Stock No. 1500001.

\section{Notes:}

1. Minimum $d B$ ratings are calculated from integrated sound pressure measurements made at Underwiters Laboratories as specified in UL Standard 464. UL, temperature range is $-30^{\circ}$ to $150^{\circ} \mathrm{F}\left(-34^{\circ}\right.$ to $\left.66^{\circ} \mathrm{C}\right)$.

2. Typical dB ratings are calculated fron measurements made with a conventional sound level meter and are indieative of output levels in an actual installation.

3. ULC only applies to MBA DC bells.

\begin{tabular}{|c|c|c|c|c|c|c|}
\hline $\begin{array}{c}\text { Size inches } \\
(\mathrm{mm})\end{array}$ & Witagc & $\begin{array}{c}\text { Model } \\
\text { Number }\end{array}$ & $\begin{array}{c}\text { Stock } \\
\text { Number }\end{array}$ & $\begin{array}{c}\text { Current } \\
(\text { Max. })\end{array}$ & $\begin{array}{c}\text { Typical dB at } \\
10 \mathrm{ft} .(3 \mathrm{~m})(2)\end{array}$ & $\begin{array}{c}\text { Minimum aB at } \\
10 \mathrm{ft}(3 \mathrm{~m})(1)\end{array}$ \\
\hline $6(150)$ & $12 \mathrm{VDC}$ & MBA126 & 1750070 & $.12 \mathrm{~A}$ & 85 & 76 \\
\hline $8(200)$ & $12 \mathrm{VDC}$ & MBA128 & 1750080 & $.12 \mathrm{~A}$ & 90 & 77 \\
\hline $10(250)$ & $12 \mathrm{VDC}$ & MBA1210 & 1750060 & $.12 \mathrm{~A}$ & 92 & 78 \\
\hline $6(150)$ & $24 \mathrm{VDC}$ & MBA246 & 1750100 & $.06 \mathrm{~A}$ & 87 & 77 \\
\hline $8(200)$ & $24 \mathrm{VDC}$ & MBA248 & 1750110 & $.06 \mathrm{~A}$ & 91 & 79 \\
\hline $10(250)$ & $24 \mathrm{VDC}$ & MBA2410 & 1750090 & $.06 \mathrm{~A}$ & 94 & 80 \\
\hline $6(150)$ & $24 \mathrm{VAC}$ & PBA246 & $1806024^{*}$ & $.17 \mathrm{~A}$ & 91 & 78 \\
\hline $8(200)$ & $24 \mathrm{VAC}$ & PBA248 & $1808024^{*}$ & $.17 \mathrm{~A}$ & 94 & 77 \\
\hline $10(250)$ & $24 \mathrm{VAC}$ & PBA2410 & $1810024^{*}$ & $.17 \mathrm{~A}$ & 94 & 78 \\
\hline $6(150)$ & $120 \mathrm{VAC}$ & PBA1206 & $1806120^{*}$ & $.05 \mathrm{~A}$ & 92 & 83 \\
\hline $8(200)$ & $120 \mathrm{VAC}$ & PBA1208 & $1808120^{*}$ & $.05 \mathrm{~A}$ & 99 & 84 \\
\hline $10(250)$ & $120 \mathrm{VAC}$ & PBA12010 & $1810120^{*}$ & $.05 \mathrm{~A}$ & 99 & 86 \\
\hline
\end{tabular}

All DC bells are polarized and have built-in transient protection. - Does not have ULC listing.

\section{WARING}

In outdoor or wet installations, bell must be mounted with weatherproof backbox, BBK-1 or BBX-1. Standard electrical boxes will not provide a weatherproof enciosure. If the bell and/or assembly is exposed to moisture, it may fail or create an electrical hazand.

Potter Electric SignaJ Company, LLC · 2081 Craig Road, St. Louis, MO, 63146-416] * Phone: 800-325-3936/Cananda 888-882-1833 • www.pottersignal.com PRINTED WN USA 
Bells Dimensions Inches (mm)

Fig. 1

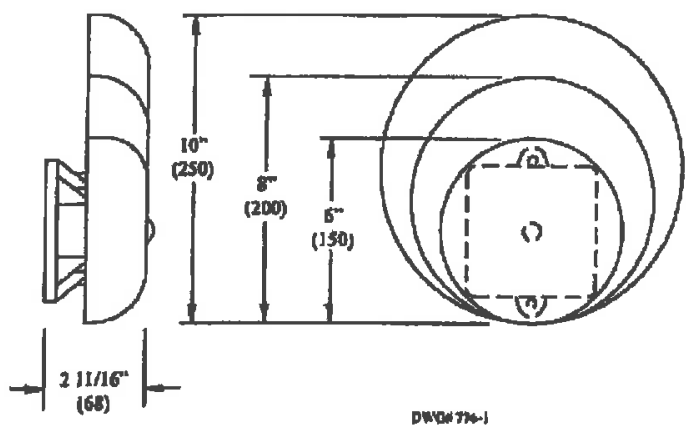

Wring (rear view)

Fig. 3

\section{A.C. BELLS}

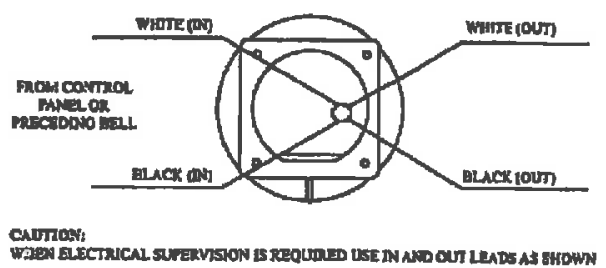

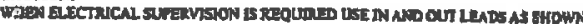

моте:

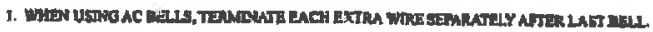

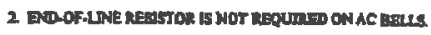

andow

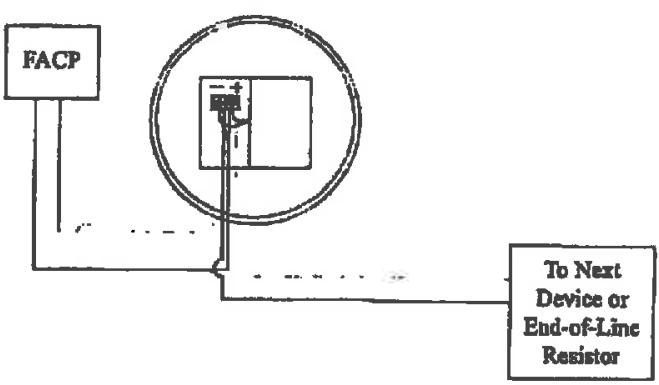

\section{Installation}

1. The bell shall be installed in accordance with NFPA 13,72, or local AHJ. The top of the device shall be no less than 90" AFF and not less than 6" below the ceiling.

2. Remove the gong.

3. Connect wiring (see Fig. 3).

4. Mount bell mecharism to backbox (bell mechanism must be mounted with the striker pointing down).

5. Reinstall the gong (be sure that the gong positioning pin, in the mechanism housing, is in the hole in the gong).

6. Test all bells for proper operation and observe that they can be heard wherc required (bells must be heard in all areas as designated by the authority having juriedietion).

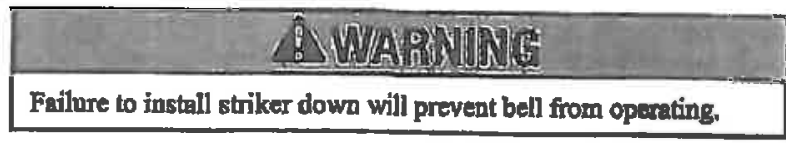




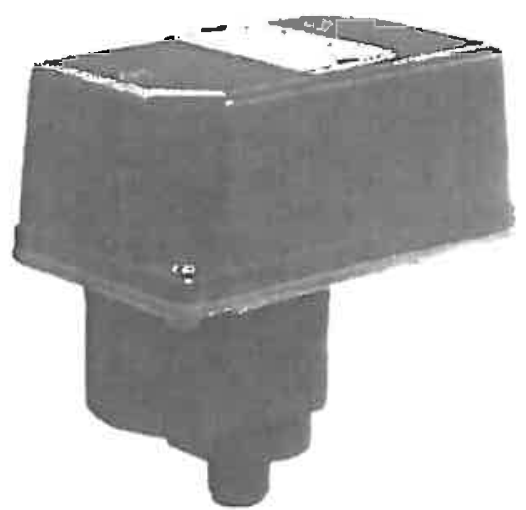

UL, cUL and CSFM Listed, FM Approved and NYMEA

Accepted, CE Marked, VdS Approved

Dimensions: 59/16"H $\times 31$ 3"W $^{\prime \prime} 57 / 8^{\prime \prime} \mathrm{D}$

Weight: 1.5 lbs. $(3,3 \mathrm{~kg}$.)

(14,1 cm H X 8,9cm W $\times 14,9 \mathrm{~cm}$ D)

Enclosure: Cover - Die-cast with textured red powdercout finish Base - Die-cast aluminum

Pressure Connection: $1 / 2^{\text {" }}$ Male NPT

Pressure Adjustments: Factory adjusted to operate between 5 and $8 \mathrm{PSI}(0.35$ and $0,55 \mathrm{BAR})$ on rising pressure

Marimum system pressure: 175 PSI (12,1 BAR)

Contact Ratings: Two Sets of SPDT (Form C)

15.0 Amps at $125 / 250 \mathrm{VAC}$

2.0 Amps at 30VDC Resistive

Stock number - 1010080

Conduit Entrances: Two lonockouts provided for $1 / 2^{\text {n }}$ conduit

Environmental Spectifications: $40^{\circ} \mathrm{F}$ to $120^{\circ} \mathrm{F}\left(4,5^{\circ} \mathrm{C}\right.$ to $\left.49^{\circ} \mathrm{C}\right)$ NEMA 4 Enelosure - when used with proper conduit fittings

\section{$\triangle$ CAUTION}

This device is not intended for applications in explosive environments.

Waterflow Alarn Switch With Retard For Supervision of Wet Alarm Check Vhlve

The Model WFSR-F is a pressure operated switch with an adjustable, instantly recycling pneumatic retard to prevent false alaros due to water pressure variation. The WFSR-F is connected into the alarmport of a wet sprinkler system alarm check valve (see " WARNING", page 2).

\section{Installation}

A male $1 / 2$ " NPT pipe fitting is provided for connection to the alarm port of the alarm check valve, No additional mounting or support is required.

Fig 1 WFSR-F

TO BPRINKLERS

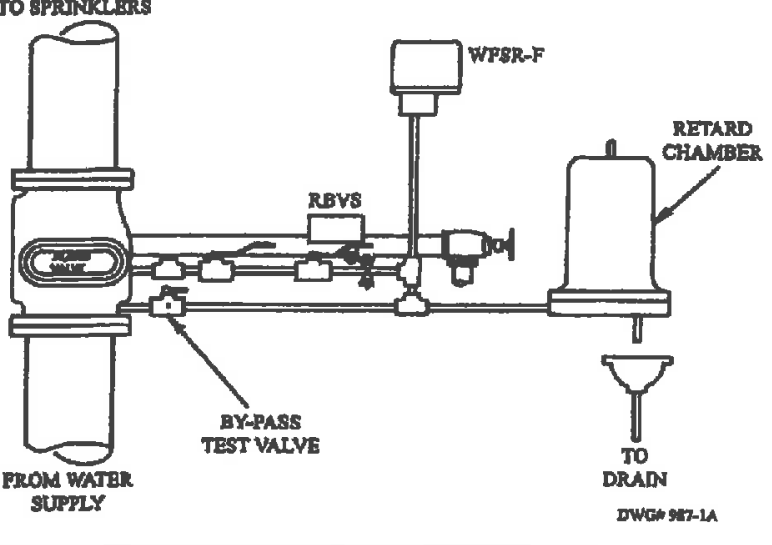

Service Use: Automatic Sprinkler

One or two family dwelling

Residential oceupancy up to four stories NFPA-13R

National Fire Alarm Code

NFPA-72

Tamper: Cover incorporates tamper resistant fasteners that require a special key for removal. One key is supplied with each device. For optional cover tamper switch kit, order Stock No. 0090018.

Allow $5^{\prime \prime}(12,7 \mathrm{~cm})$ to the front of the unit for removal of the cover. Install with the pressure connection down.

Testing

Operation of the unit is checked by opening the by-pass test valve or inspector's test valve. The frequency of the inspectionand testing for the Model WFSR-F and its associnted protective monitoring system should be in accordance with applicable NFPA Codes and Standands and/or anthority having jurisdiction (manufacturer recommends quarterly or more frequently).

Fig. 2 Typical Electrical Connections
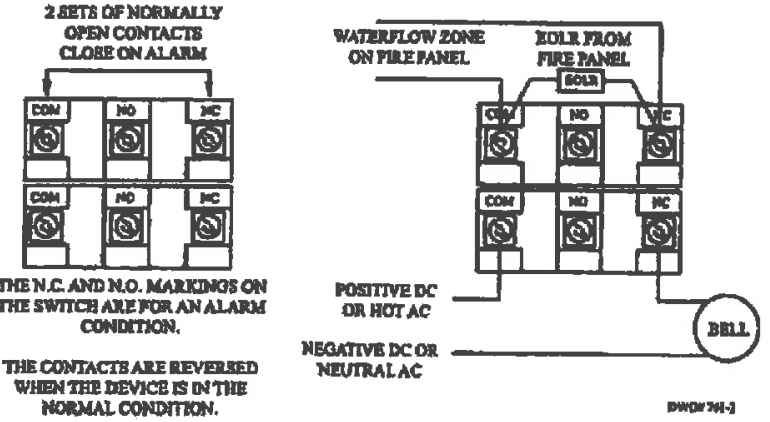

Note: For supervised cirevits see "Switch Terminal Connections" drawing and caution note (Fig. 4).

Potter Electric Signai Company, LLC · 2081 Craig Road, St. Louis, MO, 69146-4161 - Phone: 800-325-3936/Candda 888-882-1833 - www.pottersignal.com 


\section{WISR-F \\ WATERILOW ALARM SWTCH WITH RETARD}

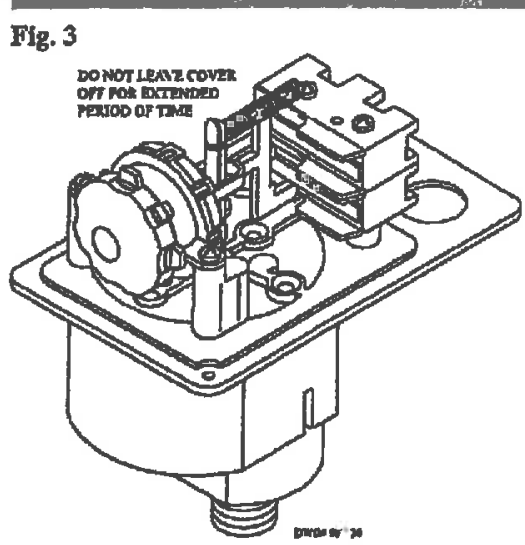

Retard Adjustment:

To change time turn knob (either direction) for desired time delay. Use the minimum amount of retard necesary to prevent false alarms, a "B" setting is usually adequate for this. Factory set at "B".

\begin{tabular}{|cccccc|}
\hline \multicolumn{5}{c}{ APPROX. RETARD SETTINGS (N SEC.) } \\
0 & A & B & C & D & E \\
0 & $10-25$ & $20-40$ & $35-55$ & $50-70$ & $60-90$ \\
\hline
\end{tabular}

Fig. 4 Switch Terminal Connections Clamping Plate Terminal

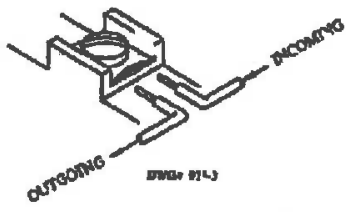

\section{A CAUTION}

An uninsulated section of a single conductor should not be looped around the terminal and serve as two separate connections. The wire must be severed, thereby providing supervision of the connection in the event that the wire becomes dislodged from under the terminal.

\section{Fig. 5 Typleal Wet System}

\begin{tabular}{l}
\hline \multicolumn{1}{|c|}{ 9 N/2WNWG } \\
\hline Use tefion tape sealant only. Apply only \\
to male threads of commectors. \\
Use of pipe cement voids warranty as this \\
material may obstruct pressure aperture \\
resulting in loss of alam signal. \\
Device must be installed before any shut \\
off valve on alam port line unless it is \\
supervised by a supervisory switch such \\
as Potter Model RBVS. \\
The system should be tested on a \\
quarterly basis or more frequently to \\
insure proper operation.
\end{tabular}
quarterly basis or more frequently to ingure proper operation.

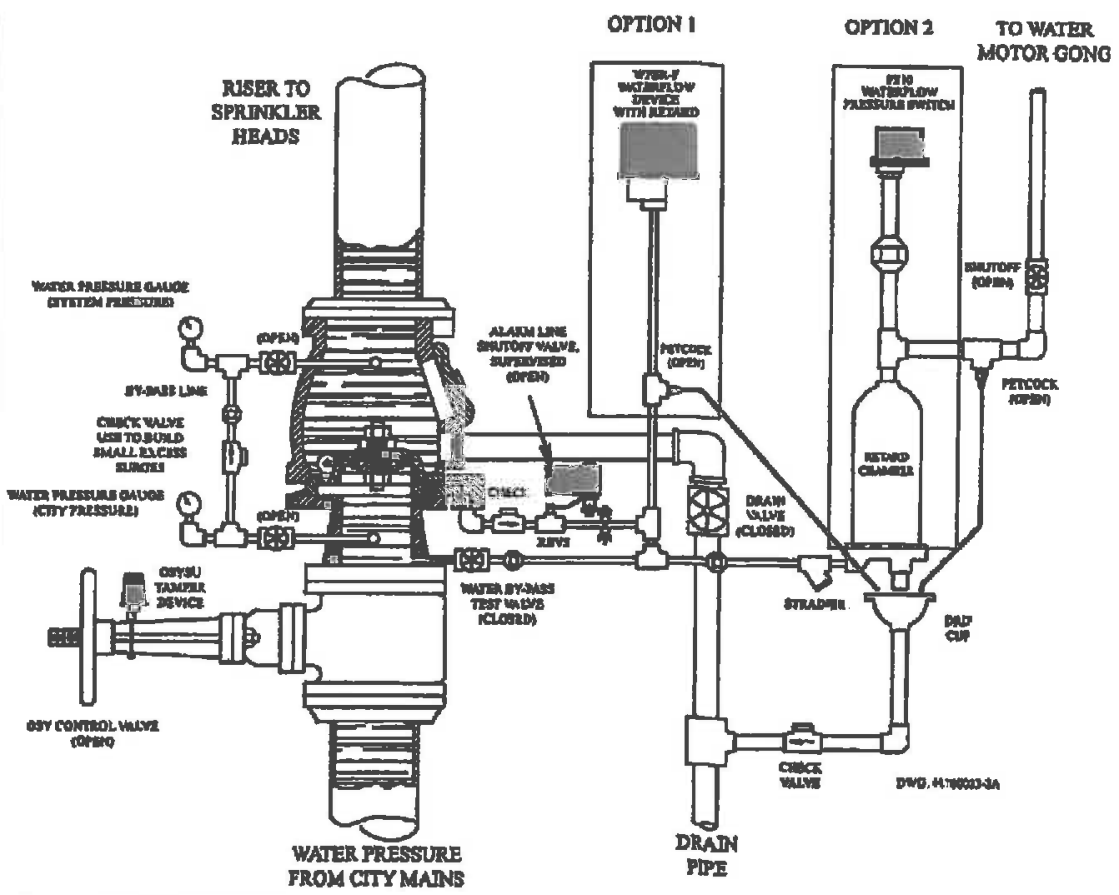

\section{A CAUTION}

Due to the possibility of unintended discharges caused by pressure surges, trapped air, or short retard times, waterflow switches that are monitoring wet pipe sprinkler systems shall not be used as the sole initiating device to discharge AFF, deluge, or chemical suppression systems. 


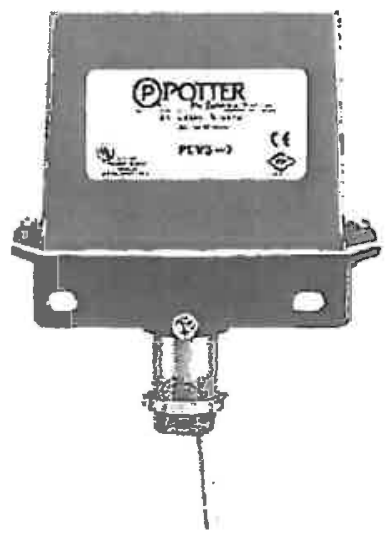

Conduit Entrancer: Two knockouts for $1 / 2$ " conduit provided. Service Use:

Automatic Sprinkler

One or two farnily dwelling

Residential occupancy up to four stories

National Fire Alarm Code
NFPA-13

NFPA-13D

NFPA-13R

NFPA-72

The Model PCVS is a weather proof and tamper resistant switch for monitoring the open position of fire sprinkler control valves of the post indicator, butterfly and other types. Depending on the model, one or two SPDT (Form C) contacts are provided which will operate when the valve position is altered from an open state.

The unit mounts in a 1/2" NPT tapped hole in the post indicator or butterfly valve housing. The device is engaged by the indicating assembly of the post indicator or the operating mechanism of the butterfly valve, actuating switch(es) when the valve is fully open. The unit should be installed where it is accessible for service.

The cover is held in place by two tamper resistant serews that require a special tool to remove. The tool is furnished with each device and

should be left with the building owner or responsibleparty. Replacement or additional cover serews and hex keys are available. See ordering information.

Optional Cover Tamper Switch

Afield installable cover tamper switch is availableas an option which may be used to indicate removal of the cover. See ordering information.

Testing

The PCVS and its associated protective monitoring system should be tested in accordance with applicable NFPA codes and standards and/or the authority having jurisdiction (manuf acturer recommends quarterly or more frequently).

Ordering Information

\begin{tabular}{|l|l|l|}
\hline Model & Deseription & Stock No. \\
\hline PCVS-1 & Potter Control Valve Switch (single switoh) & 1010107 \\
\hline PCVS-2 & Potter Control Valve Switch (double switch) & 1010207 \\
\hline- & Cover Screw & 5490424 \\
\hline- & Hex Key for Cover Serews and Installation Adjustments & 5250062 \\
\hline PBK-S & Prat Butterfly Valve Kit - Up to 12" (300mm) & 0090133 \\
\hline PBK-L & Prutt Butterfly Valve Kit - 14" (355mm) and Up & 0090132 \\
\hline PVK & Pratt Valve Kit & 1000060 \\
\hline- & Optional Cover Tamper Switch Kit & 0090131 \\
\hline KBK & Kennedy Butterfly Valve Kit & 0090143 \\
\hline
\end{tabular}

For pressure reducer type valve installation kits (if required) contact valve manufactures.

Potter Electric Signal Company - St. Louis, MO - Phone: 866-956-0988/Canada 888-882-1833 * www.potiersignal.com 
Fig. 1 Dimensions

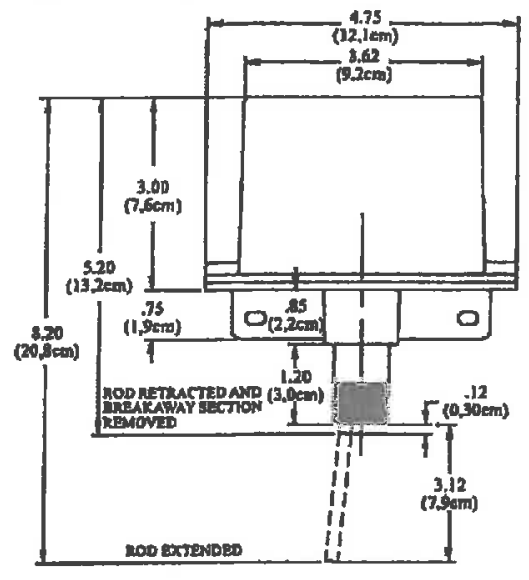

Fig. 2 Parts

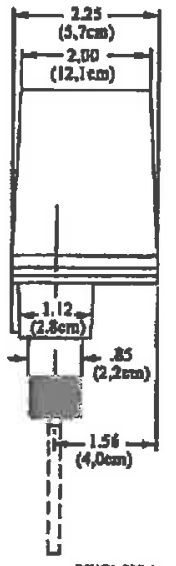

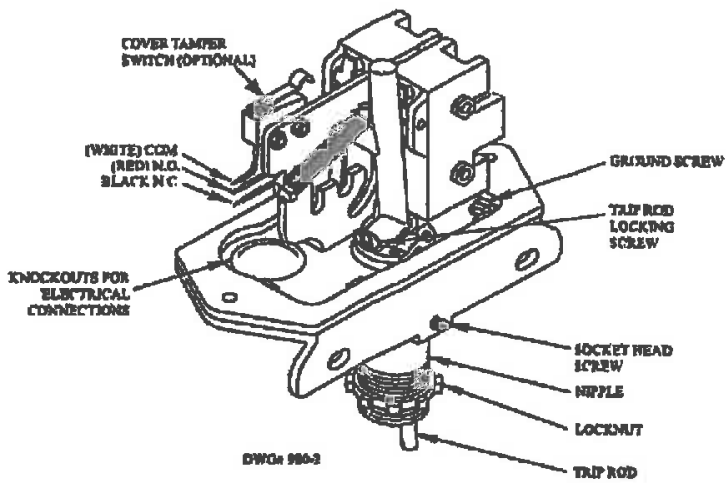

Typical Installations On Post Indicator Vave Hounings (See Figs. 3 Thru 6)

Refer to Fig. 2 for the location of parts described in the following instructions. Noto: If the sprinkler system is in service the owner or authoriced representative should be notified, before any work is done on the system, that the valve controlling the water supply to the system may be closed for periods of time during the installation smd testing of this device, resulting in all or portions of the system being inoperative during these periods.

If the system is not in service and valve is closed, be sure that opening the valve will not allow any umwanted water flow due to openings in the system, such as heeds off, broken or incomplete piping, etc.

1. Position the valve to fully open ("OPEN" should appear in the window of the housing). Partially close the valve while observing the direction that the target assembly moves. Reopen the valve.

If the valve housing is predrilled with a $12^{\prime \prime}$ NPT for installation of a monitoring switch, remove the $1 / 2^{n}$ plug and folly open the valve. Malie sure that "OPEN" appears in the window of the housing. 60 TO STEP NO. 6.

2. Remove the heed and target assembly (consultation with valve manufacture is recommended).

3. If the targot assembly rooved up as the yalve was closed, measure the distance from the bottom of the head to the lower part of the target assembly that will contact the trip rod of the PCVS (ace Fig. 3). This is usually a plate or bar on the target assembly, on a side adjecent to the "OPEN/SHUT" plates. Subtract $1 / 8$ " from the measurement.

If the target moved down as the valve was closed, measure the distance from the bottom of the head to the upper portion of the target assembly that will conlact the trip rod of the PCVS (seo Fig. 4). Add 1/8" (3,2mm) to this measurement.

4. Mark the housing at the proper location. Using a $23 / 32^{\prime \prime}(18,2 \mathrm{~mm})$ drill bit, drill and then tap $1 / 2$ "NPT in the housing on the side that coincides with the portion of the target assembly that will engege the trip rod of the PCVS.

5. Replace the head and target assembly.

6. Loosen the socket head serew that holds the nipple in the PCVS and remove the nipple.

7. Serew the locimut that is provided onto the nipple.

8. Screw the nipple into the 1/2" NPT hole in the valve housing - hand tighten. Tighten the locknut against the valve housing to secure the nipple firmly in place.

9. Insert a scule or probe thru the nipple to measure the distance from the open end of the nipple to the target essembly. Subtract $1 / 2^{n}$ (12,5mm) from this measurement.

NOTE: In some cases, it may be necessary to attach an mgle bracket to the target assembly to cogage the PCVS trip rod.

10. Using the special tool provided, loosen the two cover Bcrews and remove the cover from the PCVS.

11. Loosen the locking screw that bolds the trip rod in place and adjust the rod length, from the end of the collar to the end of the rod, using the dimension determined in Step 9. Tighten the locking serew to hold the rod in place.

NOTE: If trip rod leagth is excessive, loosen the looking screw and remove the trip rod from the trip lever. Using pliers, break off the one (1) inch long notched section (see Fig. 7). Reinstall trip rod and repent Step 11 procedure.

12. Partially close the valve ( 3 to 4 revolutions of the handie/hand wheel).

13. Slide the PCVS unit as far as possible onto the ripple, observing which direction the rod will move when the valve is closed. Orient the device to actuate the switches when the valve is open. Tighten the socket bead serew in the collar.

14. Carefully open the valve to the filly open position As the target moves to the open position it should engage the trit rod and actuate the switch(es). There should be a minimum overtravel of $[/ 2$ revolution of the handle/ hand wheel after the switch(es) actuate (a continuity meter connected to each set of contacts is one method that could be nsed to determine this)

15. Slowly close the valve. The switoh must operate during the first two revolutions of the handle/hand wheel or during $1 / 5$ of the travel distance of the valve control appuratus from its normal condition.

NOTE: Small adjustments of the target position may be necossary (consultetion with valve mamufacturer is recommended).

16. Complete the required eleotrical wiring, connections and tests. The valve should be operated through the entire cycle of filly closed and fully open to determine the integrity of the PCVS installation and the signaling system. Check that all electrical and mechmical connections are secure.

17. When the installation and testing are complete, return valve to its proper position.

18. Alternative installation for other post indicator valve housing shown in Fig. 5 and 6. 


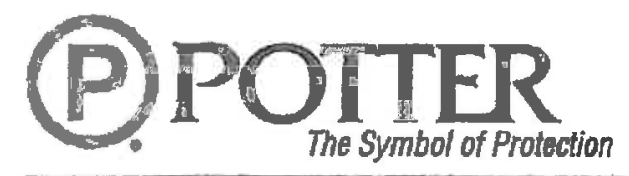

\author{
PCVS-1, -2 \\ CONTROL VALVE \\ SUPERVISORY SWITCH
}
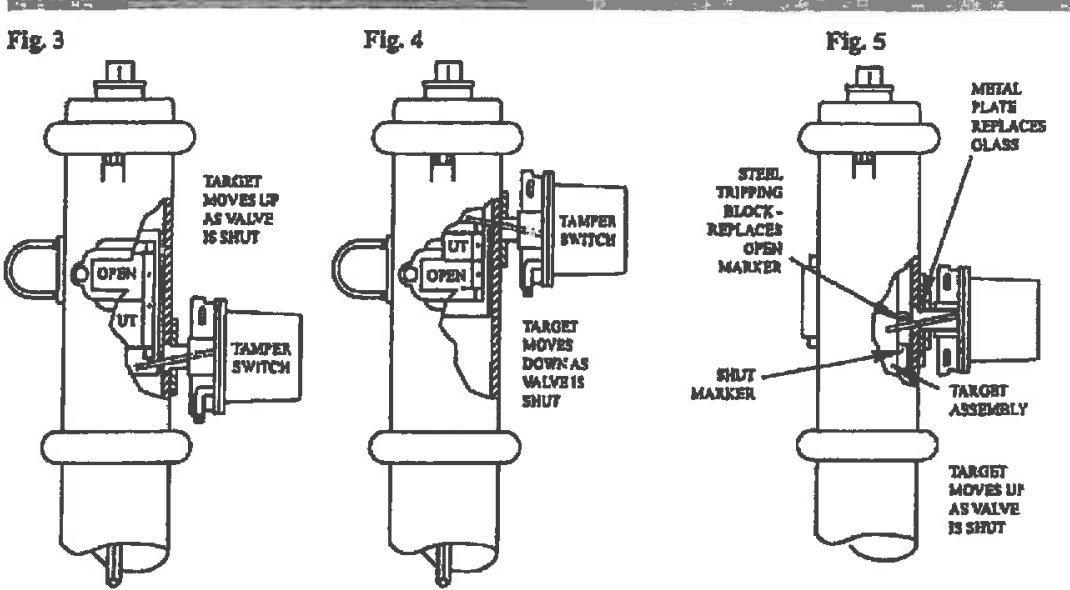

Fig. 6

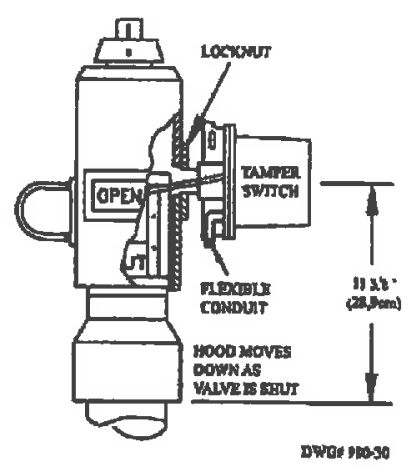

Notes:

1. Subject to the approval of the "authority having jurisdiction" the alternate method of installation shown in Fig. 5 may be used. In this method, one of the glass windows of the housing is replaced with a $1 / 4^{\prime \prime}$ thick metal plate that is cut to fit in place of the glass and drilled and tapped to receive the 1/2" NPT pipe nipple. In some cases it may be necessary to attech an angle bracket to the target assembly to engage the PCVS trip rod.

2. If the target is stationary and a hood arrangement is used, such as is shown in Fig. 6, the hood must be drilled with a 23/32" drill and tapped with a 1/2" NPT. The center line of this hole should be 1/8" below the portion of target assembly that strikes the PCVS trip rod. The 11 3/8" dimension shown is for a Clow Valve. Flexible conduit must be used for this type of installation.

Typleal Installation On A. Butterfly Valve (See Figs, 9 And 10)

Refer to Fig. 2 for location of parts described in the following instructions:

BI. Remove the I/2" NPT plug from the gear operator case.

B2. Locsen the set screw thet holds the nippie in the PCVS and renove the nipple

B3. Serew the locknut that is provided onto the nipple.

B4. Screw the rijpleinto the 1/2"NPThole in the gearoperator-hand tighten. Tighten the lockmut against the case, to secure the ripple firmly in place

B5. Partially close the valve (3 or 4 revolutions of the hand wheel or crank).

B6. Using the special tool provided, loosen the two cover serews and remove the cover from the PCVS.

B7. Loosen the locking serew that holds the trip rod in place. Estimate trip rod length required and extend slightly past that point. Slide the PCVS unit as far as possible onto the nipple, observing which direction the rod will move when the valve is closed. Orient the device to actuate switches when valve is open.

Note: If trip rod length is excessive, loosen the locking screw and remove the trip rod from the trip Iever. Using pliers, break off the one (1) inch long notched section (see Fig. 7). Reinstall trip rod and repeat Step B7 procedure.

B8. Remove device from nipple and withdraw trip rod $1 / 32^{\prime \prime}(0,80 \mathrm{~mm})$ (this dimension is important). Tighten the locking serew to hold the

rod in plece. Re-install the device on the nipple. Tighten the screw in the coller against the nipple.

Note: In some cases it may be necessary to remove the gear box cover to ensure correct operation (consultation with the valve manufacturer is recommended).

B9. Carefully open the valve to its full open position, as the boss on the gear hub moves to the open position it must engage the PCVS trip rod and actuate the switch(es). There should be a minimum overtravel or revolution of the crank or hand wheel after the switch(es) actuate (a continuity meter connected to each set of contacts is one method that could be used to determine this).

Note:Slightadjustment of gearstops may benecessery topreventovertavel of the trip rod (consultetion with valve manufacture is recommended).

B 10. Carefilly close the val ve. The switch(es) must operate during the first two revolutions of the crank or hand wheel or during $1 / 5$ of the travel distance of the valve control apparatus from its normal condition.

B11. Complete the required electrical wiring, connections and tests. The vaive should be operated through the entire cycle of fully closed and fully open to determine the integrity of the PCVS installation and signaling system.

Check that all electrical and mechanical comections are secure.

B12. When the installation and testing are complete, return valve to its proper position.

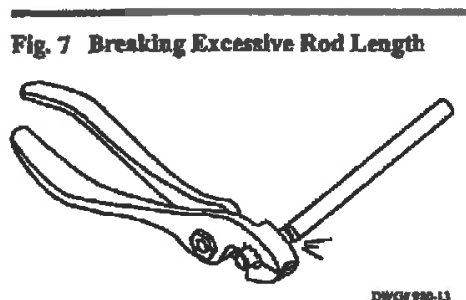

Deromed
$\mathrm{Ig} 8$ Switch Terminal Connections Clamping Plate Terminal

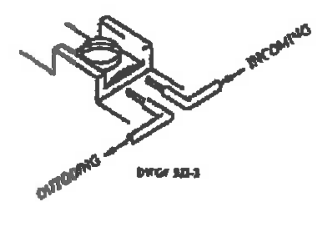

\section{CAUTION}

Av uninsulated section of 1 single condpetor should not be looped around the terminal and serve as two separate comections. The wire must be severed, thereby providing supervision of the conpection in the event that the wire becomes dislodged from under the teminal. 


\section{P.POTIER}

ITT Grinnell/Kennedy Indienting Butterify Valve

Fig. 9
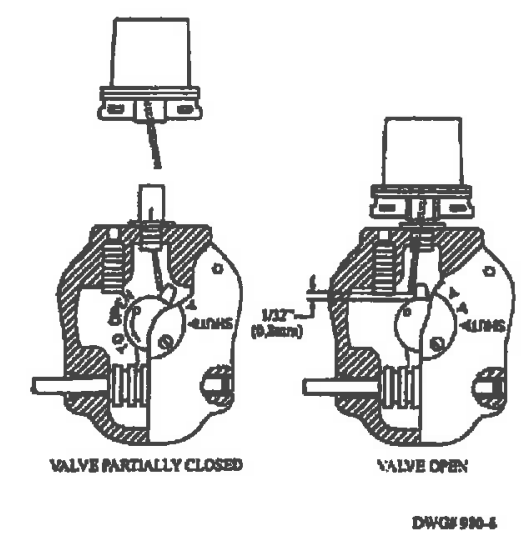

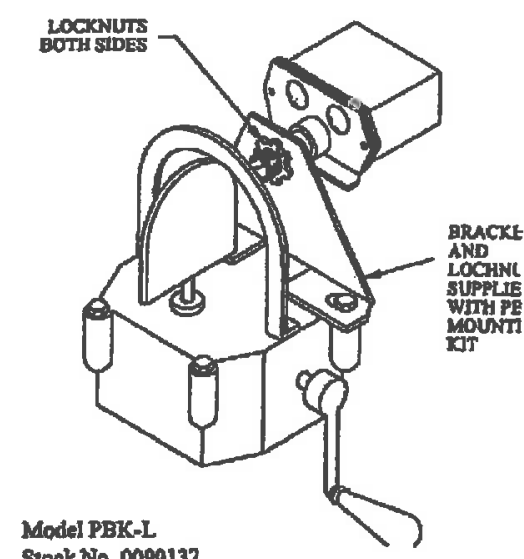

Stock No. 0090132

(MDT-4S Aelualor)

Model PBK-M

Stock Na. 00901 46

(MDT-3S Actuator)

Model PBK-S

Stock No. 0090133

(MDT-2S Acturtor)

Pratl Brttently Valve Kit as nsed 10 mount a PCVS on - Prats Moded IBV Vive.

Kits contain: Bracket, nuts and inetruetion:

Note: This application is wubject to the approval of the axthority having jurisdietion.

Dresser Indicating Dutterlly Valve Fig. 10
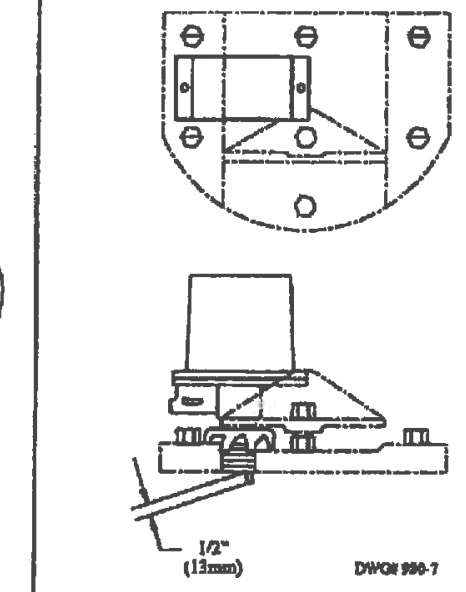

PVK - Pratt PIVA Past

Indicator Valve Kat

(Stock No. 1000060)

Fig. 13

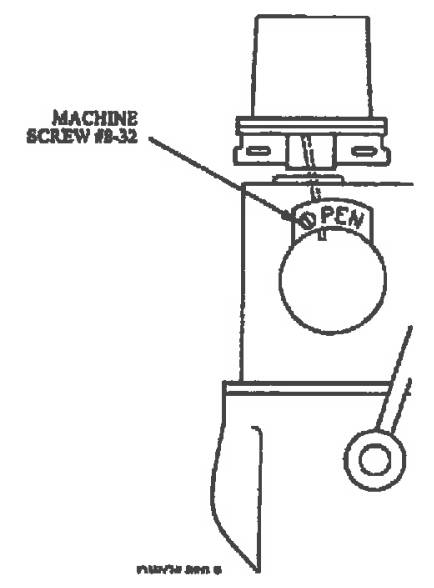

Pratt Vhlve Kit as wed to mount a PCVS on a Prat Model PiVA Vilve.

Kit contrins: Instructions, lamplate, serew and nut.

Nole: This application is subject to the epproval of the authority having jurisdiction.
PCVS-1, -2

CONTROL VALVE

SUPERVISORY SWITCH

Typleal Pressure Reducer Type Valve Installation

Fig 11

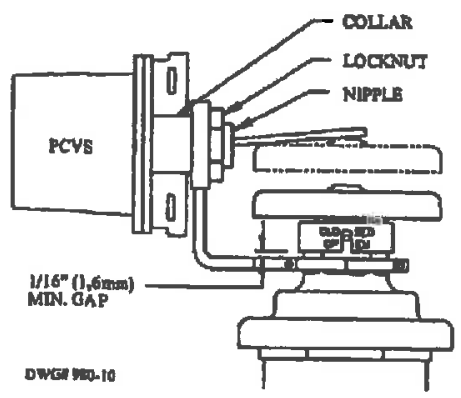

This figure shows the Model PCVS mounted on the valve yoke, with a brecket supplied by the valvemunuficturer 10 supervite a pressure reducer tope valve.

Note: This application is subject to the approval of the uthority havine juriedietion.
Typical Blectrical Connettions

Pletele Hote: This device should be wired in

accondance with the epplieablit parts of the Netional Electrical Code, atl atto and local codes, applicable NFPA Standands and the requirements of the suthority having juristiction

Nis. 14

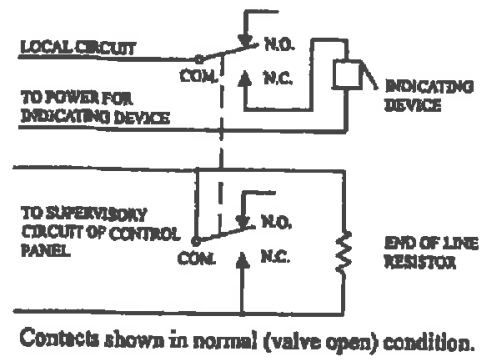

Typieal Switch Aetion

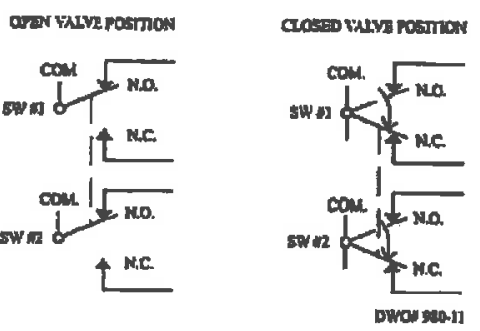

Swilches Shown in Vatve Open Position 


\section{CALIFORNIA DEPARTMENT OF FORESTRY \& FIRE PROTECTION OFFICE OF THE STATE FIRE MARSHAL \\ FIRE ENGINEERING - BUILOING MATERINLS LISTING PROGRAM \\ LISTING SERVICE}

LISTINC No.

$7770-0328: 0001$

CATEGORY: $\quad 7770$ - VALVESISWTCHES

LISTEE:

DESICN:

MARKING:

APPROVAL:
Potter Electric Signal Co, 1609 Park 370 Place, Hazelwood, MO 63042

Contact. BIII Witherspoon (314) 595-6731 Fax (314) 595-6797

Email: billwepottersignal.com

Vane and pressure type water flow alam switches listed below. Refer to listee's dala sheet for detailed product description and operational considerations.

\section{Vane Troes:}

$\begin{array}{llll}\text { VSR-CF } & \text { VSR-D } & \text { VSR-F } & \text { VSR-SF } \\ \text { VSR-FE-2 } & \text { VS-SP } & \text { VS-F } & \text { VSR-SFG } \\ \text { VSR-SFT } & \text { VSG } & \text { VSR } & \text { VSR-S } \\ \text { VSR-C } & \text { VSR-ST } & \text { VSR-SG } & \end{array}$

Pressure Type:

$\begin{array}{llll}\text { WFS-B } & \text { WFSR-C } & \text { WFSPD-B } & \text { PS10 } \\ \text { PS-10A } & \text { PS-100A } & \text { WFSR-F } & \text { PS100 }\end{array}$

In accordance with listee's printed installation instructions, applicable codes and ordinances and in a manner acceptable to the authority having jurisdiction.

Listee's name, model number and UL or FM label.

Listed as waterflow alarm switches for use with fire sprinkler systems. Vane models may be used In wet plpe systems; pressure models may be used in wat or dny systems. Model VSF-CF is for use on $K, L$ or M copper pipe $\left(2^{\prime \prime}, 2-1 / 2^{\prime \prime}, 3^{\prime \prime}, 4^{\prime \prime}\right)$ and listed CPVC pipe (2", 2-1/2", $3^{\prime \prime)}$. Model VSR-SF for use on $1 ", 1-1 / 4^{4}, 1-1 / 2^{\prime \prime}$ and ' 2 " steel, copper or listed plastic pipe. Model VSG is for low flow rate. Model VSR-SFG and VSR-SFT are for use on 1", 1-1/4", 1-1/2" and "2" plastic pipe. Models VS-F, VSR-F, VSR-FE and VSR-FE-2 is for use on 2", 2-1/2", 3", $3-1 / 2^{\prime \prime}, 4^{\prime \prime}, 5^{\prime \prime}, 6^{n}, 8^{\prime \prime}$ and $10^{\prime \prime}$ pipe. "Model VSR is for use on steel pipe sizes from $2^{\prime \prime}$ through $8^{n 4}$. Vane type switches may be used outdoors when the outdoor temperature never falls below $400 F$.

This listing is based upon technical data submilted by the applicant. CSFM Fire Enginearing ataff has reviewed the test results and/or other date but does not make an independent verification of any claims. This listing is not an endorsement or recommendition of the item tisted. This listing sthould not be used to verify comect operational requirements or Installation crtteria. Refer to Ilstee's data sheet, installation instructions and/or other subtable information sources.

Date Issued: July 01, 2010 Listing Expires June 30, 2011

\section{Authorized By: FRANCIS MATEO, Program Coordinator}




\section{CALIFORNIA DEPARTMENT OF FORESTRY \& FIRE PROTECTION OFFICE OF THE STATE FIRE MARSHAL \\ FIRE ENGINEERING - BUILDING MATERIALS LISTING PROGRAM \\ LISTING SERVICE}

LISTING No.

$7770-0328: 0010$

Page 1 of 1

CATECORY:

7770 - VALVESISWTCHES

LISTEE:

Potter Electric Signal Co, 1609 Park 370 Place, Hazelwood, MO 63042

Contact: Bill Witherspoon (314) 595-6731 Fax (314) 595-6797

Email: billw@pottersignal.com

DESIGN: $\quad$ Supervisory switches listed below to monitor pressure, OS\&Y, gate, globe/gate, PIV, tank temperature or water level valves. Refer to listee's data sheet for detailed product description and operational considerations.

$\begin{array}{llll}\text { HLS-B } & \text { WS-W } & \text { WLS-S } & \text { PS-40A } \\ \text { PS-120A } & \text { OSYSU-2 } & \text { OSYS-B } & \text { PMS } \\ \text { PTS-B } & \text { OSYSU-1 } & \text { GVS } & \text { PCVS-1 } \\ \text { PIVS-B } & \text { TTS-S } & \text { TIS-W } & \text { PCVS-2 } \\ \text { WLS } & \text { PTS-C } & \text { PS40 } & \text { PS120 } \\ \text { "RBVS } & & & \end{array}$

RATING:

INSTALLATION: $\quad n$ accordance with listee's printed instructions, applicable codes and ordinances and in a manner acceptable to the authority having Jurisdiction.

MARKINC: $\quad$ Listee's name, model designation and FM or UL label.

APPROVAL: Listed as sprinkler system supervisory switches.

NOTE:

Formerly $7738-0328: 010$

This listing is based upon technical data submitted by the applicant. CSFM Fire Enginearing staff has revibwed the test results and/or other data but does not make an independent verfification of any claims. This listing is not an endorsement or recommendation of the them listed. This listing should nol be used to verify correct operational requirements or Installation criterla. Refer to listee's dala sheet, installation instructions and/or olher suitable information sources.

Date lssued: July 01, 2010

Listing Expires June 30, 2011

Authorized By: FRANCIS MATEO, Program Coordinetor

Fire Engineering Division 


\section{CALIFORNIA DEPARTMENT OF FORESTRY \& FIRE PROTECTION OFFICE OF THE STATE FIRE MARSHAL \\ FIRE ENGINEERING - BUILDING MATERIALS LISTING PROGRAM LISTINC SERVICE}

LISTING No.

7135-0328:0119

CATEGORY: $\quad 7135$ - AUDIBLE DEVICES

LSTEE: $\quad$ Potter Electric Signal Co, 1609 Park 370 Place, Hazelwood, MO 63042 Contact: Bill Witherspoon (314) 595-6731 Fax (314) 595-6797 Emall: bilkwepottersignal.com

DESIGN:

Models"SB624-153075, "SB624-75110, PBA246, PBA248, PBA2410, PBA1206, PBA1208 and PBA12010 vibrating bells. Sultable for outdoor use when used with Model BBK-1 backbox. Models are AC or DC powered and available in $6^{\circ \prime}, 8^{\prime \prime}$ and $10^{\prime \prime}$. Models MBA-6, -8 and -10 bells, sultable for outdoor use when used with Model BBX-1 backbox. Refer to listee's data sheet for detailed product description and operational considerations.

RATING:

PBA-246, -248, -2410: 24 VAC

PBA-1206, -1208, -12010: 120 VAC

MBA-6, $-8,-10$ :

12 or 24 VDC

NSTALLATION: In accordance with listee's printed installation instruction, applicable codes \& ordinances, and in a manner acceptable to the authority having jurisdiction.

MARKING: $\quad$ Listee's name, model number and UL label.

APPROVAL: $\quad$ Listed as audible devices for use with separately listed compatible fire alarm control units. If this appliance is required to produce a distinctive three-pulse Temporal Pettem Fire Alarm Evacuation Signal (for total evacuation) in accordance with NFPA 72, 2002 Edition, the appliance must be used with a fire alarm contral unit that can generate the temporal pattern signal. Refer to manufacturer's Installation Manual for details.

NOTE:

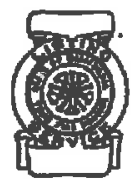

This listing is besed upon technical date submitted by the applicant CSFM Fire Engineering staff has reviewed the test results and/or other data but does not make an independent verification of any claims. This listing is not an endorsement or recommendation of the ltem listed. This listing should not be used to verify correct operational requirements or installation oriteria. Rafer to listee's data sheet, installation instructions andior other suitable Information sources.

Date Issued: July 01, 2010 Listing Expires June 30, 2011

Authorized By: FRANCIS MATEO, Program Coordinator 


\section{APPENDIX J: FIRE EVACUATION AND SAFETY PLAN}




\section{Fire Evacuation and Fire Safety Plans}

\section{Fire Evacuation Plan}

The fire evacuation plan for this elementary school shall comply with the requirements of the 2012 International Fire Code, Section 404.3.1 Fire Evacuation Plans and the district requirements. The school principal is in charge of the overall plan and implementation of the plan at the campus. The fire evacuation plan shall contain the following:

1. During a fire event the building shall be completely evacuated upon activation of fire alarm system. Evacuation shall be by use of emergency egress or escape routes. The plans and routes shall clearly be posted in the main corridors, classrooms, multi-use, administration office and other areas as noted by the fire code. Occupants shall evacuate to predefined assembly points outside of the building. Teachers are responsible for students in their charge and shall direct evacuation of students in there charge to pre determined assembly areas.

2. No equipment in the building is deemed critical where it needs to remain in operation during evacuation.

3. Staff as pre directed by the school district fire safety coordinator shall follow district procedures for the evacuation of any employees or students unable to use general means of egress.

4. After evacuation administered staff and teaching staff shall follow the district procedures for accounting for accounting for students and staff after evacuation has been completed. Principal shall be in overall charge and teachers shall account for their classes. Teachers shall immediately report any missing students in there charge to the principal or there designee.

5. Identification and assignment of personnel responsible for rescue or emergency medical aid shall be pre determined by the district fire safety coordinator. Per district standards the school nurse will administer first aid, supervise the administration of first aid and organize first aid and medical supplies. Teachers shall send students in need of first aid to the nurse or make nurse aware of need for aid.

6. Notification of a fire or emergency event shall be by the activation of the fire alarm system. If the fire alarm system fails a manual bell will be used for signals.

7. Fire and emergency events shall be monitored by the central station service. The central service shall notify emergency services as required.

8. The school district office shall maintain a full current contact and assignment list for the site and for administration of the district standards. Contact information shall be readily available in the campus administration office of the school and at the district office. The 
site principal shall be the main contact for information regarding the fire evacuation plan for the site.

9. Emergency alarm communication system description and instructions shall be provided to all staff and shall be readily available in the campus administration office. Instructions and on alarm codes shall be clearly posted as required by the fire code.

\section{Fire Evacuation Drills}

The fire evacuation drills for this elementary school shall comply with the requirements of the 2012 International Fire Code, Section 405 Fire Evacuation Drills and the district requirements. The school principal is in charge of coordination of the drills and compliance with the code. Drills will occur monthly for all occupants per the provisions of the International Fire Code section 405.2. The leadership of the drills and the time of the drills shall be per sections 405.3 and 405.4. Recoded keeping of the drills shall be per section 405.5 and shall include the following minimum information:

1. Identity of the person conducting the drill.

2. Date and time of the drill.

3. Notification method used.

4. Staff members on duty and participating.

5. Number of occupants evacuated.

6. Special conditions simulated.

7. Problems encountered.

Notification of drills shall be given to the local responding fire department prior to running of the drill.

The drill will begin with the activation of the fire alarm system.

Building occupants shall be accounted for as they arrive at the assembly points.

A separate and distinct signal from the alarm drill shall be used to recall occupants after the evacuation.

\section{Fire Safety Plan}

The fire safety plan for this elementary school shall comply with the requirements of the 2012 International Fire Code, Section 404.3.2 Fire Safety Plans and the district requirements. The school principal is in charge of the overall plan and implementation of the plan at the campus. The fire safety plan shall contain the following: 
1. The procedure for reporting a fire. The procedure shall be as defined by the district fire safety coordinator and the site principal.

2. A life safety strategy and procedures for notifying, relocating or evacuating occupants, including occupants who need assistance shall be implemented by the site principal and shall be approved by the district fire safety coordinator.

3. Site plans shall be included which show occupancy points, locations of fire hydrants and the show the normal routes of the fire department vehicle access.

4. Floor plans shall include exits, primary evacuations routes, secondary evacuation routes, accessible egress routes, areas of refuge, exterior areas for assisted rescue, manual fire alarm boxes, portable fire extinguishers, occupant-use hose stations and fire alarm annunciations and controls.

5. A list of any major fire hazards associated with normal use and occupancy of the premises shall be kept. A list of maintenance and housekeeping procedures shall be kept.

6. The plan shall identify personnel responsible for the maintenance of systems and equipment installed to prevent or control fire.

7. The plan shall identify personnel responsible for the maintenance, housekeeping and controlling of fuel hazard sources.

\section{Emplovee Training}

Employees shall be trained in the fire emergency procedures as described in the fire evacuation plan and the fire safety plan. Employees shall be trained upon being hired and shall receive training annually thereafter. Records shall be maintained and shall be made available to the fire code official if requested. Employee training shall follow the guidelines of the International Fire Code section 406.3 and shall include fire prevention training and evacuation training. 


\section{APPENDIX K: FIRE SPRINKLER INSPECTION, TESTING AND MAINTENANCE REQUIREMENTS}




\section{Fire Sprinkler Inspection, Testing and Maintenance}

\section{$\underline{\text { Requirements }}$}

System maintenance and inspections are the responsibility of the school district. General observations by the district maintenance staff are done as they perform routine maintenance on the site, but a service contract with a sprinkler contractor is in place to perform routine maintenance and testing. Routine inspections, maintenance and test that are done quarterly and annually are by the sprinkler contractor. Any weekly or monthly observations and tests are done by the district staff. All inspection, testing and maintenance should be done according to the guidelines of NFPA 25. Additionally any time the building or spaces are modified the maintenance staff or design team doing the work should schedule or provide additional inspection and testing for modified areas.

Additional Requirements and Frequency data should follow NFPA 25

Table 5.1.1.2, Table 6.1.1.2 and Table 13.1.1.2.

\begin{tabular}{|l|l|}
\hline $\begin{array}{l}\text { Sprinkler } \\
\text { Components }\end{array}$ & Standard Care and Maintenance Requirements \\
\hline City Water Main & Maintained by city. Water should be available at all times. \\
Visual review of connection should be done as part of quarterly testing by the \\
contractor performing the maintenance contract. \\
\hline $\begin{array}{l}\text { Above Ground } \\
\text { Piping/Supports } \\
\begin{array}{l}\text { The above ground } \\
\text { piping includes the } \\
\text { riser, the feed main, } \\
\text { cross mains and } \\
\text { branch lines. }\end{array}\end{array}$ & $\begin{array}{l}\text { Annual inspection should be done by the contractor performing the } \\
\text { maintenance contract. This inspection should cover the review of piping and } \\
\text { supports to verify that no hangers are loose or that objects are not being }\end{array}$ \\
\hline
\end{tabular}




\begin{tabular}{|c|c|}
\hline $\begin{array}{l}\text { Control Valves and } \\
\text { Gauges } \\
\text { Includes check } \\
\text { valves, backflow } \\
\text { preventer and drain } \\
\text { and test valves. }\end{array}$ & $\begin{array}{l}\text { Valves should all be kept readily accessible and unobstructed so that they can } \\
\text { be operated promptly and examined to see that they are open and in good } \\
\text { operative condition, turn easily and do not leak. } \\
\text { The post indicator valve outside the building by the riser should be open at } \\
\text { all times. Periodic inspection is done by the local fire department. District } \\
\text { staff should visually inspect monthly. } \\
\text { Quarterly inspection and testing should be part of the quarterly testing by } \\
\text { the contractor performing the maintenance contract. These quarterly } \\
\text { inspections and tests should be timed to include the spring and fall tests } \\
\text { noted below. } \\
\text { A spring inspection should be done after low temperatures have passed. This } \\
\text { should include a flow test and review of valve operation. } \\
\text { A fall inspection should be conducted of the building envelope to ensure that } \\
\text { cold air will not enter to expose the sprinkler system to freezing. } \\
\text { Additional inspections should be done any time occupancy changes or } \\
\text { modifications to the building are done. }\end{array}$ \\
\hline $\begin{array}{l}\text { Water Flow Alarm, } \\
\text { supervisory and } \\
\text { tamper Switches } \\
\text { Devices }\end{array}$ & $\begin{array}{l}\text { District staff should visually inspect monthly. } \\
\text { Water flow alarm devices, supervisory signals should be tested as part of the } \\
\text { quarterly testing by the contractor performing the maintenance contract. } \\
\text { A spring inspection should be done after low temperatures have passed. This } \\
\text { should include a flow test and review of alarm and tamper switch operation. } \\
\text { This should be done as part of one of the scheduled quarterly visits by the } \\
\text { contractor performing the service contract. }\end{array}$ \\
\hline $\begin{array}{l}\text { Standpipe and Hose } \\
\text { System }\end{array}$ & $\begin{array}{l}\text { Inspection of the gauges should be done weekly by district staff. } \\
\text { Annually inspection and testing should be done by the contractor performing } \\
\text { the maintenance contract. }\end{array}$ \\
\hline
\end{tabular}




\begin{tabular}{|c|c|}
\hline Signs & $\begin{array}{l}\text { Sign information should be inspected annually by the contractor performing } \\
\text { the maintenance contract. } \\
\text { Additional inspections should be done any time occupancy changes or } \\
\text { modifications to the building are done. }\end{array}$ \\
\hline Sprinklers & $\begin{array}{l}\text { The sprinklers installed in the building are fast-response type and should be } \\
\text { tested at } 20 \text { years and then every } 10 \text { years after. When tested } 1 \text { percent of } \\
\text { the sprinklers should be tested. } \\
\text { Annually inspection of the following items should be done by the contractor } \\
\text { performing the maintenance contract. } \\
\text { Annual sprinkler inspections should review the following items. } \\
\text { 1. Observe and note absence of sprinklers from any rooms. } \\
\text { 2. Observe location of sprinklers. Are they under shelves, benches racks or } \\
\text { platforms. } \\
\text { 3. Do they have proper clearance. Are they obstructed. } \\
\text { 4. Deflector distance should conform to NFPA } 13 \text {. } \\
\text { 5. The sprinkler installation should be reviewed. The rating, type and } \\
\text { condition of the sprinklers should be reviewed. Sprinklers should be } \\
\text { reviewed for corrosion, paint coatings and deposits. } \\
\text { Additional inspections should be done any time occupancy changes or } \\
\text { modifications to the building are done. }\end{array}$ \\
\hline
\end{tabular}

